

\section{Physiology and application of sulfur-reducing microorganisms from acidic environments}

Anna Patrícya Florentino 


\section{Thesis committee}

\section{Promotor}

Prof. Dr Alfons J. M. Stams

Personal Chair at the Laboratory of Microbiology

Wageningen University \& Research

\section{Co-promotors}

Dr Irene Sánchez-Andrea

Assistant Professor, Laboratory of Microbiology

Wageningen University \& Research

Dr Jan Weijma

Researcher, Sub-department of Environmental Technology

Wageningen University \& Research

\section{Other members}

Prof. Dr Willem J.H. van Berkel, Wageningen University \& Research

Prof. Dr Huub J.M. Op den Camp, Radboud University Nijmegen, The Netherlands

Dr Michael Pester, University of Konstanz, Germany

Dr Paula A. González Contreras, Paques BV, Balk, The Netherlands

This research was conducted under the auspices of the Graduate School for SocioEconomic and Natural Sciences of the Environment (SENSE) 


\section{Physiology and application of sulfur-reducing microorganisms from acidic environments}

\section{Anna Patrícya Florentino}

Thesis

submitted in fulfilment of the requirements for the degree of doctor

at Wageningen University

by the authority of the Rector Magnificus,

Prof. Dr A. P. J. Mol,

in the presence of the

Thesis Committee appointed by the Academic Board

to be defended in public

on Tuesday 21 March 2017

at 1:30 p.m. in the Aula. 
Anna Patrícya Florentino

Physiology and application of sulfur-reducing microorganisms from acidic environments, 264 pages.

$\mathrm{PhD}$ thesis, Wageningen University, Wageningen, the Netherlands (2017)

With references, with summary in English

ISBN 978-94-6343-097-5

DOI: $10.18174 / 405942$ 


\section{Table of Contents}

Chapter 1 General introduction and thesis outline

Chapter 2 Ecophysiology and application of acidophilic sulfur-reducing microorganisms

Chapter 3 Sulfur reduction in acid rock drainage environments

Chapter 4 Desulfurella amilsii sp. nov., a novel acidotolerant sulfur-

Chapter 5 Genome sequence of Desulfurella amilsii strain TR1 and comparative genomics of Desulfurellaceae family

Chapter 6 Mechanisms for sulfur reduction in Desulfurella amilsii at low and circumneutral $\mathrm{pH}$

New insights into sulfur metabolism from differential

Chapter 7 proteomoc analysis of the acidotolerant sulfur-reducing bacterium Desulfurella amilsii TR1

Chapter 8 versatile fermentative microorganism: Lucifera butyrica gen. nov. sp. nov.

Chapter 9 General discussion

References

Summary

List of publications

Appendices Co-author affiliations

About the author

Acknowledgements 

I do not know what I may appear to the world, but to myself I seem to have been only like a child playing on the seashore, and having fun in now and then finding a smoother pebble or a prettier shell than ordinary, whilst the great ocean of truth lay all undiscovered before me.

Isaac Newton 



\section{Chapter 1}

General introduction and thesis outline 


\section{Elemental sulfur - a brief story}

Elemental sulfur is a pale yellow, odorless, fragile and insoluble mineral, while the chemical element sulfur has symbol $\mathrm{S}$ and atomic number 16 . This element is thought to be involved in one of the first man-made chemical reactions in history. In the Stone-Age, one likely discovered this reaction by intentionally or not, dropping sulfur into fire. The yellow compound burned resulting in an astonishing blue flame and a strong odor due to the sulfur dioxide formation (Kutney 2013). Therefore, elemental sulfur itself became associated with itsburning characteristic and it was referred to as brimstone ("burning stone") in the Genesis book in the bible. In Assyrian texts from 700-600 BC, sulfur was referred as the product of the riverside, as deposits of the element could be found near rivers. In the $9^{\text {th }}$ century BC, Homer mentioned the disinfectant property of sulfur combustion to prevent pest spreading (Homer 1998). Around the $3^{\text {rd }}$ century, the Chinese found out that sulfur could be extracted from pyrite and by the $12^{\text {th }}$ century they discovered gun powder (a mixture of potassium nitrate, carbon, and sulfur) (Yunming 1986) (Yunming 1986). Other evidence of sulfur utilization in ancient times are reported (French 2002, Rapp 2009), but it was not before 1777 that Antoine Lavoisier convinced the scientific community that sulfur was actually a chemical element and not a compound (Mckie 1953).

The name of the element derives from the latin sulphurium and before that from the Sanskrit sulvere, later Hellenized to sulphur. The true Greek word for sulfur, $\theta \varepsilon i$ iov, is the source of the international chemical prefix thio. The spelling sulfur, however, appeared in the end of the Classical Era. In $12^{\text {th }}$ century, the Anglo-French word for sulfur was sulfre; in the $14^{\text {th }}$ century the Latin $p h$ was restored, and the spelling became sulphre; and by the $15^{\text {th }}$ century the spelling switched to sulfur, sulphur. Later, in the $19^{\text {th }}$ century, Britain standardized the spelling as sulphur, while in United States, the writing form sulfur was chosen.

\section{Sulfur metabolism}

Circa 0.05 mass\% of the lithosphere consists of the element sulfur (Steudel 2003), mostly concentrated in metal sulfide ore deposits, like pyrite $\left(\mathrm{FeS}_{2}\right)$, chalcopyrite $\left(\mathrm{CuFeS}_{2}\right)$ and pyrrhotite $\left[\mathrm{Fe}_{(1-\mathrm{x})} \mathrm{S}(\mathrm{x}=0\right.$ to 0.2$\left.)\right]$, or in sulfate deposits, such as gypsum $\left(\mathrm{CaSO}_{4} \cdot 2 \mathrm{H}_{2} \mathrm{O}\right)$ and barite $\left(\mathrm{BaSO}_{4}\right)$. Microbial activity is essential for the transformation and fate of sulfur compounds in the environment, leading to profound effects on chemical, physical and biological properties of the biosphere (Figure 1). Elemental sulfur is the chemical state of sulfur with a valence of 0 and it normally consists of cyclic octatomic molecules $\left(S_{8}\right)$. In nature, reduced sulfur compounds easily undergo oxidative reactions, leading to the formation of sulfate as the completely oxidized form of sulfur (oxidation state +6 ); or reductive reactions, in which sulfide is formed as the completely reduced sulfur compound 
(oxidation state -2). Moreover, sulfate reduction can be performed in an assimilative way, in which it is reduced to organic sulfhydryl groups ( $\mathrm{R}-\mathrm{SH}$, oxidation state -2); and the organic groups can undergo further sulfhydration reaction, in which sulfide is released.

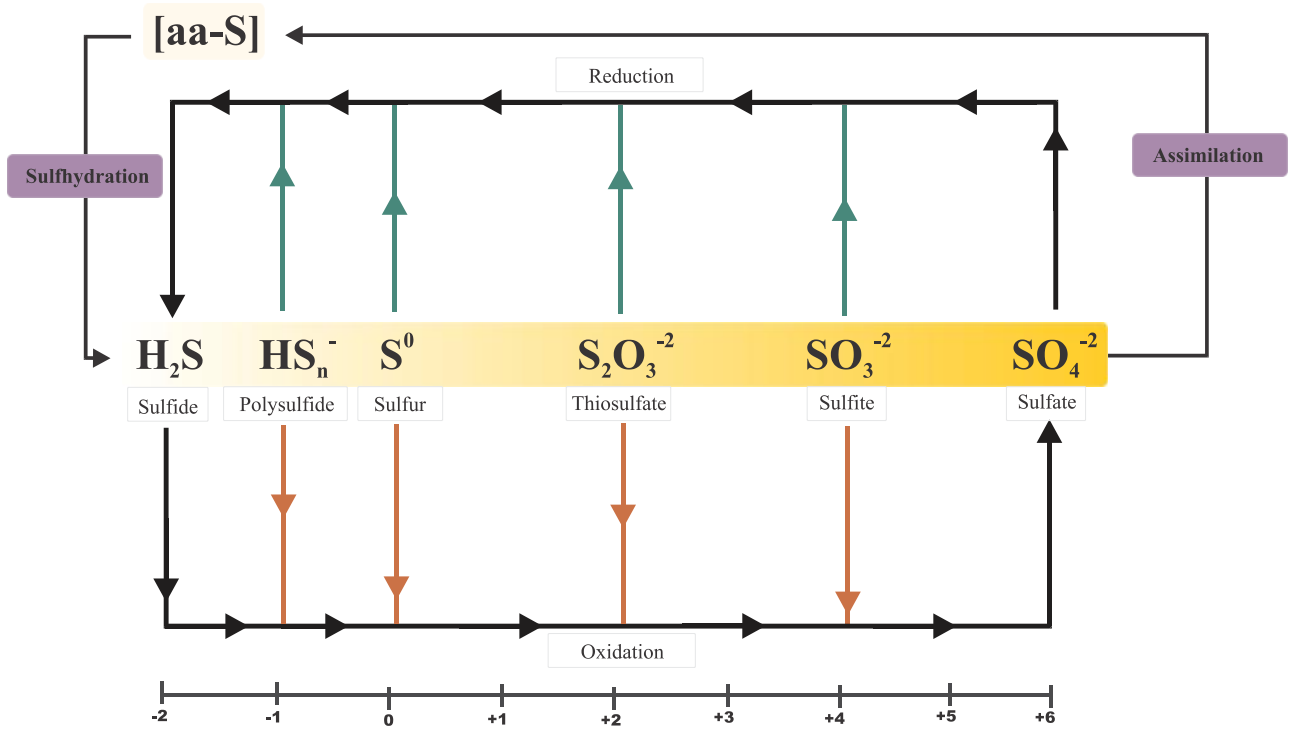

Figure 1 - Biological sulfur cycle. The upper part shows the possible reductive reactions in the cycle, leading to the formation of sulfide. The oxidative reactions are displayed in lower part, forming sulfate. Disproportionation routes, in addition to pure oxidation or reduction are represented by green and orange arrows.

Hydrogen sulfide is the ultimate product reduction of sulfur compounds and it has a prominent impact on the chemistry of the environment, due to its corrosive properties and reactivity with metals. Furthermore, it can serve as electron donor for a great diversity of microorganisms coupled to either oxygen, nitrate or iron reduction (Rabus, Hansen et al. 2013).

Sulfur reducing microorganisms are able to grow at a broad range of $\mathrm{pH}$ and temperature. Although the majority of known species thrives at neutral conditions, they are also frequently isolated from deep-sea vents, hot springs and other extreme environments (Figure 2) (Stetter 1996). While sulfur-reducing bacteria are mesophilic or moderately thermophilic, all archaeal sulfur reducers described so far are extremely thermophilic (Fauque and Barton 2012). Several members of the bacterial hyperthermophilic genus Thermotoga are able to use elemental sulfur as electron acceptor, although this is not always an energy-gaining metabolic process, as sulfur can probably acts as a hydrogen sink during fermentative metabolism (Huber, Langworthy et al. 1986), or it may even be reduced in co-metabolic reactions without any obvious bioenergetics benefit. 


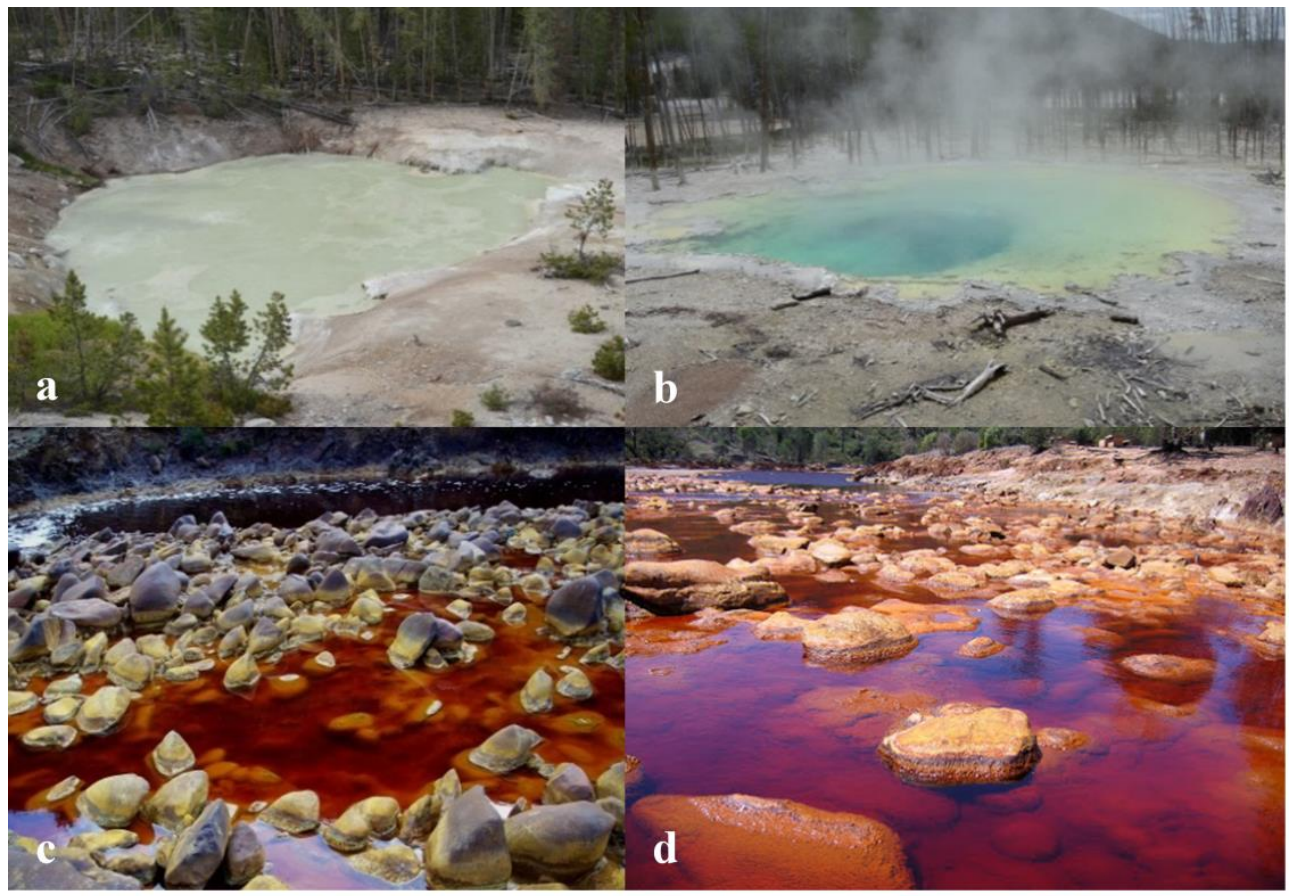

Figure 2a-d - Extreme environments source of acidophilic sulfur-reducing prokaryotes. Hot springs in the Yellowstone National Park, USA ( $a-b$, pictures from the author collection). The acidic Tinto river in Spain (c-d, pictures are courtesy from Prof. José Luis Sanz, Universidad Autónoma de Madrid).

The oxidation of organic substrates by sulfur reducers can be complete, in which $\mathrm{CO}_{2}$ is the only end product besides sulfide (such as in Desulfurella, Desulfuromusa, or Desulfuromonas species); or incomplete, leading to acetate as final carbon product (as happens in Wolinella, Shewanella, or Sulfurospirillum species) (Liesack and Finster 1994, Rabus, Hansen et al. 2013). Those microorganisms might use many different types of metabolic systems for oxidizing organic compounds. However, heterotrophic growth of sulfur reducers was only studied in Desulfuromonas acetooxidans and Desulfurella acetivorans with acetate as electron donor (Gebhardt, Thauer et al. 1985, Schmitz, BonchOsmolovskaya et al. 1990).

\section{Sulfur and thiosulfate respiration}

Although elemental sulfur is chemically quite reactive and its activation prior to reduction is not energy-dependent, it is almost insoluble compound in water $\left(5 \mu \mathrm{g} \mathrm{L}^{-1}\right.$ at $20^{\circ} \mathrm{C}$ ) (Boulegue 1978, Blumentals, Itoh et al. 1990, Schauder and Müller 1993). Some microorganisms are thought to overcome the low solubility of this element by utilizing more hydrophilic sulfur forms for gaining energy for their metabolism. In aqueous solution containing nucleophiles (molecules, such as sulfide or cysteine, able to donate electrons to 
form a covalent bond), elemental sulfur can be readily converted into polysulfide, the most likely electron acceptor for sulfur reducers due to its higher solubility (Blumentals, Itoh et al. 1990, Schauder and Müller 1993). However, the instability of polysulfide at low pH, makes it an unlikely substrate for acidophilic prokaryotes. Therefore, solid elemental sulfur is hypothesized to be reduced by direct contact with the microorganism (Stetter and Gaag 1983, Pihl, Schicho et al. 1989, Finster, Leiesack et al. 1998, Laska, Lottspeich et al. 2003) as has been observed for reduction of insoluble iron or manganese minerals by e.g. Geobacter (Reguera, McCarthy et al. 2005) or Shewanella spp (Moser and Nealson 1996). The actual terminal electron acceptor is still unclear for the great majority of sulfurreducing microorganisms. At least four different enzymes are involved in sulfur reduction, but the actual substrates for the enzymes are still not clearly understood. Details on the metabolism of sulfur respiration are addressed in the review presented in Chapter 2.

Biological thiosulfate reduction has been described in mesophilic facultative and strict anaerobes of the Bacteria domain, as well as by psychrophilic bacteria (Isaksen and Jorgensen 1996, Knoblauch, Sahm et al. 1999) and thermophilic members of the Archaea and Bacteria domains (Stetter, Fiala et al. 1990, Fardeau, Ollivier et al. 1997, Fardeau, Magot et al. 2000).

The molecular basis of thiosulfate respiration has been comprehensively studied in the pathogen Salmonella enterica serovar Typhimurium. The electron transfer between respiratory dehydrogenases and terminal reductases in this microorganism under anaerobic conditions is mediated by two membrane naphthoquinones: the so-called menaquinone and the demethylmenaquinone (Unden and Bongaerts 1997, Unden and Dunnwald 2008). Thiosulfate reductase (Figure 3), isolated from this microorganism, is encoded by the phsABC operon (Heinzinger, Fujimoto et al. 1995). The PhsC subunit of this enzyme is an integral membrane protein that anchors the other two subunits to the membrane. In this subunit, a site for menaquinone oxidation and two heme cofactors on opposite sides of the membrane were detected by sequence analysis (Berks, Page et al. 1995). The catalytic subunit PhsA is a peripheral membrane protein with an active site bis(molybdopterin guanine dinucleotide) molybdenum cofactor (Hinsley and Berks 2002). The subunit PhsB contains four iron-sulfur centers that transfer electrons between the subunits $\mathrm{PhsC}$ and PhsA. The thiosulfate reductase is postulated to perform the first step of thiosulfate reduction into sulfite and sulfide in S. enterica. The sulfite formed was shown to be further reduced by the NADH-linked cytoplasmic dissimilatory sulfite reductase in an energyyielding reaction (Hallenbeck, Clark et al. 1989, Stoffels, Krehenbrink et al. 2012). 


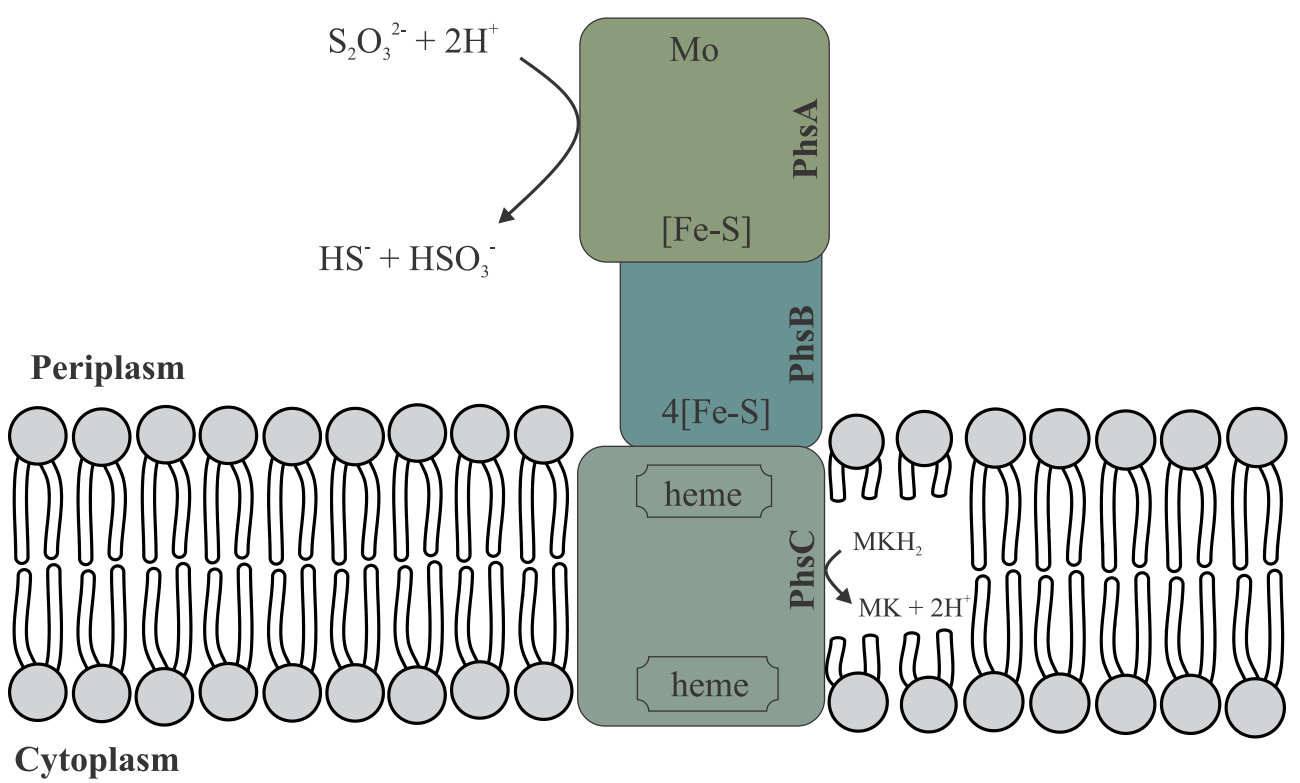

Figure 3 - PhsABC subunits of the enzyme thiosulfate reductase. [Fe-S] stands for ironsulfur cluster; Mo for bis(molybdopterin guanine dinucleotide) molybdenum cofactor; heme for heme $b$; and MK for menaquinone.

Physiological studies of some thiosulfate-oxidizing or reducing bacteria, such as Thiobacillus and Halanaerobium species showed that no thiosulfate reductase was active in the cultures, but thiosulfate:cyanide sulfurtransferase activity was consistently detected (Singleton and Smith 1988, Ravot, Casalot et al. 2005), and therefore, the rhodanese-like sulfurtransferase was postulated to play a role in the first step of thiosulfate respiration. The likely reaction catalyzed by this enzyme is the transfer of sulfane sulfur from thiosulfate to cyanide to form thiocyanate and sulfite (Alexander and Volini 1987). Conversely, it has also been proposed that rhodaneses, using the dithiol dihydrolipoate as the sulfur acceptor, may act as a sulfur insertase in the formation of prosthetic groups in iron-sulfur proteins, such as ferredoxin. Although those thiosulfate sulfurtransferases are widespread enzymes, their physiological role has not yet been clearly established.

In both cases, however, sulfite seems to be a key intermediate in thiosulfate reduction. Increased concentrations of sulfite in the medium is shown to be toxic and inhibit growth of some microorganisms, and the presence and activity of the dissimilatory sulfite reductase is thus crucial for the conversion of the toxic sulfite (Badziong and Thauer 1978, Pereira, He et al. 2008). 


\section{Sulfur disproportionation}

Disproportionation is a chemolithotrophic bacterial metabolism discovered in anaerobic marine enrichment cultures (Thamdrup, Finster et al. 1993), in which a compound undergoes both oxidation and reduction. The disproportionation of elemental sulfur to sulfide an sulfate at standard temperature and pressure conditions is thermodynamically unfavorable $\left(\Delta G^{0}=+33 \mathrm{~kJ} \mathrm{~mol}^{-1}\right.$ per $\left.S^{0}\right)$. However, as the activity of the insoluble elemental sulfur does not change in the medium, the free energy of the reaction becomes strongly influenced by the concentrations of the products and the $\mathrm{pH}$ of the environment (Finster 2008). Thus, under physiological conditions, the conversion becomes thermodynamically possible.

The ability to disproportionate elemental sulfur is described for some sulfur reducers from the Proteobacteria, Firmicutes and Thermodesulfobacteria phyla (Finster, Leiesack et al. 1998, Finster 2008, Hardisty, Olyphant et al. 2013). Disproportionation of elemental sulfur, thiosulfate and sulfite has been proven to be an ecologically relevant process in the sulfur cycle (Thamdrup, Finster et al. 1993, Finster, Leiesack et al. 1998, Finster 2008).

Despite its importance, microbial disproportionation of elemental sulfur into a more reduced (sulfide) and a more oxidized (sulfate) species (equation 1) is still a poorly characterized part of the sulfur cycle. The process has been studied in the sulfur and thiosulfate-disproportionating species Desulfocapsa sulfoexigens. In this microorganism, sulfite was detected as key intermediate of sulfur disproportionation, which is then further oxidized to sulfate via the encoded reverse sulfate reduction pathway or via sulfite oxidoreductase. Enzymes responsible for sulfur reduction, however, were not described in the disproportionation process (Finster 2008).

$$
4 \mathrm{~S}^{0}+4 \mathrm{H}_{2} \mathrm{O} \rightarrow \mathrm{SO}_{4}^{2-}+3 \mathrm{H}_{2} \mathrm{~S}+2 \mathrm{H}^{+} \text {(equation 1) }
$$

In sulfur reducers, sulfide is thought to be generated during disproportionation by a classical sulfur-reducing enzyme (Finster 2008, Hardisty, Olyphant et al. 2013). The enzyme that performs the conversion of sulfur into sulfite, however, is not yet reported in literature.

\section{Sulfur reduction at low $\mathrm{pH}$}

Acidophiles or acidotolerant microorganisms withstand larger $\mathrm{pH}$ gradients across the cytoplasmic membrane than neutrophiles (Baker-Austin and Dopson 2007). Therefore, some energy-dependent processes driven by proton motive force over the cell membrane are performed to foster the homeostasis of $\mathrm{pH}$. Several strategies can be adopted by microorganisms to keep their internal $\mathrm{pH}$ stable: a) a membrane with high impermeability 
or with low fluidity (Konings, Albers et al. 2002); b) membrane channels with reduced size and permeability (Amaro, Chamorro et al. 1991); c) inversion of the electrochemical potential between the intra and extra-cellular environment, the known Donnan potential (Suzuki, Lee et al. 1999, Dopson, Lindstrom et al. 2002); d) active pumping of excess of protons out of the cell (Golyshina and Timmis 2005); e) buffering capacity of the cytoplasm (Zychlinsky and Matin 1983); f) intrinsic systems of DNA and protein repair (Crossman, Holden et al. 2004), and g) stabilization of intracellular enzymes by metal cofactors (Ferrer, Golyshina et al. 2007).

Although several acidophilic sulfur reducers have been described, their physiology and specific mechanisms adopted to face those extreme conditions are still poorly understood. The microbial strategies for acidic resistance commented here are addressed in more detail in Chapter 2.

\section{Biotechnological application}

Acid mine drainage (AMD) or more generally acid rock drainage (ARD), are acidic waters with high concentrations of heavy metals in solution and result from a combination of biological and physicochemical phenomena. Initially, the sulfide minerals are normally chemically oxidized by ferric iron $\left(\mathrm{Fe}^{3+}\right)$, leading to the formation of sulfate and ferrous iron $\left(\mathrm{Fe}^{2+}\right)$, which will be used by iron-oxidizing microorganisms to regenerate $\mathrm{Fe}^{3+}$. The acid runoff further dissolves heavy metals such as copper, lead, mercury into ground or surface water. Even though this process occurs naturally, mining activities have greatly contributed to the heavy metals contamination in the water bodies, by increasing atmospheric exposure of sulfide ore (Johnson and Hallberg 2005, Bratty, Lawrence et al. 2006, Sánchez-Andrea, Stams et al. 2016). Although the prevention of contamination is the ideal scenario, it is rarely realistic and so, remediation of polluted waters is needed for protection of the environment and ground and surface water sources.

Many chemical and/or physical methods have been applied to remove heavy metals from contaminated wastewaters. Despite their effectiveness, they are relatively expensive and produce large volumes of residual metal-contaminated sludge with no or low metal reuse potential (Gallegos-Garcia, Celis et al. 2009, Tekerlekopoulou, Tsiamis et al. 2010). The alkalinity generated by microbial processes, such as methanogenesis, denitrification, and reduction of iron and manganese may result in metal precipitation as hydroxides (Johnson and Hallberg 2005). However, such biological procedures precipitate all the soluble metals together and therefore, the generated waste requires disposal, leading to extra costs to the process.

The bioremediation of acid mine drainage based on biological sulfate reduction has been proposed as a suitable alternative, as sulfate is present in acid mine drainage waters, as product of the sulfide minerals oxidation. The sulfide produced from sulfate 
reduction reacts with divalent metal ions in solution, forming insoluble and stable metal sulfides that precipitate as a dense sludge (Kaksonen and Puhakka 2007), exhibiting better thickening and dewatering characteristics compared to conventional chemical treatments (Huisman, Schouten et al. 2006). The solubility of most metal sulfides is extremely low and the reaction rates between some metals and sulfide are higher at low $\mathrm{pH}$, and so the stable generated metal sulfides present good settling properties (Gallegos-Garcia, Celis et al. 2009, Sánchez-Andrea, Sanz et al. 2014), facilitating its removal and re-utilization.

Several studies have reported the application of sulfate reduction for metal precipitation in natural and engineered acidic environments (Johnson 1995, Johnson and Hallberg 2005, Kaksonen and Puhakka 2007, Bijmans, Dopson et al. 2009, Johnson 2010, Sánchez-Andrea, Sanz et al. 2014). Many configurations of off-line sulfidogenic reactor types are normally constructed and operated to optimize sulfide production in the process. However, only some of them have been applied for sulfate reduction and metal precipitation in a single stage; the most applied configuration comprise two-stage systems, in which the sulfidogenic tank is not part of the waste stream scheme (Johnson and Hallberg 2005, Huisman, Schouten et al. 2006, Sánchez-Andrea, Sanz et al. 2014).

Although the single stage treatment process is a low-cost alternative for active biological systems treatment, it is not viable when the wastewater is very acidic or contains high concentrations of heavy metals (Hao, Huang et al. 1994). Besides, the optimum $\mathrm{pH}$ for sulfate reduction usually lies around neutral values; only three species of moderate acidophilic sulfate-reducing bacteria have been described: Thermodesulfobium narugense, growing at pH 4 (Mori, Kim et al. 2003), Desulfosporosinus acidiphilus, at pH 3 (Jameson, Rowe et al. 2010), and Desulfosporosinus acididurans, growing at pH 3.8 (SánchezAndrea, Stams et al. 2015).

Acidophilic sulfur-reducing microorganisms, more commonly isolated from extreme environments and reported to grow at $\mathrm{pH}$ as low as 1 (Segerer, Neuner et al. 1986, Ohmura, Sasaki et al. 2002, Yoneda, Yoshida et al. 2012) rouses as a cheaper alternative than sulfate reducers to the metals recovery from acidic waste streams. Besides, considering the requirement for electron donors in the systems, due to the low organic matter content in the wastewater from mining and metals industries - usually $10 \mathrm{mg} \mathrm{L}^{-1}$ (Johnson 2010), elemental sulfur is more attractive as electron acceptor than sulfate, since only two electrons per mol of sulfide produced are needed in the process, instead of eight electrons needed for sulfate reduction.

Moreover, many sulfate reducers are incomplete oxidizers: Desulfotomaculum sp., Desulfobulbus sp., Archaeoglobus sp. (Castro, Reddy et al. 2002), Desulfovibrio sp., Thermodesulfobacterium sp. (Widdel 1988, Widdel and Pfennig 1991), Desulfosporosinus sp. (Sánchez-Andrea, Stams et al. 2015). The incomplete oxidation by those microorganisms leads to additional costs and the accumulation of acetic acid, which may 
cause inhibition of the process. In sulfur reducers, especially the ones belonging to the Deltaproteobacteria class, such as Desulfuromonas sp., Geobacter sp., Pelobacter sp. and Desulfurella sp., the oxidation of organic substrates leads to $\mathrm{CO}_{2}$ as the end product (Bonch-Osmolovskaya, Sokolova et al. 1990, Finster, Coates et al. 1997). Therefore, sulfidogenesis based on the reduction of elemental sulfur is attractive for treatment of acidic metal-laden streams in metallurgical processes. Details on the application of sulfidogenesis for metals precipitation and recovery are given in Chapter 2.

\section{Research aim and thesis outline}

The research reported in this thesis investigates the microbiological suitability of sulfur reduction at low $\mathrm{pH}$ for biotechnological application by enriching, isolating and providing a first understanding on the metabolism of sulfur compounds in acidotolerant sulfur-reducing bacteria. Sediments from an acidic river, Tinto river, were the source of the novel described sulfur-reducing bacteria, Desulfurella amilsii and Lucifera butyrica; and in vivo growth and activity experiments in combination with genome and proteome analyses were employed to address the possible pathways of sulfur utilization by the $D$. amilsii as the major research subject. Moreover, a combined growth of the two isolates was performed to improve the sulfidogenesis in the process while added-value compounds could be produced from glycerol degradation.

Chapter 2 provides an overview on the ecology and physiology of elemental sulfur reducers, and discusses technologies that can be set up to exploit acidophilic sulfur reducers. It highlights the importance of acidophilic sulfidogenic microorganisms from the industrial and environmental point of view, which also includes research on their sulfur metabolism and specific mechanisms adopted to tackle extreme conditions.

Chapter 3 describes enrichments for sulfur reducers and the isolation procedure. Sediments from the acidic Tinto river in Spain were used as source of microorganisms adapted to low $\mathrm{pH}$ and their suitability for treatment of acidic and metal-laden wastewater was investigated. Acidophilic sulfur-reducing bacteria were enriched with various electron donors at low $\mathrm{pH}$ and mesophilic conditions. A sulfur-reducing bacterium belonging to the Desulfurella genus was isolated (strain TR1) and its applicability was tested at different $\mathrm{pH}$ and temperature conditions, utilization of electron donors, and growth in the presence of heavy metals in solution. A solid-media with colloidal sulfur was developed to facilitate the isolation of true elemental sulfur reducers at low $\mathrm{pH}$.

Chapter 4 describes the morphological, biochemical and physiological characterization of the novel sulfur-reducing bacterium Desulfurella amilsii TR1. The isolate is affiliated to the Deltaproteobacteria class showing 97\% of $16 \mathrm{~S}$ rRNA gene identity to the four species described in the Desulfurella genus. Besides elemental sulfur, $D$. amilsii is able to use thiosulfate as electron acceptor and to disproportionate elemental 
sulfur into sulfate and sulfide. As a complete oxidizer, it degraded all substrates to $\mathrm{H}_{2} \mathrm{~S}$ and $\mathrm{CO}_{2}$ when growing by sulfur or thiosulfate respiration.

The draft genome sequence of Desulfurella amilsii TR1 is reported in Chapter 5, and a comparison is made with the available genome sequences of other members of the Desulfurellaceae family. Pairwise comparison revealed that two described species, $D$. acetivorans and D. multipotens, should be merged to one species since they showed average nucleotide identity and in silico DNA hybridization values higher than the estimated thresholds for species description. Comparative genome analysis revealed that the genes involved in sulfur respiration differed between the genera Hippea and Desulfurella and within Desulfurella genus. Sulfur reductase was suggested to play a role in sulfur reduction by $D$. amilsii, especially when it grows at low $\mathrm{pH}$. Genes prediction supported by experimental analysis in Desulfurella species indicated a more versatile metabolism in this group. Although genes encoding resistance to acidic conditions are present in all Desulfurellaceae members, this ability was only confirmed in $D$. amilsii, which might be an essential factor for growth environments with high concentration of metals in solution and therefore for its biotechnological application.

Chapter 6 describes the requirement for cell-sulfur interaction of $D$. amilsii at different $\mathrm{pH}$ values (3.5 and 6.5) and the abundance of enzymes possibly involved in chemolithotrophic growth, acid resistance and sulfur respiration. By comparing activity and cell numbers of cultures grown on suspended and dialysis bag-trapped sulfur, we showed that sulfur respiration and growth of $D$. amilsii benefit from contact with elemental sulfur. Proteomic analysis revealed the involvement of the hydrogenase HydABC for oxidation of hydrogen during chemolitotrophic growth, as well as complete pathway for $\mathrm{CO}_{2}$ fixation via the reductive TCA cycle. There is a possible constitutive expression of genes involved in the resistance to acid conditions in $\mathbf{D}$. amilsii. Besides, some proteins were exclusively detected at low $\mathrm{pH}$, but very few overlapped with acid resistance-related known proteins. This chapter also reports different sulfurtransferases highly abundant at low and neutral $\mathrm{pH}$, suggesting that they represent key enzymes in sulfur/polysulfide reduction in $D$. amilsii, while sulfide dehydrogenase seems to function as a ferredoxin:NADP oxidoreductase in this bacterium.

In Chapter 7, the proteomes of D. amilsii cultures grown at its optimum $\mathrm{pH}$ (6.5), using acetate as electron donor and sulfur or thiosulfate as electron acceptors and grown by elemental sulfur disproportionation were compared. The analysis revealed the ability of this bacterium to activate acetate to acetyl-CoA via the acetyl-CoA synthetase enzyme and its oxidation via the TCA cycle. Besides, the respiration of thiosulfate is most likely to happen via the thiosulfate reductase and the dissimilatory sulfite reductase, although the presence of sulfurtransferases was consistent in all the analyzed conditions, suggesting that they might play role in the process. In sulfur respiration and disproportionation, however, 
sulfurtransferases are likely to be the key players, as no other sulfur enzyme was reported in the analysis. The underrepresentation of sulfur reductase in this study, however, must be taken into consideration, as the applied technique may have some issues with membranebound proteins.

Chapter 8 describes a genome-guided characterization of another acidotolerant sulfur respirer, Lucifera butyrica ALE. Its metabolic interaction with $D$. amilsii is also studied. The new isolate is able to reduce sulfur and utilize a broad range of substrates (organic acids, amino acids, sugars, etc). One of these substrates is of biotechnological interest due to its current low price, glycerol. When growing on glycerol by fermentation or by respiration of elemental sulfur, L. butyrica produced acetate, hydrogen and 1,3propanediol as major products, being the latter one also of biotechnological interest as precursor of plastics. Elemental sulfur reduction by this bacterium, however, led to a maximal sulfide production of $2.5 \mathrm{mM}$. When $L$. butyrica grew in a co-culture with $D$. amilsii, the acetate produced by the first was consumed by the latter and the production of sulfide was boosted in the culture. As D. amilsii is not able to degrade glycerol, the coculture represents a strategy to couple the consumption of the compound to the production of a valuable compound (1,3-propanediol) and an enhance in sulfide production that can be drained to precipitation of heavy metals from acidic waste streams.

Chapter 9 summarizes the findings of this thesis, discusses the outcome in a broader context and provides perspectives and directions for future research into the biology and biotechnological application of sulfur-reducing microorganisms. 


\section{Chapter 2}

\section{Ecophysiology and application of acidophilic sulfur- reducing microorganisms}

This chapter has been published as:

Florentino, A. P., J. Weijma, A. J. M. Stams and I. Sánchez-Andrea (2016). Ecophysiology and application of acidophilic sulfur-reducing microorganisms. In: Biotechnology of Extremophiles: Advances and Challenges. H. P. Rampelotto. Cham, Springer International Publishing: 141-175. 


\begin{abstract}
Sulfur-reducing prokaryotes play an important role in the sulfur biogeochemical cycle, especially in deep-sea vents, hot springs and other extreme environments. The reduction of elemental sulfur is not very favorable thermodynamically, but still provides enough energy for growth of microorganisms. Currently known sulfur reducers are spread over about 69 genera within 9 phyla in the Bacteria domain and 37 genera within 2 phyla in the Archaea domain. Elemental sulfur reduction can occur with polysulfide as an intermediate or via direct cell attachment to the solid substrate. At least four different enzymes are involved in those pathways, and these enzymes are also detected in several microorganisms that are potential sulfur reducers, but not reported as such in literature so far. The ecological distribution of sulfur respiration seems to be more widespread at high temperatures with neutral $\mathrm{pH}$. However, some sulfur reducers can grow at $\mathrm{pH}$ as low as 1 . The sulfide produced from sulfur reduction can selectively precipitate metals by varying the $\mathrm{pH}$ values from 2 to 7, depending on the target metal. Therefore, acidophilic sulfur reducers are of particular interest for application in selective precipitation and recovery of heavy metals from metalliferous waste streams. This chapter explores the ecology and physiology of elemental sulfur reducers, and discusses technologies that can be set up to exploit acidophilic sulfur reducers.
\end{abstract}




\section{Sulfur compounds in nature}

Sulfur is an important element in the lithosphere, with an average abundance by weight of about $0.05 \%$ (Steudel and Eckert 2003)However, sulfur is highly concentrated in various continental rocks, such as metal sulfide ore deposits [e.g. pyrite $\left(\mathrm{FeS}_{2}\right)$, chalcopyrite $\left(\mathrm{CuFeS}_{2}\right)$, pyrrhotite $(\mathrm{FeS})$ ] or sulfate deposits [e.g. gypsum $\left(\mathrm{CaSO}_{4} 2 \mathrm{H}_{2} \mathrm{O}\right)$, barite $\left(\mathrm{BaSO}_{4}\right)$ ]. Sulfur can exist in nine different oxidation states, from which -2 (sulfide and reduced organic sulfur), 0 (elemental sulfur) and +6 (sulfate) are most significant in nature (Steudel 2000, Tang, Baskaran et al. 2009).

The oxidation reaction of sulfide to sulfate involves the transfer of eight electrons and can be performed in different steps, in which elemental sulfur, thiosulfate, sulfite, and polysulfide (Hedderich, Klimmek et al. 1999) can appear as intermediates. The importance and stability of these intermediates in solution depends on $\mathrm{pH}$, temperature, presence of chemical oxidizing and reducing agents, catalysts, and the species involved (Knickerbocker, Nordstrom et al. 2000). Sulfur transformations and fate in the environment are highly dependent on microbial activities (Steudel 2000). Microbial transformation of both inorganic and organic sulfur compounds has a profound effect on chemical, physical and biological properties of the biosphere.

There are two different ways to look at the sulfur cycle (Canfield and Farquhar 2012). From a geological perspective, the three most significant long-term pathways by which sulfur is transferred from the earth mantle into the surface environment, and eventually the oceans, are associated with generation of oceanic crust (Canfield 2004). These include volcanic outgassing of $\mathrm{SO}_{2}$ and $\mathrm{H}_{2} \mathrm{~S}$, release of $\mathrm{H}_{2} \mathrm{~S}$ during hydrothermal circulation, and the weathering of igneous sulfide minerals during the hydrothermal circulation of oxic seawater (Canfield and Farquhar 2012).

From the biological perspective, sulfate and/or sulfur reduction may be either assimilatory, when the product sulfide is used for anabolic needs, or dissimilatory, when used for energy conservation and growth (Tang, Baskaran et al. 2009, Canfield and Farquhar 2012). In the presence of light, a large number of so-called anoxygenic phototrophic bacteria use sulfide as electron donor for photosynthesis. They form elemental sulfur, sulfate (Ghosh and Dam 2009) or, sometimes, thiosulfate (Pfennig 1975) as products (equations 1, 2 and 3). Sulfide may be oxidized by chemotrophic prokaryotes coupled to $\mathrm{O}_{2}$, nitrate, manganese or iron reduction (Hedderich, Klimmek et al. 1999, Ohmura, Sasaki et al. 2002).

$$
\begin{gathered}
\mathrm{H}_{2} \mathrm{~S}+1 / 2 \mathrm{O}_{2} \rightarrow \mathrm{S}^{0}+\mathrm{H}_{2} \mathrm{O} \text { (equation 1) } \\
\mathrm{H}_{2} \mathrm{~S}+2 \mathrm{O}_{2} \rightarrow \mathrm{H}_{2} \mathrm{SO}_{4} \text { (equation 2) } \\
4 \mathrm{H}_{2} \mathrm{~S}+5 \mathrm{O}_{2} \rightarrow 2 \mathrm{~S}_{2} \mathrm{O}_{3}+4 \mathrm{H}_{2} \mathrm{O} \text { (equation 3) }
\end{gathered}
$$


Elemental sulfur $\left(\mathrm{S}^{0}\right)$, thiosulfate $\left(\mathrm{S}_{2} \mathrm{O}_{3}{ }^{2-}\right)$ and sulfite $\left(\mathrm{SO}_{3}{ }^{2-}\right)$, as products of sulfide oxidation, can be microbially oxidized, reduced, or disproportionated to sulfate and sulfide. The disproportionation of elemental sulfur seems to be of great significance in the environment (Steudel 2000, Tang, Baskaran et al. 2009, Canfield and Farquhar 2012). Biological reactions described in this section are summarized in Figure 1. Chemical reactions are described in the next section.

\section{GENERATION ： CONSUMPTION}

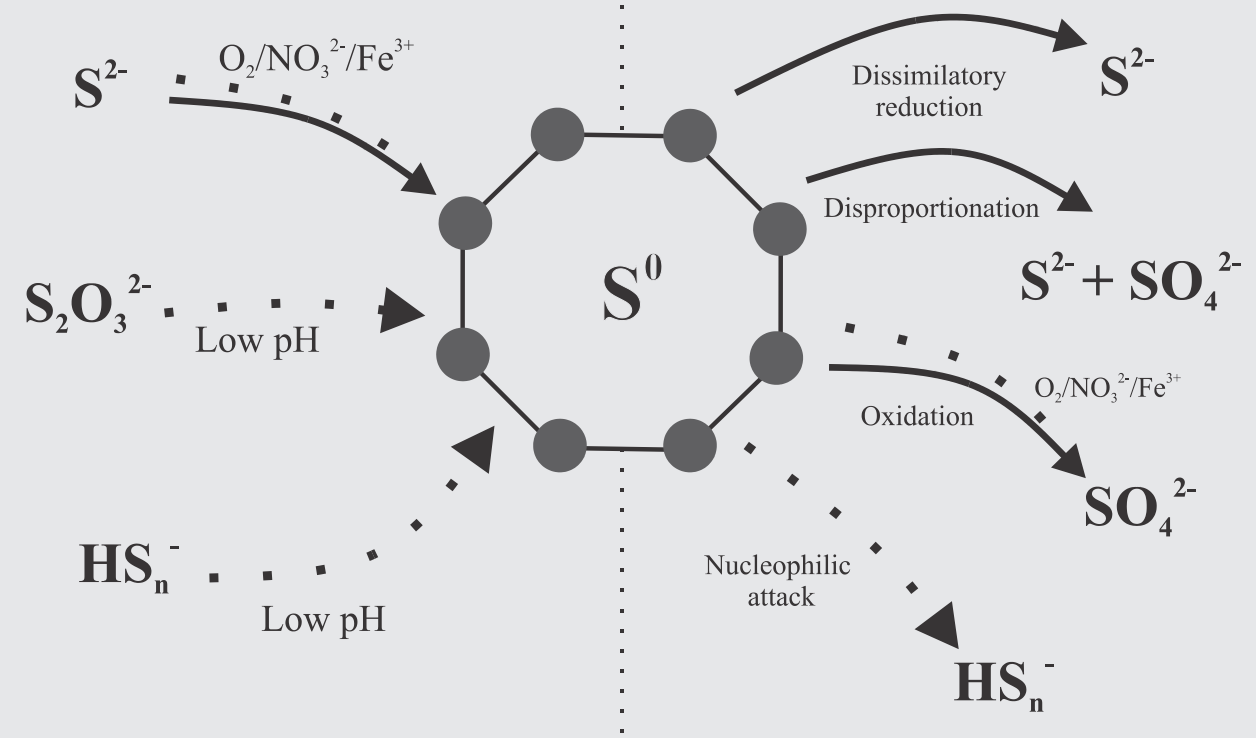

Figure 1 - Possible reactions with elemental sulfur as product or reagent. On the left side, reactions that lead to sulfur (by oxidation processes or acidification of the medium) are shown. On the right side, consuming reactions (sulfur reduction, disproportionation, oxidation and nucleophilic attack by sulfide) shown. Biological reactions are represented as full lines and chemical reactions as dashed lines.

\section{Chemistry of elemental sulfur}

Elemental sulfur $\left(\mathrm{S}_{8}^{0}\right)$ is the molecule with the largest number of solid structural forms that can be divided into ambient pressure and high-pressure allotropes. Although there exist over 180 different allotropes and polymorphs (Box 1), the only stable form of elemental sulfur at standard temperature and pressure conditions $(273.15 \mathrm{~K}$ and 1 bar) is the orthorhombic $\alpha-S_{8}^{0}$ modification (Steudel and Eckert 2003).

Sulfur is hardly soluble in water; the solubility of the $\alpha-S_{8}$ at $20^{\circ} \mathrm{C}$ is only $5 \mu \mathrm{g} \mathrm{L}^{-1}$ (Boulegue 1978). In general, the solubility of elemental sulfur allotropes in organic solvents decreases with the increasing molecular size. Carbon disulfide, toluene and 
dichloromethane are the best sulfur solvents, while cyclo-alkanes are suitable for the smaller ring molecules only at ambient temperatures (Steudel and Eckert 2003). At higher temperatures $\left(65-140^{\circ} \mathrm{C}\right)$, elemental sulfur is also soluble in compressed gases like nitrogen, methane, carbon dioxide, and hydrogen sulfide, which is of importance for the gas industry since many natural gas reservoirs also contain $\mathrm{H}_{2} \mathrm{~S}$ and elemental sulfur. For example, in a range of pressure from 10 to $30 \mathrm{MPa}$, solubility of elemental sulfur in hydrogen sulfide increases from $38.6 \mathrm{mg} \mathrm{L}^{-1}$ at $65^{\circ} \mathrm{C}$ (Roof) to 65.7 at $90^{\circ} \mathrm{C}(\mathrm{Gu}, \mathrm{Li}$ et al. 1993), 68.1 at $100^{\circ} \mathrm{C}, 91.2$ at $110^{\circ} \mathrm{C}$ (Roof) and $110.8 \mathrm{mg} \mathrm{L}^{-1}$ at $140^{\circ} \mathrm{C}$ (Brunner and Woll).

The customary form in which elemental sulfur is typically trade, also called sulfur flower, mainly consists of $\mathrm{S}_{8}$ rings and some polymeric sulfur which consists of chain-like macromolecules (Steudel and Eckert 2003) (Figure 2). The bonding energy between S-S bonds in polymeric sulfur is $2.3 \mathrm{~kJ} \mathrm{~mol}^{-1}$ weaker than in $\mathrm{S}_{8}$, for which the heat of reaction $\mathrm{S}_{8}$ (ring) $\rightarrow \mathrm{S}$ (chain) is $115.14 \mathrm{~kJ} \mathrm{~mol}^{-1}$ per sulfur atom (Franz, Lichtenberg et al. 2007). Chain-like sulfur might be easier to access by sulfur-reducing or sulfur-oxidizing microorganisms.
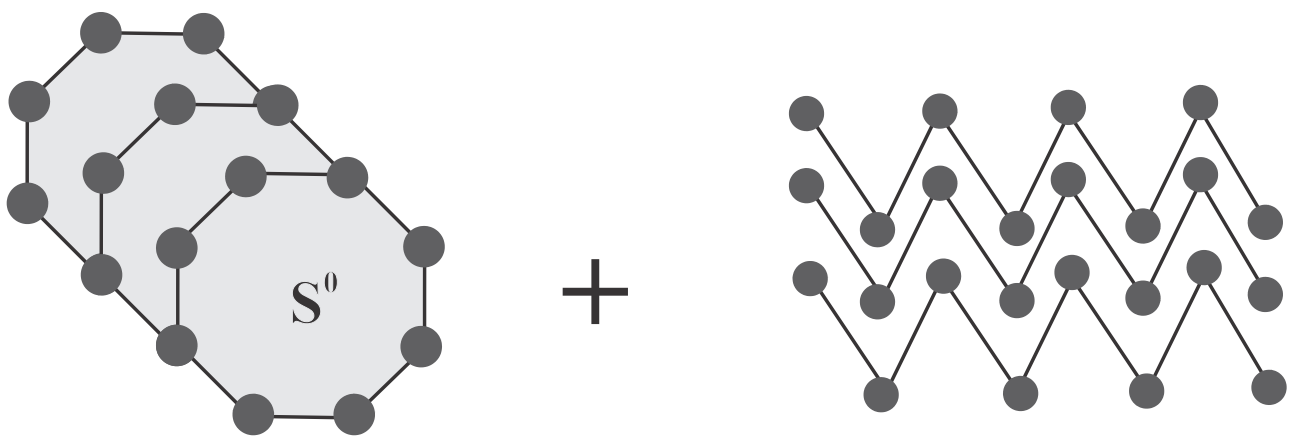

Figure 2 - Rings and chain-like macromolecules of polymeric sulfur that compose the commercialized sulfur flower.

When sulfide $\left(\mathrm{S}^{2-}\right)$ is present in the same environment as elemental sulfur, normally at high $\mathrm{pH}$ values, the $\mathrm{S}_{8}$-ring of elemental sulfur is cleaved by nucleophilic attack of $\mathrm{HS}^{-}$anion, leading to the formation of polysulfide (Rabus, Hansen et al. 2006). Polysulfide is considered to be preferred over elemental sulfur as electron acceptor by microbes at high temperature and neutral-high $\mathrm{pH}$ values due to its higher availability at these conditions (Schauder and Müller 1993). The most important forms of polysulfide are tetrasulfide $S_{4}^{2-}$ and pentasulfide $S_{5}^{2-}$ (Rabus, Hansen et al. 2006) which can interconvert rapidly at neutral environments, supporting the growth of neutrophilic sulfur-reducing microorganisms (Schauder and Müller 1993).

The equilibrium concentration of polysulfide $\left(\mathrm{S}_{\mathrm{n}}{ }^{2-}\right)$ in sulfide solution is dependent on $\mathrm{pH}$, temperature and sulfide concentration. With decreasing $\mathrm{pH}$ equilibrium concentration of polysulfide drops drastically, due to the instability of $\mathrm{S}_{\mathrm{n}}{ }^{2-}$ in the presence 
of high proton concentrations, and the reaction goes towards elemental sulfur and sulfide, as represented in equation 4 (Schauder and Müller 1993).

$$
2 \mathrm{~S}_{5}^{2-}+4 \mathrm{H}^{+} \leftrightarrow \alpha \mathrm{S}_{8}+2 \mathrm{H}_{2} \mathrm{~S} \text { (equation 4) }
$$

However, the equilibrium concentration increases with increasing temperatures. Thus, $0.1 \mathrm{mM} \mathrm{S}^{0}$ will dissolve at $\mathrm{pH} 6.7$ and at $30^{\circ} \mathrm{C}$, while at $\mathrm{pH} 5.5$, the same amount will only dissolve at $90^{\circ} \mathrm{C}$. Due to the dissociation constant, the amount of $\mathrm{S}^{0}$ that can maximally be dissolved as polysulfide in a sulfide solution at $\mathrm{pH} 8.0$ and $37^{\circ} \mathrm{C}$ is nearly equivalent to the sulfide concentration (Klimmek, Kröger et al. 1991). Much less polysulfide however is formed at $\mathrm{pH}$ values below the $\mathrm{pK}$ of $\mathrm{H}_{2} \mathrm{~S}$ (Hedderich, Klimmek et al. 1999), which is 7.0 at $25^{\circ} \mathrm{C}$.

Thiosulfate is also unstable under acidic $\mathrm{pH}$ conditions and decomposes into sulfur oxides, sulfide and colloidal/dissolved sulfur as nanocrystals (equation 5) (Wang, Tessier et al. 1998). The colloidal sulfur form turns the solutions into milky color upon the formation of elemental sulfur. In natural environments organic polymers may adsorb to colloidal sulfur particles, altering their solubility, making them more hydrophilic (Breher 2004). As the sulfur particles are generated together with sulfide, they can react, producing an aqueous solution of polysulfide ions, which has implications for the mobility of sulfur in the environment, in the availability for sulfur bio-oxidation, and in the kinetics of polysulfide and sulfide formation (Breher 2004). However, colloidal sulfur is thermodynamically unstable and eventually precipitates as small settleable crystals (Kleinjan, de Keizer et al. 2005).

$$
2 \mathrm{~S}_{2} \mathrm{O}_{3}+2 \mathrm{H}^{+} \leftrightarrow \mathrm{H}_{2} \mathrm{~S}+2 \mathrm{SO}_{3}+\mathrm{S}^{0} \text { (equation 5) }
$$

Another form of elemental sulfur, more hydrophilic than the orthorhombic form, is the so-called bio-sulfur (Steudel and Eckert 2003), which is formed through biotic oxidation of sulfide and can be stored inter- or extra-cellularly in the form of sulfur globules (Kleinjan, de Keizer et al. 2005). It has been suggested that the more hydrophilic nature of bio-sulfur is due to organic end groups and absorbed organic polymers, such as proteins, and its structure may differ between species of sulfur bacteria (Steudel, Kleinjan et al. 2003). Phototrophic bacteria produce long sulfur chains stabilized by organic compounds; whereas chemotropic bacteria mainly form sulfur rings consisting of eight sulfur atoms (Kleinjan, de Keizer et al. 2005).

\section{Sulfur-reducing microorganisms}

Many prokaryotes are able to colonize environments without any presence of oxygen, evolving not only fermentation pathways, but also respiration, coupling the 
oxidation of hydrogen or organic substrates with the reduction of organic or inorganic compounds, to conserve energy for anaerobic growth (Hedderich, Klimmek et al. 1999, Rabus, Hansen et al. 2006). Nitrate, manganese (IV), ferric iron, carbon dioxide, protons, selenite, uranium (VI), chromate (VI), arsenate, trymethylamine-N-oxide (TMAO), and sulfur compounds, such as sulfate, elemental sulfur, sulfite, thiosulfate, sulfoxides, dimethylsulfoxides (DMSO), and organic disulfides are possible electron acceptors reduced by prokaryotes under anoxic conditions (Rabus, Hansen et al. 2006).

Dissimilatory reduction of $\mathrm{Fe}$ (III) and sulfur compounds are significant geobiochemical reactions that occur in soils, aquatic and subsurface environments (Lovley, Phillips et al. 1995). Reduction of iron has a pronounced influence on the distribution of iron and on the fate of trace metals and nutrients. Additionally, it plays an important role on the degradation of organic matter and can be a promising agent for bioremediation of organic and metals contaminated environments (Lovley, Holmes et al. 2004). Reduction of Fe (III) can be performed by several microorganisms in the presence of sulfur compounds as energy source.

Reduction of sulfur compounds by it turn attracts attention as it generates hydrogen sulfide as the main end product. Sulfide is known by its pronounced impact on the chemistry of the environment and, furthermore, can serve as electron donor for a great diversity of microorganisms (Rabus, Hansen et al. 2006). Due to the abundancy and thermodynamic stability, sulfate is the sulfur compound most studied as electron acceptor for anaerobic respiration.

Elemental sulfur reduction, however, is of great importance especially in deep-sea vents, hot springs and other extreme environments, from where microorganisms have been isolated most frequently and their diversity is equivalent to that of sulfate reducers (Stetter 1996).

\section{Ecophysiology of sulfur reducers}

Currently known sulfur reducers are spread over about 69 genera within 9 phyla in the Bacteria domain (Figure $3 \mathrm{a}$ and b) and 37 genera within 2 phyla in the Archaea domain (Figure 4). They use elemental sulfur as the main electron acceptor for the oxidation of organic compounds or $\mathrm{H}_{2}$.

Although microbial sulfur reduction was already reported in several early studies as mentioned by Rabus, Hansen et al. (2006), Pelsh (1936) reported the first evidence of elemental sulfur reduction as the sole source of energy for microbial growth in enrichments of a vibrioid bacterium from mud using sulfur and $\mathrm{H}_{2}$ as defined substrates. The first pure culture growing by sulfur reduction was Desulfuromonas acetoxidans, an obligately anaerobic acetate-degrading mesophile (Pfennig and Biebl 1976). The first sulfur reducers 
described were obligate sulfur reducers, not able to use sulfate $\left(\mathrm{SO}_{4}{ }^{2-}\right)$ (Pfennig and Biebl 1976).

Many sulfur reducers have the ability to reduce other compounds such as thiosulfate, iron (III), nitrate and even oxygen, though anoxic environments are more favorable (Rabus, Hansen et al. 2006). The capability for sulfur reduction was also observed for microorganisms isolated with other electron acceptors, such as sulfate (Biebl and Pfennig 1977), iron (III) (Caccavo Jr., Lonergan et al. 1994) and manganese (IV) (Myers and Nealson 1988). Among the sulfate reducers, only a few species can grow with elemental sulfur, and growth of many sulfate reducers can be even inhibited by sulfur (Bak and Pfennig 1987, Burggraf, Jannasch et al. 1990).

Sulfur-reducing prokaryotes are able to grow at a broad range of temperature (from -2 to $110^{\circ} \mathrm{C}$ ) and $\mathrm{pH}$ (from 1-10.5) (Supplemental material - Table 1). Most of the sulfur reducers identified thrive at neutral environments. However, some hyperthermophilic Archaea isolated from solfatara fields are reported to grow at $\mathrm{pH}$ as low as 1 , such as Acidianus ambivalens, Acidianus brierleyi, Styogiolobus azoricus, Thermoplasma volcanium and Thermoplasma acidophilum (Segerer, Neuner et al. 1986, Segerer, Langworthy et al. 1988, Segerer, Trincone et al. 1991). The lowest $\mathrm{pH}$ reported $\mathrm{pH}$ so far for sulfur-reducing bacteria growth is 1.3 for Acidithiobacillus ferrooxidans (Ohmura, Sasaki et al. 2002), but several acidophiles and acidotolerants species have been described within this domain, such as Desulfosporosinus acididurans (pH 3.6), Desulfosporosinus acidiphilus ( $\mathrm{pH}$ 3.8), Desulfurobacterium thermolithotrophum, Marinitoga hydrogenitolerans and Thermanaerovibrio velox ( $\mathrm{pH}$ 4.5) (L'Haridon, Cilia et al. 1998, Zavarzina, Zhilina et al. 2000, Postec, Breton et al. 2005, Alazard, Joseph et al. 2010, Sánchez-Andrea, Stams et al. 2015).

Even though several mesophilic microorganisms able to reduce elemental sulfur have been described such as Desulfuromonas, Beggiatoa, or Sulfurospirillum (Pfennig and Biebl 1976), sulfur respiration seems to be more widespread at higher temperature. Slightly thermophilic bacteria $\left(\mathrm{T}_{\mathrm{opt}}=40-60^{\circ} \mathrm{C}\right)$ such as Desulfurella and Thermoanaerobacter (Bonch-Osmolovskaya, Sokolova et al. 1990, Bonch-Osmolovskaya, Miroshnichenko et al. 1997) ) and moderately thermophilic bacteria $\left(\mathrm{T}_{\mathrm{opt}}=60-80^{\circ} \mathrm{C}\right)$, such as Ammonifex (Huber, Rossnagel et al. 1996) and Desulfurobacterium (L'Haridon, Cilia et al. 1998) have been described as well as some hyperthermophilic sulfur reducers such as Aquifex (Huber, Wilharm et al. 1992).

Extreme habitats such as hot water pools in solfataric fields, acidic hot springs, hydrothermal systems in shallow and deep sea, hypersaline lakes and anoxic mud sediments harbor sulfur reducers that grow at high temperature and low $\mathrm{pH}$ (Stetter 1996, Rabus, Hansen et al. 2006). Due to their abundance and specialized metabolic activities sulfurreducing prokaryotes are thought to play an important role in the sulfur biogeochemical 
cycle in deep-sea vents, hot springs and other extreme environments (BonchOsmolovskaya, Miroshnichenko et al. 1990, Alain, Callac et al. 2009, Birrien, Zeng et al. 2011).

a

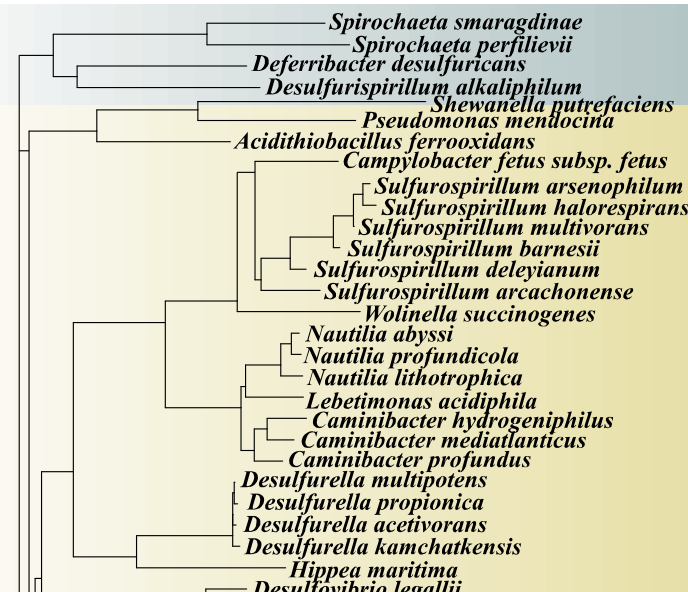

Desulfovibrio legallii

Desulfovibrio desulfuricans subsp. desulfuricans

Desulfovibrio termitidis

Desulfovibrio indonesiensis

Desulfovibrio gigas

Desulfovibrio frigidus

- Desulfovibrio mexicanus

Desulfovibrio burkinensis

Desulfovibrio fructosovorans

Desulfonatronum thioautotrophicum

Desulfomicrobium baculatum

Desulfovermiculus halophilus

Desulfonatronovibrio thiodismutans

esulfobotulus alkaliphilus

Desulfobacter postgatei

Desulfobulbus propionicu
Desulfurivibrio alkaliphilus

Desulfomonile tiedjei

Desulfuromusa bakii

Lesulfuromusa kysingii

Lesulfuromusa succinoxidans

Pelobacter seleniigenes

Geoalkalibacter subterraneus

Pelobacter carbinolicus

esulfuromonas acetexigens

Desulfuromonas acetoxidan

Geobacter chapelleii

Geobacter bremensis

Geobacter humireducen

$\underline{1 \%}$

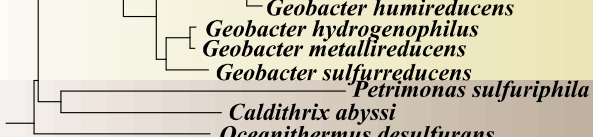

Oceanithermus desulfurans

\section{Spirochaetes}

Deferribacteres

Chrysiogenetes

] Gammaproteobacteria

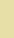

Campylobacterales

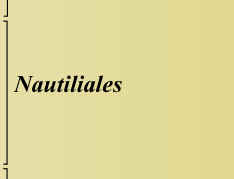

Desulfurellales
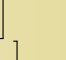

Desulfovibrionales

Epsilonproteobacteria
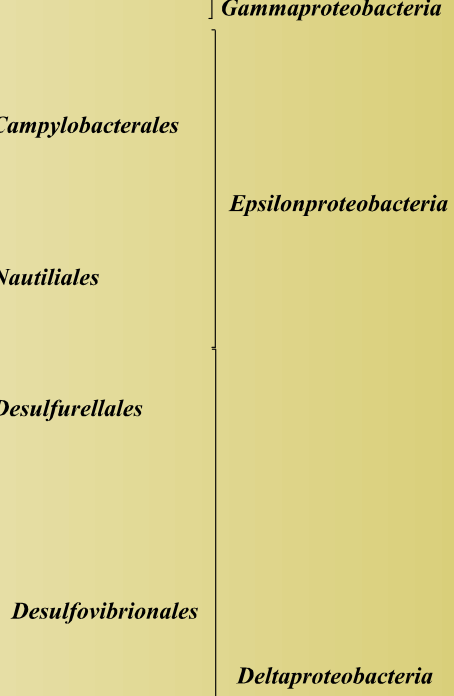

Deltaproteobacteria

Desulfobacterales

Syntrophobacterales

Desulfuromonadales 


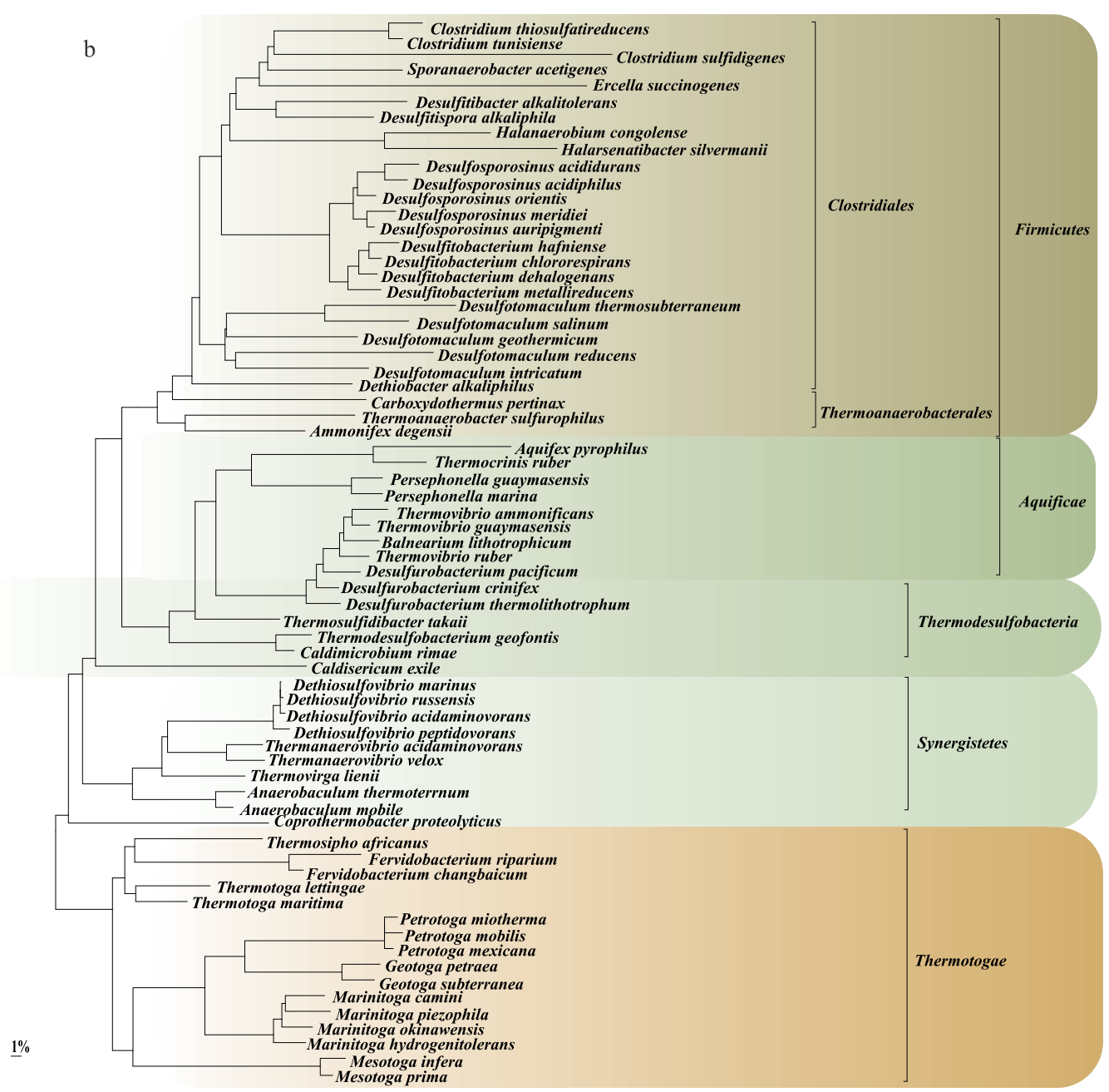

Figure 3 - Phylogenetic affiliation of 16S rRNA gene sequences of sulfur-reducing bacteria in The All-Species Living Tree Project (Yarza, Richter et al., 2008). In 3a, the sequences belonging to the phyla Proteobacteria, Spirochaetes, Deferribacteres and Chrysiogenetes are represented, and in $3 \mathrm{~b}$ sequences belonging to the phyla Firmicutes, Aquificae, Thermodesulfobacteria, Synergistetes and Thermotogae are represented. 1\% estimated sequence divergence.

In anoxic mud sediment environments, sulfur-reducing microorganisms often form associations with sulfide oxidizers, which provide them with elemental sulfur. The sulfur reducers by their turn reduce the elemental sulfur back to sulfide that will be used as electron donor by the sulfide oxidizers (Pfennig 1975). In hydrothermal vents, some sulfur reducers can be found as free-living organisms on vent chimneys or plumes, or as endosymbionts of animals such as tube worms and shrimps, in which they do the same job 
as their counterparts in the vents by reducing and oxidizing sulfur compounds (Alain, Callac et al. 2009).

Described sulfur-reducing bacteria are widespread within the phylogenetic tree of life. They belong to the phyla Proteobacteria (Delta, Epsilon- and Gammaproteobacteria classes), Thermodesulfobacteria, Spirochaetes, Deferribacteres, Chrysiogenetes, Firmicutes, Aquificiae, Synergistetes and Thermotogae (Figure 3a and b). In the order Clostridiales and Thermoanaerobacterales, sulfur reduction seems to be a quite widespread metabolic trait (Hernandez-Eugenio, Fardeau et al. 2002, Sallam and Steinbüchel 2009). Within the Archaea, sulfur reduction occurs in the phyla Euryarchaeota (Fiala and Stetter 1986, Burggraf, Jannasch et al. 1990) and Crenarchaeota (Figure 4) (Itoh, Suzuki et al. 1998, Prokofeva, Miroshnichenko et al. 2000, Itoh, Suzuki et al. 2003).

The metabolism of sulfur reducers has been poorly studied, with the exception of few microorganisms, such as the bacterium Wolinella succinogenes and the archaeon Pyrococcus furiosus. Besides to the biochemistry and bioenergetics of sulfur respiration, little attention has been paid to the conversion of the electron donors in sulfur reducers. Most of the literature related to metabolic pathways and energy conservation is focused on lithotrophic growth on hydrogen or formate as electron donors. Heterotrophic growth on acetate has been investigated only in a few bacteria (Schröder, Kröger et al. 1988, Klimmek, Kröger et al. 1991, Kreis-Kleinschmidt, Fahrenholz et al. 1995). For instance, oxidation of acetate with sulfur as electron acceptor was studied in Desulfurella and Desulfuromonas species, which occurs via the citric acid cycle. The electron transport is carried out by ferredoxin that might accept electrons from the 2-oxoglutarate via NADP in a 2-oxoglutarate dehydrogenase reaction and menaquinone mediates electron flow to sulfur reductase (Schmitz, Bonch-Osmolovskaya et al. 1990, Rosenberg, DeLong et al. 2013). The mechanism of acetate activation and of succinate formation, however, is different. In $D$. acetoxidans, acetyl-CoA and succinate are formed from acetate and succinyl-CoA, and only one enzyme, the succinyl-CoA:acetate CoA transferase, seems to be involved. In $D$. acetivorans, acetyl-CoA is formed from acetate via acetyl phosphate involving acetate kinase and phosphate acetyltransferase and succinate is formed from succinyl-CoA via succinyl-CoA synthetase (Schmitz, Bonch-Osmolovskaya et al. 1990).

Other substrates, including alcohols, such as methanol and ethanol; organic acids, like propionate, butyrate, and lactate; sugars, such as glucose, fructose, cellobiose, cellulose, lactose, arabinose, rhamnose, maltose; starch and molasses have also been described as organic substrates for sulfur reducers (Bonch-Osmolovskaya, Sokolova et al. 1990, Finster, Coates et al. 1997, Dirmeier, Keller et al. 1998, Boyd, Jackson et al. 2007).

The oxidation of carbon substrates by sulfur reducers can be complete or incomplete. In the first case, it leads to the solely production of $\mathrm{CO}_{2}$ (Desulfuromonas and Desulfurella) (Pfennig and Biebl 1976, Rainey and Hollen 2005) while in the second, 
acetate and $\mathrm{CO}_{2}$ are produced as final products (Wolinella and Shewanella) (Macy, Schröder et al. 1986).

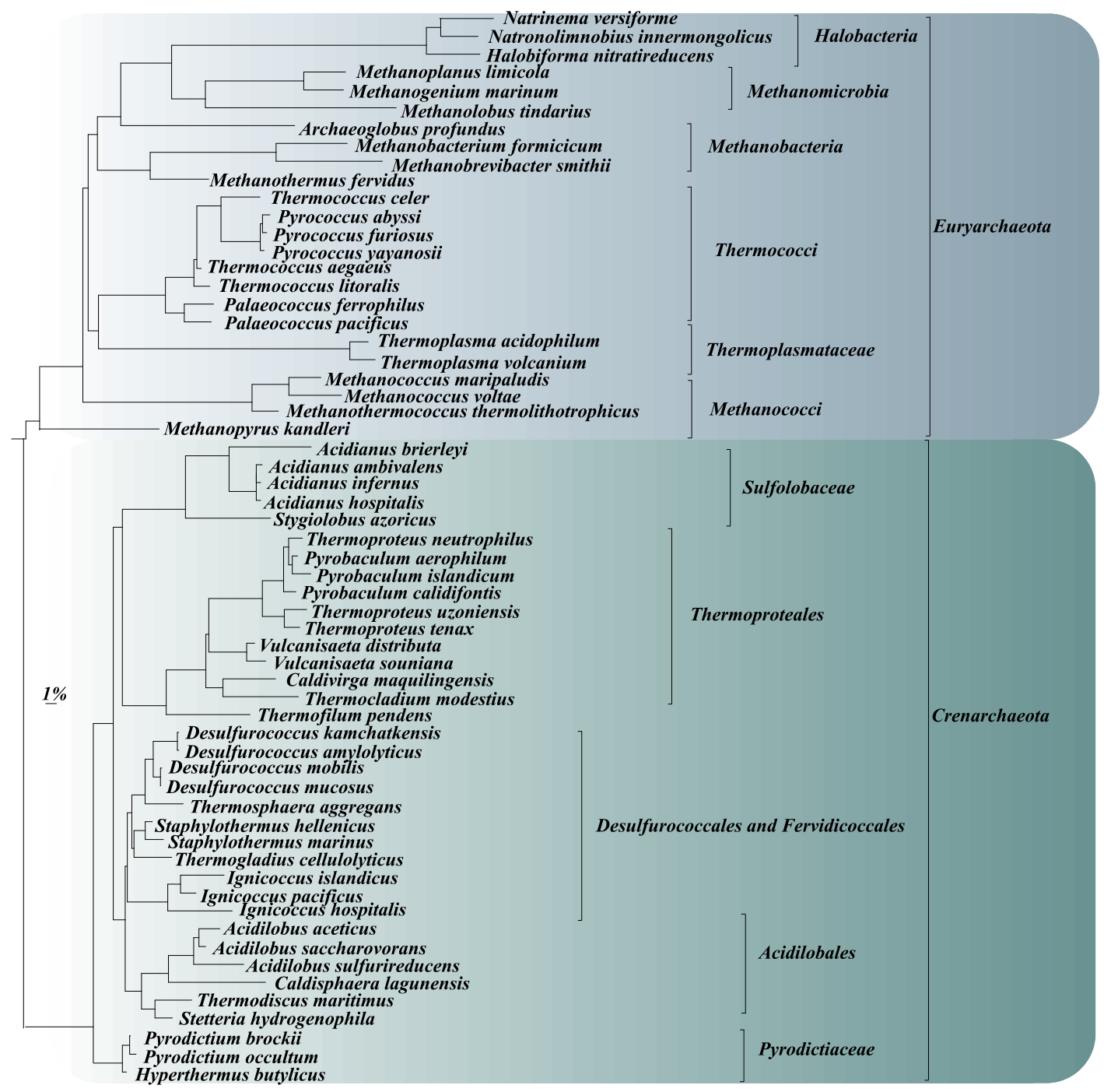

Figure 4 - Phylogenetic affiliation of 16S rRNA gene sequences of sulfur-reducing archaea in The All-Species Living Tree Project (Yarza, Richter et al., 2008). 1\% estimated sequence divergence.

\section{Sulfur metabolism}

The poor solubility of $\alpha-S_{8}^{0}$ is a bottleneck for fast growth of sulfur reducers (Bonch-Osmolovskaya, Sokolova et al. 1990, Schauder and Müller 1993, Miroshnichenko, 
Rainey et al. 1998, Prokofeva, Miroshnichenko et al. 2000). Two possible mechanisms to overcome the low solubility of elemental sulfur have been reported (Cammack, Fauque et al. 1984, Zöphel, Kennedy et al. 1991, Schauder and Müller 1993). One possibility is that sulfur is converted to a more hydrophilic and/or soluble form, such as polysulfide, that can support faster growth (Blumentals, Itoh et al. 1990, Schauder and Müller 1993). It is likely that the increasing solubility of sulfur and the formation of polysulfide at higher temperatures and $\mathrm{pH}$ is beneficial for growth of thermophilic and hyperthermophilic microorganisms (Belkin, Wirsen et al. 1985).

However, as polysulfides are unstable at low $\mathrm{pH}$, it can be that the binding proteins synthesized by sulfur reducers, such as polysulfide sulfur transferases, allow fast polysulfide respiration at low polysulfide concentration (Klimmek 2005), and thus polysulfide is still the substrate. Alternatively, it could be that acidophiles use nanocrystalline that is formed from polysulfide decomposition as electron acceptor. So far, there is still no agreement if polysulfides or nanocrystalline can serve as electron acceptor for acidophilic/acidotolerant microorganisms (Boyd and Druschel 2013). Besides polysulfide, hydrophilic sulphur formed by the association of elemental sulfur with small portions of oxo-compounds (Box 1), such as aldehydes, carboxylic acids, ketones, amides, and esters (Steudel, Göbel et al. 1989) can serve as electron acceptor for microorganisms.

\section{Box 1}

Allotropy: ability of a material to have more than one structure under different conditions of temperature and pressure and to regain these structures when conditions are reversed. Hence, allotropy is a reversible polymorphism.

Polymorphism: ability of solid material to exist in more than one form or crystal structure. If there is change in temperature and pressure, and it is not accompanied by melting or vaporization of the solid, it will cause the solid to change its internal structure of atoms.

Oxo-compounds: compounds containing an oxygen atom doubly bound to carbon or another element $(=\mathrm{O})$.

It is remarkable, however, that some bacteria are reported to grow with elemental sulfur when there is no possibility of solubilization in the form of polysulfide (Thamdrup, Finster et al. 1993, Finster, Leiesack et al. 1998). As an alternative mechanism, the physical attachment of the microbes to the elemental sulfur is proposed, resulting in a direct conversion of sulfur to sulfide.

Even though it is still not clear which mechanism of sulfur reduction is used by the different sulfur reducers, it is likely that hyperthermophilic chemolithoautotrophic archaea reduce elemental sulfur to sulfide via physical attachment (Pihl, Schicho et al. 1989, Stetter, Huber et al. 1993). Moreover, since polysulfides are unstable at low $\mathrm{pH}$ and rapidly 
dissociate into sulfur and sulfide, it is reasonable to hypothesize that elemental sulfur can be the real substrate for the sulfur reductase identified in A. ambivalens, an extreme acidophile (Laska, Lottspeich et al. 2003)

The reductases that mediate sulfur reduction (either via attachment or via polysulfide) have been purified and characterized from a few sulfur reducers (Schröder, Kröger et al. 1988, Childers and Noll 1994, Ng, Sawada et al. 2000, Laska, Lottspeich et al. 2003), but sulfur reduction through polysulfide has only been confirmed in $W$. succinogenes (Klimmek, Kröger et al. 1991), Pyrococcus furiosus (Blumentals, Itoh et al. 1990) and some Clostridium species (Takahashi, Suto et al. 2010).

\section{Enzymes involved in sulfur reduction}

In general, the nomenclature of the enzymes involved in sulfur reduction is not well standardized in the published literature. Sometimes the enzymes receive one name related to specific characteristics when they are first isolated and, afterwards, due to more general properties, the name is changed. That was the case for the enzyme sulfhydrogenase. The two hydrogenases isolated from $P$. furiosus were formerly called sulfhydrogenases (Shy). However, as these enzymes seem to be regulated by metabolites other than sulfur, the name sulfhydrogenase became confusing and out of date; so, it was proposed to rename as hydrogenase from hyperthermophiles (Hyh) (Vignais, Billoud et al. 2001). However, sulfhydrogenase is still present in the database as the main name of the enzyme and is therefore used in this manuscript.

In the genomes database, it is common to find enzymes in reported sulfur reducers named only as sulfur reductase, without specificity about the groups to which they are related. It is also possible to find the mentioned names as synonyms, when they actually refer to different enzymes. In some searches on the available databases, for example MetaCyc (http://metacyc.org/), sulfide dehydrogenase can be referred as sulfhydrogenase and vice-versa.

So far, three enzymes involved in reduction of elemental sulfur and polysulfide to hydrogen sulfide are characterized and described in literature: polysulfide reductase, isolated from Wolinella succinogenes (Hedderich, Klimmek et al. 1999), and sulfide dehydrogenase and sulfhydrogenase, both isolated from P. furiosus (Ma and Adams 1994).

\section{Polysulfide reductase}

The membrane-bound enzyme is a molybdopterin-containin protein that consists of three subunits predicted by the operon psrABC (Krafft, Gross et al. 1995). The molybdopterein cofactor is located at the catalytic subunit PsrA, which has an [4Fe-4S] iron-sulfur center. The purified enzyme contains $20 \mathrm{~mol}$ of free iron and sulfide per mol of 
enzyme. Since the subunit PsrB contains four [4Fe-4S] iron-sulfur centers, the mentioned amount is consistent with the whole enzyme (Hedderich, Klimmek et al. 1999).

The subunit PsrC is a hydrophobic protein that anchors the enzyme in the membrane. PsrB likely serve as a mediator of electron transfer between the membrane anchor (PsrC) and the catalytic subunit (PsrA). PsrA is probably bound to PsrB which is bound to PsrC at the periplasmic side of the membrane (Dietrich and Klimmek 2002). The purified enzyme contains menaquinone as cofactor. Due to its lipophilic nature, it is likely that the menaquinone is bound to the subunit PsrC of the enzyme.

The hypothetical mechanism of polysulfide reduction at the catalytic subunit PsrA indicates that a sulfur atom is cleaved from the end of the polysulfide chain and bound to the molybdenum cofactor, that is further oxidized. The molybdenum cofactor in the PsrA is most likely coordinated by two molybdopterin guanine nucleotide molecules. Thus, after the uptake of a proton, probably via sulfide dehydrogenase, and two electrons, $\mathrm{HS}^{-}$is released and the molybdenum returns to its reduced stage (Figure 5) (Klimmek, Kröger et al. 1991).

Sequences of the gene subunits deposited in the JGI genome database are available under accession numbers: PsrA: NP906381; PsrB: NP906382; PsrC: NP906383.

\section{Sulfide dehydrogenase}

Sulfide dehydrogenase, also called flavocytochrome c sulfide dehydrogenase, is a bifunctional cytoplasmic enzyme that catalyzes the reduction of polysulfides to sulfide using NADPH as electron donor (Ma and Adams, 1994), but it can also function as a ferredoxin:NADP ${ }^{+}$oxidoreductase (Ma and Adams 1994). Reduction of $\mathrm{NADP}^{+}$is thought to be a required step in the disposal of reducing equivalents as $\mathrm{H}_{2}$. The protein contains two flavins and three different $[\mathrm{Fe}-\mathrm{S}]$ centers: a putative $[2 \mathrm{Fe}-2 \mathrm{~S}]$ cluster coordinated by a motif of an aspartate and three cysteine $\left(\mathrm{Asp}(\mathrm{Cys})_{3}\right)$ that combines physic-chemical properties known as exclusive from protein clusters coordinated by hystidine (Rieske-type), a regular [3Fe-4S] cluster with high reduction potential, and a [4Fe-4S] cluster also with unusual reduction properties (Hagen, Silva et al. 2000). The role of the high reduction potentials for the last two clusters is not yet clear, but the redox potential of the flavins is consistent with the function of sulfide dehydrogenase and ferredoxin: $\mathrm{NADP}^{+}$oxidoreductase.

As the properties of the iron-sulfur clusters in the subunits of the sulfide dehydrogenase are not yet completely understood, the mechanism of action is not clear.

Sequences of the gene subunits deposited in the JGI genome database are available under accession numbers: SudHA: AAL81451 / AAL82034; SudHB: AAL81452 / AAL82035. 


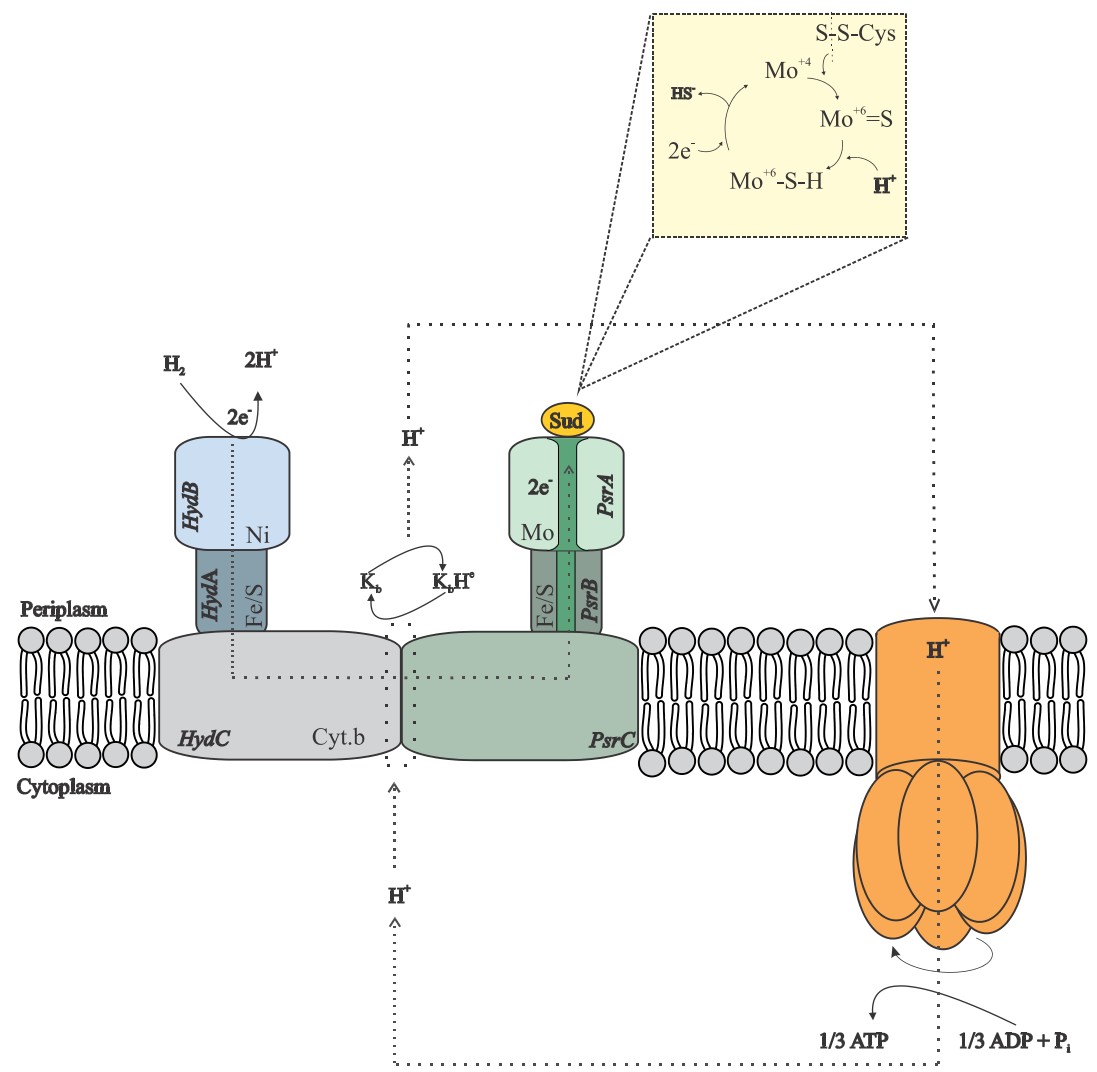

Figure 5 - Hypothetical view of elemental sulfur reduction (via polysulfide) and anaerobic electron transport chain in W. succinogenes. For the electron transfer to happen between the enzymes, collision of the enzymes is assumed to be required and menaquinone seems to be bound to the subunit $\mathrm{C}$ of the polysulfide reductase. Protons are also assumed to be translocated to the periplasm via menaquinone. Subunits of the hydrogenase are labeled HydA, HydB and HydC and subunits of the polysulfide reductase are labeled PsrA, PsrB and PsrC. K stands for quinone and Sud stands for a sulfur/polysulfide transferase. Model adapted from Hedderich, Klimmek et al. (1999) and Rosenberg, DeLong et al. (2013).

\section{Sulfhydrogenase}

Two different cytoplasmic hydrogen-metabolizing enzymes were purified from $P$. furiosus and showed sulfur reductase activity. Both are referred as sulfhydrogenases, I and II, also called $\mathrm{NAD}(\mathrm{P}) \mathrm{H}$ :sulfur oxidoreductase, or coenzyme A (CoA)-dependent NADP(H) sulfur oxidoreductase (Bryant and Adams 1989, Ma, Schicho et al. 1993, Ma, Weiss et al. 2000).

Both, sulfhydrogenases I (Bryant and Adams 1989) and II (Ma, Weiss et al. 2000) can reduce $\mathrm{S}_{8}^{0}$ and polysulfide to $\mathrm{H}_{2} \mathrm{~S}$ using $\mathrm{H}_{2}$ as electron donor. Both proteins have four subunits, with nickel, iron-sulfur centers and flavin adenine dinucleotide, but their subunits differ in catalytic activities and arrangements; sulfhydrogenase I is a heterotetramer $(\alpha \beta \gamma \delta)$ 
and sulfhydrogenase II is suggested to be a dimer of heterotetramer $(\alpha \beta \gamma \delta)_{2}$ (Bryant and Adams 1989). In both cases $\beta$ and $\gamma$ subunits function as sulfur reductase, while $\alpha$ and $\delta$ function as hydrogenases.

There are three main differences between the enzymes: i) sulfhydrogenase II was shown to be less active for hydrogen production, uptake and sulfur reduction assays developed by Ma, Weiss et al. (2000).Ma, Weiss et al. (2000). ii) The authors also showed that sulfhydrogenase II has higher affinity for elemental sulfur and polysulfide, suggesting a physiological relevance of this enzyme when the concentration of sulfur is low. iii) Sulfhydrogenase II also differs from I in its ability to use $\operatorname{NAD}(H)$ and $\operatorname{NADP}(H)$ with comparable efficiencies and has in general a much higher affinity for these nucleotides than the sulfhydrogenase I.

Sequences of the gene subunits of the two complexes deposited in the JGI genome database are available under accession numbers: shyA: AAL81018 / AAL81456; shyB: AAL81015 / AAL81453; shyC: AAL81016 / AAL81454; shyD: AAL81017 / AAL81455.

A possible novel enzyme involved in elemental sulfur reduction was purified from the acidophilic archaeon A. ambivalens, which reduces elemental sulfur with $\mathrm{H}_{2}$ or $\mathrm{NADPH}_{2}$ as electron donors. The sulfur reductase is shown to be a membrane-bound protein that has subunits similar in structure and properties as their homologues from $W$. succinogenes. The core enzyme is probably composed of at least three main structural proteins, a catalytic subunit, most likely a molybdopterin (SreA), an iron-sulfur protein (SreB) and a membrane anchor (SreC). The membrane anchor, however, was shown to be phylogenetically unrelated to the analogous protein in $W$. succinogenes. As the enzyme was isolated in the absence of sulfide, it is most likely that it reduces elemental sulfur itself, instead of polysulfide. Deeper investigations on the sulfur reductase were not possible, as the enzyme could not be purified in the absence of hydrogenase (Laska, Lottspeich et al. 2003). A complete characterization of the enzyme is still necessary to reveal if it is a true novel enzyme in sulfur-reducing microorganisms which will help in the elucidation of the mechanisms.

A similar enzyme is present in several microorganisms within Archaea and Bacteria domains, such as Deferribacter desulfuricans, Desulfitobacterium dehalogenans, Pelobacter carbinolicus Desulfovibrio frigidus, Acidilobus sulfurireducens, Desulfurella acetivorans, Thermanaerovibrio acidaminovorans, Thermodesulfobacterium geofontis, Acidilobus sulfurireducens, Caldisphaera lagunensis, Vulcanisaeta distributa, Pyrobaculum islandicum, Methanococcus maripaludis and Natronolimnobius innermongolicus.

A general overview of the enzymes present in reported sulfur reducers is given as supplemental material (Supplemental material - Table 2). A search on the online Joint Genome Institute database (http://img.jgi.doe.gov/) shows that the aforementioned enzymes 
are present in the genome of many microorganisms not reported so far as sulfur reducers. These potential sulfur-reducing prokaryotes are spread over the tree of life, including some phyla without reported species of sulfur-reducing bacteria, such as Chloroflexi, Actinobacteria, Nitrospira, Chlorobi or Rikenellaceae (Supplemental material - Figure 1). In Archaea, the potential sulfur reducers are spread only over the phyla Crenarchaeota and Euryarchaeota (Supplemental material - Figure 2), where the reported sulfur reducers are also distributed. Even though some of these microorganisms have been tested and did not show sulfur reduction activity, it is not known whether the conditions applied were optimal for growth and/or sulfur reduction. In some cases, e.g. Desulfonatronovibrio thiodismutans, Desulfonatronum thioautotrophicum and Desulfobotulus alkaliphilus elemental sulfur reduction occurred in resting cells, but sulfur did not support growth. It is suggested that the reaction between the sulfide produced and elemental sulfur generates polysulfide. Due to its toxicity, the polysulfide produced inhibits growth of some of those microorganisms (Sorokin, Tourova et al. 2011).

\section{Reduction of sulfur via polysulfide}

Analyzing Sulfurospirillum deleyianum, formerly called Spirillum 5175, Zöphel, Kennedy et al. (1991) showed that the addition of thiols, such as glutathione and sulfide, to the medium facilitated elemental sulfur reduction by the membrane fractions of cell extract; and cleaving of S-S bonds by nucleophilic attack was enhanced, which increased the activity. It has also been suggested that polysulfide chains formed from sulfide and sulfur are intermediates in the reduction of sulfur by cytochrome $\mathrm{c}_{3}$ of Desulfovibrio desulfuricans (Cammack, Fauque et al. 1984). The sulfide $\left(\mathrm{S}^{2-}\right)$ formed by reduction of the polysulfide opens up the -ring by nucleophilic attack leading back to the appearance of new molecules of polysulfides, which are rapidly reduced to $\mathrm{S}^{2-}$ by cytochrome $\mathrm{c}_{3}$ (Cammack, Fauque et al. 1984).

Sulfur reduction via polysulfide has been extensively studied in W. succinogenes. Macy, Schröder et al. (1986) reported growth of W. succinogenes on formate and elemental sulfur, with $\mathrm{H}_{2} \mathrm{~S}$ and $\mathrm{CO}_{2}$ as products. Later, Klimmek, Kröger et al. (1991) reported growth of $W$. succinogenes with formate and polysulfide.

Ringel, Gross et al. (1996) questioned the involvement of polysulfide as intermediate for sulfur respiration in $W$. succinogenes and added $\mathrm{Fe}^{2+}$ to the medium to precipitate all the sulfide produced by the bacterium as FeS. In that case, polysulfide formation was prevented. Under the mentioned conditions, anaerobic growth of $W$. succinogenes was observed with formate and elemental sulfur and it was concluded that elemental sulfur was the terminal electron acceptor for sulfur reduction in W. succinogenes. Three years later, Hedderich, Klimmek et al. (1999) isolated a soluble sulfur-containing fraction and a periplasmic sulfide dehydrogenase, so-called Sud protein, from the cultures 
to which $\mathrm{Fe}^{2+}$ was added. When they treated the isolated protein with $\mathrm{CN}^{-}$and thiosulfate, no reaction was observed; but when polysulfide was added to the medium, thiocyanate was formed (equation 6).

$$
S_{n}^{2-}+C N^{-} \rightarrow S C N^{-}+S_{n-1}^{2-}(\text { equation 6) }
$$

The Sud protein was found to be involved in the transfer of sulfur from aqueous polysulfide to the active site of polysulfide reductase (Psr) (Klimmek, Kröger et al. (1991) . The menaquinone present in the Psr is assumed to serve as electron acceptor of the hydrogenase in polysulfide/sulfur reduction (Rosenberg, DeLong et al. 2013). The electron transport chain of polysulfide reduction with hydrogen or formate consists of polysulfide reductase (Psr) and hydrogenases or formate dehydrogenase. Hydrogenases and polysulfide reductase are thought to be randomly distributed in the membrane of $W$. succinogenes (Jankielewicz, Klimmek et al. 1995).

Later studies indicated that 8-methyl-menaquinone is essential for sulfur reduction in W. succinogenes (Jankielewicz, Klimmek et al. 1995, Hedderich, Klimmek et al. 1999). As most of the menaquinones are thought to be dissolved in the lipid phase of the membrane and to serve in transferring electrons by diffusion, this was the first hypothesis for its involvement in the mechanisms of sulfur/polysulfide reduction by $W$. succinogenes. However, the redox potential of the menaquinone dissolved in the membrane is much more positive than that of polysulfide, which makes the electron transfer from formate dehydrogenase to polysulfide reductase mediated by diffusion improbable (Hedderich, Klimmek et al. 1999). Alternatively, the menaquinone is likely bound to polysulfide reductase and is the primary electron acceptor for the cytochrome b subunit of the hydrogenase (Hedderich, Klimmek et al. 1999). Therefore, it is possible that the electron transfer from hydrogenase to polysulfide reductase requires collision or aggregation of the two enzymes within the membrane (Figure 5). As the menaquinone is intramembrane, it is assumed that its reduction is coupled to the uptake of protons from the cytoplasm by the hydrogenase and the oxidation is coupled to protons release at the periplasm, by the polysulfide reductase (Dietrich and Klimmek 2002).

Several genes were subcloned from genomic libraries of $W$. succinogenes, such as frh genes, coding for formate dehydrogenase (Bokranz, Gutmann et al. 1991), psr genes coding for polysulfide reductase (Krafft, Gross et al. 1995), and sud genes coding for the periplasmic sulfide dehydrogenase (Kreis-Kleinschmidt, Fahrenholz et al. 1995).

Blumentals, Itoh et al. (1990) investigated the mechanism of sulfur reduction in the archaeon Pyrococcus furiosus. The authors observed sulfide and polysulfide formation in cultures in which elemental sulfur was physically separated from the microorganism, indicating that contact between the archaeon and elemental sulfur is not necessary for the 
metabolism and that soluble polysulfides serve as substrates for sulfur reduction. It is not yet clear whether sulfur reduction in $P$. furiosus is coupled to energy conservation. Sulfur can serve merely as electron sink allowing a more effective fermentation of organic compounds (Rosenberg, DeLong et al. 2013).

$P$. furiosus can use protons as terminal electron acceptors, and the production of $\mathrm{H}_{2}$ is coupled directly to ATP synthesis. The multiprotein membrane bound hydrogenase complex and ferredoxin, a low-potential electron donor, couple electron transfer to proton reduction and proton translocation (Sapra, Bagramyan et al. 2003).

\section{Reduction of sulfur via physical attachment to solid phase}

Due to the low solubility of elemental sulfur in water, some microorganisms reduce it at the surface of the outer membrane. The mechanisms adopted by these microorganisms are poorly studied. As some prokaryotes are also able to reduce insoluble mineral-oxides outside the membrane (Lovley 1991, Lovley, Holmes et al. 2004, Hartshorne, Reardon et al. 2009), different strategies for electron transfer have been proposed, which can be related to sulfur reducers.

For example, in species of the iron-reducing genera Shewanella and Geobacter, in which some sulfur reducer members can be found, external insoluble iron oxides reduction is reported to happen by four different mechanisms: i) cytochrome c extends the respiratory chain to the cell surface (Richardson 2000, Lovley, Holmes et al. 2004, Richter, Schicklberger et al. 2012); ii) extracellular redox mediators, such as humic acids, quinones, phenazines and cysteine, can shuttle electrons between the terminal electron donor of the electron transport chain and the insoluble acceptor (Lovley, Fraga et al. 1998, Scott, McKnight et al. 1998, Newman and Kolter 2000, Hernandez and Newman 2001); and, iii) in the absence of cytochrome c, microorganisms can produce modified pili, so-called nanowires, that can serve as an electrical connection between the cell and the surface of the oxides (Reguera, McCarthy et al. 2005) and, some strains can construct electrically conductive networks with nanoparticles of crystalline, conductive or semiconductive minerals, such as iron oxides (Kato, Nakamura et al. 2010).

Some microorganisms are reported to reduce elemental sulfur directly to sulfide, such as A. ambivalens, A. ferrooxidans, Pyrodictium abyssi and Pyrodictium brockii, from which several studies were performed and are here summarized.

Hydrogenase, quinone and cytochrome c were detected in membranes of $P$. brockii (Pihl and Maier 1991, Pihl, Black et al. 1992). The purified hydrogenase is of the Ni-Fe type, with two subunits (Pihl and Maier 1991). Even though the quinone in this microorganism shows chromatographic properties of migration like ubiquinone-6, nuclear magnetic resonance analysis performed by Pihl, Black et al. (1992) revealed evidence for a quinone different from all quinones compared. When the quinone was inactivated by 
exposition to UV light, the electron transport activity was inactivated. The addition of quinone reactivated the process, implying that the electron transfer sequence is: hydrogenase $\rightarrow$ quinone $\rightarrow$ cytochrome $\mathrm{c}$. With this, cytochrome $\mathrm{c}$ is supposed to serve as electron donor to the sulfur reductase, which has not been identified yet.

Dirmeier, Keller et al. (1998) isolated a sulfur-oxidoreductase complex from the membrane fraction of $P$. abyssi isolate TAG11 and showed that the electron transport chain that catalyzes sulfur reduction by hydrogen is different from $P$. brockii in composition and organization of the components. The entire respiratory chain of the organism is suggested to be represented by an enzyme multi-complex, in which hydrogenase, electron transport components and sulfur reductase are stably arranged. The reductase consists of at least nine subunits, with two b-type cytochromes and one c-type. No quinone has been detected in the membrane fraction complex enzyme of $P$. abyssi. The presence of nickel in the sulfuroxidoreductase suggests that its hydrogenase is of the Ni-Fe type (Rosenberg, DeLong et al. 2013), as for P. brockii.

A sulfur reductase purified from $A$. ambivalens was shown to reduce elemental sulfur with hydrogen as electron donor in the presence of a co-purified hydrogenase, with a quinone as electron carrier (Laska, Lottspeich et al. 2003). The hydrogenase has similar main subunits as the hydrogenase purified from $W$. succinogenes, one homologous $\mathrm{Ni}$ containing catalytic subunits $(\mathrm{HynL} / \mathrm{HydB})$, one homologous $\mathrm{Fe}-\mathrm{S}$ containing electron transfer subunit (HynS/HydB) and one non-homologous membrane anchor (IspI/HydC) (Laska, Lottspeich et al. 2003). Thus, the electron transport chain in this microorganism is most likely composed of the two enzymes connected by quinones (Figure 6). As the net balance of protons from the periplasmic reactions is zero, an electrochemical gradient is most likely generated with protons taken up by quinone from the cytoplasm and released at the periplasm.

\section{Mechanisms of adaptation to acidic conditions}

Many sulfur-reducing microorganisms prefer neutral $\mathrm{pH}$ to grow. Nonetheless, several species that are capable to thrive in acidic environments have been identified (Stetter 1996, Hedderich, Klimmek et al. 1999, Yoneda, Yoshida et al. 2012). Those species of acidophiles or acidotolerants tolerate larger $\mathrm{pH}$ gradients across the cytoplasmic membrane than neutrophilic organisms. These microorganisms normally face a proton motive force across the cell membrane that can drive energy dependent processes to promote $\mathrm{pH}$ homeostasis (Baker-Austin and Dopson 2007). To maintain a physiological $\mathrm{pH}$ despite the external acidic conditions, microorganisms adopt several strategies. BakerAustin and Dopson (2007) presented a extremely valuable review on the pathways and mechanisms proposed that enable microorganisms to thrive at low $\mathrm{pH}$, which are 
summarized in this section, such as utilization of specific transporters and enzymes for proton export, adoption of particular permeability properties, increment of buffer capacity and enhancement of positive surface charges.

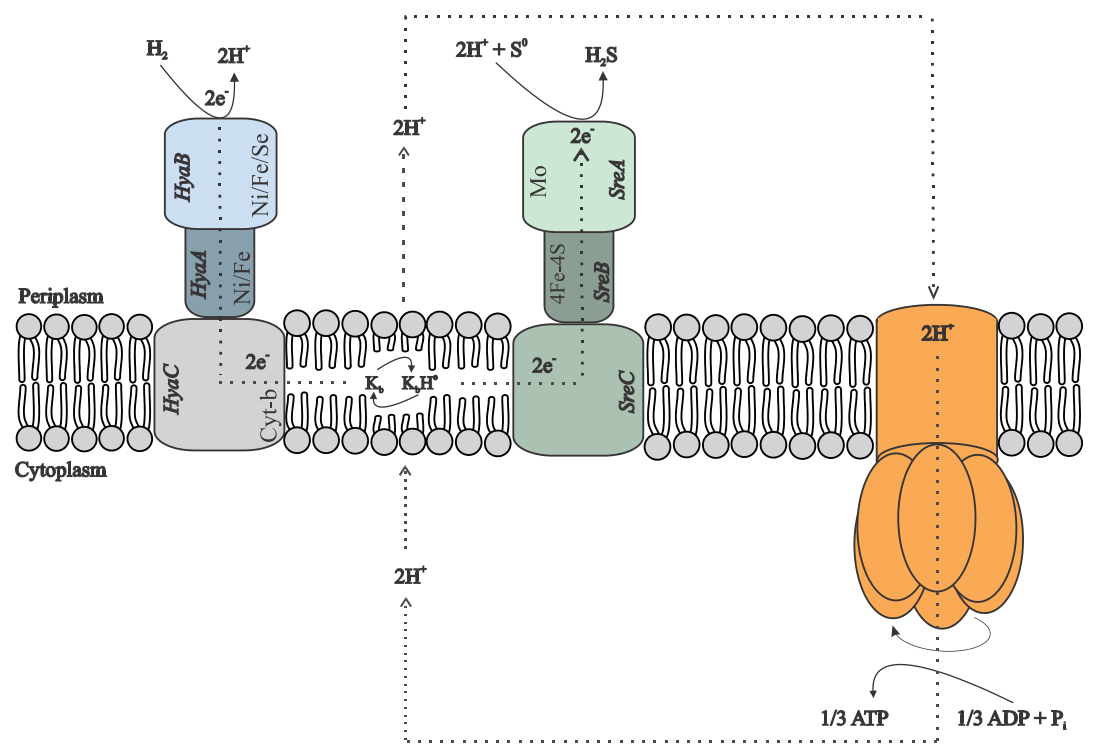

Figure 6 - Hypothetical view of elemental sulfur reduction and anaerobic electron transport chain in A. ambivalens. Protons are assumed to be translocated to the periplasm via quinone. Only major structural subunits are represented. Subunits of the hydrogenase are labeled HynL, HynS and IspI and subunits of the sulfur reductase are labeled SreA, SreB and SreC. K stands for quinone. Model adapted from Laska (2003).

In general, acidophiles and acidotolerants have a highly impermeable cell membrane or low membrane fluidity to restrict proton influx to the cytoplasm (Benjamin and Datta 1995, Dilworth and Glenn 1999, Konings, Albers et al. 2002). The membranes of some acidophilic archaea are composed of tetraether lipids which make them rather impermeable to protons. Additionally, ether linkages are less sensitive to acid hydrolysis than ester linkages, commonly found in bacterial and eukaryotic cell membranes (Macalady and Banfield 2003, Golyshina and Timmis 2005). Moreover, the membrane lipids are also characterized by a substantially higher content of glycolipids with one or more sugar units exposed at the outer surface of the cell (De Rosa, Gambacorta et al. 1983, Chong 2010). Although there is a lack of direct evidence, it was suggested that the abundance of sugar modifications on the cell surface of archaea can provide a protection against proton influx (Shimada, Nemoto et al. 2008, Wang, Lv et al. 2012).

Reduction of the size and permeability of the membrane channels is another mechanism for $\mathrm{pH}$ homeostasis in acidophiles. The membrane pore reduces its size and 
selects the ions at the porin entrance on the basis of their size and charge (Amaro, Chamorro et al. 1991).

A further mechanism used by acidophiles to reduce proton influx is the maintenance of a difference in electrical potential between the intra and extra-cellular environment without any current flowing through the membrane, which involves the development of inside positive $\Delta \Psi$ which is opposite to inside negative $\Delta \Psi$ in neutrophiles, the so-called Donnan potential. This Donnan potential is probably generated by a greater influx of potassium ions. The importance of this mechanism is suggested by a very high number of putative cation transporters identified in the genomes of several acidophiles, including some related to sulfur cycle, such as Acidithiobacillus thiooxidans (Suzuki, Lee et al. 1999), Acidithiobacillus caldus (Dopson, Lindstrom et al. 2002), Acidithiobacillus ferrooxidans (Cox, Nicholls et al. 1979) and Acidiphilium acidophilum (Goulbourne, Matin et al. 1986).

Proton efflux pump systems, such as proton ATPases, antiporters and symporters (Box 2), are also used by some acidophiles to maintain the $\mathrm{pH}$ homeostasis (Tyson, Chapman et al. 2004, Golyshina and Timmis 2005, Baker-Austin and Dopson 2007). Protons that enter the cell must be balanced by extrusion during electron transport and reduction of terminal electron acceptors.

The cytoplasm of all microbes presents a buffering capacity (Box 3) to sequester or release protons, according to the shifts in $\mathrm{pH}$. This buffering capacity is performed by small organic molecules such as amino acids and ionizable groups in proteins and inorganic polymers, such as polyphosphate (Slonczewski, Macnab et al. 1982, Zychlinsky and Matin 1983, Krulwich, Agus et al. 1985, Leone, Ferri et al. 2007). Zychlinsky and Matin (1983) compared the buffering capacity of Acidiphilium acidophilum and Escherichia coli and the result showed a slightly higher capacity for the acidophile, 97 and $85 \mathrm{mmol} \mathrm{H}^{+}$per $\mathrm{pH}$ unit, respectively. It was also found by Krulwich, Agus et al. (1985) that Bacillus acidocaldarius has a higher buffering capacity (around $600 \mathrm{mmol} \mathrm{H}^{+}$per $\mathrm{pH}$ unit) than other bacilli in neutrophilic conditions (around $400-550 \mathrm{mmol} \mathrm{\textrm {H } ^ { + }}$ per $\mathrm{pH}$ unit). However, the results obtained in both studies show that the buffering capacity of the acidophiles is not necessarily higher than their counterpart of neutrophiles. This suggests that the buffering capacity can contribute to $\mathrm{pH}$ homeostasis only together with other mechanisms.

The low $\mathrm{pH}$ of the environments can damage biomolecules in the cell, which requires repair mechanisms. This can explain the presence of large number of DNA and protein repair genes in the genomes of several acidophiles (Crossman, Holden et al. 2004). At low $\mathrm{pH}$, chaperones involved in protein refolding are highly expressed in a wide range of acidophiles, suggesting that they can play a role in the survival of microorganisms under acidic conditions. 


\section{Box 2}

Antiporters: integral membrane proteins that actively transport a substance through the membrane, while transporting ions in the opposite direction. The ions, typically hydrogen $\left(\mathrm{H}^{+}\right)$or sodium $\left(\mathrm{Na}^{+}\right)$ions, flow down their concentration gradient, and in doing so provide the energy for the transport of another substance in the other direction.

Symporters: integral membrane proteins that simultaneously transports two substances across membrane in the same direction. Often, one molecule can move up an electrochemical gradient because the movement of the other molecule is more favourable.

Investigation on Ferroplasma acidiphilum, an obligate acidophile with an intracellular predicted $\mathrm{pH}$ of 5.6 during active growth, showed that several enzymes were functional at $\mathrm{pH}$ values in a range of 1.7-4.0, suggesting that they need to be functional to get the metabolism started when the cells grow at extreme low $\mathrm{pH}$ values. It has also been found that most of the proteomes of acidophiles contain a unique high proportion of iron proteins that contribute to the $\mathrm{pH}$ stability of enzymes at low $\mathrm{pH}$ (Ferrer, Golyshina et al. 2007). Removal of iron from purified proteins from these acidophiles leads to loss of secondary structure of the proteins and, consequently their activity. This suggests that iron is crucial in maintaining the three dimensional structures of the proteins and that iron functions as an iron rivet - an ancient property that has a role in stabilizing proteins in acidic condition (Ferrer, Golyshina et al. 2007).

Most of the organic acids like acetic acid and lactic acid facilitate transfer of protons across the membrane at low $\mathrm{pH}$. In this condition, the acids diffuse into the cell in the protonated form followed by dissociation of a proton in the cytoplasm where the $\mathrm{pH}$ is higher (Baker-Austin and Dopson 2007). Therefore, the organic acid degradation ability in some acidophiles can play a detoxifying role.

\section{Box 3}

Buffering capacity: It is the ability of a solution to resist to changes in $\mathrm{pH}$ by either absorbing or desorbing $\mathrm{H}^{+}$and $\mathrm{OH}^{-}$ions. It is represented by the moles of an acid or base needed to change the $\mathrm{pH}$ of a solution by 1 , divided by the $\mathrm{pH}$ change and the volume of buffer.

\section{Biotechnological application}

\section{Industrial wastes and acid mine drainage}

The biological oxidation of sulfidic minerals and formation of acidic metal-rich mine drainage waters have been described in several studies (Hoffert 1947, Johnson 1995, Johnson 2003). Briefly, due to their exposure to oxidants $\left(\mathrm{O}_{2}\right.$ or $\left.\mathrm{Fe}^{3+}\right)$, the geobiochemical 
oxidation of metal sulfides such as pyrite is the root cause of acid mine drainage (AMD) (Johnson and Hallberg 2005). In most situations, ferric iron is the primary oxidant which chemically oxidize the ores (equations 7 and 8) and its biological regeneration (equation 9) maintains the open-ended oxidation of the mineral (Schippers and Sand 1999, Johnson and Hallberg 2005, Vera, Schippers et al. 2013) and the acidic environment formation, in which metals are commonly dissolved.

$$
\begin{gathered}
\mathrm{FeS}_{2}+6 \mathrm{Fe}^{3+}+3 \mathrm{H}_{2} \mathrm{O} \rightarrow \mathrm{S}_{2} \mathrm{O}_{3}^{2-}+7 \mathrm{Fe}^{2+}+6 \mathrm{H}^{+} \quad \text { (equation 7) } \\
\mathrm{S}_{2} \mathrm{O}_{3}^{2-}+8 \mathrm{Fe}^{3+}+5 \mathrm{H}_{2} \mathrm{O} \rightarrow 2 \mathrm{SO}_{4}^{2-}+8 \mathrm{Fe}^{2+}+10 \mathrm{H}^{+} \quad \text { (equation 8) } \\
4 \mathrm{Fe}^{2+}+\mathrm{O}_{2}+4 \mathrm{H}^{+} \rightarrow 4 \mathrm{Fe}^{3+}+2 \mathrm{H}_{2} \mathrm{O} \text { (equation 9) }
\end{gathered}
$$

Metals of particular interest in acid mine drainage and industrial wastewaters include copper, zinc, cadmium, arsenic, manganese, aluminium, lead, nickel, silver, mercury, chromium and iron, in a concentration that can range from $10^{-6}$ to $10^{2} \mathrm{~g} \mathrm{~L}^{-1}$ (Huisman, Schouten et al. 2006). As examples, in Tinto River, a natural acidic rock drainage, iron can be detected up to $20.2 \mathrm{~g} \mathrm{~L}^{-1}$, copper up to $0.7 \mathrm{~g} \mathrm{~L}^{-1}$, and zinc up to $0.56 \mathrm{~g}$ $\mathrm{L}^{-1}$ (Lopez-Archilla, Marin et al. 2001); while in the effluent of a textile industry iron was detected up to $0.11 \mathrm{~g} \mathrm{~L}^{-1}$, and copper and zinc up to $0.01 \mathrm{~g} \mathrm{~L}^{-1}$ (Joshi and Santani 2012).

\section{State of the art methods for metal removal and recovery}

\section{Chemical/physical methods}

Many chemical/physical methods have been applied to remove heavy metals from contaminated wastewaters, such as absorption, ion exchange, complex formation and precipitation by addition of chemicals, which is the most widely applied chemical/physical approach for the treatment of acid mine drainage (AMD) and other metal-contaminated streams (Johnson and Hallberg 2005). In this process of mitigation, neutralizing chemicals, such as calcium carbonate, calcium oxide, calcium hydroxide or sodium hydroxide are added to raise the $\mathrm{pH}$ and precipitate the metals (Weijma, Copini et al. 2002). Despite effective treatments, these methods are relatively expensive and produce large volumes of residual metal-contaminated sludge with no or low metal reuse potential (Gallegos-Garcia, Celis et al. 2009, Tekerlekopoulou, Tsiamis et al. 2010).

\section{Microbiological methods}

Microbial processes, such as methanogenesis, denitrification, and reduction of iron and manganese, generate alkalinity, which may result in metal precipitation as hydroxides (Johnson and Hallberg 2005). Even though hydroxides can be removed from the effluent, as all the metals precipitate together, the generated waste needs to be disposed, which results in extra costs of the process. Metals may also be recovered bioelectrochemical systems, 
where an organic substrate is biologically oxidized at the anode, thereby generating electrons which are used to reduce metals like $\mathrm{Cu}^{2+}$ at the cathode (Heijne, Liu et al. 2010). Much research in the past used the concept of metal biosorption, i.e. the adsorption of metal ions to the surface of biological matter such as bacterial cells and plants. This method is not widely applied, presumably due to the low metal loading capacity and the production of a residue from which metal recovery is hardly feasible.

Bioreactors systems to precipitate metals based on sulfidogenesis are as effective as the physical methods while operating at substantially lower costs and producing lower amounts of residual sludge (Johnson and Hallberg 2005). Sulfidogenesis is based on the oxidation of simple organic compounds or hydrogen by microorganisms under anaerobic conditions, generating sulfide from the reduction of sulfur compounds, such as sulfate, sulfite, thiosulfate, organic sulfoxides, elemental sulfur, polysulfide, and organic disulfides. The versatility of sulfidogenic microorganisms allows for many combinations of electron donor and sulfur sources, and also for a wide range of operational conditions for the process (temperature, salinity, $\mathrm{pH}$ ).

\section{Sulfidogenesis for metal removal and recovery}

In sulfidogenic processes for metal removal and recovery, the biologically produced sulfide reacts with dissolved heavy metals such as $\mathrm{Cu}^{2+}, \mathrm{Zn}^{2+}$, and $\mathrm{Ni}^{2+}$ to form insoluble metal sulfides precipitates (Hulshof, Blowes et al. 2006, Neculita, Zagury et al. 2007). The theoretical solubility of most metal sulfides at neutral to alkaline $\mathrm{pH}$ is extremely low, much lower than that of the corresponding metal hydroxides. Thus, better effluent qualities can be reached and more metal can be recovered. Also the reactions rates are higher and the acid-stable metal sulfides, such as $\mathrm{Co}, \mathrm{Ni}$ and $\mathrm{Cu}$, present good settling properties and high potential for re-use (Tsukamoto, Killion et al. 2004, Gallegos-Garcia, Celis et al. 2009, Lewis 2010, Sánchez-Andrea, Sanz et al. 2014).Smelter facilities for base metal production use ore concentrates that often contain the metal in their sulfidic mineral form, such as sphalerite in the case of $\mathrm{ZnS}$. This facilitates the use of biologically precipitated metals sulfides as feedstock for smelters. For $\mathrm{ZnS}$, this is practised at the zinc refinery of Nyrstar in The Netherlands (Weijma, Copini et al. 2002)

Sulfate reduction is the most used biological process for the treatment of mining and metallurgical streams. However, there are only a few described species of moderate acidophilic sulfate-reducing bacteria: Thermodesulfobium narugense, which can grow at pH 4 (Mori, Kim et al. 2003), Desulfosporosinus acidiphilus, which can grow at pH 3 (Jameson, Rowe et al. 2010), Desulfosporosinus acididurans, which can grow at pH 3.8 (Sánchez-Andrea, Stams et al. 2015). Since most of the described sulfate-reducing bacteria are neutrophilic, in most of the bioreactors systems used to precipitate metals, the $\mathrm{pH}$ is 
kept neutral (Johnson and Hallberg 2005), which implies an early step of neutralization of the influent.

Two designs of sulfidogenic bioreactors have been proposed. One is based on a biological and a chemical compartment operating independently (Tabak, Sharp et al 2003). In the biological compartment, hydrogen sulfide is produced and transferred via a gas circulation to the chemical circuit, which receives the raw influent (Figure 7a). Thus, the biological production of sulfide and the precipitation of metals are separated by stripping hydrogen sulfide from the biological solution with a carrier gas (nitrogen) and then the hydrogen sulfide gas dissolves in the metal-contaminated (waste)water. In this device, there is no contact between the sulfidogenic biomass and the metal-contaminated stream. This is the major advantage of this design because it prevents possible biomass toxicity effects due to high acidity and metal concentrations (Johnson and Hallberg 2005).The drawback is that the carrier gas recycle requires a high energy input. This technique has been studied with metals like $\mathrm{Cu}$ and $\mathrm{Zn}$ (Foucher, Battaglia-Brunet et al. 2001, Al-Tarazi, Heesink et al. 2005, Gramp, Wang et al. 2009). Because of the separate sulfide production and metal sulfide precipitation, both process parts can be controlled at their optimal conditions. For example, selective precipitation of individual heavy metals can be achieved by carefully controlling the $\mathrm{pH}$ and the $\mathrm{pS}\left(-\log \left[\mathrm{S}^{2-}\right]\right.$ ) in the precipitator (Veeken and Rulkens 2003, König, Keesman et al. 2006, Sampaio, Timmers et al. 2009).

This results in relatively pure precipitates of metal sulfides that have a higher value as supplement to ore concentrate feedstock in the metallurgical industry (Grootscholten, Keesman et al. 2008).

The other designed system has only one compartment, in which biological sulfide production and metal precipitation occur simultaneously (Figure $7 \mathrm{~b}$ ). In this configuration, since the sulfidogenic culture remains in contact with the dissolved metals from the influent, metal toxicity is of great importance. Depending on the $\mathrm{pH}$ and sulfide concentration in the system, and the dissolved metals concentrations, sulfate reducers are capable of binding and accumulating high quantities of heavy metals (Labrenz, Druschel et al. 2000, Steed, Suidan et al. 2000, Weijma, Copini et al. 2002, Kaksonen, RiekkolaVanhanen et al. 2003, Johnson and Hallberg 2005, Sierra-Alvarez, Karri et al. 2006, Gallegos-Garcia, Celis et al. 2009, Sánchez-Andrea, Triana et al. 2012). Full-scale operations for biogenic sulfide production are described in Weijma, Copini et al. (2002) and Möbius, Demel et al. (2015). 


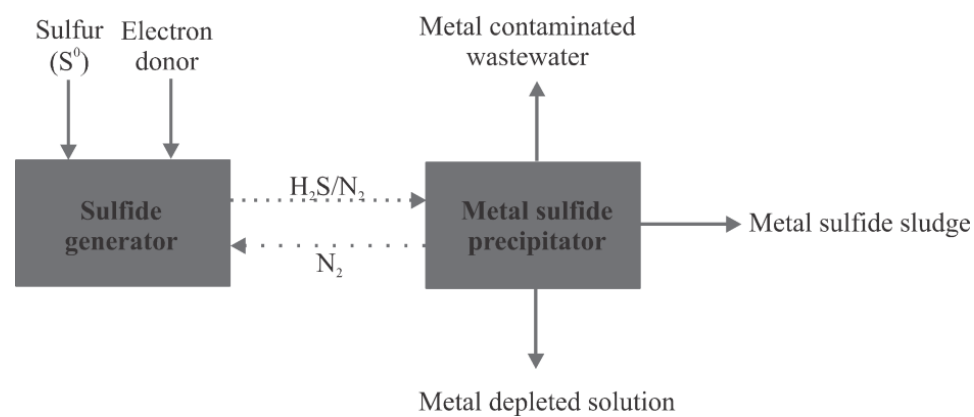

$\mathrm{b}$

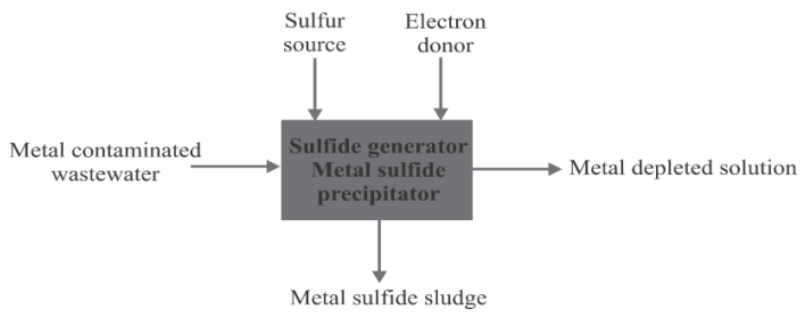

Figure 7 - Flowsheet for two-stage biological metal removal with no direct contact between the sulfidogenic microorganisms and the metal-contaminated wastewater (7a). One-stage biological metal removal with direct contact between the sulfidogenic microorganisms and the metal-contaminated wastewater (7b).

\section{Comparative analysis of cost between sulfate and sulfur reduction processes}

Wastewater from mining or metals industries contains, normally, low organic matter content. To completely reduce the sulfur compounds to sulfide, electron donors need to be added (Liamleam and Annachhatre 2007). Based on the stoichiometry of the reactions, elemental sulfur is more attractive as electron acceptor than sulfate, since only two electrons per mol of sulfide produced are needed in the process (equation 10), instead of eight needed for sulfate (equation 11). The sulfide produced determines the amount of metals to be recovered (equation 12), therefore with the same amount of metal precipitated, the process needs 4 times less of electron donor for sulfur reduction in comparison with sulfate reduction.

Hedrich and Johnson (2014) performed analysis of costs for modular reactors to oxidize iron and reduce sulfate to precipitate metals operating at low $\mathrm{pH}$. The $42 \mathrm{~m}^{3}$ sulfidogenic reactor needed to treat $1 \mathrm{~m}^{3}$ mine water operated with glycerol as electron donor, would produce $3.96 \mathrm{~mol}$ of sulfide. As the stoichiometric reaction of glycerol with sulfate is 4 to 7 (equation 12), $2.26 \mathrm{~mol}$ (208.52 g) of glycerol would be required in the 
reactor. Assuming the market price of glycerol as $2400 \$ /$ ton, the cost of this reagent in the process result on $0.5 \$$, as described in the article.

If instead of sulfate, sulfur is applied as electron acceptor, to reach the same amount of sulfide in a $42 \mathrm{~m}^{3}$ reactor, an input of $0.126 \mathrm{~kg}$ of sulfur is required. As an estimated market price of sulfur of $61 \$ /$ ton, an additional cost of $0.008 \$$ is needed in the process. However, as sulfur reduction requires four times less electron donors (equation 13), the same amount of sulfide is reached with only $52.13 \mathrm{~g}$ of glycerol, implying a global reduction in costs of $\$ 0.37$ per $\mathrm{m}^{3}$ of mine water treated.

In accordance with equation 11 and as expressed in Hedrich and Johnson (2014), with the amount of sulfide produced via sulfur or sulfate reduction, $0.46 \mathrm{~kg}$ can be recovered, which represents about $0.80 \$$ of return per $\mathrm{m}^{3}$ of mine water treated. Considering copper, which is common in acid mine drainage, $0.46 \mathrm{~kg} \mathrm{Cu}$ recovered would imply $2.71 \$$ of return per $\mathrm{m}^{3}$ of mine treated, taking $5900 \$ /$ ton as an average market price of copper.

Another advantage of implementing elemental sulfur reduction for remediation of AMD streams is that sulfur reducers can generally reduce elemental sulfur at $\mathrm{pH}$ values lower than the so far described sulfate reducers. Sulfur reduction is reported in extremely acidophilic microorganisms, such as A. ferrooxidans ( $\mathrm{pH} 1.8$ ) (Osorio, Mangold et al. 2013), Acidilobus sulfurireducens ( $\mathrm{pH}$ 2) (Boyd, Jackson et al. 2007), Acidianus infernus (pH 1.5) (Stetter 1996), Stygiolobus azoricus (pH 1) (Svetlichnyi, Slesarev et al. 1987), Thermoplasma acidophilum and volcanicum (pH 1) (Segerer, Langworthy et al. 1988). The lowest reported $\mathrm{pH}$ for sulfate reduction by isolates is 3.6-3.8 by members of Desulfosporosinus genus (Alazard, Joseph et al. 2010, Sánchez-Andrea, Stams et al. 2015) and Ňancucheo and Johnson (2012) reported activity at a pH as low as 2.5 in bioreactors.

Half reaction: $\mathrm{H}_{2} \rightarrow 2 \mathrm{e}^{-}+2 \mathrm{H}^{+}$

Half reaction: $\mathrm{S}+2 \mathrm{e}^{-} \rightarrow \mathrm{S}^{2-}$

Global reaction: $\mathbf{S}+\mathbf{H}_{2} \rightarrow \mathbf{S}^{2-}+\mathbf{2} \mathbf{H}^{+}$(equation 10)

Half reaction: $4 \mathrm{H}_{2} \rightarrow 8 \mathrm{e}^{-}+8 \mathrm{H}^{+}$

Half reaction: $\mathrm{SO}_{4}{ }^{2-}+8 \mathrm{e}^{-}+8 \mathrm{H}^{+} \rightarrow \mathrm{S}^{2-}+4 \mathrm{H}_{2} \mathrm{O}$

Global reaction: $\mathrm{SO}_{4}{ }^{2-}+4 \mathrm{H}_{2} \rightarrow \mathrm{S}^{2-}+4 \mathrm{H}_{2} \mathrm{O}$ (equation 11)

$$
\mathrm{H}_{2} \mathrm{~S}+\mathrm{Me}^{2+} \rightarrow \mathrm{MeS}_{(\mathrm{s})}+2 \mathrm{H}^{+}(\text {equation 12) }
$$

where $\mathrm{Me}^{2+}=$ metal, such as $\mathrm{Zn}^{2+}, \mathrm{Cu}^{2+}, \mathrm{Pb}^{2+}$ and $\mathrm{Ni}^{2+}$

$4 \mathrm{C}_{3} \mathrm{H}_{8} \mathrm{O}_{3}+7 \mathrm{SO}_{4}^{2-} \rightarrow 7 \mathrm{H}_{2} \mathrm{~S}+12 \mathrm{CO}_{2}+16 \mathrm{H}_{2} \mathrm{O}$ (equation 13)

$\mathrm{C}_{3} \mathrm{H}_{8} \mathrm{O}_{3}+7 \mathrm{~S}+3 \mathrm{H}_{2} \mathrm{O} \rightarrow 7 \mathrm{H}_{2} \mathrm{~S}+3 \mathrm{CO}_{2}$ (equation 14) 
Additionally, many sulfate reducers are incomplete oxidizers (e.g.: Desulfotomaculum sp., Desulfobulbus sp., Archaeoglobus sp. (Castro, Reddy et al. 2002), Desulfovibrio sp., Thermodesulfobacterium sp. (Widdel and Pfennig 1981, Widdel 1988, Widdel and Pfennig 1991), Desulfosporosinus sp. (Sánchez-Andrea, Stams et al. 2015) which means that they contribute to the accumulation of acetic acid in the medium, with the consequent possible inhibition of the process. This is not the case for most of the sulfur reducers, especially the ones belonging to the Deltaproteobacteria class, which are able to oxidize organic substrates to $\mathrm{CO}_{2}$, such as Desulfuromonas sp., Geobacter sp., Pelobacter sp. and Desulfurella sp. the latter ones are usually found in acid environments (BonchOsmolovskaya, Sokolova et al. 1990, Miroshnichenko, Rainey et al. 1998).

Sulfur reduction looks more promising for treatment of metal-laden streams in metallurgical processes, which are free of sulfate, often acidic and sometimes hot. However, for obvious reasons such as the natural presence of sulfate in AMD water, sulfate reduction might be still the easiest option for in situ systems such as permeable reactive barriers.

\section{Concluding remarks and future perspectives}

Microorganisms involved in the sulfur cycle are of great importance from the industrial and environmental point of view, especially the ones that perform sulfidogenesis. Sulfur-reducing prokaryotes are ubiquitously distributed in marine and terrestrial environments and able to grow in a broad range of temperature and $\mathrm{pH}$. Species able to thrive in acidic environments are of interest for selective metals precipitation and bioremediation processes.

Several acidophilic sulfur reducers were described but their physiology and specific mechanisms adopted to face extreme conditions are still poorly understood. Ongoing and future research on these microorganisms will provide more insight into the real substrate used by sulfur reducers, physiology and ecology of those microorganisms and their behavior in engineered ecosystems such as reactors for the selective precipitation and recovery of heavy metals from mining and metallurgical industries.

\section{Acknowledgements}

The doctoral study program of A. P. Florentino is supported by the organization of the Brazilian Government for the development of Science and Technology $\mathrm{CNPq}$ (Conselho Nacional de Desenvolvimento Científico e Tecnológico). Research of I. Sánchez-Andrea and A.J.M. Stams is financed by ERC grant project 323009 and by Gravitation grant project 024.002.002 from the Netherlands Ministry of Education, Culture and Science. 


\section{Supplementary data}

Table S1 - Archaeal and bacterial species harbouring members able to perform dissimilatory sulfur reduction. ND: Not determined. Optima or maxima values/ranges of temperature and $\mathrm{pH}$ are reported in brackets.

\begin{tabular}{|c|c|c|c|}
\hline Species & $\begin{array}{l}\text { Temperature } \\
\text { Range }\end{array}$ & $\begin{array}{c}\text { pH } \\
\text { Range }\end{array}$ & Reference \\
\hline \multicolumn{4}{|c|}{ Bacteria } \\
\hline Acidithiobacillus ferrooxidans & $10-37$ & $1.3-4.5$ & (Kelly and Wood 2000) \\
\hline Ammonifex degensii & $57-77$ & $5-8$ & (Huber et al. 1992) \\
\hline Anaerobaculum mobile & $35-65$ & $5.4-8.7$ & (Menes and Muxí 2002) \\
\hline Anaerobaculum thermoterrenum & $28-60$ & $5.5-8.6$ & (Rees et al. 1997) \\
\hline Aquifex pyrophilus & $67-95$ & $5.4-7.5$ & (Pudritz et al. 2007) \\
\hline Balnearium lithotrophicum & $45-80$ & $5-7$ & (Takai et al. 2003) \\
\hline Caldimicrobium rimae & $52-82$ & $6.8-7.4$ & (Miroshnichenko et al. 2009) \\
\hline Caldisericum exile & $55-70$ & $5.5-7.5$ & (Mori et al. 2009) \\
\hline Caldithrix abyssi & $40-70$ & $5.8-7.8$ & (Miroshnichenko et al. 2003) \\
\hline Caminibacter hydrogeniphilus & $50-70$ & $5.5-7.5$ & (Alain et al. 2009) \\
\hline Caminibacter mediatlanticus & $45-70$ & $4.5-7.5$ & (Alain et al. 2009) \\
\hline Caminibacter profundus & $45-65$ & $6.5-7.9$ & (Alain et al. 2009) \\
\hline Campylobacter species & $30-45$ & $7-7.5$ & (Madigan 2012) \\
\hline Carboxydothermus pertinax & $45-97$ & $4.6-8.6$ & (Yoneda et al. 2012) \\
\hline Clostridium sulfidigenes & $18-48$ & $5.5-9$ & $\begin{array}{c}\text { (Sallam and Steinbüchel } \\
\text { 2009) }\end{array}$ \\
\hline Clostridium thiosulfatireducens & $18-45$ & $6-9.8$ & $\begin{array}{c}\text { (Sallam and Steinbüchel } \\
\text { 2009) }\end{array}$ \\
\hline Clostridium tunisiense & $18-43$ & $5.5-8.7$ & $\begin{array}{c}\text { (Sallam and Steinbüchel } \\
\text { 2009) }\end{array}$ \\
\hline Coprothermobacter proteolyticus & $35-70$ & $5-8.5$ & $\begin{array}{c}\text { (Rainey and Stackebrandt } \\
1993 \text { ) }\end{array}$ \\
\hline Deferribacter desulfuricans & $40-70$ & $5-7.5$ & (Takai et al. 2003) \\
\hline Desulfitibacter alkalitolerans & $23-44$ & $7.6-10.5$ & (Nielsen et al. 2006) \\
\hline Desulfitispora alkaliphila & $43(\max )$ & $8.5-10.3$ & (Sorokin and Muyzer 2010) \\
\hline Desulfitobacterium chlororespirans & $15-37$ & $6.8-7.5$ & (Sanford et al. 1996) \\
\hline Desulfitobacterium dehalogenans & $13-45$ & $6-9$ & (Utkin et al. 1994) \\
\hline Desulfitobacterium hafniense & 37 & 7 & $\begin{array}{c}\text { (Christiansen and Ahring } \\
\text { 1996) }\end{array}$ \\
\hline Desulfitobacterium metallireducens & $20-37$ & 7 & (Finneran et al. 2002) \\
\hline Desulfobacter postgatei & 32 & 7.3 & (Lien and Beeder 1997) \\
\hline Desulfobotulus alkaliphilus & $40(\max )$ & $8.7-10.7$ & $\begin{array}{l}\text { (Sorokin, Detkova et al. } \\
\text { 2010) }\end{array}$ \\
\hline Desulfobulbus propionicus* & $10-43$ & $6-8.6$ & (Pagani, Lapidus et al. 2011) \\
\hline Desulfomicrobium species* & $2-41$ & $6.6-7.5$ & $\begin{array}{c}\text { (Pfennig and Biebl 1976, } \\
\text { Biebl and Pfennig 1977, } \\
\text { Widdel 1988) }\end{array}$ \\
\hline Desulfomonile tiedjei & $30-38$ & $6.5-7.8$ & $\begin{array}{c}\text { (DeWeerd, Mandelco et al. } \\
1990)\end{array}$ \\
\hline Desulfonatronovibrio thiodismutans* & $40-42(\max )$ & $8.5-10.5$ & $\begin{array}{c}\text { (Sorokin, Tourova et al. } \\
\text { 2011) }\end{array}$ \\
\hline Desulfonatronum thioautotrophicum* & $40-41(\max )$ & $8.3-10.5$ & $\begin{array}{c}\text { (Sorokin, Tourova et al. } \\
\text { 2011) }\end{array}$ \\
\hline Desulfosporosinus acididurans* & $15-40$ & $3.8-7$ & (Sánchez-Andrea et al. 2015) \\
\hline Desulfosporosinus acidiphilus* & $25-40$ & $3.6-5.6$ & (Alazard et al. 2010, \\
\hline
\end{tabular}




\begin{tabular}{|c|c|c|c|}
\hline & & & Sánchez-Andrea et al. 2015) \\
\hline Desulfosporosinus auripigmenti* & $4-42$ & $6.4-7.0$ & $\begin{array}{c}\text { (Ramamoorthy et al. 2006, } \\
\text { Lee et al. 2009) }\end{array}$ \\
\hline Desulfosporosinus meridiei* & $10-37$ & 7.0 & $\begin{array}{c}\text { (Ramamoorthy et al. 2006, } \\
\text { Lee et al. 2009) }\end{array}$ \\
\hline Desulfosporosinus orientis* & $30-42$ & $6.4-7.0$ & $\begin{array}{c}\text { (Ramamoorthy et al. 2006, } \\
\text { Lee et al. 2009) }\end{array}$ \\
\hline Desulfotomaculum geothermicum* & $30-65$ & $5.7-8.2$ & (Sass and Cypionka 2004) \\
\hline Desulfotomaculum intricatum* & $28-58$ & $6-7.3$ & (Watanabe et al. 2013) \\
\hline Desulfotomaculum reducens & 37 & $7-7.2$ & (Tebo and Obraztsova 1998) \\
\hline Desulfotomaculum salinus* & $45-55$ & $6.6-7.6$ & (Nazina et al. 2008) \\
\hline $\begin{array}{c}\text { Desulfotomaculum } \\
\text { thermosubterraneum }\end{array}$ & $50-72$ & $6.4-7.8$ & (Kaksonen et al. 2006) \\
\hline Desulfovermiculus halophilus* & $25-47$ & $6.4-8.2$ & (Belyakova et al. 2006) \\
\hline Desulfovibrio burkinensis* & $13-42$ & $5.8-8$ & (Ouattara et al. 1999) \\
\hline Desulfovibrio desulfuricans & $30-37$ & $6.8-8.2$ & (Gilmour et al. 2011) \\
\hline Desulfovibrio frigidus & $-2-26$ & $6.9-7.5$ & (Vandieken et al. 2006) \\
\hline Desulfovibrio fructosovorans* & 35 & $6.5-7$ & (Ollivier et al. 1988) \\
\hline Desulfovibrio gabonensis* & $15-40$ & $6.4-8.2$ & (Tardy-Jacquenod et al. 1996) \\
\hline Desulfovibrio gigas* & $10-45$ & $5.8-9.8$ & $\begin{array}{c}\text { (Pfennig and Biebl 1976, } \\
\text { Biebl and Pfennig 1977, } \\
\text { Widdel 1988) }\end{array}$ \\
\hline Desulfovibrio indonesiensis* & $15-48$ & $5.5-8.7$ & (Sass and Cypionka 2004) \\
\hline Desulfovibrio legallis & $22-43$ & $5-9.2$ & (Thabet et al. 2011) \\
\hline Desulfovibrio marrakechensis* & $20-50$ & $6.5-8.5$ & (Chamkh et al. 2009) \\
\hline Desulfovibrio mexicanus & $20-40$ & $6.3-8.2$ & $\begin{array}{c}\text { (Hernandez-Eugenio et al. } \\
\text { 2000) }\end{array}$ \\
\hline Desulfovibrio termitidis & $18-45$ & $6-7$ & (Trinkerl et al. 1990) \\
\hline Desulfurella acetivorans & $52-70$ & $6.8-7$ & $\begin{array}{c}\text { (Bonch-Osmolovskaya et al. } \\
1990)\end{array}$ \\
\hline Desulfurella kamchatkensis & $40-70$ & $6.9-7.2$ & (Miroshnichenko et al. 1998) \\
\hline Desulfurella multipotens & $42-77$ & $6-7.2$ & (Miroshnichenko et al. 1998) \\
\hline Desulfurella propionica & $33-63$ & $6.9-7.2$ & (Miroshnichenko et al. 1998) \\
\hline Desulfurispirillum alkaliphilum & $45(\max )$ & $8-10.2$ & (Sorokin et al. 2007) \\
\hline Desulfurivibrio alkaliphilus & $45(\max )$ & $8.5-10.3$ & (Sorokin et al. 2008) \\
\hline Desulfurobacterium crinifex & $50-70$ & $5-7.5$ & (Alain et al. 2003) \\
\hline Desulfurobacterium pacificum & $55-85$ & $5.5-7.5$ & (L'Haridon et al. 2006) \\
\hline $\begin{array}{l}\text { Desulfurobacterium } \\
\text { thermolithotrophum }\end{array}$ & $40-75$ & $4.4-7.5$ & (L'Haridon et al. 1998) \\
\hline Desulfuromonas acetexigens & $30-35$ & $7.6-7.8$ & (Finster et al. 1994) \\
\hline Desulfuromonas acetoxidans & $25-35$ & $6.5-8.5$ & $\begin{array}{c}\text { (Pfennig and Biebl 1976, } \\
\text { Biebl and Pfennig 1977, } \\
\text { Widdel 1988) }\end{array}$ \\
\hline Desulfuromusa bakii & $25-30$ & $6.7-7.4$ & (Liesack and Finster 1994) \\
\hline Desulfuromusa kysingii & $30-35$ & $6.5-7.9$ & (Liesack and Finster 1994) \\
\hline Desulfuromusa succinoxidans & $30-35$ & $6.5-7.9$ & (Liesack and Finster 1994) \\
\hline Dethiobacter alkaliphilus & $45(\max )$ & $8.5-10.3$ & (Sorokin et al. 2008) \\
\hline Dethiosulfovibrio acidaminovorans & $15-40$ & $5.5-8$ & (Surkov et al. 2001) \\
\hline Dethiosulfovibrio marinus & $15-40$ & $5.5-8$ & (Surkov et al. 2001) \\
\hline Dethiosulfovibrio peptidovorans & $20-45$ & $5.5-8.8$ & (Magot et al. 1997) \\
\hline Dethiosulfovibrio russensis & $15-40$ & $5.5-8$ & (Surkov et al. 2001) \\
\hline Ercella succinigenes & $25-40$ & $7-9$ & (van Gelder et al. 2014) \\
\hline Fervidobacterium changbaicum & $55-90$ & $6.3-8.5$ & (Cai et al. 2007) \\
\hline Fervidobacterium riparium & $46-80$ & $5.7-9$ & (Podosokorskaya et al. 2011) \\
\hline
\end{tabular}




\begin{tabular}{|c|c|c|c|}
\hline Geoalkalibacter subterraneus & $30-50$ & $5.8-8$ & (Greene et al. 2009) \\
\hline Geobacter bremensis & $30-32$ & $5.5-6.7$ & $\begin{array}{c}\text { (Straub and Buchholz-Cleven } \\
\text { 2001) }\end{array}$ \\
\hline Geobacter chapelleii & 25 & & (Coates et al. 2001) \\
\hline Geobacter humirreducens & 30 & & (Shelobolina et al. 2008) \\
\hline Geobacter hydrogenophilus & 35 & 6.5 & (Coates et al. 2001) \\
\hline \multicolumn{4}{|l|}{ Geobacter metallireducens } \\
\hline Geobacter sulfurreducens & $4-50$ & $6-8$ & (Caccavo Jr. et al. 1994) \\
\hline Geotoga petraea & $30-60$ & $5.5-9$ & (Davey et al. 1993) \\
\hline Geotoga subterranea & $30-60$ & $5.5-9$ & (Davey et al. 1993) \\
\hline Haloanaerobium congolense & $20-45$ & $6.3-8.5$ & (Ravot et al. 1997) \\
\hline Haloarsenatibacter silvermanii & - & 9.4 & (Blum et al. 2009) \\
\hline Hippea maritima & $40-65$ & $5.7-6.5$ & (Huntemann et al. 2011) \\
\hline Lebctimonas acidiphila & $30-68$ & $4.2-7$ & (Alain et al. 2009) \\
\hline Marinitoga camini & $25-65$ & $5-9$ & (Wery et al. 2001) \\
\hline Marinitoga hydrogenitolerans & $35-65$ & $4.5-8.5$ & (Postec et al. 2005) \\
\hline Marinitoga okinawensis & $30-70$ & $5-7.4$ & (Nunoura et al. 2007) \\
\hline Marinitoga piezophila & $45-70$ & $5-8$ & (Alain et al. 2002) \\
\hline Mesotoga infera & $30-50$ & $7.3-7.5$ & (Ben Hania et al. 2013) \\
\hline Mesotoga prima & 37 & 7.5 & (Nesbø et al. 2012) \\
\hline Nautilia abyssi & $33-65$ & $5-8$ & (Alain et al. 2009) \\
\hline Nautilia lithotrophica & $37-68$ & $6.4-7.4$ & (Alain et al. 2009) \\
\hline Nautilia profundicola & $30-55$ & $6-9$ & (Alain et al. 2009) \\
\hline Oceanithermus desulfurans & $30-65$ & $6-8$ & (Mori et al. 2004) \\
\hline Pelobacter carbinolicus & $4-45$ & $6-8$ & $\begin{array}{c}\text { Schink 1984, Lovley et al. } \\
1995) \\
\end{array}$ \\
\hline Pelobacter seleniigenes & $4-45$ & $6-8$ & $\begin{array}{c}\text { (Narasingarao and Haggblom } \\
\text { 2007) }\end{array}$ \\
\hline Persephonella guaymasensis & $55-80$ & $4.7-7.5$ & (Götz, et al. 2002) \\
\hline Persephonella marina & $55-75$ & $4.7-7.5$ & (Götz et al. 2002) \\
\hline Petrimonas sulfuriphila & $15-40$ & 7.2 & (Grabowski et al. 2005) \\
\hline Petrotoga mexicana & $25-65$ & $5.8-8.5$ & $\begin{array}{c}\text { (Miranda-Tello, Fardeau et } \\
\text { al. 2004) }\end{array}$ \\
\hline Petrotoga miotherma & $35-65$ & $5.5-9$ & $\begin{array}{c}\text { (Miranda-Tello, Fardeau et } \\
\text { al. 2007) }\end{array}$ \\
\hline Petrotoga mobilis & $40-65$ & $5.5-8.5$ & $\begin{array}{c}\text { (Miranda-Tello, Fardeau et } \\
\text { al. 2007) }\end{array}$ \\
\hline Pseudomonas mendocina & $20-36$ & 7.0 & $\begin{array}{c}\text { (Balashova } 1985, \text { Kao, et al. } \\
\text { 2005) }\end{array}$ \\
\hline Shewanella putrefaciens & $15-42$ & $6.2-9.6$ & $\begin{array}{c}\text { (Saeed et al. 1987, Moser and } \\
\text { Nealson 1996) }\end{array}$ \\
\hline Spirochaeta perfilievii & $4-32$ & $6-8.5$ & (Dubinina et al. 2011) \\
\hline Spirochaeta smaragdinae & $20-40$ & $5.5-8$ & (Magot et al. 1997) \\
\hline Sporanaerobacter acetigenes & $25-50$ & $5.5-8.5$ & $\begin{array}{c}\text { (Hernandez-Eugenio, et al. } \\
\text { 2002) }\end{array}$ \\
\hline Sulfospirillum arcachonense & $8-30$ & $6.1-8.2$ & (Finster et al. 1997) \\
\hline Sulfurospirillum barnesii & $25-30$ & 7.5 & (Stolz et al. 1999) \\
\hline Sulfurospirillum deleyianum & $20-36$ & $7.0-7.1$ & (Wolfe and Pfennig 1977) \\
\hline Sulfurospirillum halorespirans & $20-32$ & $7-7.2$ & (Luijten et al. 2003) \\
\hline Sulfurospirillum multivorans & 30 & $7-7.5$ & $\begin{array}{c}\text { (Scholz-Muramatsu et al. } \\
\text { 1995) }\end{array}$ \\
\hline Thermanaerovibrio acidaminovorans & $50-55$ & $6.5-8.1$ & (Zavarzina et al. 2000) \\
\hline Thermanaerovibrio velox & $45-70$ & $4.5-8$ & (Zavarzina et al. 2000) \\
\hline Thermoanaerobacter sulfurophilus & $44-75$ & $4.5-8$ & (Bonch-Osmolovskaya et al. \\
\hline
\end{tabular}




\begin{tabular}{|c|c|c|c|}
\hline & & & 1997) \\
\hline Thermocrinis ruber & 44-89 & $7-8.5$ & (Huber et al. 1998) \\
\hline Thermodesulfobacterium geofontis & $70-90$ & $5.5-8.5$ & (Hamilton-Brehm et al. 2013) \\
\hline Thermosipho species & $45-75$ & $5.5-8.2$ & $\begin{array}{l}\text { (Antoine et al. 1997, } \\
\text { L'Haridon et al. 2001) }\end{array}$ \\
\hline Thermosulfidibacter takaii ${ }^{*}$ & $55-78$ & $5-7.5$ & (Nunoura et al. 2008) \\
\hline Thermotoga species & $62-80$ & $6-8.7$ & $\begin{array}{c}\text { (Windberger et al. 1989, } \\
\text { Huber et al. 1996) }\end{array}$ \\
\hline Thermovibrio ammonificans & $60-80$ & $5-7$ & (Vetriani et al. 2004) \\
\hline Thermovibrio guaymasensis & $50-88$ & $5.5-7.5$ & (L'Haridon et al. 2006) \\
\hline Thermovibrio ruber & $50-80$ & $5-6.5$ & (Huber et al. 2002) \\
\hline Thermovirga lienii & $37-68$ & $6.2-8$ & (Dahle and Birkeland 2006) \\
\hline Wolinella succinogenes & $25-37$ & $7.5-8.5$ & $\begin{array}{c}\text { (Macy et al. 1986, Segerer et } \\
\text { al. 1986) }\end{array}$ \\
\hline \multicolumn{4}{|c|}{ Archaea } \\
\hline Acidolobus aceticus & $60-92$ & $2.0-6.0$ & (Prokofeva, et al. 2000) \\
\hline Acidilobus sulfurireducens & $62-89$ & $2-5.5$ & $\begin{array}{c}\text { (Boyd, Jackson et al. } \\
\text { 2007) }\end{array}$ \\
\hline Acidilobus saccharovorans & $60-90$ & $2.5-5.8$ & $\begin{array}{c}\text { (Prokofeva, Kostrikina et } \\
\text { al. 2009) }\end{array}$ \\
\hline Acidianus brierleyi & $45-75$ & $1-6$ & $\begin{array}{c}\text { (Segerer, Neuner et al. } \\
1986) \\
\end{array}$ \\
\hline Acidianus infernus & $60-95$ & $1.5-5$ & (Stetter 1996) \\
\hline Acidianus hospitalis & $65-95$ & $2-4$ & (You et al. 2011) \\
\hline Archaeoglobus profundus & $65-90$ & $4.5-7.5$ & (Burggraf et al. 1990) \\
\hline Caldisphaera lagunensis & $45-80$ & $2.3-5.4$ & (Itoh et al. 2003) \\
\hline Caldivirga maquilingensis & $60-92$ & $2.3-6.4$ & (Itoh et al. 1999) \\
\hline Caldococcus litoralis & $55-100$ & $5.9-7$ & $\begin{array}{c}\text { (Svetlichnyi, Slesarev et } \\
\text { al. 1987) } \\
\end{array}$ \\
\hline Desulfurococcus amylolyticus & $85-90$ & $5.7-7.5$ & $\begin{array}{l}\text { (Bonch-Osmolovskaya, } \\
\text { Slesarev et al. 1988) }\end{array}$ \\
\hline Desulfurococcus kamchatkensis & $65-87$ & $5.5-7.5$ & $\begin{array}{c}\text { (Kublanov, Bidjieva et al. } \\
\text { 2009) }\end{array}$ \\
\hline Desulfurococcus mobilis & 85 & $4.5-7$ & (Perevalova et al. 2005) \\
\hline Desulfurococcus mисоsus & 85 & $4.5-7$ & (Perevalova et al. 2005) \\
\hline Acidianus ambivalens & $81-87$ & $1-3.5$ & (Zillig et al. 1986) \\
\hline Halobiforma nitratireducens & $26-44$ & $8-10.5$ & (Xin, Itoh et al. 2001) \\
\hline Hyperthermus buthylicus & 80-108 & $5-7$ & (Zillig, Holz et al. 1990) \\
\hline Ignicoccus species & $70-98$ & $3.8-6.5$ & (Hedderich et al. 1999) \\
\hline Methanobacterium species & $70-98$ & $6-8.5$ & (Stetter and Gaag 1983) \\
\hline Methanobrevibacter smithii & 38 & $6.9-7.4$ & (Miller and Lin 2002) \\
\hline Methanococcus species & $45-91$ & $5-7.5$ & (Stetter 1996) \\
\hline Methanogenium marinum & $5-25$ & $5.5-7.5$ & (Chong, Liu et al. 2002) \\
\hline Methanolobus tindarius & $10-45$ & $5.5-8$ & (König and Stetter 1982) \\
\hline Methanoplanus limicola & $17-41$ & $6.5-7.5$ & (Wildgruber et al. 1982) \\
\hline Methanopyrus species & $84-110$ & $5.5-7$ & (Stetter 1996) \\
\hline $\begin{array}{l}\text { Methanothermococcus } \\
\text { thermolithotrophicus }\end{array}$ & $17-70$ & $4.9-9.8$ & (Takai et al. 2002) \\
\hline Methanothermus species & $65-97$ & $5.5-7.5$ & (Stetter 1996) \\
\hline Natrinema versiforme & $20-53$ & $6-8$ & (Xin, Itoh et al. 2000) \\
\hline Natronolimnobius innermongolicus & $37-45$ & $9-9.5$ & $\begin{array}{c}\text { (Itoh, Yamaguchi et al. } \\
\text { 2005) }\end{array}$ \\
\hline Palaeococcus ferrophilus & $60-88$ & $4-8$ & (Takai, Sugai et al. 2000) \\
\hline Palaeococcus pacificus & $50-90$ & $5-8$ & (Zeng, Zhang et al. 2013) \\
\hline
\end{tabular}




\begin{tabular}{|c|c|c|c|}
\hline Pyrobaculum aerophilum & $75-104$ & $5.8-9$ & (Volkl, Huber et al. 1993) \\
\hline Pyrobaculum calidifontis & $75-100$ & $5.5-8$ & (Amo, Paje et al. 2002) \\
\hline Pyrobaculum islandicum & $74-103$ & $5.8-9$ & $\begin{array}{c}\text { (Stetter 1996, Huber, } \\
\text { Kristjansson et al. 1987) }\end{array}$ \\
\hline Pyrococcus species & $70-105$ & $5-9$ & $\begin{array}{c}\text { (Fiala and Stetter 1986, } \\
\text { Stetter 1996, González et } \\
\text { al. 1998) }\end{array}$ \\
\hline Pyrodictium occultum & $82-110$ & $5-7$ & $\begin{array}{c}\text { (Fischer et al. 1983, } \\
\text { Stetter and Gaag 1983, } \\
\text { Stetter 1996) }\end{array}$ \\
\hline Pyrodictium brockii & $80-110$ & $5-7$ & (Stetter et al, 1983) \\
\hline Staphylothermus hellenicus & $70-90$ & $4.5-7$ & (Arab et al. 2000) \\
\hline Staphylothermus marinus & $65-98$ & $4.5-8.5$ & $\begin{array}{c}\text { (Fiala and Stetter 1986, } \\
\text { Stetter 1996) }\end{array}$ \\
\hline Stetteria hydrogenophila & $70-102$ & $4.5-7$ & (Jochimsen et al. 1997) \\
\hline Stygiolobus azoricus & $57-89$ & $1-5.5$ & $\begin{array}{c}\text { (Segerer et al. 1991, } \\
\text { Stetter 1996) }\end{array}$ \\
\hline Thermocladium modestius & $45-82$ & $2.6-5.9$ & (Itoh et al. 1998) \\
\hline Thermococcus species & $56-93$ & $4-10.5$ & $\begin{array}{c}\text { (Neuner et al. 1990, } \\
\text { Dirmeier et al. 1998) }\end{array}$ \\
\hline Thermodiscus maritimus & $75-98$ & $5-7$ & (Fischer et al. 1983) \\
\hline Thermofilum pendes & $70-95$ & $4-6.5$ & (Zillig et al. 1983) \\
\hline Thermogladius species & $64-93$ & $3.5-8.5$ & $\begin{array}{c}\text { (Osburn and Amend } \\
\text { 2011) }\end{array}$ \\
\hline Thermoplasma acidophilum & $45-63$ & $1-4$ & (Segerer et al. 1988) \\
\hline Thermoplasma volcanicum & $33-67$ & $1-4$ & (Segerer et al. 1988) \\
\hline Thermoproteus species & $70-95$ & $4-6.7$ & (Fischer et al. 1983) \\
\hline Thermosphaera aggregans & $65-90$ & $5-7$ & $\begin{array}{c}\text { (Huber et al. 1998, } \\
\text { Garrity 2001) }\end{array}$ \\
\hline Vulcanisaeta distributa & $70-92$ & $3.5-5.6$ & (Itoh et al. 2002) \\
\hline Vulcanisaeta souniana & $65-89$ & $3.5-5$ & (Itoh et al. 2002) \\
\hline
\end{tabular}

*Microorganisms able to reduce also sulfate. 
Table S2 - Distribution of sulfur reduction related enzymes in sulfur-reducing microorganisms with sequenced genome.

\begin{tabular}{|c|c|}
\hline$\overline{\text { Species name }}$ & $\overline{\text { Enzyme }}$ \\
\hline \multicolumn{2}{|r|}{ Bacteria } \\
\hline Acidilobus sulfurireducens & $\begin{array}{l}\text { NADPH-dependent 2,4-dienoyl-CoA reductase, sulfur } \\
\text { reductase, or a related oxidoreductase }\end{array}$ \\
\hline Caldisericum exile & Sulfide dehydrogenase \\
\hline Caldithrix abyssi & Sulfide dehydrogenase \\
\hline Caminibacter mediatlanticus & Polysulfide reductase \\
\hline Clostridium tunisiense & Sulfide dehydrogenase \\
\hline Deferribacter desulfuricans & $\begin{array}{l}\text { NADPH-dependent 2,4-dienoyl-CoA reductase, sulfur } \\
\text { reductase, or a related oxidoreductase }\end{array}$ \\
\hline Desulfitobacterium dehalogenans & $\begin{array}{l}\text { NADPH-dependent 2,4-dienoyl-CoA reductase, sulfur } \\
\text { reductase, or a related oxidoreductase }\end{array}$ \\
\hline Desulfitobacterium hafniense & Sulfide dehydrogenase \\
\hline Desulfobotulus alkaliphilus & Sulfide dehydrogenase \\
\hline Desulfomicrobium baculatum & Polysulfide reductase \\
\hline Desulfosporosinus acidiphilus & $\begin{array}{l}\text { NADPH-dependent 2,4-dienoyl-CoA reductase, sulfur } \\
\text { reductase, or a related oxidoreductase }\end{array}$ \\
\hline Desulfovermiculus halophilus & Sulfide dehydrogenase \\
\hline Desulfovibrio desulfuricans & Sulfide dehydrogenase \\
\hline Desulfovibrio frigidus & $\begin{array}{l}\text { NADPH-dependent 2,4-dienoyl-CoA reductase, sulfur } \\
\text { reductase, or a related oxidoreductase }\end{array}$ \\
\hline Desulfovibrio fructosovorans & Sulfide dehydrogenase \\
\hline Desulfovibrio gigas & Polysulfide reductase \\
\hline Desulfovibrio termitidis & Sulfide dehydrogenase \\
\hline Desulfurella acetivorans & $\begin{array}{l}\text { NADPH-dependent 2,4-dienoyl-CoA reductase, sulfur } \\
\text { reductase, or a related oxidoreductase }\end{array}$ \\
\hline Desulfurivibrio alkaliphilus & Polysulfide reductase \\
\hline $\begin{array}{l}\text { Desulfurobacterium } \\
\text { thermolithotrophum }\end{array}$ & Sulfide dehydrogenase and sulfhydrogenase \\
\hline Desulfuromonas acetoxidans & $\begin{array}{l}\text { NADPH-dependent 2,4-dienoyl-CoA reductase, sulfur } \\
\text { reductase, or a related oxidoreductase and sulfide dehydrogenase }\end{array}$ \\
\hline Dethiobacter alkaliphilus & Sulfide dehydrogenase and sulfhydrogenase \\
\hline Geobacter bremensis & Sulfide dehydrogenase \\
\hline Mesotoga prima & Sulfide dehydrogenase \\
\hline Nautilia profundicola & Sulfide dehydrogenase \\
\hline Pelobacter carbinolicus & $\begin{array}{c}\text { NADPH-dependent 2,4-dienoyl-CoA reductase, sulfur } \\
\text { reductase, or a related oxidoreductase }\end{array}$ \\
\hline Spirochaeta smaragdinae & Sulfide dehydrogenase \\
\hline Sulfurospirillum barnesii & Polysulfide reductase \\
\hline Sulfurospirillum deleyianum & Polysulfide reductase \\
\hline Sulfurospirillum multivorans & Polysulfide reductase \\
\hline Thermanaerovibrio acidaminovorans & $\begin{array}{l}\text { NADPH-dependent 2,4-dienoyl-CoA reductase, sulfur } \\
\text { reductase, or a related oxidoreductase }\end{array}$ \\
\hline
\end{tabular}




\begin{tabular}{|c|c|}
\hline Thermanaerovibrio velox & sulfide dehydrogenase \\
\hline Thermodesulfobacterium geofontis & $\begin{array}{l}\text { NADPH-dependent 2,4-dienoyl-CoA reductase, sulfur } \\
\text { reductase, or a related oxidoreductase }\end{array}$ \\
\hline Thermosipho africanus & Sulfide dehydrogenase \\
\hline Thermotoga lettingae & Sulfide dehydrogenase \\
\hline \multirow[t]{2}{*}{ Wolinella succinogenes } & Polysulfide reductase/sulfur reductase \\
\hline & Archaea \\
\hline Acidianus hospitalis & Sulfur oxygenase/reductase (similar to A. ambivalens) \\
\hline Acidilobus sulfurireducens & $\begin{array}{l}\text { NADPH-dependent 2,4-dienoyl-CoA reductase, sulfur } \\
\text { reductase, or a related oxidoreductase }\end{array}$ \\
\hline Caldisphaera lagunensis & $\begin{array}{l}\text { NADPH-dependent 2,4-dienoyl-CoA reductase, sulfur } \\
\text { reductase, or a related oxidoreductase }\end{array}$ \\
\hline Caldivirga maquilingensis & Sulfide dehydrogenase \\
\hline Desulfurococcus kamchatkensis & Sulfide dehydrogenase \\
\hline Desulfurococcus тисоsиs & Sulfide dehydrogenase \\
\hline Halobiforma nitratireducens & Polysulfide reductase \\
\hline Hyperthermus butylicus & Sulfide dehydrogenase \\
\hline Methanococcus maripaludis & $\begin{array}{l}\text { NADPH-dependent 2,4-dienoyl-CoA reductase, sulfur } \\
\text { reductase, or a related oxidoreductase }\end{array}$ \\
\hline Methanolobus tindarius & Sulfide dehydrogenase \\
\hline Methanoplanus limicola & Sulfide dehydrogenase \\
\hline Natronolimnobius innermongolicus & $\begin{array}{l}\text { NADPH-dependent 2,4-dienoyl-CoA reductase, sulfur } \\
\text { reductase, or a related oxidoreductase }\end{array}$ \\
\hline Palaeococcus ferrophilus & Sulfide dehydrogenase/disulfide reductase/sulfhydrogenase \\
\hline Palaeococcus pacificus & Sulfide dehydrogenase/disulfide reductase/sulfhydrogenase \\
\hline Pyrobaculum islandicum & $\begin{array}{l}\text { NADPH-dependent 2,4-dienoyl-CoA reductase, sulfur } \\
\text { reductase, or a related oxidoreductase }\end{array}$ \\
\hline Pyrococcus abyssi & Sulfide dehydrogenase/disulfide reductase/sulfhydrogenase \\
\hline Pyrococcus furiosus & Sulfide dehydrogenase/disulfide reductase/sulfhydrogenase \\
\hline Pyrococcus yayanosii & Sulfide dehydrogenase/disulfide reductase/sulfhydrogenase \\
\hline Thermococcus litoralis & Sulfide dehydrogenase/disulfide reductase/sulfhydrogenase \\
\hline Thermofilum pendens & Sulfide dehydrogenase/disulfide reductase \\
\hline Thermogladius cellulolyticus & Sulfide dehydrogenase \\
\hline Thermoplasma volcanium & Sulfhydrogenase \\
\hline Thermoproteus neutrophilus & Sulfide dehydrogenase/disulfide reductase \\
\hline Thermoproteus tenax & Sulfur/polysulfide reductase \\
\hline Thermoproteus uzoniensis & Sulfhydrogenase \\
\hline Thermosphaera aggregans & Sulfide dehydrogenase \\
\hline Vulcanisaeta distributa & $\begin{array}{l}\text { NADPH-dependent 2,4-dienoyl-CoA reductase, sulfur } \\
\text { reductase, or a related oxidoreductase }\end{array}$ \\
\hline
\end{tabular}




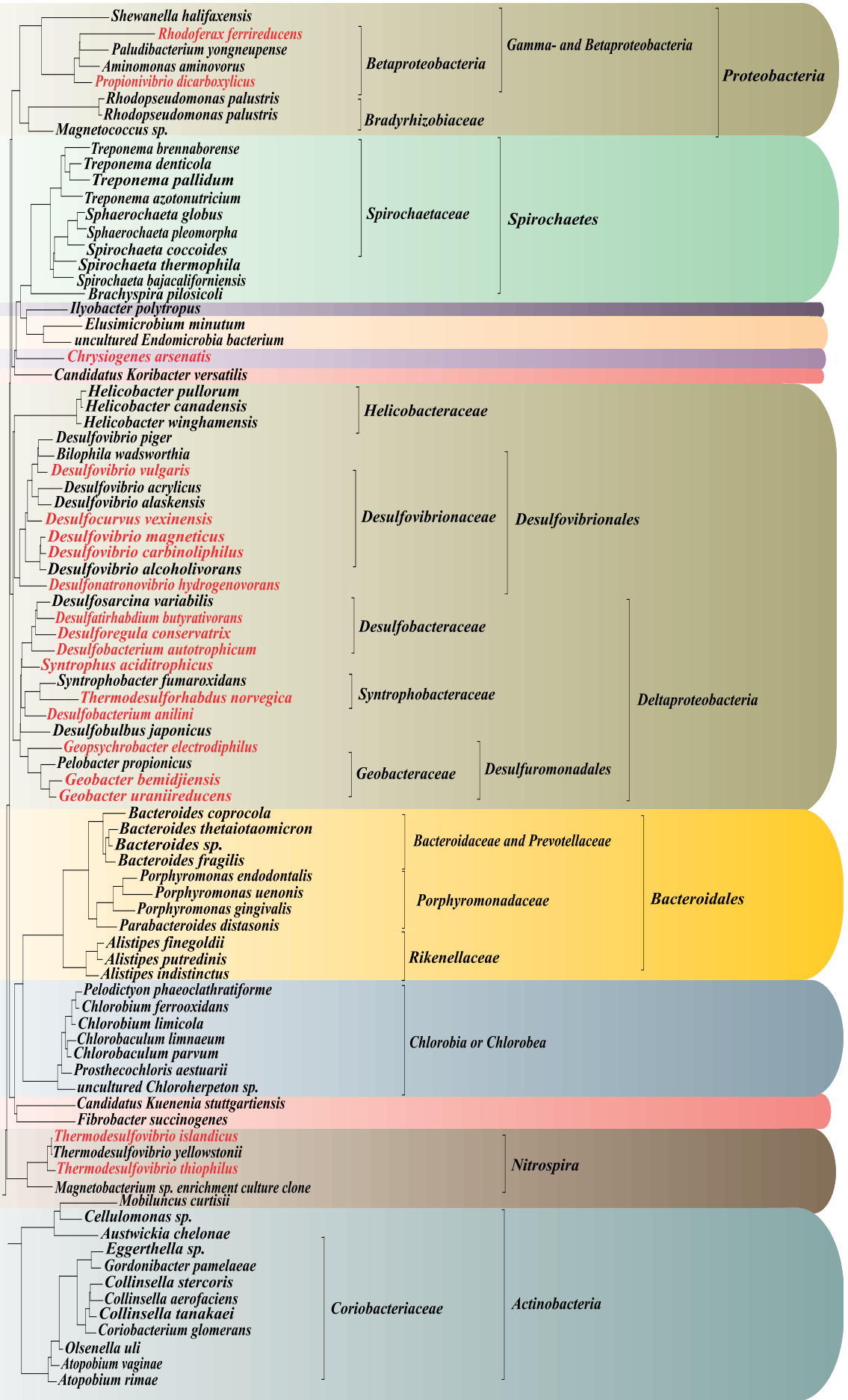




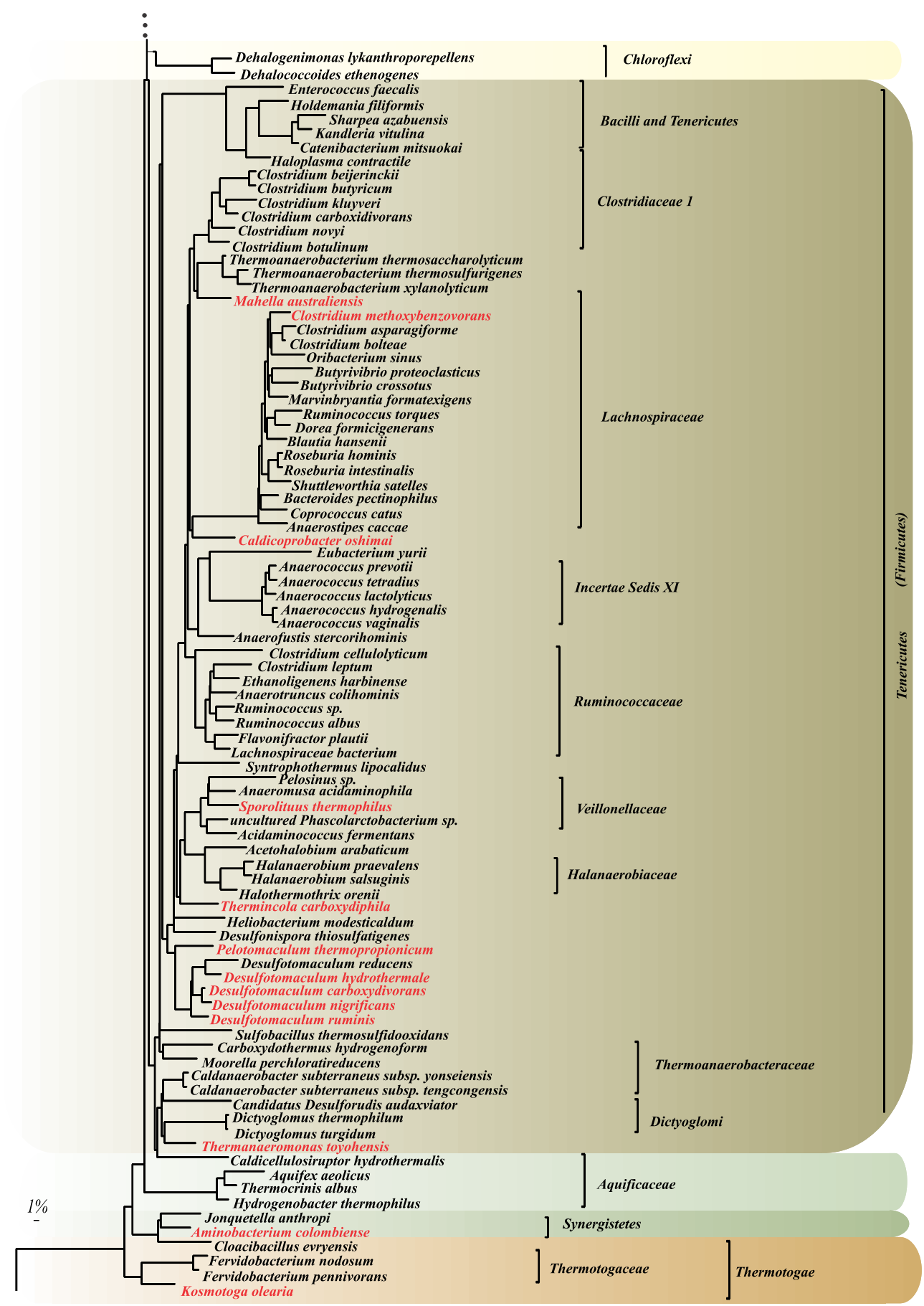

Figure S1 - Phylogenetic affiliation of 16S rRNA gene sequences of potential sulfurreducing bacteria in The All-Species Living Tree Project (Yarza, Richter et al., 2008). 1\% estimated sequence divergence. Microorganisms without sulfur reduction activity (tested experimentally) but with enzymes present in their genome are represented in red. 


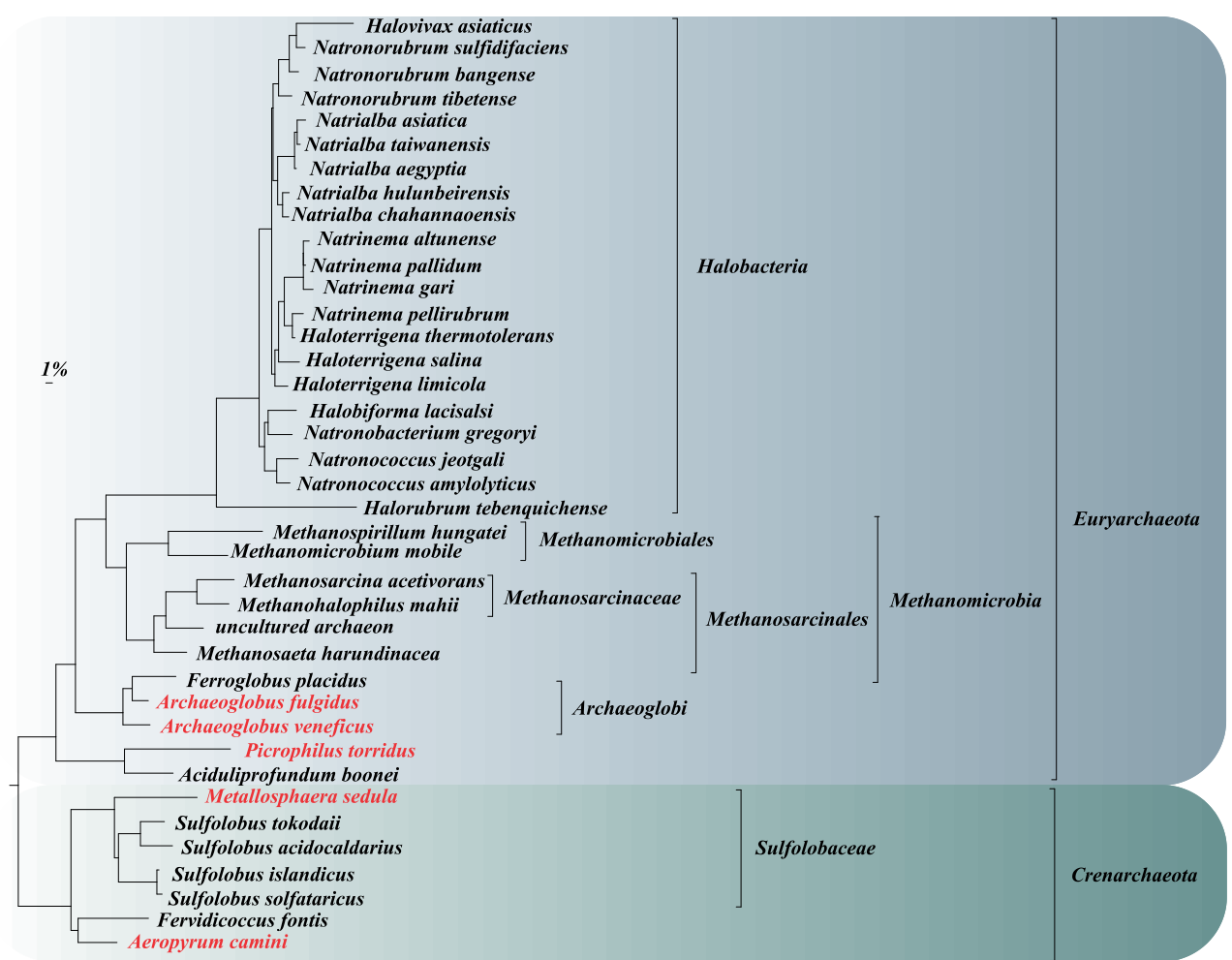

Figure S2 - Phylogenetic affiliation of 16S rRNA gene sequences of potential sulfurreducing archaea in The All-Species Living Tree Project (Yarza, Richter et al., 2008). 1\% estimated sequence divergence. Microorganisms without sulfur reduction activity (tested experimentally) but with enzymes present in their genome are represented in red. 


\section{Chapter 3}

\section{Sulfur reduction in acid rock drainage environments}

This chapter has been published as:

Florentino, A. P., J. Weijma, A. J. Stams and I. Sánchez-Andrea (2015). "Sulfur reduction in acid rock drainage environments." Environmental Science and Technology 49(19): 1174611755 . 


\begin{abstract}
Microbiological suitability of acidophilic sulfur reduction for metal recovery was explored by enriching sulfur reducers from acidic sediments at low $\mathrm{pH}$ (from 2 to 5 ) with hydrogen, glycerol, methanol and acetate as electron donors at $30^{\circ} \mathrm{C}$. The highest levels of sulfide in the enrichments were detected at $\mathrm{pH} 3$ with hydrogen and $\mathrm{pH} 4$ with acetate. Cloning and sequencing of the $16 \mathrm{~S}$ rRNA gene showed dominance of the deltaproteobacterial sulfurreducing genus Desulfurella in all the enrichments and subsequently an acidophilic strain (TR1) was isolated. Strain TR1 grew at a broad range of $\mathrm{pH}(3-7)$ and temperature (20 $\left.50^{\circ} \mathrm{C}\right)$ and showed good metal tolerance $\left(\mathrm{Pb}^{+2}, \mathrm{Zn}^{+2}, \mathrm{Cu}^{+2}, \mathrm{Ni}^{+2}\right)$, especially for $\mathrm{Ni}^{2+}$ and $\mathrm{Pb}^{2+}$, with maximal tolerated concentrations of 0.09 and $0.03 \mathrm{mM}$, respectively. Different sources of sulfur were tested in the enrichments, from which bio-sulfur showed fastest growth (doubling time of 1.9 days), followed by colloidal, chemical and sublimated sulfur (doubling times of 2.2, 2.5 and 3.6 days, respectively). Strain TR1's physiological traits make it a good candidate to cope with low $\mathrm{pH}$ and high metal concentration in biotechnological processes for treatment of metal-laden acidic streams at low and moderately-high temperature.
\end{abstract}




\section{Introduction}

Sulfidogenic extremophiles are of scientific and technological interest (Johnson and Hallberg 2005) because they extend the range of operating conditions of biotechnological processes, such as metal recovery. Depending on $\mathrm{pH}$ and its concentration, biogenic hydrogen sulfide precipitates a number of chalcophilic metals often present in industrial streams (e.g. $\mathrm{Cu}^{2+}, \mathrm{Zn}^{2+}, \mathrm{Ni}^{2+}, \mathrm{Pb}^{2+}, \mathrm{Cd}^{2+}$ and $\mathrm{Co}^{2+}$ ) as metal sulfides (Tang, Baskaran et al. 2009) (equation 1).

$$
\mathrm{H}_{2} \mathrm{~S}+\mathrm{Me}^{2+} \rightarrow \mathrm{MeS}_{(\mathrm{s})}+2 \mathrm{H}^{+} \text {(equation 1) }
$$

Sulfate is often used as sulfur source for biosulfidogenesis to remove and recover metals from wastewater from the mining and metallurgical industry (Johnson 1998, Koschorreck 2008, Sánchez-Andrea, Knittel et al. 2012), as it is naturally present in many metal-rich waters, such as acid mine drainage. Microbiological sulfate reduction has been successfully applied at $\mathrm{pH}$ down to 2.5 (Nancucheo and Johnson 2012), which renders treatment of the acidic and metalliferous waters feasible. This type of water is generally characterized by a low content of organic matter (Liamleam and Annachhatre 2007) and therefore, suitable electron donors need to be added for sulfate reduction. Organic waste materials may be used for low-rate, low-tech bioprocesses such as permeable reactive barriers (Younger, Jayaweera et al. 2003), but their variable composition makes it less suitable for controlled, high-rate biogenic technologies. These require relatively pure bulk electron donors such as ethanol, glycerol, methanol or hydrogen (Liamleam and Annachhatre 2007). Therefore, a critical bottleneck for widespread application of high-rate biogenic sulfide technologies is the cost of the electron donors (Weijma, Copini et al. 2002). In that respect, elemental sulfur reduction is economically much more attractive than sulfate reduction, as only two electrons (equation 2) are needed instead of eight (equation 3) per sulfide formed.

$$
\begin{gathered}
\mathrm{S}^{0}+2 \mathrm{H}^{+}+2 \mathrm{e}^{-} \rightarrow \mathrm{H}_{2} \mathrm{~S} \text { (equation 2) } \\
\mathrm{SO}_{4}^{2-}+8 \mathrm{e}^{-}+10 \mathrm{H}^{+} \rightarrow \mathrm{H}_{2} \mathrm{~S}+4 \mathrm{H}_{2} \mathrm{O} \text { (equation 3) }
\end{gathered}
$$

Consequently, 4 times less electron donor needs to be added for sulfur reduction. Even though sulfate, the electron acceptor, is already present in metal contaminated waters; the additional costs of electron donors for sulfate reduction is higher than the costs of the combined addition of elemental sulfur and electron donors for sulfur reduction (Florentino, Weijma et al. 2016).

Elemental sulfur has a low solubility in water $\left(5 \mu \mathrm{g} \mathrm{L^{-1 }}\right.$ at $\left.25^{\circ} \mathrm{C}\right)$, which may hamper its availability for microorganisms. The customary form of bulk elemental sulfur is 
sulfur flower that is mainly composed by $\mathrm{S}_{8}$ rings and some polymeric sulfur that consists of chain-like macromolecules (Steudel and Eckert 2003). This commercial product is normally obtained by the Claus-process or by sublimation. Colloidal sulfur produced by the acidification of polysulfide or thiosulfate and microbiologically produced sulfur (bio-sulfur) by oxidation of sulfide, have smaller particle sizes and are more soluble in water, which could make them more accessible for microorganisms (Breher 2004).

A natural extreme environment, Tinto River (Huelva, south-western Spain) presents a $\mathrm{pH}$ in the water column around 2.3 and high concentrations of heavy metals in solution (iron up to $20.2 \mathrm{~g} \mathrm{~L}^{-1}$, copper up to $0.70 \mathrm{~g} \mathrm{~L}^{-1}$, and zinc up to $0.56 \mathrm{~g} \mathrm{~L}^{-1}$ ) (LopezArchilla, Marin et al. 2001). A novel acidophilic sulfate-reducing bacterium, Desulfosporosinus acididurans (Sánchez-Andrea, Stams et al. 2015), and a novel fermenter, Microbacter margulisiae, have been recently isolated from these sediments (Sánchez-Andrea, Sanz et al. 2014), revealing that this environment is a promising source for novel acidophiles. We used sediments from Tinto River as a source of low $\mathrm{pH}$ adapted microorganisms and the suitability of those microorganisms for treatment of acidic and metal-laden wastewater was investigated. Acidophilic sulfur-reducing microorganisms were enriched with various electron donors at low $\mathrm{pH}$ ( $\mathrm{pH} 2$ to 5) at mesophilic conditions $\left(30^{\circ} \mathrm{C}\right)$. A sulfur-reducing bacterium belonging to the Desulfurella genus was isolated (strain TR1) and its applicability was tested at different conditions, e.g. $\mathrm{pH}$, temperature, utilization of electron donors, and growth in the presence of metals $\left(\mathrm{Cu}^{2+}, \mathrm{Ni}^{2+}, \mathrm{Zn}^{2+}\right.$ and $\left.\mathrm{Pb}^{2+}\right)$.

\section{Material and Methods}

\section{Inoculum source}

Samples were collected from three sampling sites in Tinto River basin: JL, Los Frailes and Moguer in March 2013. JL site (37'16'57.89"N, 650'59.76"W) is a dam point, relatively close to the origin, where wastewaters from the close municipality of Nerva join the river. Los Frailes point $\left(37^{\circ} 37^{\prime} 37.39^{\prime \prime} \mathrm{N}, 6^{\circ} 32^{\prime} 16.19^{\prime \prime} \mathrm{W}\right)$ is located in the middle course of the river. Moguer site $\left(37^{\circ} 16^{\prime} 28.70^{\prime \prime} \mathrm{N}, 6^{\circ} 50^{\prime} 12.868^{\prime \prime} \mathrm{W}\right)$ is located in the estuary part of the river. The $\mathrm{pH}$ values of the samples measured in situ were 2.6, 2.8 and 6.6 at the JL, Los Frailes and Moguer sites, respectively. To increase the potential diversity of the inoculum, samples from the three sampling sites were pooled together. All the sediment samples $(\sim 10$ $\mathrm{mL}$ each) were mixed and the mixture was diluted in a $0.9 \%(\mathrm{w} / \mathrm{v}) \mathrm{NaCl}$ anoxic solution to a final volume of $50 \mathrm{~mL}$. 


\section{Microbial diversity analysis of the inoculum (16S rDNA gene pyrosequencing)}

DNA was extracted from the sediment mixture and from the selected enrichments using the FastDNA SPIN Kit for Soil (Qbiogene, Carlsbad, USA), following the instructions of the manufacturer. The DNA was quantified with a Nanodrop spectrophotometer (Nanodrop Technologies, Wilmington, DE).

For pyrosequencing analysis of the inoculum, DNA concentration was adjusted to $10-20 \mathrm{ng} \mu \mathrm{L}^{-1}$ as template for PCR amplification. PCR was performed in a total volume of

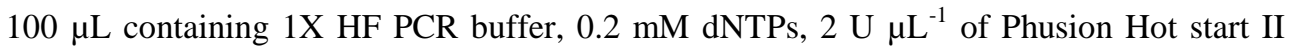
DNA polymerase (Promega, Madison, WI), $10 \mu \mathrm{M}$ of forward and the reverse primer mixture, $200 \mu \mathrm{M}$ of barcoded forward primer with titanium sequence adaptor, 338R-I+II (Biolegio BV, Nijmegen, The Netherlands), 0.2-0.4 ng $\mu \mathrm{L}^{-1}$ of template DNA and nuclease free water up to final volume. The amplification program consisted of an initial denaturation step at $98^{\circ} \mathrm{C}$ for $30 \mathrm{~s}, 30$ cycles of denaturation at $98^{\circ} \mathrm{C}$ for $10 \mathrm{~s}$, annealing at $56^{\circ} \mathrm{C}$ for $20 \mathrm{~s}$ and elongation at $72^{\circ} \mathrm{C}$ for $20 \mathrm{~s}$; and a final extension step at $72^{\circ} \mathrm{C}$ for $10 \mathrm{~min}$. The size of the PCR products was checked by gel electrophoresis on an $1 \%(\mathrm{w} / \mathrm{v})$ agarose gel containing 1x SYBR® Safe (Invitrogen, Carlsbad, CA). Negative control for PCR reactions were performed in parallel without addition of template, and consistently yielded no product. PCR products were purified with the High Pure Cleanup Micro Kit (Roche, Basel, Switzerland). Purified PCR products were mixed in equimolar amounts with a final DNA concentration of $100 \mathrm{ng} \mu \mathrm{L}^{-1}$. The pooled amplicons were pyrosequenced using a FLX Genome Sequencer in combination with titanium chemistry (GATC-Biotech, Konstanz, Germany).

All sequence reads were processed by the NGS analysis pipeline of the SILVA rRNA gene database project (SILVAngs 1.0) (Quast, Pruesse et al. 2013). Reads were aligned using SINA v1.2.11 against the SILVA SSU rRNA SEED and quality controlled. Identical reads were identified, the unique reads were clustered in operational taxonomic units (OTUs), on a per sample basis, applying identity criteria of 0.98 , and the reference read of each OTU was taxonomically classified. Phylogenetic reconstruction was performed by using the maximum likelihood, neighbor-joining and maximum parsimony algorithms in the ARB package and a consensus tree was generated with ARB v 6.0 software as described elsewhere (Sánchez-Andrea, Stams et al. 2013).

\section{Screening set-up}

An aliquot $(1 \mathrm{~mL})$ of the diluted mixture of sediment was added as inoculum to $120-\mathrm{mL}$ serum bottles with $50 \mathrm{~mL}$ sterile anoxic basal medium, prepared based on the previous description of Stams, Van Dijk et al. (1993). The medium was composed of ( $\mathrm{g} \mathrm{L}^{-}$ 
$\left.{ }^{1}\right): 0.41 \quad \mathrm{KH}_{2} \mathrm{PO}_{4} ; 0.53 \quad \mathrm{Na}_{2} \mathrm{HPO}_{4} \cdot 2 \mathrm{H}_{2} \mathrm{O} ; 0.3 \quad \mathrm{NH}_{4} \mathrm{Cl} ; 0.3 \mathrm{NaCl} ; 0.1 \quad \mathrm{MgCl}_{2} \cdot 6 \mathrm{H}_{2} \mathrm{O} ; 0.11$ $\mathrm{CaCl}_{2} \cdot 2 \mathrm{H}_{2} \mathrm{O}$; and $1 \mathrm{~mL} \mathrm{~L}^{-1}$ of each acid and alkaline trace elements solution; $0.2 \mathrm{~mL} \mathrm{~L}^{-1}$ vitamins; $0.1 \mathrm{~g} \mathrm{~L}^{-1}$ BBL yeast extract (Becton Dickinson, Cockeysville, MA) and $1 \mathrm{~mL} \mathrm{~L}^{-1}$ resazurin sodium salt solution (Sigma-Aldrich, St. Louis, MI) (Stams, Van Dijk et al. 1993). In order to adjust the medium to low $\mathrm{pH}$ values, bicarbonate-buffer was omitted as described by Sánchez-Andrea, Stams et al. (2013) and pH was adjusted with $\mathrm{HCl}$ or $\mathrm{NaOH}$ before autoclaving to the different desired $\mathrm{pH}$ values. Serum bottles were sealed with butyl rubber stoppers (Rubber BV, Hilversum, The Netherlands) and flushed with a $1.5 \mathrm{~atm}$ $\mathrm{N}_{2} / \mathrm{CO}_{2}(80: 20$, v/v) headspace.

Enrichments were incubated statically in the dark at $30^{\circ} \mathrm{C}$, and at $\mathrm{pH}$ varying from 2 to 5. Acetate, glycerol and methanol were added as electron donors and carbon source from sterile anaerobic stock solutions to a final concentration of $5 \mathrm{mM}$. $\mathrm{H}_{2} / \mathrm{CO}_{2}(80: 20$, v/v) was also tested with hydrogen as electron donor and $\mathrm{CO}_{2}$ as carbon source at $1.5 \mathrm{~atm}$. Elemental sulfur was added to all bottles in a concentration of $25 \mathrm{mM}$. Two control incubations were performed in the absence of additional external electron donor or elemental sulfur.

\section{Screening track}

For this set of 40 bottles, sulfur reduction activity was regularly monitored by substrates consumption, sulfide production, possible products accumulation, $\mathrm{pH}$ change and planktonic cell counting (Supplemental material - Figure S1). Measurements were performed every 5 days. Acetate, glycerol and methanol were quantified using an LKB high-performance liquid chromatograph (HPLC) with a Varian Metacarb 67H $300 \mathrm{~mm}$ column and $0.01 \mathrm{~N} \mathrm{H}_{2} \mathrm{SO}_{4}$ eluent at a flow rate of $0.8 \mathrm{~mL} \mathrm{~min}^{-1}$. Hydrogen and methane were determined gas-chromatographically (Shimadzu, Kyoto, Japan), equipped with a Molsieve 13X column (2 m, ID $2 \mathrm{~mm}$ ) and TCD detector. Sulfide concentrations in solution were determined by the photometric method using methylene blue as described previously by Cline (1969). After incubation, some enrichments were selected and transferred to fresh medium with the same $\mathrm{pH}$ and electron donors, in duplicate.

The morphology of the cultures was followed and phase contrast microphotographs were taken with a Leica DM2000 microscope. The number of cells in the cultures was determined in technical duplicates by using a Petroff-Hausser counting chamber with a cell-depth of $0.02 \mathrm{~mm}$ and ruling pattern 1:400 $\mathrm{mm}^{2}$ (Hausser Scientific, Horsham, PA).

The cellular elemental sulfur reduction rates (cESRR) were calculated from the cell numbers and the formation of hydrogen sulfide adapted from Surkov, Bottcher et al. (2000), as described (equation 4): 


$$
\operatorname{cESRR}\left[\mu \mathrm{mol} \mathrm{S} \mathrm{cell}^{-1} \mathrm{day}^{-1}\right]=\left(\mathrm{S}_{\mathrm{i}}-\mathrm{S}_{\mathrm{i}-1}\right)\left[\frac{\mathrm{C}_{\mathrm{i}}+\mathrm{C}_{\mathrm{i}-1}}{2}\right]^{-1}\left(\mathrm{t}_{\mathrm{i}}-\mathrm{t}_{\mathrm{i}-1}\right)^{-1}, \text { (equation 4) }
$$

where $\mathrm{S}, \mathrm{C}$ and $\mathrm{t}$ refer to the amounts of hydrogen sulfide produced $(\mu \mathrm{mol})$, the total cell number and reaction time (day), respectively, at time intervals i and i-1.

Microbial diversity analysis was performed in the selected enrichments. DNA was extracted from $10 \mathrm{~mL}$ culture as aforementioned. Extracted DNA was then amplified and cloned following the protocol described elsewhere (Sánchez-Andrea, Stams et al. 2013). Inserts were screened by Amplified rDNA Restriction Analysis (ARDRA) using endonuclease $\mathrm{MspI}\left(1 \mathrm{U}, 3.5 \mathrm{~h}, 37^{\circ} \mathrm{C}\right)$ and grouped according to the restriction patterns obtained. Two members of each group were then sequenced at GATC Biotech AG, Konstanz, Germany.

\section{Solid media development and isolation}

Common solid media for sulfur reducers are standardly based on polysulfide (Tuovinen 1979, Boyd and Druschel 2013). Due to its instability at low pH and its unspecificity for truely sulfur reducers, new solid medium needed to be developed. Four different sulfur types were used as electron acceptors: chemical sulfur obtained by Clausprocess from the manufacture of barium and strontium carbonate (Boom, Netherlands); biosulfur obtained from a process for biological sulfide oxidation (Industriewater Eerbeek, Eerbeek, The Netherlands); purified sulfur obtained by sublimation (Sigma-Aldrich, St. Louis, MI); and colloidal sulfur (Sigma-Aldrich, St. Louis, MI).They were then added to a final concentration of $0.4 \%(\mathrm{w} / \mathrm{v})$ to a $2 \%(\mathrm{w} / \mathrm{v})$ agar medium using acetate $(5 \mathrm{mM})$ as electron donor. Both techniques, streak plate and Hungate tubes were tested. For the plates, $100 \mu \mathrm{L}$ of the culture were spread on to the surface of the plates and incubated in anaerobic jars pressurized with $\mathrm{N}_{2} / \mathrm{CO}_{2}(80: 20, \mathrm{v} / \mathrm{v})$. For the tubes, $1 \mathrm{~mL}$ of the culture was transferred to $9 \mathrm{~mL}$ of a molten agar medium in Hungate tubes pressurized with $\mathrm{N}_{2} / \mathrm{CO}_{2}(80: 20, \mathrm{v} / \mathrm{v})$. Anaerobic jars and tubes were incubated in the dark at $30^{\circ} \mathrm{C}$ until colony development was observed.

Isolation was performed by combining colonies growth in solid medium and serial dilution with antibiotic addition in concentrations of 5 and $100 \mu \mathrm{g} \mathrm{mL}^{-1}$. The purity of the cultures was checked: i) microscopically, ii) by $16 \mathrm{~S}$ rRNA gene sequences analysis of around 100 clones grouped by ARDRA (as described in the section Enrichments selection) and iii) by inoculation into fresh medium with $1 \mathrm{~g} \mathrm{~L}^{-1}$ yeast extract and $5 \mathrm{mM}$ glucose to detect contamination by fermenters.

\section{Sulfur sources comparison}

Due to the insolubility of sulfur (Boulegue 1978), the four different sources of elemental sulfur described above were tested to check which one could promote higher 
rates of sulfur reduction. Acetate $(5 \mathrm{mM})$ was used as electron donor and $25 \mathrm{mM}$ of the different sulfur sources were added in each bottle. The highly enriched culture on acetate at $\mathrm{pH} 4$, so called [Acet, $\mathrm{pH} 4$ ] obtained in the previous step was used as inoculum. Sulfur reduction activity was regularly monitored by acetate consumption and sulfide production. Measurements were performed every 2 days. The analyses were carried out in biological duplicates and the results were averaged.

\section{Metals tolerance analysis}

Tolerance to 4 metals often found in metalliferous wastes (copper, nickel, lead and zinc) was tested for the obtained isolate. Concentrations of free metal ions were chosen in the range of reported toxic concentrations of metals for bacteria involved in the sulfur cycle (Cabrera, Perez et al. 2006). To account with the metal precipitation due to phosphate or reducing agent present in the medium, the concentration of free metals was recalculated measuring the free metal concentration after their addition to the medium.

Copper, lead, nickel and zinc chloride salt solutions were used to get the following range of maximum exposure concentrations: copper 0.1-0.5 mM, lead 0.02-0.04 mM, nickel $0.3-10.2 \mathrm{mM}$ and zinc $0.02-1.2 \mathrm{mM}$. Bottles that did not contain inoculum or metal were prepared as controls. Acetate was used as electron donor and $\mathrm{pH}$ in the cultures was adjusted to 3 before inoculation. Experiments were conducted in duplicate and cultures were incubated statically for one month at $50^{\circ} \mathrm{C}$ (optimum temperature for the isolate). Samples were taken periodically for monitoring of sulfide production and electron donor consumption. Soluble metals concentrations were determined at time zero and after 28 days of incubation. Free metal ions were quantified with Spectroquant ${ }^{\circledR}$ cell tests (Merck Millipore, Darmstadt, Germany).

\section{Other physiological tests}

Temperature range for growth of the isolate was assessed from 15 to $60^{\circ} \mathrm{C}$ as well as $\mathrm{pH}$ range from 2.8 to 8 , using $5 \mathrm{mM}$ of acetate as electron donor and $25 \mathrm{mM}$ of elemental sulfur as electron acceptor. The analyses were carried out in biological duplicates and the results averaged. The following electron donors were tested for growth at a final concentration of $5 \mathrm{mM}$ at $\mathrm{pH} 4$ and at $30^{\circ} \mathrm{C}$ : acetate, arginine, benzoate, butyrate, caproate, ethanol, formate, fructose, fumarate, glucose, glycerol, glycine, hexadecane, hydrogen, isobutyrate, lactate, leucine, lysine, malate, methanol, palmitate, peptone, propionate, pyruvate, starch, stearate, sucrose and succinate. Sulfur as substrate for disproportionation was also tested. Growth rates were assessed by Gompertz model (Zwietering, Jongenburger et al. 1990). 


\section{Nucleotide sequence accession numbers}

The cloned 16S rRNA gene sequences from the enrichments, the isolate sequence and the sequences obtained from the pyrosequencing analysis were deposited in the EMBL database and are available under accession numbers LN624405-LN624412, LN624414, LN624416, LN649261-LN649263, LN680091 and LN680092.

\section{Results}

\section{Microbial diversity in Tinto River sediments used as inoculum}

Analysis of the 16S rDNA gene amplicons of the sediment mixture yielded 10852 sequences, from which 10792 reads passed the quality control with an average length of 330 nucleotides. The individual phylotypes could be clustered (identity criteria of 0.98) into 3595 tag phylotypes, representing 8 known phyla or candidate division. The three most representative phyla were Firmicutes (60\% of the sequences), Proteobacteria $(21 \%)$ and Acidobacteria (13\%). Actinobacteria, Cyanobacteria, Bacteriodetes, Nitrospirae and Candidate division TM7 represented together around $6 \%$ of the diversity. At the genus level, sequences clustered into 322 genera (Supplemental material - Table S1). About 6\% of all the sequences could not be identified at the genus level and were classified at the next highest possible resolution level. Some sequences belonged to microorganisms known to perform sulfur reduction (Lopez-Archilla, Marin et al. 2001), such as Desulfosporosinus spp., Thermoplasma spp. or Acidithiobacillus ferrooxidans, showing the potential of the inoculum to perform sulfur reduction at low $\mathrm{pH}$. Sequences belonging to the obligate sulfur reducer genus Desulfurella were also identified, representing about $3 \%$ of the proteobacterial sequences and about $0.6 \%$ of the bacterial sequences of the inoculum used. The main groups identified in the inoculum are represented in Figure 1a.

\section{Sulfur reduction activity of enrichments}

Sulfide production was detected in the cultures incubated at the range of $\mathrm{pH} 3$ to 5 but not at pH 2 (Supplemental material - Table S2). $\mathrm{CO}_{2}$ and $\mathrm{H}_{2} \mathrm{~S}$ were the only products detected in the cultures, indicating complete oxidation of the organic compounds. Methane was not detected in the headspace of any culture. Incubations with acetate and hydrogen yielded the highest production of sulfide in all conditions in which growth was observed. When glycerol and methanol were added as electron donors, growth was observed and sulfide was weakly produced. In this case, no consumption of the substrates was detected. 


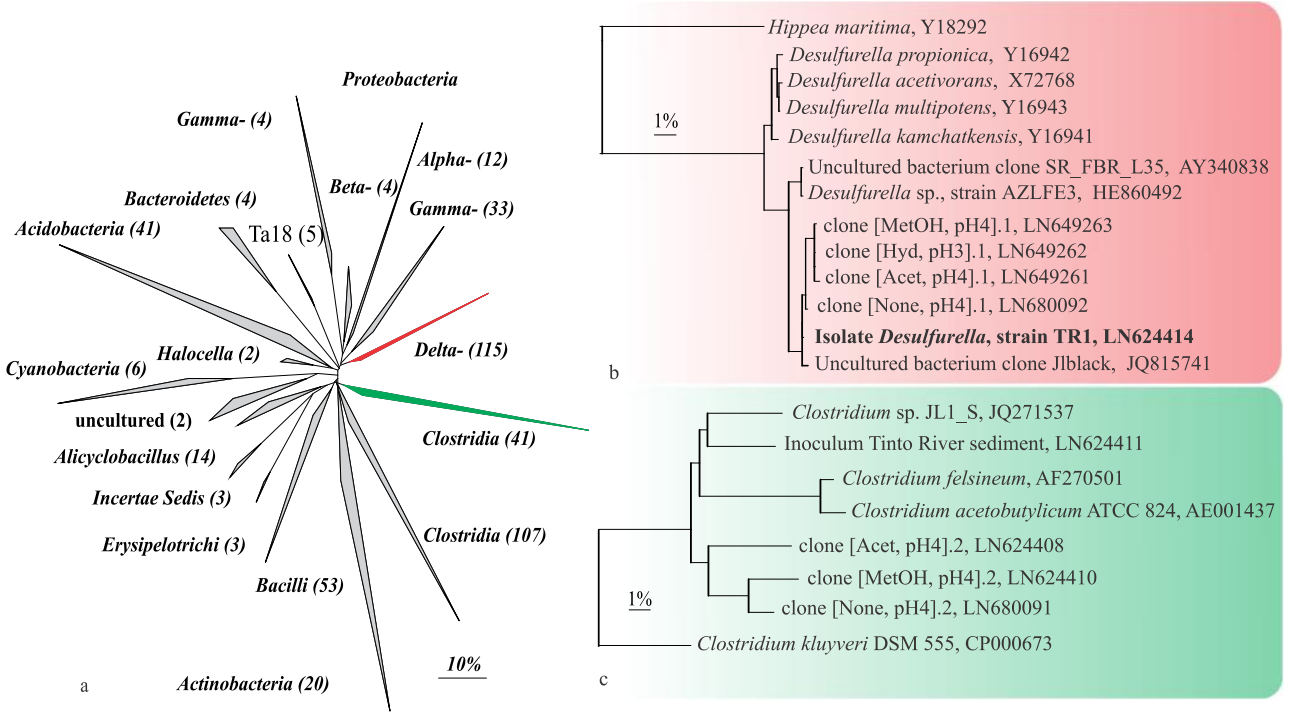

Figure 1a-c - Phylogenetic affiliations of 16S rDNA sequences obtained (a) from the inoculum and from the enrichments as (b) dominant closest related and (c) main contaminant closest related sequences. The trees display a consensus from neighborjoining, maximum likelihood and maximum parsimony algorithms. Bars represent 1 change per site or $100 \%$ divergence in sequence. Numbers of sequences per group are represented in parentheses.

From the 40 bottles, a pre-selection was made prioritizing, per substrate, the lowest $\mathrm{pH}$ with the highest production of sulfide. Accordingly, the following conditions were selected and transferred to fresh medium in a second set of enrichments: $\mathrm{pH} 3$ with hydrogen as electron donor ([Hyd, pH3]), and $\mathrm{pH} 4$ with acetate ([Acet, $\mathrm{pH} 4]$ ), in which the production of $\mathrm{H}_{2} \mathrm{~S}$ reached 16.4 and $10.9 \mathrm{mM}$, with 10.5 and $4.6 \mathrm{mM}$ of acetate consumption, respectively; $\mathrm{pH} 4$ with methanol ([MetOH, $\mathrm{pH} 4]$ ), and one group without external electron donor at $\mathrm{pH} 4$ ([None, $\mathrm{pH} 4]$ ), in which sulfide did not reach more than 2 $\mathrm{mM}$.

At the end of the second set of enrichments, the sulfide concentration reached 9.3 and $11.6 \mathrm{mM}$ in the enrichments [Acet, $\mathrm{pH} 4$ ] and [Hyd, $\mathrm{pH} 3$ ], respectively (Figure 2). For the enrichment with sulfur as single substrate [None, $\mathrm{pH} 4$ ], the maximum sulfide production was around $1.9 \mathrm{mM}$. Similar sulfide concentration $(1.0 \mathrm{mM})$ was detected in the enrichment with methanol [MetOH, pH4], and consistently, no methanol consumption was detected. Since no external electron donor was present or consumed in both cases, the sulfide production in those cultures is not coupled to the oxidation of substrates in sulfur reduction. In these cultures, 0.7 and $0.5 \mathrm{mM}$ of sulfate was also formed, respectively. 


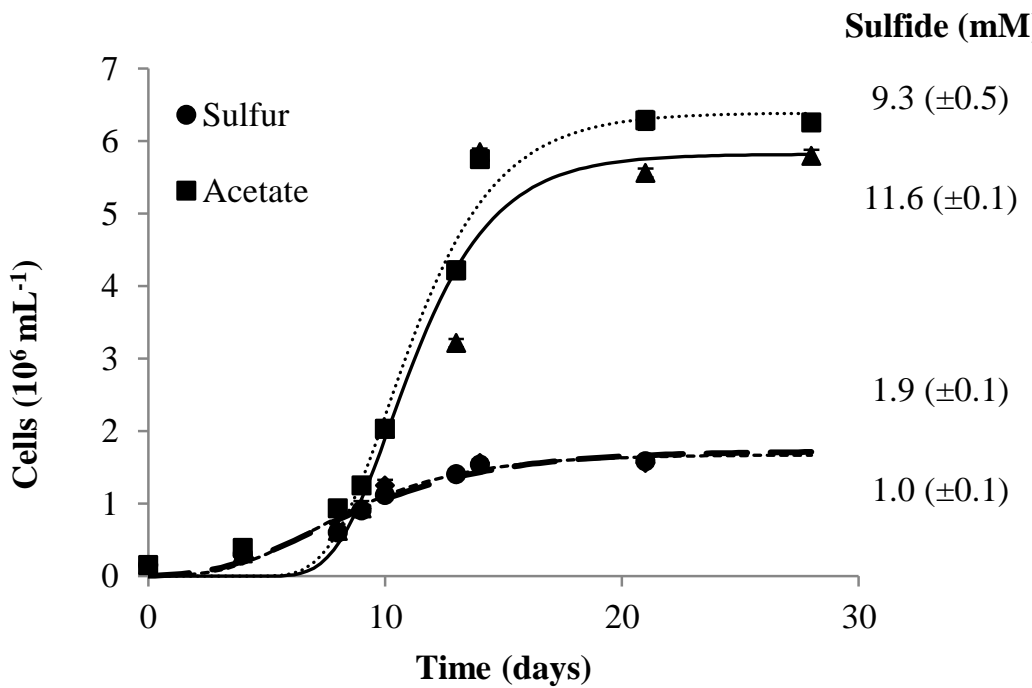

Figure 2 - Number of cells and sulfide production reached in the secondary enrichments incubated at $30^{\circ} \mathrm{C}$ with different electron donors. The values on the right side refer to the final value of sulfide production in the respective culture in the represented in the curve. The cells counting analysis was carried out in technical duplicates, and the sulfide production measurement was performed in biological duplicates. The results were averaged and the standard deviation is shown.

Under the microscope, different cell morphologies were observed in the cultures, but short rod-shaped bacteria were predominant in all of them. Sulfide production paralleled microbial growth, with maximum culture cell densities for the enrichments

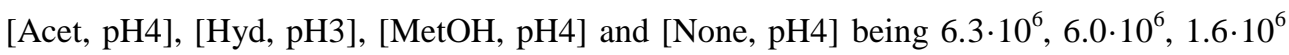
and $2.0 \cdot 10^{6}$ cells $\mathrm{mL}^{-1}$, respectively (Figure 2). Application of the Surkov equation indicated rates of $0.48 \mathrm{fmol} \mathrm{cell}^{-1} \mathrm{day}^{-1}$ for the enrichment [Hyd, $\mathrm{pH} 3$ ] and 0.36, 0.45 and $0.47 \mathrm{fmol} \mathrm{cell}^{-1} \mathrm{day}^{-1}$ for the enrichments [Acet, pH4], [MetOH, pH4], [None, pH4], respectively. No attempts were made to count cells attached to elemental sulfur particles, so that the counts considered only planktonic cells.

\section{Microbial community analysis of the enrichments}

DNA was extracted from the four selected enrichments. Amplification of both archaeal and bacterial 16S rDNA genes was done. Only amplification of the bacterial genes gave positive results indicating that no archaeal communities developed in the conditions tested. A rather low bacterial diversity was observed for all the enrichments, with 2, 3, 4 and 2 OTUs for the enrichments [None, pH4]; [Acet, pH4]; [MetOH, pH4] and [Hyd, pH3], respectively (Table 1). 
Sequences belonging to the sulfur-reducing bacterial genus Desulfurella (Deltaproteobacteria), dominated all the clone libraries A phylogenetic reconstruction of the closest organisms reveals that related sequences to our Desulfurella strain do not cluster together with the four species already described in this genus (Figure 1b). Other microorganisms were co-enriched, such as Clostridium and Bacillus with acetate; Acidobacteria, Clostridium and Acidocella with methanol; and Clostridium with hydrogen, mainly related to fermentative metabolism. Clostridium sp. appeared as the main contaminant in the primary enrichments and remained as the only contaminant (Figure 1c) in further transfers up to the addition of vancomycin $\left(5 \mu \mathrm{g} \mathrm{mL}^{-1}\right)$.

\section{Solid medium and isolation of Desulfurella sp., strain TR1}

Different sulfur sources (chemical, sublimated, colloidal and bio-sulfur) were tested for solid medium. Incubation with colloidal sulfur gave the best results, with visible growth of small whitish colonies (0.5-1.0 mm diameter) after one month of incubation (Supplemental material - Figure S2). All the other forms of elemental sulfur did not show growth on solid medium. Therefore, due to its bioavailability and solubility properties, colloidal sulfur was selected as sulfur source for isolation of sulfur reducers at low $\mathrm{pH}$ on solid medium.

The selected enrichments performing sulfur reduction ([Hyd, $\mathrm{pH} 3]$ and [Acet, $\mathrm{pH} 4]$ ) were inoculated in this medium. Analysis of the 16S rDNA gene of the colonies growing on agar showed that in all the conditions studied, Clostridium spp. sequences appeared as the major contaminant. As a strategy to avoid this contamination with Grampositive bacteria, the solid medium was supplemented with $5 \mu \mathrm{g} \mathrm{mL}^{-1}$ vancomycin and the medium was inoculated again. After antibiotic addition, Clostridium sequences were not further detected when 96 clones were analysed by ARDRA profiles. However, another contaminant was detected, with $5 \%$ of the sequences belonging to Sediminibacterium genus, 99\% related to Sediminibacterium ginsengisoli (accession number: EF067860). One Desulfurella colony was transferred to liquid medium and two serial dilutions were performed with vancomycin $\left(100 \mu \mathrm{g} \mathrm{mL}^{-1}\right)$ to avoid Sediminibacterium contamination. Finally, a pure culture (strain TR1) was obtained.

\section{Desulfurella sp. strain TR1 phylogeny and physiology}

Growth of strain TR1 was detected in a wide range of temperature varying from 25 to $50^{\circ} \mathrm{C}$ with an optimum at $50^{\circ} \mathrm{C}$; at $55^{\circ} \mathrm{C}$ no growth occurred (Supplemental material Figure S3). Growth occurred at $\mathrm{pH}$ varying from 3 to 7 with an optimum at $\mathrm{pH} 6$ (Supplemental material - Figure S4). In cultures where growth occurred, the final $\mathrm{pH}$ of the medium stated around 5.5-6. The isolated strain was able to grow heterotrophically in the presence of sulfur with acetate, stearate, lactate, pyruvate and arginine; and autotrophically 
with $\mathrm{H}_{2} / \mathrm{CO}_{2}$. As expected, methanol and glycerol were not used by the bacterium, neither benzoate, butyrate, caproate, ethanol, formate, fumarate, glucose, glycine, hexadecane, isobutyrate, leucine, lysine, malate, palmitate, peptone, propionate, starch sucrose and succinate were used. It also grew by disproportionation of elemental sulfur and by reduction of thiosulfate (data not shown).

Table 1 - Phylotypes in the selected enrichments. Accession numbers: LN624405LN624410, LN649261-LN649263, LN680091 and LN680092.

\begin{tabular}{|c|c|c|c|}
\hline Sample & $\begin{array}{c}\mathbf{N}^{\mathbf{0}} \\
\text { sequences }\end{array}$ & Closest organism (acc. number) & $\begin{array}{c}\text { identity } \\
(\%)\end{array}$ \\
\hline \multirow{2}{*}{ [None, pH4] } & 30 & Desulfurella sp. (LN680092) & 98 \\
\hline & 6 & Clostridium sp.(LN680091) & 99 \\
\hline \multirow{3}{*}{ [Acet, pH4] } & 17 & Desulfurella sp. (LN649261) & 98 \\
\hline & 3 & Clostridium sp. (LN624408) & 97 \\
\hline & 1 & Bacillus sp. (LN624407) & 98 \\
\hline \multirow{4}{*}{ [MetOH, pH4] } & 11 & Desulfurella sp. (LN649263) & 98 \\
\hline & 2 & Acidobacteria bacterium (LN624405) & 94 \\
\hline & 2 & Clostridium sp. (LN624410) & 94 \\
\hline & 5 & Acidocella aromatica (LN624406) & 99 \\
\hline \multirow{2}{*}{ [Hyd, pH3] } & 18 & Desulfurella sp. (LN649262) & 98 \\
\hline & 1 & Clostridium sp. (LN624409) & 95 \\
\hline
\end{tabular}

The 16S rDNA sequence of the isolate showed 98\% identity with other Desulfurella species, not clustering together with them (Figure 1b). The genus Desulfurella comprises four species so far: D. acetivorans (Bonch-Osmolovskaya, Miroshnichenko et al. 1990), D. multipotens (Miroshnichenko, Gongadze et al. 1994), D. kanchatkensis and D. propionica (Miroshnichenko, Rainey et al. 1998), and they share 99\% similarity between them. This, together with the threshold established for species (98.7\%) (Yarza, Yilmaz et al. 2014), suggests that our isolate represents a novel species within the Desulfurella genus. Strain TR1 shares 99\% similarity with strain AZLFE3, isolated from a hydrothermal spring system in the Mexican Volcanic Axis, Los Azufres (Brito, Villegas-Negrete et al. 2014). Unfortunately, no physiological description of that strain is available.

\section{Reduction of different sulfur sources}

To study the influence of the type of elemental sulfur on the sulfur reduction rate of the isolate, different forms of elemental sulfur were also tested in duplicates with acetate as electron donor at $\mathrm{pH} 4$ (Figure 3). High final sulfide production (between 12.1 to 13.5 $\mathrm{mM}$ ) was found for all sulfur forms, except for the sublimated sulfur in which $8.3 \mathrm{mM}$ was the maximum detected. Bio-sulfur promoted the fastest growth of the culture, with doubling 
time of 1.9 day, followed by colloidal sulfur, and chemical sulfur with doubling times of 2.2 and 2.5 respectively and accordingly, sublimated sulfur showed the highest doubling time (3.6 days).

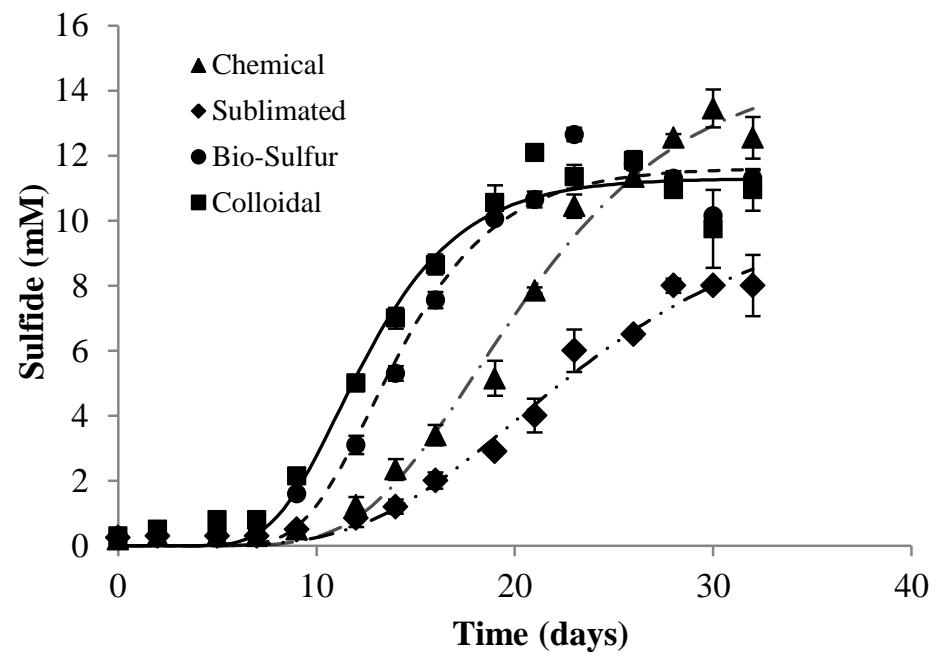

Figure 3 - Sulfide production of enrichments inoculated with different forms of elemental sulfur as electron acceptor and acetate as electron donor at $30^{\circ} \mathrm{C}$. The analyses were carried out in biological duplicates and the results averaged.

\section{Sensitivity to metals}

Growth and activity of Desulfurella strain TR1 were affected by metal ions $\left(\mathrm{Cu}^{2+}\right.$, $\mathrm{Ni}^{2+}, \mathrm{Pb}^{2+}$ and $\mathrm{Zn}^{2+}$ ), but still occurred. A common observation was that with increasing metal concentration, the lag phase of the cultures increased, and the final sulfide production decreased, which coincided with a decrease in the total acetate consumption (Figure 4a-d) and by a decrease in metal precipitation levels (Table 2). In cultures where growth occurred, the $\mathrm{pH}$ of the medium increased from $\mathrm{pH} 3$ to 5 . 
Table 2 - Percentage of bio-precipitation for the different concentrations of metals added and the maximum tolerated studied concentration (MTSC) of each metal for Desulfurella strain TR1.

\begin{tabular}{|c|c|c|c|}
\hline Metal & $\begin{array}{l}\text { Initial Concentration } \\
(\mathrm{mM})\end{array}$ & Precipitation (\%) & $\begin{array}{l}\text { MTSC } \\
(\mathrm{mM})\end{array}$ \\
\hline \multirow{3}{*}{ Copper } & 0.1 & $97.2( \pm 1.1)$ & \multirow{3}{*}{$>0.5$} \\
\hline & 0.2 & $87.6( \pm 7.8)$ & \\
\hline & 0.5 & $69.7( \pm 6.6)$ & \\
\hline \multirow{3}{*}{ Lead } & 0.02 & $100.0( \pm 0.0)$ & \multirow{3}{*}{0.03} \\
\hline & 0.03 & $100.0( \pm 0.0)$ & \\
\hline & 0.04 & $4.6( \pm 5.0)$ & \\
\hline \multirow{6}{*}{ Nickel } & 0.3 & $77.5( \pm 8.2)$ & \multirow{6}{*}{0.9} \\
\hline & 0.9 & $52.9( \pm 4.2)$ & \\
\hline & 1.7 & $7.1( \pm 0.8)$ & \\
\hline & 2.6 & $4.1( \pm 2.9)$ & \\
\hline & 5.1 & $2.4( \pm 1.1)$ & \\
\hline & 10.2 & $0.2( \pm 1.6)$ & \\
\hline \multirow{6}{*}{ Zinc } & 0.02 & $60.9( \pm 2.7)$ & \multirow{6}{*}{0.09} \\
\hline & 0.04 & $63.6( \pm 6.1)$ & \\
\hline & 0.06 & $36.5( \pm 4.7)$ & \\
\hline & 0.09 & $32.3( \pm 0.9)$ & \\
\hline & 0.2 & $4.0( \pm 0.1)$ & \\
\hline & 1.2 & $0.8( \pm 0.2)$ & \\
\hline
\end{tabular}

Copper precipitation occurred in all the concentrations tested. Even though the precipitation decreased about $27 \%$ from initial measured concentrations of 0.1 to $0.5 \mathrm{mM}$, acetate consumption by Desulfurella strain TR1 did not differ much and cell growth occurred in both cultures, showing a good tolerance of the isolate to copper, one of the most toxic metals present in industrial wastewaters. Lead was completely precipitated by the sulfide produced at initial concentrations of 0.02 and $0.03 \mathrm{mM}$. After metal precipitation, an increase of free sulfide was detected, confirming the activity of the culture. Nickel was tolerated by Desulfurella strain TR1 up to an initial concentration of $0.9 \mathrm{mM}$, when acetate was almost depleted in 28 days, and free sulfide and cells were detected. For zinc, $0.09 \mathrm{mM}$ was the maximum added concentration at which acetate consumption, free sulfide and cell growth were observed.

Consequently, the rates for acetate or sulfur consumption were also affected. The controls showed rates of 0.31 and $0.07 \mathrm{mM} \mathrm{day}^{-1}$ of acetate and sulfur consumption, respectively. These rates decreased for the maximum tolerated concentration per metal. 
Rates $\left(\mathrm{mM} \mathrm{day}{ }^{-1}\right)$ for acetate and sulfur consumption were: 0.53 and 0.01 at $0.5 \mathrm{mM}$ of copper; 0.05 and 0.014 at $0.03 \mathrm{mM}$ of lead; 0.23 and 0.05 at $0.9 \mathrm{mM}$ of nickel; and 0.11 and 0.03 at $0.09 \mathrm{mM}$ of zinc.

\section{Discussion}

Our results showed that elemental sulfur reduction with different electron donors occurred at low $\mathrm{pH}$ when an inoculum from a natural acidic environment, Tinto river sediments, was used. Sulfur reduction activity with the highest sulfide production levels occurred in the primary enrichments with $\mathrm{H}_{2} / \mathrm{CO}_{2}$ and acetate at $\mathrm{pH}$ values down to 3 and 4 , respectively. No methane production or archaeal communities were detected. Thus, no competition for the electron donors added took place between sulfur reducers and methanogens. As the dominant sequences detected in all the enrichments were related to a strain in the sulfur-reducing genus Desulfurella, isolation strategies targeted it as the key player in the sulfur-reducing enrichments at low-pH.

The isolation of a Desulfurella strain at low $\mathrm{pH}$ and moderate temperature with different substrates was unexpected. Strain TR1 was able to grow at temperature as low as $20^{\circ} \mathrm{C}$ and $\mathrm{pH}$ as low as 3, unlike other members of the Desulfurella genus. All described members of this genus are thermophiles with temperature optima between 50 and $60^{\circ} \mathrm{C}$, with minimum temperature for growth stated at $33^{\circ} \mathrm{C}$ for D. propionica (Miroshnichenko, Rainey et al. 1998), and 40, 42 and $44^{\circ} \mathrm{C}$ for D. Kamchatkensis (Miroshnichenko, Rainey et al. 1998), D. multipotens (Miroshnichenko, Gongadze et al. 1994) and D. acetivorans (Bonch-Osmolovskaya, Sokolova et al. 1990), respectively. Other Desulfurella spp. are neutrophilic with $\mathrm{pH}$ optima between 6.4 and 7.2, and minimum $\mathrm{pH}$ for growth is stated at 4.3 for D. acetivorans (Bonch-Osmolovskaya, Sokolova et al. 1990). During growth of Desulfurella strain TR1, the $\mathrm{pH}$ of the unbuffered medium increased from 3 up to 5. Although there is an increase in $\mathrm{pH}$ in the medium during growth, the isolate started growing at $\mathrm{pH} 3$, which certainly implies proton resistance with sulfide production starting at this low $\mathrm{pH}$. 

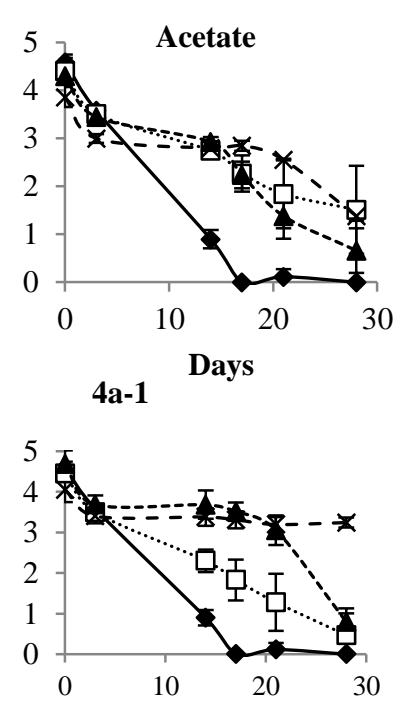

4b-1 Days

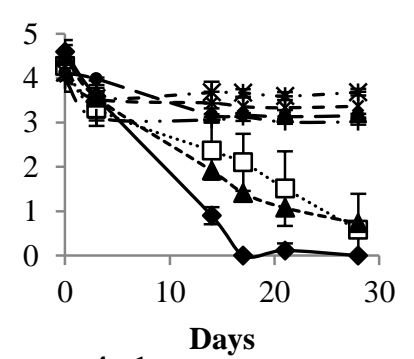

4c-1

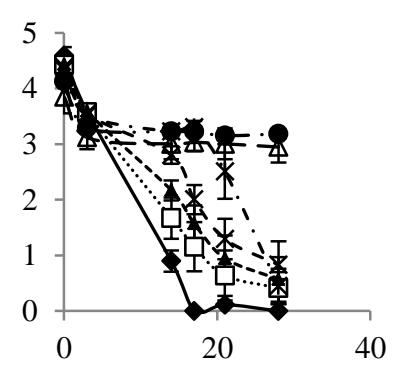

4d-1
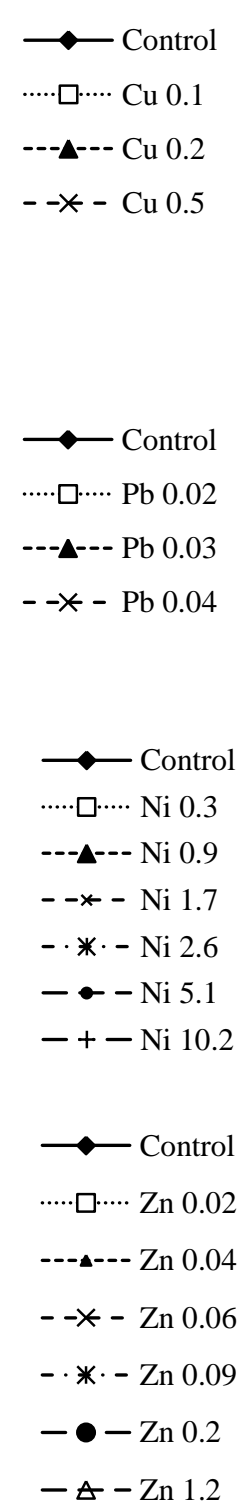

$-A-\operatorname{Zn} 1.2$

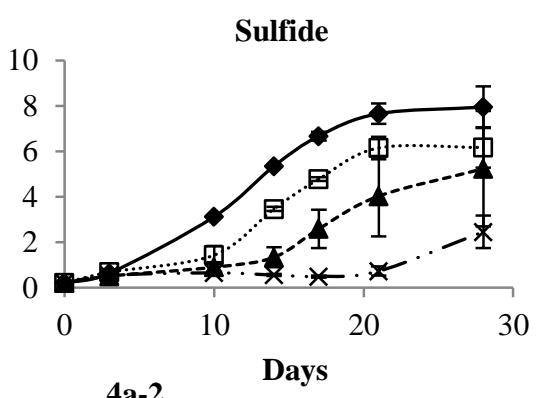

4a-2

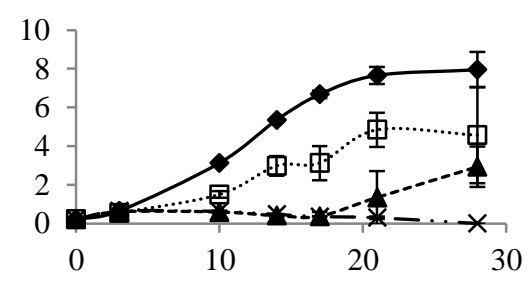

4b-2

Days

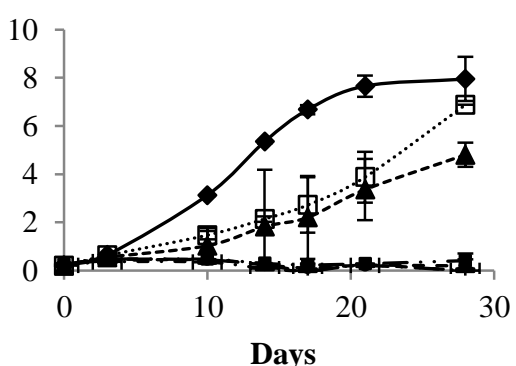

4c-2

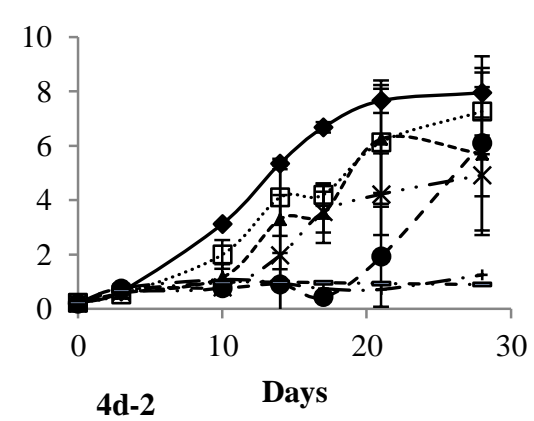

Figure 4a-d - Evolution of acetate (1) and sulfide (2) concentrations (mM) during incubation of Desulfurella strain TR1 in the presence of (a) copper in a range from 0.1 to $0.5 \mathrm{mM}$; (b) lead from 0.02 to $0.04 \mathrm{mM}$; (c) nickel from 0.3 to $10.2 \mathrm{mM}$ and (d) zinc in a range from 0.02 to $1.2 \mathrm{mM}$. Data points are mean values of replicate cultures and error bars show the range. 
Described acidophilic sulfate-reducing bacteria (SRB) of the genus Desulfosporosinus (D. acidiphilus and D. acididurans) can grow at a minimum $\mathrm{pH}$ of 3.6 and 3.8 respectively (Alazard, Joseph et al. 2010, Sánchez-Andrea, Stams et al. 2015). However, D. acididurans was still active when tested in a reactor treating acidic waters at $\mathrm{pH}$ as low as 2.5 (Nancucheo and Johnson 2012). The high proton resistance of Desulfurella strain TR1 represents a new opportunity to develop a biotechnological process based on acidophilic sulfur reduction for removal and recovery of metals.

At low $\mathrm{pH}$, growth on acetate was faster than growth with $\mathrm{H}_{2} / \mathrm{CO}_{2}$ and also more sulfide was produced, indicating that the isolate did not suffer from acetic acid toxicity at low $\mathrm{pH}$, as has been found for other anaerobes. This ability is an interesting feature of Desulfurella strain TR1, as no described pure culture of acidophilic SRB can grow on acetate at low pH (Rabus, Hansen et al. 2013). Instead, they accumulate acetic acid by incomplete oxidation of the substrates used (e.g. glycerol) which can create inhibitory effects at low pH (Sánchez-Andrea, Sanz et al. 2014). Since acetic acid is toxic at low pH, microorganisms able to utilize it can have an important role in detoxification (Tuttle and Dugan 1976). Kimura, Hallberg et al. (2006) showed acetate oxidation in an anaerobic syntrophic culture at low $\mathrm{pH}$ by the acetogenic strain PPBF, which was afterwards described as Acidocella aromatica (Jones, Hedrich et al. 2013) and the sulfate reducer Desulfosporosinus strain M1, afterwards described as Desulfosporosinus acididurans (Sánchez-Andrea, Stams et al. 2015). Apart from the ecological role of acetate oxidizers, they can also have an important role in bioreactors treating acid mine drainage where acetate accumulation would occur. Other bacteria are able to reduce sulfur at low $\mathrm{pH}$ such as Acidithiobacillus ferrooxidans, which reduces sulfur at $\mathrm{pH} 2.5$ coupled to hydrogen utilization (Jameson, Rowe et al. 2010). However, A. ferrooxidans is unable to use acetate, and is inhibited at $5 \mathrm{mM}$ acetic acid (Tuttle and Dugan 1976).

Sánchez-Andrea, Rodriguez et al. (2011) quantified the abundance of diverse microbial populations inhabiting Tinto river and showed that Desulfurella spp. dominated in certain sediment layers (up to $36 \%$ of total cell count). Due to the reduction of sulfur compounds in those layers, the $\mathrm{pH}$ increases up to 6.2 and the redox potential decreases to $246 \mathrm{mV}$, contrasting with the surroundings layers, some of them with $\mathrm{pH} 4.3$ and redox potential stated at $0 \mathrm{mV}$. Desulfurella related sequences are also found in other acidic environments. Burton and Norris (2000) analysed sediment samples from acidic, geothermal pools on the Caribbean island of Montserrat and they reported that 43 out of 375 sequences related to Desulfurella species in sampling sites at $\mathrm{pH} 3$ and temperatures varying from 30 to $48^{\circ} \mathrm{C}$. Kaksonen, Plumb et al. (2004) found some Desulfurella related sequences in a lactate-degrading enrichment at $\mathrm{pH} 4$ and $35^{\circ} \mathrm{C}$. Willis, Hedrich et al. (2013) examined the bacterial diversity from the hot spring sediment Agua del Limón (with pH varying from $<1$ to 8 ) at the geothermal Caviahue-Copahue system and Desulfurella related 
sequences were also reported. Our results and the reported detection of Desulfurella suggest that it is an important player in the sulfur cycle not only at high temperature and close to neutral $\mathrm{pH}$ values, but also at moderate temperature and low $\mathrm{pH}$.

Of the types of elemental sulfur tested in this study, colloidal sulfur was the only suitable for isolation of sulfur reducers at low $\mathrm{pH}$ on solid medium. In liquid medium, however, bio-sulfur showed the fastest growth of strain TR1. This may have a practical implication, as the use of bio-sulfur might lead to higher reduction rates in bioreactors, and thus smaller required bioreactor volumes and lower investment cost for the conversion. Bio-sulfur is produced at large-scale during bio-desulfurization of biogas and natural gas (Janssen, Ruitenberg et al. 2001). The reuse of this bio-sulfur in acidophilic sulfur reduction processes for metal sulfide precipitation may therefore be favourable compared to the use of chemical sulfur.

The sulfide produced in the enrichments without any electron donor added, as well as in the enrichments with methanol is not coupled to oxidation of substrates in dissimilatory microbial sulfur reduction. Thus, microbial disproportionation of elemental sulfur can explain the formation of sulfide in both enrichments. Disproportionation of elemental sulfur to sulfide and sulfate (equation 5) is an endergonic process at standard conditions ( $1 \mathrm{M}, 1 \mathrm{~atm}$ ); the free Gibbs energy change $\left(\Delta \mathrm{G}^{0}\right)$ is $+33 \mathrm{~kJ} \mathrm{~mol}^{-1} \mathrm{~S}^{0}$. Although the Gibbs free energy of the reaction can be affected by the concentration of sulfide, limiting growth when it accumulates; the variation in $\mathrm{pH}$ values imposes stronger energetic impact. Performing calculations with eQuilibrator (Flamholz, Noor et al. 2012), when 2 $\mathrm{mM}$ of sulfide is considered, the free Gibbs energy change of the reaction $\left(\Delta \mathrm{G}^{\prime}\right)$ decreases from 58.3 to $-27.3 \mathrm{~kJ} \mathrm{~mol}^{-1} \mathrm{~S}^{0}$ when the $\mathrm{pH}$ increases from 4 to 7 , respectively. When the $\mathrm{pH}$ is kept constant (at 4, for example) and the sulfide concentration decreases from 2 to 0.2 $\mathrm{mM}$, however, the Gibbs free energy decreases from 58.3 to $35.5 \mathrm{~kJ} \mathrm{~mol}^{-1} \mathrm{~S}^{0}$.

$$
4 \mathrm{~S}^{0}+4 \mathrm{H}_{2} \mathrm{O} \rightarrow \mathrm{SO}_{4}^{2-}+3 \mathrm{H}_{2} \mathrm{~S}+2 \mathrm{H}^{+} \text {(equation 5) }
$$

Some acidophilic microorganisms are shown to have a high heavy metal resistance (Dopson, Baker-Austin et al. 2003, Nancucheo and Johnson 2012, Dopson and Holmes 2014). Desulfurella strain TR1 is rather resistant as well. Comparing with other sulfidogenic microorganisms, strain TR1 is somewhat higher resistant towards metals even at a pH as low as pH 3 (Table 3), where actually other factors could also affect cell growth, such as the high proton concentration itself, the acetic acid, or the free hydrogen sulfide inhibition (Utgikar, Harmon et al. 2002, Dopson, Ossandon et al. 2014). Toxic concentrations of different heavy metals to bacteria involved in the sulfur cycle vary widely from a few to $100 \mathrm{mg} \mathrm{L}^{-1}$. Cabrera, Perez et al. (2006) reported for Desulfovibrio spp. in batch culture precipitation levels in the highest tolerated concentration of copper, nickel and zinc in a range of $45-71 \%$ at $0.06 \mathrm{mM}, 96 \%$ at $0.14 \mathrm{mM}$ and $9-93 \%$ at $0.3 \mathrm{mM}$, 
respectively. Hao, Huang et al. (1994) assessed the inhibitory metal concentrations towards sulfate-reducing communities in wastewaters. They indicated critical free metal concentrations for inhibition of sulfate reduction as being $0.36,0.04,0.31$ and $0.34 \mathrm{mM}$ for lead, zinc, copper and nickel, respectively. The inhibitory metal concentrations towards Desulfurella strain TR1 were $0.04,0.2,>0.5$ and $2.6 \mathrm{mM}$ for lead, zinc, copper and nickel, respectively. In practice, in a continuous sulfur-reducing bioreactor for precipitation of heavy metals at $\mathrm{pH} 3-4$, there should be at any time, several $\mathrm{mM}$ of sulfide in solution for process stability. Especially for metal sulfides, like $\mathrm{ZnS}$, which are slightly soluble at such $\mathrm{pH}$ levels, toxicity is most relevant. Figure 4-d2 shows that at $0.09 \mathrm{mM}$ added $\mathrm{Zn}^{2+}$ there is still sulfide formation, but only about $1 / 3$ of the zinc ultimately precipitates. Apparently, about $0.06 \mathrm{mM}$ zinc remains in solution despite the excess of sulfide, confirming the higher solubility of zinc at lower $\mathrm{pH}$. This shows that sulfur reduction can still proceed with some zinc in solution, which is beneficial for practical feasibility. For $\mathrm{Pb}$, this is clearly different, once it does not precipitate completely, it becomes toxic.

Compared to sulfate, sulfur requires 4 times less electron donor to generate the same amount of sulfide, which would reduce the need of electron donors and therefore the operating costs of biological sulfide generation technology. Although this results in some additional cost for sulfur (whereas sulfate is normally present in sufficiently high concentrations in the mining and metallurgical waste), the net cost reduction is large. For example, Hedrich and Johnson (2014) performed iron oxidation and sulfate reduction to precipitate metals at low $\mathrm{pH}$ in modular reactors. The analysis of costs revealed that a projected $42 \mathrm{~m}^{3}$ sulfidogenic reactor needed to treat $1 \mathrm{~m}^{3}$ mine water with glycerol as electron donor, would produce 3.9 mol of sulfide in the process. Thus, considering the stoichiometry of the glycerol oxidation coupled to sulfate reduction (equation 6), the reactor would require $208.5 \mathrm{~g}$ of glycerol $(2.3 \mathrm{~mol})$, implying $0.5 \$$ as cost for this reagent, if we consider the market price of the glycerol as $2400 \$ /$ ton.

If sulfur is applied as electron acceptor, about $0.13 \mathrm{~kg}$ of it would be required to form the same amount of sulfide in a $42 \mathrm{~m}^{3}$ reactor. Considering the market price of sulfur as $61 \$ /$ ton, $0.008 \$$ is the additional cost for the process. However, as sulfur reduction requires four times less electron donors (equation 7 ), the same amount of sulfide is formed with only $52.1 \mathrm{~g}$ of glycerol, and a global reduction in costs of $0.37 \$$ per $\mathrm{m}^{3}$ of mine water treated is achieved. 
Table 3 - Summary of maximum tolerated concentration of different metals for sulfate/sulfur-reducing bacterial cultures. ${ }^{\mathrm{a}}$ - Brito, Villegas-Negrete et al. (2014); ${ }^{\mathrm{b}}$ - Hao, Huang et al. (1994); ${ }^{c}$ - Hedrich and Johnson (2014).

\begin{tabular}{ccccc}
\hline Metals & $\begin{array}{c}\text { Desulfovibrio } \\
\text { sp. }\end{array}$ & $\begin{array}{c}\text { Mixed culture } \\
\mathbf{b}\end{array}$ & $\begin{array}{c}\text { Mixed culture } \\
\mathbf{c}\end{array}$ & $\begin{array}{c}\text { Desulfurella } \text { sp. } \\
\text { strain TR1 }\end{array}$ \\
\hline $\mathbf{C u}$ & 0.06 & 0.31 & 0.2 & $>0.5$ \\
\hline $\mathbf{N i}$ & 0.14 & 0.34 & NR & 0.09 \\
\hline $\mathbf{P b}$ & $\mathrm{NR}$ & 0.36 & NR & 0.03 \\
\hline $\mathbf{Z n}$ & 0.3 & 0.04 & 0.31 & 0.09 \\
\hline
\end{tabular}

NR stands for Not Reported

$$
\begin{gathered}
4 \mathrm{C}_{3} \mathrm{H}_{8} \mathrm{O}_{3}+7 \mathrm{SO}_{4}{ }^{2-} \rightarrow 7 \mathrm{H}_{2} \mathrm{~S}+12 \mathrm{CO}_{2}+16 \mathrm{H}_{2} \mathrm{O} \text { (equation 6) } \\
\mathrm{C}_{3} \mathrm{H}_{8} \mathrm{O}_{3}+7 \mathrm{~S}+3 \mathrm{H}_{2} \mathrm{O} \rightarrow 7 \mathrm{H}_{2} \mathrm{~S}+3 \mathrm{CO}_{2} \text { (equation 7) }
\end{gathered}
$$

As an estimated market price of copper as 5900\$/ton and considering $0.46 \mathrm{~kg}$ of this metal being recovered by the amount of sulfide produced in the process, a return of $2.71 \$$ per $\mathrm{m}^{3}$ of mine treated can be obtained.

In summary, the metal tolerance, broad temperature and $\mathrm{pH}$ range of Desulfurella strain TR1 show the feasibility to apply Desulfurella strain TR1 to perform sulfur reduction to precipitate and recover heavy metals from acidic wastewater and mining water, without the need to neutralize the water before treatment. The growth and activity at such a broad range of $\mathrm{pH}$ makes the operation of reactor for selective precipitation of metals such as zinc, copper, nickel, lead and iron at controlled $\mathrm{pH}$ feasible.

\section{Acknowledgments}

The authors would like to thank CNPq (Conselho Nacional de Desenvolvimento Científico e Tecnológico), organization of the Brazilian Government for the development of Science and Technology, for supporting the doctoral study program; Esther Velasco for providing sediment samples, José Luis Sans for providing a picture from Tinto River and Ton van Gelder and Ricardo Pereira for their laboratory help. Research of I. SánchezAndrea. and A.J.M. Stams is financed by ERC grant project 323009, and Gravitation grant project 024.002.002 from the Netherlands Ministry of Education, Culture and Science. 


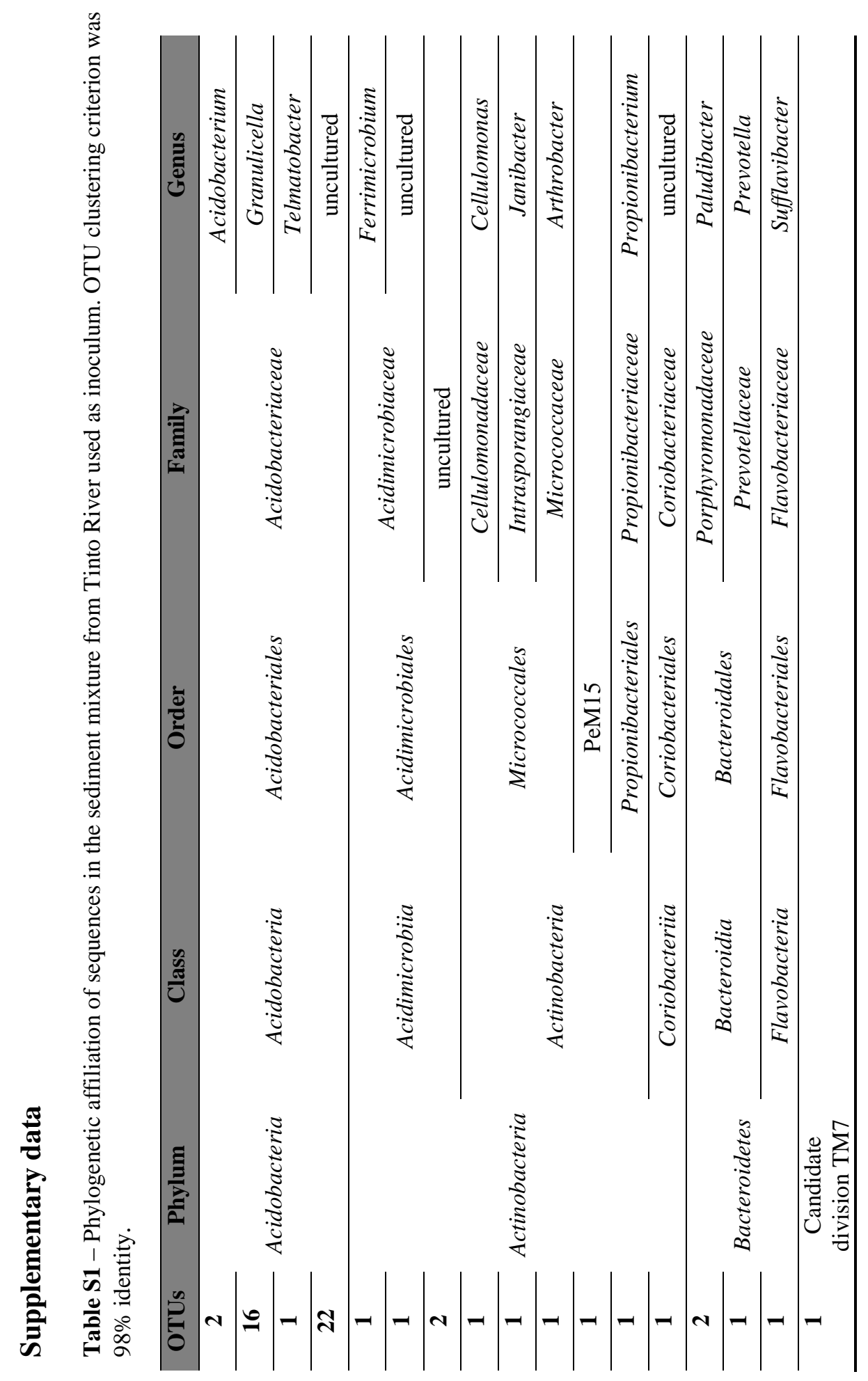




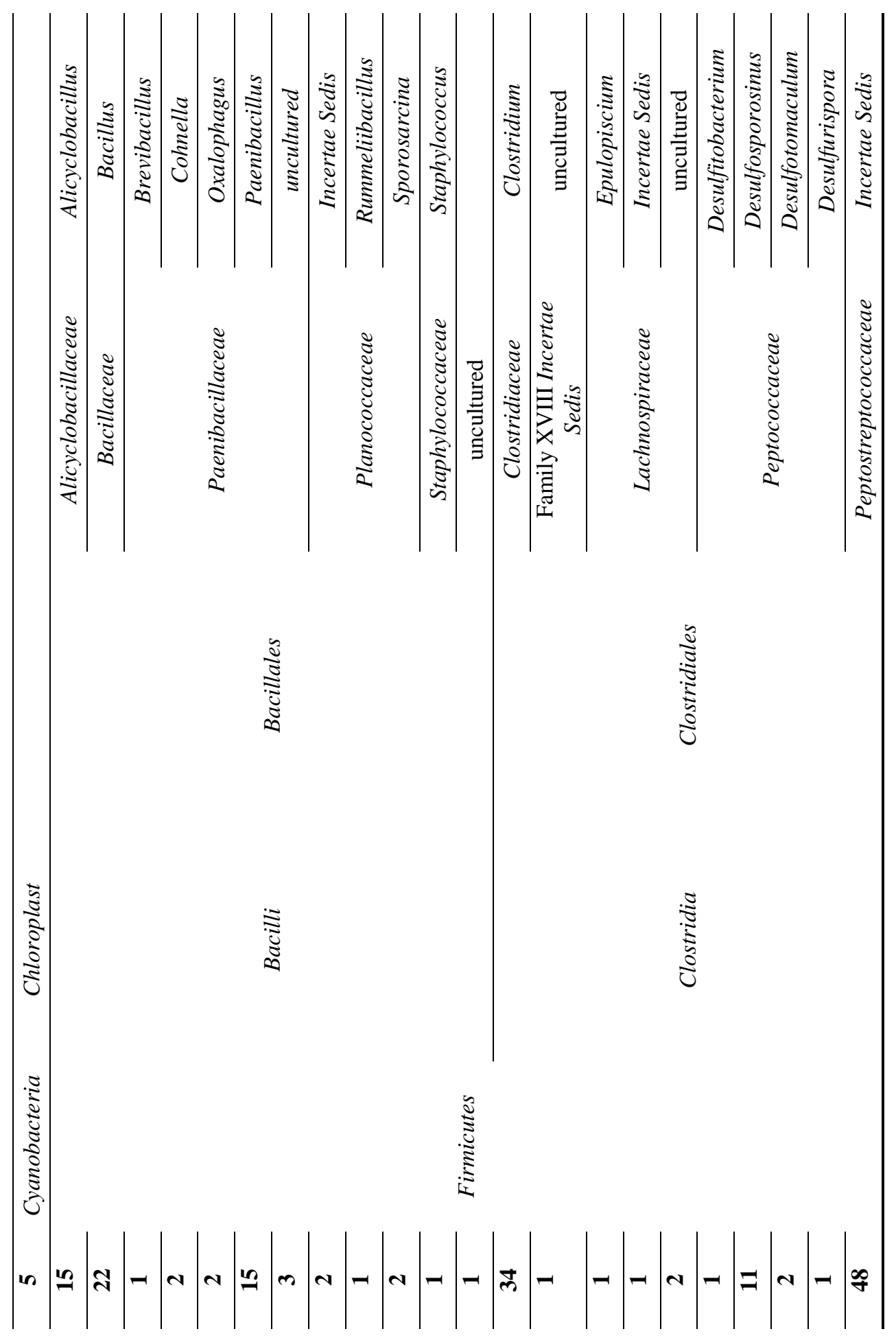




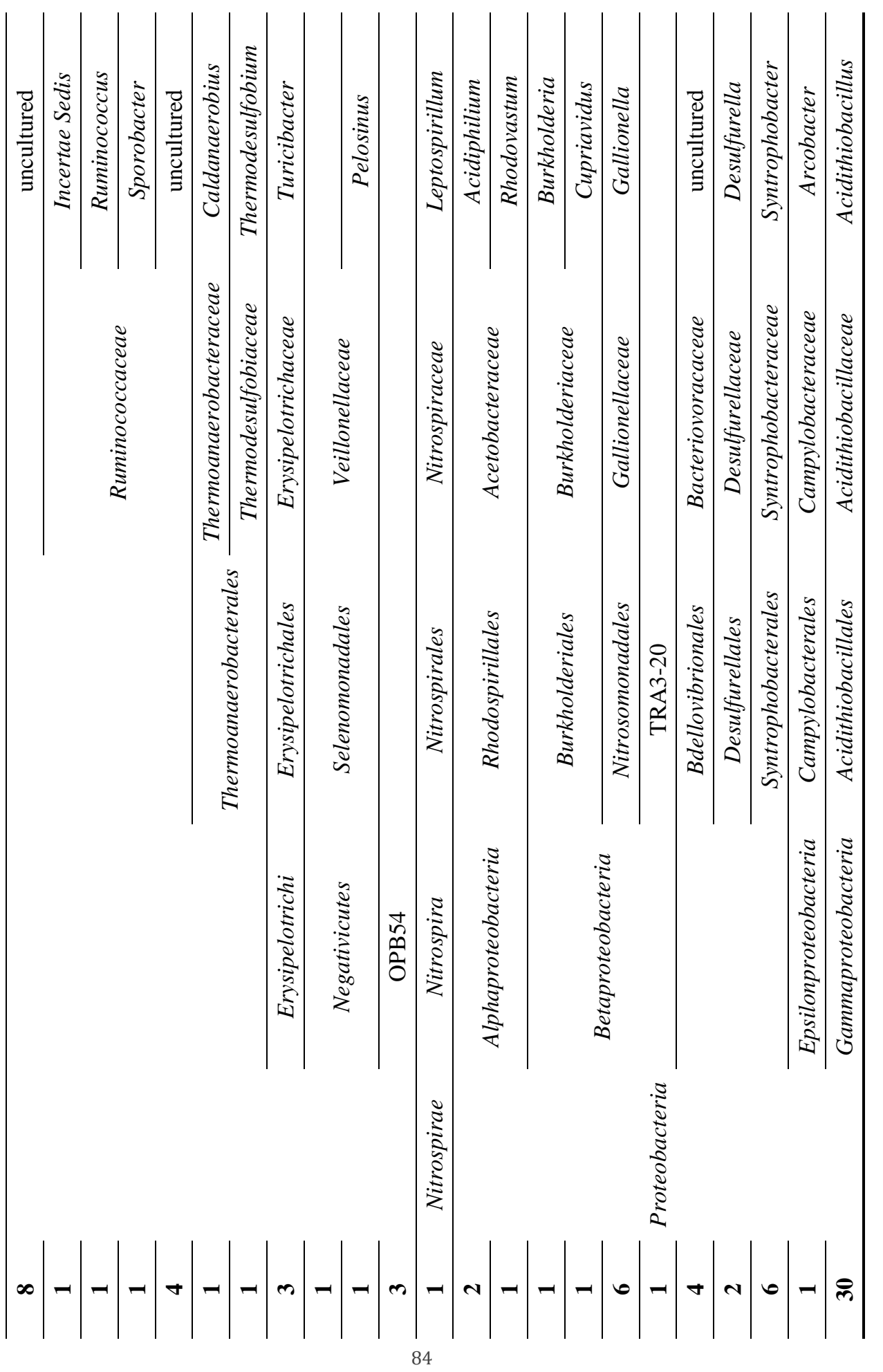


Sulfur reduction at low $\mathrm{pH}$

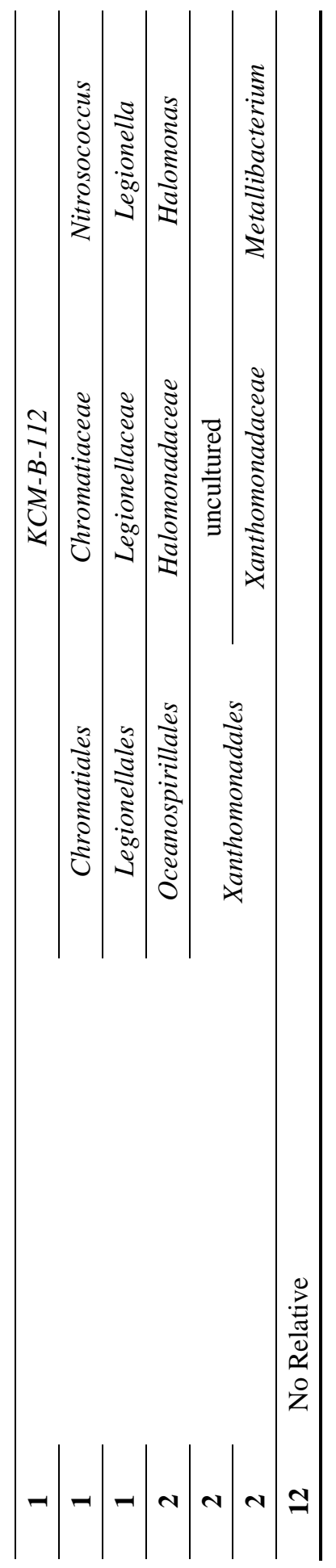


Table S2 - Averaged sulfide production $(\mathrm{mM})$ from the enrichments incubated at different $\mathrm{pH}$ and with different electron donors.

\begin{tabular}{lccccc} 
& \multicolumn{5}{c}{ Electron donors added } \\
\cline { 2 - 7 } & Acetate & Glycerol & Hydrogen & Methanol & No donor \\
\hline $\mathbf{2}$ & - & - & - & - & - \\
\hline $\mathbf{3}$ & 8.7 & 1.9 & 10.9 & 1.5 & 1.5 \\
\hline $\mathbf{4}$ & 16.4 & 2.3 & 10.5 & 1.3 & 1.5 \\
\hline $\mathbf{5}$ & 8.11 & 1.1 & 6.9 & 1.6 & 1.7 \\
\hline
\end{tabular}

Figure S1 - Experimental flow diagram.

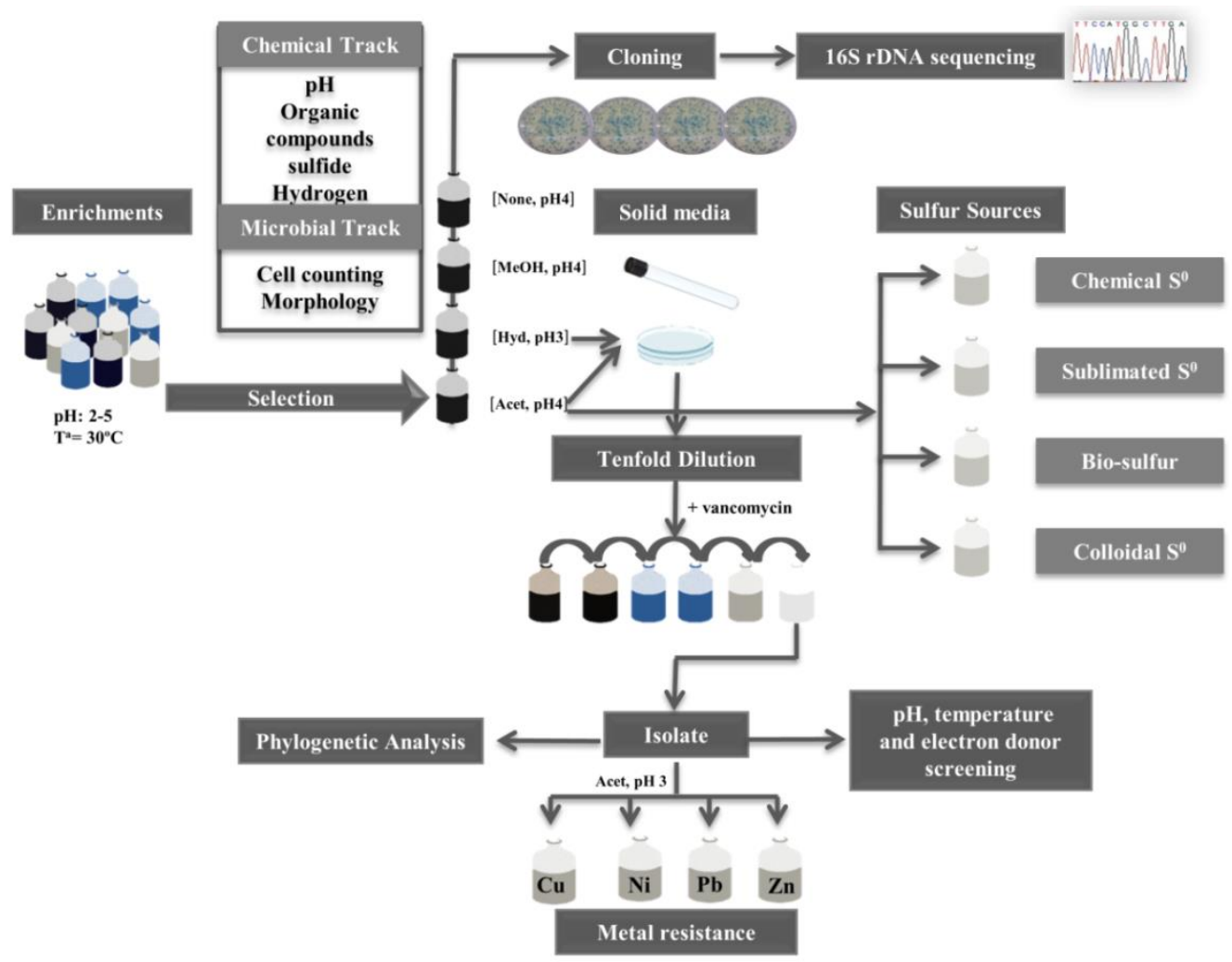


Figure S2 - Colonies of the strain TR1 grown at $\mathrm{pH} 4$, with acetate as electron donor and colloidal sulphur as electron acceptor.

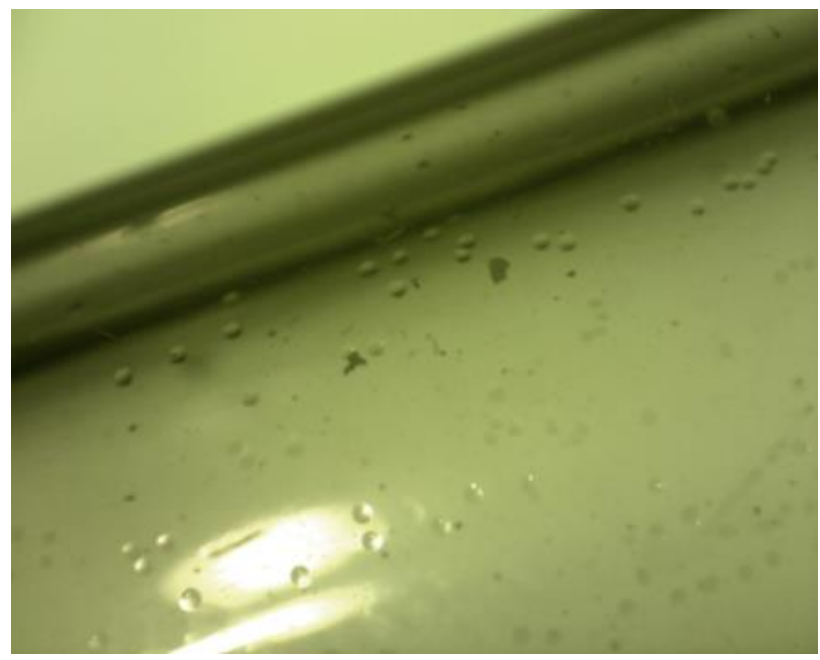

Figure S3 - Effect of temperature on the growth rate of strain TR1 growing at pH 6 and on $5 \mathrm{mM}$ acetate. The analyses were carried out in biological duplicates and the results averaged.

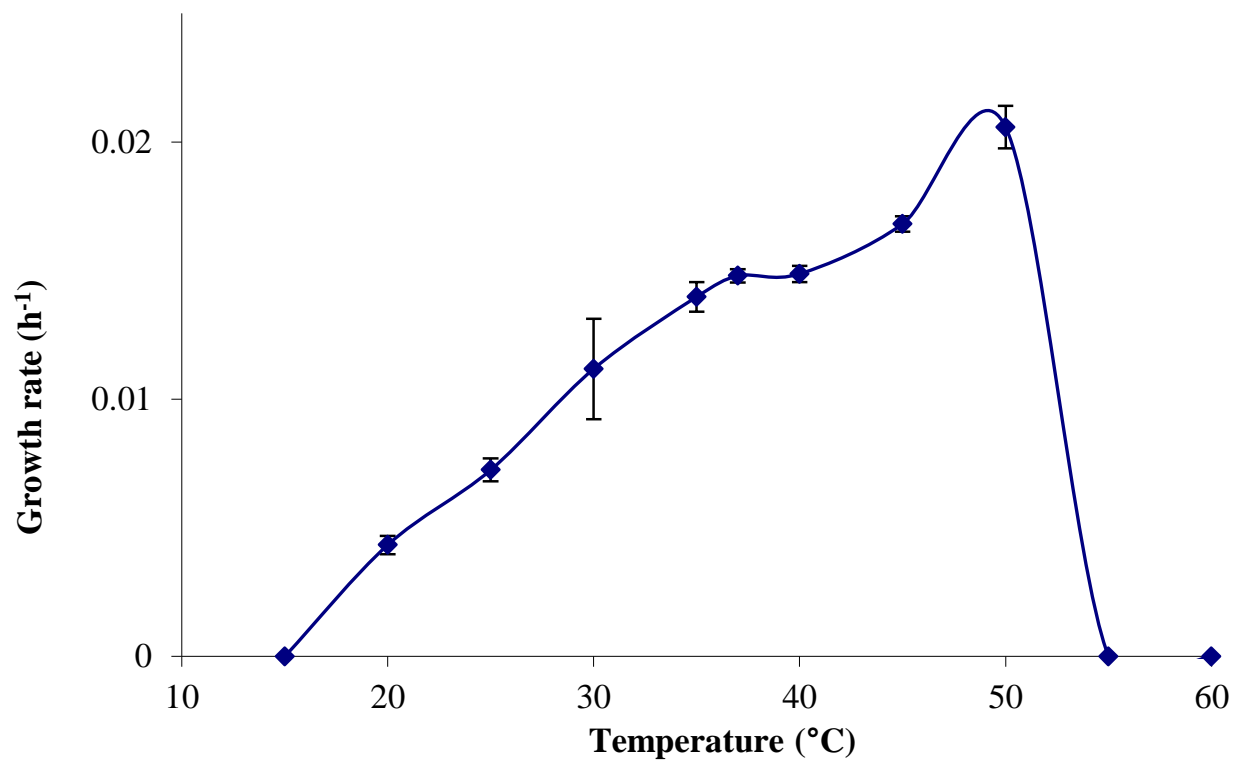


Figure S4 - Effect of $\mathrm{pH}$ on the growth rate of strain TR1 growing at $30^{\circ} \mathrm{C}$ and on $5 \mathrm{mM}$ acetate. The analyses were carried out in biological duplicates and the results averaged.

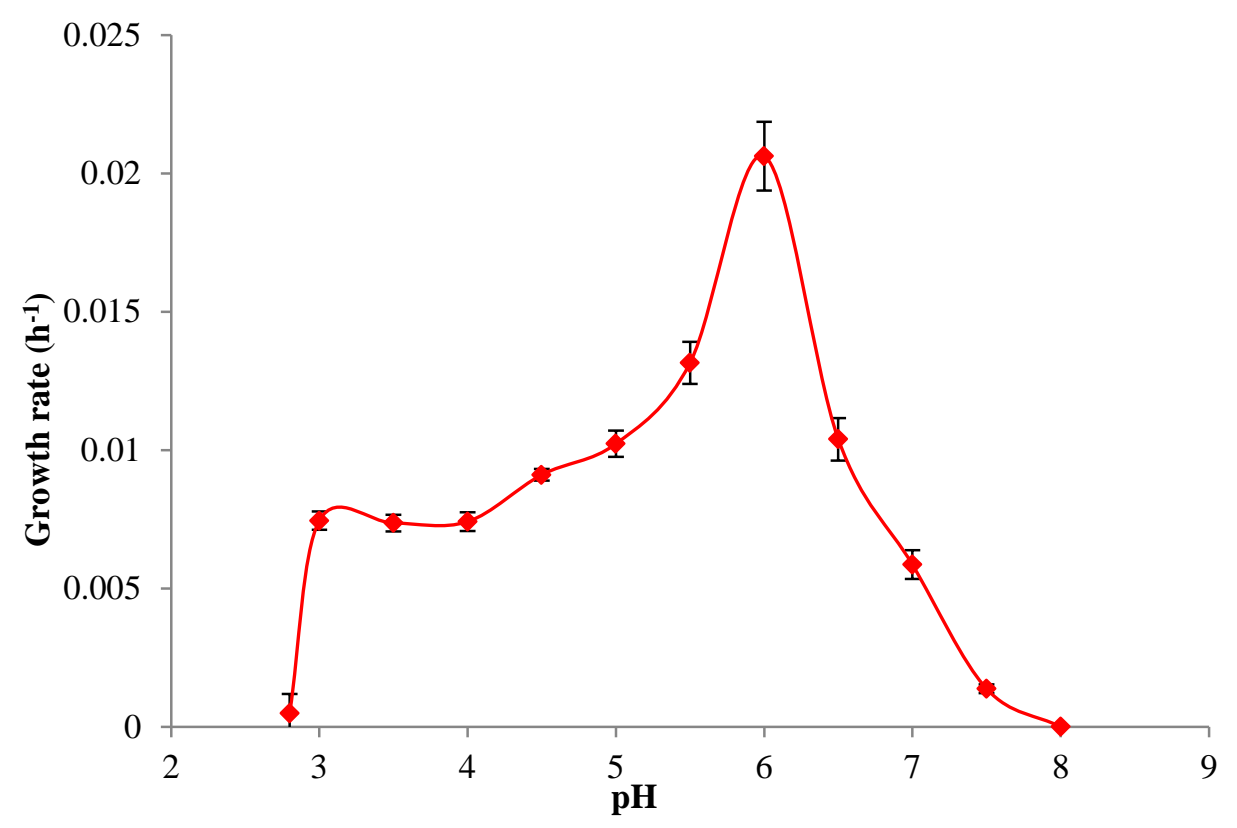




\section{Chapter 4}

\section{Desulfurella amilsii sp. nov., a novel acidotolerant sulfur-respiring bacterium isolated from acidic river sediments}

This chapter has been published as:

Florentino, A. P., C. Brienza, A. J. Stams and I. Sánchez-Andrea (2016). "Desulfurella amilsii sp. nov., a novel acidotolerant sulfur-respiring bacterium isolated from acidic river sediments." International Journal of Systematic and Evolutionary Microbiology 66(3): 1249-1253. 


\begin{abstract}
A novel acidotolerant and moderately thermophilic sulfur-reducing bacterium was isolated from sediments of the Tinto River (Spain), an extremely acidic environment. Strain $\mathrm{TR} 1^{\mathrm{T}}$ stains Gram-negative, is obligately anaerobic, non-spore forming and motile. Cells are short rods $(1.5-2$ by $0.5-0.7 \mu \mathrm{m})$, appearing single or in pairs. Strain TR $1^{\mathrm{T}}$ is catalase negative and slightly oxidase positive. Urease activity and indole formation were absent. But gelatin hydrolysis occurred. Growth was observed at 20 to $52^{\circ} \mathrm{C}$ with optimum close to $50^{\circ} \mathrm{C}$ and a $\mathrm{pH}$ range of 3 to 7 , with optimum between 6 and 6.5. Yeast extract was essential for growth, but extra vitamins were not required. In the presence of sulfur, strain TR $1^{\mathrm{T}}$ grew on acetate, lactate, pyruvate, stearate, arginine and $\mathrm{H}_{2} / \mathrm{CO}_{2}$. All substrates were completely oxidized and $\mathrm{H}_{2} \mathrm{~S}$ and $\mathrm{CO}_{2}$ were the only metabolic products detected. Besides elemental sulfur, thiosulfate was used as electron acceptor. The isolate also grew by disproportionation of elemental sulfur. The predominant cellular fatty acids were saturated $\mathrm{C}_{16: 0}(26.2 \%)$, anteiso- $\mathrm{C}_{17: 0}(13.2 \%)$ and $\mathrm{C}_{18: 0}(21.8 \%)$. The only quinone component detected was menaquinone $\mathrm{MK}-7\left(\mathrm{H}_{2}\right)$. The $\mathrm{G}+\mathrm{C}$ content of genomic DNA was $34 \%$. The isolate is affiliated to the genus Desulfurella of the Deltaproteobacteria class showing $97 \%$ of $16 \mathrm{~S}$ rRNA gene identity to the four species described in the Desulfurella genus. Considering the distinct physiological and phylogenetic characteristics, strain $\mathrm{TR} 1^{\mathrm{T}}$ represents a novel species within the genus Desulfurella, for which the name Desulfurella amilsii sp. nov. is proposed. The type strain of Desulfurella amilsii is TR $1^{\mathrm{T}}\left(=\mathrm{DSM} 29984^{\mathrm{T}}\right.$ $=$ JCM $30680^{\mathrm{T}}$ ).
\end{abstract}

The EMBL accession number for the 16S rRNA sequence of Desulfurella amilsii strain TR $1^{\mathrm{T}}$ is LN624414. 
Respiratory growth with elemental sulfur has been reported for phylogenetically diverse microorganisms. They belong to about 69 bacterial genera falling into 9 phyla and 37 archaeal genera from 2 phyla (Florentino, Weijma et al. 2016). Sulfidogenic microorganisms can be potentially applied for the treatment of acidic and metal-rich effluents from the mining and metallurgical industries (Johnson 1998, Koschorreck 2008); the sulfide that they produce can precipitate metals as insoluble metal sulfides that can be recovered. Bacteria that thrive at low $\mathrm{pH}$ are of special ecological and biotechnological interest due to their higher proton resistance. Sequences belonging to the sulfur-reducing genus Desulfurella have been detected in acid mine drainage environments (SánchezAndrea, Rodriguez et al. 2011, Brito, Villegas-Negrete et al. 2014). Selective enrichments for sulfur reducers at low $\mathrm{pH}$ using sediments from the acidic Tinto river led to the isolation of strain TR1 ${ }^{\mathrm{T}}$ (Florentino, Weijma et al. 2015), which is described and characterized here.

Sediment samples were collected in March 2013 from three sampling sites in the Tinto river basin. Briefly, strain TR $1^{\mathrm{T}}$ was isolated by combining solid media growth, with serial dilution technique and vancomycin addition. Details on the isolation process and basal media preparation can be found elsewhere (Florentino, Weijma et al. 2015). Cell morphology, motility and spore formation were analyzed using a phase contrast Leica DM2000 microscope (Leica Microsystems, Wetzlar, Germany) with an oil immersion objective. Gram-staining was performed according to standard procedures (Doetsch 1981) and confirmed by checking reaction of cells with $3 \%(\mathrm{w} / \mathrm{v}) \mathrm{KOH}$. For scanning electron microscopy, a 3\% (v/v) solution of glutaraldehyde (Sigma Aldrich, Zwijndrecht, The Netherlands) in PBS was used to fix the cells for $24 \mathrm{~h}$ at $4{ }^{\circ} \mathrm{C}$; afterwards samples were dehydrated in increasing concentrations of ethanol and air dried. Cells were analysed using JEOL JSM-6480LV microscope. For physiological analyses, strain TR $1^{\mathrm{T}}$ was grown in the basal medium supplemented with $5 \mathrm{mM}$ of acetate as carbon and energy source, and 25 $\mathrm{mM}$ of elemental sulfur as an electron acceptor at $\mathrm{pH} 5$ and at $30^{\circ} \mathrm{C}$. Agar roll tubes $(0.8 \%$ Agar noble, Difco) were prepared as described by Florentino, Weijma et al. (2015) using colloidal sulfur as an electron acceptor. When molecular hydrogen was used as a substrate, the head space was filled with $\mathrm{H}_{2} / \mathrm{CO}_{2}(80: 20$, v/v). Different electron acceptors and donors were tested at final concentrations of 25 and $5 \mathrm{mM}$, respectively. The ability of the isolate to disproportionate elemental sulfur and thiosulfate was tested by adding elemental sulfur or thiosulfate $(25 \mathrm{mM})$ to a medium free of electron donor. For these tests the head space was filled with $\mathrm{N}_{2} / \mathrm{CO}_{2}(80: 20, \mathrm{v} / \mathrm{v})$. Growth of strain $\mathrm{TR} 1^{\mathrm{T}}$ was studied in a range of temperature from 15 to $60^{\circ} \mathrm{C}, \mathrm{pH}$ from 2.5 to 8.0 (in 0.5 intervals) and $\mathrm{NaCl}$ from 0.8 to $3.8 \%$ (in $0.5 \%$ intervals). Influence of dependence on vitamins and yeast extract was studied by removing them from the medium. The sensitivity of strain TR $1^{\mathrm{T}}$ to antibiotics was determined by addition of vancomycin, streptomycin, rifampicin, penicillin and chloramphenicol applied at 25,50 and $100 \mu \mathrm{g} \mathrm{mL}^{-1}$. All the tests were done in triplicate. In 
all physiological tests, activity was followed by hydrogen sulfide measurements every three days during incubation and confirmed by comparison to the respective negative controls. Hydrogen sulfide was measured by a colorimetric method (Cline 1969). Liquid substrates were monitored using an LKB high-performance liquid chromatograph (HPLC) with a Varian Metacarb $67 \mathrm{H} 300 \mathrm{~mm}$ column and $0.01 \mathrm{~N} \mathrm{H}_{2} \mathrm{SO}_{4}$ eluent at a flow rate of $0.6 \mathrm{~mL}$ $\min ^{-1}$. Gaseous compounds $\left(\mathrm{H}_{2}\right.$ and $\left.\mathrm{CO}_{2}\right)$ were determined with a Shimadzu GC-2014 gas chromatograph (Shimadzu, Kyoto, Japan) with a Molsieve 13X column, $2 \mathrm{~m} * 3 \mathrm{~mm}$ (Varian, Middelburg, The Netherlands) and a thermal conductivity detector set at $70 \mathrm{~mA}$. Sulfate and thiosulfate concentrations were quantified using Dionex ICS-1000 ion chromatograph equipped with an IonPac AS22 column and $4.5 \mathrm{mM}$ carbonate- $1.4 \mathrm{mM}$ bicarbonate eluent at a flow rate of $1.2 \mathrm{~mL} \mathrm{~min}^{-1}$ (Dionex Corporation, Sunnyvale, CA). Catalase activity was determined by reaction with $3 \%(\mathrm{w} / \mathrm{v})$ solution of $\mathrm{H}_{2} \mathrm{O}_{2}$. Oxidase activity was carried out with a filter saturated with $1 \%(\mathrm{w} / \mathrm{v})$ solution of tetramethyl- $p$ phenylenediamine in dimethyl sulfoxide (Sigma-Aldrich, St. Louis, MO). Formation of indole and urease, and hydrolysis of gelatin and esculin were determined with API 20A (bioMérieux, Marcy l'Etoile, France). An aliquot of $5 \mathrm{~mL}$ was taken from a grown culture; the cells were washed and re-suspended in the basal medium described and used to fill the strips. Analyses of fatty acids profiles and respiratory quinones were performed by the Identification Service of DSMZ - Deutsche Sammlung von Mikroorganismen und Zellkulturen $\mathrm{GmbH}$ (Braunschweig, Germany). To establish a comparison of cellular fatty acid composition, strain $\mathrm{TR} 1^{\mathrm{T}}$ was grown in parallel with $D$. propionica, using the same medium containing $5 \mathrm{mM}$ of acetate and $25 \mathrm{mM}$ of elemental sulfur. The $\mathrm{G}+\mathrm{C}$ content of the DNA was determined via genome sequencing (GATC- Biotech, Konstanz, Germany). Cloning of the $16 \mathrm{~S}$ rRNA gene was performed to determine the phylogenetic affiliation of the isolate and the analysis was performed following the workflow described in Florentino, Weijma et al. (2015). The 16S rRNA gene sequence determined has been deposited in the EMBL database under the accession number LN624414.

Strain TR $1^{\mathrm{T}}$ cells stained Gram-negative, and reacted positively to $\mathrm{KOH}$ addition, confirming a Gram-negative cell wall structure. Cells were motile short rods, 0.5 by 1.5-2 $\mu \mathrm{m}$ in size and appeared single or in pairs (Fig. S1, available in Supplemental Material). Spores were never detected. Strain $\mathrm{TR} 1^{\mathrm{T}}$ was catalase negative and slightly oxidase positive (blue colour development took 60 minutes instead of $15 \mathrm{~min}$ ). Urease activity and indole formation were absent, but gelatin hydrolysis occurred. Whitish colonies with circular shape $(0.5-1 \mathrm{~mm})$ and regular edges were detected after one month of incubation in roll tubes.

The isolate grew in a range of temperature between 20 and $52^{\circ} \mathrm{C}$; the optimum was close to $50^{\circ} \mathrm{C}$; and in a range of $\mathrm{pH}$ from 3 to 7 , with optimum at 6-6.5. It was able to ferment pyruvate, with malate and citrate as products, and to couple the oxidation of 
hydrogen, acetate, formate, lactate, pyruvate, stearate and arginine to the reduction of elemental sulfur, with $\mathrm{H}_{2} \mathrm{~S}$ and $\mathrm{CO}_{2}$ as the only products. Although elemental sulfur was the electron acceptor from which the highest concentration of sulfide and fastest growth were achieved, thiosulfate was also reduced by the isolate. Elemental sulfur was disproportionated, with a production of $0.6 \mathrm{mM}$ of sulfate and $1.9 \mathrm{mM}$ of sulfide, in accordance to the expected stoichiometry of disproportionation equation (1:3). The specific growth rate on acetate under optimal growth conditions was $0.0206 \mathrm{~h}^{-1}$ (generation time of 32.8 hours). Growth occurred in the presence of up to $3.8 \%$ of $\mathrm{NaCl}$, with optimum growth between 0.3 and $0.8 \% \mathrm{NaCl}$. Strain TR $1^{\mathrm{T}}$ could grow in the presence of vancomycin and streptomycin in concentrations up to $100 \mu \mathrm{g} \mathrm{mL}$. The isolate presented weak growth in bottles supplemented with benzylpenicillin at $25 \mu \mathrm{g} \mathrm{mL}^{-1}$. No growth was observed when chloramphenicol or rifampicin were added at any of the concentrations tested.

Major components in the fatty acid profile of strain TR $1^{\mathrm{T}}$ were mainly saturated fatty acids: $\mathrm{C}_{16: 0}(26.2 \%)$, anteiso- $\mathrm{C}_{17: 0}(13.2 \%)$ and $\mathrm{C}_{18: 0}(21.8 \%)$. Profiles of cellular fatty acid composition of strain $\mathrm{TR} 1^{\mathrm{T}}$ and one of its relatives (D. propionica) are shown in Supplementary Material (Table S1). The only quinone component detected was menaquinone MK-7(H2). The $\mathrm{G}+\mathrm{C}$ content of the genomic DNA of the isolate was 34 mol\% (Genome Online Database submission ID Ga0101804). The comparative analysis of the $16 \mathrm{~S}$ rRNA gene sequence revealed that strain $\mathrm{TR} 1^{\mathrm{T}}$ represents a new species of the Desulfurella genus, showing $97 \%$ identity with the other 4 described Desulfurella species. Although clustering with the described species in the Desulfurella genus, it forms a new branch point in the phylogenetic tree (Figure 1).

Characterization of strain $\mathrm{TR} 1^{\mathrm{T}}$ showed some interesting phylogenetic and physiological aspects of the isolate that differ from its relatives (Table 1). The sulfurreducing genus Desulfurella belongs to the family Desulfurellaceae (order Desulfurellales, Deltaproteobacteria class), which comprises two genera: Desulfurella (BonchOsmolovskaya, Sokolova et al. 1990) and Hippea (Miroshnichenko, Rainey et al. 1999). So far, the genus Desulfurella comprises 4 species with validly published names: $D$. acetivorans (Bonch-Osmolovskaya, Sokolova et al. 1990), D. kamchatkensis (Miroshnichenko, Rainey et al. 1998), D. multipotens (Miroshnichenko, Gongadze et al. 1994) and D. propionica (Miroshnichenko, Rainey et al. 1998), all sharing 99\% 16S rRNA gene identity. Despite the high 16S rRNA gene sequence similarities for the 4 described species, they presented low levels of DNA-DNA hybridization $(<70 \%)$, which together with phenotypic features, confirmed the novelty of the species (Miroshnichenko, Rainey et al. 1998). All described members in the genus are thermophiles with temperature optima between 50 and $60^{\circ} \mathrm{C}$, with minimum temperature for growth at $33^{\circ} \mathrm{C}$ for $\mathrm{D}$. propionica, and 40,42 and $44^{\circ} \mathrm{C}$ for D. kamchatkensis, D. multipotens and D. acetivorans, respectively. Known Desulfurella species are neutrophilic with $\mathrm{pH}$ optima between 6.4 and 7.2, and 
minimum $\mathrm{pH}$ for growth is 4.3 for $D$. acetivorans. Strain $\mathrm{TR} 1^{\mathrm{T}}$ was able to grow at temperature as low as $20^{\circ} \mathrm{C}$ and $\mathrm{pH}$ as low as 3, the lowest limits for described Desulfurella species. Strain TR1 ${ }^{\mathrm{T}}$ also presented $97 \%$ 16S rRNA gene sequence identity with the other Desulfurella members. Yeast extract is not required for the four described Desulfurella species, but it is required for growth of strain TR $1^{\mathrm{T}}$. Another difference from strain TR $1^{\mathrm{T}}$ to the known Desulfurella species is the generation time at optimum conditions is 32.8 hours, while the doubling times for D. acetivorans, D. kamchatkensis are 2 and 2.5 hours, respectively; and for D. multipotens and D. propionica the generation time is 5 hours.

Based on its distinctive phenotypic, genotypic and phylogenetic characteristics, strain $\mathrm{TR} 1^{\mathrm{T}}$ is proposed to represent a novel species, Desulfurella amilsii sp. nov., within the genus Desulfurella.

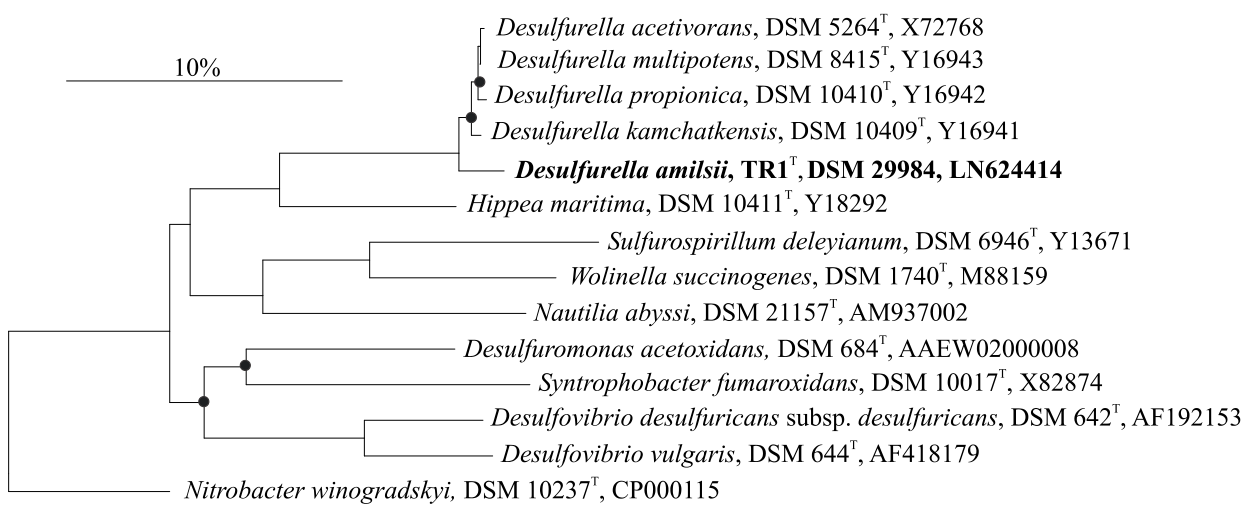

Figure 1 - 16S rRNA gene-based neighbor-joining tree (with Jukes-Cantor correction) showing the phylogenetic affiliation of strain $\mathrm{TR} 1^{\mathrm{T}}$ in relation to the other representatives of the Desulfurellaceae family. Bar represents $10 \%$ sequence divergence. Black circles indicate support in bootstrap analyses with values greater than 90\% (1000 replicates). 


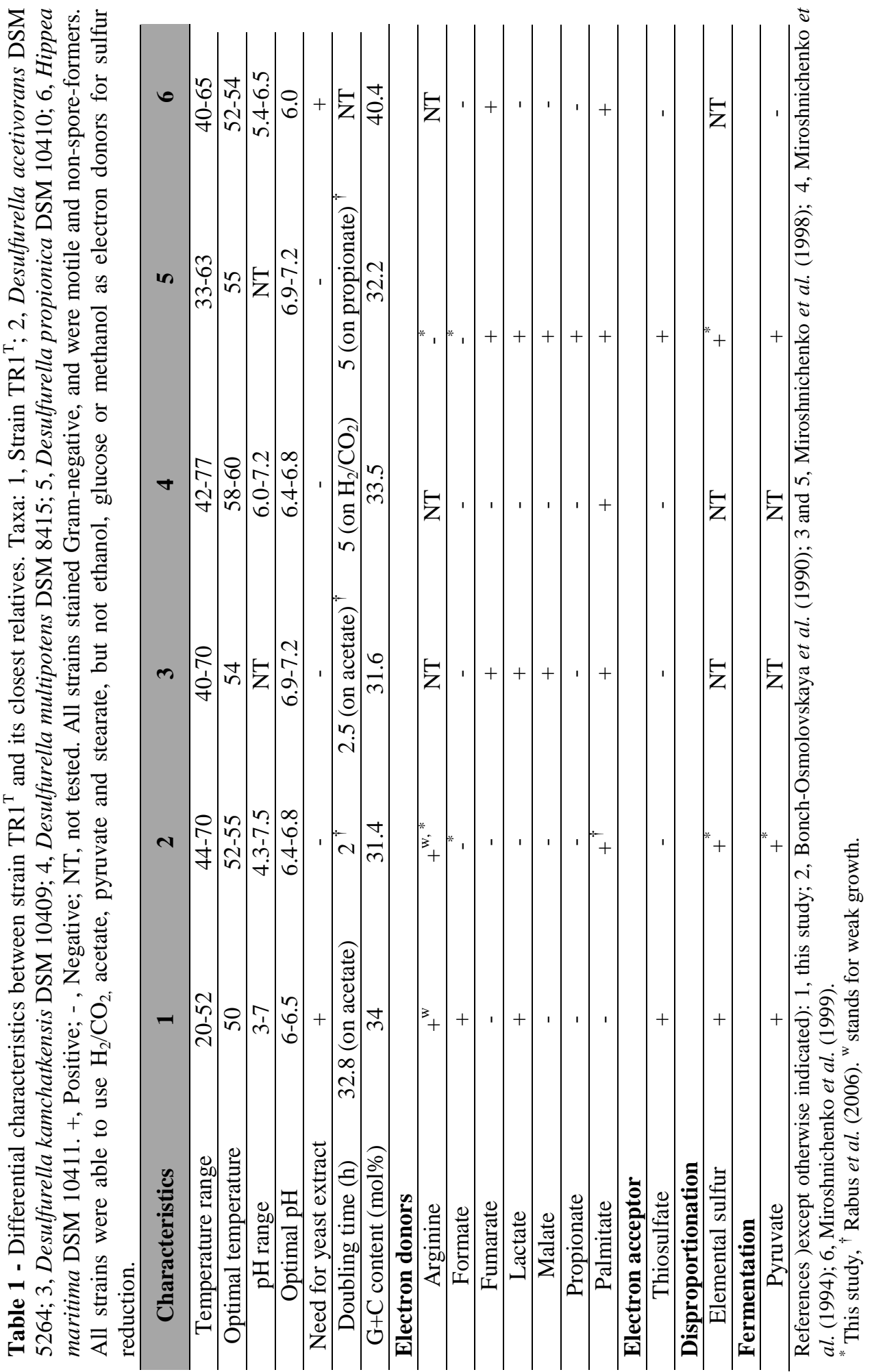




\section{Description of Desulfurella amilsii sp. nov.}

Desulfurella amilsii (a.mils'i.i. N.L. masc. gen. n. amilsii of Amils, named after Ricardo Amils, a Spanish microbiologist, in recognition of his contribution to the understanding of Tinto River microbial ecology).

Cells are rod-shaped $(0.5 \times 1.5-2.0 \mu \mathrm{m})$ appearing single or in pairs, and motile. Cells stain Gram-negative and are strictly anaerobic. Strain $\mathrm{TR} 1^{\mathrm{T}}$ is catalase negative and oxidase slightly positive. Urease activity and indole formation are absent, but gelatin hydrolysis occurs. Colonies are whitish, circular, opaque with entire margins and 0.5-1.0 $\mathrm{mm}$ in diameter after 1 month of incubation. The temperature range for growth is $25-52^{\circ} \mathrm{C}$, with optimum close to $50^{\circ} \mathrm{C}$. The $\mathrm{pH}$ range for growth is $3-7$, with optimum 6-6.5. $\mathrm{NaCl}$ is tolerated at a maximum of $3.8 \%$. Yeast extract is required for growth, but additional vitamins are not needed. Elemental sulfur and thiosulfate are used as electron acceptors. Sulfate, sulfite, nitrate, and ferric iron are not reduced. Disproportionation of elemental sulfur supported growth. Utilizes hydrogen, acetate, formate, lactate, pyruvate, stearate and arginine as electron donors for sulfur reduction. Organic substrates are completely oxidized to $\mathrm{CO}_{2}$. Does not use formate, propionate, fumarate, succinate, butyrate, isobutyrate, malate, caproate, benzoate, palmitate, ethanol, methanol, glucose, sucrose, glycine, leucine, lysine, peptone, hexadecane or starch. Pyruvate is fermented. Glucose and glycerol are not fermented. The only quinone component detected was menaquinone $\mathrm{MK}-7\left(\mathrm{H}_{2}\right)$. The $\mathrm{G}+\mathrm{C}$ content of the genomic DNA is $34 \%$.

\section{Acknowledgements}

This research was supported by the organization of the Brazilian Government for the development of Science and Technology CNPq (Conselho Nacional de Desenvolvimento Científico e Tecnológico), by ERC grant project 323009, and Gravitation grant project 024.002.002 from the Netherlands Ministry of Education, Culture and Science. The authors thank Monika Jarzembowska (WUR, Wageningen, The Netherlands) for the scanning electron microscopy analysis. 


\section{Supplementary data}

Table S1 - Cellular fatty acid composition of strain TR $1^{\mathrm{T}}$ and Desulfurella propionica (the major fatty acids are shown in bold). Taxa: 1 , Strain TR1 $1^{\mathrm{T}} ; 2$, Desulfurella propionica.

\begin{tabular}{|c|c|c|}
\hline Fatty acids & 1 & 2 \\
\hline \multicolumn{3}{|c|}{ Saturated straight-chain } \\
\hline $\mathrm{C}_{12: 0}$ & 0.9 & - \\
\hline $\mathrm{C}_{14: 0}$ & 1.7 & 1.9 \\
\hline $\mathrm{C}_{16: 0}$ & 26.2 & 19.0 \\
\hline $\mathrm{C}_{18: 0}$ & 21.8 & 6.1 \\
\hline $\mathrm{C}_{20: 0}$ & 3.1 & - \\
\hline \multicolumn{3}{|c|}{ Unsaturated straight-chain } \\
\hline $\mathrm{C}_{18: 1} \mathrm{w} 7 \mathrm{c}$ & 5.6 & 9.8 \\
\hline $\mathrm{C}_{18: 1} \mathrm{w} 9 \mathrm{c}$ & 0.7 & 2.5 \\
\hline \multicolumn{3}{|c|}{ Hydroxy acids } \\
\hline $\mathrm{C}_{16: 0} 3 \mathrm{OH}$ & 3.4 & 5.4 \\
\hline $\mathrm{C}_{17: 0} 2 \mathrm{OH}$ & - & 2.0 \\
\hline $\mathrm{C}_{17: 0} 3 \mathrm{OH}$ & - & 2.3 \\
\hline Iso-C $\mathrm{C}_{17: 0} 3 \mathrm{OH}$ & 1.1 & - \\
\hline \multicolumn{3}{|c|}{ Saturated branched-chain } \\
\hline Anteiso- $\mathrm{C}_{15: 0}$ & 1 & 4.2 \\
\hline Iso- $C_{15: 0}$ & 1.4 & - \\
\hline Iso- $\mathrm{C}_{16: 0}$ & 2.9 & 3.2 \\
\hline Anteiso- $\mathrm{C}_{17: 0}$ & 13.3 & 36.5 \\
\hline Iso-C $_{17: 0}$ & 3.2 & - \\
\hline Iso-C $\mathrm{C}_{18: 0}$ & 3.0 & - \\
\hline $\mathrm{C}_{19: 0}$ cyclo w8c & 1.6 & - \\
\hline Anteiso- $\mathrm{C}_{19: 0}$ & 1.1 & - \\
\hline Iso- $\mathrm{C}_{19: 0}$ & 0.7 & - \\
\hline
\end{tabular}


Figure S1 - Image of cells of strain TR $1^{\mathrm{T}}$ obtained by scanning electron microscopy. Bar represents $3 \mu \mathrm{m}$.

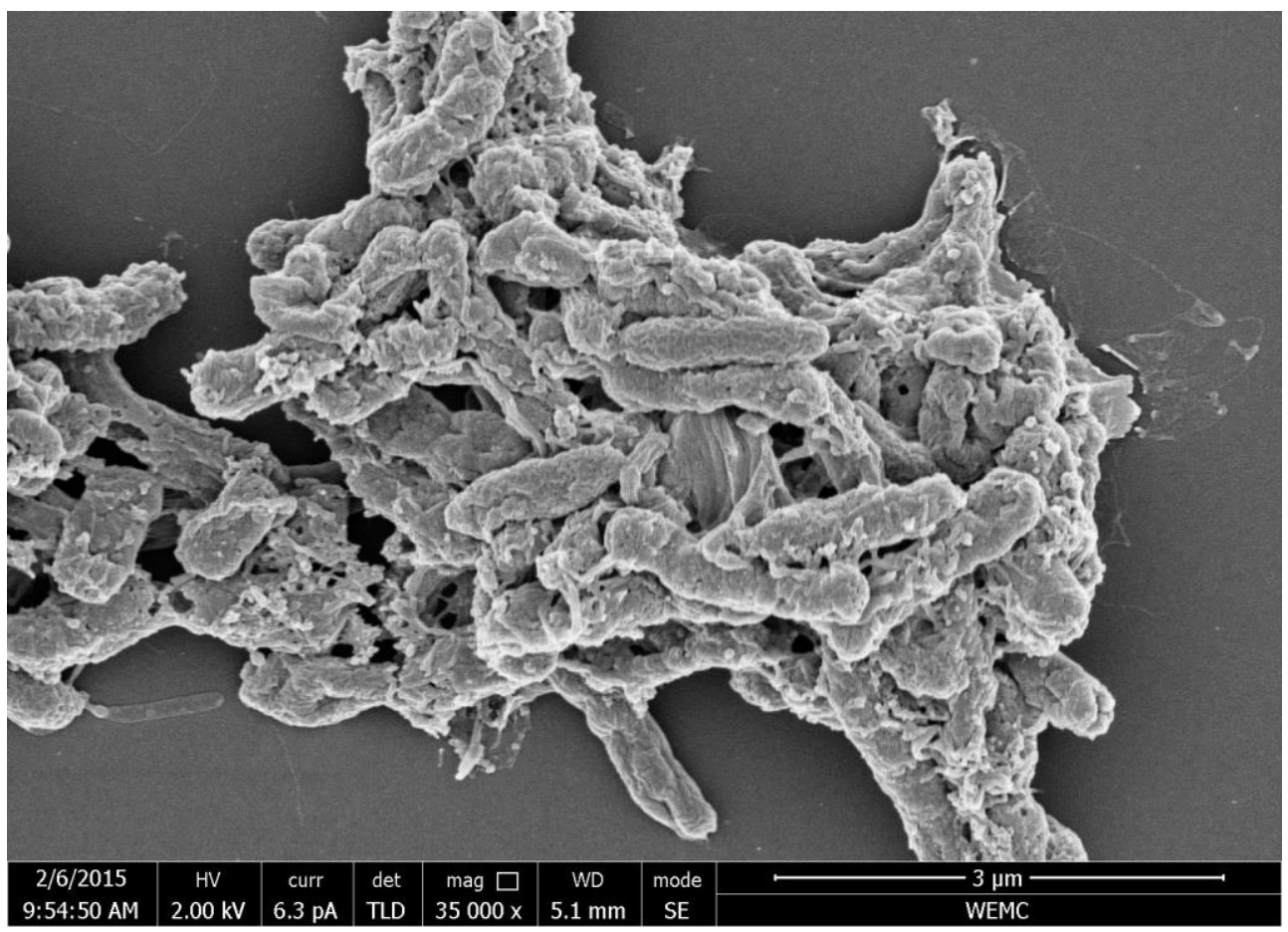




\section{Chapter 5}

\section{Genome sequence of Desulfurella amilsii strain TR1 and comparative genomics of Desulfurellaceae family}

This chapter has been published as:

Florentino A. P., Stams A. J. and Sánchez-Andrea I. (2017). Genome sequence of Desulfurella amilsii strain TR1 and comparative genomics of Desulfurellaceae family. Frontiers in Microbiology 8:222. doi: 10.3389/fmicb.2017.00222. 


\begin{abstract}
The acidotolerant sulfur reducer Desulfurella amilsii was isolated from sediments of Tinto river, an extremely acidic environment. Its ability to grow in a broad range of $\mathrm{pH}$ and to tolerate certain heavy metals offers potential for metal recovery processes. Here we report its high-quality draft genome sequence and compare it to the available genome sequences of other members of Desulfurellaceae family: D. acetivorans, D. multipotens, Hippea maritima, H. alviniae, H. medeae and H. jasoniae. For most species, pairwise comparisons for average nucleotide identity (ANI) and in silico DNA-DNA hybridization (DDH) revealed ANI values from 67.5 to $80 \%$ and DDH values from 12.9 to $24.2 \%$. D. acetivorans and D. multipotens, however, surpassed the estimated thresholds of species definition for both DDH (98.6\%) and ANI (88.1\%). Therefore, they should be merged to a single species. Comparative analysis of Desulfurellaceae genomes revealed different gene content for sulfur respiration between Desulfurella and Hippea species. Sulfur reductase is only encoded in D. amilsii, in which it is suggested to play a role in sulfur respiration, especially at low pH. Polysulfide reductase is only encoded in Hippea species; it is likely that this genus uses polysulfide as electron acceptor. Genes encoding thiosulfate reductase are present in all the genomes, but dissimilatory sulfite reductase is only present in Desulfurella species. Thus, thiosulfate respiration via sulfite is only likely in this genus. Although sulfur disproportionation occurs in Desulfurella species, the molecular mechanism behind this process is not yet understood, hampering a genome prediction. The metabolism of acetate in Desulfurella species can occur via the acetyl-CoA synthetase or via acetate kinase in combination with phosphate acetyltransferase, while in Hippea species, it might occur via the acetate kinase. Large differences in gene sets involved in resistance to acidic conditions were not detected among the genomes. Therefore, the regulation of those genes, or a mechanism not yet known, might be responsible for the unique ability of D. amilsii. This is the first report on comparative genomics of sulfur-reducing bacteria, which is valuable to give insight into this poorly understood metabolism, but of great potential for biotechnological purposes and of environmental significance.
\end{abstract}

The prefix of the locus tags for the analysed species are: D. amilsii - DESAMIL20_, D. acetivorans - Desace_, H. maritima - Hipma_, H. jasoniae - EK17DRAFT, H. alviniae G415DRAFT_, and H. medeae - D891DRAFT_. 


\section{Introduction}

Elemental sulfur reduction is a respiratory-chain dependent redox process that yields ATP by utilizing sulfur as an oxidizing agent. This metabolism is of great importance for the biogeochemical cycle of sulfur in extreme environments, from where sulfur reducers have most frequently been isolated (Bonch-Osmolovskaya et al., 1990; Stetter, 1996; Alain et al., 2009; Birrien et al., 2011). Sulfur reduction leads to the formation of sulfide, a compound that, despite its corrosive properties, has an important role in biotechnological applications, such as metal precipitation (Johnson and Hallberg, 2005). Early assumptions considered sulfur reduction to be of low physiological importance as reviewed by Rabus et al. (2006). However, it is now known that this metabolism can yield energy for growth coupled to the utilization of several electron donors, such as alcohols, organic acids and sugars (Bonch-Osmolovskaya et al., 1990; Finster et al., 1997; Dirmeier et al., 1998; Boyd et al., 2007; Florentino et al., 2016b); and the majority of sulfur-reducing microorganisms are able to grow chemolithotrophically (Segerer et al., 1986; Bonch-Osmolovskaya et al., 1990; Caccavo Jr. et al., 1994; Stetter, 1996; Miroshnichenko et al., 1999). Although sulfurreducing microorganisms have a versatile metabolism (Dirmeier et al., 1998; Boyd et al., 2007), little attention has been paid to its genomic features beyond the biochemistry and bioenergetics of the process.

From current observations, microorganisms able to reduce elemental sulfur are spread over more than a hundred genera in the tree of life (Florentino et al., 2016a). In the Bacteria domain, the majority of the sulfur-reducing species align within the Proteobacteria phylum. In this group, the Desulfurellaceae family comprises the genera Desulfurella and Hippea, inhabiting terrestrial environments and submarine hot vents, respectively (Blumentals et al., 1990; Greene, 2014). Although the genomes of several members of the Desulfurellaceae family are sequenced, Hippea maritima is the only species with its genome description reported.

Desulfurella amilsii, an acidotolerant sulfur reducer, was recently isolated from sediments of the Tinto river, an extreme acidic environment (Florentino et al., 2015). The phenotypic characterization of $D$. amilsii revealed its ability to utilize not only sulfur but also thiosulfate as an electron acceptor (as was reported for D. propionica) and to ferment pyruvate (as also reported for D. acetivorans). Unlike other members in the Desulfurellaceae family, D. amilsii utilizes formate as an electron donor and thrives at $\mathrm{pH}$ as low as 3 (Florentino et al., 2016a). The utilization of acetate is common among the species. However, the ability of $D$. amilsii to metabolize it at low $\mathrm{pH}$ is peculiar, since at acidic conditions, acetate is protonated and become acetic acid, a toxic compound for most prokaryotic species (Holyoak et al., 1996). 
The respiration of elemental sulfur is thought to be coupled to ADP phosphorylation, in which hydrogenases or dehydrogenases transfer electrons to sulfurreducing enzymes via electron carriers, such as menaquinones or cytochromes (Rabus et al., 2006) together with proton translocation. The biochemical mechanisms via which microorganisms reduce elemental sulfur to $\mathrm{H}_{2} \mathrm{~S}$ and the nature of the enzymes involved in the process are not yet completely understood, especially at low $\mathrm{pH}$. The low solubility of elemental sulfur in aqueous medium $\left(5 \mu \mathrm{g} \mathrm{\textrm {L } ^ { - 1 }}\right.$ at $\left.20^{\circ} \mathrm{C}\right)$ and the chemical transformation of sulfur compounds, that is dependent on $\mathrm{pH}$, hamper a broad understanding of sulfidogenic processes (Schauder and Müller, 1993; Florentino et al., 2016c). Some microorganisms, as for example Wolinella succinogenes (Macy et al., 1986) can overcome the low solubility of elemental sulfur by utilizing more hydrophilic forms of the compound, such as polysulfides. In aqueous solution containing nucleophiles, such as sulfide or cysteine, elemental sulfur can be readily converted to polysulfide (Blumentals et al., 1990; Schauder and Müller, 1993), particularly at neutral and high pH levels. The most studied sulfur reducers are neutrophiles where the enzymes that have been suggested to use polysulfide as a substrate -sulfhydrogenase ( $\mathrm{SH}$ ) and polysulfide reductase (PSR) - are targeted (Macy et al., 1986). However, the instability of polysulfide at low $\mathrm{pH}$, makes it an unlikely substrate for acidophiles.

A sulfur reductase (SRE) was purified from the membrane fraction of Acidianus ambivalens, which respires elemental sulfur in a range of $\mathrm{pH}$ from 1 to 3.5 (Laska et al., 2003b). This enzyme uses elemental sulfur as a substrate and seems to be responsible for sulfur respiration at low $\mathrm{pH}$ values, where the formation of soluble intermediates, such as polysulfide is unlikely. Therefore, direct contact is hypothesized to be essential for elemental sulfur reduction at low pH (Stetter and Gaag, 1983; Pihl et al., 1989; Finster et al., 1998; Laska et al., 2003a). The mechanisms by which sulfur reducers get access to insoluble sulfur, however, are still unclear.

Although the optimum $\mathrm{pH}$ for growth of Desulfurellaceae members states around neutral values (6.0-7.0), D. acetivorans withstands $\mathrm{pH}$ as low as 4.3 for its growth. However, the ability of $D$. amilsii to thrive at very acidic conditions, $\mathrm{pH}$ as low as 3 , is unique in the Desulfurellaceae family, which makes it a potential catalyst for biotechnological processes, such as metal precipitation from acidic waste streams. To get insights into the encoded pathways for sulfur reduction by this strain, we analyzed the genome of $D$. amilsii and compared it with available genome sequences of other members within the Desulfurellaceae family. To the best of our knowledge, there is no reported study on comparative genomics of acidophilic sulfur-reducing microorganisms adapted to different conditions. 


\section{Material and Methods}

\section{Cultivation, genome sequencing and assembly}

For genome sequencing, a 500-mL culture of D. amilsii was grown on acetate and sulfur as described elsewhere (Florentino et al., 2015). Cells were harvested at the earlystationary phase, when the sulfide production in the culture reached $10 \mathrm{mM}$, by centrifuging at $19000 \mathrm{x}$ g for $20 \mathrm{~min}$. Genomic DNA was extracted using the MasterPure ${ }^{\mathrm{TM}}$ Gram Positive DNA Purification Kit (Epicentre, Madison, WI), following the instructions of the manufacturer. The genome was sequenced using the Illumina HiSeq2000 paired-end sequencing platform of GATC Biotech (Konstanz, Germany). Sequence assembly was performed using two independent assemblers: the OLC-assembler Edena (Hernandez et al., 2008) and the de-Bruijn-Graph-assembler Ray (Boisvert et al., 2010). Sets of overlapping sequences were identified from both assembling procedures and further merged into a more contiguous and consistent assembly, using the hybrid sequencing technology assembler Zorro (Argueso et al., 2009). The obtained sequences were further improved by scaffolding with Opera and by gap-closing with GapFiller (Boetzer and Pirovano, 2012). The closed gaps were manually verified.

\section{Genome annotation}

Automated annotation was performed using the RAST annotation server (Aziz et al., 2008), followed by manual curation. Additional gene prediction analysis and functional annotation were done within the Integrated Microbial Genomes - Expert Review from the DOE - Joint Genome Institute pipeline (Markowitz et al., 2014). The predicted coding sequences (CDSs) were translated into amino acid sequences and used in homology searches in the National Center for Biotechnology Information (NCBI) non-redundant database and the Uniprot, TIGRFam, Pfam, SMART, PRIAM, KEGG, COG and Interpro databases. These data sources were combined to assign a product description for each predicted protein. Clusters of regularly interspaced repeats (CRISPR) were identified via the web available tools CRISPRFinder (Grissa et al., 2007) and CRISPRTarget (Biswas et al., 2013). The N-terminal twin arginine translocation (Tat) signal peptides and the transmembrane helices were predicted using the online tools from TMHMM server v. 2.03 (http://www.cbs.dtu.dk/services/TMHMM/) and PROTTER V. 1.0 (http://wlab.ethz.ch/protter/start/). 
The Whole Genome Shotgun project of Desulfurella amilsii has been deposited at DDBJ/ENA/GenBank under the accession MDSU00000000. The version described in this paper is version MDSU01000000. The genome ID in the integrated microbial genomesexpert review (IMG) database is 2693429826.

\section{Comparative genomics}

The genome sequences used for the comparative study (and their accession numbers) were: D. acetivorans strain A63 (CP007051), D. multipotens strain RH-8 (SAMN05660835), H. maritima strain MH2 (CP002606), H. alviniae strain EP5-r (ATUV00000000), H. medeae strain KM1 (JAFP00000000), and H. jasoniae strain Mar08272r (JQLX00000000).

The average nucleotide identity analysis (ANI) between the genome dataset pairs was performed using the online tool ANI calculator, available at http://enveomics.ce.gatech.edu/ani/index. The best hits (one-way ANI) and the reciprocal best hits (two-way ANI) were considered, as calculated by (Goris et al., 2007). In silico DNA-DNA hybridization $(\mathrm{DDH})$ values were determined using the recommended settings of the Genome-to-Genome Distance Calculator (GGDC) web server version 2.0 (Meier-Kolthoff et al., 2013).

The number of genes shared between Desulfurella and Hippea species was assessed by OrthoMCL tool (Wang et al., 2015) and a Venn diagram was built using the web-based tool InteractiVenn (Heberle et al., 2015). Orthology between two genes was defined as best bidirectional hits, which were required to have at least $30 \%$ identity over at least $80 \%$ coverage of both sequences (Chen et al., 2006). All analyzed genes and predicted proteins from the Desulfurellaceae members' genomes were compared using BLAST (Altschul et al., 1990).

The genomes were compared in terms of gene content using the 'Phylogenetic Profiler for Single Genes' of JGI-IMG website (https://img.jgi.doe.gov/) to identify genes in the query genome that have homologues present or absent in other genomes. The 'Phylogenetic Profiler for Gene Cassettes' tool of the same website was also used to find part of a gene cassette in a query genome, as well as conserved part of gene cassettes in other genomes. In terms of functional capabilities, comparisons of relative abundance of protein families (COGs, Pfams, TIGRfams) across selected genomes were performed with the 'Abundance Profile Overview' and 'Function Profile' tools. The potential metabolic capabilities of genomes were compared in the context of KEGG pathways. 


\section{Results and Discussion}

\section{General characteristics of $D$. amilsii genome}

The D. amilsii genome consists of 2.010 .635 bp with a $\mathrm{G}+\mathrm{C}$ content of $33.98 \%$ $\mathrm{mol} / \mathrm{mol}$. The initial sequencing resulted in 2.287 .922 paired-end reads with a length of 301 bases, which were assembled into 20 contigs with a 687 fold coverage and a completeness of $99.9 \%$. The largest scaffold consisted of $1,269,579 \mathrm{bp}$ and the second and third largest scaffolds together consisted of $400,000 \mathrm{bp}$, covering more than $85 \%$ of the genome.

From the 2137 genes predicted by automated annotation in the genome, 49 were tRNA and rRNA genes, and 2088 protein coding genes (CDS). Two identical copies of the 16S rRNA gene (100\% similarity) were identified. From the 2088 CDS (Supplementary Table S1), 1625 were predicted to have assigned COGs function, whilst 680 could not be assigned to any function in the database, and therefore were annotated as hypothetical proteins or proteins of unknown function. No pseudo genes were detected in the genome of D. amilsii, which is a unique characteristic in the Desulfurellaceae family. Two CRISPR regions were identified in the genome of 684 bp length with 10 spacers, and 291 bp length with 4 spacers, respectively. The spacers' sequences from the first locus match viral DNA sequences found in several species, including Bacillus sp., Ralstonia sp., Shewanella sp., Acinetobacter sp., Propionibacterium sp., Campylobacter sp., Escherichia sp., Staphylococcus sp., Sphingomonas sp. and Moraxella sp. The spacers sequences related to the second locus match sequences of viral DNA also detected in Edwardsiella hoshinae, Owenweeksia hongkongensis, Parascaris equorum and Ovis canadensis species.

The genome encodes a complete tricarboxylic acid (TCA) cycle pathway (Supplementary Table S2). Besides, routes for pyruvate fermentation are encoded, and physiological tests revealed acetate, hydrogen and $\mathrm{CO}_{2}$ as the end products (Florentino et al., 2016a). D. amilsii is able to grow chemolithotrophically; the $\mathrm{CO}_{2}$ fixation could be possible via the reductive TCA cycle for which all the genes are encoded (Supplementary Table S3). The genome encodes Ni-Fe, Ni-Fe-Se, and Fe-S hydrogenases, an intracellular formate dehydrogenase and a formate-hydrogen lyase. Genes encoding for dinitrogenase iron-molybdenum cofactor, nitrogen fixation protein NifU and glutamine synthetase type I are present in the genome and might be involved in nitrogen fixation by $D$. amilsii. Sulfur and thiosulfate were reported to serve as electron acceptors for this microorganism (Florentino et al., 2015; Florentino et al., 2016a) and genes essential for sulfur and thiosulfate reduction are encoded (Supplementary Table S3). Moreover, the importance of electron transport in this microorganism is highlighted by a high number of electron transport related genes (159). Genes encoding resistance to acidic conditions (Supplementary Table S4), oxygen stress tolerance (Supplementary Table S5), and metals 
resistance (Supplementary Table S6) are also identified, which is in line with the reported ability of the microorganism to grow at $\mathrm{pH}$ as low as 3 (Florentino et al., 2016a) and in the presence of heavy metals in solution (Florentino et al., 2015).

\section{Comparative genomics}

\section{ANI and in silico DDH analysis}

ANI and in silico DDH values obtained from pairwise comparison of the available genome sequences of Desulfurellaceae family members are shown in Table 1. ANI values in the range of $\geq 95-96 \%$ correspond to $\geq 70 \%$ DDH standard for species definition (Goris et al., 2007). In general, the values are consistent with their phylogenetic relationships. While the taxonomic status of D. amilsii is well supported by the genomic signatures analysis, ANI and DDH values of D. multipotens and D. acetivorans were $98.6 \%$ and $88.1 \%$ respectively, surpassing the thresholds for species definition. The wet lab DNADNA hybridization experiment reported a borderline value of $69 \pm 2 \%$ (Miroshnichenko et al., 1994) and the phylogenetic reconstruction of the Desulfurella genus shown by Florentino et al. (2016a) revealed more than $99.9 \%$ shared identity of $16 \mathrm{~S}$ rRNA sequences for the two strains, while all the other members of the Desulfurellaceae family shared 92.197.7\% identity (Supplementary Table S7).

Table 1 - Average nucleotide identity and in silico DNA-DNA hybridization pairwise comparison of the available genomes sequences of Desulfurellaceae family. Dam $-D$. amilsii; Dac - D. acetivorans; Dmu - D. multipotens; Hma - H. maritima; Hme $-H$. medeae; Hal $-H$. alviniae; $\mathrm{Hja}-H$. jasoniae. The table is split by the empty diagonal cells; the ANI values are shown on the upper side and the in silico DDH values are shown on the lower side.

\begin{tabular}{|c|c|c|c|c|c|c|c|}
\hline \multicolumn{8}{|c|}{ Average Nucleotide Identity (ANI) } \\
\hline & Dam & Dac & Dmu & Hma & Hme & Hal & Hja \\
\hline 1 & & 80.0 & 80.0 & 68.4 & 67.5 & $68.7( \pm 0.1)$ & 68.4 \\
\hline 2 & $21.9( \pm 2.4)$ & & 98.6 & $68.9( \pm 0.1)$ & $69.1( \pm 0.2)$ & 69.8 & 69.1 \\
\hline 3 & $21.8( \pm 2.4)$ & $88.1( \pm 2.3)$ & & 68.8 & 67.8 & 69.4 & 69.0 \\
\hline 4 & $24.2( \pm 2.4)$ & $23.7( \pm 2.4)$ & $23.2( \pm 2.4)$ & & 78.7 & $74.0( \pm 0.1)$ & 72.9 \\
\hline 5 & $27.2( \pm 2.4)$ & $23.9( \pm 2.4)$ & $24.1( \pm 2.4)$ & $20.7( \pm 2.3)$ & & 73.4 & 72.6 \\
\hline 6 & $21.6( \pm 2.4)$ & $17.4( \pm 2.2)$ & $17.0( \pm 2.2)$ & $16.9( \pm 2.2)$ & $12.9( \pm 2.5)$ & & 73.1 \\
\hline 7 & $16.5( \pm 6.4)$ & $14.9( \pm 3.5)$ & $14.9( \pm 3.5)$ & $16.1( \pm 1.0)$ & $15.8( \pm 1.4)$ & $16.3( \pm 0.7)$ & \\
\hline
\end{tabular}

Standard deviation values derived from bi-directional calculation are shown in brackets when they differed from 0 . 
The physiological characterization of these two strains revealed different abilities to utilize butyrate and $\mathrm{H}_{2}$ as electron donors, which are oxidized by $D$. multipotens (Miroshnichenko et al., 1994) but not by D. acetivorans (Bonch-Osmolovskaya et al., 1990). Furthermore, the generation time was shown to be 2 hours for D. acetivorans, while it was 5 hours for $D$. multipotens, although generation time can generally vary with the growth conditions. The optimum range of temperature for growth ranged from $52-55^{\circ} \mathrm{C}$ in D. acetivorans (Bonch-Osmolovskaya et al., 1990) to $58-60^{\circ} \mathrm{C}$ in D. multipotens (Miroshnichenko et al., 1994). No chemotaxonomic information is provided in the characterization manuscripts of the mentioned strains. Although the characterization studies showed a $\mathrm{G}+\mathrm{C}$ content of $31.4 \% \mathrm{~mol} / \mathrm{mol}$ for D. acetivorans (Bonch-Osmolovskaya et al., 1990) and $33.5 \% \mathrm{~mol} / \mathrm{mol}$ for D. multipotens (Miroshnichenko et al., 1994), the G+C content calculation based on the genome sequences shows no difference between them, with $32 \% \mathrm{~mol} / \mathrm{mol}$ of $\mathrm{G}+\mathrm{C}$ content. Despite the different physiological characteristics mentioned, the mentioned ANI values combined with an in silico DDH evaluation and a phylogenetic analysis of the 16S rRNA sequences support the similarity of both strains. Therefore, D. multipotens and D. acetivorans might belong to the same species and should be reclassified. Due to this finding, the comparative genomics described in this manuscript was performed with $D$. acetivorans as representative of $D$. multipotens, as it was the first species described and so represents the type strain of the genus.

In general, members of the Desulfurellaceae family possess a small genome, ranging from 1.7 to $2.0 \mathrm{Mbp}$ of which more than $93 \%$ represent DNA coding regions, $80 \%$ of proteins with a predicted function and $70 \%$ of clusters of orthologous groups of proteins (COGs). General features of the genomes are compared in Table 2. In total, 2738 clusters of orthologous groups with functional prediction were found within the 6 members studied as shown in a Venn-diagram (Figure 1). The core genome consisted of 1073 shared sequences, 411 sequences shared by both Desulfurella genomes and 250 shared within the Hippea genus. D. amilsii showed the biggest genome size in the family and the biggest number of unique genes encoded, 283 (Supplementary Table S8), from which 62\% are related to hypothetical proteins. Divergences in unique and shared gene sets might also explain other differences that have been found when conducting comparative studies on metabolism among the species, especially with respect to enzymes involved in sulfur reduction, sulfur disproportionation, pyruvate fermentation, and formate utilization. 


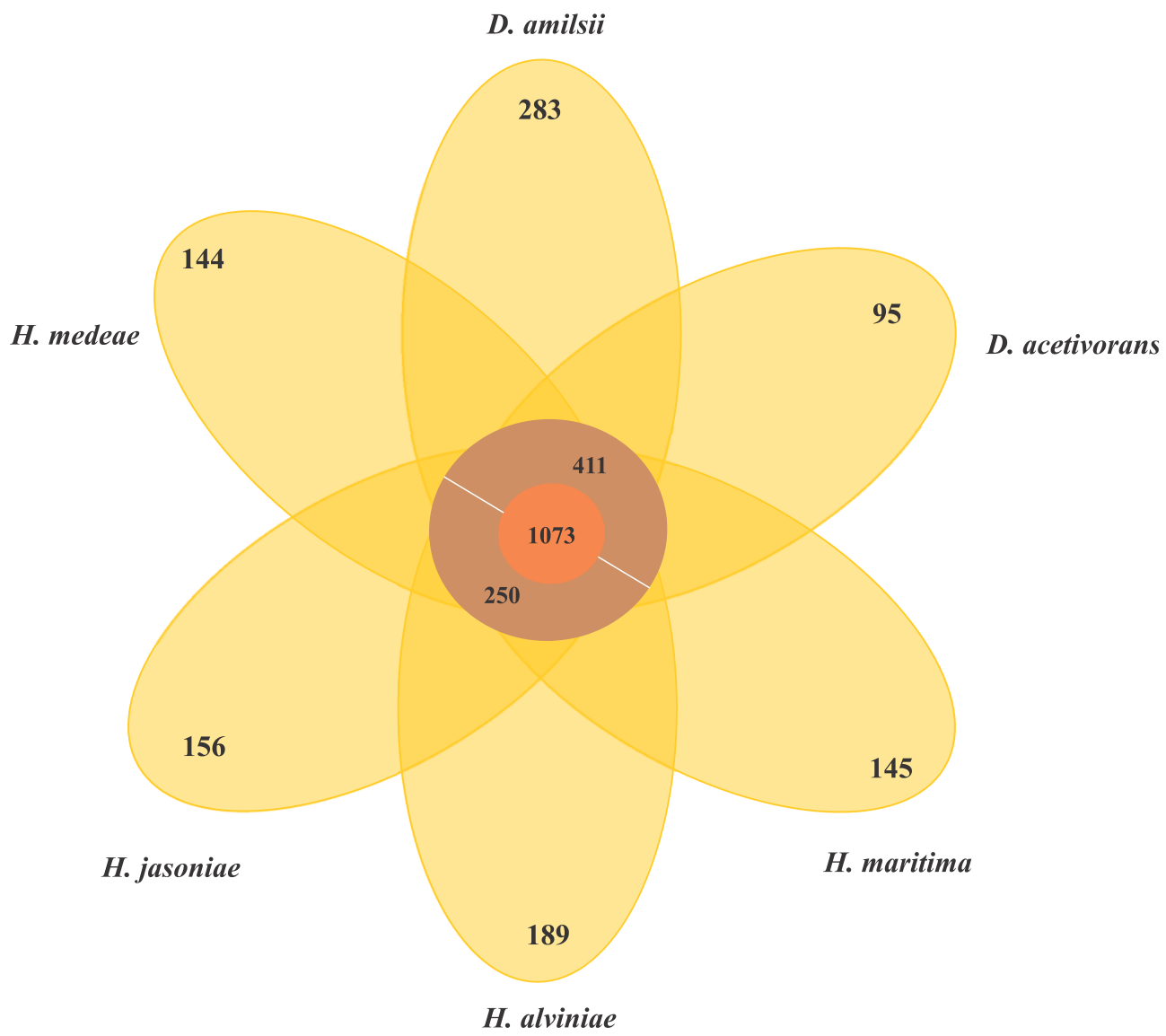

Figure 1 - Venn-diagram of the orthologous clusters of genes for Desulfurellaceae family members.

\section{Sulfur reduction and energy conservation}

The electron transport chain in sulfur reducers normally links hydrogenases or dehydrogenases to membrane bound or cytoplasmic sulfur/polysulfide reductases (Laska et al., 2003a; Fauque and Barton, 2012; Florentino et al., 2016c). However, the electrontransfer pathways in the microorganisms analyzed here are not yet fully understood.

Sulfur metabolism in Desulfurellaceae members is quite diverse, as genes encoding for at least three enzymes involved in sulfur reduction are present in the group. Sulfur, sulfide and polysulfide are present in solution in a pH-dependent equilibrium $\left(H S^{-}+\frac{x-1}{8} S_{8} \leftrightarrow S_{n}^{2-}+H^{+}\right)$. At higher $\mathrm{pH}$ values, polysulfide is present as the dominant form, while at low $\mathrm{pH}$ values elemental sulfur prevails (Kleinjan et al., 2005). 
Table 2 - General genome features of Desulfurellaceae members.

\begin{tabular}{|c|c|c|c|c|c|c|}
\hline Features & $\begin{array}{c}\text { D. } \\
\text { amilsii }\end{array}$ & $\begin{array}{c}D . \\
\text { acetivorans }\end{array}$ & $\begin{array}{c}H . \\
\text { maritima }\end{array}$ & $\begin{array}{c}H . \\
\text { alviniae }\end{array}$ & $\begin{array}{c}H . \\
\text { medeae }\end{array}$ & $\begin{array}{c}H . \\
\text { jasoniae }\end{array}$ \\
\hline Strain & TR1 & A63 & $\mathrm{MH} 2$ & EP5-r & KM1 & Mar08-272r \\
\hline DSM number & 29984 & 5264 & 10411 & 24586 & - & 24585 \\
\hline $\begin{array}{c}\text { Genome size } \\
\text { (Mbp) }\end{array}$ & 2.0 & 1.8 & 1.7 & 1.7 & 1.7 & 1.7 \\
\hline $\begin{array}{c}\text { Completeness } \\
(\%)\end{array}$ & 99.9 & 100 & 99.1 & 72.6 & 99.1 & 100 \\
\hline DNA coding & 1877485 & 1731246 & 1624527 & 1672554 & $\begin{array}{c}166946 \\
3\end{array}$ & 1655666 \\
\hline $\mathrm{G}+\mathrm{C}(\%)$ & 33.98 & 32.08 & 37.47 & 37.03 & 42.85 & 37.00 \\
\hline Scaffolds & 20 & 2 & 1 & 4 & 1 & 18 \\
\hline Total genes & 2135 & 1875 & 1780 & 1814 & 1776 & 1768 \\
\hline CDS & 2086 & 1819 & 1723 & 1757 & 1719 & 1710 \\
\hline RNA genes & 49 & 56 & 57 & 57 & 57 & 58 \\
\hline tRNA genes & 45 & 48 & 48 & 46 & 48 & 46 \\
\hline Pseudo genes & - & 53 & 46 & 39 & 23 & 11 \\
\hline $\begin{array}{c}\text { Function } \\
\text { prediction }\end{array}$ & 1723 & 1586 & 1498 & 1477 & 1499 & 1495 \\
\hline COGs & 1456 & 1402 & 1287 & 1327 & 1320 & 1306 \\
\hline Pfam domains & 1719 & 1633 & 1529 & 1535 & 1541 & 1536 \\
\hline $\begin{array}{c}\text { CRISPR } \\
\text { counts } \\
\end{array}$ & 2 & 3 & - & 1 & 4 & - \\
\hline
\end{tabular}

Hippea species genomes possess genes encoding for the membrane bound polysulfide reductase (PSR), an integral membrane protein complex responsible for quinone oxidation coupled to polysulfide reduction, and the cytoplasmic sulfide dehydrogenase (SUDH), reported to catalyze the reduction of polysulfide to hydrogen sulfide with NADPH as the electron donor (Macy et al., 1986; Ma et al., 2000). The domains $4 \mathrm{Fe}-4 \mathrm{~S}, 4 \mathrm{Fe}-\mathrm{S}$ Mo-bis of the catalytic subunit and $\mathrm{Nfr}$ of the membrane-bound subunit with 9 transmembrane helices of the polysulfide reductase are conserved in all the Hippea species. The pH range for growth of Hippea species (Miroshnichenko et al., 1999; Flores et al., 2012) supports the hypothesis of sulfur reduction through polysulfide in these microorganisms.

The alpha and beta subunits of the sulfide dehydrogenase encoded in all genomes of the Desulfurellaceae family show domains conserved in all the microorganisms: NADbinding and iron-sulfur clusters $(3 \mathrm{Fe}-4 \mathrm{~S}$ and $4 \mathrm{Fe}-4 \mathrm{~S})$ domains in the subunit SudhA and FAD-binding and iron-sulfur cluster $2 \mathrm{Fe}-2 \mathrm{~S}$ domains in the subunit SudhB. In $D$. acetivorans, only SUDH-coding genes are present (Desace_0075-0076), which would suggest that polysulfide is the terminal electron acceptor in its respiration process. $D$. amilsii is unique as, in addition to SUDH (DESAMIL20_1852-1853), sulfur reductase (SRE) is encoded (DESAMIL20_1357-1361). A SRE was isolated from the acidophile 
Acidianus ambivalens, and its subunits were partially characterized and compared to their homologous in the polysulfide reductase isolated from Wolinella succinogenes (Laska et al., 2003b). SRE is reported to be involved in direct reduction of elemental sulfur, with the electrons being donated by hydrogenase, quinones and cytochrome $c$. SRE also uses NADPH as an electron donor, but at low activity (Laska et al., 2003a). The sulfur reductase encoded in the D. amilsii genome presents, in general, conserved domains for four of its subunits. The membrane anchor subunit (SreC), with nine transmembrane helices, has a polysulfide reductase domain (Figure 2) similar to the one encoded in A. ambivalens, which was shown by Laska et al. (2003b) to be phylogenetically unrelated to the analogous $W$. succinogenes protein. The catalytic subunit (SreA) contains the conserved molybdopterin domain, predicted to be functional with respect to oxidoreductase activity. The sequence, however, does not present a twin-arginine motif and so, in contrary to the sulfur reductase from A. ambivalens, it might be cytoplasm oriented. The subunit SreB also presents the $4 \mathrm{Fe}-4 \mathrm{~S}$ domain conserved, which has a high degree of sequence similarity to Mo-FeS enzymes of the DMSO reductase family. The subunit SreD in D. amilsii does not contain the conserved $4 \mathrm{Fe}-4 \mathrm{~S}$ domain; but its function in sulfur respiration is not yet clear (Laska et al., 2003b). The sreE gene encodes a protein of 209 aa length with similarity to reductase assembly proteins required either for the assembly of the Mo-containing large subunit of DMSO reductase or nitrate reductase (Blasco et al., 1998; Ray et al., 2003).

Since the reduction of elemental sulfur through polysulfide is unlikely at low $\mathrm{pH}$, The enzyme sulfide dehydrogenase isolated from Pyrococcus furiosus was reported to show sulfur reductase activity in vitro. However, the expression of its coding-genes also correlated to the carbon source rather than to elemental sulfur/polysulfide, especially when its intracellular concentration is below $1.25 \mathrm{mM}$ (Ma and Adams, 2001). It is likely that this enzyme acts in vivo as a ferredoxin:NADPH oxidoreductase (NfnAB). In this case, in Hippea species, the sulfur reduction process might be carried out by the polysulfide reductase. In $D$. amilsii, the encoded sulfur reductase might play a role in sulfur respiration. However, this enzyme is not encoded in D. acetivorans and so, thiosulfate sulfurtransferases with rhodanese domains, exclusively encoded in Desulfurella species, might play an essential role in the process. In Figure 2, a metabolic reconstruction of the possible sulfur reduction pathways in $D$. amilsii is depicted. 


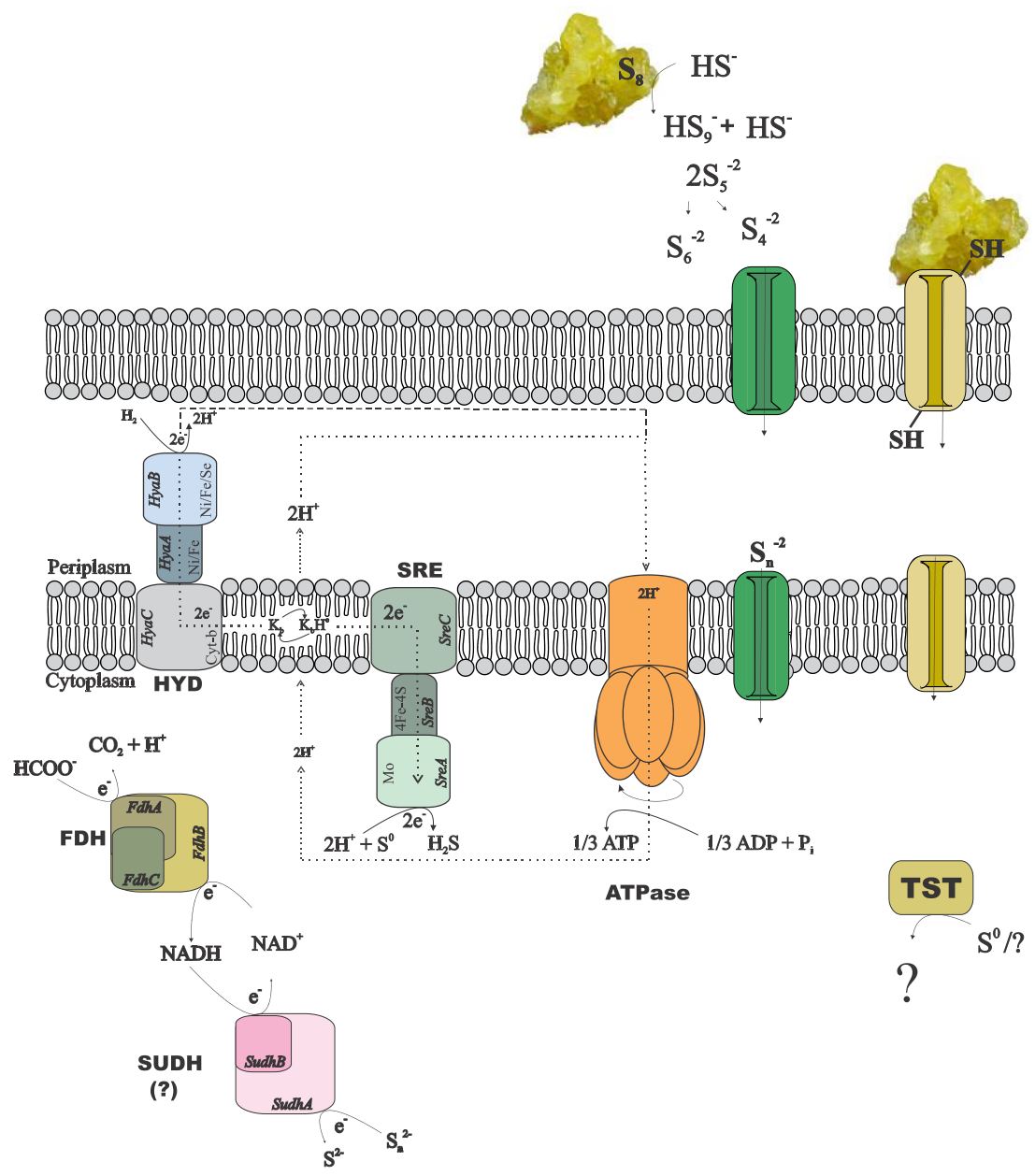

Figure 2 - Possible mechanisms of sulfur/polysulfide respiration in Desulfurella amilsii. During chemolithotrophic growth, hydrogenases (HYD) might transfer electrons to sulfur reductase (SRE) via menaquinones $(\mathrm{K})$ encoded in the genome, and protons to an encoded ATPase, creating a proton motive force. If sulfide dehydrogenase (SUDH) plays a role in sulfur respiration, its cytoplasmic nature hampers the generation of proton motive force by any conventional mechanisms and therefore, it is likely that the membrane-bound hydrogenases pump protons out of the cell to generate a gradient. In case of formate used as electron donor, the intracellular formate dehydrogenase (FDH) encoded might transfer electrons to $\mathrm{SUDH}$, with $\mathrm{NAD}^{+} / \mathrm{NADH}$ as intermediates. Moreover, rhodanese-like proteins (TST) encoded in the genome might have a role in the process, but its performance in sulfur-respiring microorganisms is not yet clearly understood.

D. amilsii is able to use thiosulfate as a terminal electron acceptor in a range of $\mathrm{pH}$ from 5 to 7, an ability not reported for any of the other analyzed genomes of the members of Desulfurellaceae. Although D. propionica was also shown in vivo to utilize thiosulfate as an electron acceptor, its genome sequence is not yet available. The known pathway of 
thiosulfate reduction refers to a two-step process, involving the enzymes thiosulfate reductase and the dissimilatory sulfite reductase (Stoffels et al., 2012). The first is reported to be involved in the conversion of thiosulfate into sulfide and sulfite, which can be toxic for most microorganisms. The dissimilatory reductase converts the generated sulfite into sulfide, eliminating the toxicity of sulfite from the medium. In D. amilsii, it is likely that thiosulfate respiration occurs via this pathway, as the thiosulfate reductase, the dissimilatory sulfite reductase (DsrAB), the DsrC protein and the subunits DsrM and DsrK of the Dsr MKJOP complex are encoded in the genome. The genome of $D$. acetivorans encodes a thiosulfate reductase and the dissimilatory sulfite reductase, but subunits of the Dsr MKJOP transmembrane complex and the DsrC protein are not encoded. Therefore, the absence of subunits of Dsr MKJOP and DsrC might explain the inability of D. acetivorans to respire thiosulfate. Table 3 summarizes the enzymes involved in sulfur and thiosulfate respiration, with their respective reactions and the orthologues genes.

Desulfurella species grow and produce sulfide and sulfate from sulfur in the absence of an organic electron donor (Florentino et al., 2016a), in a specific redox reaction that undergoes oxidation and reduction, also called disproportionation. Sulfur could be converted into sulfide via a sulfur-reducing enzyme (e.g.: SRE/SUDH) and to sulfite by an unidentified enzyme. In general, the sulfite could be oxidized to sulfate by sulfite oxidoreductase (SUOR) or adenosine-5'-phosphosulfate (APS) reductase, with ATP sulfurylase or adenylylsulfate:phosphate adenylyltransferase (APAT) being involved (Finster et al., 1998;Frederiksen and Finster, 2003;Hardisty et al., 2013). Although the enzyme responsible for the conversion of sulfur into sulfite is not known, SUDH/SRE and DSR coding genes were detected in both Desulfurella members' genomes, suggesting that these bacteria might disproportionate elemental sulfur using this pathway. APS reductase was not detected in any species, which supports the inability of this group to use sulfate as electron acceptor or to disproportionate elemental sulfur via the reverse pathway from sulfite to APS and then to sulfate.

Sulfur metabolism in Desulfurellaceae family members is quite diverse. The presence of unique proteins in $D$. amilsii might explain its ability to respire elemental sulfur at low $\mathrm{pH}$, where polysulfide is not available. The ability of $D$. amilsii to respire thiosulfate in a two-step process is also unique among the analyzed members of the family. Besides, disproportionation appears as a feature only shared by members of Desulfurella genus, and so this genus, with a more versatile metabolism, offers more possibilities for biotechnological application based on sulfidogenesis. 
Table 3 - Enzymes, reactions and occurrence of orthologous genes involved in elemental sulfur and thiosulfate respiration in Desulfurellaceae family. Dam - D. amilsii; Dac - D. acetivorans; $\mathrm{Hma}-H$. maritima; $\mathrm{Hja}-H$. jasoniae, $\mathrm{Hal}-H$. alviniae; $\mathrm{Hme}-H$. medeae.

\begin{tabular}{|c|c|c|c|c|c|c|c|c|}
\hline \multirow[b]{2}{*}{ Enzyme } & \multirow[b]{2}{*}{ Reaction } & \multicolumn{7}{|c|}{ Occurrence of orthologous genes } \\
\hline & & $\begin{array}{l}\text { Sub } \\
\text { units }\end{array}$ & Dam & Dac & Hma & Hja & Hal & Hme \\
\hline \multirow{3}{*}{$\begin{array}{l}\text { Polysulfide } \\
\text { reductase }\end{array}$} & \multirow{3}{*}{$S_{n}^{2-} \rightarrow S^{2-}+S_{n-1}^{2-}$} & PsrA & - & - & 0433 & $\begin{array}{c}137 \\
0\end{array}$ & 0846 & 0560 \\
\hline & & PsrB & - & - & 0434 & $\begin{array}{c}137 \\
1\end{array}$ & 0847 & 0561 \\
\hline & & PsrC & - & - & 0435 & $\begin{array}{c}137 \\
2\end{array}$ & 0848 & 0562 \\
\hline \multirow{2}{*}{$\begin{array}{c}\text { Sulfide } \\
\text { dehydroge } \\
\text { nase }\end{array}$} & \multirow{2}{*}{$S_{n}^{2-} \rightarrow S^{2-}+S_{n-1}^{2-}$} & SudhA & 1853 & 0076 & 0231 & $\begin{array}{c}160 \\
1\end{array}$ & 1361 & 1618 \\
\hline & & SudhB & 1852 & 0075 & 0230 & $\begin{array}{c}160 \\
0\end{array}$ & 1360 & 1617 \\
\hline \multirow{5}{*}{$\begin{array}{l}\text { Sulfur } \\
\text { reductase }\end{array}$} & \multirow{5}{*}{$S^{0} \rightarrow S^{2-}$} & SreA & 1359 & - & - & - & - & - \\
\hline & & SreB & 1357 & - & - & - & - & - \\
\hline & & SreC & 1358 & - & - & - & - & - \\
\hline & & SreD & 1360 & - & - & - & - & - \\
\hline & & SreE & 1361 & - & - & - & - & - \\
\hline \multirow{3}{*}{$\begin{array}{l}\text { Thiosulfate } \\
\text { reductase }\end{array}$} & \multirow{3}{*}{$\mathrm{S}_{2} \mathrm{O}_{3}^{2-} \rightarrow \mathrm{S}^{2-}+\mathrm{SO}_{3}^{2-}$} & PhsA & 9 & 1254 & 0433 & $\begin{array}{c}117 \\
1 \\
\end{array}$ & 1675 & 0227 \\
\hline & & $\mathrm{PhsB}$ & 8 & 1253 & - & - & - & - \\
\hline & & $\mathrm{PhsC}$ & 10 & 1255 & - & $\begin{array}{c}117 \\
2 \\
\end{array}$ & 1676 & 0228 \\
\hline \multirow{2}{*}{$\begin{array}{c}\text { Sulfite } \\
\text { reductase }\end{array}$} & \multirow{5}{*}{$\mathrm{SO}_{3}^{2-} \rightarrow \mathrm{S}^{2-}$} & DsrA & 1435 & 1402 & - & - & - & - \\
\hline & & DsrB & 1434 & 1401 & - & - & - & - \\
\hline DsrC & & DsrC & $\begin{array}{l}1431, \\
2056 \\
\end{array}$ & - & - & - & - & - \\
\hline \multirow{2}{*}{$\begin{array}{l}\text { Complex } \\
\text { Dsr MK }\end{array}$} & & $\begin{array}{c}\text { Dsr } \\
M\end{array}$ & 1430 & - & - & - & - & - \\
\hline & & DsrK & 1429 & - & - & - & - & - \\
\hline
\end{tabular}

The prefix of the locus tags for the analysed species are: DESAMIL20_(D. amilsii); Desace_(D. acetivorans); Hipma_ (H. maritima); EK17DRAFT_ (H. jasoniae); $\mathrm{G}_{415 \mathrm{DRAFT}}$ (H. alviniae) and D891DRAFT_ $H$. medeae). To avoid repetition of the prefix in the table, all the locus tags are represented only by the specific identifier.* Possibly functioning as bifurcating/confurcating enzyme.

Sulfur metabolism in Desulfurellaceae family members is quite diverse. The presence of unique proteins in $D$. amilsii might explain its ability to respire elemental sulfur at low $\mathrm{pH}$, where polysulfide is not available. The ability of $D$. amilsii to respire thiosulfate in a two-step process is also unique among the analyzed members of the family. Besides, disproportionation appears as a feature only shared by members of Desulfurella genus, and so this genus, with a more versatile metabolism, offers more possibilities for biotechnological application based on sulfidogenesis. 


\section{Other aspects of Desulfurellaceae members' metabolism}

Enzymes involved in the central carbon metabolism of Desulfurellaceae members are listed in Supplementary Table S2 and the ones involved in energy metabolism and conservation are listed in Supplementary Table S3. The general metabolic reconstruction of D. amilsii is depicted in Figure 3, in which the differential central carbon metabolism for Desulfurellaceae members can also be seen. Proteins for complete Embden-MeyerhofParnas and oxidative TCA cycle pathways are encoded in all the genomes of the Desulfurellaceae members, as well as decarboxylating malate dehydrogenase (ME), which can catalyze the reversible conversion of malate to pyruvate. Although the malate dehydrogenase is present, malate transporters are not encoded in the genome of the analyzed Desulfurella genus members, which might explain their inability to use malate as an electron donor for growth.

Besides the conversion of phosphoenolpyruvate to pyruvate via pyruvate kinase (PYK) and the irreversible carboxylation of pyruvate to form oxaloacetate via pyruvate carboxylase (PYC) common for all Desulfurellaceae members, Desulfurella and $H$. jasoniae genomes also encode the phosphoenolpyruvate carboxylase (PCK). Pyruvate:ferredoxin oxidoreductase (PFOR) and related 2-oxoacid:ferredoxin oxidoreductases are encoded in all the genomes in the group, where pyruvate oxidation is a main intermediate metabolic reaction. Moreover, all the genomes possess the gene encoding pyruvate:formate lyase (PFL), involved in pyruvate metabolism and leading to the production of acetyl-CoA and formate. D. amilsii and D. acetivorans were shown to ferment pyruvate in laboratorial analyses, but formate could only be used as an electron donor by D. amilsii (Florentino et al., 2016a), despite the subunits FdoG, FdoH and FdoI of a formate dehydrogenase (FDH) being encoded in D. acetivorans genome.

All members of the Desulfurellaceae family can utilize acetate (Florentino et al., 2016a). The metabolism of acetate starts with its activation to acetyl-CoA, an essential intermediate of various anabolic and catabolic pathways in all forms of life (Ingram-Smith et al., 2006). Acetate activation involves either the enzymes acetyl-CoA synthetase (ACS), acetate kinase (ACK) in combination with phosphate acetyltransferase (PTA), or the enzyme succinyl-CoA: acetate CoA-transferase (SCACT). All Desulfurellaceae species have the enzyme ACS encoded in their genome. In Desulfurella species, however, acetylCoA could also be generated from acetate via acetylphosphate involving ACK and PTA. The genome analysis shows both pathways for acetate oxidation are encoded in Desulfurella species. However, experimental studies performed by Schmitz et al. (1990) showed that cell extracts of $D$. acetivorans had high specific activities of ACK $(5 \mathrm{U} / \mathrm{mg})$ and PTA (14 U/mg), but no activity of the alternative ACS nor the SCACT. Although Goevert and Conrad (2010) demonstrated acetate activation via ACK and its metabolization 
via the TCA cycle in $H$. maritima, genes encoding ACK are not found in any Hippea members' genome.

Chemolithotrophic growth of Desulfurellaceae members with $\mathrm{H}_{2}$ as electron donor and $S^{0}$ as electron acceptor requires at least two enzymes in a short electron transport chain composed by a hydrogenase, an electron carrier, and a sulfur/polysulfide reductase. Only one Ni-Fe type hydrogenase (HybABC), which catalyzes reversible hydrogen production/consumption, is encoded in Desulfurellaceae members together with its maturation protein HypABCDEF (Supplementary Table S3). The subunit HybB is embedded in the membrane and the subunit HybA possess a tat signal, therefore the hydrogenase is membrane-bound facing periplasm. The hydrogen is converted into protons, creating proton motive force and electrons which are transferred via intramembrane electron carriers, such as the encoded menaquinone, to the membrane bound SRE or PSR, or to the cytoplasmic SUDH.

Although physiological tests revealed some differences among the studied species, the comparative genomic analysis on the general metabolism of Desulfurellaceae members does not show great divergence in gene sets involved in chemolithotrophic growth, TCA cycle and pyruvate fermentation. However, the utilization of acetate might have different routes of metabolization by the two analyzed genera.

Figure 3 - Metabolic reconstruction of D. amilsii. Acetate, hydrogen or formate are possible electron donors for the given scheme while sulfur or thiosulfate are reflected as electron acceptors. The amino acids, cations and phosphate transporters encoded in the genome and likely involved in resistance to stress conditions are also depicted. ACK acetate kinase; ACLY - ATP citrate lyase; ACS - acetyl-CoA synthetase; CS - citrate synthase; DSR - Dissimilatory sulfite reductase; FDH - formate dehydrogenase; FH fumarate hydratase; FHL - formate hydrogen lyase; FRD - fumarate reductase; HYDhydrogenase; ICL - Isocitrate lyase; IDH - Isocitrate dehydrogenase; KGD- $\alpha$-ketoglutarate dehydrogenase; MDH - malate dehydrogenase; ME - malic enzymes; MK - menaquinone; PCK - phosphoenolpyruvate carboxinase; PFL - pyruvate:formate lyase; PFOR pyruvate:ferredoxin oxidoreductase; PHS - thiosulfate reductase; PPDK pyruvate phosphate dikinase; PTA - phosphotransacetylase; PYC - pyruvate carboxylase; PYK - pyruvate kinase; PYS - Pyruvate synthase; SCS - Succinyl-CoA synthetase; SQR Succinate-coenzyme Q reductase; SRE - sulfur reductase; SUDH - sulfide dehydrogenase; SUOR - sulfite oxidoreductase; TST - thiosulfate sulfurtransferase. The central carbon metabolism in the figure can be extended to all the members of Desulfurellaceae family, as most of the features are conserved among the species. The dashed lines represent exclusive possible conversions for Desulfurella species and the solid lines represent possible conversions common to all members of the studied family. 


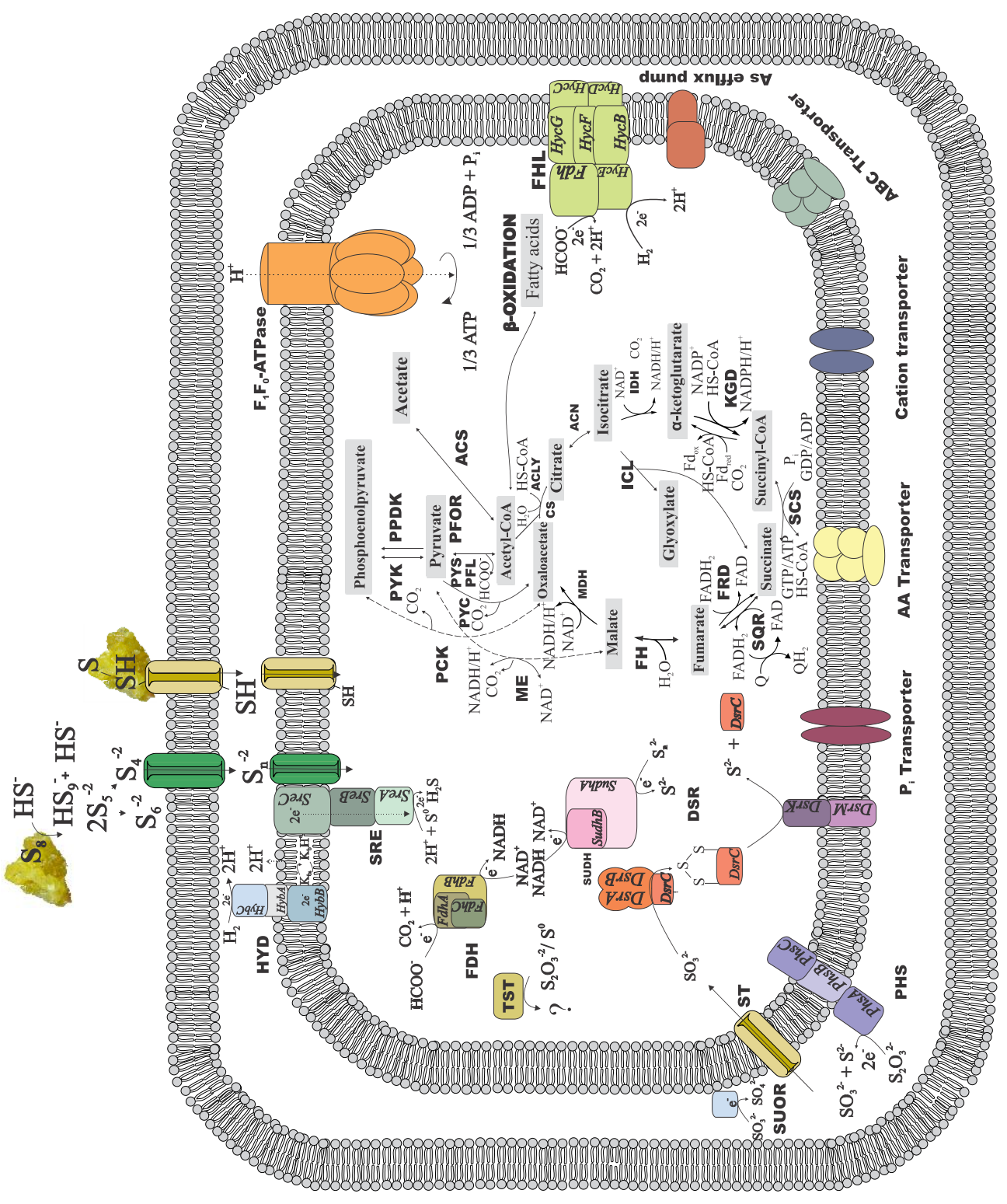




\section{Resistance mechanisms at low pH}

Acidophiles and acidotolerant microorganisms can have a broad range of adaptation mechanisms to thrive at acidic environments, while ensuring higher cytoplasmic $\mathrm{pH}$ values than the surrounding environment (Baker-Austin and Dopson, 2007).

It is predicted that Desulfurella species can synthesize degradative arginine decarboxylase to consume intracellular protons via the amino acid decarboxylation reaction and, consequently, neutralize the medium. Moreover, the analyzed Desulfurella species encode the $\mathrm{K}^{+}$-transporting ATPase and a putative regulating histidine kinase, involved in the generation of positive internal membrane potential by influx of potassium ions in order to inhibit the flux of protons (Dopson and Johnson, 2012). ABC phosphate transporters, sodium-coupled antiporters and amino acid antiporters that are $\mathrm{pH}$ dependent (Kanjee and Houry, 2013) and related to acid resistance are also encoded in the referred genomes (Supplementary Table S4). The genomic components potentially involved in stress response to acidic environments in Desulfurellaceae members are listed in supplementary Table S4.

The ability of Desulfurella species to thrive at low $\mathrm{pH}$ using acetate as an electron donor requires resistance mechanisms. When the $\mathrm{pH}$ of the medium is lower than the $\mathrm{pKa}$ value of acetic acid (4.75), the weak organic acid prevails in its protonated form, which crosses the cytoplasmic membrane by diffusion. At neutral cytoplasmic $\mathrm{pH}$, the acid dissociates, leading to the release of protons and respective anions, resulting in the acidification of the cytoplasm (Holyoak et al., 1996). Desulfurella species genomes encode the ATP-binding cassette transporter (AatA) reported to be involved in acetic acid resistance in acetic acid bacteria (Nakano et al., 2006). This putative ABC transporter contains two $\mathrm{ABC}$ motifs in tandem on a single polypeptide, which possibly serves as an exporter of acetic acid, maintaining a low level of intracellular acetic acid concentration (Nakano et al., 2006).

The genes encoded in Desulfurellaceae family members possibly involved in resistance to low $\mathrm{pH}$ do not vary. However physiological tests showed the ability of Desulfurella species to grow at more acidic environments, with $D$. amilsii being able to grow at $\mathrm{pH}$ as low as 3 (Florentino et al., 2016a) and D. acetivorans at $\mathrm{pH} 4.3$ (BonchOsmolovskaya et al., 1990). Different regulation of those genes, or a completely unknown mechanism encoded in those microorganisms, might be key to explain the differences in resistance of high proton concentrations.

\section{Response to oxidative stress}

Survival of strict anaerobic microorganisms, such as the members of the Desulfurellaceae family, in environments exposed to high redox potential would include 
antioxidant strategies. Furthermore, the acidotolerant $D$. amilsii was isolated from acidic sediments from the Tinto river which possess zones with very high redox conditions (up to $+400 \mathrm{mV}$ ) and high concentrations of soluble metals, such as copper, iron and zinc (Florentino et al., 2015). The excess of metals contributes to redox-active metals toxicity, generating reactive oxygen species (ROS) via the slow Fenton and Haber-Weiss reactions. When the oxidation states of the metal ions switches, reactive species, such as hydrogen peroxide $\left(\mathrm{H}_{2} \mathrm{O}_{2}\right)$ and superoxide $\left(\cdot \mathrm{O}^{2-}\right)$ are activated to the hydroxyl radical $(\cdot \mathrm{OH})$, resulting in a highly reactive form (Flora et al., 2008). Therefore, the presence of genes encoding oxidative stress related enzymes is of great importance for the survival of this species in its original habitat.

Superoxide reductase desulfoferrodoxin is encoded in all Desulfurellaceae members' species, as well as rubredoxin, that can transfer electrons and reduce the superoxide dismutase (Supplementary Table S5) (Sheng et al., 2014). Reduction of peroxides is performed by enzymes such as glutathione peroxidase, peroxirredoxin, rubrerythrins, alkylhydroperoxidases and catalases. Rubrerythrin is encoded in all the genomes; in Desulfurella species, $H$. alviniae and $H$. jasoniae the rubrerythrin-coding gene is flanked by a peroxiredoxin, while in $H$. maritima and $H$. medea it is flanked by a DNA repair mechanism involved in gene spore photoproduct lyase. Peroxiredoxins and thioredoxins-coding genes are present in all Desulfurellaceae genomes studied. Together with rubrerythrin and the ferric uptake regulator (Fur) family, the peroxiredoxins and thioredoxins are well-represented in acidophiles and acidotolerant microorganisms (Cárdenas et al., 2016). The rubrerythrin and the Fur family replace activities of catalase and oxidative stress response regulators in neutrophiles, while peroxiredoxins and thioredoxins remove organic peroxides originated when ROS attack organic molecules (Cárdenas et al., 2012).

Oxidizing agents normally modify the DNA in complex patterns, leading to mutagenic effects. Three different DNA repair pathways are involved in the removal of the oxidized bases in DNA and their mismatches: base excision repair (BER), nucleotide excision repair (NER) and mismatch repair (MMR). The genomes of the Desulfurella species encode DNA repair mechanisms, including the protein RecA, the excinuclease UvrABC and the GroEL protein (Supplementary Table S4). All bacterial genomes analyzed contained genes for the detection and removal of modified purine and pyrimidine bases (BER pathway), including orthologues of the uracyl-DNA glycosylase gene. The UvrABC repair system for NER pathway, which operates on the removal of bulky lesions from the DNA duplex, was present in the genome of all species. Additionally, genes responsible for the SOS response to DNA damage, RecA/RadA were found in all organisms; LexA, however, is only present in D. acetivorans. Genes encoding the Dps protein, endonucleases 
and the minimal essential complex for mismatched base repair were not detected in any of the analyzed genomes.

Despite the different isolation sources of the Desulfurellaceae members and a lack of physiological data from Hippea species and D. acetivorans, differences in genes encoding resistance to oxidative stress were not detected in the genome, and so regulatory processes might be responsible for them to tackle the harsh conditions.

\section{Metals resistance}

Several prokaryotes show specific genetic mechanisms of resistance to toxic concentrations of metals in the environment, which include their oxidation or reduction to less toxic valence states, incorporation or precipitation of heavy metals as metal sulfides complexes, and the direct transport of metals out of the membrane (Ji and Silver, 1995). Generally, the mechanisms for uptake of metals can be ATP-independent and driven by chemosmotic gradients across the membrane or is dependent on the energy released from ATP hydrolysis in a substrate-specific manner (Ahemad, 2012).

One of the ATP-based mechanisms proposed for metals resistance in bacteria is the synthesis of polyphosphates via the enzyme polyphosphate kinase, which can interact with metal ions due to its polyanion nature (Pan-Hou et al., 2002). Genes encoding the polyphosphate kinase are present in Desulfurella species and in H. maritima. D. amilsii was shown to be resistant to relatively high concentrations of copper and nickel (Florentino et al., 2015). The resistance to copper can also be related to the presence of genes encoding the copper-exporting P-type ATPase, present in all species.

Desulfurella species and $H$. maritima genomes encode the $\mathrm{Co} / \mathrm{Zn} / \mathrm{Cd}$ efflux system, components of inorganic ion transport and metabolism. Desulfurella species and $H$. alviniae encode some cation transporters (Supplementary Table S6), that are unspecific and chemiosmotic gradient driven across their cytoplasmic membrane.

Although genes encoding resistance to heavy metals are in all the analyzed species, the isolation source of $D$. amilsii is a metal rich environment, and, as many metals are more soluble at acidic $\mathrm{pH}$, this microorganism is more exposed to the high metal concentrations than the other members of Desulfurellaceae family isolated from neutrophilic environments (Bonch-Osmolovskaya et al., 1990; Miroshnichenko et al., 1999; Flores et al., 2012). Besides, as described by Dopson et al (2014), high concentrations of sulfate are also normally present in acidic environments, which can complex metal cations and lower the concentration of free metals that can enter the microbial cell cytoplasm. Therefore, it is likely that such abiotic factor, in combination with other factors, such as the competition with protons for binding sites, might contribute to the increased tolerance to metals in solution by $D$. amilsii in comparison to its neutrophilic relatives. 


\section{Concluding remarks}

Analysis of available genomes of the Desulfurellaceae family provided insight into their members' energy and carbon metabolism, helping in the elucidation of the genomic diversity in this group of microbes. Comparative genome analysis revealed that the gene content for sulfur respiration differs between genera and within the Desulfurella genus. Polysulfide reductase might be the responsible enzyme for indirect sulfur reduction in Hippea. Sulfur reductase is suggested to play a role in sulfur reduction by $D$. amilsii, especially when it grows at low $\mathrm{pH}$. Since the enzyme annotated as sulfide dehydrogenase might act as a bifurcating enzyme, respiration of elemental sulfur by Desulfurella spp. possibly occurs via other enzymes, such as the encoded rhodanese-like sulfurtransferases. Gene prediction supported by experimental analysis in Desulfurella species indicate a more versatile metabolism in this group. Although the ability to grow at extreme acidic environments is only confirmed in $D$. amilsii, great differences in the gene sets involved in the resistance to low $\mathrm{pH}$ conditions could not be detected in a comparative genome analysis. Therefore, the regulation of those genes in $D$. amilsii, or a resistance mechanism not yet known, might be responsible for the unique ability of this microorganism to survive in acidic conditions. This is the first report on comparative genomics of sulfur-reducing microorganisms able to grow at different conditions, which might help follow up analyses to broaden the knowledge on this poorly understood group of prokaryotes. Further studies need to be performed to address remaining questions about the active pathways and how environmental conditions interfere with them.

\section{Acknowledgements}

The authors thank CNPq (Conselho Nacional de Desenvolvimento Cientifíco e Tecnológico), organization of the Brazilian Government for supporting the doctoral study program for the development of Science and Technology. Research of I. Sánchez-Andrea. and A.J.M. Stams is financed by ERC grant project 323009, and Gravitation grant project 024.002.002 from The Netherlands Ministry of Education, Culture and Science. Thanks to Bastian Hornung for the bioinformatics support and to Robert Smith for the English revision. 


\section{Supplementary data}

Table S1 - Number of coding sequences assigned to COG functions for Desulfurella amilsii.

\begin{tabular}{|c|c|c|}
\hline COG category & Number of CDS & Percentage \\
\hline Amino acid transport and metabolism & 134 & 8.27 \\
\hline Carbohydrate transport and metabolism & 63 & 3.89 \\
\hline Cell cycle control, cell division, chromosome portioning & 23 & 1.42 \\
\hline Cell motility & 71 & 4.38 \\
\hline Cell wall/ membrane/ envelope biogenesis & 124 & 7.65 \\
\hline Coenzyme transport and metabolism & 118 & 7.28 \\
\hline Defense mechanisms & 26 & 1.6 \\
\hline Energy production and conversion & 159 & 9.81 \\
\hline Extracellular structures & 17 & 1.05 \\
\hline Function unknown & 52 & 3.21 \\
\hline General function predicted only & 109 & 6.72 \\
\hline Inorganic transport and metabolism & 91 & 5.61 \\
\hline Intracellular trafficking, secretion and vesicular transport & 32 & 1.97 \\
\hline Lipid transport and metabolism & 91 & 5.37 \\
\hline Mobilome: prophages, transposons & 12 & 0.74 \\
\hline Nucleotide transport and metabolism & 55 & 3.39 \\
\hline Posttranscriptional modification, protein turnover, chaperones & 72 & 4.44 \\
\hline Replication, recombination and repair & 72 & 4.44 \\
\hline Secondary metabolites biosynthesis, transport and catabolism & 17 & 1.05 \\
\hline Signal transduction mechanisms & 69 & 4.26 \\
\hline Transcription & 58 & 3.58 \\
\hline Translation, ribosomal structure and biogenesis & 160 & 9.87 \\
\hline No function & 680 & 31.84 \\
\hline
\end{tabular}


Table S2 - Enzymes involved in the central carbon metabolism of Desulfurellaceae members. Dam - D. amilsii, Dac - D. acetivorans, Hma - H. maritima, Hja - H. jasoniae, Hal - H. alviniae, Hme - H. medeae.

\begin{tabular}{|c|c|c|c|c|c|c|c|}
\hline & Dam & Dac & Hma & Hja & Hal & Hme & Dam \\
\hline & & & \multicolumn{5}{|c|}{ Embden-Meyerhof-Parnas Pathway } \\
\hline phosphoglycerate kinase & 553 & 0175 & 01309 & 0158 & 0687 & 1447 & 1655 \\
\hline $\begin{array}{c}\text { glyceraldehyde-3- } \\
\text { phosphate dehydrogenase }\end{array}$ & 554 & 0176 & 01308 & 0157 & 0686 & 1448 & 1654 \\
\hline phosphoglycerate mutase & $\begin{array}{l}558 \\
730 \\
106\end{array}$ & $\begin{array}{l}0180 \\
0837 \\
1097 \\
1209\end{array}$ & $\begin{array}{l}00482, \\
00828, \\
01304\end{array}$ & $\begin{array}{l}0199 \\
0839\end{array}$ & $\begin{array}{c}0013 \\
1208\end{array}$ & $\begin{array}{c}0355 \\
1774\end{array}$ & $\begin{array}{c}0916,1647 \\
1655\end{array}$ \\
\hline $\begin{array}{l}\text { fructose-bisphosphate } \\
\text { aldolase }\end{array}$ & $\begin{array}{l}731 \\
1935\end{array}$ & $\begin{array}{c}0029 \\
0836, \\
1097 \\
\end{array}$ & 01647 & 1172 & 0083 & 0784 & 1211 \\
\hline pyruvate kinase & 732 & 0835 & 00826 & 0462 & - & 1377 & 1337 \\
\hline $\begin{array}{c}\text { phosphopyruvate } \\
\text { hydratase }\end{array}$ & $\begin{array}{l}154 \\
1024\end{array}$ & 1049 & 00530 & 0808 & 1157 & 0689 & 0886 \\
\hline 6-phosphofructokinase & 1865 & 1829 & 01117 & 0795 & 1144 & 0702 & 0873 \\
\hline $\begin{array}{c}\text { Glucose-6-phosphate } \\
\text { isomerase }\end{array}$ & 1936 & 0030 & 01648 & 1170 & 0081 & 0782 & 1209 \\
\hline $\begin{array}{c}\text { Fructose-1,6- } \\
\text { bisphosphatase }\end{array}$ & 26 & 1193 & 01704 & 0344 & 0779 & 0381 & 0519 \\
\hline \multirow[t]{2}{*}{$\begin{array}{c}\text { Triose phosphate } \\
\text { isomerase }\end{array}$} & 553 & 0174 & 01310 & 0159 & 0688 & 1446 & 1656 \\
\hline & & & \multicolumn{5}{|c|}{ Pyruvate metabolism } \\
\hline Malate dehydrogenase & $\begin{array}{l}1542 \\
1998\end{array}$ & $\begin{array}{c}0393, \\
0423 \\
1793 \\
\end{array}$ & $\begin{array}{c}00616, \\
00646, \\
01156\end{array}$ & 0134 & 1703 & 1462 & 0580 \\
\hline Malic enzyme & 1512 & 0423 & 00646 & 0099 & 1753 & 1514 & 1738 \\
\hline pyruvate kinase & 732 & 0835 & 00826 & 0462 & - & 1377 & 1337 \\
\hline Pyruvate carboxylase & 537 & 0154 & 01331 & 0131 & 1482 & 0581 & 1706 \\
\hline $\begin{array}{l}\text { Phosphoenolpyruvate } \\
\text { carboxylase }\end{array}$ & 942 & 0682 & 00992 & - & - & 1002 & - \\
\hline $\begin{array}{c}\text { Pyruvate phosphate } \\
\text { dikinase }\end{array}$ & 1215 & 1460 & 00126 & 0076 & 1539 & 1730 & 1762 \\
\hline Pyruvate synthase & $\begin{array}{l}1627- \\
1628 \\
1974\end{array}$ & $\begin{array}{l}0299- \\
0300 \\
1025 \\
1810\end{array}$ & $\begin{array}{l}00554, \\
01137 \\
01553- \\
01554\end{array}$ & $\begin{array}{c}0589- \\
0591 \\
0797- \\
0798\end{array}$ & $\begin{array}{c}0875- \\
0876 \\
0729-0732\end{array}$ & $\begin{array}{c}0357- \\
0358, \\
1017- \\
1018, \\
1146- \\
1147\end{array}$ & $\begin{array}{c}0699-0700, \\
1021-1022\end{array}$ \\
\hline $\begin{array}{c}\text { Pyruvate- } \\
\text { ferredoxin/flavodoxin } \\
\text { oxidoreductase }\end{array}$ & $\begin{array}{l}1627- \\
1628 \\
1974\end{array}$ & $\begin{array}{l}0299- \\
0300 \\
1025 \\
1810\end{array}$ & $\begin{array}{l}00554, \\
01137 \\
01553- \\
01554\end{array}$ & $\begin{array}{c}0589- \\
0591 \\
0797- \\
0798\end{array}$ & $\begin{array}{c}0729- \\
0732 \\
0875-0876\end{array}$ & $\begin{array}{c}0357- \\
0358, \\
1017- \\
1018, \\
1146- \\
1147 \\
\end{array}$ & $\begin{array}{c}0699-0700, \\
1021-1022\end{array}$ \\
\hline Acetate kinase & 1989 & 1802 & 01147 & - & - & - & - \\
\hline Phosphotransacetylase & 1988 & 1803 & $\begin{array}{c}01145- \\
01146\end{array}$ & 0099 & 1738 & 1753 & 1514 \\
\hline Pyruvate: formate lyase & $\begin{array}{c}541, \\
1072, \\
1223, \\
1707\end{array}$ & $\begin{array}{c}0159, \\
0553, \\
0806, \\
1468, \\
1619 \\
\end{array}$ & $\begin{array}{c}00134, \\
00371, \\
00797, \\
01326, \\
01767\end{array}$ & 1145 & 0186 & 1268 & 1308 \\
\hline
\end{tabular}




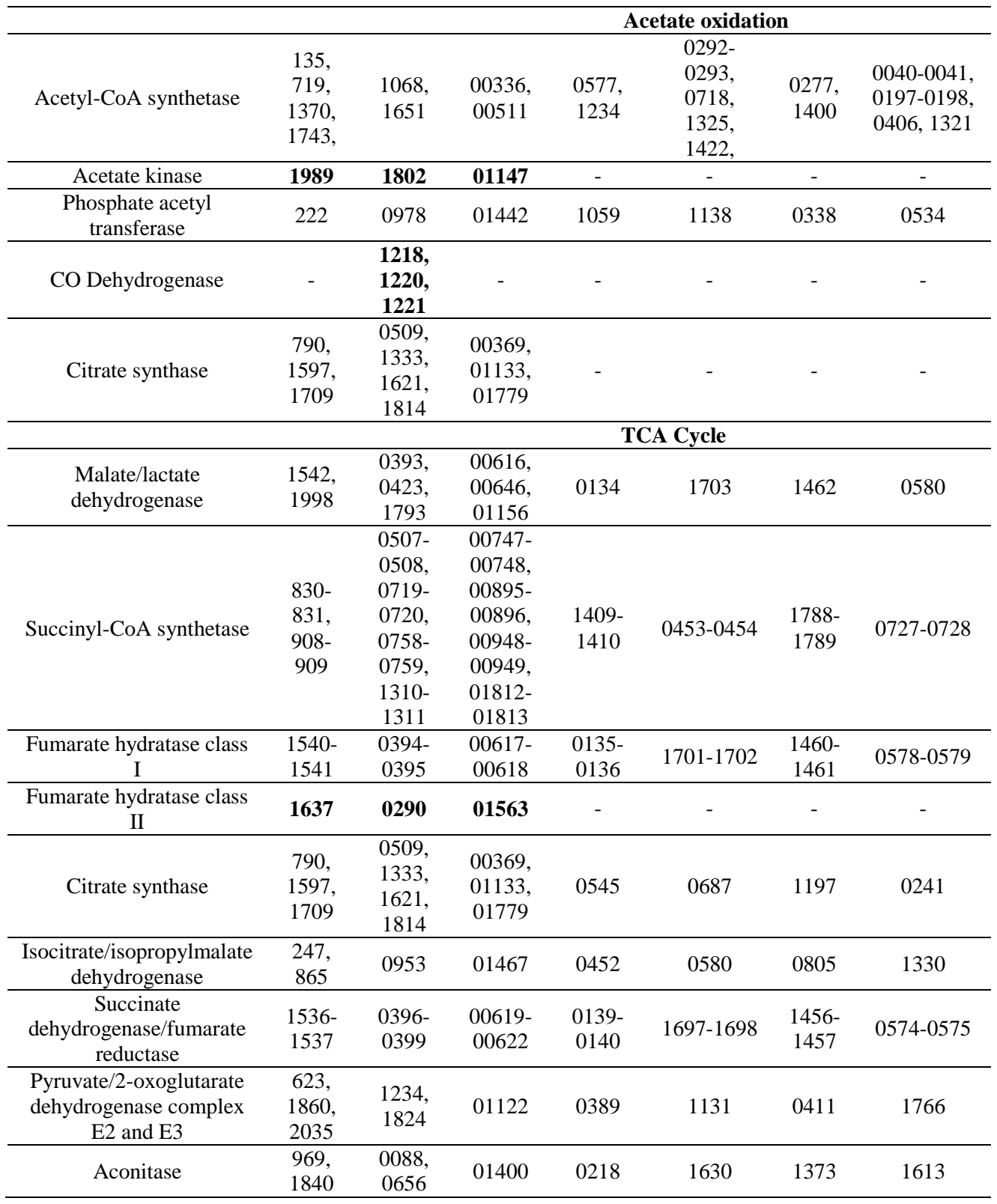


Table S3 - Enzymes involved in the energy conservation and metabolism of Desulfurellaceae members. Dam - D. amilsii, Dac - D. acetivorans, Hma - H. maritima, $\mathrm{Hja}-H$. jasoniae, $\mathrm{Hal}-H$. alviniae, Hme - H. medeae.

\begin{tabular}{|c|c|c|c|c|c|c|c|}
\hline & Dam & Dac & Hma & Hјa & Hal & Hme & Dam \\
\hline & & \multicolumn{6}{|c|}{ Electron transport chain } \\
\hline $\begin{array}{c}\text { Ni-Fe type } \\
\text { hydrogenase } \\
\text { HybABC } \\
\end{array}$ & $502-504$ & 0124-0126 & $\begin{array}{l}01359- \\
01361\end{array}$ & $\begin{array}{c}1096- \\
1098\end{array}$ & $1668-1670$ & $\begin{array}{l}0120- \\
0122\end{array}$ & $1196-1198$ \\
\hline $\begin{array}{c}\text { Hydrogenase } \\
\text { maturation protein } \\
\text { (HypABCDEF) }\end{array}$ & $\begin{array}{l}499,500 \\
505-508\end{array}$ & $\begin{array}{c}0121- \\
0123,0127- \\
0130\end{array}$ & $\begin{array}{c}01355- \\
01358, \\
01362- \\
01364\end{array}$ & $\begin{array}{l}1093- \\
1095\end{array}$ & $1665-1667$ & $\begin{array}{l}0127- \\
0129\end{array}$ & $1193-1195$ \\
\hline Fe_S hydrogenase & 510,1789 & 0132,1217 & 01353 & 1488 & 1519 & - & 0330 \\
\hline $\begin{array}{c}\text { formate } \\
\text { hydrogenlyase }\end{array}$ & $\begin{array}{c}1015- \\
1020 \\
\end{array}$ & 0604-0609 & $\begin{array}{c}01599- \\
01604\end{array}$ & $\begin{array}{l}1312- \\
1317 \\
\end{array}$ & $1467-1472$ & $\begin{array}{l}1381- \\
1386 \\
\end{array}$ & $1492-1497$ \\
\hline Menaquinone & 264 & 0937 & 01483 & 1576 & 0558 & 1708 & 0215 \\
\hline Polysulfide reductase & - & - & - & $\begin{array}{l}0434- \\
0435\end{array}$ & 1371-1372 & $\begin{array}{l}0847- \\
0848\end{array}$ & $0560-0562$ \\
\hline $\begin{array}{c}\text { Sulfide } \\
\text { dehydrogenase }\end{array}$ & $\begin{array}{c}1852- \\
1853 \\
\end{array}$ & $0075-0076$ & $\begin{array}{l}01412- \\
01413\end{array}$ & $\begin{array}{c}0230- \\
0231 \\
\end{array}$ & $1600-1601$ & $\begin{array}{c}1360- \\
1361 \\
\end{array}$ & $1617-1618$ \\
\hline Sulfur reductase & $\begin{array}{l}1357- \\
1361\end{array}$ & - & - & - & - & - & - \\
\hline $\begin{array}{l}\text { Rhodanese-like } \\
\text { thiosulfate } \\
\text { sulfurtransferase }\end{array}$ & $\begin{array}{l}270,1100, \\
1419 \\
1987 \\
2007\end{array}$ & $\begin{array}{c}0521,0931, \\
1491,1783, \\
1804\end{array}$ & $\begin{array}{c}00162, \\
00743, \\
01143, \\
01144, \\
01165, \\
01489\end{array}$ & - & - & - & - \\
\hline Thiosulfate reductase & 9,10 & $1254-1255$ & $\begin{array}{l}01690- \\
01691\end{array}$ & 0433 & 1171-1172 & $\begin{array}{l}1675- \\
1676 \\
\end{array}$ & $0227-0228$ \\
\hline $\begin{array}{c}\text { Sulfite } \\
\text { oxidoreductase }\end{array}$ & 1907 & 1876 & 01071 & - & - & - & - \\
\hline \multirow[t]{2}{*}{$\begin{array}{c}\text { Dissimilatory sulfite } \\
\text { reductase }\end{array}$} & $\begin{array}{l}1434- \\
1435 \\
\end{array}$ & 1401-1402 & $\begin{array}{l}00067 \\
00069\end{array}$ & - & - & - & - \\
\hline & & \multicolumn{6}{|c|}{$\mathrm{CO}_{2}$ fixation } \\
\hline CO dehydrogenase & - & 1220-1221 & - & - & - & - & - \\
\hline acetyl-CoA synthase & 1743,135 & 1068,1651 & $\begin{array}{l}00336, \\
00511\end{array}$ & $\begin{array}{r}0577, \\
1234 \\
\end{array}$ & 0277,1400 & $\begin{array}{l}0197- \\
0198 \\
\end{array}$ & 0718,1422 \\
\hline Fumarate reductase & $\begin{array}{l}1536- \\
1537 \\
\end{array}$ & 0396-0399 & $\begin{array}{l}00619- \\
00622 \\
\end{array}$ & 0140 & 0574 & 1456 & 1697 \\
\hline $\begin{array}{c}\text { ferredoxin-dependent } \\
\text { 2-oxoglutarate } \\
\text { synthase } \\
\end{array}$ & 1790 & $1699-1703$ & $\begin{array}{c}00287- \\
00288\end{array}$ & 1489 & 1518 & 0081 & 0329 \\
\hline ATP-Citrate lyase & $\begin{array}{c}1597- \\
1598 \\
\end{array}$ & 0509 & $\begin{array}{l}00730- \\
00731\end{array}$ & - & - & - & - \\
\hline $\begin{array}{c}\text { 2-oxoglutarate } \\
\text { carboxylase / } \\
\text { pyruvate carboxylase }\end{array}$ & 537 & 0154 & 01331 & 0131 & 0581 & 1482 & 1706 \\
\hline $\begin{array}{c}\text { Isocitrate } \\
\text { dehydrogenase }\end{array}$ & 247,865 & 0953,1028 & 00551 & 0452 & 1330 & 0805 & 0580 \\
\hline pyruvate synthase & $\begin{array}{l}1627- \\
1628 \\
1974\end{array}$ & $\begin{array}{l}0299-0300 \\
1025,1810\end{array}$ & $\begin{array}{l}00554, \\
01137, \\
01553- \\
01554\end{array}$ & $\begin{array}{c}0589 \\
0797- \\
0798\end{array}$ & $\begin{array}{l}0357,1018 \\
1146-1147\end{array}$ & $\begin{array}{l}0700 \\
1023- \\
1024\end{array}$ & $\begin{array}{c}0729- \\
0731,0875\end{array}$ \\
\hline phosphoenolpyruvate & 942 & 0682 & 00992 & - & - & 1002 & - \\
\hline
\end{tabular}




\begin{tabular}{|c|c|c|c|c|c|c|c|}
\hline carboxylase & & & & & & & \\
\hline $\begin{array}{l}\text { Acetyl/propionyl- } \\
\text { CoA carboxylases }\end{array}$ & $\begin{array}{c}800,1110, \\
1521\end{array}$ & $\begin{array}{c}\text { 0414-0415, } \\
0511,1322- \\
1323,\end{array}$ & $\begin{array}{c}00636- \\
00637, \\
00732- \\
00733\end{array}$ & $\begin{array}{l}0703 \\
0822\end{array}$ & 0364,1189 & 0963 & 0798 \\
\hline
\end{tabular}


Table S4 - Enzymes potentially involved in the resistance to acidic environments in Desulfurellaceae members. Dam - D. amilsii, Dac - D. acetivorans, Hma - H. maritima, $\mathrm{Hja}-H$. jasoniae, Hal - H. alviniae, Hme - H. medeae.

\begin{tabular}{|c|c|c|c|c|c|c|c|}
\hline & Dam & Dac & Hma & Hja & Hal & Hme & Dam \\
\hline & & \multicolumn{6}{|c|}{ DNA repair } \\
\hline Protein RecA & 136 & 1067 & 00512 & 0248 & 1583 & 1343 & 1599 \\
\hline Excinuclease $\mathrm{ABC}$ & 757 & 0811 & 00802 & 1579 & 0253 & 1154 & 0699 \\
\hline GroEL & 1280 & 1539 & 00208 & 1268 & 0228 & 1106 & 1450 \\
\hline & & \multicolumn{6}{|c|}{ Decarboxylases } \\
\hline $\begin{array}{c}\text { Arginine } \\
\text { decarboxylase }\end{array}$ & 90 & 1123 & & 00465 & $\begin{array}{c}0369 \\
0390 \\
\end{array}$ & 1641 & 0210 \\
\hline & & \multicolumn{6}{|c|}{ Symporters/Antiporters } \\
\hline $\begin{array}{c}\text { Sodium coupled } \\
\text { symporters }\end{array}$ & 786 & 0782 & 00771 & $\begin{array}{l}0364 \\
0382\end{array}$ & - & - & - \\
\hline $\begin{array}{l}\text { Sodium coupled } \\
\text { antiporter }\end{array}$ & $\begin{array}{c}1647, \\
1684, \\
1515\end{array}$ & $\begin{array}{l}0280, \\
0420, \\
1269\end{array}$ & $\begin{array}{l}01481 \\
01722\end{array}$ & $\begin{array}{l}0365 \\
0382\end{array}$ & & & \\
\hline \multirow[t]{2}{*}{ Amino acid antiporter } & $\begin{array}{c}256- \\
257, \\
411, \\
565- \\
566, \\
572- \\
573, \\
766, \\
1489- \\
1490, \\
1465, \\
1533, \\
1783, \\
2003,\end{array}$ & $\begin{array}{l}0138, \\
0187- \\
0188, \\
0194- \\
0195, \\
0213, \\
0402, \\
0444- \\
0445, \\
0555, \\
0802, \\
0909, \\
0943- \\
0944, \\
1132, \\
1228, \\
1438, \\
1522 \\
\end{array}$ & $\begin{array}{l}01297, \\
00668, \\
01476, \\
01290, \\
01161, \\
01271, \\
01477, \\
00793, \\
00667, \\
01289, \\
01296, \\
00456\end{array}$ & $\begin{array}{c}0013, \\
0045, \\
0097, \\
0741, \\
1007, \\
1619\end{array}$ & $\begin{array}{c}0273- \\
0274, \\
0445, \\
0560, \\
0655, \\
0656 \\
0673- \\
0674 \\
0823- \\
0824, \\
0898, \\
1199, \\
1543\end{array}$ & $\begin{array}{c}0352, \\
0475- \\
0476, \\
1484- \\
1487, \\
1628- \\
1631, \\
1714- \\
1717\end{array}$ & $\begin{array}{c}0080- \\
0081, \\
0200- \\
0201, \\
0354, \\
0720, \\
1085- \\
1086, \\
1311, \\
1710- \\
1711\end{array}$ \\
\hline & & \multicolumn{6}{|c|}{ Phosphate transport } \\
\hline \multirow[t]{2}{*}{$\mathrm{ABC}$ transporter } & $\begin{array}{l}206, \\
1152\end{array}$ & 0996 & 01060 & $\begin{array}{c}0887- \\
0890\end{array}$ & 937 & $\begin{array}{c}0607, \\
0925\end{array}$ & 967 \\
\hline & & \multicolumn{6}{|c|}{ Membrane potential } \\
\hline Histidine kinase & 1383 & $\begin{array}{l}0069, \\
0580, \\
0993, \\
1174, \\
1347, \\
1467, \\
1486, \\
1544 \\
\end{array}$ & $\begin{array}{l}00133, \\
00156, \\
00213, \\
00416, \\
00572, \\
01419, \\
01427, \\
01725\end{array}$ & $\begin{array}{c}0349- \\
0352, \\
1470\end{array}$ & $\begin{array}{c}0367, \\
0784, \\
0940, \\
1537\end{array}$ & $\begin{array}{c}0102, \\
0960, \\
1083\end{array}$ & $\begin{array}{c}0348, \\
0429, \\
0795, \\
0964\end{array}$ \\
\hline
\end{tabular}


Table S5 - Enzymes involved in the response to oxidative stress in Desulfurellaceae members. Dam - D. amilsii, Dac - D. acetivorans, Hma - H. maritima, $\mathrm{Hja}-H$. jasoniae, $\mathrm{Hal}-H$. alviniae, Hme - H. medeae.

\begin{tabular}{|c|c|c|c|c|c|c|c|}
\hline & Dam & Dac & Hma & Hja & Hal & Hme & Dam \\
\hline & & \multicolumn{6}{|c|}{ Hydrogen peroxide stress } \\
\hline $\begin{array}{l}\text { Peroxide } \\
\text { stress } \\
\text { regulator }\end{array}$ & $\begin{array}{l}548 \\
1785\end{array}$ & 0169, 1698 & $\begin{array}{l}00289 \\
01316\end{array}$ & 1578 & 0553 & 1703 & 0213 \\
\hline Alkylhydroperoxide & $\begin{array}{l}547, \\
965\end{array}$ & $\begin{array}{c}0708,1020 \\
1233\end{array}$ & $\begin{array}{l}00559, \\
00965\end{array}$ & 0417 & - & - & - \\
\hline Rubrerythrins & 1608 & $\begin{array}{c}0320,0651 \\
0654\end{array}$ & $\begin{array}{l}01021, \\
01024, \\
01534\end{array}$ & 1117 & 0088 & 0854 & 1216 \\
\hline Peroxiredoxin & $\begin{array}{l}547, \\
930, \\
965 \\
\end{array}$ & $\begin{array}{l}0168,0652 \\
0697,1118\end{array}$ & 01317 & 0750 & $\begin{array}{l}1107 \\
1303\end{array}$ & $\begin{array}{l}0715 \\
0853\end{array}$ & $\begin{array}{l}0545 \\
0829\end{array}$ \\
\hline Thioredoxin & 1131 & 0490 & 00470 & $\begin{array}{c}0617 \\
1036\end{array}$ & $\begin{array}{l}0401 \\
1367\end{array}$ & $\begin{array}{l}0431 \\
0991\end{array}$ & $\begin{array}{l}0202, \\
0762, \\
1111 \\
\end{array}$ \\
\hline \multirow[t]{2}{*}{ Fur family } & $\begin{array}{c}80 \\
548, \\
1785\end{array}$ & $\begin{array}{c}0169,1698 \\
1131\end{array}$ & $\begin{array}{l}00289 \\
01316\end{array}$ & 1578 & 0553 & 1703 & 0213 \\
\hline & & \multicolumn{6}{|c|}{ Superoxide stress } \\
\hline $\begin{array}{c}\text { Redox-sensitive } \\
\text { transcriptional } \\
\text { activator SoxR }\end{array}$ & 1086 & 0161,1585 & $\begin{array}{l}00406, \\
01324\end{array}$ & - & - & - & - \\
\hline Rubredoxin & 1603 & 0325 & 01529 & 0415 & 1391 & 0856 & 0543 \\
\hline $\begin{array}{c}\text { Superoxide dismutase } \\
\text { desulfoferrodoxin }\end{array}$ & 1606 & 0322 & 01532 & 0419 & 1395 & 0857 & 0547 \\
\hline & & \multicolumn{6}{|c|}{ Redox and oxygen sensors } \\
\hline $\begin{array}{l}\text { Methyl-accepting } \\
\text { chemotaxis protein }\end{array}$ & $\begin{array}{c}283, \\
386, \\
491, \\
532, \\
1098, \\
1379, \\
1382, \\
1594\end{array}$ & $\begin{array}{c}0113, \\
0150, \\
0336, \\
0523 \\
0920-0921, \\
1483\end{array}$ & $\begin{array}{l}01372, \\
01514, \\
01506, \\
00854, \\
00010, \\
00152\end{array}$ & $\begin{array}{c}0599, \\
0628- \\
0629, \\
0758, \\
0907, \\
1171, \\
1274, \\
1236\end{array}$ & $\begin{array}{l}0054, \\
0082, \\
0222, \\
0413, \\
0901, \\
1031, \\
1057, \\
1111, \\
1312\end{array}$ & $\begin{array}{c}0166, \\
0602, \\
0610, \\
0783, \\
0989, \\
1009, \\
1070, \\
1169, \\
1112\end{array}$ & $\begin{array}{l}0119, \\
0539, \\
0641, \\
0744, \\
0989, \\
1041, \\
1182, \\
1210, \\
1424, \\
1456, \\
1489, \\
1490\end{array}$ \\
\hline $\begin{array}{l}\text { Flagellar motor } \\
\text { rotation proteins }\end{array}$ & $1791-1792$ & 1705 & 00282 & 0575 & 0279 & 0195 & 0716 \\
\hline \multirow[t]{2}{*}{$\begin{array}{c}\text { Quinol oxidase - } \\
\text { cytochrome bd type }\end{array}$} & 1439 & 1408 & 00074 & 1558 & 1443 & 1405 & 0154 \\
\hline & & \multicolumn{6}{|c|}{ DNA repair } \\
\hline UvrABC system & 757 & 0811 & 00802 & 0557 & 0253 & 1154 & 0699 \\
\hline $\begin{array}{l}\text { Uracil- DNA } \\
\text { glycosylase }\end{array}$ & 1848 & 0080 & 01408 & 0225 & 1606 & 1366 & 1623 \\
\hline Protein RecA & 136 & 1067 & 00512 & 0248 & 1583 & 1343 & 1599 \\
\hline LexA & - & 1741 & 00251 & - & - & - & - \\
\hline
\end{tabular}


Table S6 - Enzymes involved in the resistance to metals toxicity in Desulfurellaceae members. Dam - D. amilsii, Dac - D. acetivorans, Hma - H. maritima, Hja - H. jasoniae, Hal - H. alviniae, Hme - H. medeae.

\begin{tabular}{|c|c|c|c|c|c|c|c|}
\hline & Dam & Dac & Hma & Hja & Hal & Hme & Dam \\
\hline & & \multicolumn{6}{|c|}{ ATP-based } \\
\hline Polyphosphate kinase & 882 & $\begin{array}{c}0746, \\
1836, \\
1840 \\
\end{array}$ & $\begin{array}{l}01106 \\
01110\end{array}$ & 1006 & 0825 & 0472 & 1084 \\
\hline copper-exporting P-type ATPase & 1050 & 1817 & 01130 & 0745 & 0377 & $\begin{array}{c}1148, \\
1792\end{array}$ & 1705 \\
\hline & & \multicolumn{6}{|c|}{ Non-ATP based } \\
\hline Cation transporters & $\begin{array}{l}49 \\
597\end{array}$ & $\begin{array}{c}0185, \\
0214, \\
0705, \\
1171\end{array}$ & $\begin{array}{l}01299, \\
00419, \\
00968, \\
01270\end{array}$ & $\begin{array}{c}1423, \\
1426- \\
1427\end{array}$ & $\begin{array}{c}0179 \\
1365, \\
1676\end{array}$ & 1178 & 0441 \\
\hline $\begin{array}{l}\text { ABC-type zinc and iron } \\
\text { transporters }\end{array}$ & $\begin{array}{l}215- \\
217 \\
\end{array}$ & $\begin{array}{c}0983- \\
0985 \\
\end{array}$ & $\begin{array}{l}01435- \\
01437\end{array}$ & $\begin{array}{c}1038- \\
1040\end{array}$ & $\begin{array}{c}1361- \\
1363 \\
\end{array}$ & $\begin{array}{l}0427- \\
0429 \\
\end{array}$ & $\begin{array}{l}1113- \\
1115\end{array}$ \\
\hline zinc-chromate transporters & 1196 & - & - & - & - & - & - \\
\hline & & \multicolumn{6}{|c|}{ Enzymatic reduction } \\
\hline Uptake of selenite (DedA protein) & 6,266 & $\begin{array}{l}935 \\
1257 \\
\end{array}$ & 01485 & $\begin{array}{c}0495, \\
1447 \\
\end{array}$ & $\begin{array}{l}1055 \\
1662 \\
\end{array}$ & $\begin{array}{c}0833 \\
1066 \\
\end{array}$ & $\begin{array}{l}0433, \\
0634 \\
\end{array}$ \\
\hline Arsenic efflux pump & 1318 & 1269 & 01722 & - & - & - & - \\
\hline Arsenic resistance operon & $\begin{array}{c}1348- \\
1349 \\
\end{array}$ & - & - & - & - & - & - \\
\hline
\end{tabular}


Table S7 - Unique genes encoded in D. amilsii

\begin{tabular}{|c|c|}
\hline Locus Tag & Gene Name \\
\hline 7 & hypothetical protein \\
\hline 11 & hypothetical protein \\
\hline 12 & hypothetical protein \\
\hline 13 & hypothetical protein \\
\hline 14 & voltage-gated potassium channel \\
\hline 15 & hypothetical protein \\
\hline 24 & hypothetical protein \\
\hline 37 & hypothetical protein \\
\hline 76 & hypothetical protein \\
\hline 78 & hypothetical protein \\
\hline 81 & hypothetical protein \\
\hline 89 & hypothetical protein \\
\hline 95 & acetoin utilization protein $\mathrm{AcuB}$ \\
\hline 156 & hypothetical protein \\
\hline 234 & hypothetical protein \\
\hline 274 & hypothetical protein \\
\hline 275 & hypothetical protein \\
\hline 276 & hypothetical protein \\
\hline 284 & Uncharacterized conserved protein YbjQ, UPF0145 family \\
\hline 285 & Tetratricopeptide repeat-containing protein \\
\hline 286 & TraX protein \\
\hline 287 & hypothetical protein \\
\hline 289 & hypothetical protein \\
\hline 290 & hypothetical protein \\
\hline 292 & DNA polymerase III sliding clamp (beta) subunit, PCNA homolog \\
\hline 293 & hypothetical protein \\
\hline 294 & hypothetical protein \\
\hline 295 & dUTP pyrophosphatase \\
\hline 296 & hypothetical protein \\
\hline 298 & DNA topoisomerase-3 \\
\hline 299 & hypothetical protein \\
\hline 300 & hypothetical protein \\
\hline 301 & hypothetical protein \\
\hline 302 & hypothetical protein \\
\hline 304 & hypothetical protein \\
\hline 305 & hypothetical protein \\
\hline 306 & AAA-like domain-containing protein \\
\hline
\end{tabular}




\begin{tabular}{|c|c|}
\hline 307 & hypothetical protein \\
\hline 308 & conjugation TrbI-like protein \\
\hline 309 & hypothetical protein \\
\hline 310 & hypothetical protein \\
\hline 311 & type IV conjugative transfer system protein TraL \\
\hline 312 & hypothetical protein \\
\hline 313 & hypothetical protein \\
\hline 314 & Type II secretory pathway, component PulF \\
\hline 315 & prepilin-type N-terminal cleavage/methylation domain-containing protein \\
\hline 317 & hypothetical protein \\
\hline 318 & prepilin-type N-terminal cleavage/methylation domain-containing protein \\
\hline 319 & prepilin-type N-terminal cleavage/methylation domain-containing protein \\
\hline 320 & hypothetical protein \\
\hline 321 & hypothetical protein \\
\hline 322 & hypothetical protein \\
\hline 323 & transposase, IS605 OrfB family, central region \\
\hline 324 & hypothetical protein \\
\hline 325 & hypothetical protein \\
\hline 326 & hypothetical protein \\
\hline 330 & hypothetical protein \\
\hline 331 & transposase, IS605 OrfB family, central region \\
\hline 333 & hypothetical protein \\
\hline 384 & hypothetical protein \\
\hline 397 & hypothetical protein \\
\hline 398 & hypothetical protein \\
\hline 399 & hypothetical protein \\
\hline 403 & hypothetical protein \\
\hline 404 & transposase, IS605 OrfB family, central region \\
\hline 406 & hypothetical protein \\
\hline 408 & transposase, IS605 OrfB family, central region \\
\hline 409 & hypothetical protein \\
\hline 410 & hypothetical protein \\
\hline 460 & hypothetical protein \\
\hline 485 & Major Facilitator Superfamily protein \\
\hline 489 & transposase, IS605 OrfB family, central region \\
\hline 517 & Cupin domain-containing protein \\
\hline 519 & Uncharacterised ArCR, COG2043 \\
\hline 534 & hypothetical protein \\
\hline 593 & cobalt-zinc-cadmium efflux system protein \\
\hline
\end{tabular}




\begin{tabular}{|c|c|}
\hline 594 & hypothetical protein \\
\hline 595 & hypothetical protein \\
\hline 612 & hypothetical protein \\
\hline 614 & hypothetical protein \\
\hline 615 & Uncharacterized protein, UPF0261 family \\
\hline 616 & Predicted TIM-barrel enzyme \\
\hline 617 & pyruvate dehydrogenase E1 component alpha subunit \\
\hline 618 & pyruvate dehydrogenase E1 component beta subunit \\
\hline 619 & hypothetical protein \\
\hline 620 & pyruvate dehydrogenase E1 component alpha subunit \\
\hline 621 & pyruvate dehydrogenase E1 component beta subunit \\
\hline 622 & methylmalonyl-CoA epimerase \\
\hline 630 & hypothetical protein \\
\hline 631 & hypothetical protein \\
\hline 633 & hypothetical protein \\
\hline 634 & hypothetical protein \\
\hline 635 & PH domain-containing protein \\
\hline 638 & hypothetical protein \\
\hline 639 & Antirestriction protein ArdC \\
\hline 640 & hypothetical protein \\
\hline 641 & hypothetical protein \\
\hline 642 & hypothetical protein \\
\hline 643 & hypothetical protein \\
\hline 644 & hypothetical protein \\
\hline 645 & hypothetical protein \\
\hline 646 & hypothetical protein \\
\hline 647 & hypothetical protein \\
\hline 648 & hypothetical protein \\
\hline 649 & hypothetical protein \\
\hline 651 & Transglycosylase SLT domain-containing protein \\
\hline 652 & hypothetical protein \\
\hline 654 & hypothetical protein \\
\hline 656 & UvrD/REP helicase $\mathrm{N}$-terminal domain-containing protein \\
\hline 657 & hypothetical protein \\
\hline 658 & Transglycosylase SLT domain-containing protein \\
\hline 659 & hypothetical protein \\
\hline 660 & Helicase conserved $\mathrm{C}$-terminal domain-containing protein \\
\hline 661 & hypothetical protein \\
\hline 662 & hypothetical protein \\
\hline
\end{tabular}




\begin{tabular}{|c|c|}
\hline 663 & hypothetical protein \\
\hline 664 & hypothetical protein \\
\hline 665 & hypothetical protein \\
\hline 666 & hypothetical protein \\
\hline 667 & Toprim-like \\
\hline 669 & hypothetical protein \\
\hline 671 & hypothetical protein \\
\hline 672 & hypothetical protein \\
\hline 673 & hypothetical protein \\
\hline 674 & hypothetical protein \\
\hline 675 & hypothetical protein \\
\hline 676 & hypothetical protein \\
\hline 678 & hypothetical protein \\
\hline 679 & protein of unknown function DUF87 \\
\hline 682 & hypothetical protein \\
\hline 683 & hypothetical protein \\
\hline 684 & TraU protein \\
\hline 685 & hypothetical protein \\
\hline 686 & hypothetical protein \\
\hline 687 & hypothetical protein \\
\hline 688 & TraG-like protein, N-terminal region \\
\hline 689 & hypothetical protein \\
\hline 690 & hypothetical protein \\
\hline 691 & hypothetical protein \\
\hline 692 & hypothetical protein \\
\hline 695 & hypothetical protein \\
\hline 696 & ERF superfamily protein \\
\hline 697 & hypothetical protein \\
\hline 698 & CRISPR/Cas system-associated exonuclease Cas4, RecB family \\
\hline 699 & hypothetical protein \\
\hline 701 & hypothetical protein \\
\hline 703 & transposase, IS605 OrfB family, central region \\
\hline 705 & hypothetical protein \\
\hline 706 & hypothetical protein \\
\hline 707 & hypothetical protein \\
\hline 718 & benzoyl-CoA reductase, subunit $\mathrm{C}$ \\
\hline 720 & hypothetical protein \\
\hline 806 & hypothetical protein \\
\hline 839 & FlgN protein \\
\hline
\end{tabular}




\begin{tabular}{|c|c|}
\hline 842 & hypothetical protein \\
\hline 843 & hypothetical protein \\
\hline 844 & hypothetical protein \\
\hline 845 & hypothetical protein \\
\hline 849 & $\mathrm{Na}+\mathrm{H}+$-dicarboxylate symporter \\
\hline 850 & aspartate racemase \\
\hline 852 & transposase \\
\hline 855 & (2R)-sulfolactate sulfo-lyase subunit alpha \\
\hline 856 & (2R)-sulfolactate sulfo-lyase subunit beta \\
\hline 857 & Tripartite-type tricarboxylate transporter, receptor component TctC \\
\hline 858 & putative tricarboxylic transport membrane protein \\
\hline 859 & Tripartite tricarboxylate transporter TctB family protein \\
\hline 860 & L-alanine-DL-glutamate epimerase \\
\hline 861 & hypothetical protein \\
\hline 867 & hypothetical protein \\
\hline 868 & hypothetical protein \\
\hline 870 & hypothetical protein \\
\hline 871 & Flavin reductase like domain-containing protein \\
\hline 874 & hypothetical protein \\
\hline 876 & Uncharacterized protein YuzE \\
\hline 877 & protein of unknown function (DUF4258) \\
\hline 879 & Antitoxin Phd_YefM, type II toxin-antitoxin system \\
\hline 880 & hypothetical protein \\
\hline 938 & hypothetical protein \\
\hline 976 & hypothetical protein \\
\hline 1010 & hypothetical protein \\
\hline 1023 & Right handed beta helix region \\
\hline 1025 & MutS domain V \\
\hline 1026 & MutS domain V \\
\hline 1053 & hypothetical protein \\
\hline 1056 & hypothetical protein \\
\hline 1059 & hypothetical protein \\
\hline 1083 & hypothetical protein \\
\hline 1094 & hypothetical protein \\
\hline 1115 & hypothetical protein \\
\hline 1121 & hypothetical protein \\
\hline 1139 & hypothetical protein \\
\hline 1164 & hypothetical protein \\
\hline 1185 & PLD-like domain-containing protein \\
\hline
\end{tabular}




\begin{tabular}{|c|c|}
\hline 1186 & hypothetical protein \\
\hline 1188 & L,D-transpeptidase catalytic domain \\
\hline 1189 & hypothetical protein \\
\hline 1190 & Predicted arabinose efflux permease, MFS family \\
\hline 1191 & Uncharacterized protein YcsI, UPF0317 family \\
\hline 1192 & Metallo-beta-lactamase superfamily protein \\
\hline 1193 & UPF0271 protein \\
\hline 1194 & sensor histidine kinase inhibitor, KipI family \\
\hline 1195 & biotin-dependent carboxylase uncharacterized domain-containing protein \\
\hline 1196 & chromate transporter \\
\hline 1199 & hypothetical protein \\
\hline 1204 & hypothetical protein \\
\hline 1206 & hypothetical protein \\
\hline 1207 & Uncharacterized protein, contains HEPN domain, UPF0332 family \\
\hline 1208 & hypothetical protein \\
\hline 1209 & TIGR04255 family protein \\
\hline 1211 & Restriction endonuclease \\
\hline 1213 & hypothetical protein \\
\hline 1214 & hypothetical protein \\
\hline 1217 & hypothetical protein \\
\hline 1228 & hypothetical protein \\
\hline 1234 & hypothetical protein \\
\hline 1247 & hypothetical protein \\
\hline 1248 & DNA helicase-2 / ATP-dependent DNA helicase PcrA \\
\hline 1251 & type II restriction enzyme \\
\hline 1345 & hypothetical protein \\
\hline 1348 & transcriptional regulator, ArsR family \\
\hline 1349 & arsenite transporter, ACR3 family \\
\hline 1350 & $4 \mathrm{Fe}-4 \mathrm{~S}$ binding domain-containing protein \\
\hline 1351 & hypothetical protein \\
\hline 1352 & Carboxymuconolactone decarboxylase family protein \\
\hline 1353 & RND family efflux transporter, MFP subunit \\
\hline 1355 & phosphonate transport system substrate-binding protein \\
\hline 1356 & histidine kinase \\
\hline 1357 & two component transcriptional regulator, LuxR family \\
\hline 1358 & Sulfur reductase subunit $\mathrm{C}$ \\
\hline 1359 & Sulfur reductase subunit $\mathrm{A}$ \\
\hline 1360 & Sulfur reductase subunit D \\
\hline 1361 & Sulfur reductase subunit E \\
\hline
\end{tabular}




\begin{tabular}{|c|c|}
\hline 1362 & hypothetical protein \\
\hline 1366 & hypothetical protein \\
\hline 1389 & hypothetical protein \\
\hline 1404 & hypothetical protein \\
\hline 1406 & hypothetical protein \\
\hline 1471 & hypothetical protein \\
\hline 1472 & protein of unknown function (DUF4917) \\
\hline 1473 & Superfamily I DNA or RNA helicase \\
\hline 1474 & hypothetical protein \\
\hline 1477 & hypothetical protein \\
\hline 1503 & hypothetical protein \\
\hline 1596 & hypothetical protein \\
\hline 1633 & hypothetical protein \\
\hline 1674 & hypothetical protein \\
\hline 1692 & hypothetical protein \\
\hline 1727 & hypothetical protein \\
\hline 1729 & hypothetical protein \\
\hline 1744 & hypothetical protein \\
\hline 1797 & KUP system potassium uptake protein \\
\hline 1828 & hypothetical protein \\
\hline 1892 & hypothetical protein \\
\hline 1925 & UDP-glucose:(heptosyl)LPS alpha-1,3-glucosyltransferase \\
\hline 1952 & T/G mismatch-specific endonuclease \\
\hline 1953 & Z1 domain-containing protein \\
\hline 1954 & NgoFVII restriction endonuclease \\
\hline 1955 & DNA (cytosine-5)-methyltransferase 1 \\
\hline 1959 & Methyltransferase domain-containing protein \\
\hline 1960 & Putative flippase GtrA (transmembrane translocase of bactoprenol-linked \\
\hline 1961 & hypothetical protein \\
\hline 1979 & hypothetical protein \\
\hline 1980 & hypothetical protein \\
\hline 1981 & hypothetical protein \\
\hline 1982 & hypothetical protein \\
\hline 2010 & hypothetical protein \\
\hline 2025 & hypothetical protein \\
\hline 2026 & hypothetical protein \\
\hline 2033 & hypothetical protein \\
\hline 2034 & hypothetical protein \\
\hline 2035 & dihydrolipoamide dehydrogenase \\
\hline
\end{tabular}




\begin{tabular}{lc}
\hline 2038 & hypothetical protein \\
\hline 2044 & hypothetical protein \\
\hline 2045 & two component transcriptional regulator, LuxR family \\
\hline 2046 & Signal transduction histidine kinase \\
\hline 2047 & hypothetical protein \\
\hline 2048 & Cytochrome c553 \\
\hline 2049 & hypothetical protein \\
\hline 2050 & O-acetylhomoserine sulfhydrylase \\
\hline 2051 & cyclic pyranopterin phosphate synthase \\
\hline 2052 & homoserine O-acetyltransferase \\
\hline 2053 & methionine biosynthesis protein MetW \\
\hline 2054 & sulfide:quinone oxidoreductase \\
\hline
\end{tabular}




\section{Chapter 6}

\section{Mechanisms for sulfur reduction in Desulfurella amilsii at low and circumneutral pH}

Anna P. Florentino, Inês Pereira, Michael van den Born, Sjef Boeren, Alfons J. M.

Stams, Irene Sánchez-Andrea 


\begin{abstract}
Sulfur-reducing prokaryotes play an important role in the sulfur biogeochemical cycle in diverse environments, such as deep-sea vents, hot springs or soils. The poor solubility of elemental sulfur is a bottleneck to support high growth rates and growth yields of microorganisms that use $\mathrm{S}^{0}$ as terminal electron acceptor. In the presence of sulfide, sulfur is in equilibrium with polysulfide. Since polysulfide is more soluble than elemental sulfur, it is thought to be the electron acceptor for some sulfur reducers. However, at low $\mathrm{pH}$ this is improbable due to the instability of polysulfide and displacement of the equilibrium towards elemental sulfur. To confirm the terminal electron acceptor used by the acidotolerant Desulfurella amilsii for sulfur reduction, the requirement of physical contact between the bacterium and the bulk solid-phase $\mathrm{S}^{0}$ was studied. D. amilsii was cultivated at $\mathrm{pH} 3.5$ and 6.5 with hydrogen and sulfur trapped in a dialysis tube with a pore size of 6-8 $\mathrm{kDa}$ and with dispersed sulfur. Sulfide production levels decreased by $51 \%$ and $47 \%$ when $\mathrm{S}^{0}$ was trapped in dialysis bags at $\mathrm{pH} 3.5$ and 6.5 , respectively. A decrease of $97 \%$ and $78 \%$ in number of cells in solution was observed in the sulfur-trapped cultures at $\mathrm{pH} 3.5$ and 6.5 , respectively. This suggests that both growth and activity of $D$. amilsii benefit from contact with elemental sulfur. Proteomic analysis was performed at both studied $\mathrm{pH}$ values under hydrogen and dispersed sulfur conditions. The proteome revealed that the hydrogenase HybABC, some markers of acid resistance, extracellular polymeric substance-related proteins, flagellar proteins and glycosyl transferase were equally abundant in both $\mathrm{pH}$ conditions. No indication of the involvement of sulfur reductase was obtained, and sulfide dehydrogenase was produced at low and high $\mathrm{pH}$ cultures, and it is thought to function as a ferredoxin:NADP oxidoreductase, due to its high affinity for ferredoxin, also highly abundant in the cultures. Besides, thiosulfate sulfurtransferases were highly abundant, especially at low $\mathrm{pH}$, in which two of them were exclusively produced. The abundance of thiosulfate sulfurtransferases revealed in this study suggest that they might play a crucial role in the sulfur respiration by $D$. amilsii with affinity for different substrates in different $\mathrm{pH}$ values.
\end{abstract}

The locus tag for the genes encoded in D. amilsii is DESAMIL20_*. To avoid repetition of the prefix along the text, the locus tags are represented only by the specific identifier. 


\section{Introduction}

Elemental sulfur is one of the most ubiquitous sulfur species in sediments and geological deposits, generated by biological and chemical oxidation processes of $\mathrm{H}_{2} \mathrm{~S}$ (Rabus, Hansen et al. 2013). Chemically, it is a quite reactive compound and its activation, prior to reduction, is not energy-dependent. However, its low solubility in water $-5 \mu \mathrm{g} \mathrm{L}{ }^{-1}$ at $20^{\circ} \mathrm{C}$ (Boulegue 1978) - hampers the fast growth of sulfur-reducing prokaryotes (Blumentals, Itoh et al. 1990, Schauder and Müller 1993).

Despite its low solubility, the ability to respire elemental sulfur is widespread over the tree of microbial life (Florentino, Weijma et al. 2016). Such microorganisms are able to grow at a broad range of temperature (from -2 to $110^{\circ} \mathrm{C}$ ) and $\mathrm{pH}$ (from 1-10.5), while reducing elemental sulfur and oxidizing organic compounds or $\mathrm{H}_{2}$ (Rabus, Hansen et al. 2013, Florentino, Weijma et al. 2016).

To cope with the low solubility of elemental sulfur, two mechanisms have been postulated for the microbial sulfur respiration: reduction via an intermediate soluble form of sulfur, or via direct attachment of the cells to the solid substrate. The solubilization of sulfur by a nucleophilic attack of sulfide to the $S^{0}$-ring of elemental sulfur (equation 1 ), cleaving it and generating polysulfide, would make possible that it plays a crucial role in the sulfur respiration process when sulfide is available in the environment (Blumentals, Itoh et al. 1990, Schauder and Müller 1993, Hedderich, Klimmek et al. 1999).

$$
\mathrm{S}_{8}^{0}+\mathrm{HS}^{-} \rightleftharpoons S_{8} S^{2-}+\mathrm{H}^{+} \text {equation (1) }
$$

The concentration and chain length of these polysulfide species depend on several parameters, such as $\mathrm{pH}$, elemental sulfur concentration, redox potential, and temperature. The maximum polysulfide concentration in solution increases with increasing $\mathrm{pH}$ (Schauder and Müller 1993). The maximum concentration of polysulfide in solution at $\mathrm{pH}$ 3 (in the presence of elemental sulfur in excess and $1 \mathrm{mM}$ of hydrogen sulfide) is just around $10^{-12} \mathrm{M}$ at $80^{\circ} \mathrm{C}$ (Schauder and Müller 1993). Some binding proteins produced by sulfur-reducing microorganisms, such as polysulfide sulfurtransferases, previously called sulfide dehydrogenase in Wolinella succinogenes (Kreis-Kleinschmidt, Fahrenholz et al. 1995), could allow faster polysulfide respiration at its lower concentrations.

As at low $\mathrm{pH}$, polysulfide is unstable and precipitate as crystals of elemental sulfur (Steudel 2003). Therefore, it has been postulated that acidophilic or acidotolerant microorganisms convert elemental sulfur directly into sulfide by physical attachment to the bulk solid-phase $S^{0}$ (Laska, Lottspeich et al. 2003). Nanocrystals of sulfur precipitated from polysulfide at low $\mathrm{pH}$ are speculated to play a role in sulfur respiration (Boyd and Druschel 2013). 
The sulfur respiration process might be highly influenced by the temperature and $\mathrm{pH}$ of the environment. Enzymes possibly involved in sulfur respiration by Wolinella succinogenes (Klimmek, Kröger et al. 1991), Pyrococcus furiosus (Blumentals, Itoh et al. 1990) and Acidianus ambivalens (Laska, Lottspeich et al. 2003) were isolated and characterized. The membrane-bound polysulfide reductase was isolated from $W$. succinogenes and reported to be involved in the reduction of polysulfide (Macy, Schröder et al. 1986, Klimmek, Kröger et al. 1991). The cytoplasmic sulfide dehydrogenase and sulfhydrogenase were isolated from $P$. furiosus and, while the first is reported to be involved in the respiration of polysulfide (Blumentals, Itoh et al. 1990), the second is thought to reduce polysulfide and elemental sulfur (Bryant and Adams 1989, Ma, Weiss et al. 2000). The sulfur reductase from A. ambivalens was shown to reduce elemental sulfur when cells are in direct contact with sulfur (Laska, Lottspeich et al. 2003).

Desulfurella amilsii is an acidotolerant sulfur-reducing bacterium isolated from acidic river sediments. It can grow in a broad $\mathrm{pH}$ range (from 3 - 7) (Florentino, Brienza et al. 2016) and its genome encodes two enzymes involved in sulfur respiration: sulfide dehydrogenase and sulfur reductase (Chapter 5), suggesting that both polysulfide and sulfur might serve as terminal electron acceptors for this microorganism depending on the $\mathrm{pH}$ of the culture.

This study aimed to investigate the cell-sulfur interactions of $D$. amilsii at different $\mathrm{pH}$. For that, activity and growth on hydrogen with sulfur dispersed in the medium and with sulfur trapped in dialysis membranes were investigated. The abundance of enzymes involved in chemolithotrophic growth, acid resistance and sulfur respiration related proteins were determined by proteomics.

\section{Material and Methods}

\section{Culture conditions}

Cells were grown in 500-mL anoxic medium prepared as described elsewhere (Florentino, Weijma et al. 2015). To adjust the $\mathrm{pH}$ of the medium, bicarbonate-buffer was omitted as described by Sánchez-Andrea, Stams et al. (2013), and pH was adjusted to 3.5 and 6.5 with $\mathrm{HCl}$. A mixture of $\mathrm{H}_{2} / \mathrm{CO}_{2}(1.5 \mathrm{~atm}, 80: 20$, v/v) was supplied to the cultures to provide $\mathrm{H}_{2}$ as electron donor and $\mathrm{CO}_{2}$ as carbon source. Elemental sulfur was added to all the bottles in a concentration of $25 \mathrm{mM}$. Cultures were incubated at $50{ }^{\circ} \mathrm{C}$ and statically, to avoid any disturbance in the contact between the cells and the dialysis membranes.

\section{Dialysis membranes experiment}

Per $\mathrm{pH}$ value, two groups of triplicates were performed (and their respective uninoculated controls): one group had sulfur particles dispersed in the medium and the other 
had sulfur trapped in dialysis bags. To maintain the bacterium physically separated from the insoluble substrate, sulfur particles were enclosed in sulfur- and heavy metals-free Spectra/Por (Spectrum, CA) dialysis tubing membranes with a limited pore size of 6 to 8 kilodalton $(\mathrm{kDa})$. This permeable membrane ensured that cells had no direct contact with elemental sulfur, but allowed soluble molecules smaller than 6-8 $\mathrm{kDa}$ to diffuse in either direction through the pores. Prior to the utilization, the membranes were briefly rinsed and dipped in demineralized water to remove preservatives and metals. The bags were filled with elemental sulfur and $4 \mathrm{~mL}$ of the cultivation medium, sealed with standard Spectra/Por closures (Spectrum, CA) and placed in the culture vials containing $500 \mathrm{~mL}$ of anoxic medium. Bottles were sealed with butyl rubber stoppers (Rubber BV, Hilversum, The Netherlands) and autoclaved for 30 minutes at $105^{\circ} \mathrm{C}$. The differences in total sulfide production and cell counts between biological triplicates and un-inoculated controls were used as representatives for sulfur reduction activity and cellular growth, respectively. Integrity of the dialysis membranes was checked after each experiment by visual inspection and scanning electron microscopy.

\section{Growth and activity track}

Growth and sulfur reduction activity were tracked weekly. Hydrogen consumption, sulfide production and planktonic cells were measured. Sulfide production was determined colorimetrically using the methylene blue method described by Cline (1969). Hydrogen consumption was determined by a gas chromatograph (Shimadzu, Kyoto, Japan), equipped with a Molsieve 13X column ( $2 \mathrm{~m}$, ID $2 \mathrm{~mm}$ ) and a TCD detector. The number of cells in the cultures was determined by using a Petroff-Hausser counting chamber with a cell-depth of $0.02 \mathrm{~mm}$ and ruling pattern 1:400 $\mathrm{mm}^{2}$ (Hausser Scientific, PA). The cellular elemental sulfur reduction rates (cESRR) were calculated from the cell numbers and the formation of hydrogen sulfide as described by Surkov, Bottcher et al. (2000) with modifications (equation 2):

$$
\operatorname{cESRR}\left[\mu \mathrm{mol} \mathrm{S} \mathrm{S}^{0} \operatorname{cell}^{-1} \mathrm{day}^{-1}\right]=\left(\mathrm{S}_{\mathrm{i}}-\mathrm{S}_{\mathrm{i}-1}\right)\left[\frac{\mathrm{C}_{\mathrm{i}}+\mathrm{C}_{\mathrm{i}-1}}{2}\right]^{-1}\left(\mathrm{t}_{\mathrm{i}-\mathrm{t}_{\mathrm{i}-1}}\right)^{-1} \quad \text { equation (2) }
$$

where $\mathrm{S}, \mathrm{C}$ and $\mathrm{t}$ refer to the amounts of hydrogen sulfide produced ( $\mu \mathrm{mol})$, the total cell number and reaction time (day), respectively, at time intervals i and i-1.

\section{Polysulfide measurement}

Samples for polysulfide anion analysis were taken with glass syringes to avoid losses of any compound as a result of adsorption onto plastics. A subsequent derivatization was carried out in a glove box to prevent contact with oxygen $\left(\mathrm{O}_{2} \leq 0.1 \mathrm{vol} \%\right)$. The samples 
were mixed with $60 \mathrm{~mL}$ of methyl triflate in a methanol-water medium as described by Kamyshny, Ekeltchik et al. (2006). Polysulfide standards were prepared as described elsewhere (Roman, Bijmans et al. 2014). Derivatized polysulfides in the form of dimethyl disulfide (DMDS), dimethyl trisulfide (DMTS) and higher dimethyl polysulfanes $\left(\mathrm{Me}_{2} \mathrm{~S}_{4}\right.$ to $\mathrm{Me}_{2} \mathrm{~S}_{8}$ ) were determined by a high-performance liquid chromatography (HPLC) device equipped with a UV detector (Dionex UltiMate 3000RS, Breda, The Netherlands).

\section{Scanning electron microscopy}

Scanning electron microscopy was performed on the surface of the dialysis membranes. A 3\% (v/v) solution of glutaraldehyde (Sigma Aldrich,St. Louis, MI, USA) in phosphate-buffered saline (PBS) solution was used to fix the cells for 1 hour at room temperature; afterwards samples were dehydrated in increasing concentrations of ethanol $(10 \%, 30 \%, 50 \%, 70 \%, 80 \%, 90 \%, 96 \%$ and 100\%) and air-dried. Cells were analyzed using a JEOL JSM-6480LV microscope (JEOL, USA).

\section{Proteomics}

\section{Protein extraction}

Cultures grown with sulfur dispersed in the medium at $\mathrm{pH} 3.5$ and $\mathrm{pH} 6.5$ were used to compare sulfur enzyme levels. The total proteins were extracted from cultures in the late exponential phase, in which the sulfide production was around $10 \mathrm{mM}$, corresponding to an average protein concentration of $5 \mu \mathrm{g} \mathrm{mL}{ }^{-1}$. Cultures were centrifuged $\left(10 \mathrm{~min}, 4^{\circ} \mathrm{C}\right.$, $14000 \mathrm{rpm})$ and the cell pellets were re-suspended in $0.5 \mathrm{~mL}$ SDT-lysis buffer $(50 \mathrm{mM}$ $\mathrm{DTT}+4 \%(\mathrm{w} / \mathrm{v}) \mathrm{SDS}$ in $100 \mathrm{mM}$ Tris/HCl pH 7.6) with $50 \mu \mathrm{l}$ of phenylmethylsulfonyl fluoride (PMFS) $1 \mathrm{mM}$. The suspension was sonicated 6 times, in cycles of 30 seconds pulse and 30 seconds rest intervals on ice. Unbroken cells and cell debris were removed by centrifugation at $13000 \mathrm{rpm}$ for $10 \mathrm{~min}$ and the protein concentration in the supernatant was measured with the Pierce BCA Protein Assay Kit (Thermo Scientific, Illinois).

\section{Protein identification}

Proteins $(15 \mu \mathrm{g})$ were loaded to Precise ${ }^{\mathrm{TM}} 12 \%$ Tris-HEPES Gels, $58 \mathrm{~mm} \times \mathrm{m} 80 \mathrm{~mm}$ x $1 \mathrm{~mm}, 10-$ Well (Thermo Scientific, Illinois, USA) and run for 30 minutes at $120 \mathrm{~V}$. The gels were stained for 3 hours with the Colloidal Blue Staining Kit (Thermo Scientific, Illinois, USA) and de-stained for 15 hours in demineralized water. Three slices of $1 \mathrm{~cm}$ were individually cut into pieces of ca. $1 \mathrm{~mm}^{2}$ prior to cysteines reduction, alkylation and enzymatic digestion with $50 \mu \mathrm{L}$ of trypsin solution. A volume of $18 \mu \mathrm{L}$ trypsin-digested peptide sample was loaded onto 0.10*32 mm Magic C18AQ 200A (5 $\mu \mathrm{m}$ bead size) (Bruker Nederland B.V.) pre-concentration column (prepared in-house) at a constant 
pressure of 270 bar (normally resulting in a flow of ca. $7-10 \mu \mathrm{L} \mathrm{min}{ }^{-1}$ ). Peptides were eluted from the pre-concentration column onto a 0.10*250 mm Magic C18AQ 200A (3 $\mu \mathrm{m}$ bead size) analytical column (prepared in-house) with an acetonitrile gradient at a flow of $0.5 \mu \mathrm{L} \mathrm{min}{ }^{-1}$ with a Proxeon EASY nanoLC. The gradient consisted of an increase from 8 to $33 \%$ acetonitrile in water with $5 \mathrm{~mL} \mathrm{~L}^{-1}$ acetic acid in 50 minutes, followed by a fast increase in the percentage acetonitrile to $80 \%$ (with $20 \%$ water and $5 \mathrm{~mL} \mathrm{~L}^{-1}$ acetic acid in both the acetonitrile and the water) in 3 minutes as a column cleaning step.

A P777 Upchurch microcross was positioned between the pre-concentration and analytical column. An electrospray potential of $3.5 \mathrm{kV}$ was applied directly to the eluent via a stainless steel needle fitted into the waste line of the microcross. Full scan positive mode FTMS spectra were measured between m/z 380 and 1400 on a LTQ-Orbitrap XL (Thermo electron, San Jose, CA, USA) in the Orbitrap at high resolution (60000). CID fragmented MSMS scans of the four most abundant $2^{+}$and $3^{+}$charged peaks in the FTMS scan were recorded in data dependent mode in the linear trap (MSMS threshold $=5.000,45 \mathrm{~s}$ exclusion duration for the selected $\mathrm{m} / \mathrm{z}+/-25 \mathrm{ppm}$ ).

LCMS data with all MSMS spectra were analyzed with MaxQuant 1.5.2.8 (Cox and Mann 2008) using default settings for the Andromeda search engine (Cox, Neuhauser et al. 2011), except that extra variable modifications were set for deamidation of $\mathrm{N}$ and $\mathrm{Q}$. Desulfurella amilsii protein sequence database (NCBI accession number MDSU00000000) was used together with a database of contaminants which contains sequences of common contaminants, such as: BSA (P02769, bovine serum albumin precursor), Trypsin (P00760, bovine), Trypsin (P00761, porcine), Keratin K22E (P35908, human), Keratin K1C9 (P35527, human), Keratin K2C1 (P04264, human) and Keratin K1CI (P35527, human). The "label-free quantification" (LFQ) as well as the "match between runs" options were enabled. De-amidated peptides were allowed to be used for protein quantification. Other quantification settings were kept default.

Filtering and further analysis of the MaxQuant/Andromeda workflow output and the analysis of the abundances of the identified proteins were performed with the Perseus 1.5.5.3 module (available at the MaxQuant suite). Peptides were accepted for further analysis when they had a false discovery rate (FDR) of less than $1 \%$ and proteins with at least 2 identified peptides of which at least one was unique and one unmodified. Reversed hits were deleted from the MaxQuant output. The nLC-MSMS system quality was checked with PTXQC (Bielow, Mastrobuoni et al. 2016) using the MaxQuant result files. 


\section{Results and Discussion}

\section{Dialysis membranes experiment}

Sulfide production levels - as marker for metabolic activity - decreased $47 \%$ and $51 \%$ when $\mathrm{S}^{0}$ was trapped in dialysis bags at $\mathrm{pH} 6.5$ and 3.5, respectively (Figure 1a), with the corresponding consumption of electron donor (data not shown). When tracking the number of planktonic cells, a similar tendency was found, samples with dispersed sulfur showed higher number of cells than samples with sulfur trapped in dialysis bags, regardless the $\mathrm{pH}$ value (Figure $1 \mathrm{~b}$ ). However, the decrease in final cell yield was larger than the decrease in metabolic activity, reaching about $78 \%$ and $97 \%$ of the yield from sulfurdispersed medium culture at $\mathrm{pH} 6.5$ and 3.5, respectively.

Sulfide levels in the control groups were below $0.8 \mathrm{mM}$, which is due to the presence of cysteine (nucleophile) as reducing-agent in the medium. These results also suggest that a soluble intermediate might be formed from elemental sulfur. This soluble sulfur molecule would be able to diffuse through the dialysis bag and became available for respiration by $D$. amilsii. The formation and diffusion of this compound seems to be a bottleneck for the process, lowering, therefore, the rates and activity of the sulfur-reducing microorganism.
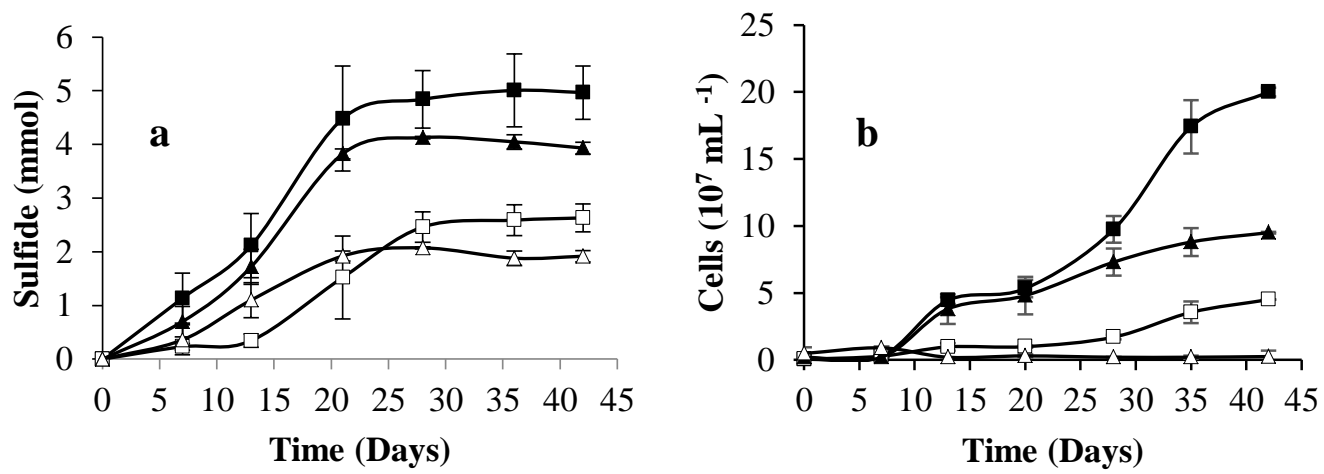

Figure 1 - Hydrogen sulfide production (a) and number of planktonic cells (b) of D. amilsii by $D$. amilsii at $\mathrm{pH} 6.5$ and 3.5 with sulfur dispersed in the medium and sulfur trapped in dialysis bags of $6-8 \mathrm{kDa}$ pore size. The results were averaged from biological triplicate measurements and the standard deviation is shown. The squares represent cultures grown at pH 6.5 and the triangles represent $\mathrm{pH}$ 3.5. Filled symbols represent cultures with sulfur dispersed in the medium and open symbols represent cultures with sulfur trapped in dialysis bags.

Despite the excess of sulfur in the medium and a concentration of sulfide higher than $1 \mathrm{mM}$, HPLC analysis could not detect any polysulfide form in the cultures at $\mathrm{pH} 3.5$ 
or 6.5 , as the detection limits of the method utilized range from 5.4 to $10 \mathrm{mM}$ for derivatized polysulfanes (Roman, Bijmans et al. 2014). The instability of polysulfide at low $\mathrm{pH}$ normally leads to its precipitation as nanocrystals of elemental sulfur, however $\mathrm{S}^{0}$ could not be detected in the cultures grown with dialysis bags.

By applying the Surkov equation (equation 2), rates of sulfur reduction per cell were obtained for both cultures of $D$. amilsii. Cultures incubated with sulfur dispersed in the medium at $\mathrm{pH} 6.5$ and 3.5 showed rates of 18.9 and $10.7 \mathrm{fmol} \mathrm{cell}^{-1}$ day $^{-1}$, respectively. For the cultures inoculated with sulfur trapped in dialysis bags, the obtained rates were higher (18.9 $\mathrm{fmol} \mathrm{cell}^{-1} \mathrm{day}^{-1}$ at $\mathrm{pH} 6.5$ and $7.3 \times 10^{8} \mathrm{fmol} \mathrm{cell}^{-1} \mathrm{day}^{-1}$ at $\mathrm{pH} 3.5$ ) than the obtained rates for cultures with sulfur dispersed in the medium. This can be explained by the lower number of cells counted in suspension, especially at $\mathrm{pH} 3.5$. Combining the sulfide production and the cell yield results (Table 1), the most feasible explanation would be that the low number of planktonic cells was an underestimation of the real cell number. Therefore, scanning electron microscopy was performed at the surface of the dialysis bags at both $\mathrm{pH}$ conditions to assess adhesion of cells to the membrane surface.

Table 1 - Differential characteristics of $D$. amilsii cultures growing at different $\mathrm{pH}$ with sulfur dispersed in the medium or trapped in dialysis bags (6-8 $\mathrm{kDa}$ pore size).

\begin{tabular}{cccccc}
\hline \multirow{2}{*}{$\mathbf{p H}$} & Sulfur & $\begin{array}{c}\text { Sulfide } \\
(\mathbf{m m o l})\end{array}$ & $\begin{array}{c}\text { Cell yield } \\
\left(\mathbf{1 0} \mathbf{~ m L}^{\mathbf{- 1}}\right)\end{array}$ & $\begin{array}{c}\text { Cell rate } \\
\left(\mathbf{f m o l ~ c e l l ~}^{-1} \mathbf{d a y}^{-\mathbf{1}}\right)\end{array}$ & Cell aggregation \\
\hline \multirow{2}{*}{$\mathbf{6 . 5}$} & Dispersed & 5.0 & 20 & 18.9 & - \\
\cline { 2 - 6 } & Trapped & 2.6 & 4.5 & 18.9 & - \\
\hline \multirow{2}{*}{$\mathbf{3} 5$} & Dispersed & 3.9 & 9.5 & 10.7 & + \\
\cline { 2 - 6 } & Trapped & 1.9 & 0.2 & $7.3 \times 10^{8}$ & + \\
\hline
\end{tabular}

A similar strategy adopted by Blumentals, Itoh et al. (1990) and by Pihl, Schicho et al. (1990) also showed that growth and final hydrogen sulfide levels of P. furiosus were considerably lower when elemental sulfur was isolated from the cells in dialysis bags with 6-8 $\mathrm{kDa}$ pore size. The cultures were incubated at $\mathrm{pH} 8.7$ to avoid the conversion of polysulfide into sulfur, and therefore, they were able to detect polysulfide in the medium at concentrations ranging from 0.05 to $0.5 \mathrm{mM}$. In this study diffusion limitations occurred as the differences in hydrogen sulfide production and number of cells in suspension increased with the decrease of sulfur particles size used inside the dialysis bags. They hypothesized that $\mathrm{S}^{0}$ is activated to polysulfide, and this soluble form could support the growth of $P$. furiosus.

Boyd and Druschel (2013) analyzed Acidilobus sulfurireducens in batch cultures with $S^{0}$ sequestered in semipermeable dialysis tubing of 6-8 and 12-14 $\mathrm{kDa}$ pore size and showed that the sulfide production and cellular production rates decreased with decreasing dialysis tubing pore sizes. The net sulfide production rate in their study decreased by $78 \%$ when $S^{0}$ was sequestered in dialysis tubing with pore sizes of $6-8 \mathrm{kDa}$ and $45 \%$ with pore 
sizes of $12-14 \mathrm{kDa}$; the final cell yield decreased by $62 \%$ and $44 \%$, respectively. The conclusion of this study pointed out to different sizes of nanocrystalline $\mathrm{S}^{0}$ as electron acceptors, since nanocrystalline $\mathrm{S}^{0}$ was detected in the medium (Boyd and Druschel 2013).

At $\mathrm{pH} 3.5$, where no increment of planktonic cells was measured, a large number of cells was observed growing attached to the surface of the dialysis membrane (Figure $2 \mathrm{a}$ and $2 \mathrm{~b}$ ). Although some cells could be visualized on the surface of the membrane at $\mathrm{pH} 6.5$, cells were mostly present in suspension, and so, the number of planktonic cells at stationary phase was $20 \times 10^{7}$ cells $\mathrm{mL}^{-1}$. Extracellular polymeric substance (EPS) was visible in both conditions, but at low $\mathrm{pH}$ a significant cell aggregation was observed (Figure 2b), while at high $\mathrm{pH}$ cells appear mostly single or in pairs (Figures $3 \mathrm{a}$ and $3 \mathrm{~b}$ ).

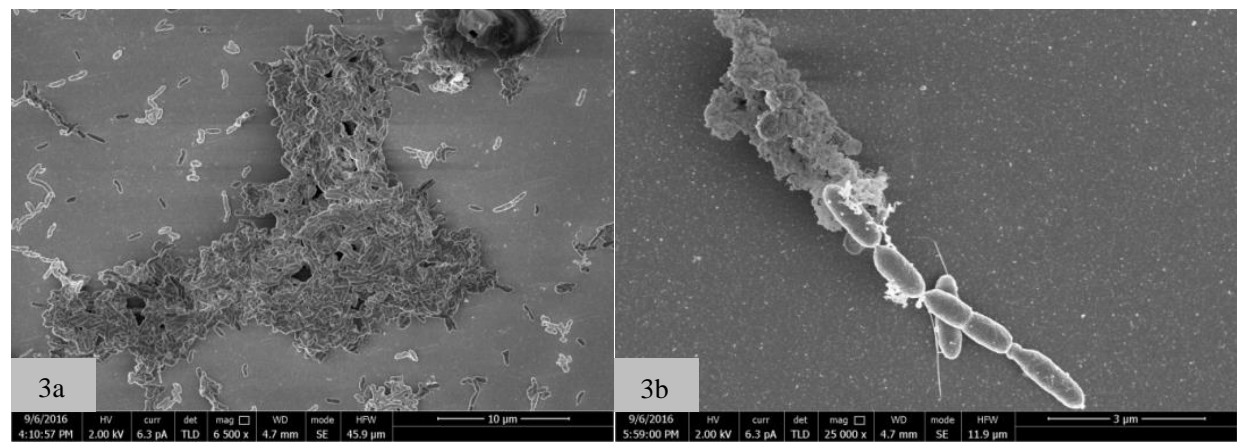

Figure 2a-b - Scanning electron micrographs of the dialysis bags surface in cultures incubated at $\mathrm{pH}$ 3.5. (a) Aggregate of cells of D. amilsii depicted from a larger field. (b) Presence of extracellular polymeric substance (EPS) and flagella in the cells attached to the surface of the membrane.

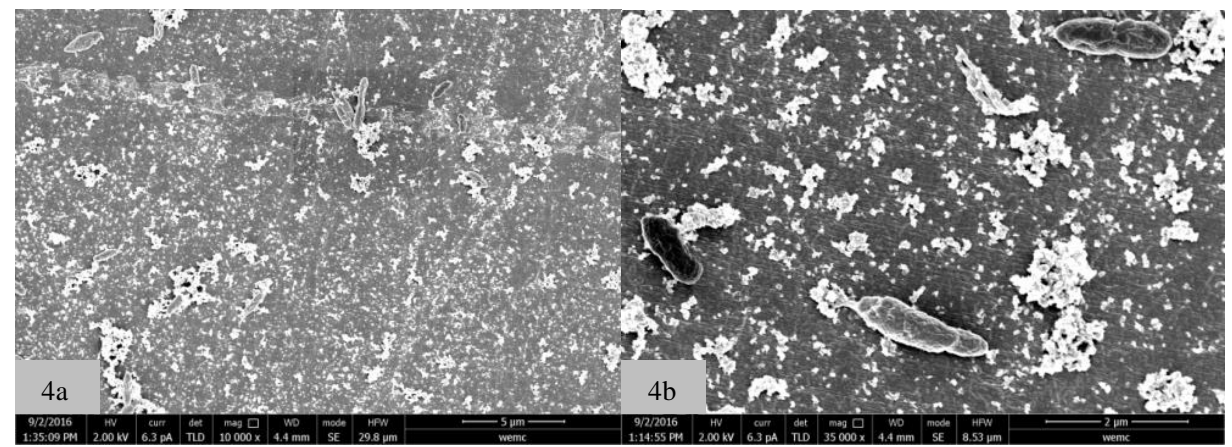

Figure 3a-b - Scanning electron micrographs of the dialysis bags surface in cultures incubated at $\mathrm{pH}$ 6.5. (a) Presence of EPS covering and attaching the cells to the membrane. (b) Larger field depicted revealing few cells attached to surface of the membrane. 


\section{Proteomic analysis}

\section{Differential proteomes}

In the whole proteome, 1012 proteins were identified from 2088 protein coding sequences (CDS) in the genome of D. amilsii (Chapter 5). After very strict filtering, in which only proteins comprising minimally 2 peptides of which at least 1 is unique and 1 is unmodified were considered, 589 protein remained. From the remaining group, 47 proteins showed significantly different intensities within $\mathrm{pH} 3.5$ and 6.5 (p value $<0.05$ and $\mathrm{S} 0=1$ ) (Figure 4). The complete list of proteins with significantly different abundances is given in Supplementary Table S1.

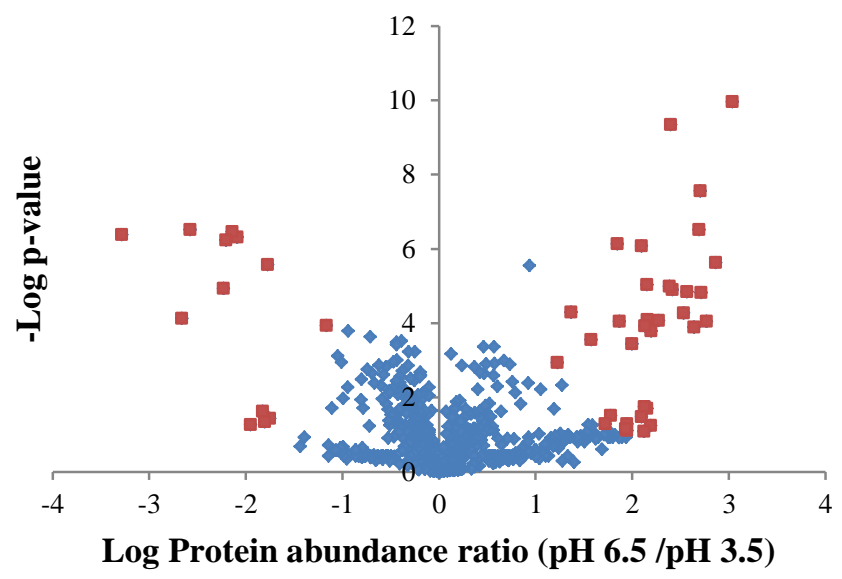

Figure 4 - Volcano plot showing - $\log \mathrm{P}$ values versus $\log$ of protein abundance ratio of all 589 proteins fulfilling strict quantitation criteria. Red dots on the right side, 34 up-regulated proteins at $\mathrm{pH} 6.5$; orange dots on the left side, 13 up-regulated proteins at $\mathrm{pH} 3.5$; blue, not significantly different protein abundances; $\mathrm{p}<0.05$.

\section{Chemolithotrophic Growth}

The [Ni-Fe] membrane-bound hydrogenase - HybABC (HybA - 502; HybB 503; HybC - 504) and its maturation complex HypABCDEF (HypA - 500; HypB - 499; HypC - 506; HypD - 507; HypE - 508; HypF - 505) are encoded in the genome of $D$. amilsii TR1. HybABC was highly abundant in the proteome of the cultures. However the membrane-bound $\mathrm{b}$ cytochrome subunit $\mathrm{HybB}$ could not be identified, likely due to proteomics preparation process. Therefore, $\mathrm{Hyb} \mathrm{ABC}$ is most likely involved in hydrogen metabolism of $D$. amilsii during chemolithotrophic growth, while it might be involved in the export of protons from the cytoplasm to generate proton motive force which will be coupled to ATP generation via $\mathrm{F}_{1} \mathrm{~F}_{0}-\mathrm{ATP}$ synthase activity. 
Carbon dioxide fixation during chemolithotrophic growth of D. amilsii seems to occur via the reductive TCA cycle, producing acetyl-CoA. All the enzymes involved in the TCA cycle operation are found in the proteome when $D$. amilsii is grown with $\mathrm{H}_{2} / \mathrm{CO}_{2}$ as substrates. ATP citrate lyase (1597), fumarate reductases (1536 and 1537) and the catalytic subunit of 2-oxoglutarate ferredoxin oxidoreductases (178) are active and might play a key role in the reversal operation of TCA cycle, as shown by Fuchs (2011). Moreover, three subunits of the tetrameric pyruvate synthase/pyruvate:ferredoxin oxidoreductase (1626, 1627 and 1628) were found in high abundance in both conditions. This enzyme is likely to convert the acetyl-CoA generated into pyruvate that might enter the classical gluconeogenesis route, for which all component enzymes could be detected.

\section{Resistance to High Proton Concentration}

Although the proton translocating $\left(\mathrm{H}^{+}\right)$-ATPase is normally referred to play major role in the maintenance of intracellular $\mathrm{pH}$ homeostasis (Hutkins and Nannen, Cotter and Hill 2003), none of the putative determinants of acid resistance identified in this study correlates to $\left(\mathrm{H}^{+}\right)$-ATPase activity. It seems like D. amilsii does not utilize the reversibility of ATPase to maintain a near-neutral internal $\mathrm{pH}$ in response to acid stress. The proteome showed abundance of some potential acid resistance mechanisms (GroEL, GroES, RecA, excinuclease $\mathrm{ABC}$, amino acid transporters, histidine kinase and $\mathrm{ABC}$ transporters genes). However, except for the amino acid transporters by ATP binding proteins or ABC-type, all the mentioned markers were equally abundant in both culture conditions (Table 2).

Although the chaperonins GroEL and GroES are normally involved in the proper folding of several proteins, they have been reported to be highly abundant at acidic conditions in some species, such as in Lactobacillus plantarum (Heunis, Deane et al. 2014), in which $\mathrm{ABC}$ transporters are also reported to be involved in the resistance to high proton concentration. RecA protein and the damage-specific UvrABC endonuclease were reported to play a central role in mediating SOS responses and to repair DNA by nucleotide excision at acidic conditions in some bacterial species (Sousa, Lima et al. 2006, van der Veen, van Schalkwijk et al. 2010). In H. pylori, Loh and Cover (2006) reported the role of histidine kinase as an acid sensor, increasing its transcription when at acidic conditions.

Considering that the environment from where D. amilsii was isolated has an average $\mathrm{pH}$ around 2.3 (Chapter 3), it sounds reasonable that genes conferring resistance to acidic conditions can be constitutively expressed in this microorganism. Therefore, the similar levels of proteins under different cultivation conditions might reflect the low influence of internal and external stimuli on the gene expression or repression. 
Table 2 - Differential proteomic data on the acid resistance markers present in $D$. amilsii TR1 at low and high $\mathrm{pH}$. The logarithm values of the intensities were calculated as average of biological triplicates.

\begin{tabular}{cccc}
\hline Locus Tag & Protein & Hyd_S_3.5 & Hyd_S_6.5 \\
\hline 1280 & GroEL & 10.0 & 10.0 \\
\hline 1281 & GroES & 8.6 & 8.4 \\
\hline 136 & RecA & 6.8 & 7.2 \\
\hline 493 & Excinuclease ABC & 6.9 & 6.5 \\
\hline 572 & Amino acid transporter & 6.0 & 5.4 \\
\hline 573 & Amino acid transporter & 5.8 & 5.8 \\
\hline 1489 & Amino acid transporter & 6.6 & 5.5 \\
\hline 1490 & Amino acid transporter & 5.9 & - \\
\hline 254 & Amino acid transporter & 7.1 & 7.0 \\
\hline 1381 & Histidine kinase & 7.4 & 7.6 \\
\hline 576 & ABC transporter & 7.2 & 8.2 \\
\hline 768 & ABC transporter & 8.3 & 7.2 \\
\hline 1493 & ABC transporter & 8.7 & 6.8 \\
\hline 1716 & ABC transporter & 7.5 & 7.2 \\
\hline 2006 & ABC transporter & 7.1 & 7.2 \\
\hline 203 & ABC transporter & 7.0 & 8.2 \\
\hline 1745 & ABC transporter & 7.0 & 6.7 \\
\hline 260 & ABC transporter & 8.4 &
\end{tabular}

The multimodular transpeptidase transglycolase enzyme (483), involved in cell envelope biogenesis, as well as the glutamate-1-semialdehyde aminotransferase (55), the last enzyme in the $\mathrm{C}_{5}$ pathway for the conversion of glutamate into the tetrapyrrole precursor $\delta$-aminolaevulinate in plants, algae and several bacteria (Palmieri, Di Palo et al. 1996); the phosphoglycerate dehydrogenase (1993), which catalyzes the conversion of 3 phosphoglycerate into 3-phosphohydroxypyruvate, a committed step in the phosphorylated pathway of L-serine, cysteine and glycine biosynthesis (Dey, Hu et al. 2005); and an amino acid-binding protein (569), reported to have increased abundances in cultures of Bradyrhizobium japonicum growing at $\mathrm{pH} 4.7$ (Puranamaneewiwat, Tajima et al. 2006) were exclusively produced in $D$. amilsii cultures at $\mathrm{pH} 3.5$, and therefore, they might also be key determinants of acid tolerance in this species.

\section{Cell-sulfur interaction related enzymes}

Some microorganisms have been shown to reduce or oxidize elemental sulfur by direct contact. Sulfur reducers/oxidizers normally produce exopolysaccharides via different biosynthesis pathways: (a) the Wzx/Wzy-dependent pathway, in which the polymerization and export of EPS are carried out by a secretion system consisting of proteins encoded by pssL and pssTNOP genes; (b) the ATP-binding cassette (ABC) transporter-dependent 
pathway, that is mainly present in capsular polysaccharide biosynthesis instead of EPS; (c) the synthase-dependent pathway, which secretes complete polymer strands across the membranes and the cell wall and is thought to be mediated by a glycosyltransferase that serves as a polymerase and as an exporter, and (d) the extracellular synthesis by use of a single sucrase (Schmid, Sieber et al. 2015, Chrismas, Barker et al. 2016).

In D. amilsii cultures, the glycosyl transferase (738) was produced in both conditions, with no significant difference in intensities. Flagellar proteins were also abundant in both conditions, such as FliL (467), FliD (474), FliH (1176), FlhA (457), FlgK (840), FlgL (841), FlaG (475) and FlaA (542), as well as proteins involved in the biosynthesis of pili, such as TraB (308), PilQ (309, 1257), PilT (316, 1454), PilB (650), PliM (1261) and PilC (1455), which are reported to be involved in attachment and biofilm formation of microorganisms (O'Toole and Kolter 1998, Klausen, Heydorn et al. 2003).

Although the pathways for production of EPS and cell-sulfur attachment are well studied, the mechanism of sulfur uptake by microbial cells remains enigmatic. A thiol:disulfide interchange protein (DsbC) that is equally abundant in both conditions might be involved in the uptake and mobilization of sulfur by formation of a covalent disulfide bond with the thiol groups present in the outer membrane of the microorganism, as described for some green sulfur bacteria (Sakurai, Ogawa et al. 2010). Besides, one rhodanese-like thiosulfate sulfurtransferase (1100) was found to be highly abundant at both $\mathrm{pH}$ values, while two others (1987 and 2007) were only abundant in cultures growing at $\mathrm{pH}$ 3.5. The identification and the intensities of all the proteins abundant in proteome analysis and potentially involved in cell attachment, respiration and uptake of elemental sulfur are described in Table 3.

In this study, cell-sulfur interaction and the uptake of elemental sulfur seem to be essential for D. amilsii to thrive at low $\mathrm{pH}$. No planktonic cells were detected, and cells jsut accumulated around the membrane, in close proximity to the sulfur. This would be a considerable bottleneck that explains the reduction of sulfide production at low $\mathrm{pH}$. The presence of planktonic cells at $\mathrm{pH} 6.5$ suggest that polysulfide might play a role in the respiration process, although the membrane clearly reduced activity as well, likely due to the diffusion of polysulfide through it. The abundance of glycosyl transferase reinforce the hypothesis that growth of $D$. amilsii benefits from EPS production. Besides, the presence of proteins involved in the production of flagellum and pili also indicate that the direct cell contact with the bulk solid-phase $S^{0}$ might be involved in the uptake of the substrate.

Although the formation and excretion of EPS ensures cell adhesion to the insoluble substrate, the mechanisms of elemental sulfur uptake by the cells are still not understood. Different hypotheses have been proposed for sulfur-oxidizing microorganisms. Findings support the direct uptake of the polymeric fraction of elemental sulfur (Franz, Lichtenberg et al. 2007, Franz, Gehrke et al. 2009), or the reaction of membrane low- 
molecular-mass substances (such as thiols) with $-\mathrm{SH}$ or $-\mathrm{S}-\mathrm{S}$ - groups on the surface of elemental sulfur, generating linear soluble polysulfanes that can be further metabolized (Rohwerder and Sand 2003).

Evidence of a flagellar protein that can be involved in a close approach to elemental sulfur through a chemical bond was found in Acidithiobacillus ferrooxidans (Ohmura, Tsugita et al. 1996). However, the sulfur-binding mechanism in this organism is not fully elucidated. Besides, EPS production in A. ferrooxidans and A. thiooxidans when grown attached to pyrite or sulfur was shown to have similar adhesion functions (Gehrke, Telegdi et al. 1998, Harneit, Göksel et al. 2006). Takakuwa, Fujimori et al. (1979) elucidated the properties of the adhesion of A. thiooxidans to solid sulfur particles during the sulfur oxidation process by the presence of thiol groups in the outer-membrane of the microorganism. Later, Rohwerder and Sand (2003) analyzed the sulfur oxidation process in A. thiooxidans, A. ferrooxidans and Acidiphilium acidophilum and suggested the presence of thiols in the outer membrane as essential for the mobilization of elemental sulfur and its transport into the cytoplasm as persulfide sulfane sulfur. Conversely, cell envelope thiol groups did not play a role in cell adhesion of the sulfur-oxidizing A. albertensis, but this microorganism was shown to produce a glycocalyx that enabled interaction between cells and solid surfaces, such as sulfur and glass (Bryant, Costerton et al. 1984). The mechanism of sulfur uptake in these microorganisms, however, is still not understood. Moreover, Giuliani, Jourlin-Castelli et al. (2010) characterized a periplasmic rhodanese sulfurtransferase with a disulfide bridge from the hyperthermophilic bacterium Aquifex aeolicus. They reported high activity in cultures grown by sulfur reduction, in which there was bacterial adhesion to the solid substrate. The rhodanese has been reported to catalyze sulfur transfers from thiosulfates and polysulfide in bacteria, archaea and eukaryotes.

\section{Sulfur reduction pathway}

Genome analysis of $D$. amilsii revealed the presence of genes encoding two sulfur enzymes: sulfide dehydrogenase (SudhB - 1852 and SudhA - 1853) and sulfur reductase (SreB - 1357; SreC - 1358, SreA - 1359, SreD - 1360 and SreE - 1361) (Chapter 5), which are reported to be involved in the reduction of polysulfide and elemental sulfur (Ma and Adams 1994, Laska, Lottspeich et al. 2003, Florentino, Weijma et al. 2016). The presence of enzymes involved in reduction of soluble and insoluble forms of sulfur encoded in the genome and the ability of $D$. amilsii to grow in a range of $\mathrm{pH}$ in which polysulfide can be present $(\mathrm{pH} 6.5)$ and absent $(\mathrm{pH} 3.5)$ arouses the possibility of $D$. amilsii to use both elemental sulfur and polysulfide as terminal electron acceptors. 
Table 3 - Abundant enzymes potentially involved in cell attachment and uptake of elemental sulfur in the proteome analysis of cultures grown at $\mathrm{pH} 3.5$ and 6.5. The logarithm values of the intensities were calculated as average of biological triplicates.

\begin{tabular}{|c|c|c|c|}
\hline Locus Tag & Description & Log LFQ & Log LFQ \\
\hline \multicolumn{4}{|c|}{ Cell-sulfur attachment } \\
\hline 1408 & Glycosyl transferase & 5.6 & 6.3 \\
\hline 467 & Flagellar biosynthesis, FliL & 6.9 & 6.8 \\
\hline 474 & Flagellar hook-associated, & 6.3 & 7.1 \\
\hline 1176 & Flagellar assembly, FliH & 5.8 & 5.1 \\
\hline 457 & Flagellar biosynthesis, FlhA & 5.2 & 5.4 \\
\hline 840 & $\begin{array}{l}\text { Flagellar hook-associated, } \\
\text { FlgK }\end{array}$ & 5.9 & 6.7 \\
\hline 841 & $\begin{array}{c}\text { Flagellar hook-associated, } \\
\text { FlgL }\end{array}$ & 5.8 & 6.5 \\
\hline 475 & Flagellar biosynthesis, FlaG & 6.1 & 7.3 \\
\hline 542 & Flagellin, FlaA & 7.4 & 8.4 \\
\hline 308 & Pilus assembly, TraB & 7.1 & 7.0 \\
\hline 309 & $\begin{array}{l}\text { Type IV pilus biogenesis, } \\
\text { PilQ }\end{array}$ & 7.5 & 7.7 \\
\hline 1257 & $\begin{array}{c}\text { Type IV pilus biogenesis, } \\
\text { PilO }\end{array}$ & 7.0 & 8.0 \\
\hline 316 & Twitching motility, PilT & 7.4 & 7.5 \\
\hline 1454 & Twitching motility, PilT & 6.1 & 6.4 \\
\hline 650 & $\begin{array}{l}\text { Type IV fimbrial assembly, } \\
\text { PilB }\end{array}$ & 7.1 & .8 \\
\hline 1261 & $\begin{array}{c}\text { Type IV fimbrial assembly, } \\
\text { PilM }\end{array}$ & - & 6.7 \\
\hline 1455 & $\begin{array}{c}\text { Type IV fimbrial assembly, } \\
\text { PilC }\end{array}$ & 6.9 & 7.0 \\
\hline \multicolumn{4}{|c|}{ Sulfur uptake } \\
\hline 693 & $\begin{array}{l}\text { Thiol:disulfide interchange } \\
\text { DsbC }\end{array}$ & 7.8 & 7.8 \\
\hline 1987 & $\begin{array}{l}\text { Rhodanese-related } \\
\text { sulfurtransferase }\end{array}$ & 7.3 & - \\
\hline 2007 & $\begin{array}{l}\text { Rhodanese-related } \\
\text { sulfurtransferase }\end{array}$ & 6.6 & - \\
\hline 1100 & Thiosulfate sulfurtransferase & 7.8 & 7.9 \\
\hline
\end{tabular}

The subunits of the sulfur reductase were not detected in any condition in our proteome, while sulfide dehydrogenase was highly abundant at low and high pH (Table 4). However, as sulfur reductase is a membrane-bound protein, the proteomics preparation process might have led to an underrepresentation of this enzyme in the dataset. 
It is debated that these water-soluble sulfur compounds would be sufficiently mobile to cross the outer membrane, probably by diffusion, whereas elemental sulfur would precipitate at the cell membrane. However, the instability of polysulfide at acidic solutions would lead it to decompose into elemental sulfur and sulfide (Steudel 2003). Consequently, even if there is an initial nucleophilic attack of sulfide to sulfur and polysulfide formation, elemental sulfur would accumulate in the medium. As shown by Rohwerder and Sand (2003), elemental sulfur formed from the decomposition of polysulfide might not precipitate, but react with the thiol groups of the outer-membrane proteins, generating persulfide sulfur, and therefore, the last compound can be transported to the cytoplasm by thiol bearing membrane proteins.

Table 4 - Abundant enzymes potentially involved in respiration of elemental sulfur in the proteome analysis of cultures grown at $\mathrm{pH} 3.5$ and 6.5 . The logarithm values of the intensities were calculated as average of biological triplicates.

\begin{tabular}{clcc}
\hline Locus Tag & Description & $\begin{array}{c}\text { Log LFQ } \\
\text { intensity } \\
\text { pH 3.5 }\end{array}$ & $\begin{array}{c}\text { Log LFQ } \\
\text { intensity } \\
\text { pH 6.5 }\end{array}$ \\
\hline \multicolumn{1}{c}{ Sulfur reduction } & & \\
\hline 1853 & Sulfide dehydrogenase SudhA & 7.0 & 7.2 \\
\hline 1852 & Sulfide dehydrogenase SudhB & 7.4 & 7.3 \\
\hline
\end{tabular}

The high abundance of sulfide dehydrogenase in the cultures could imply a crucial role of this enzyme in the reduction of elemental sulfur. However, ferredoxins were abundant in the cultures, with 2.6 fold abundance at $\mathrm{pH} 6.5$ and therefore, this enzyme could also function as a reduced ferredoxin:NADP oxidoreductase (NfnAB), since it has a very high affinity for reduced ferredoxin, as shown to happen in Pyrococcus furiosus cultures (Ma and Adams 1994). Later in (2001), the same authors studied the properties of the ferredoxin:NADP oxidoreductase and showed that high activity during the NADPHdependent reduction of polysulfide to $\mathrm{H}_{2} \mathrm{~S}$ (14 units/mg), which was comparable to that measured in the ferredoxin-dependent reduction of NADP (18 units/mg). The authors, however, could not measure the intracellular concentration of polysulfide, and so, as the apparent $\mathrm{Km}$ value for polysulfide is $1.25 \mathrm{mM}$, more than three orders of magnitude greater than that for reduced ferredoxin, the role of this enzyme in catalyzing $\mathrm{S}^{0}$ reduction in vivo was not defined.

In $D$. amilsii, the $\mathrm{pH}$ of the analyzed cultures (3.5 and 6.5) does not allow great formation of polysulfide, as at $\mathrm{pH} 3$ the concentration of polysulfide in the medium with excessive sulfide is in average $10^{-12} \mathrm{M}$ and at $\mathrm{pH} 6$ around $8 \mu \mathrm{M}$ at temperatures around $60^{\circ} \mathrm{C}$ (Schauder and Müller 1993). Therefore, polysulfide is not expected to be available for the enzyme to act as sulfide dehydrogenase, and so it is most likely that the thiosulfate sulfurtransferase is the key enzyme in the process, especially at low $\mathrm{pH}$, when two 
thiosulfate sulfurtransferases were exclusively abundant. Figure 6 shows the possible mechanisms adopted by $D$. amilsii for the uptake and respiration of sulfur via sulfide dehydrogenase.

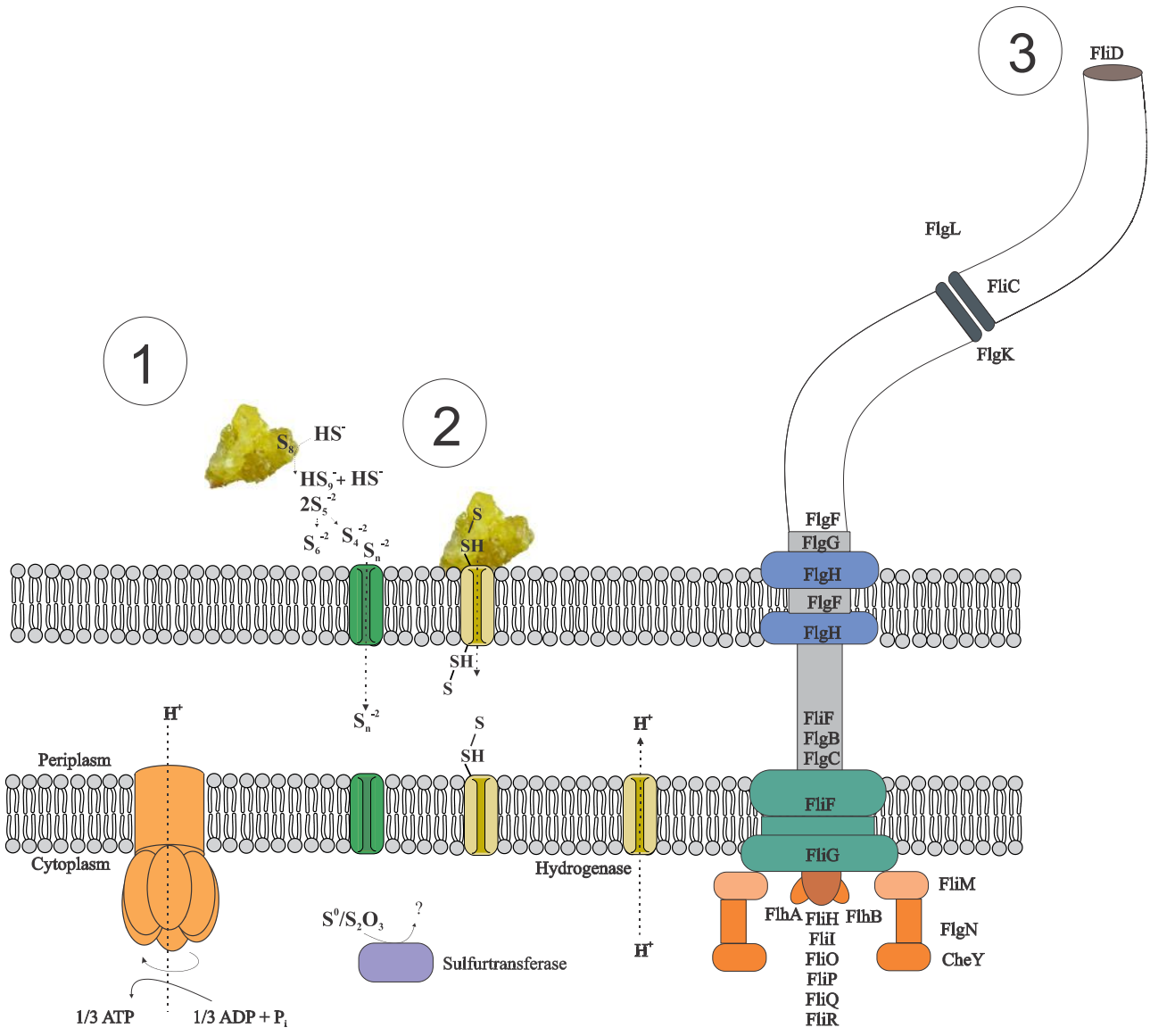

Figure 6 - Summary scheme of the possible strategies adopted by $D$. amilsii to uptake and reduce element sulfur or polysulfide/persulfide sulfanes via different membrane-bound sulfurtransferases. 1 - Nucleophilic attack of sulfur by sulfide, generating polysulfide that crosses the cell membrane. 2 - Attachment of elemental sulfur to the cell and interaction between sulfur and thiol groups present in the outer-membrane, generating soluble polysulfanes. 3 - Chemical bond between polymeric elemental sulfur and the flagellar protein (FliD).

\section{Concluding remarks}

In this study, we showed that sulfur respiration and growth of $D$. amilsii benefit from contact with the elemental sulfur. Proteomic analysis revealed the involvement of hydrogenase $\mathrm{HydABC}$ for oxidation of hydrogen during chemolitotrophic growth, as well as complete pathway for $\mathrm{CO}_{2}$ fixation via the reductive TCA cycle. There is a possible constitutive expression of genes involved in the resistance to acid conditions in D. amilsii, 
but proteins with very few overlapping in acid resistance related literature were exclusively detected at low $\mathrm{pH}$. Therefore, deeper investigation and a comparative assessment is needed to confirm the true involvement of the putative markers identified in this study. This study also revealed different sulfurtransferases highly abundant at low and high $\mathrm{pH}$, suggesting that they might be key players in the sulfur/polysulfide reduction in $D$. amilsii, while sulfide dehydrogenase seems to function as a ferredoxin:NADP oxidoreductase in this microorganism. Further analysis need to be performed to confirm the role of the rhodaneselike proteins in sulfur respiration and the specific substrate for them at different $\mathrm{pH}$ conditions.

\section{Acknowledgements}

This research was supported by the organization of the Brazilian Government for the development of Science and Technology CNPq (Conselho Nacional de Desenvolvimento Científico e Tecnológico), by ERC project 323009 and a Gravitation project from the Netherlands Ministry of Education, Culture and Science (024.002.002). The authors thank Monika Jarzembowska (WUR, Wageningen, The Netherlands) for the support with the scanning electron microscopy analysis. 


\section{Supplementary data}

Table S1 - Differentially expressed proteins in a pairwise comparison Hyd_S_6.5 vs Hyd_S_3.5. Positive values of the t-test difference (highlighted blue) represent the proteins up-regulated at circumneutral $\mathrm{pH}$, while the negative values (highlighted orange) represent the proteins up-regulated in acidotolerant cultures ( $\mathrm{pH} 3.5$ ). The locus tag for the genes encoded in D. amilsii is DESAMIL20_*. To avoid repetition of the prefix in the table, the locus tags are represented only by the specific identifier.

\begin{tabular}{|c|c|c|c|}
\hline $\begin{array}{c}\text { Locus } \\
\text { Tag }\end{array}$ & Protein & $\begin{array}{l}-\log P \\
\text { value }\end{array}$ & $\begin{array}{c}\text { t-test } \\
\text { difference }\end{array}$ \\
\hline 673 & Hypothetical protein & 9.96 & 3.04 \\
\hline 1531 & Threonine synthase & 5.63 & 2.86 \\
\hline 1855 & Bacillosamine/Legionaminic acid biosynthesis aminotransferase & 4.05 & 2.77 \\
\hline 272 & Superfamily II DNA/RNA helicases & 4.82 & 2.72 \\
\hline 946 & Aspartate carbamoyltransferase & 7.56 & 2.71 \\
\hline 1574 & LSU ribosomal protein $\mathrm{L} 23 p$ & 6.52 & 2.69 \\
\hline 687 & Hypothetical protein & 3.89 & 2.64 \\
\hline 1902 & SSU ribosomal protein S16p & 4.84 & 2.57 \\
\hline 1714 & Molybdenum transport system protein ModD & 4.27 & 2.53 \\
\hline 187 & GTP-binding and nucleic acid-binding protein YchF & 4.90 & 2.41 \\
\hline 658 & Hpa2 protein & 9.35 & 2.40 \\
\hline 1705 & Hypothetical protein & 4.99 & 2.39 \\
\hline 405 & Mobile element protein & 4.07 & 2.27 \\
\hline 332 & Mobile element protein & 4.07 & 2.27 \\
\hline 222 & $\mathrm{~N}$-acetylglucosamine-1-phosphate uridyltransferase & 3.80 & 2.19 \\
\hline 192 & Hypothetical protein & 1.24 & 2.19 \\
\hline 969 & Aconitate hydratase & 4.10 & 2.16 \\
\hline 1610 & $\mathrm{~N}$-acetyl-gamma-glutamyl-phosphate reductase & 1.70 & 2.15 \\
\hline 301 & Hypothetical protein & 5.04 & 2.15 \\
\hline 1235 & L-aspartate oxidase & 3.93 & 2.13 \\
\hline 1038 & UDP-N-acetylmuramoylalanine-D-glutamate ligase & 1.75 & 2.13 \\
\hline 1001 & MotA/TolQ/ExbB proton channel family protein & 1.09 & 2.12 \\
\hline 2011 & Threonine dehydratase biosynthetic & 6.08 & 2.10 \\
\hline 218 & Inositol-1-monophosphatase & 1.48 & 2.10 \\
\hline 1679 & Glycogen branching enzyme & 3.45 & 2.00 \\
\hline 1905 & LSU ribosomal protein L19p & 1.29 & 1.95 \\
\hline 1004 & ATP synthase gamma chain & 1.11 & 1.94 \\
\hline 840 & Flagellar hook-associated protein FlgK & 1.16 & 1.93 \\
\hline 1726 & Molybdopterin-guanine dinucleotide biosynthesis protein MobB & 4.05 & 1.87 \\
\hline 1251 & Type II restriction enzyme MjaIII & 6.14 & 1.85 \\
\hline 1353 & Efflux transporter, RND family, MFP subunit & 1.52 & 1.78 \\
\hline
\end{tabular}




\begin{tabular}{cccc}
\hline $\mathbf{3 3}$ & Hypothetical protein YebC & 1.29 & 1.72 \\
\hline $\mathbf{1 6 9 4}$ & Phosphoribosylformylglycinamidine cyclo-ligase & 3.55 & 1.57 \\
\hline $\mathbf{1 4 2 9}$ & $\begin{array}{c}\text { Sulfite reduction-associated complex DsrMKJOP protein DsrK } \\
(=\text { HmeD) }\end{array}$ & 4.30 & 1.37 \\
\hline $\mathbf{1 3 3 7}$ & Respiratory nitrate reductase alpha chain & 2.94 & 1.23 \\
\hline $\mathbf{5 1 4}$ & Tungstate ABC transporter, $\mathrm{p}$ & 3.93 & -1.16 \\
\hline $\mathbf{2 0 1 4}$ & hypothetical protein & 1.43 & -1.75 \\
\hline $\mathbf{7 9 6}$ & Enoyl-CoA hydratase & 5.57 & -1.78 \\
\hline $\mathbf{1 5 9 9}$ & 2-methylcitrate dehydratase & 1.35 & -1.80 \\
\hline $\mathbf{5 6 3}$ & Acriflavin resistance protein & 1.63 & -1.83 \\
\hline $\mathbf{1 1 9 1}$ & Hypothetical protein & 1.27 & -1.95 \\
\hline $\mathbf{8 8 2}$ & NAD kinase & 6.31 & -2.09 \\
\hline $\mathbf{1 9 1 6}$ & Transketolase, N-terminal section & 6.46 & -2.14 \\
\hline $\mathbf{9 2 6}$ & Manganese-dependent inorganic pyrophosphatase & 6.23 & -2.20 \\
\hline $\mathbf{5 5}$ & Glutamate-1-semialdehyde aminotransferase & 4.94 & -2.23 \\
\hline $\mathbf{2 0 0 7}$ & Thiosulfate sulfurtransferase, rhodanese-like & 6.52 & -2.58 \\
\hline $\mathbf{6 1 6}$ & TIM-barrel signal transduction protein & 4.13 & -2.66 \\
\hline $\mathbf{1 9 8 7}$ & Putative thiosulfate sulfurtransferase & 6.38 & -3.28 \\
\hline
\end{tabular}


Chapter 6 



\begin{abstract}
Desulfurella amilsii strain TR1 is an acidotolerant, slightly thermophilic sulfur-reducing bacterium that was isolated from sediments of the acidic Tinto river in Spain. The strain requires elemental sulfur or thiosulfate as terminal electron acceptor for growth on organic compounds or $\mathrm{H}_{2} / \mathrm{CO}_{2}$, and it is also able to grow in the absence of external electron donor, by splitting elemental sulfur into sulfate and sulfide. To gain insight into the enzymes involved in sulfur metabolism, the proteome of D. amilsii cultures grown on acetate with sulfur, acetate with thiosulfate and by sulfur disproportionation was analyzed. The presence of rhodanese-like thiosulfate sulfurtransferase proteins suggests their involvement in sulfur and thiosulfate respiration and sulfur disproportionation although further biochemical studies are needed to confirm their role. The respiration of thiosulfate likely involves thiosulfate reductase and dissimilatory sulfite reductase. Utilization of acetate in D. amilsii likely occurs with its activation via the acetyl-CoA synthetase enzyme and further oxidation in the citric acid cycle. This is the first reported evidence of acetate activation via ACS in sulfur-reducing bacteria. Besides, the $\mathrm{CO}_{2}$ fixation in $D$. amilsii cultures seems to occur via the reductive citric acid cycle operation. This is the first comparative proteomics study on an acidotolerant sulfur reducer.
\end{abstract}

The locus tag for the genes encoded in D. amilsii is DESAMIL20_*. To avoid repetition of the prefix in the tables, the locus tags are represented only by the specific identifier. 


\section{Introduction}

Microorganisms able to respire elemental sulfur are scattered over the tree of life, with more than one hundred genera represented (Florentino, Weijma et al. 2016). The majority of sulfur-reducing prokaryotes is able to use reduced inorganic compounds, such as hydrogen as source of energy (Segerer, Neuner et al. 1986, Bonch-Osmolovskaya, Sokolova et al. 1990, Caccavo Jr., Lonergan et al. 1994, Stetter 1996, Miroshnichenko, Rainey et al. 1999), as well as several organic substrates, such as alcohols, organic acids and sugars (Bonch-Osmolovskaya, Sokolova et al. 1990, Finster, Coates et al. 1997, Dirmeier, Keller et al. 1998, Boyd, Jackson et al. 2007). Besides, they can, depending on the species, grow in a very broad range of $\mathrm{pH}(1-10.5)$ though the majority is neutrophilic, and temperature $\left(-2-110^{\circ} \mathrm{C}\right)$. Although those microorganisms are of great importance for the biogeochemical cycle of sulfur in extreme environments, from where they have most frequently been isolated (Bonch-Osmolovskaya, Sokolova et al. 1990, Stetter 1996, Alain, Callac et al. 2009, Birrien, Zeng et al. 2011), little detailed knowledge on sulfur compounds respiration, disproportionation and oxidation of organic substrates is available. The majority of the known sulfur reducers in the bacterial domain belong to the phylum Proteobacteria. In this group, Desulfurellaceae family comprises the genera Desulfurella and Hippea, inhabiting terrestrial environments and submarine hot vents, respectively (Greene 2014). Desulfurella amilsii is an acidotolerant and slightly thermophilic sulfurreducing bacterium isolated from sediments of the acidic Tinto river in Spain able to reduce disproportionate and reduce sulfur and reduce thiosulfate.

Only few sulfur reducers are studied in detail, such as Wolinella succinogenes (Klimmek, Kröger et al. 1991), Pyrococcus furiosus (Ma and Adams 1994) and Acidianus ambivalens (Laska, Lottspeich et al. 2003), from which all enzymes reported to be involved in sulfur reduction were isolated; and Desulfuromonas acetooxidans and Desulfurella acetivorans that were investigated for the mechanisms of acetate activation and oxidation (Schmitz, Bonch-Osmolovskaya et al. 1990).

The ability to reduce thiosulfate is widespread among sulfur reducers (Stetter, Fiala et al. 1990, Fardeau, Ollivier et al. 1997, Fardeau, Magot et al. 2000, Florentino, Brienza et al. 2016). Thiosulfate respiration involves a thiosulfate reductase which catalyzes the reaction displayed in equation 1. Although this enzyme is called thiosulfate reductase, when generating sulfite in the cultures, it performs a kind of disproportionation, in which thiosulfate (oxidation state +2 ) is split into sulfide (oxidation state -2 ) and sulfite (oxidation state +4 ) The sulfite produced in the thiosulfate reductase reaction is reduced by dissimilatory sulfite reductase, in association with the DsrMKJOP complex, to sulfide in an energy-yielding reaction (equation 2) (Stoffels, Krehenbrink et al. 2012). 


$$
\begin{aligned}
& \mathrm{S}_{2} \mathrm{O}_{3}^{2-}+2 \mathrm{H}^{+}+2 e^{-} \rightarrow \mathrm{HS}^{-}+\mathrm{HSO}_{3}^{-} \text {equation (1) } \\
& \mathrm{SO}_{3}^{2-}+6 \mathrm{H}^{+}+6 e^{-} \rightarrow \mathrm{S}^{2-}+3 \mathrm{H}_{2} \mathrm{O} \text { equation (2) }
\end{aligned}
$$

Sulfur disproportionationis described for some sulfur reducers from the Proteobacteria, Firmicutes and Thermodesulfobacteria phyla (Finster, Leiesack et al. 1998, Finster 2008, Hardisty, Olyphant et al. 2013, Florentino, Brienza et al. 2016). However, microbial disproportionation of elemental sulfur into sulfide and sulfate (equation 3 ) is a poorly characterized part of the sulfur cycle. Based on enzyme assays, it is reported that sulfite is a key intermediate that is oxidized to sulfate. In sulfur (non-sulfate) reducers, sulfide is thought to be generated by a sulfur-reducing enzyme (Finster 2008, Hardisty, Olyphant et al. 2013). The mechanism of sulfite formation in sulfur disproportionation is not yet understood.

$$
4 \mathrm{~S}^{0}+4 \mathrm{H}_{2} \mathrm{O} \rightarrow \mathrm{SO}_{4}^{2-}+3 \mathrm{H}_{2} \mathrm{~S}+2 \mathrm{H}^{+} \text {equation (3) }
$$

In Chapter 6, we focused on the chemolithotrophic growth of D. amilsii with sulfur respiration at low and high $\mathrm{pH}$. In this chapter, we compared the proteomes of $D$. amilsii cultures grown at its optimum $\mathrm{pH}$ (6.5), using acetate as electron donor and sulfur or thiosulfate as electron acceptors and by disproportionation of elemental sulfur to elucidate the potential metabolic systems involved in each condition. This is the first comparative proteomics analysis on acidotolerant sulfur-utilizing species growing in 3 different conditions.

\section{Materials and methods}

\section{Culture conditions}

Cells were grown in 500-mL anoxic medium prepared as described elsewhere (Florentino, Weijma et al. 2015) bicarbonate-buffer was omitted as described by SánchezAndrea, Stams et al. (2013) and $\mathrm{pH}$ was adjusted with $\mathrm{HCl}$ before autoclaving. Cultures were supplemented with elemental sulfur or thiosulfate as electron acceptors in a concentration of $25 \mathrm{mM}$. Acetate $(5 \mathrm{mM})$ was added as electron donor to the corresponding cultures. One group was analyzed for disproportionation of elemental sulfur and therefore did not receive any external electron donor. Cultivation was performed in biological triplicates. The conditions in which the cultures were grown is described in Table 1.

Table 1 - Experimental conditions for comparative proteomic analysis

\begin{tabular}{ccc} 
Description & Electron donor & Electron acceptor \\
Acet_S_6.5 & Acetate & Sulfur \\
Acet_Thio_6.5 & Acetate & Thiosulfate \\
Disp_S_6.5 & - & Sulfur \\
\hline
\end{tabular}




\section{Proteins extraction and identification}

Proteins were extracted from cultures grown in the above mentioned conditions (Table 1) during the late exponential phase, when the average protein concentration was 5 $\mu \mathrm{g} \mathrm{mL}{ }^{-1}$. Cultures were centrifuged $\left(10 \mathrm{~min}, 4^{\circ} \mathrm{C}, 14000 \mathrm{rpm}\right)$ and the cell pellets were resuspended in $0.5 \mathrm{~mL}$ SDT-lysis buffer (50 mM DTT + 4\% (w/v) SDS in $100 \mathrm{mM}$ Tris/HCl $\mathrm{pH}$ 7.6) and $10 \mu \mathrm{M}$ phenylmethylsulfonyl fluoride (PMFS). The suspension was sonicated 6 times using a probe sonicator, in cycles of 30 seconds pulse and 30 seconds rest intervals on ice. Unbroken cells and cell debris were removed by centrifugation at $13000 \mathrm{rpm}$ for 10 min and the protein concentration in the supernatant was measured with the Pierce BCA Protein Assay Kit (Thermo Scientific, Illinois, USA) according to manufacturer's instructions.

The identification of proteins, filtering and bioinformatics analysis for each biological replicate were performed in technical triplicates as described in Chapter 6. A Desulfurella amilsii protein sequence database (NCBI accession number MDSU00000000) was used together with a database of sequences of common contaminants, such as: BSA (P02769, bovin serum albumin precursor), Trypsin (P00760, bovin), Trypsin (P00761, porcin), Keratin K22E (P35908, human), Keratin K1C9 (P35527, human), Keratin K2C1 (P04264, human) and Keratin K1CI (P35527, human).

\section{Results and discussion}

\section{Differentially expressed proteome analysis}

A set of 1012 proteins was identified in the three conditions studied from a total of 2088 protein coding sequences (CDS) identified in the genome of D. amilsii (Florentino, Stams et al. 2016, Chapter 5), from which 601 protein groups remained after strict filtering of the data across the three analyzed conditions.

Of the 601 protein groups, 112 showed significantly different intensities between sulfur-reducing and sulfur-disproportionating cultures; 92 between sulfur and thiosulfatereducing cultures and 137 between thiosulfate-reducing and sulfur-disproportionating cultures ( $\mathrm{p}$ value $<0.05$ and $\mathrm{S} 0=1$ ). The complete lists of proteins with significantly different abundances in pairwise comparisons are given in Supplementary Tables S1, S2 and S3.

A core of 481 proteins was identified in all the analyzed conditions. More total proteins were identified in the culture growing on sulfur respiration (576), while thiosulfate respiration showed the lowest number of total proteins identified (514). In Figure 1 the number of common proteins identified within the different conditions tested is displayed. Biological and technical replicates of each condition clustered together when visualizing 
full-proteome relatedness in a hierarchical clustering-based heatmap (Supplementary Figure 1). In terms of unique proteins, samples of sulfur disproportionation presented 19 exclusive proteins, samples of sulfur respiration possess 15 and 2 were exclusively produced in cultures growing by thiosulfate reduction. Proteins observed exclusively on a single condition are listed in Table 2.

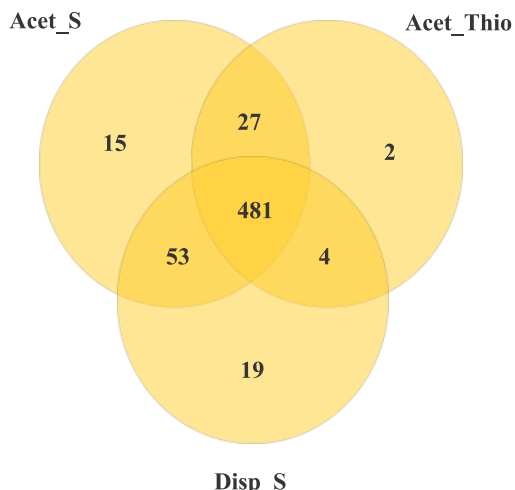

Figure 1 - Overview of common and unique proteins identified among different conditions in D. amilsii.

\section{Sulfur and thiosulfate reduction}

The electron-transfer pathway in the oxidative phosphorylation across the cytoplasmic membrane in sulfur-reducing microorganisms is not yet well understood. The electron transport chain normally links hydrogenases or dehydrogenases to membrane bound or cytoplasmic sulfur/polysulfide reductases (Laska, Lottspeich et al. 2003, Fauque and Barton 2012, Florentino, Weijma et al. 2016). As shown in Chapter 5, the genome of D. amilsii harbors genes encoding two enzymes reported to be involved in the reduction of elemental sulfur or soluble forms of sulfur: the cytoplasmic sulfide dehydrogenase, postulated to reduce polysulfide, and the membrane-bound sulfur reductase, reported to reduce elemental sulfur. Surprisingly, as discussed in Chapter 6, sulfur reductase (DESAMIL20_1358-DESAMIL20_1361) was not detected at any analyzed pH values of the performed experiment, and the sulfide dehydrogenase (DESAMIL20_1852, DESAMIL20_1853) was detected in equal abundance in all the conditions. This enzyme has been linked with bifurcating properties (Ma and Adams, 1994), since in our proteome ferredoxin (DESAMIL20_110) showed up in high abundance this might indicate that this enzyme has a ferredoxin:NADP oxidoreductase activity. As described in Chapter 6, the sulfide dehydrogenase can reduce polysulfide by oxidizing ferredoxin, however, the low $\mathrm{pH}$ of the cultures would not allow a concentration of polysulfide in the medium high enough $(1.25 \mathrm{mM})$ to make its intracellular reduction feasible. Therefore, it was speculated that not the expected sulfur-reducing enzymes, but a rhodanese-like sulfurtransferase is the key enzyme in the sulfur/polysulfide respiration process in D. amilsii. In cultures grown by 
sulfur respiration with acetate as electron donor, the mentioned rhodanese-like proteins were also detected in high abundance, corroborating the findings of the previous chapter and supporting the hypothesis of rhodaneses as key enzymes in the reduction of elemental sulfur by $D$. amilsii.

Table 2 - Unique proteins detected per condition analyzed.

\begin{tabular}{|c|c|}
\hline Locus Tag & Protein \\
\hline & Acet_Thio \\
\hline 1429 & Sulfite reduction-associated complex DsrMKJOP protein DsrK \\
\hline \multirow[t]{2}{*}{1435} & Dissimilatory sulfite reductase, alpha subunit \\
\hline & Acet_S \\
\hline 1551 & SSU ribosomal protein S13p (S18e) \\
\hline 1557 & LSU ribosomal protein L15p (L27Ae) \\
\hline 284 & Hypothetical protein \\
\hline 300 & Hypothetical protein \\
\hline 306 & Conjugative transposon protein TraG \\
\hline 308 & IncF plasmid conjugative transfer pilus assembly protein TraB \\
\hline 405 & Mobile element protein \\
\hline 332 & Mobile element protein \\
\hline 528 & Signal peptidase I \\
\hline 657 & Hypothetical protein \\
\hline 680 & Hypothetical protein \\
\hline 687 & Hypothetical protein \\
\hline 688 & Hypothetical protein \\
\hline 692 & Hypothetical protein \\
\hline 883 & DNA repair protein $\mathrm{RecN}$ \\
\hline \multirow[t]{2}{*}{924} & Cell division inhibitor \\
\hline & Disp_S \\
\hline 1159 & LSU ribosomal protein L31p, zinc-dependent \\
\hline 1179 & hypothetical protein \\
\hline 1192 & Zn-dependent hydrolases, including glyoxylases \\
\hline 1343 & PAS/PAC domain containing protein \\
\hline 1476 & Carbon starvation protein $\mathrm{A}$ \\
\hline 1488 & Hypothetical protein \\
\hline 1826 & 18K peptidoglycan-associated outer membrane lipoprotein \\
\hline 1867 & DNA-binding protein $\mathrm{HU}$ \\
\hline 2007 & Thiosulfate sulfurtransferase, rhodanese-like \\
\hline 503 & Uptake hydrogenase large subunit \\
\hline 565 & Branched-chain amino acid transport ATP-binding protein LivF \\
\hline
\end{tabular}




\begin{tabular}{cc}
\hline 573 & Branched-chain amino acid transport ATP-binding protein LivG \\
\hline 722 & Phospholipase/lecithinase/hemolysin \\
\hline 735 & 5-deoxy-glucuronate isomerase \\
\hline 780 & 3-ketoacyl-CoA thiolase \\
\hline 792 & Butyryl-CoA dehydrogenase \\
\hline 793 & Hydroxymethylglutaryl-CoA synthase \\
\hline 800 & Biotin carboxylase of acetyl-CoA carboxylase \\
\hline 802 & Methylmalonyl-CoA epimerase \\
\hline
\end{tabular}

D. amilsii was shown to utilize thiosulfate as electron acceptor (Florentino, Brienza et al. 2016). Although the reduction of thiosulfate is common among the sulfateand sulfur-reducing prokaryotes, the utilization of thiosulfate is reported to result in growth inhibition in some microorganisms due to the increasing intracellular concentrations of toxic sulfite (Badziong and Thauer 1978, Pereira, He et al. 2008). Beta and gamma subunits of the thiosulfate reductase (DESAMIL20_9 and DESAMIL20_8, respectively) were not differentially produced in comparison to the sulfur-respiring cultures, even though they were 2.5 times more abundant than in sulfur-disproportionating cultures (Table 3 ). The catalytic subunit, PhsA (DESAMIL20_10), however, was 8.3 times more abundant than in sulfur-reducing cultures and 31.4 times more abundant than in sulfur-disproportionating cultures (Table 3 ). The subunits alpha and beta of the dissimilatory sulfite reductase (DsrAB, DESAMIL20_1434-1435), together with the DsrC (DESAMI120_1431) and the subunit DsrK (DESAMIL20_1429) of the DsrKMJOP complex were produced in much greater abundance in thiosulfate-reducing cultures. The subunit DsrM (DESAMIL20_1430) of this complex was identified but not included in the proteome dataset after strict filtering process, most likely due to its membrane-bound nature. The subunits DsrJ, DsrO and DsrP, however are not encoded in the genome of $D$. amilsii. This is an interesting anomaly. It is recognized that DsrMK are the minimum subunits needed for electron transfer from the quinone pool to the sulfite reduction process (Pereira, Ramos et al. 2011). However, all the Deltaproteobacteria sulfite reducers analyzed so far possess the complete DsrMKJOP complex (Grein, Ramos et al. 2013), while just gram-positive Firmicutes possess only DsrMK subunits (Pereira, Ramos et al. 2011; Junier, Junier et al. 2010).

Although the role of the enzymes in the microbial reduction of thiosulfate is not yet clearly understood, this study reveals that thiosulfate reductase and dissimilatory sulfite reductase are most likely the key players in thiosulfate reduction by $D$. amilsii. The thiosulfate reductase might be involved in the initial step of conversion of thiosulfate to sulfite and sulfide. The generated sulfite is reduced by the dissimilatory sulfite reductase (DsrAB) by means of the DsrC protein, generating a protein-based trisulfide, with a sulfitederived sulfur connecting two conserved cysteines of DsrC, as proposed by Santos, 
Venceslau et al. (2015). The trisulfide DsrC is further reduced to sulfide by the electrons transferred via the DsrMK subunits of the DsrMKJOP complex, eliminating the toxicity of sulfite from the medium (Figure 2).

There are five encoded rhodanese-like thiosulfate sulfurtransferases in the genome (DESAMIL20_270, DESAMIL20_1100, DESAMIL20_1419, DESAMIL20_1987 and DESAMIL20_2007) and one is exclusively abundant in D. amilsii cultures growing by sulfur respiration at low pH (DESAMIL20_1987), one is only abundant in sulfur-respiring and sulfur-disproportionating cultures (DESAMIL20_2007), while the others are equally abundant in sulfur- and thiosulfate-respiring cultures (Table 3). These monomeric rhodanese-like enzymes contain two rhodanese domains with one catalytic cysteine residue. Similar rhodanese-containing domains are thought to transfer a sulfur ion to thiol compounds, such as glutathione, L-cysteine and L-homocysteine (Chauncey and Westley 1983), but it is still not known which thiols are the natural substrates for the enzyme. Its reaction with glutathione was investigated in detail by Aird, Heinrikson et al. (1987) and kinetic studies showed the formation of S-sulfanylglutathione. The enzyme could only catalyze the transfer of the sulfane sulfur to the thiol, forming sulfite and a persulfide, and the spontaneous reaction of the persulfide with excess thiol released the free hydrogen sulfide as the final product.

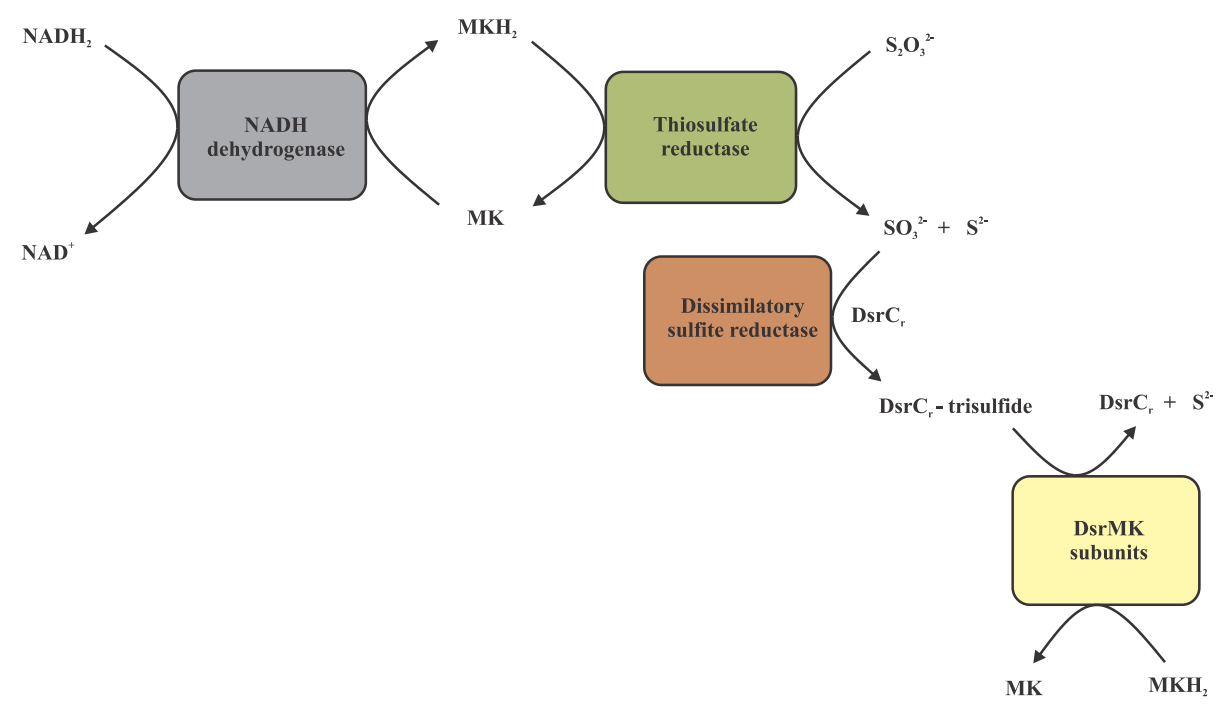

Figure 2 - The proposed thiosulfate respiratory pathway, involving the reduction of thiosulfate by the thiosulfate reductase (DESAMIL20_9, DESAMIL20_10), generating sulfite and sulfite by the oxidation of quinones; sulfite reduction to the DsrC-trisulfide by the dissimilatory sulfite reductase (DESAMIL20_1434, DESAMIL20_1435); and the reduction of the DsrC-trisulfide to sulfide and regenerated DsrCr (DESAMIL20_1431) by the DsrMK complex (DESAMIL20_1429, DESAMIL20_1430). 
Enzymatic processes during thiosulfate reduction by Thiobacillus spp. showed a consistent activity of thiosulfate sulfurtransferase, while thiosulfate reductase could not be detected (Singleton and Smith 1988). In Halanaerobium congolense cultures growing on thiosulfate, a high activity of this enzyme was detected and Ravot, Casalot et al. (2005) cloned the thiosulfate sulfurtransferase-encoding gene from this microorganism in Escherichia coli. The gene sequence analysis in the NCBI database revealed that closely related genes were also characterized in other thiosulfate-reducing anaerobes belonging to phylogenetically distant microorganisms. In accordance to reported studies, the thiosulfate sulfurtransferase highly abundant in $D$. amilsii seems to have a significant importance in the thiosulfate reduction pathway in several members of the domain Bacteria.

Interestingly, two enzymes annotated as NADH dehydrogenase (DESAMIL20_1427) and hypothetical protein (DESAMIL20_1428) were highly abundant in thiosulfate and sulfur-reducing cultures (Table 3), as well as in the conditions analyzed in Chapter 6. Both proteins have DsrE/DsrF-like domains, which are proteins with sulfurtransferase activity, involved in the intracellular reduction or oxidation of sulfur (Bagchi and Ghosh 2008, Grimm, Dobler et al. 2010). Besides, a pyridine nucleotidedisulfide oxidoreductase (DESAMIL20_1432), which includes oxidoreductases and NADH oxidase domains and peroxidases, that could be shuttling reducing equivalents from $\mathrm{NAD}(\mathrm{P}) \mathrm{H}$ to a Cys residue, part of a redox-active disulfide bridge; and a NAD kinase (DESAMIL20_882), likely converting $\mathrm{NAD}^{+}$to $\mathrm{NADP}^{+}$, were detected in high abundance in cultures grown by thiosulfate or sulfur respiration at $\mathrm{pH} 6.5$.

\section{Disproportionation of elemental sulfur}

Proteomic analysis of $D$. amilsii growing under disproportionation revealed the largest number of unique proteins expressed in the pool of samples studied (Table 2).

During disproportionation, elemental sulfur acts simultaneously as electron donor and electron acceptor, and it is transformed into sulfate and sulfide in a ratio 1:3, as commented in Chapter 3 (Florentino, Weijma et al. 2015). The biochemistry of sulfur disproportionation process has only been investigated for Desulfocapsa sulfoexigens. Although $D$. sulfoexigens is not able to utilize sulfate as electron donor, its genome encodes the complete set of genes known to be involved in dissimilatory sulfate reduction (ATP sulfurylase and adenylyl-sulfate reductase) (Bradley, Leavitt et al. 2011), as well as the subunits of the dissimilatory sulfite reductase (DsrAB) and (DsrC) (Finster, Kjeldsen et al. 2013). Sulfite was shown to be an intermediate in the disproportionation of elemental sulfur, and D. sulfoexigens was reported to oxidize sulfite by two different pathways: the sulfite oxidoreductase pathway and the APS reductase pathway via ATP sulfurylase or adenylylsulfate:phosphate adenylyltransferase (APAT) in the reverse way of sulfate reduction (Finster 2008). 
Conversely, D. amilsii is not able to use sulfate as electron acceptor and its genome does not encode many enzyme involved in this pathway (Chapter 5). Although the dissimilatory sulfite reductase is encoded in its genome, physiological tests did not reveal sulfite in sulfur-disproportionating cultures and the proteomics analysis only revealed high abundance of dissimilatory sulfite reductase subunits in cultures growing by thiosulfate reduction (Table 4). In sulfur-disproportionating conditions, D. amilsii TR1 produces a rhodanese-like thiosulfate sulfurtransferase (DESAMIL20_2007 - reported in Chapter 6 for acidophilic cultures) with rhodanese domains and a catalytic cysteine residue. Similar thiosulfate sulfurtransferases (DESAMIL20_270, DESAMIL20_1100, DESAMIL20_1419) were observed in abundance in thiosulfate and sulfur-respiring cultures. Interestingly, the DESAMIL20_2007 rhodanese seems to be exclusive to sulfur-disproportionating cultures. Interestingly this rhodanese seems to be exclusive from sulfur-disproportionating cultures. Therefore, the high and exclusive abundance of these rhodanese domains suggest their importance in disproportionation of elemental sulfur by D. amilsii. This enzyme is postulated to catalyze the transfer of a sulfur atom from a suitable donor to a nucleophilic sulfur acceptor (Aird, Heinrikson et al. 1987, Singleton and Smith 1988, Libiad, Sriraman et al. 2015), but its physiological role has not yet been completely understood. Besides, a monomeric sulfide:quinone reductase was measured in 2 samples of the triplicates, with 3 peptides. Unfortunately, the rather low concentration resulted in poor statistics (-Log pvalue $=0.93$ ); and therefore, its role in sulfur disproportionation by $D$. amilsii is not clear.

In sulfur-disproportionating cultures, butyryl-CoA dehydrogenase (DESAMIL20_792 and DESAMIL20_1079), enoyl-CoA hydratase (DESAMIL20_796 and DESAMIL20_805) and 3-ketoacyl-CoA thiolase (DESAMIL20_780 and DESAMIL20_794) were highly abundant, and therefore they might play a role in carbon fixation or in gluconeogenesis during chemolitothrophic growth of D. amilsii.

Several ribosomal proteins could be detected in D. amilsii cultures grown by sulfur disproportionation: SSU ribosomal proteins S4, S5, S8, S10, S12 and LSU ribosomal proteins L1, L2, L3, L13, L16, L17, L22 and L31. Interestingly, when sulfurdisproportionating cultures are compared to the thiosulfate-respiring cultures, all the mentioned proteins are highly produced in the first condition (Supplementary table S3); when compared to sulfur-respiring cultures, only the L31p protein is highly produced under disproportionation conditions, while the SSU proteins S7, S9 and S13, and the LSU proteins L14, L15 and L23 are highly produced under respiration of elemental sulfur. Moreover, a carbon starvation protein A (DESAMIL20_1476) involved in the peptide utilization during carbon starvation, likely from the addition of $0.1 \mathrm{~g} \mathrm{~L}^{-1}$ of yeast extract in the medium, in only produced under disproportionation condition, as well as some amino acid transport ATP-binding proteins (DESAMIL20_576, DESAMIL20_572 and DESAMIL20_2006). 
Carbon dioxide fixation during growth of $D$. amilsii by sulfur disproportionation likely occurs via the reductive TCA cycle, as identified in the litotrophic cultures, similar to cultures grown by sulfur respiration with hydrogen as electron donor described in Chapter 6. All the enzymes involved in the reductive TCA cycle could be detected in the proteome. The enzymes described by Hügler, Wirsen et al. (2005), Fuchs (2011) as key in the reductive TCA cycle, were detected in high abundance in sulfur-disproportionating cultures: ATP citrate lyase (DESAMIL20_1597), 2-oxoglutarate:ferredoxin oxidoreductase (DESAMIL20_178), and fumarate reductases (DESAMIL20_1536 and DESAMIL20_1537), as well as three subunits of the tetrameric pyruvate synthase/pyruvate:ferredoxin oxidoreductase (DESAMIL20_1626-1628).

In Figure 3, a proposed metabolic reconstruction of D. amilsii is graphically displayed, summarizing the most relevant aspects of the sulfur metabolism addressed in this chapter.

Table 3 - Differential proteomic data on the enzymes involved in thiosulfate reduction in D. amilsii TR1. The logarithm values of the intensities were calculated as average of biological triplicates. The colour code table considers Acet_Thio_6.5 as a reference state and the fold changes varies from red to green in which the more intense green represents the higher fold-changes.

\begin{tabular}{|c|c|c|c|c|}
\hline Locus & Protein & Acet_Thio_6.5 & Acet_S_6.5 & Disp_S_6.5 \\
\hline 10 & PhsA & 8.2 & 7.3 & 6.7 \\
\hline 9 & $\mathrm{PhsB}$ & 8.4 & 8.3 & 8.0 \\
\hline 8 & PhsC & 7.7 & 7.8 & 7.3 \\
\hline 1428 & DsrE & 7.8 & 5.3 & - \\
\hline 1429 & DsrK & 7.5 & - & - \\
\hline 1431 & DsrC & 7.1 & 5.0 & - \\
\hline 1434 & DsrB & 8.0 & 4.9 & 4.2 \\
\hline 1435 & DsrA & 7.9 & - & - \\
\hline 270 & TST & 8.7 & 8.3 & 7.0 \\
\hline 1100 & TST & 8.2 & 7.7 & 6.5 \\
\hline 1419 & TST & 7.8 & 7.8 & 6.6 \\
\hline
\end{tabular}

PhsA - Thiosulfate reductase, alpha subunit; PhsB - thiosulfate reductase, beta subunit; PhsC - thiosulfate reductase, gamma subunit; DsrE, DsrK, DsrC, DsrB, DsrA - proteins related to DsrAB dissimilatory sulfite reductase; TST - thiosulfate sulfurtransferase; Rhd rhodanese domain protein. - stands for the absence of protein in the related condition. 


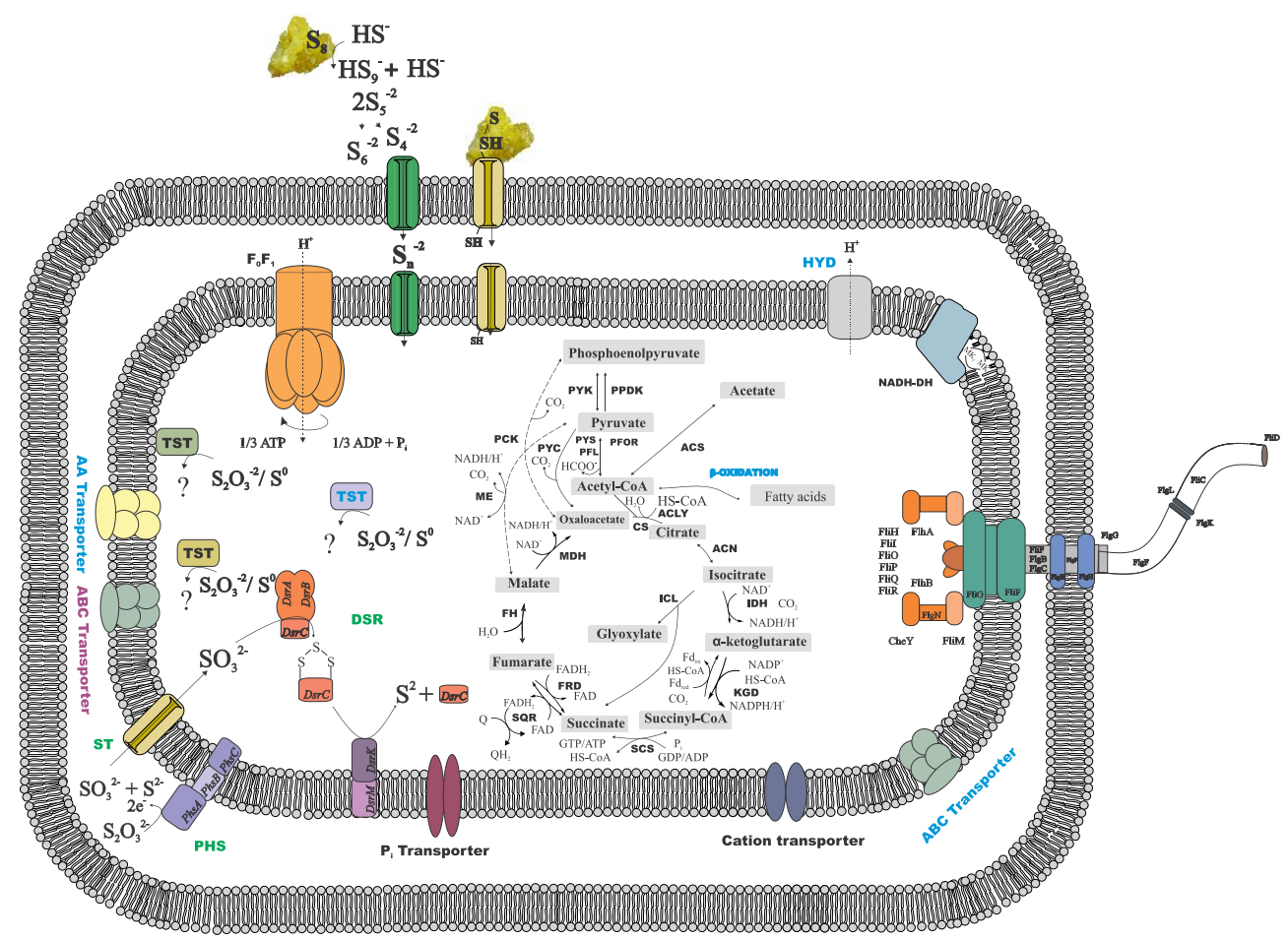

Figure 3 - Metabolic reconstruction of $D$. amilsii. Relative abundance of proteins during heterotrophic growth by sulfur or thiosulfate reduction and sulfur disproportionation is shown. Proteins highlighted in black are found in similar levels in all the analyzed conditions, proteins highlighted in blue are found more abundantly present in sulfurdisproportionating cultures, proteins highlighted in green are found exclusively during thiosulfate respiration; and proteins highlighted in purple are found exclusively during sulfur reduction. ACLY - ATP citrate lyase; ACS - acetyl-CoA synthetase; CS - citrate synthase; DSR - Dissimilatory sulfite reductase; FH - fumarate hydratase; FR - fumarate reductase; HYD- hydrogenase; ICL - Isocitrate lyase; IDH - Isocitrate dehydrogenase; KGD- $\alpha$-ketoglutarate dehydrogenase; $\mathrm{MDH}$ - malate dehydrogenase; ME - malic enzymes; PCK - phosphoenolpyruvate carboxinase; PFL - pyruvate:formate lyase; PFOR pyruvate:ferredoxin oxidoreductase; PHS - thiosulfate reductase; PPDK - pyruvate phosphate dikinase; PTA - phosphotransacetylase; PYC - pyruvate carboxylase; PYK pyruvate kinase; PYS - Pyruvate synthase; SCS - Succinyl-CoA synthetase; SQR Succinate-coenzyme Q reductase; NADH-DH - NADH dehydrogenase; MK menaquinone; ST - sulfite transporter. The thiosulfate sulfurtransferase represented in blue has the locus tag DESAMIL20_2007; while the locus tags for the ones represented in black are DESAMIL20_270, DESAMIL20_1100, DESAMIL20_1419. 


\section{Heterotrophic growth}

Acetyl-CoA is an essential intermediate in various metabolic pathways of all kinds of organisms. For acetate to be metabolized, its activation to acetyl-CoA is required, which can occur via acetyl-CoA synthetase (ACS), acetate kinase (AK) in combination with phosphate acetyltransferase (PAT), or the succinyl-CoA: acetate CoA-transferase (SCACT) (Ingram-Smith, Martin et al. 2006). As showed in Chapter 5, D. amilsii encodes the enzymes ACS, AK and the PAT. However, only acetyl-CoA synthetase (DESAMIL20_135) was produced when acetate was used as electron donor (Acet_S and Acet_Thio).

All the enzymes required for the operation of the tricarboxylic acid (TCA) cycle were also abundant in the cultures grown with acetate, being most likely the route for acetate oxidation in this species. Acetate oxidation via the TCA cycle involves the reduction of $\mathrm{NAD}\left(\mathrm{E}^{0}=-320 \mathrm{mV}\right)$, mediating the conversion of malate into oxaloacetate and isocitrate into $\alpha$-ketoglutarate; NADP $\left(\mathrm{E}^{0,}=-324 \mathrm{mV}\right)$, mediating the conversion of $\alpha$ ketoglutarate into succinyl-CoA; menaquinone $\left(\mathrm{E}^{0,}=-74 \mathrm{mV}\right)$, mediating the oxidation of $\mathrm{FADH}_{2}$ into FAD during the conversion of succinate into fumarate; and ferredoxin $\left(\mathrm{E}^{0,}=-\right.$ $400 \mathrm{mV}$ ), mediating the conversion of $\alpha$-ketoglutarate into succinyl-CoA. As none of the reactions mentioned involves consumption or generation of ATP, the electron transport from one of the reduced coenzymes to the terminal electron acceptors used $\left(\mathrm{S}^{0}\right.$ or thiosulfate) must be coupled to proton motive force for the phosphorylation of ADP. Heterotrophic cultures of $D$. amilsii showed high abundance of a putative sulfurtransferase DsrE-like protein (DESAMIL20_1427), a flavoprotein-quinone oxidoreductase (DESAMIL20_1711) and an uncharacterized ferredoxin oxidoreductase (DESAMIL20_1499), while NADPH dehydrogenase was not detected in any culture. Although some proteins show changes in abundance when comparing heterotrophic and chemolithotrophic growth, this essential metabolic pathway in living cells is apparently constitutive in D. amilsii (Table 5).

Acetate oxidation by sulfur-reducing bacteria has only been investigated for Desulfuromonas acetooxidans and Desulfurella acetivorans. Although the operation of the TCA cycle seems thermodynamically improbable in both mentioned microorganisms due to the fact that the oxidation of succinate to fumarate has a redox potential of $+32 \mathrm{mV}$, which is much higher than that of the $\mathrm{S}^{0} / \mathrm{H}_{2} \mathrm{~S}$ couple $\left(\mathrm{E}^{0}=-240 \mathrm{mV}\right),{ }^{14} \mathrm{C}$-labeling studies revealed that acetate oxidation in $D$. acetoxidans occurs via the citric acid cycle, with high specific activities of a NADP-dependent isocitrate dehydrogenase, a 2-oxoglutarate: ferredoxin oxidoreductase, a membrane-bound succinate: menaquinone oxidoreductase, and a NADspecific malate dehydrogenase. Citrate synthase, aconitase, and fumarase activities were also found, and acetate activation was shown to happen via SCACT (Gebhardt, Thauer et 
al. 1985). D. acetivorans, Schmitz, Bonch-Osmolovskaya et al. (1990) showed a similar metabolism, differing only in the acetate activation and succinate formation, which was reported to occur via AK, PAT and SCS.

Table 4 - Differential proteomic data on the acetate activation and oxidation via TCA cycle in $D$. amilsii TR1. The logarithm values of the intensities were calculated as average of biological triplicates. The colour code table considers Acet_S_6.5 as a reference state and the fold changes varies from red to green in which the more intense green represents the higher fold-changes.

\begin{tabular}{ccccc}
\hline $\begin{array}{l}\text { Locus } \\
\text { Tag }\end{array}$ & Protein & Acet_S_6.5 & Acet_Thio_6.5 & Disp_S_6.5 \\
\hline 135 & ACS & 7.2 & 6.8 & 8.1 \\
\hline 623 & PD & 7 & 7.4 & 7.5 \\
\hline 1709 & CS & 9.2 & 9.6 & 9 \\
\hline 969 & Aconitase & 6.1 & 6.6 & 5.9 \\
\hline 1840 & Aconitase & 8.1 & 8 & 7.8 \\
\hline 830 & SCS, alpha & 7.2 & 6.9 & 8 \\
\hline 831 & SCS, beta & 7.2 & 6.4 & 8 \\
\hline 908 & SCS, beta & 6 & 5.7 & 6 \\
\hline 909 & SCS, alpha & 5.8 & 5.4 & 5.6 \\
\hline 1536 & SD/ FR & 8 & 7.6 & 8.3 \\
\hline 1537 & SD/ FR & 8.4 & 8.1 & 8.7 \\
\hline 1540 & FH I, beta & 7.8 & 8 & 7.1 \\
\hline 1541 & FH I, alpha & 7.7 & 7.8 & 7.7 \\
\hline 1637 & FH II & 6.9 & 7.1 & 7 \\
\hline 1542 & MD & 8.9 & 9.3 & 8.5 \\
\hline 1998 & MD & 8.5 & 8.6 & 8.3 \\
\hline ACS & Acetyl-CoA synthetas; & MD &
\end{tabular}

ACS - Acetyl-CoA synthetase; MD - Malate dehydrogenase; SCS - Succinyl-CoA synthetase; FH - Fumarase; CS - Citrate synthase; SD - Succinate dehydrogenase; FR Fumarate reductase; PD - Pyruvate dehydrogenase. - stands for the absence of protein in the related condition.

ACS showed no activity in D. acetivorans and Hippea maritima cultures, while AK and PAT presented high specific activity (Schmitz, Bonch-Osmolovskaya et al. 1990, Goevert and Conrad 2010). As discussed in Chapter 5, AK coding-genes were not found in any species of the genus Hippea. This is the first reported evidence of acetate activation via ACS in sulfur-reducing bacteria. Besides the forward TCA cycle, the enzymes involved in the reverse operation of the citric acid cycle are encoded and highly abundant in $D$. amilsii cultures. As discussed in Chapter 6, the carbon assimilation in this microorganism might happen via the reverse TCA cyle. Those genes, however, seem to be constitutively expressed in D. amilsii. 


\section{Concluding remarks}

A comparative analysis of $D$. amilsii cultures grown by sulfur or thiosulfate respiration with acetate as electron donor and by disproportionation of elemental sulfur revealed the ability of this microorganism to activate acetate to acetyl-CoA via the acetylCoA synthetase enzyme and its metabolization via the TCA cycle. Besides, the respiration of thiosulfate in D. amilsii is most likely to happen via the thiosulfate reductase and the dissimilatory sulfite reductase, although the presence of different rhodanese-like so-called thiosulfate sulfurtransferases was confirmed in all the cultures, suggesting that they might play a key role not only in the sulfur respiration but also in thiosulfate respiration and disproportionation of elemental sulfur. Proteomic insights into energy and carbon metabolism of sulfur and thiosulfate-respiring cultures of $D$. amilsii, as well as into the sulfur disproportionation process will stimulate and facilitate further biochemical and genetic studies required for the understanding of enzymatic pathways of the metabolism of this microorganism and to broaden up the knowledge on microbial sulfur metabolism.

\section{Acknowledgements}

The authors thank CNPq (Conselho Nacional de Desenvolvimento Cientifíco e Tecnológico), organization of the Brazilian Government for supporting the doctoral study program for the development of Science and Technology. Research of I. Sánchez-Andrea. and A.J.M. Stams is financed by ERC grant project 323009, and Gravitation grant project 024.002.002 from The Netherlands Ministry of Education, Culture and Science. 


\section{Supplementary data}

The locus tag for the genes encoded in D. amilsii is DESAMIL20_*. To avoid repetition of the prefix in the tables, the locus tags are represented only by the specific identifier.

Table S1 - Differentially expressed proteins in a pairwise comparison Acet_S_6.5 vs Acet_thio_6.5. Positive values of the t-test difference (highlighted blue) represent the proteins up-regulated in sulfur respiration, while the negative values (highlighted orange) represent the proteins up-regulated during thiosulfate respiration.

\begin{tabular}{|c|c|c|c|}
\hline $\begin{array}{c}\text { Locus } \\
\text { Tag }\end{array}$ & Protein & -Log P value & t-test difference \\
\hline 883 & DNA repair protein $\mathrm{RecN}$ & 4.4 & 4.2 \\
\hline 316 & Twitching motility protein PilT & 4.7 & 3.4 \\
\hline 650 & Type IV fimbrial assembly, ATPase PilB & 2.8 & 3.3 \\
\hline 302 & hypothetical protein & 6.5 & 3.3 \\
\hline 399 & hypothetical protein & 4.2 & 3.3 \\
\hline 326 & hypothetical protein & 4.2 & 3.3 \\
\hline 667 & hypothetical protein & 5.1 & 3.3 \\
\hline 704 & Mobile element protein & 9.1 & 3.3 \\
\hline 702 & Mobile element protein & 9.1 & 3.3 \\
\hline 295 & Deoxyuridine 5-triphosphate nucleotidohydrolase & 5.3 & 3.3 \\
\hline 402 & Integration host factor alpha subunit & 1.9 & 3.2 \\
\hline 329 & Integration host factor alpha subunit & 1.9 & 3.2 \\
\hline 303 & General secretion pathway protein D & 2.3 & 3.2 \\
\hline 308 & $\begin{array}{c}\text { IncF plasmid conjugative transfer pilus assembly } \\
\text { protein TraB }\end{array}$ & 4.7 & 3.1 \\
\hline 1571 & LSU ribosomal protein L22p (L17e) & 5.4 & 3.0 \\
\hline 1576 & LSU ribosomal protein L3p (L3e) & 6.1 & 3.0 \\
\hline 398 & hypothetical proteinn & 4.2 & 3.0 \\
\hline 325 & hypothetical proteinn & 4.2 & 3.0 \\
\hline 1562 & SSU ribosomal protein $\mathrm{S} 8 \mathrm{p}(\mathrm{S} 15 \mathrm{Ae})$ & 7.2 & 2.9 \\
\hline 657 & hypothetical protein & 4.4 & 2.9 \\
\hline 707 & hypothetical protein & 1.4 & 2.9 \\
\hline 320 & hypothetical protein & 1.4 & 2.9 \\
\hline 306 & Conjugative transposon protein TraG & 5.7 & 2.9 \\
\hline 696 & hypothetical protein & 7.3 & 2.8 \\
\hline 1547 & LSU ribosomal protein L17p & 5.0 & 2.8 \\
\hline 1612 & LSU ribosomal protein L13p (L13Ae) & 4.0 & 2.7 \\
\hline 1569 & LSU ribosomal protein L16p (L10e) & 3.5 & 2.7 \\
\hline
\end{tabular}




\begin{tabular}{|c|c|c|c|}
\hline 682 & hypothetical protein & 6.8 & 2.7 \\
\hline 405 & Mobile element protein & 3.3 & 2.7 \\
\hline 332 & Mobile element protein & 3.3 & 2.7 \\
\hline 680 & hypothetical protein & 5.7 & 2.7 \\
\hline 300 & hypothetical protein & 4.8 & 2.7 \\
\hline 1568 & hypothetical protein & 4.7 & 2.6 \\
\hline 1581 & SSU ribosomal protein $\mathrm{S} 12 \mathrm{p}(\mathrm{S} 23 \mathrm{e})$ & 2.2 & 2.6 \\
\hline 110 & Ferredoxin & 2.0 & 2.6 \\
\hline 1574 & LSU ribosomal protein L23p (L23Ae) & 6.2 & 2.6 \\
\hline 1557 & LSU ribosomal protein L15p & 6.2 & 2.6 \\
\hline 1575 & LSU ribosomal protein $\mathrm{L} 4 \mathrm{p}(\mathrm{L} 1 \mathrm{e})$ & 5.4 & 2.5 \\
\hline 247 & 3-isopropylmalate dehydrogenase & 4.0 & 2.5 \\
\hline 688 & hypothetical protein & 4.9 & 2.5 \\
\hline 693 & Thiol:disulfide interchange protein DsbC & 1.7 & 2.5 \\
\hline 408 & Transposase & 3.4 & 2.5 \\
\hline 1587 & LSU ribosomal protein L11p (L12e) & 6.3 & 2.5 \\
\hline 1902 & SSU ribosomal protein S16p & 6.9 & 2.5 \\
\hline 1045 & $\begin{array}{l}\text { Imidazole glycerol phosphate synthase cyclase } \\
\text { subunit }\end{array}$ & 1.8 & 2.4 \\
\hline 979 & hypothetical protein & 4.8 & 2.4 \\
\hline 1538 & $\begin{array}{l}\text { Succinate dehydrogenase hydrophobic membrane } \\
\text { anchor protein }\end{array}$ & 1.4 & 2.4 \\
\hline 632 & hypothetical protein & 1.6 & 2.3 \\
\hline 1275 & Ferrous iron transport protein $B$ & 4.1 & 2.3 \\
\hline 304 & hypothetical protein & 1.6 & 2.3 \\
\hline 922 & Acriflavin resistance protein & 2.0 & 2.3 \\
\hline 1738 & hypothetical protein & 1.8 & 2.3 \\
\hline 694 & Single-stranded DNA-binding protein & 4.0 & 2.2 \\
\hline 677 & hypothetical protein & 2.7 & 2.2 \\
\hline 1531 & Threonine synthase & 5.4 & 2.2 \\
\hline 1991 & hypothetical protein & 6.7 & 2.2 \\
\hline 1559 & SSU ribosomal protein $\mathrm{S} 5 \mathrm{p}$ & 1.1 & 2.2 \\
\hline 284 & hypothetical protein & 5.5 & 2.2 \\
\hline 1340 & Hydroxylamine reductase & 6.4 & 2.1 \\
\hline 1551 & SSU ribosomal protein S13p & 4.7 & 2.1 \\
\hline 750 & OstA family protein & 3.8 & 2.1 \\
\hline 924 & Cell division inhibitor & 4.4 & 2.1 \\
\hline 1577 & SSU ribosomal protein $\mathrm{S} 10 \mathrm{p}(\mathrm{S} 20 \mathrm{e})$ & 1.1 & 2.1 \\
\hline
\end{tabular}




\begin{tabular}{|c|c|c|c|}
\hline 1747 & Protein-export membrane protein SecF & 1.1 & 2.1 \\
\hline 1905 & LSU ribosomal protein L19p & 1.2 & 2.1 \\
\hline 1493 & Branched-chain amino acid $\mathrm{ABC}$ transporter & 3.9 & 2.1 \\
\hline 687 & hypothetical protein & 4.6 & 2.0 \\
\hline 685 & hypothetical protein & 10.5 & 2.0 \\
\hline 1586 & LSU ribosomal protein L1p (L10Ae) & 1.4 & 2.0 \\
\hline 2064 & Indolepyruvate oxidoreductase subunit IorA & 1.3 & 1.9 \\
\hline 120 & 3-oxoacyl-[acyl-carrier-protein] synthase & 1.1 & 1.9 \\
\hline 166 & TPR domain protein & 1.3 & 1.9 \\
\hline 514 & Tungstate $\mathrm{ABC}$ transporter & 5.2 & 1.9 \\
\hline 1611 & SSU ribosomal protein S9p (S16e) & 1.3 & 1.9 \\
\hline 1306 & $\begin{array}{c}18 \mathrm{~K} \text { peptidoglycan-associated outer membrane } \\
\text { lipoprotein }\end{array}$ & 1.3 & 1.8 \\
\hline 692 & hypothetical protein & 3.3 & 1.8 \\
\hline 1573 & LSU ribosomal protein L2p (L8e) & 1.3 & 1.8 \\
\hline 437 & Cell binding factor 2 precursor & 6.6 & 1.8 \\
\hline 361 & Cell binding factor 2 precursor & 6.6 & 1.8 \\
\hline 1388 & Hydroxymethylpyrimidine phosphate synthase ThiC & 1.2 & 1.8 \\
\hline 1195 & Allophanate hydrolase 2 subunit 2 & 5.0 & 1.8 \\
\hline 563 & RND multidrug efflux transporter & 4.5 & 1.8 \\
\hline 1520 & Pyruvate carboxyl transferase subunit B & 1.3 & 1.7 \\
\hline 1963 & LSU ribosomal protein L25p & 1.2 & 1.7 \\
\hline 1580 & SSU ribosomal protein S7p (S5e) & 1.3 & 1.7 \\
\hline 1454 & Twitching motility protein PilT & 1.8 & 1.7 \\
\hline 305 & hypothetical protein & 4.5 & 1.6 \\
\hline 1363 & signal peptide peptidase SppA & 6.6 & 1.5 \\
\hline 309 & Type IV pilus biogenesis protein PilQ & 4.7 & 1.5 \\
\hline 528 & Signal peptidase I & 4.0 & 1.4 \\
\hline 620 & Acetoin dehydrogenase E1 component alpha & 2.9 & 1.3 \\
\hline 475 & Flagellin protein FlaG & 2.8 & 1.3 \\
\hline 1432 & Pyridine nucleotide-disulphide oxidoreductase & 1.9 & -1.5 \\
\hline 1183 & NAD-dependent formate dehydrogenase alpha & 1.2 & -1.9 \\
\hline 1431 & Dissimilatory sulfite reductase, gamma & 1.8 & -2.2 \\
\hline 1428 & hypothetical protein & 5.5 & -2.5 \\
\hline 1434 & Dissimilatory sulfite oxidoreductase, beta & 3.2 & -3.4 \\
\hline 1429 & $\begin{array}{c}\text { Sulfite reduction-associated complex DsrMKJOP } \\
\text { protein DsrK }\end{array}$ & 6.2 & -3.5 \\
\hline 1435 & Dissimilatory sulfite reductase, alpha subunit & 7.2 & -3.9 \\
\hline
\end{tabular}


Table S2 - Differentially expressed proteins in a pairwise comparison Acet_S_6.5 vs Disp_S_6.5. Positive values of the t-test difference (highlighted blue) represent the proteins up-regulated in sulfur respiration, while the negative values (highlighted orange) represent the proteins up-regulated during sulfur disproportionation.

\begin{tabular}{|c|c|c|c|}
\hline Locus Tag & Protein & $\begin{array}{l}-\log p \\
\text { value }\end{array}$ & $\begin{array}{c}\text { t-test } \\
\text { difference }\end{array}$ \\
\hline 883 & DNA repair protein $\mathrm{RecN}$ & 4.4 & 4.2 \\
\hline 308 & IncF plasmid conjugative transfer pilus assembly protein & 4.7 & 3.1 \\
\hline 1058 & hypothetical protein & 4.4 & 2.9 \\
\hline 657 & hypothetical protein & 4.4 & 2.9 \\
\hline 306 & Conjugative transposon protein TraG & 5.7 & 2.9 \\
\hline 650 & Type IV fimbrial assembly, ATPase PilB & 2.1 & 2.7 \\
\hline 332 & Mobile element protein; & 3.3 & 2.7 \\
\hline 405 & Mobile element protein & 3.3 & 2.7 \\
\hline 680 & hypothetical protein & 5.7 & 2.7 \\
\hline 300 & hypothetical protein & 4.8 & 2.7 \\
\hline 302 & hypothetical protein & 1.6 & 2.6 \\
\hline 1557 & LSU ribosomal protein L15p (L27Ae) & 6.2 & 2.6 \\
\hline 449 & Methyl-accepting chemotaxis protein & 4.1 & 2.6 \\
\hline 373 & Methyl-accepting chemotaxis protein & 4.1 & 2.6 \\
\hline 1611 & SSU ribosomal protein S9p (S16e) & 5.7 & 2.6 \\
\hline 688 & hypothetical protein & 4.9 & 2.5 \\
\hline 1388 & Hydroxymethylpyrimidine phosphate synthase ThiC & 5.7 & 2.5 \\
\hline 1427 & NADH dehydrogenase & 3.1 & 2.3 \\
\hline 1897 & Exopolyphosphatase & 5.2 & 2.3 \\
\hline 1152 & ABC transporter, ATP-binding protein & 6.8 & 2.3 \\
\hline 882 & NAD kinase & 4.1 & 2.2 \\
\hline 1384 & Adenylosuccinate lyase & 0.9 & 2.2 \\
\hline 284 & hypothetical protein & 5.5 & 2.2 \\
\hline 546 & MinD superfamily P-loop ATPase & 3.7 & 2.2 \\
\hline 1261 & Type IV pilus biogenesis protein PilM & 3.9 & 2.1 \\
\hline 1551 & SSU ribosomal protein $\mathrm{S} 13 \mathrm{p}(\mathrm{S} 18 \mathrm{e})$ & 4.7 & 2.1 \\
\hline 1408 & Polymyxin resistance protein ArnC, glycosyl transferase & 5.6 & 2.1 \\
\hline 833 & hypothetical protein & 5.8 & 2.1 \\
\hline 901 & Iron-sulfur cluster regulator IscR & 5.9 & 2.1 \\
\hline 924 & Cell division inhibitor & 4.4 & 2.1 \\
\hline 932 & Porphobilinogen synthase & 4.5 & 2.1 \\
\hline 1457 & Phosphoribosyl-AMP cyclohydrolase & 3.4 & 2.1 \\
\hline 687 & hypothetical protein & 4.6 & 2.0 \\
\hline
\end{tabular}




\begin{tabular}{|c|c|c|c|}
\hline 1454 & Twitching motility protein PilT & 4.0 & 2.0 \\
\hline 673 & hypothetical protein & 0.9 & 2.0 \\
\hline 682 & hypothetical protein & 1.4 & 2.0 \\
\hline 451 & hypothetical proteiN & 4.6 & 2.0 \\
\hline 375 & hypothetical proteiN & 4.6 & 2.0 \\
\hline 1004 & ATP synthase gamma chain & 1.2 & 2.0 \\
\hline 1996 & 2-hydroxy-6-oxo-6-phenylhexa-2,4-dienoate hydrolase & 4.6 & 1.9 \\
\hline 22 & Aspartate 1-decarboxylase & 0.9 & 1.9 \\
\hline 338 & DNA ligase & 0.9 & 1.9 \\
\hline 414 & DNA ligase & 0.9 & 1.9 \\
\hline 1566 & LSU ribosomal protein L14p (L23e) & 1.0 & 1.9 \\
\hline 684 & hypothetical protein & 0.9 & 1.9 \\
\hline 1455 & Type IV fimbrial assembly protein PilC & 0.9 & 1.8 \\
\hline 488 & hypothetical protein & 5.3 & 1.8 \\
\hline 2090 & NADH-ubiquinone oxidoreductase chain $\mathrm{N}$ & 0.9 & 1.8 \\
\hline 692 & hypothetical protein & 3.3 & 1.8 \\
\hline 244 & Serine acetyltransferase & 1.0 & 1.8 \\
\hline 1574 & LSU ribosomal protein L23p (L23Ae) & 1.0 & 1.8 \\
\hline 2077 & RNA polymerase sigma factor RpoD & 6.2 & 1.8 \\
\hline 1275 & Ferrous iron transport protein B & 1.3 & 1.7 \\
\hline 1918 & Cell division transporter, ATP-binding protein FtsE & 6.2 & 1.7 \\
\hline 1580 & SSU ribosomal protein $\mathrm{S} 7 \mathrm{p}(\mathrm{S} 5 \mathrm{e})$ & 1.3 & 1.7 \\
\hline 677 & hypothetical protein & 1.3 & 1.7 \\
\hline 545 & MinD superfamily P-loop ATPase & 1.1 & 1.7 \\
\hline 707 & hypothetical protein & 2.0 & 1.7 \\
\hline 320 & hypothetical protein & 2.0 & 1.7 \\
\hline 239 & TldE protein, part of TldE/TldD proteolytic complex & 5.4 & 1.7 \\
\hline 303 & General secretion pathway protein D & 3.6 & 1.5 \\
\hline 667 & hypothetical protein & 3.3 & 1.4 \\
\hline 528 & Signal peptidase I & 4.0 & 1.4 \\
\hline 1432 & Pyridine nucleotide-disulphide oxidoreductase & 2.4 & 1.3 \\
\hline 270 & Thiosulfate sulfurtransferase, rhodanese & 3.1 & 1.3 \\
\hline 1428 & hypothetical protein & 5.3 & 1.3 \\
\hline 694 & Single-stranded DNA-binding protein & 2.4 & 1.3 \\
\hline 304 & hypothetical protein & 2.5 & 1.3 \\
\hline 1100 & Thiosulfate sulfurtransferase, rhodanese & 3.5 & 1.2 \\
\hline 1419 & Rhodanese domain protein & 3.5 & 1.2 \\
\hline 305 & hypothetical protein & 3.0 & 1.2 \\
\hline 309 & Type IV pilus biogenesis protein PilQ & 3.4 & 1.1 \\
\hline
\end{tabular}




\begin{tabular}{|c|c|c|c|}
\hline 704 & Mobile element protein & 6.1 & 1.0 \\
\hline 702 & Mobile element protein & 6.1 & 1.0 \\
\hline 1865 & 6-phosphofructokinase & 3.8 & -1.1 \\
\hline 804 & 4-hydroxyphenylacetate 3-monooxygenase & 2.5 & -1.2 \\
\hline 1080 & 3-hydroxybutyryl-CoA dehydratase & 3.3 & -1.3 \\
\hline 789 & N-acyl homoserine lactone hydrolase & 1.9 & -1.4 \\
\hline 1079 & Butyryl-CoA dehydrogenase & 3.4 & -1.4 \\
\hline 1374 & Chemotaxis regulator & 1.3 & -1.5 \\
\hline 272 & Superfamily II DNA/RNA helicases & 1.4 & -1.6 \\
\hline 617 & Acetoin dehydrogenase E1 component alpha-subunit & 1.1 & -1.6 \\
\hline 726 & Acetyl-CoA acetyltransferase & 1.2 & -1.6 \\
\hline 1826 & peptidoglycan-associated outer membrane lipoprotein & 4.0 & -1.7 \\
\hline 1179 & hypothetical protein & 4.7 & -1.8 \\
\hline 1467 & RND efflux system, outer membrane lipoprotein CmeC & 1.3 & -1.8 \\
\hline 475 & Flagellin protein FlaG & 3.0 & -1.9 \\
\hline 735 & 5-deoxy-glucuronate isomerase & 5.4 & -1.9 \\
\hline 606 & Ribose 5-phosphate isomerase B & 2.3 & -1.9 \\
\hline 1159 & LSU ribosomal protein L31p, zinc-dependent & 4.0 & -2.1 \\
\hline 576 & branched-chain amino acid $\mathrm{ABC}$ transporter & 5.0 & -2.1 \\
\hline 1488 & hypothetical protein & 7.2 & -2.1 \\
\hline 2006 & Branched-chain amino acid $\mathrm{ABC}$ transporter & 3.1 & -2.1 \\
\hline 556 & hypothetical protein & 4.0 & -2.2 \\
\hline 780 & 3-ketoacyl-CoA thiolase & 4.2 & -2.2 \\
\hline 503 & Uptake hydrogenase large subunit & 5.1 & -2.4 \\
\hline 787 & D-beta-hydroxybutyrate dehydrogenase & 5.4 & -2.5 \\
\hline 1292 & 3-dehydroquinate dehydratase II & 5.4 & -2.5 \\
\hline 572 & Branched-chain amino acid transport LivF & 1.8 & -2.5 \\
\hline 565 & Branched-chain amino acid transport LivF & 6.1 & -2.5 \\
\hline 474 & Flagellar hook-associated protein FliD & 1.7 & -2.5 \\
\hline 1095 & hypothetical protein & 2.4 & -2.5 \\
\hline 1192 & Zn-dependent hydrolases, including glyoxylases & 5.7 & -2.7 \\
\hline 1476 & Carbon starvation protein $\mathrm{A}$ & 4.9 & -2.8 \\
\hline 1867 & DNA-binding protein $\mathrm{HU}$ & 4.0 & -2.9 \\
\hline 2002 & Glutaryl-CoA dehydrogenase & 6.0 & -2.9 \\
\hline 795 & protein associated with acetyl-CoA C-acyltransferase & 2.2 & -2.9 \\
\hline 2007 & Thiosulfate sulfurtransferase, rhodanese & 5.8 & -2.9 \\
\hline 573 & Branched-chain amino acid transport LivG & 5.8 & -3.0 \\
\hline 802 & Methylmalonyl-CoA epimerase & 7.5 & -3.0 \\
\hline 793 & Hydroxymethylglutaryl-CoA synthase & 5.1 & -3.0 \\
\hline
\end{tabular}




\begin{tabular}{cccc}
\hline $\mathbf{7 2 2}$ & Phospholipase/lecithinase/hemolysin & 8.7 & -3.1 \\
\hline $\mathbf{1 3 4 3}$ & PAS/PAC domain containing protein & 7.2 & -3.1 \\
\hline $\mathbf{8 0 0}$ & Biotin carboxylase of acetyl-CoA carboxylase & 3.7 & -3.2 \\
\hline $\mathbf{7 9 6}$ & Enoyl-CoA hydratase & 2.7 & -3.2 \\
\hline $\mathbf{1 0 7 7}$ & B12 binding domain / kinase domain / Methylmalonyl-CoA & 4.4 & -3.6 \\
\hline $\mathbf{7 9 2}$ & Butyryl-CoA dehydrogenase & 6.0 & -3.6 \\
\hline $\mathbf{7 9 4}$ & 3-ketoacyl-CoA thiolase & 4.7 & -3.8 \\
\hline
\end{tabular}


Table S3 - Differentially expressed proteins in a pairwise comparison Acet_thio_6.5 vs Disp_S_6.5. Positive values of the t-test difference (highlighted blue) represent the proteins up-regulated in thiosulfate respiration, while the negative values (highlighted orange) represent the proteins up-regulated during sulfur disproportionation.

\begin{tabular}{|c|c|c|c|}
\hline Locus Tag & Protein & $\begin{array}{l}-\log p \\
\text { value }\end{array}$ & $\begin{array}{c}\text { t-test } \\
\text { difference }\end{array}$ \\
\hline 1435 & Dissimilatory sulfite reductase, alpha & 7.2 & 3.9 \\
\hline 1428 & hypothetical protein & 6.6 & 3.8 \\
\hline 1434 & Dissimilatory sulfite oxidoreductase, beta & 4.1 & 3.8 \\
\hline 1429 & $\begin{array}{l}\text { Sulfite reduction-associated complex DsrMKJOP protein DsrK } \\
\qquad(=\mathrm{HmeD})\end{array}$ & 6.2 & 3.5 \\
\hline 1384 & Adenylosuccinate lyase & 5.1 & 3.5 \\
\hline 1427 & NADH dehydrogenase & 4.0 & 3.5 \\
\hline 1431 & Dissimilatory sulfite reductase, gamma subunit & 3.1 & 3.0 \\
\hline 1623 & $\begin{array}{c}\text { membrane protein involved in aromatic hydrocarbon } \\
\text { degradation }\end{array}$ & 4.6 & 2.8 \\
\hline 1432 & Pyridine nucleotide-disulphide oxidoreductase family protein & 3.3 & 2.8 \\
\hline 882 & NAD kinase & 5.1 & 2.5 \\
\hline 2084 & NADH-ubiquinone oxidoreductase chain $\mathrm{H}$ & 0.9 & 2.3 \\
\hline 616 & TIM-barrel signal transduction protein & 1.2 & 2.0 \\
\hline 1301 & putative aldo/keto reductase & 0.9 & 1.9 \\
\hline 1100 & Thiosulfate sulfurtransferase, rhodanese & 3.6 & 1.7 \\
\hline 270 & Thiosulfate sulfurtransferase, rhodanese & 3.7 & 1.7 \\
\hline 1528 & UTP-glucose-1-phosphate uridylyltransferase & 4.0 & 1.6 \\
\hline 10 & Thiosulfate reductase electron transport protein PhsA & 3.7 & 1.5 \\
\hline 103 & Alcohol dehydrogenase & 3.6 & 1.4 \\
\hline 176 & Isocitrate dehydrogenase [NADP] & 3.4 & 1.4 \\
\hline 1419 & Rhodanese domain protein & 3.3 & 1.2 \\
\hline 900 & 2-hydroxy-3-oxopropionate reductase & 3.9 & 1.2 \\
\hline 518 & Oxidoreductase & 3.1 & 1.1 \\
\hline 1079 & Butyryl-CoA dehydrogenase & 5.0 & -1.0 \\
\hline 2017 & 3-oxoadipate CoA-transferase subunit B & 3.4 & -1.1 \\
\hline 1337 & Respiratory nitrate reductase alpha chain & 4.3 & -1.1 \\
\hline 768 & Glutamine $\mathrm{ABC}$ transporter & 3.5 & -1.1 \\
\hline 2016 & 3-oxoadipate CoA-transferase subunit $\mathrm{A}$ & 3.8 & -1.1 \\
\hline 830 & Succinyl-CoA ligase [ADP-forming] alpha chain & 3.1 & -1.1 \\
\hline 621 & Acetoin dehydrogenase E1 component beta-subunit & 3.9 & -1.3 \\
\hline 135 & Acetyl-coenzyme A synthetase & 4.6 & -1.3 \\
\hline 1805 & hypothetical protein & 1.6 & -1.6 \\
\hline 831 & Succinyl-CoA ligase [ADP-forming] beta chain & 4.7 & -1.6 \\
\hline 805 & Enoyl-CoA hydratase & 1.1 & -1.6 \\
\hline
\end{tabular}




\begin{tabular}{|c|c|c|c|}
\hline 1505 & Phenylacetate-coenzyme A ligase & 1.3 & $\overline{-1.6}$ \\
\hline 1581 & SSU ribosomal protein $\mathrm{S} 12 \mathrm{p}(\mathrm{S} 23 \mathrm{e})$ & 1.5 & -1.7 \\
\hline 171 & hypothetical protein & 1.2 & -1.7 \\
\hline 1826 & 18K peptidoglycan-associated outer membrane lipoprotein & 4.0 & -1.7 \\
\hline 303 & General secretion pathway protein $\mathrm{D}$ & 1.3 & -1.7 \\
\hline 1156 & Probable component of the lipoprotein assembly complex & 1.2 & -1.7 \\
\hline 1045 & Imidazole glycerol phosphate synthase cyclase subunit & 1.4 & -1.8 \\
\hline 1179 & hypothetical protein & 4.7 & -1.8 \\
\hline 1306 & Peptidoglycan-associated lipoprotein & 1.2 & -1.8 \\
\hline 632 & hypothetical protein & 1.3 & -1.8 \\
\hline 563 & RND multidrug efflux transporter & 6.6 & -1.8 \\
\hline 1363 & signal peptide peptidase SppA & 4.7 & -1.8 \\
\hline 166 & TPR domain protein & 1.3 & -1.8 \\
\hline 232 & Chemotaxis protein methyltransferase CheR & 1.1 & -1.8 \\
\hline 945 & Probable M18-family aminopeptidase 1 & 4.7 & -1.8 \\
\hline 1078 & hypothetical protein & 1.4 & -1.8 \\
\hline 1549 & SSU ribosomal protein $S 4 p$ & 1.2 & -1.8 \\
\hline 1125 & Trehalose synthase, nucleoside diphosphate glucose dependent & 1.1 & -1.8 \\
\hline 667 & hypothetical protein & 4.9 & -1.9 \\
\hline 1506 & Glutaredoxin and related proteins & 1.3 & -1.9 \\
\hline 735 & 5-deoxy-glucuronate isomerase & 5.4 & -1.9 \\
\hline 2064 & Indolepyruvate oxidoreductase subunit IorA & 1.4 & -1.9 \\
\hline 804 & 4-hydroxyphenylacetate 3-monooxygenase & 1.4 & -1.9 \\
\hline 1080 & 3-hydroxybutyryl-CoA dehydratase & 1.0 & -1.9 \\
\hline 1573 & LSU ribosomal protein L2p (L8e) & 1.5 & -2.0 \\
\hline 1577 & SSU ribosomal protein $\mathrm{S} 10 \mathrm{p}(\mathrm{S} 20 \mathrm{e})$ & 1.0 & -2.0 \\
\hline 620 & Acetoin dehydrogenase E1 component alpha-subunit & 4.0 & -2.0 \\
\hline 1626 & Pyruvate:ferredoxin oxidoreductase, gamma subunit & 1.2 & -2.0 \\
\hline 1374 & Chemotaxis regulator & 4.9 & -2.0 \\
\hline 398 & hypothetical protein & 3.3 & -2.1 \\
\hline 325 & hypothetical protein & 3.3 & -2.1 \\
\hline 921 & membrane-fusion protein & 6.6 & -2.1 \\
\hline 1865 & 6-phosphofructokinase & 1.3 & -2.1 \\
\hline 789 & $\mathrm{~N}$-acyl homoserine lactone hydrolase & 1.3 & -2.1 \\
\hline 1159 & LSU ribosomal protein L31p, zinc-dependent & 4.0 & -2.1 \\
\hline 1547 & LSU ribosomal protein $\mathrm{L} 17 \mathrm{p}$ & 4.7 & -2.1 \\
\hline 1488 & hypothetical protein & 7.2 & -2.1 \\
\hline 272 & Superfamily II DNA/RNA helicases & 4.8 & -2.1 \\
\hline 110 & Ferredoxin & 1.7 & -2.1 \\
\hline
\end{tabular}




\begin{tabular}{|c|c|c|c|}
\hline 1569 & LSU ribosomal protein L16p (L10e) & 4.2 & -2.1 \\
\hline 1586 & LSU ribosomal protein L1p (L10Ae) & 1.5 & -2.2 \\
\hline 780 & 3-ketoacyl-CoA thiolase & 4.2 & -2.2 \\
\hline 1122 & TPR repeat & 1.1 & -2.2 \\
\hline 1738 & hypothetical protein & 1.8 & -2.2 \\
\hline $402 ; 329$ & Integration host factor alpha subunit;329 & 1.4 & -2.2 \\
\hline 559 & UPF0047 protein Bsu YugU & 4.8 & -2.2 \\
\hline $704 ; 702$ & Mobile element protein & 7.7 & -2.2 \\
\hline 726 & Acetyl-CoA acetyltransferase & 4.4 & -2.2 \\
\hline 295 & Deoxyuridine 5-triphosphate nucleotidohydrolase & 5.5 & -2.2 \\
\hline 1571 & LSU ribosomal protein L22p (L17e) & 6.0 & -2.3 \\
\hline 922 & Acriflavin resistance protein & 2.0 & -2.3 \\
\hline 1559 & SSU ribosomal protein S5p (S2e) & 1.2 & -2.3 \\
\hline 316 & Twitching motility protein PilT & 6.3 & -2.3 \\
\hline 1225 & Phosphoribosyl transferase domain protein & 8.8 & -2.3 \\
\hline 1195 & Allophanate hydrolase 2 subunit 2 & 3.3 & -2.3 \\
\hline 1076 & Fe-S oxidoreductase & 3.5 & -2.4 \\
\hline 1562 & SSU ribosomal protein $\mathrm{S} 8 \mathrm{p}(\mathrm{S} 15 \mathrm{Ae})$ & 5.4 & -2.4 \\
\hline 2002 & Glutaryl-CoA dehydrogenase & 2.2 & -2.4 \\
\hline 1538 & Succinate dehydrogenase hydrophobic membrane anchor & 1.4 & -2.4 \\
\hline 1467 & RND efflux system, outer membrane lipoprotein CmeC & 5.0 & -2.4 \\
\hline 1095 & hypothetical protein & 2.3 & -2.4 \\
\hline 503 & Uptake hydrogenase large subunit & 5.1 & -2.4 \\
\hline 247 & 3-isopropylmalate dehydrogenase & 7.0 & -2.4 \\
\hline 750 & OstA family protein & 5.7 & -2.5 \\
\hline 565 & $\begin{array}{l}\text { Branched-chain amino acid transport ATP-binding protein } \\
\text { LivF }\end{array}$ & 6.1 & -2.5 \\
\hline 1568 & hypothetical protein & 5.2 & -2.5 \\
\hline 569 & $\begin{array}{l}\text { Leucine-, isoleucine-, valine-, threonine-, and alanine-binding } \\
\text { protein }\end{array}$ & 7.1 & -2.5 \\
\hline 606 & Ribose 5-phosphate isomerase B & 4.9 & -2.5 \\
\hline 1747 & Protein-export membrane protein $\mathrm{SecF}$ & 1.3 & -2.5 \\
\hline 1520 & Pyruvate carboxyl transferase subunit B & 1.7 & -2.6 \\
\hline 556 & hypothetical protein & 2.1 & -2.6 \\
\hline 1991 & hypothetical protein & 7.4 & -2.6 \\
\hline 787 & D-beta-hydroxybutyrate dehydrogenase & 2.1 & -2.6 \\
\hline 696 & hypothetical protein & 5.3 & -2.6 \\
\hline 1612 & LSU ribosomal protein L13p (L13Ae) & 4.7 & -2.6 \\
\hline 811 & Butyryl-CoA dehydrogenase & 1.8 & -2.7 \\
\hline 1340 & Hydroxylamine reductase & 4.2 & -2.7 \\
\hline
\end{tabular}




\begin{tabular}{|c|c|c|c|}
\hline 1192 & Zn-dependent hydrolases & 5.7 & -2.7 \\
\hline 1230 & Aspartate aminotransferase & 7.9 & -2.8 \\
\hline 1476 & Carbon starvation protein $\mathrm{A}$ & 4.9 & -2.8 \\
\hline 1493 & Branched-chain amino acid $\mathrm{ABC}$ transporter & 4.6 & -2.8 \\
\hline 1576 & LSU ribosomal protein L3p (L3e) & 5.7 & -2.9 \\
\hline 1867 & DNA-binding protein $\mathrm{HU}$ & 4.0 & -2.9 \\
\hline 408 & Transposase & 5.6 & -2.9 \\
\hline 514 & Tungstate $\mathrm{ABC}$ transporter & 3.9 & -2.9 \\
\hline 2007 & Thiosulfate sulfurtransferase, rhodanese & 5.8 & -2.9 \\
\hline 979 & hypothetical protein & 3.8 & -2.9 \\
\hline 1001 & MotA/TolQ/ExbB proton channel family protein & 5.9 & -2.9 \\
\hline 573 & Branched-chain amino acid transport ATP-binding protein & 5.8 & -3.0 \\
\hline 1077 & B12 binding domain / kinase domain / Methylmalonyl-CoA & 2.0 & -3.0 \\
\hline 802 & Methylmalonyl-CoA epimerase & 7.5 & -3.0 \\
\hline 793 & Hydroxymethylglutaryl-CoA synthase & 5.1 & -3.0 \\
\hline 722 & Phospholipase/lecithinase/hemolysin & 8.7 & -3.1 \\
\hline 1343 & PAS/PAC domain containing protein & 7.2 & -3.1 \\
\hline 572 & $\begin{array}{l}\text { Branched-chain amino acid transport ATP-binding protein } \\
\text { LivF }\end{array}$ & 6.0 & -3.1 \\
\hline 800 & Biotin carboxylase of acetyl-CoA carboxylase & 3.7 & -3.2 \\
\hline 475 & Flagellin protein $\mathrm{FlaG}$ & 4.6 & -3.2 \\
\hline 474 & Flagellar hook-associated protein FliD & 4.6 & -3.2 \\
\hline 576 & Branched-chain amino acid $\mathrm{ABC}$ transporter & 2.0 & -3.2 \\
\hline 796 & Enoyl-CoA hydratase & 3.1 & -3.3 \\
\hline 795 & $\begin{array}{l}\text { conserved protein associated with acetyl-CoA C- } \\
\text { acyltransferase }\end{array}$ & 6.3 & -3.5 \\
\hline 2006 & $\begin{array}{l}\text { Branched-chain amino acid ABC transporter, amino acid- } \\
\text { binding protein }\end{array}$ & 2.7 & -3.5 \\
\hline 792 & Butyryl-CoA dehydrogenase & 6.0 & -3.6 \\
\hline 542 & Flagellin protein FlaA & 6.0 & -3.7 \\
\hline 794 & 3-ketoacyl-CoA thiolase & 8.8 & -4.0 \\
\hline
\end{tabular}


Figure S1 - Heat map of the proteomes generated for $D$. amilsii cultures grown under different experimental conditions. The LFQ intensities of the proteins were normalized and the standard scores used as data input for the heat map generation by Perseus 1.5.5.3 module. Identified and differentially expressed proteins are displayed across the vertical axis, where the experimental conditions are displayed. The relative scale ranges from -4.0 (green) to 4.0 (red), in which the higher intensity of red correlates to higher protein abundance and the higher intensity of green correlates to lower protein abundance.

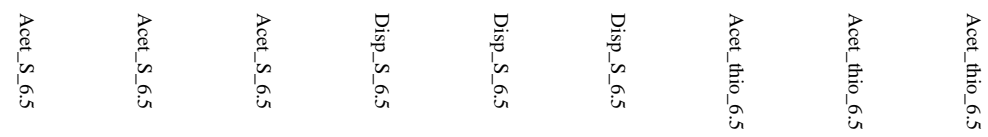

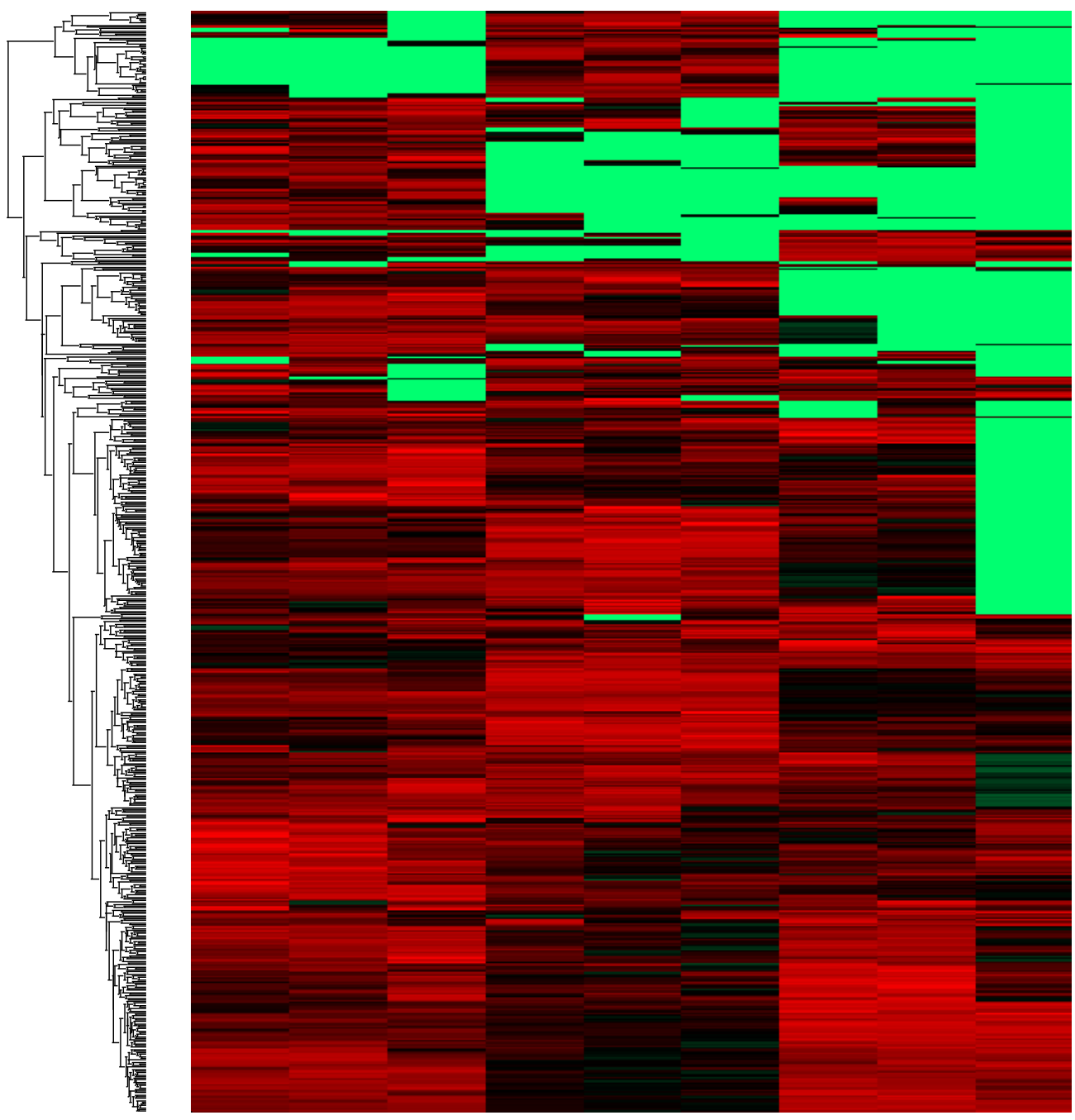





\section{Abstract}

Elemental sulfur reduction needs 4 times less electrons than sulfate reduction to produce the same amount of sulfide. As so, sulfur reducers are a promising source of sulfide for saving costs in metal sulfide precipitation, and especially, those able to deal with a broad range of $\mathrm{pH}$, which allows selective metal precipitation. Known acidotolerant sulfur reducers, such as Desulfurella amilsii, can only utilize a narrow range of substrates for sulfur reduction. Interestingly, a screening for sulfate reducers from acidic sediments from Tinto river (Spain) resulted in the isolation of strain $\mathrm{ALE}^{\mathrm{T}}$, which has a rather versatile metabolism. It utilized $\mathrm{H}_{2}$, sugars, organic acids, alcohols, amino acids and complex substances, such as peptone, starch and glycogen substrates, leading to the production of mainly acetate and butyrate. It was able to use iron, thiosulfate, molybdate DMSO and (weakly) sulfur as electron acceptors in the presence of glycerol. Strain $\mathrm{ALE}^{\mathrm{T}}$ was obligate anaerobic, mesophilic, spore-forming straight rod with variable motility, and it stained Gram-positive. The $\mathrm{pH}$ range for growth was 3.5 to 7 , with an optimum at 5.5, and temperature range from 25 to $40^{\circ} \mathrm{C}$, with an optimum at $37^{\circ} \mathrm{C}$. Phylogenetically, strain $\mathrm{ALE}^{\mathrm{T}}$ was affiliated to the Veillonellaceae family of Firmicutes phylum. The closest cultured species were Propionispora genome has a size of $4.7 \mathrm{Mb}$ with 5122 detected protein-coding sequences, 84 tRNAs, single copies of $16 \mathrm{~S}$ and $23 \mathrm{~S}$ rRNA and 10 copies of 5S rRNA. The genomic $\mathrm{G}+\mathrm{C}$ content is $46.96 \%$. Based on the distinctive ecological, physiological and chemotaxonomical characteristics of strain $\mathrm{ALE}^{\mathrm{T}}$, a new genus and species Lucifera butyrica gen. nov., sp. nov., is proposed. The type strain is $\mathrm{ALE}^{\mathrm{T}}\left(=\mathrm{JCM} 19373^{\mathrm{T}}=\mathrm{DSM}\right.$ $27520^{\mathrm{T}}$ ). Interestingly, in the presence of glycerol and sulfur, L. butyrica produced acetate, butyrate, ethanol and 1,3-PDO. However, the sulfide released reached a maximum concentration of $2.5 \mathrm{mM}$. By combining, L. butyrica with D.amilsii, D.amilsii was able to use the acetate produced by L. butyrica and coupled it to sulfur reduction. The sulfide produced by both microorganisms together was higher than the adittion of the sulfide from the individual monocultures. The co-culture strategy revealed a good opportunity to broaden the range of substrates that could be used and to enhance yields of sulfide, which could be used to further precipitate heavy metals in solution from acidic waste streams.

The prefix of the locus tags for Lucifera butyrica is Lbut_*. To avoid repetition of the prefix along the text, all the locus tags are represented only by the specific identifier. 


\section{Introduction}

Respiration of sulfur compounds with hydrogen sulfide as the main end product has attracted attention for biotechnological application, especially for processes as metal recovery. Due to its abundancy and stability, sulfate is the most studied sulfur compound for this purpose. Sulfate reduction reactions play a significant role in mediating redox conditions and biogeochemical processes. Elemental sulfur reduction is also of environmental importance, especially in deep-sea vents, hot springs and other extreme environments. A variety of archaeal and bacterial sulfur reducers have been isolated from different environments (Stetter 1996, Florentino, Weijma et al. 2016). Sulfur reducers can use a range of alcohols, sugars, organic acids and complex substances as substrates for growth (Bonch-Osmolovskaya, Sokolova et al. 1990, Finster, Coates et al. 1997, Dirmeier, Keller et al. 1998, Boyd, Jackson et al. 2007) but most of the studies on sulfur reduction focused on acetate oxidation (Gebhardt, Thauer et al. 1985, Bonch-Osmolovskaya, Sokolova et al. 1990). The degradation of organic substrates can be complete until $\mathrm{CO}_{2}$, or incomplete, leading to the accumulation of intermediate products, such as acetic acid. Production of acetic acid may cause inhibition of microbial growth by dissipation of membrane potential (van Niel, Claassen et al. 2003).

Glycerol is a cheap carbon source for microbial biotechnological processes since it is an abundant by-product $(10 \% \mathrm{w} / \mathrm{w})$ of the biodiesel production (Leoneti, AragãoLeoneti et al. 2012, Garlapati, Shankar et al. 2016). The use of glycerol as electron donor for sulfur reduction to form sulfide for metal recovery is attractive. A few sulfur- and sulfate-reducing bacteria have been reported to utilize glycerol as energy and carbon source, such as few Desulfosporosinus spp (D. meridiei, D. auripigmenti, or $D$. acididurans) (Robertson, Bowman et al. 2001, Stackebrandt, Schumann et al. 2003, Sánchez-Andrea, Stams et al. 2015) and Desulfovibrio indonesiensis (Feio, Beech et al. 1998). The ability to reduce elemental sulfur and oxidize glycerol makes those microorganisms promising as catalysts for sulfidogenic bioprocesses, overcoming the challenges of cost and availability of the electron source.

A novel acidotolerant glycerol utilizer, strain $\mathrm{ALE}^{\mathrm{T}}$, was isolated from an enrichment of acidic sediments from Tinto River (Spain) (Sánchez-Andrea, Stams et al. 2013). Results show that strain $\mathrm{ALE}^{\mathrm{T}}$ is a novel species and genus, for which the name Lucifera butyrica gen. nov., sp. nov. is proposed. Among other features, the isolate was able to produce 1,3-propanediol (PDO) by fermenting glycerol. Likely, it reduced sulfur since sulfide was produced in the presence of elemental sulfur. Due to its potential technological application, the genome of this isolate has been sequenced and a complete physiological and phylogenetic characterization is provided in this chapter. 
Strain $\mathrm{ALE}^{\mathrm{T}}$ showed a very versatile metabolism. The degradation of glycerol, and many other substrates, was incomplete and acetate was accumulated in the cultures, which could be used by a sulfur reducer such as Desulfurella amilsii. A combined growth of strain $\mathrm{ALE}^{\mathrm{T}}$ with $D$. amilsii was performed as strategy to be able to produce sulfide with a broad range of substrates.

\section{Material and methods}

\section{Source of the organisms}

Enrichment cultures were performed with acidic sediments from the Tinto River basin (southwestern Spain): JL dam (37.691207N, 6.560587W). Detailed information about the physicochemical characteristics of the site was published before (Sánchez-Andrea, Rodriguez et al. 2011). One of the enrichment supplemented with $5 \mathrm{mM}$ of succinate served as source for the isolation. The isolation procedure was performed by plating $100 \mu \mathrm{L}$ of the culture on solid agar medium containing 0.9\% Agar Noble. Colonies were transferred to liquid anoxic medium with $5 \mathrm{mM}$ succinate. Two sets of serial dilution were performed, the first with the addition of $5 \mu \mathrm{g} \mathrm{mL}^{-1}$ vancomycin and the second with $20 \mu \mathrm{g} \mathrm{mL}^{-1}$. The purity of the cultures between the steps was checked by contrast phase microscopy and direct PCR. After a last set of serial dilution, the absence of contaminants was confirmed by 16S rRNA gene sequences analysis of around 100 clones, as described in (Sánchez-Andrea, Stams et al. 2013).

For comparison purposes, Propionispora hippei (DSM 15287 $7^{\mathrm{T}}$ ) and Propionispora vibrioides (DSM $13305^{\mathrm{T}}$ ) were purchased from the German Collection of Microorganisms and Cell Cultures (DSMZ) (Braunschweig, Germany). A culture of D. amilsii, major subject of previous chapters, was available from the laboratory collection of microorganisms.

\section{Media preparation}

Otherwise indicated, the general cultivation media were prepared as follows. Samples were inoculated in an $\mathrm{O}_{2}$-free basal medium prepared as previously described by Stams, Van Dijk et al. (1993). Modifications were done according to (Sánchez-Andrea, Stams et al. 2013) supplementing the basal media with $0.1 \mathrm{~g}^{-1}$ yeast extract and $0.5 \mathrm{~g} \mathrm{l}^{-1} \mathrm{~L}$ cysteine as reducing agent and removing the bicarbonate-buffer. Medium was adjusted with $\mathrm{HCl}$ and $\mathrm{NaOH}$ to the different experimental $\mathrm{pH}$ values before autoclaving depending on the final desired $\mathrm{pH}$. The gas phase on the cultures was set to $1.5 \mathrm{~atm}$ of $\mathrm{N}_{2} / \mathrm{CO}_{2}(80: 20$, $\mathrm{v} / \mathrm{v})$. All compounds were heat-sterilized except for the vitamins, which were filtersterilized. 


\section{Genome analysis}

Strain $\mathrm{ALE}^{\mathrm{T}}$ was cultivated with the media described before supplemented with $5 \mathrm{mM}$ of glycerol. To avoid DNA degradation, L-cysteine was removed from the medium. Total genomic DNA was extracted with the MasterPure ${ }^{\mathrm{TM}}$ Gram Positive DNA Purification Kit (Epicentre, Madison, WI). Quality and quantity of the DNA were checked on agarose gels using lambda phage DNA as mass standard and Hind III digested lambda phage DNA as a size marker. DNA was sequenced at GATC Biotech (Konstanz, Germany) on an Illumina MiSeq Personal Sequencer, generating 887692 paired end reads with a length of $250 \mathrm{bp}$. Genome size was estimated by using kmer spectrumanalyzer on the complete left end set of the paired-end reads. Genome sequences assembly, merging and scaffolding were performed as described in Chapter 5. The annotation was carried out with an in-house pipeline. In short, this pipeline includes Prodigal version 2.5 for open reading frame identification (Hyatt et al., 2010), InterproScan version 5RC7 for protein annotation (Hunter et al., 2012), tRNAscan SE 1.3.1 for tRNA identification (Lowe \& Eddy, 1997) and RNAmmer 1.2 for the prediction of rRNAs (Lagesen et al., 2007). The draft genome sequence of Lucifera butyrica was deposited ion GenBank (http://www.ebi.ac.uk/ena/data/view/PRJB13757).

\section{Phylogeny of the isolate}

The 16S rRNA gene sequence of strain $\mathrm{ALE}^{\mathrm{T}}$ was retrieved from the genome sequence and added to a database of over 260000 homologous prokaryotic 16S rRNA gene primary structures by using the merging tool of the ARB program package (Ludwig et al., 2004). The sequence was manually corrected with the alignment tool of the same software, and added by parsimony to the tree generated in the Living Tree Project (LTP) (Yarza et al., 2008). Phylogenetic reconstruction was performed using the three algorithms as implemented in the ARB package. The maximum-likelihood method was preferably used for the generation of the consensus tree and bootstrap analysis performance. The 16S rRNA sequence has been deposited in the EMBL database under accession numbers HG316990 and refers to the type strain $\mathrm{ALE}^{\mathrm{T}}$.

\section{Phenotypic characterization}

Cell morphology, motility and spore formation of strain $\mathrm{ALE}^{\mathrm{T}}$ were examined by phase contrast microscopy using a Leica DM2000 microscope (Leica Microsystems, Wetzlar, Germany). Scanning electron microscopy (SEM) was performed as described before (Alphenaar, Groeneveld et al. 1994) using a JEOL JSM-6480LV microscope (JEOL, 
Tokyo, Japan). The lengths and widths of several cells were measured and mean dimensions recorded. Gram staining was performed according to standard procedures (Doetsch 1981). Gram-structure was additionally confirmed by checking the reaction of cells with $3 \%(\mathrm{w} / \mathrm{v})$ solution of $\mathrm{KOH}$. Catalase activity was determined by reaction with $3 \%$ (w/v) solution of $\mathrm{H}_{2} \mathrm{O}_{2}$. Oxidase test was performed with a filter impregnated in $1 \%(\mathrm{w} / \mathrm{v})$ solution of tetramethyl-p-phenylenediamine in dimethyl sulfoxide (Sigma-Aldrich, St Louis, MO). Urease formation as well as gelatin and aesculin hydrolysis were determined with API ${ }^{\circledR} 20$ A (bioMérieux, France) according manufacturer's instructions.

Growth experiments were performed in triplicates, using $120 \mathrm{~mL}$-serum bottles or agar plates. Different electron donors and acceptors were tested at final concentrations of 5 $\mathrm{mM}$ with the exception of elemental sulfur for which a concentration of $25 \mathrm{mM}$ was added. Growth of strain $\mathrm{ALE}^{\mathrm{T}}$ was studied in a range of temperature from 15 to $45^{\circ} \mathrm{C}, \mathrm{pH}$ from 2.5 to 7.5 (in $0.5 \mathrm{pH}$ intervals) and $\mathrm{NaCl}$ concentrations from 0.3 to $3.8 \%$ (w/v) (in $0.5 \%$ intervals). Dependence on vitamins and yeast extract was studied by removing them from the medium composition. The sensitivity of strain $\mathrm{ALE}^{\mathrm{T}}$ to antibiotics was determined by addition of vancomycin, streptomycin, rifampicin, penicillin and chloramphenicol applied at 25,50 and $100 \mu \mathrm{g} \mathrm{mL}^{-1}$.

In all physiological tests, activity was followed by hydrogen sulfide measurements every 2 days and confirmed by comparison with the respective negative controls. Sulfide was measured photometrically via the methylene blue method (Cline 1969). Growth was monitored by measuring optical absorbance at $600 \mathrm{~nm}\left(\mathrm{OD}_{600}\right)$ with a spectrophotometer (U-1500 Hitachi, Tokyo, Japan). Soluble substrates and intermediates (sugars and volatile fatty acids) were measured using a Thermo Electron spectra system HPLC equipped with an Agilent Metacarb 67H column. Gaseous compounds $\left(\mathrm{H}_{2}\right)$ were analyzed using a Shimadzu GC-2014 Gas Chromatograph equipped with a Molsieve 13X column. Otherwise indicated, the general conditions of the medium were $\mathrm{pH} 5.5, \mathrm{~T}=37^{\circ} \mathrm{C}$ and glycerol as substrate $(5 \mathrm{mM})$ with or without elemental sulfur. Generation times of cultures were determined from semi-logarithmic plots of changes in glycerol consumption or sulfide production values against time.

Fatty acid and quinone analyses were carried out at DSMZ (Braunschweig, Germany), with biomass grown on glycerol. For cellular fatty acids comparison, strain $\mathrm{ALE}^{\mathrm{T}}$ was grown in the same medium as $P$. hippei and $P$. vibrioides in order to avoid interference of the growing conditions in the results interpretation.

\section{Metal tolerance analysis}

L. butyrica tolerance to metals in solution was assessed at $\mathrm{pH} 3$ with copper, iron, nickel, zinc in the following concentrations: 1,5 and $10 \mathrm{mM}$ for copper and zinc chloride 
salts; and 10, 20 and $50 \mathrm{mM}$ for iron and nickel sulfate salts. Elemental sulfur was not added to the cultures and titanium citrate was used as reducing agent to avoid precipitation of metals as metal sulfides. To account with the metal precipitation due to phosphate present in the medium, the concentration of free metals was first measured after their addition to the medium.

\section{Co-culture experiments}

Monocultures were pre-grown with $25 \mathrm{mM}$ of elemental sulfur as electron acceptor and $5 \mathrm{mM}$ of acetate (D. amilsii ) or $5 \mathrm{mM}$ of glycerol (L. butyrica) as substrate.

Batch experiments were performed in triplicates in $250 \mathrm{ml}$ bottles with $100 \mathrm{ml}$ of media supplemented with $5 \mathrm{mM}$ of glycerol and $25 \mathrm{mM}$ of sulfur. One set of triplicates was inoculated solely with L. butyrica and another set with both L. butyrica and D. amilsii at equivalent biomass based on optical density measurements. One percent inoculum was added from actively growing cultures of both sets to $\mathrm{pH}$-controlled batch glass reactors (Applikon, Schiedam, The Netherlands) of $1 \mathrm{~L}$ working volume. Reactor operation was controlled by an ADI 1010 Bio-Controller with an ADI 1025 Bio-console (Applikon, Schiedam, The Netherlands). The culture had a stirring speed of $25 \mathrm{rpm}$, the temperature was controlled at $37^{\circ} \mathrm{C}$ and the $\mathrm{pH}$ was maintained at 6.0 by automatic addition of $0.1 \mathrm{M}$ of $\mathrm{KOH}$ and $\mathrm{HCl}$. Growth and activity were weekly monitored off line by number of cells and substrates and products profile measurements.

\section{Results and discussion}

\section{Isolation of strain $\mathrm{ALE}^{\mathrm{T}}$}

Strain $\mathrm{ALE}^{\mathrm{T}}$ was isolated from enrichment cultures initiated for the isolation of acidophilic sulfate-reducing bacteria growing on succinate (Sánchez-Andrea, Stams et al. 2013). In the study, one of the enrichments showed succinate consumption not linked to sulfate reduction. Clone library analyses showed that the co-enriched bacterium was distantly related to Propionispora hippei (93\% 16S rRNA sequence identity), an anaerobic propionate-producing fermenter.

\section{Phylogeny}

Analysis of the $16 \mathrm{~S}$ rRNA gene sequences of the strain $\mathrm{ALE}^{\mathrm{T}}$ revealed that it was phylogenetically affiliated to Veilloneaceae family (Bacteria, Firmicutes, Negativicutes, Selenomonadales, Veillonellaceae). Pairwise comparison analysis of $\mathrm{ALE}^{\mathrm{T}}$ sequence (HG317005) showed that the most closely related species were Propionispora hippei (92.2\% identity) and Propionispora vibrioides (92.1\% identity), followed by the members 
of Sporomusa genus (ranging from 89 to $90.7 \%$ to the type strains), forming a consistent cluster within Veillonellaceae family (Figure 1).

\section{Morphology and physiology of L. butyrica strain ALE}

Cells of strain $\mathrm{ALE}^{\mathrm{T}}$ were straight rods, $4-5 \mu \mathrm{m}$ in length and $0.6 \mu \mathrm{m}$ in width (Figure 2a), occurring singly and showing motility during the exponential phase. Spores were readily formed in the growth media tested. The spores were refractive and appeared mainly in terminal position (Figure $2 b$ ). Strain $\mathrm{ALE}^{\mathrm{T}}$ cells stained Gram-positive and the addition of $\mathrm{KOH}$ did not disrupt their cell-wall structure, a property of Gram-positive bacteria. Strain $\mathrm{ALE}^{\mathrm{T}}$ was strictly anaerobic; it required L-cysteine, ferrous iron or sulfide as reducing agents for growth. Gelatin hydrolysis occurred in the cultures, but aesculin was not hydrolyzed. The isolate tolerated up to $0.8 \mathrm{~g} \mathrm{~L}^{-1}$ of $\mathrm{NaCl}$. Growth was observed in temperatures ranging from 20 to $40^{\circ} \mathrm{C}$, with an optimum at $37^{\circ} \mathrm{C}$, and in a pH range from 3.5 to 7 , with optimum at 5.5.The specific growth rate on glycerol under optimal growth conditions was about $0.032 \mathrm{~h}^{-1}$ (generation time of about $21 \mathrm{~h}$ ). Growth rate curves per temperature and $\mathrm{pH}$ ranges are given in Figures $3 \mathrm{a}$ and $3 \mathrm{~b}$. Growth by fermentation of glucose was also seen at $\mathrm{pH}$ as low as 3 and, in general, the growth rates were higher with glucose than with glycerol, reaching $0.1 \mathrm{~h}^{-1}$ at $\mathrm{pH} 5.5$.

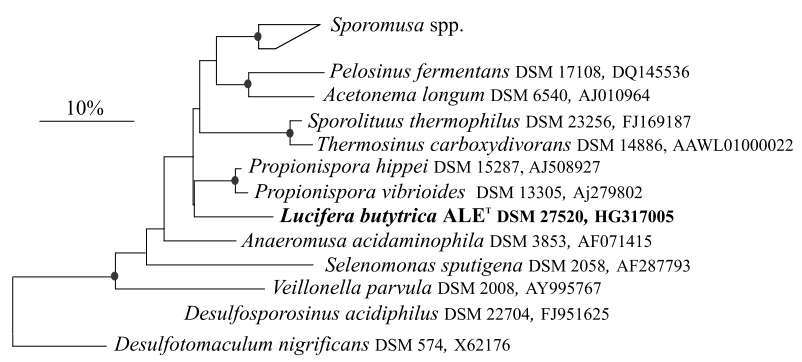

Figure 1 - Phylogenetic affiliations of 16S rRNA sequences of L.butyrica (bold type) and the related species in the Veillonellaceae family of the Firmicutes phylum in the Living Tree Project (Yarza et al., 2008). Maximum-likelihood tree was chosen after applying the three algorithms as implemented in the ARB package. Based on 1000 replications, bootstrap values greater than $90 \%$ are indicated by filled circles. Bar indicates a $10 \%$ estimated sequence divergence. The sequence of Desulfotomaculum nigrificans was used as the outgroup. 


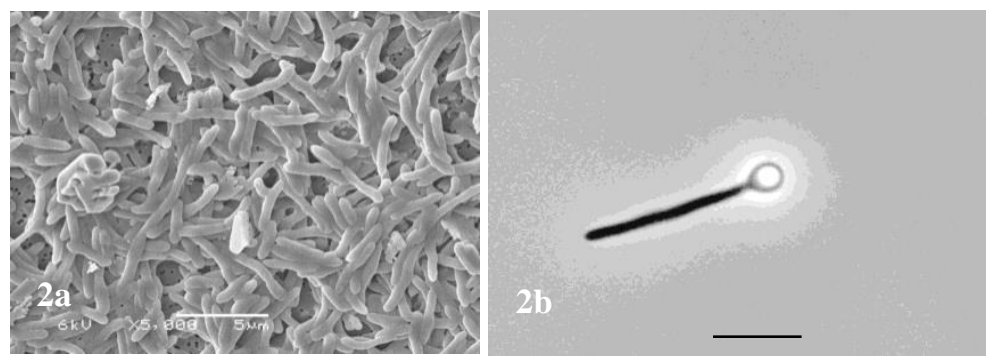

Figure 2a-b - (a) Image of cells of strain $\mathrm{ALE}^{\mathrm{T}}$ obtained by scanning electron microscopy. Bar represents $5 \mu \mathrm{m}$. (b) Phase-contrast microphotograph of strain $\mathrm{ALE}^{\mathrm{T}}$ on spore-forming phase. Bar represents $2 \mu \mathrm{m}$.

Strain $\mathrm{ALE}^{\mathrm{T}}$ was able to grow by fermentation of organic acids, such as pyruvate, succinate and lactate; amino acids such as alanine, arginine, serine, aspartate, valine, histidine, glycine, proline, isoleucine, leucine; sugars, such as glucose, lactose, fructose, xylose and mannitol and alcohols, such as ethanol, methanol, 1,2-propanediol and glycerol. The complex compounds yeast extract, peptone, glycogen, starch and cellulose were also degraded by the isolate. When glycerol was added as substrate, thiosulfate, iron, dimethyl sulfoxide and molybdate were reduced by strain $\mathrm{ALE}^{\mathrm{T}}$. Elemental sulfur was likely also used as electron acceptor, but a weak sulfidogenesis of about $2.5 \mathrm{mM}$ was always measured.

In physiological tests, an incomplete glycerol degradation was consistently observed, with $40-50 \%$ of the substrate remaining in the medium. Incomplete glycerol consumption was also observed with Enterobacter agglomerans (Barbirato, CamarasaClaret et al. 1995), Citrobacter freundii (Gottschalk and Averhoff 1990), Klebsiella pneumoniae (Kretschmann, Carduck et al. 1989).

Strain $\mathrm{ALE}^{\mathrm{T}}$ shared its cellular organization (spore formation, morphology, etc) with its closest relatives Propionispora hippei and Propionispora vibrioides. Besides, Propionispora species also show quite versatile metabolism, but the degradation of organic substrates by this group leads to the formation of propionate, acetate and $\mathrm{CO}_{2}$. The differential characteristics between strain $\mathrm{ALE}^{\mathrm{T}}$ and its closest relatives, $P$. hippei and $P$. vibrioides are shown in Table 1. 
Table 1 - Differential characteristics between strain $\mathrm{ALE}^{\mathrm{T}}$ and its closest relatives: Propionispora hippei and Propionispora vibrioides. All strains were spore-forming and were able to use fructose, mannitol, succinate, glycerol and erythritol as substrates and molybdate, thiosulfate and iron as electron acceptors (tested in this study).

\begin{tabular}{|c|c|c|c|}
\hline Characteristics & Strain $\mathrm{ALE}^{\mathrm{T} a}$ & P. hippei ${ }^{b}$ & P. vibrioides ${ }^{c}$ \\
\hline Temperature range & $25-40$ & $20-50$ & $30-40$ \\
\hline Optimal temperature & 37 & 37 & 37 \\
\hline $\mathrm{pH}$ range & $3.5-7.0$ & $5.0-8.5$ & $5.0-8.5$ \\
\hline Optimal pH & $5.0-6.0$ & 6.8 & 7.5 \\
\hline Extra vitamin requirement & - & NT & - \\
\hline Yeast requirement & + & + & + \\
\hline Doubling time $(\mathrm{h})$ & 21 & 1.26 & NT \\
\hline Gram staining & Positive & Negative & Negative \\
\hline Spore forming & + & + & + \\
\hline $\mathrm{NaCl}$ Tolerance & up to $0.8 \mathrm{mg} / \mathrm{L}$ & NT & NT \\
\hline DNA G+C content $(\mathrm{mol} \%)$ & 46.9 & 45.6 & 48.5 \\
\hline \multicolumn{4}{|c|}{ Substrates } \\
\hline Hydrogen/ $/ \mathrm{CO}_{2}$ & $+^{\delta}$ & - & $-{ }^{\mathrm{a}}$ \\
\hline pyruvate & + & - & - \\
\hline acetate & - & - & - \\
\hline glucose & + & + & - \\
\hline lactose & + & - & NT \\
\hline xylose & + & NT & - \\
\hline lactate & + & - & - \\
\hline ethanol & + & - & - \\
\hline methanol & + & - & - \\
\hline 1,2-propanediol & + & NT & - \\
\hline alanine & + & NT & - \\
\hline xylitol & - & + & + \\
\hline \multicolumn{4}{|c|}{ Electron Acceptors } \\
\hline DMSO & + & $-{ }^{a}$ & $-{ }^{\mathrm{a}}$ \\
\hline Sulfur & $(+)$ & $-^{a}$ & $-{ }^{\mathrm{a}}$ \\
\hline
\end{tabular}

+, Positive; (+), Weak; - , Negative, NT, not tested. ${ }^{\mathrm{a}}$ - this study, ${ }^{\mathrm{b}}$ - Abou-Zeid, Biebl et al. (2004), ${ }^{c}$ - Biebl, Schwab-Hanisch et al. (2000). *or pH 3 with glucose as substrate; $\delta$ with elemental sulfur as electron acceptor. 
Strain $\mathrm{ALE}^{\mathrm{T}}$ was able to grow in the presence of vancomycin and streptomycin at concentrations up to 100 and $25 \mu \mathrm{g} \mathrm{ml}^{-1}$, respectively. No growth was observed when chloramphenicol, penicillin or rifampicin were added at any concentration tested. Major components in the fatty acid profile of strain $\mathrm{ALE}^{\mathrm{T}}$ were palmitic acid - $\mathrm{C}_{16: 0}(22.66 \%)$ and the palmitoleic acids $-\mathrm{C}_{16: 1} \mathrm{w} 9 \mathrm{c}(13.77 \%)$ and $\mathrm{C}_{16: 1} \mathrm{w} 7 \mathrm{c}(13.01 \%)$. Cellular fatty acid composition profiles of strain $\mathrm{ALE}^{\mathrm{T}}$ and its phylogenetic closest relatives were markely different (Table 2). The three majoritarian CFAs of strain $\mathrm{ALE}^{\mathrm{T}}$ mentioned above showed low abundance - or where not even present- in Propionispora spp. Instead, Propionispora spp. possess high abundance of $\mathrm{C}_{11: 0}, \mathrm{C}_{15: 0}$, and $\mathrm{C}_{17: 0}$ while they are not even detected in strain $\mathrm{ALE}^{\mathrm{T}}$. The only quinone component detected was menaquinone MK6.
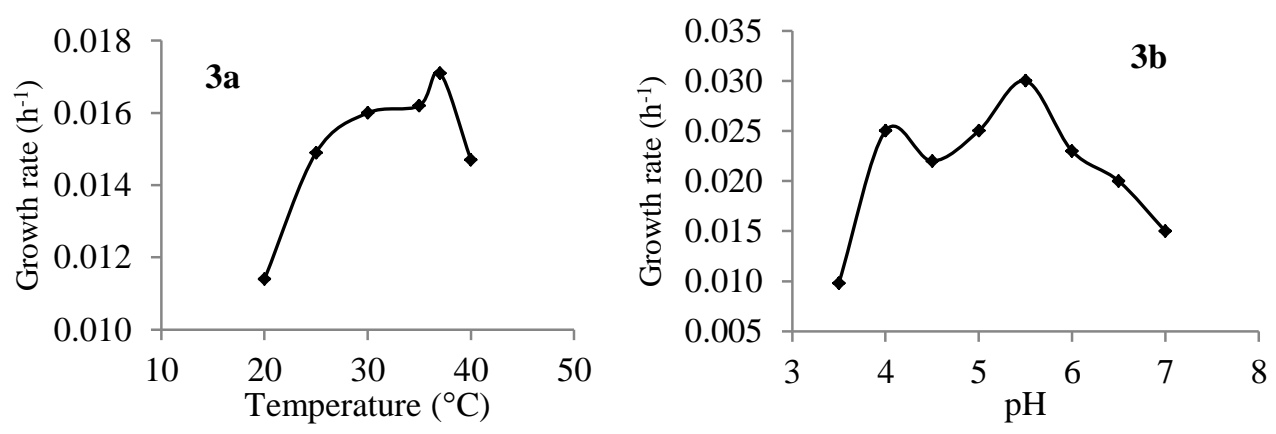

Figure 3a-b - Effect of (a) temperature and (b) $\mathrm{pH}$ on growth rates of strain $\mathrm{ALE}^{\mathrm{T}}$ (grown by fermentation of $5 \mathrm{mM}$ of glycerol at $37^{\circ} \mathrm{C}$ ).

Elemental sulfur might be weakly used as electron acceptor for glycerol oxidation. Strain $\mathrm{ALE}^{\mathrm{T}}$ produced maximally $2.5 \mathrm{mM}$ of sulfide from $2.5 \mathrm{mM}$ of glycerol consumed, when $17.5 \mathrm{mM}$ would be theoretically formed.. As L-cysteine was used as reducing agent in the medium, some tests were performed to check the influence of the sulfide released from this compound (Table 3). The presence of glycerol influenced sulfidogenesis in cultures containing L-cysteine, but when $\mathrm{CO}_{2}$ was used as carbon source, in the absence of sulfur, no sulfide was produced, and so L-cysteine was not degraded. When titanium citrate was used as reducing agent in the presence of elemental sulfur and $\mathrm{CO}_{2}$ as carbon source, sulfide was not produced and growth was not detected. Therefore, elemental sulfur is not disproportionated by strain $\mathrm{ALE}^{\mathrm{T}}$. Moreover, when cultures were grown in the presence of glycerol, titanium citrate and elemental sulfur and tested for metals resistance, sulfide was formed and precipitated as metals sulfide, confirming the ability of L. butyrica to respire elemental sulfur. 
Table 2 - Relative abundance (\% of total) of cellular fatty acids of strain $\mathrm{ALE}^{\mathrm{T}}$ and its phylogenetic closest relatives grown on glycerol.

\begin{tabular}{|c|c|c|c|}
\hline Fatty acids & $\mathbf{A L E}^{\mathrm{T}}$ & P. hippei & P. vibrioides \\
\hline \multicolumn{4}{|c|}{ Saturated straight-chain } \\
\hline $\mathrm{C}_{9: 0}$ & - & 0.38 & 0.45 \\
\hline $\mathbf{C}_{10: 0}$ & - & 0.24 & 0.27 \\
\hline $\mathrm{C}_{11: 0}$ & - & 13.45 & 14.67 \\
\hline $\mathrm{C}_{12: 0}$ & 2.47 & - & - \\
\hline $\mathbf{C}_{14: 0}$ & 5.25 & 1.02 & 0.82 \\
\hline $\mathrm{C}_{15: 0}$ & - & 13.49 & 9.87 \\
\hline $\mathrm{C}_{16: 0}$ & 22.66 & 2.81 & 2.87 \\
\hline $\mathrm{C}_{17: 0}$ & - & 15.36 & 14.12 \\
\hline $\mathrm{C}_{18: 0}$ & 3.59 & 0.61 & 0.66 \\
\hline$C_{19: 0}$ & - & 0.41 & 0.66 \\
\hline \multicolumn{4}{|c|}{ Unsaturated straight-chain } \\
\hline $\mathrm{C}_{15: 1} \mathrm{w8c}$ & - & 6.71 & 4.91 \\
\hline $\mathrm{C}_{15: 1} \mathrm{w6c}$ & - & 0.26 & 0.26 \\
\hline $\mathrm{C}_{16: 1} \mathrm{w9c}$ & 13.77 & 0.63 & 0.65 \\
\hline $\mathrm{C}_{16: 1} \mathrm{w7c}$ & 13.01 & - & - \\
\hline $\mathrm{C}_{16: 1} \mathrm{w5c}$ & - & 0.70 & 0.60 \\
\hline $\mathrm{C}_{17: 1} \mathrm{w9c}$ & - & 6.30 & 4.75 \\
\hline $\mathrm{C}_{17: 1} \mathrm{w8c}$ & - & 3.52 & 4.33 \\
\hline $\mathrm{C}_{17: 1} \mathrm{w6c}$ & 6.00 & 1.84 & 1.75 \\
\hline $\mathrm{C}_{18: 1} \mathrm{w9c}$ & - & 0.68 & 0.71 \\
\hline $\mathrm{C}_{18: 1} \mathrm{w7c}$ & 3.93 & - & - \\
\hline $\mathrm{C}_{18: 1} \mathrm{w5c}$ & - & 0.42 & 0.57 \\
\hline $\mathrm{C}_{20: 1}$ w7c & - & 1.20 & 0.86 \\
\hline \multicolumn{4}{|c|}{ Hydroxy acids } \\
\hline $\mathrm{C}_{11: 0} 3 \mathrm{OH}$ & - & 2.88 & 4.06 \\
\hline $\mathrm{C}_{12: 0} 3 \mathrm{OH}$ & - & 0.37 & 0.44 \\
\hline $\mathrm{C}_{15: 0} \mathbf{3 O H}$ & - & 0.27 & 0.31 \\
\hline Iso-C ${ }_{13: 0} 3 O H$ & 7.17 & - & - \\
\hline \multicolumn{4}{|c|}{ Saturated branched-chain } \\
\hline Iso- $C_{11: 0}$ & 4.26 & - & - \\
\hline Anteiso-C $\mathrm{C}_{13: 0}$ & - & 0.17 & 0.17 \\
\hline Iso-C $\mathrm{C}_{14: 0}$ & - & 0.82 & 0.90 \\
\hline Anteiso- $\mathrm{C}_{15: 0}$ & - & 11.76 & 12.38 \\
\hline Iso- $C_{15: 0}$ & 7.44 & 0.46 & 0.43 \\
\hline Iso-C $\mathrm{C}_{16: 0}$ & - & 2.59 & 3.21 \\
\hline Anteiso- $\mathrm{C}_{17: 0}$ & - & 1.51 & 1.51 \\
\hline Iso- $C_{17: 0}$ & 3.93 & - & - \\
\hline Iso- $C_{20: 0}$ & - & 0.54 & 0.52 \\
\hline \multicolumn{4}{|c|}{ Unsaturated branched-chain } \\
\hline Iso-C 17:1 $_{10}$ w10c & 6.53 & - & - \\
\hline
\end{tabular}


Table 3 - Sulfide observations in the presence or absence of elemental sulfur, reducing agent and carbon source when cultures of Lucifera butyrica are incubated at $37{ }^{\circ} \mathrm{C}, \mathrm{pH} 5.5$

\begin{tabular}{cccccc}
\hline $\begin{array}{c}\text { Reducing } \\
\text { agent }\end{array}$ & $\begin{array}{c}\text { Carbon } \\
\text { source }\end{array}$ & Sulfur & Sulfide $\mathbf{T}_{\mathbf{0}}$ & Growth & Sulfide $\mathbf{T}_{\mathbf{f}}$ \\
\hline L-cysteine & Glycerol & - & - & + & 1.38 \\
\hline L-cysteine & Glycerol & $0.04 \mathrm{~g} / 50 \mathrm{~mL}$ & - & + & 2.51 \\
\hline L-cysteine & $\mathrm{CO}_{2}$ & $0.04 \mathrm{~g} / 50 \mathrm{~mL}$ & - & + & 1.49 \\
\hline L-cysteine & - & - & - & - & - \\
\hline Titanium citrate & $\mathrm{CO}_{2}$ & $0.04 \mathrm{~g} / 50 \mathrm{~mL}$ & - & - & - \\
\hline
\end{tabular}

\section{General genomic features}

Annotated (and manually curated) draft genome sequence of Lucifera butyrica $\mathrm{ALE}^{\mathrm{T}}$ comprises a chromosome with the size of $4.67 \mathrm{Mbp}$ distributed over 138 scaffolds. The total coverage over the predicted genome size was $90 \%$ and the $\mathrm{G}+\mathrm{C}$ content 46.96 mol\%. A total of 5223 genes are predicted, from which 84 are tRNA and 12 are rRNA genes. There are 5122 coding DNA sequences (CDS), of which 4158 have function prediction and 964 could not be assigned to any function in the database, and therefore were annotated as hypothetical proteins or proteins of unknown function. One CRISPR region (Type I-B) was identified in the genome with a length of 945 bp and 14 spacers of 30 bp length. The spacer sequences match viral DNA sequences found in Halogeometricum borinquense, Arthrobacter phenantrenivorans, Microcoleus sp., Pseudomonas phage, Stanieria cyanosphaera, Hymenobacter sp., Azospirillum brasilense, Ralstonia solanacearum, Crinalium epipsammum and Enterobacteria phage.

The genome encodes a reverse tricarboxylic acid (TCA) cycle pathway. Routes for glycerol fermentation leading to 1,3-PDO, acetate, butyrate, propionate and ethanol, and $\beta$ oxidation of fatty acids, resistance to acidic conditions, oxygen stress, and metals are encoded. The genome encodes three subunits of the anaerobic hydrogenase $1 \mathrm{~b}$-type cytochrome HyaABCD, reported to be induced under anaerobiosis and repressed by nitrate (Unden and Bongaerts 1997). Genes possibly involved in sulfur and thiosulfate reduction are encoded. The genes involved in two operon types (VanA and VanG) for vancomycin resistance are also encoded. Although the resistance to vancomycin is generally attributed to Gram-negative bacteria, several Gram-positive species have been reported to present intrinsic resistance to this antibiotic, such as Leuconostoc spp. (Swenson, Facklam et al. 1990), Pediococcus spp. (Swenson, Facklam et al. 1990), Lactobacillus spp. (Swenson, Facklam et al. 1990), Erysipelothrix rhusiopathiae (Romney, Cheung et al. 2001), Weissella confuse (Kumar, Augustine et al. 2011), and Clostridium innocuum (David, Bozdogan et al. 2004). The list of enzymes involved in the aforementioned mechanisms is given in Supplementary Table S1. 


\section{Sulfur and energy metabolism}

Genes encoding the bifunctional sulfide dehydrogenase were detected in the genome of L. butyrica (1490 and 1491). This enzyme was isolated from Pyrococcus furiosus and showed sulfur reductase activity in vitro, but the expression of its codinggenes was also shown to correlate to the carbon source rather than to elemental sulfur (Ma and Adams 2001). Therefore, it is likely that it plays a role as bifurcating ferredoxin:NADP oxidoreductase (Ma and Adams 2001). The genome also encodes genes for rhodanese-like thiosulfate sulfurtransferases (0570, 0603, 1577 and 3290), which some of them might be involved in sulfur reduction (Chapter 7).

Physiological tests on $L$. butyrica revealed its ability to utilize thiosulfate as electron acceptor, producing up to $4.5 \mathrm{mM}$ of sulfide. However, genes coding for thiosulfate reductase and dissimilatory sulfite reductase are not encoded in the genome, implying that sulfite is not an intermediate in thiosulfate reduction in this organism, as proposed for some other thiosulfate-reducing bacteria, including D. amilsii, as shown in Chapter 7. The encoded thiosulfate sulfurtransferases (3290, 0570 and 0603) might be also involved in the direct reduction of thiosulfate to sulfide.

The activity of elemental sulfur reduction at low $\mathrm{pH}$ might benefit from cell-sulfur interaction, as also thought for sulfur oxidation (Gehrke, Telegdi et al. 1998, Franz, Lichtenberg et al. 2007). In L. butyrica, the contact might be favored by the formation of extracellular polymeric substance (EPS), such as genes encoding the glycosyl transferase enzyme $(0227,0384)$, reported to act as a polymerase and exporter of EPS, are present in the genome (Chrismas, Barker et al. 2016). Moreover, L. butyrica cell aggregation was observed when grown by fermentation or sulfur reduction, especially in cultures with initial $\mathrm{pH}$ value lower than 5.5.

\section{Glycerol degradation}

As an uncharged molecule, glycerol is able to cross the microbial membrane by passive diffusion, but a $28 \mathrm{kDa}$ integral membrane aquaglyceroporin, $\mathrm{GlpF}$, is reported to facilitate the diffusion in some microorganisms (Voegele, Sweet et al. 1993, Darbon, Ito et al. 1999). Moreover, two active glycerol uptake systems, $\mathrm{Na}^{+} /$glycerol and $\mathrm{H}^{+} /$glycerol symporters, are reported for some halophilic microorganisms (Lages, Silva-Graca et al. 1999). In Lucifera butyrica's genome, GlpF is encoded (1689, 2547 and 0660), but any active uptake symporters are present. Therefore, glycerol might diffuse into the cytoplasm of this microorganism via the channel protein.

Figure 4 displays the glycerol degradation pathway likely performed by $L$. butyrica. When glycerol crosses the cytoplasmic membrane as the only source of carbon and energy, it is metabolized, both oxidatively and reductively (Zhu, Lawman et al. 2002). 
In the oxidative pathway, a phosphate might be added to a molecule of glycerol by the enzyme glycerol kinase $(4985,4986)$, forming glycerol 3-phosphate, that will be reversibly converted into dihydroxyacetone-P by a $\mathrm{NAD}^{+}$-dependent glycerol dehydrogenase (1377, 2837). The glycolytic enzyme triose phosphate isomerase $(2987,3004)$ can catalyze its reversible conversion to glyceraldehyde-3P, which might follow the glycolysis pathway to the formation of pyruvate. Physiological tests showed further conversion of pyruvate in $L$. butyrica leading to the formation of acetate, $\mathrm{CO}_{2}$, butyrate and ethanol. The genomic set of this isolate encode genes for acetate formation via the enzymes: pyruvate:ferredoxin oxidoreductase $(3166,3177,4376,1480,2083$, 2907, 1907), converting pyruvate into acetyl-CoA; phosphate acetyl transferase $(1551,1554,164,2904,3827)$, converting acetylCoA into acetyl-P; and acetate kinase (0876), converting acetyl-P into acetate. The direct conversion of acetyl-CoA into acetate might also be possible, as $L$. butyrica also encodes the acetyl-CoA hydrolase (1562). When acetyl-CoA is formed, however, it can also undergo the butyrate generation pathway, as the enzymes are encoded in the genome. So, acetoacetyl-CoA can be formed from acetyl-CoA via an acetyl-coenzyme-A acetyltransferase (2274) and further converted to butyryl-CoA via the hydroxybutytyl-CoA dehydrogenase $(2124,2280)$. A phosphotransbutyrylase transfers the butyrate from butyrylCoA onto inorganic phosphate, after which butyrate kinase transfers the phosphate onto ADP, creating ATP. Acetyl-CoA might also be an precursor of the formation of ethanol, with acetaldehyde as an intermediate. The first conversion is mediated by the enzyme aldehyde dehydrogenase $(0513,1408,4384,5024)$, while the second occurs via one alcohol dehydrogenase (0150, 0956, 1837, 2263, 2290, 2523, 2947, 3895, 4400, 4514, 4887).

Some studies reported butanol, 2,3-butanediol, lactate, succinate, 1,2-propanediol and propionate as products of microbial glycerol degradation (Ouattara, Traore et al. 1992, Biebl 2001, Li, Lesnik et al. 2013). Although the genes encoding enzymes involved in the production of those compounds were present in the genome of L. butyrica, they were not detected in physiological tests performed in batch serum bottles. In $\mathrm{pH}$-controlled batch reactors, however, propionate was produced during glycerol degradation by sulfur respiration.

The reductive pathway is catalyzed by coenzyme $\mathrm{B}_{12}$-dependent glycerol dehydratase (4400), converting glycerol to 3-hydroxypropionaldehyde, and by the NADHdependent enzyme 1,3-propanediol dehydrogenase (1837), reducing 3hydroxypropionaldehyde to 1,3-propanediol and regenerating $\mathrm{NAD}^{+}$. 


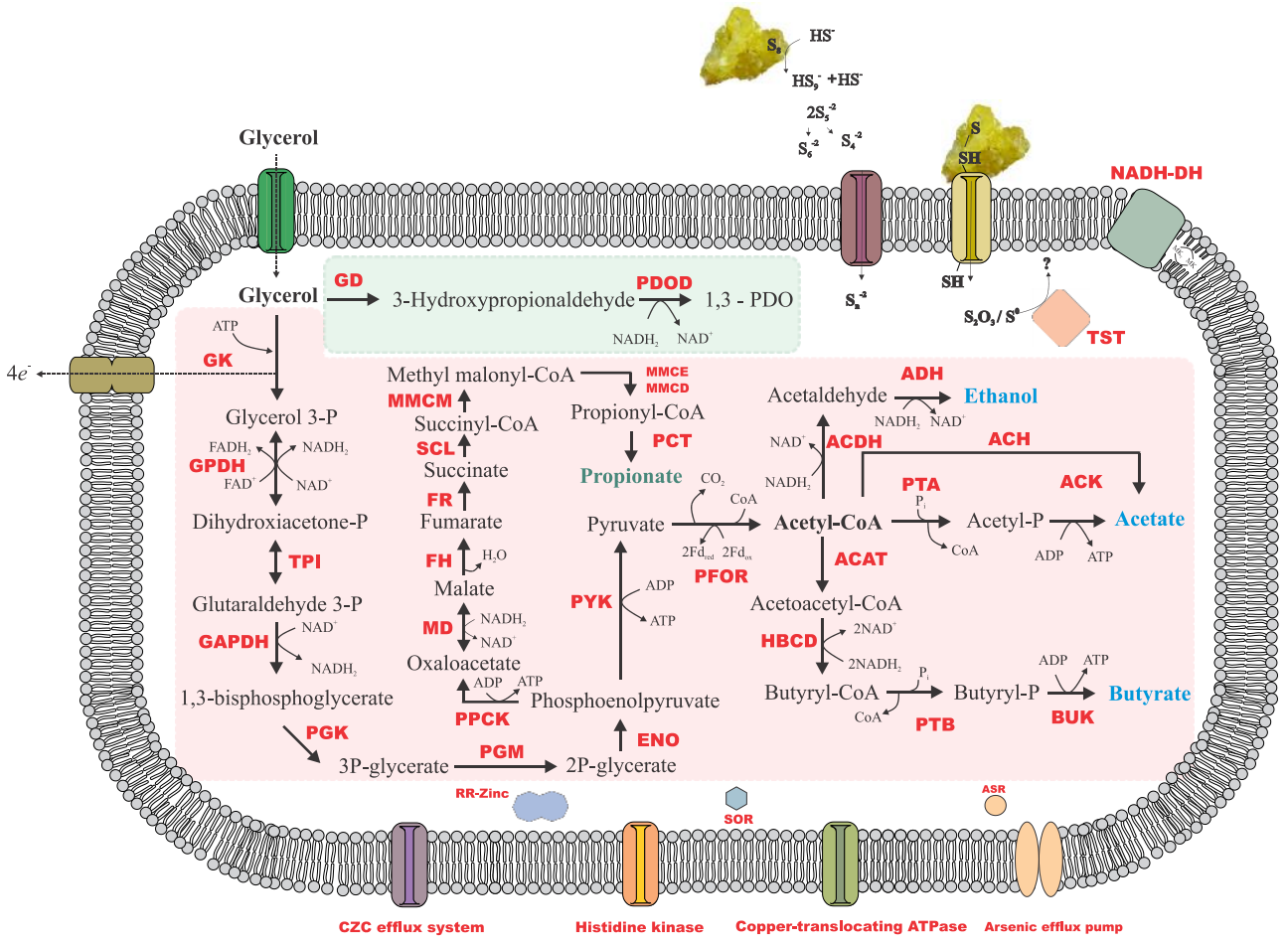

Figure 4 - Metabolic reconstruction of L. butyrica growing by glycerol fermentation or sulfur respiration with glycerol as electron acceptor. Reductive and oxidative routes of glycerol degradation are represented by the green and the pink area, respectively. GD glycerol dehydratase; PDOD - 1,3-propanediol dehydrogenase; GK - glycerol kinase; GPDH - glycerol-3P dehydrogenase; TPI - triose phosphate isomerase; GAPDH glyceraldehyde-3P dehydrogenase; PGK - phosphoglycerate kinase; PGMphosphoglycerate mutase; ENO - enolase; PYK - pyruvate kinase; PFOR pyruvate:ferredoxin oxidoreductase; PTA - phosphotransacetylase; ACK - acetate kinase; ACAT - acetyl-CoA acetyltransferase; HBCD - hydroxybutyryl dehydrogenase; PTB phosphotransbutyrylase; BUK - butyrate kinase; ACDH - acetaldehyde dehydrogenase; AD - alcohol dehydrogenase; PPCK - phosphoenolpyruvate kinase; MD - malate dehydrogenase; FH fumarate hydratase; FR fumarate reductase; SCL - succinyl-CoA ligase; MMCM - methyl malonyl-CoA mutase, MMCE - methyl malonyl-CoA epimerase; MMCD - methyl malonyl-CoA dehydrogenase; PCT - propionyl-CoA transferase; TST thiosulfate sulfur transferase; RR-Zinc - response regulator of zinc; SOR - superoxide reductase; ASR - arsenate reductase; NADH-DH - NADH dehydrogenase; MK menaquinone. 


\section{Acidic resistance}

Microorganisms can possess various mechanisms to thrive in acidic environments, as discussed in Chapter 2. L. butyrica's optimum growth is at 5.5, but it can grow at $\mathrm{pH}$ as low as 3.5 or even 3, depending on the conditions. The genes possibly responsible for L. butyrica low $\mathrm{pH}$ resistance were investigated. The genome encodes a DNA repair system that includes the recombinase RecA, the mismatch repair MutS, a hypothetical protein and a $\operatorname{Rec} A$ regulator $(\operatorname{Rec} X)$. $\operatorname{Rec} A$ is reported to play a central role in biological processes that require homologous DNA repair and recombination and a global response to DNA damage, called SOS response (Adikesavan, Katsonis et al. 2011). Moreover, a RecA-dependent acid-tolerance system has also been reported for Helicobacter pylori. Strains lacking the RecA gene showed sensitivity to DNA-damaging agents and a reduction in conversion of homologous gene related to outer membrane protein expression, resulting in a reduced survival capacity in acidic environments (Thompson and Blaser 1995, Amundsen, Fero et al. 2008).

Additionally, the excision nuclease UvrABC is encoded in the genome of $L$. butyrica. This system is reported to play an important role in DNA damage recognition in Bacillus caldontenax (Croteau, DellaVecchia et al. 2008) and acidinduced DNA damage repair of in Streptococcus mutans at pH 5 (Hanna, Ferguson et al. 2001).

The genome of L. butyrica also encodes some sodium coupled symporters $(4003,4123,4150,4331,4356,5116,5118)$ and one oxalate:formate antiporter (3096), reported by microarray experiments to be upregulated in cells of E. coli when they undergo cytoplasmic acidification by treatment with benzoate (Kannan, Wilks et al. 2008).

\section{Tolerance to heavy metals in solution}

At $\mathrm{pH} 3$, using glucose as substrate, L. butyrica was able to grow with up to 1 $\mathrm{mM}$ of zinc and $50 \mathrm{mM}$ of iron in solution in cultures without any sulfur source added to the medium. Several genes encoding resistance to zinc and iron are encoded in the genome of $L$. butyrica, such as the cobalt-zinc-cadmium resistance genes $(1692,2763$, 2963, 2975, 1700, 2101), their transcriptional regulator $(0108,0153,0163,2633$, $3905,4895,4973,0101)$ and the response regulator of zinc sigma-54-dependent twocomponent system $(1031,1930,1938,2953$, 2955, 4071, 4072, 4079, 4080, 4146, 4421, 5023).

Although L. butyrica was not resistant to copper at any concentration, its genome encodes genes for copper resistance, such as the multicopper oxidase (4187) 
and the copper-translocating P-type ATPase (3071, 3935). Additionally, genes for arsenic resistance are encoded, such as the arsenical resistance operon repressor (4106), the arsenical resistance operon trans-acting repressor (1662), the arsenical pump-driving ATPase $(1661,2676)$, the arsenic efflux pump protein $(2859,3114)$, the arsenate reductase $(1669,1685,4104,4171,4174)$ and the arsenical-resistance protein ACR3 (1667, 1687, 4172). The two mentioned families of arsenite transport proteins responsible for As(III) extrusion, ArsABC and Acr3, have been shown to confer arsenic resistance to Staphylococcus aureus, Bacillus subtilis (Rosen 2002), as well as to some soil bacteria (Achour, Bauda et al. 2007).

\section{Co-culture experiment with $L$. butyrica}

L. butyrica is a versatile microorganism able to use a wide range of substrates but it produces a low amount of sulfide. On the other hand, D. amilsii is an efficient sulfidogenic bacteria but with a more restricted utilization of substrates, which includes acetate. As proof of concept, both microorganisms were grown together on glycerol and sulfur. The co-cultivation of L. butyrica and D. amilsii yielded $9.4 \mathrm{mM}$ sulfide after degradation of $3 \mathrm{mM}$ glycerol, while only $2.4 \mathrm{mM}$ of sulfide was produced with L. butyrica growing alone (Figure 5). The sulfide production was close to the maximum of $D$. amilsii $(10 \mathrm{mM})$ growing on $5 \mathrm{mM}$ of acetate. The co-culture design also boosted the sulfide production in the medium with a parallel optimization of time, as in 12 days the maximum yield of sulfide was observed, while the monoculture of $D$. amilsii would take more than 20 days.

Both, mono - and di-cultures, were transferred to $\mathrm{pH}$-controlled reactors. The analysis of the substrate consumption and product formation profiles, together with cell counting confirmed the activity of both microorganisms in the co-culture reactor. Glycerol was used by $L$. butyrica and the acetate produced from the glycerol degradation was used by $D$. amilsii as substrate for sulfur reduction. Pure culture of $L$. butyrica degraded $2.6 \mathrm{mM}$ glycerol and produced 1,3-PDO $(1.33 \pm 0.07 \mathrm{mM})$, acetate $(1.1 \pm 0.1 \mathrm{mM})$, ethanol $(0.55 \pm 0.1 \mathrm{mM})$, butyrate $(0.25 \pm 0.03 \mathrm{mM})$ and propionate $(0.38 \pm 0.07 \mathrm{mM})$. In co-culture, less product accumulation was detected from the oxidation of $2.65 \mathrm{mM}$ of glycerol: 1,3-PDO $(0.92 \pm 0.07 \mathrm{mM})$, ethanol $(0.2 \pm 0.11$ $\mathrm{mM})$, butyrate $(0.16 \pm 0.06 \mathrm{mM})$ and propionate $(0.33 \pm 0.05 \mathrm{mM})$. 


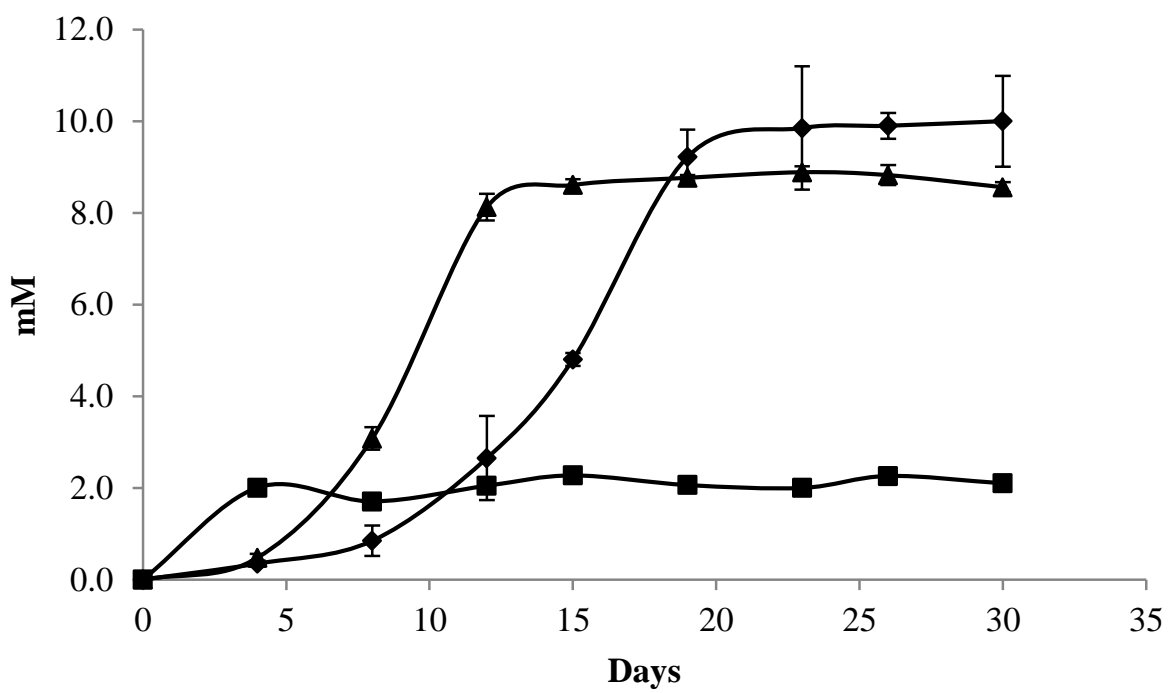

$\rightarrow$ Lucifera butyrica $\rightarrow$ Co-culture $\rightarrow$ Desulfurella amilsii

Figure 5 - Sulfide production of monocultures of L. butyrica (growing on glycerol) and $D$. amilsii, (growing on acetate) and the co-culture (growing on glycerol).

Contrary to the profile observed in $120-\mathrm{mL}$ serum bottles the degradation of glycerol by L. butyrica at $\mathrm{pH}$-controlled conditions led to the production of propionate in the culture. Additionally, ethanol was produced in concentrations up to $0.5 \mathrm{mM}$ in 17 days of co-cultivation and this amount became $0.2 \mathrm{mM}$ after 31 days of cultivation. In the $\mathrm{pH}$-controlled reactor with the monoculture, the amount of ethanol produced in the first 17 days of cultivation reached $1.6 \mathrm{mM}$, decreasing to $0.55 \mathrm{mM}$ after 31 days. The results suggest that a) between day 17 and day 31 of the cultivation, ethanol served as electron donor for sulfur respiration by L. butyrica or b) ethanol production stopped and the gassing of the reactor led evaporation of the ethanol. The consumption of glycerol by L. butyrica alone or in co-culture ceased between day 10 and day 15 of cultivation, with circa of $0.7 \mathrm{mM}$ of glycerol remaining in the medium. Growth of L. butyrica (monitored with cell counting) stopped in both culture conditions when glycerol consumption ceased (Figures 6 and 7). The concentration of acetate in the pure culture stagnated after 7 days, when it reached its maximum concentration in the medium $( \pm 1.1 \mathrm{mM}$ ) (Figure 6). In combined growth culture, acetate started to be produced after day 5, reaching a maximal concentration $(0.79$ $\mathrm{mM}$ ), and after 24 days of cultivation, it was completely depleted. D. amilsii growth in co-culture started after 5 days of cultivation, when acetate was available in the culture and it ceased when acetate was depleted (Figure 7). 


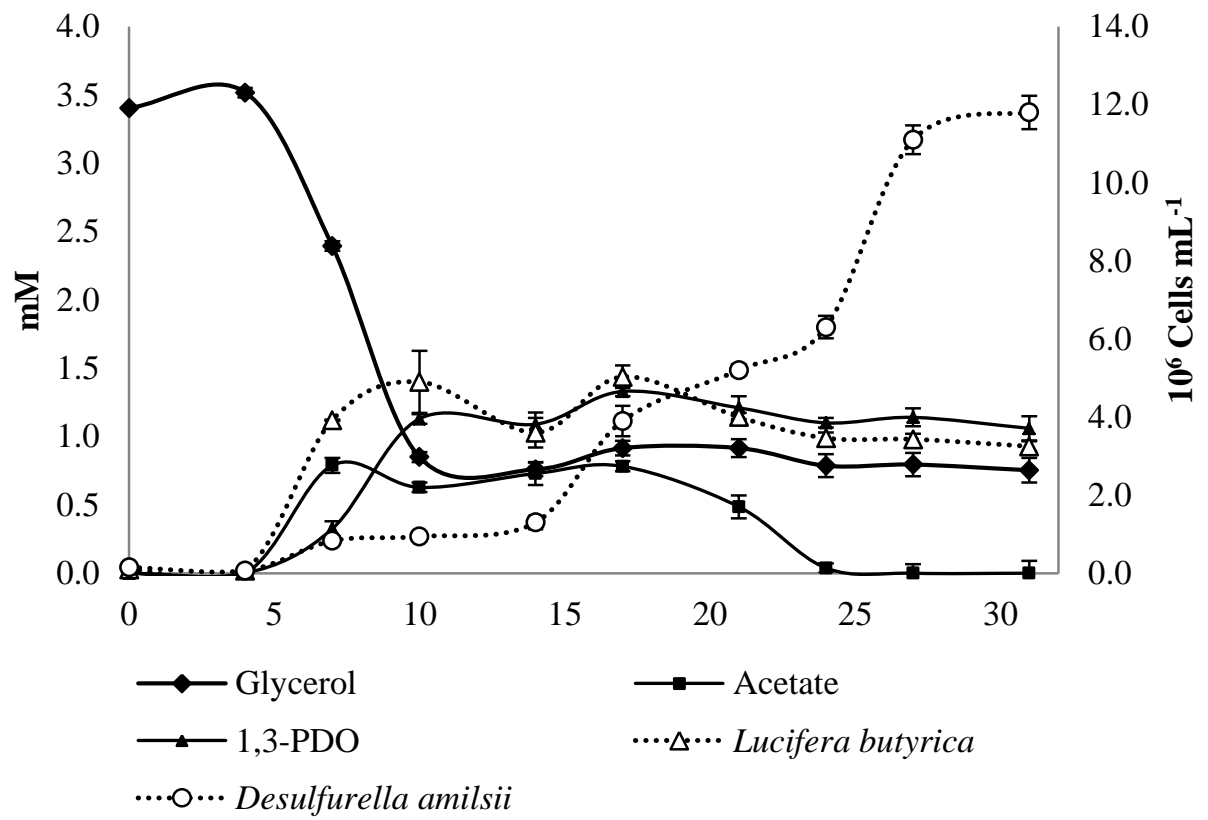

Figure 6 - Glycerol consumption, acetate production and number of cells of $L$. butyrica growing in a $\mathrm{pH}$ controlled batch reactor, with glycerol as electron donor and sulfur as electron acceptor.

The amount of sulfide produced in the coculture cannot be explained when only D. amilsii is reducing sulfur coupled to the acetate produced by L.butyrica. Therefore, it seems that the cultivation of $L$. butyrica in co-culture with $D$. amilsii improves the performance of L. butyrica in sulfur respiration, by eliminating possible toxicity of acetate in the medium and allowing the utilization of ethanol as electron donor.

\section{Concluding remarks}

A novel versatile bacterium in a novel genus of, L. butyrica strain $\mathrm{ALE}^{\mathrm{T}}$, was isolated and described in this chapter. The ability of the isolate to grow in a broad range of $\mathrm{pH}$, tolerating high concentrations of zinc and iron in solution and producing 1,3-PDO as one of the major products, makes it a potential tool for biotechnological application. The co-culture of $L$. butyrica and the acidotolerant sulfur-reducing bacterium, D. amilsii, accelerated the growth of the microorganisms and revealed high yields of sulfide, which can be used to precipitate heavy metals from acidic waste streams. Further studies at lower $\mathrm{pH}$ values and in a continuous mode system with addition of heavy metals are required to 
optimize the combined growth of the microorganisms to assure the metals precipitation property.

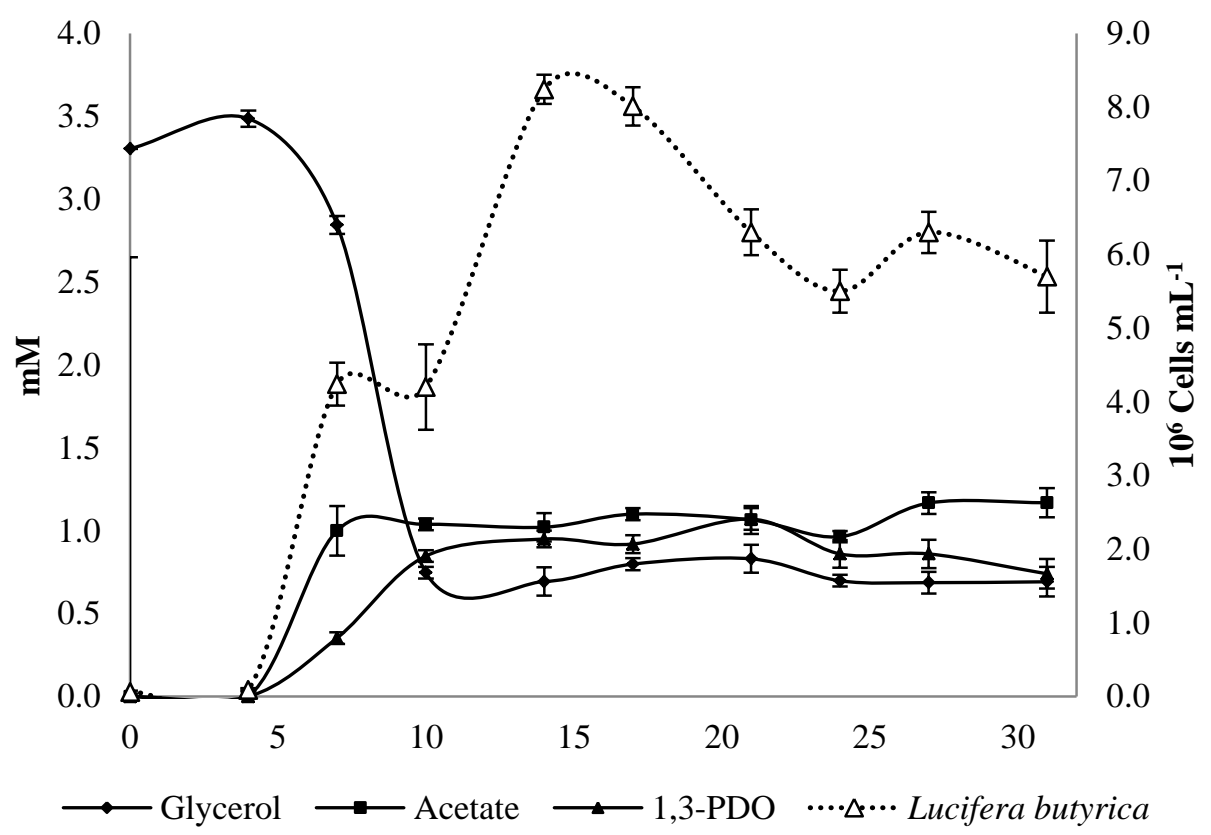

Figure 7 - Glycerol, acetate and number of cells profile of L. butyrica growing in a $\mathrm{pH}$ controlled batch reactor, with glycerol as electron donor and sulfur as electron acceptor.

\section{Description of Lucifera gen. nov.}

Lucifera (Lu.ci'fe.ra. L. fem. adj. used as a fem. n. Lucifera, light-bringing because of its match shape)

Cells stained Gram-positive, spore-forming, motile, long rods. Strictly anaerobic. Yeast extract is required for growth. Optimum growth temperature is $37^{\circ} \mathrm{C}$ within a range of 25 to $40{ }^{\circ} \mathrm{C}$. Optimum growth $\mathrm{pH}$ is 5.5 within a range from 3.5 to 7.0. The bacterium was negative for both oxidase and catalase and positive for urease activity. Gelatin hydrolysis occurred, but aesculin did not. Species utilize $\mathrm{H}_{2} / \mathrm{CO}_{2}$, sugars, alcohols and amino acids and produces 1,3-propanediol, butyrate, acetate, ethanol and propionate. Major cellular fatty acids are $\mathrm{C}_{16: 0}, \mathrm{C}_{16: 1} \mathrm{w} 9 \mathrm{c}$ and $\mathrm{C}_{16: 1} \mathrm{w} 7 \mathrm{c}$. The only respiratory quinone detected was MK6. The genomic DNA G+C content of the type species is $46.96 \% \mathrm{~mol} / \mathrm{mol}$. The type species is Lucifera butyrica. 


\section{Description of Lucifera butyrica sp. nov.}

Lucifera butyrica (bu.ti'ri.ca. Gr. n. bouturon (Latin transliteration butyrum), butter; L. fem. suff. -ica, suffix used with the sense of belonging to; N.L. fem. adj. butyrica, related to butter, butyric).

Morphology and general characteristics are as described for the genus. Cells are motile long rods, $0.4-0.6 \mu \mathrm{m}$ in diameter and $5 \mu \mathrm{m}$ in length. The temperature range for growth is 25 to $40^{\circ} \mathrm{C}$, with an optimum at $37^{\circ} \mathrm{C}$. The $\mathrm{pH}$ range for growth is 3.5 to 7.0 , with an optimum at 5.5 . $\mathrm{NaCl}$ was tolerated in concentrations up to $0.8 \%(\mathrm{w} / \mathrm{v})$. Acetogenic growth on $\mathrm{H}_{2} / \mathrm{CO}_{2}$ occurred. It fermented sugars (fructose, xylose, glucose, lactose and mannitol), organic acids (pyruvate, acetate, succinate and lactate), alcohols (methanol, ethanol, glycerol and 1,2-propanediol), amino acids (alanine, arginine, serine, aspartate, valine, histidine, glycine, proline, isoleucine, leucine, betaine and erythritol), and complex substances such as yeast extract, peptone, glycogen, starch and cellulose. In the presence of glycerol, iron, elemental sulfur, thiosulfate, and nitrate are used as electron acceptors. Arsenate, sulfite, perchlorate and fumarate are not used. Oxidase and catalase activities were negative, urease was positive. Indole formation was negative. Gelatin, but not aesculin was hydrolyzed. The predominant cellular fatty acids were $C_{16: 0}, C_{16: 1} \omega 9 c$ and $C_{16: 1} \omega 7 c$. Menaquinone MK6 was the only respiratory quinone. The $\mathrm{G}+\mathrm{C}$ content of the genomic DNA of the type strain is $46.96 \% \mathrm{~mol} / \mathrm{mol}$.

The type strain, $\operatorname{ALE}^{\mathrm{T}}\left(=\mathrm{JCM} 19373^{\mathrm{T}}=\mathrm{DSM} 27520^{\mathrm{T}}\right)$, was isolated from sediments of an acid rock drainage environment (Tinto River, Spain).

\section{Acknowledgments}

The doctoral study program was supported by $\mathrm{CNPq}$ (Conselho Nacional de Desenvolvimento Cientifíco e Tecnológico), organization of the Brazilian Government. Research of A.J.M. Stams and I. Sánchez-Andrea is financed by an ERC grant (project 323009) and the Gravitation grant (SIAM 024.002.002) of the Netherlands Ministry of Education, Culture and Science and the Netherlands Science Foundation. We thank Monika Jarzembowska (WUR, Wageningen, The Netherlands) for the scanning electron microscopy analysis. 

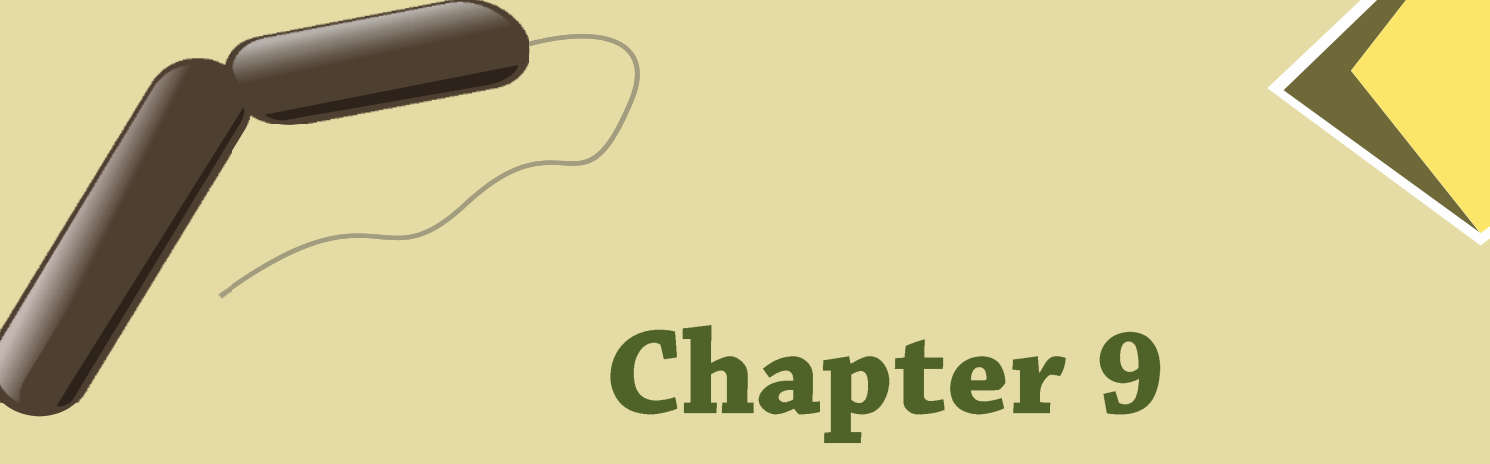

\section{Chapter 9}

General discussion

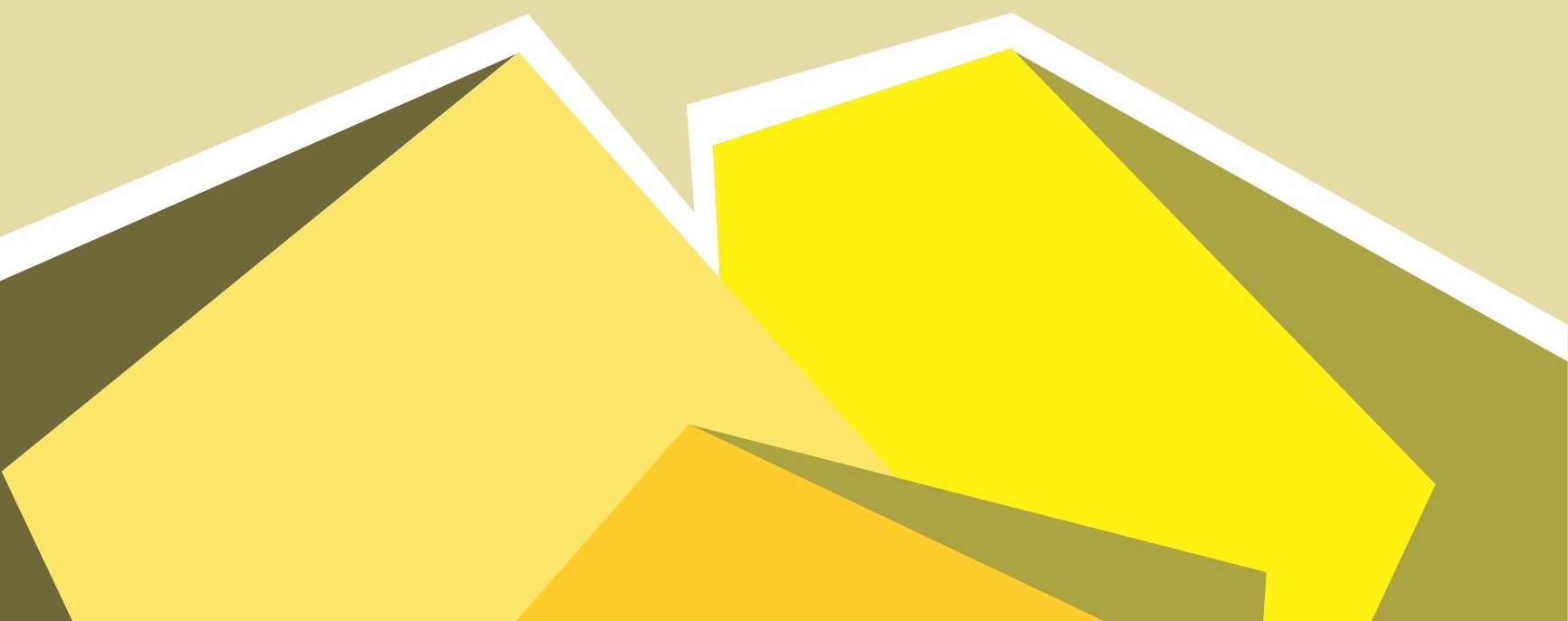


The first evidence of microbial sulfur reduction was described in 1936 (Pelsh), even though elemental sulfur reduction with endogenous or added organic electron donors was already reported in 1895 (Beijerink). The anaerobic mesophilic acetate oxidizer, Desulfuromonas acetoxidans, was the first microorganism reported to grow by sulfur reduction in pure culture (Pfennig and Biebl 1976). From that time on, many sulfur reducers were isolated directly with elemental sulfur as terminal electron acceptor or with other electron acceptors, such as sulfate (Biebl and Pfennig 1977), iron (III) (Caccavo Jr., Lonergan et al. 1994) and manganese (IV) (Myers and Nealson 1988). In Chapter 2, it is shown that sulfur reducers are currently distributed over about 70 genera within 9 phyla in the Bacteria domain and 37 genera within 2 phyla in the Archaea domain.

Sulfur reducers can thrive in a broad range of $\mathrm{pH}$ and temperature, in natural or engineered systems, where elemental sulfur is formed. The great majority of sulfur reducers has been isolated from extreme habitats, such as hot water pools in solfataric fields, acidic hot springs, hydrothermal systems in shallow and deep sea, hypersaline lakes and anoxic mud sediments (Stetter 1996, Rabus, Hansen et al. 2006). Therefore, several sulfurreducing microorganisms possess resistance systems to tackle the harsh conditions in extreme environments (Chapter 2).

\section{Novel sulfur reducers growing at low $\mathbf{p H}$}

When microorganisms are exposed to low $\mathrm{pH}$ environments, the excessive protons might enter the cells and reduce their cytoplasmic $\mathrm{pH}$, damaging biological processes and cellular structures, subsequently leading to cell death (Richard and Foster 2003). Similarly, when organic acids, such as acetate, are present in the acidic environment, their protonated form could cross the membrane and dissociate in the cytoplasm resulting in acidifaction (Holyoak, Stratford et al. 1996). Therefore, acidophilic prokaryotes have developed a diversity of mechanisms to survive under conditions of extremely low $\mathrm{pH}$ (Baker-Austin and Dopson 2007). As it has been argued previously in this thesis, such extremophiles are important for biotechnological recovery of metals from industrial waste streams, as sulfidogenesis and precipitation of metals as metal sulfides can be better performed at low pH (Vallero 2003, Pender, Toomey et al. 2004, Gallegos-Garcia, Celis et al. 2009, SánchezAndrea, Sanz et al. 2014).

Tinto river (Huelva, south-western Spain) is an extreme environment with an average $\mathrm{pH}$ in the water column of around 2.3 and high concentrations of heavy metals, such as iron, copper and zinc (López-Archilla, Marin et al. 2001). Sediments of this river are promising sources of novel acidophiles, such as fermenters (Sánchez-Andrea, Sanz et al. 2014), sulfate-reducing (Sánchez-Andrea, Stams et al. 2015) and sulfur- reducing bacteria (this thesis). In Chapter 3, elemental sulfur reduction with different electron 
donors was shown to occur at low $\mathrm{pH}$ when sediments of Tinto river were used as inoculum source. A novel acidotolerant sulfur-respiring bacterium, Desulfurella amilsii, was isolated. This novel species represented about $3 \%$ of the proteobacterial and about $0.6 \%$ of the bacterial community of the original sediment. Previously, the microbial diversity of Tinto river was assessed and Desulfurella spp. dominated up to $36 \%$ of the total cell count in certain sediment layers (Sánchez-Andrea, Knittel et al. 2012). Desulfurella species-related sequences are found in different acidic environments, such as geothermal springs and acidic anaerobic sediments (Burton and Norris 2000, Willis, Hedrich et al. 2013, Brito, VillegasNegrete et al. 2014). The presence of $D$. amilsii sequences in such environments suggests that these microorganisms are important players in the sulfur cycle at low $\mathrm{pH}$.

Using sediments of Tinto river in a different screening set up, another sulfurrespiring bacterium, Lucifera butyrica, was isolated. A genome-guided characterization has been described in Chapter 8. Among other features, the isolate produces 1,3-propanediol by glycerol degradation in a broad range of $\mathrm{pH}$, either fermentative or coupled to elemental sulfur or thiosulfate reduction, with concomitant sulfide production. The efficiency of sulfur respiration in this species, however, was low (maximum of $2.5 \mathrm{mM}$ ). The amount of sulfide produced would hamper its biotechnological application for metals recovery, since the electron donor is the main cost of the process and a big proportion does not go to sulfur reduction. Therefore, $D$. amilsii was used as a reference organism in this study, for which detailed genome analysis and proteome analyses under different conditions were performed to gain insight into the sulfur metabolism.

D. amilsii is a member of Desulfurellaceae family, that comprises the genera Desulfurella and Hippea, inhabiting terrestrial environments and submarine hot vents, respectively. In the Desulfurella genus, comparative genome analysis have shown that $D$. multipotens and D. acetivorans represent the same species and a reclassification is needed (Chapter 5). The characterization of D. amilsii was described in Chapter $\mathbf{4}$ and revealed it as a moderately thermophilic species, growing by respiration of elemental sulfur or thiosulfate, disproportionation of elemental sulfur and by fermentation of pyruvate, at $\mathrm{pH}$ as low as 3 . Therefore, D. amilsii represents an opportunity for the acidophilic sulfur reduction for removal and recovery of metals, and its isolation from a metal-rich environment might make it more robust than other microorganisms for the biotechnological purposes. Interestingly, growth and activity of $D$. amilsii respiring sulfur with acetate at $\mathrm{pH} 3$ was better than with hydrogen (Chapter 3), indicating that D. amilsii does not suffer from acetic acid toxicity as much as other anaerobes (Luli and Strohl 1990, Van Lier, Grolle et al. 1993). Many acidophilic sulfate- or sulfur-reducing microorganisms, such as L. butyrica or Desulfosporosinus acididurans (Chapter 8), are not able to completely oxidize organic substrates, leading to an accumulation of acetic acid in the medium and, therefore, to 
inhibitory effects on the cultures. The ability of $D$. amilsii to grow on acetate could be also useful to alleviate its toxicity for other microorganisms when growing on consortia.

A comparative genome analysis of the Desulfurellaceae revealed the presence of genes encoding resistance to stress conditions (GroEL, GroES, RecA, excinuclease ABC, amino acid transporters, histidine kinase and $\mathrm{ABC}$ transporters genes), as well as components of inorganic ion transport efflux systems in all members of Desulfurella and Hippea genera (Chapter 5). However, the ability to grow at $\mathrm{pH}$ below 4 is not reported for any species besides $D$. amilsii (Chapter 3). Proteomic analysis revealed equal abundance of proteins produced by all the mentioned resistance genes at low and nearly neutral $\mathrm{pH}$ cultures, indicating that they might be constitutively expressed in this microorganism (Chapter 6). The similar level of proteins under different cultivation conditions might reflect the low influence of internal and external $\mathrm{pH}$ on the gene expression or repression. Moreover, enzymes involved in the biosynthesis of cell envelope (multimodular transpeptidase transglycolase), porphyrin (glutamate-1-semialdehyde aminotransferase), Lserine (phosphoglycerate dehydrogenase), and an amino acid-binding protein seem to be key determinants of acid tolerance in D. amilsii, as also reported for low $\mathrm{pH}$ cultures of Bradyrhizobium japonicum (Puranamaneewiwat, Tajima et al. 2006).

\section{The enigmatic sulfur metabolism}

\section{Sulfur reduction}

The poor solubility of elemental sulfur is a bottleneck to support high growth rates of microorganisms that use elemental sulfur as terminal electron acceptor. In the presence of sulfide, sulfur is in equilibrium with polysulfide. Since polysulfide is more soluble than elemental sulfur, it is thought to be the electron acceptor for many sulfur reducers (Blumentals, Itoh et al. 1990, Schauder and Müller 1993, Hedderich, Klimmek et al. 1999). However, at low $\mathrm{pH}$, this is improbable due to its instability and the shift in the equilibrium towards elemental sulfur (equation 1).

$$
\left.H S^{-}+(n-1) S \leftrightarrow S_{n}^{2-}+H^{+} \text {(equation } 1\right)
$$

Therefore, microorganisms are thought to assess the insoluble substrate at low $\mathrm{pH}$ by direct contact (Laska, Lottspeich et al. 2003). Physical contact with elemental sulfur was not necessary for growth of $D$. amilsii at nearly neutral $\mathrm{pH}$, and therefore a soluble intermediate was likely formed from elemental sulfur (Chapter 6). At low $\mathrm{pH}$, however, cell-sulfur interaction and the uptake of elemental sulfur seemed to be essential. The extracellular polymeric substance production by $D$. amilsii might be also essential in this process, as it was seen by microscopic observations and supported by the abundance of glycosyl transferase and proteins involved in the production of flagellum and pili at low $\mathrm{pH}$. 
There are four enzymes postulated to be involved in sulfur or polysulfide reduction to hydrogen sulfide: polysulfide reductase, sulfide dehydrogenase, sulfhydrogenase and sulfur reductase (Schröder, Kröger et al. 1988, Bryant and Adams 1989, Ma and Adams 1994, Ma, Weiss et al. 2000, Laska, Lottspeich et al. 2003). Hippea species encode polysulfide reductase and sulfide dehydrogenase in their genomes, while Desulfurella members encode mainly sulfide dehydrogenase. Polysulfide is therefore thought to be the terminal electron acceptor in the mentioned groups. Only in D. amilsii, additionally sulfur reductase is present, supposedly to use elemental sulfur as substrate. Due to the exclusive presence of sulfur reductase in $D$. amilsii genome and its ability to thrive at $\mathrm{pH}$ as low as 3, unique in the family Desulfurellaceae, it was tempting to speculate the possibility of direct reduction of elemental sulfur at low $\mathrm{pH}$ via sulfur reductase (Chapter 5). Proteomics data showed evidence of a possible role of sulfide dehydrogenase as a reduced ferredoxin:NADP oxidoreductase rather than a sulfur-reducing enzyme (Chapter 6), while thiosulfate sulfurtransferases seemed to be the key players in sulfur reduction by D. amilsii. It was surprising the absence of sulfur reductase, even in low $\mathrm{pH}$ cultures, but its loss during protein recovery cannot be excluded due to its membrane-bound location in the cell.

\section{The case of sulfide dehydrogenase}

The cytoplasmic heterodimeric enzyme sulfide dehydrogenase, comprising the subunits SudHA (50 kDa) and SudHB (30 kDa), was isolated from Pyrococcus furiosus. It was shown to use NADPH as reductant for elemental sulfur reduction (Ma and Adams 1994), and therefore, it was initially reported as an unique sulfur-reducing enzyme. Later, Ma, Weiss et al. (2000) described its physiological activity also as a ferredoxin:NADP oxidoreductase $(\mathrm{Nfn} A B)$ with very high affinity for reduced ferredoxin. It catalyzes bifurcating reactions, as it couples the exergonic reduction of NADP with reduced ferredoxin to the reduction of NADP with $\mathrm{NADH}_{2}$. It has a broad specificity for various physiological and non-physiological substrates with varied reduction potentials (Ma and Adams 2001). A mechanism of flavin based electron bifurcation has been proposed assuming that the enzyme is organized in a complex with an electron-transfer flavoprotein and the flavin might be the site where the electrons are bifurcated to the two acceptors with different redox potentials (Figure 1). 


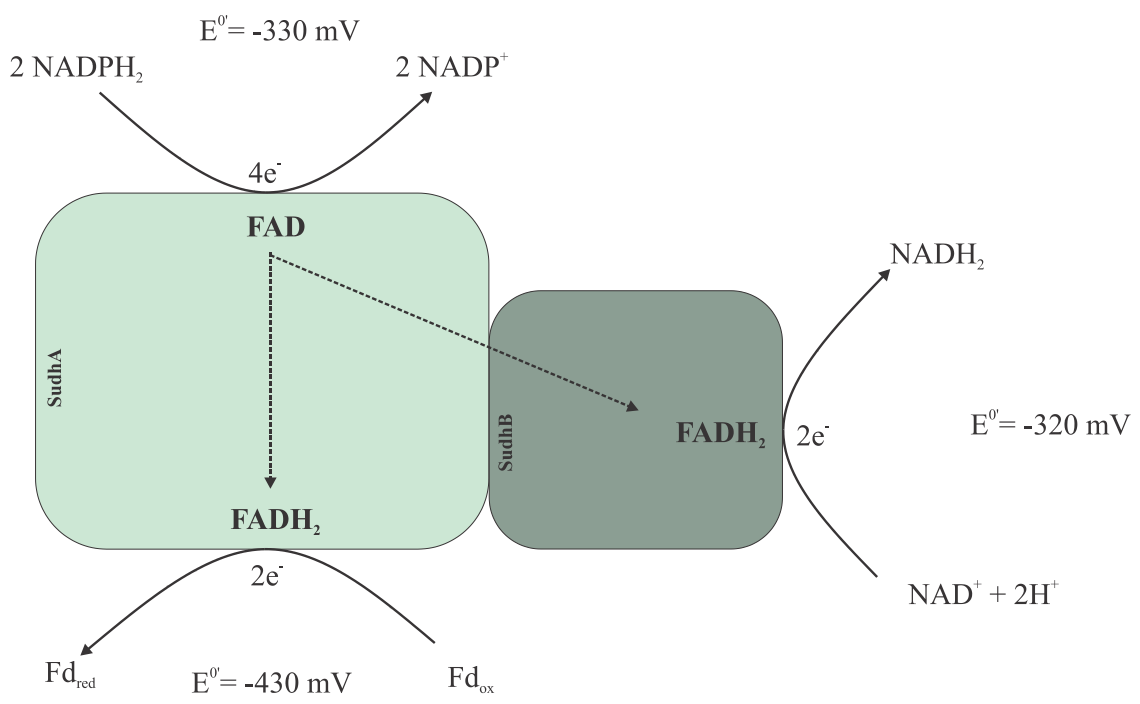

Figure 1 - Flavin-based electron bifurcation involved in the reversible reduction of ferredoxin $(\mathrm{Fd})$ and NAD with two NADPHs as catalyzed by the NfnAB complex.

Genes encoding this enzyme are present in several genera of the order Clostridiales in the phylum Firmicutes, namely Eubacterium, Thermoanaerobacter, Carboxidothermus, Desulfotomaculum and Moorella; in Bacteroides, Thermotoga, Pyrococcus, Thermococcus and in archaea such as Methanosarcina. NfnAB complex seems to be present in several sulfur-reducing and sulfur-oxidizing species (Pereira, Ramos et al. 2011), and therefore it is reasonable to assume that they play a role in sulfur metabolism. Although they are normally annotated as sulfide dehydrogenase, the role of this enzyme in microbial sulfur reduction is not yet understood. Its cytoplasmic nature hampers any attempt to couple sulfur reduction to energy conservation, at least by conventional mechanisms.

The genome characterization revealed that this enzyme is encoded in the genome of all members of Desulfurellaceae family (Chapter 5), as well as in L. butyrica (Chapter 8). It was shown to play a role in the metabolism of $D$. amilsii, but likely as a ferredoxin:NADP oxidoreductase, since its abundance was similar in all the conditions analyzed, including in thiosulfate respiration, that conventionally does not involve sulfurreducing enzymes.

\section{Thiosulfate reduction}

Thiosulfate is an important intermediate in the sulfur cycle of anoxic marine and freshwater sediments, where it is subject to reduction, oxidation, and disproportionation pathways (Ravot, Ollivier et al. 1995). Thiosulfate reduction is a widespread ability of sulfur reducers (Stetter, Fiala et al. 1990, Fardeau, Ollivier et al. 1997, Fardeau, Magot et 
al. 2000), and it is postulated to involve the formation of sulfite as an intermediate, which is further reduced to sulfide by a dissimilatory sulfite reductase. Thiosulfate reductase is likely involved in the first step conversion of thiosulfate into sulfite and sulfide, which is rather a dismutation process. The role of the enzymes in the microbial reduction of thiosulfate, however, is not yet clearly understood, as in microorganisms lacking the thiosulfate reductase, reduction of thiosulfate still occurred and might be related to rhodanese-like thiosulfate sulfurtransferases activity (Singleton and Smith 1988, Ravot, Casalot et al. 2005).

The proteogenomic analysis of $D$. amilsii grown on thiosulfate revealed that thiosulfate reductase and dissimilatory sulfite reductase are most likely involved in thiosulfate reduction (Chapters 5 and 7). Thiosulfate reductase generates sulfite and sulfide, and the sulfite reductase would reduce sulfite into sulfide. In the family Desulfurellaceae, the ability to respire thiosulfate is only shared by $D$. amilsii and $D$. propionica. The genome sequence of $D$. propionica, however, is not yet available and so the genomic search of the enzyme could not be performed (Chapter 5).

\section{Sulfur disproportionation}

Microbial disproportionation of elemental sulfur is an ecologically relevant conversion in the sulfur cycle (Thamdrup, Finster et al. 1993, Finster, Leiesack et al. 1998, Finster 2008). At neutral $\mathrm{pH}$ and under standard conditions, it is an endergonic process, with changes in Gibbs Free energy of $41 \mathrm{~kJ} \mathrm{~mol}^{-1}$ (Thauer, Jungermann et al. 1977). The $\Delta \mathrm{G}$ of the reaction can be strongly affected by the concentration of sulfide, limiting growth when it accumulates; and variation in $\mathrm{pH}$ values impose strong energetic impact (Chapter 3). The first evidence of sulfur disproportionation was reported by Bak and Cypionka (1987) in the sulfate reducer Desulfovibrio sulfodismutans and it has been increasingly described for some sulfur reducers from the Proteobacteria, Firmicutes and Thermodesulfobacteria phyla (Finster, Leiesack et al. 1998, Finster 2008, Hardisty, Olyphant et al. 2013, Florentino, Brienza et al. 2016).

The pathway by which microorganisms disproportionate elemental sulfur to sulfide and sulfate is a poorly characterized part of the sulfur cycle. Sulfite is postulated to be a key intermediate in the process, which is further oxidized to sulfate, and the sulfide produced is thought to originate directly from a sulfur-reducing enzyme (Finster 2008, Hardisty, Olyphant et al. 2013). The initial mechanism of sulfite formation, however, is still not established. The biochemistry of sulfur disproportionation process has only been investigated for the non-sulfate reducer Desulfocapsa sulfoexigens, in which sulfite was shown to be an intermediate and its oxidation was reported to happen via two possible pathways: the sulfite oxidoreductase pathway and the APS reductase pathway via ATP 
sulfurylase or adenylylsulfate:phosphate adenylyltransferase (APAT) in the reverse way of sulfate reduction (Finster 2008).

D. amilsii disproportionates elemental sulfur coupling growth to the production of sulfide and sulfate (Florentino, Brienza et al. 2016) (Chapter 3). In Desulfurellaceae family, sulfur disproportionation is an ability only tested and proven to occur in Desulfurella species (Bonch-Osmolovskaya, Sokolova et al. 1990, Miroshnichenko, Gongadze et al. 1994, Miroshnichenko, Rainey et al. 1998, Florentino, Brienza et al. 2016). Although the sulfur-reducing enzymes discussed in Chapter 5 were initially thought to play a role in the sulfide production also during disproportionation, proteomic analyses only revealed abundance of sulfide dehydrogenase, that, as discussed in Chapter 6, is likely to act as a reduced ferredoxin:NADP oxidoreductase. The enzyme responsible for sulfite production from elemental sulfur could not be deduced from the genome analysis. Sulfite could be oxidized to sulfate by sulfite oxidoreductase, as the reverse pathway of sulfate reduction is not encoded in this microorganism. Besides, although the dissimilatory sulfite reductase is encoded in its genome, physiological tests did not reveal the accumulation of sulfite in sulfur-disproportionating cultures and the proteome analysis only revealed high abundance of dissimilatory sulfite reductase subunits in cultures growing by thiosulfate reduction (Chapter 7). Moreover, proteomic analysis on sulfur-disproportionating cultures did not reveal abundance of sulfite oxidoreductase and of any other enzyme possibly responsible for elemental sulfur reduction to sulfide, but a high and exclusive abundance of a rhodanese-like enzyme (DESAMIL20_2007) was found, suggesting its importance in disproportionation of elemental sulfur by $D$. amilsii. These enzymes are postulated to catalyze the transfer of a sulfur atom from a suitable donor to a nucleophilic sulfur acceptor (Aird, Heinrikson et al. 1987, Singleton and Smith 1988, Libiad, Sriraman et al. 2015), but their physiological role has not yet been completely understood. Therefore, in the absence of a sulfur reductase enzyme and sulfite oxidoreductase, a sulfurtransferase might catalyze the conversion of elemental sulfur and possible thiol groups in the outer membrane into sulfide and sulfate.

\section{Application of sulfur reduction at low pH}

Although heavy metal-containing wastewaters generated by metal and mining industries have become an increasing global environmental problem (Johnson and Hallberg 2005, Bratty, Lawrence et al. 2006, Sánchez-Andrea, Stams et al. 2016), they also represent a potential resource of valuable metals when their recovery is possible in an economically feasible way (Lens, Hulshoff Pol et al. 2002). Several technologies have been applied to remove heavy metals from contaminated wastewaters (Chapter 2), but sometimes they are not suitable for metals recovery and may lead to high disposal expenses (Johnson and Hallberg 2005, Gallegos-Garcia, Celis et al. 2009, Tekerlekopoulou, Tsiamis et al. 2010). 
Biological sulfidogenesis by sulfate reduction is applied for the treatment of metalcontaining wastewaters enabling the recovery of metals as sulfide precipitates. A single stage system has been applied for more than 10 years by Paques BV in Budelco zinc refinery (the Netherlands) for the treatment of sulfate and zinc polluted ground water. The system is reported to recover about 8.5 tons of zinc-sulfide per day (Weijma, Copini et al. 2002). In most of the cases, however, the process is applied at large scale when sulfate reduction and metal precipitation occur in separate stages (Huisman, Schouten et al. 2006), which implies the circulation of sulfide and, therefore, increased costs.

Although the single stage treatment process is a low-cost alternative, it might present problems when the wastewater is very acidic or contains high concentrations of heavy metals (Johnson and Hallberg 2005). Naturally adapted microorganisms could be applied to tolerate low $\mathrm{pH}$ and high concentrations of heavy metals. So far, just a few sulfate reducers able to grow at low $\mathrm{pH}$ has been described (Chapter 2) and its lowest limit is around 3.6-3.8 (Alazard, Joseph et al. 2010, Sánchez-Andrea, Stams et al. 2015).

Sulfur reducers can commonly grow at lower $\mathrm{pH}$ values (e.g.: Acidianus brierleyi - $\mathrm{pH}$ 1; Acidithiobacillus ferrooxidans - $\mathrm{pH}$ 1.3; Acidilobus aceticus - $\mathrm{pH} 2$ ). The reduction of elemental sulfur requires less electron donor in comparison to sulfate reduction. Therefore, the sulfide produced from microbiological sulfur reduction at low $\mathrm{pH}$ is a promising alternative for metal precipitation and recovery in a single stage reactor process.

In acidic environments, in which protons are highly concentrated, inhibitory concentrations of hydrogen sulfide, or the presence of acetic acid could affect cell growth (Baker-Austin and Dopson 2007), some microorganisms present resistance systems to withstand and even thrive at low $\mathrm{pH}$ conditions. D. amilsii revealed higher resistance to heavy metals than other sulfidogenic cultures of Desulfovibrio sp. or mixed species, especially for copper and nickel (Chapter 3). L. butyrica was shown to tolerate very high concentrations of iron and zinc (Chapter 8). Therefore, both species are potentially interesting for metals precipitation in single stage processes, in which the biological and the chemical reactions happen in the same reactor to lower the costs of the process.

Besides the selenite and arsenic resistance systems, the ATP-dependent polyphosphate kinases and copper-exporting P-type ATPase are encoded in D. amilsii genome and these might be important in metal resistance in this microorganism (Chapter 5). In L. butyrica, the tolerance to zinc is supported by the presence of cobalt-zinc-cadmium resistance genes and the response regulator of zinc sigma-54-dependent two-component system (Chapter 8).

A comparative analysis of costs between sulfidogenesis from sulfate reduction and sulfur reduction for metals precipitation performed in Chapter 2 showed that, although the application of sulfur reduction for precipitation of metal sulfides results in some extra costs 
for the addition of sulfur (whereas sulfate is normally present in sufficiently high concentrations in the mining and metallurgical waste), the net cost reduction is large, since 4 times less electron donors are required to generate the same amount of sulfide, which would reduce the operational costs of biological sulfide production technology.

The combined growth of $D$. amilsii and L. butyrica reveals a reasonable strategy to decrease costs in the process, as glycerol is a cheap reactant, leading to the optimum substrate for $D$. amilsii performance (acetate) and therefore to sulfide as the main target of the process.

\section{Concluding remarks and future perspectives}

Sulfur reduction and sulfur disproportionation are important conversions in nature, and these have much potential for biotechnological precipitation and recovery from metals from acidic waste streams. In this thesis, two novel acidotolerant sulfur-respiring bacteria, D.amilsii and L. butyrica, are presented. The metal tolerance, and the broad temperature and $\mathrm{pH}$ range for growth of both isolates indicate the feasibility to couple the consumption of glycerol to an enhanced sulfide production that can be used for the precipitation of heavy metals from acidic waste streams without the need to neutralize the water before treatment.

Although the microbial sulfur metabolism is enigmatic and imposes several scientific challenges, this thesis provided useful perspectives on the reduction and disproportionation of insoluble sulfur. Thiosulfate reduction might involve thiosulfate reductase and sulfite reductase in $\mathbf{D}$. amilsii. Rhodanese-like sulfurtransferases likely play a crucial role in sulfur reduction and sulfur disproportionation. Further research is necessary to better understand the mechanism of sulfur uptake by D. amilsii at low $\mathrm{pH}$, as well as to provide further evidence for the proposed role of rhodanese-like thiosulfate sulfurtransferases. Besides, to confirm the (in)activity of sulfur reductase in D. amilsii, a proteomic identification of membrane-bound proteins is recommended. The study of the enzymes responsible for sulfur reduction and sulfur disproportionation at low and high $\mathrm{pH}$ environments would benefit from anaerobic biochemistry strategies to circumvent the lack of knowledge in this field. Besides, sensitive techniques for polysulfide measurement would help to clarify the role of this compound during sulfur reduction by $D$. amilsii at circumneutral $\mathrm{pH}$ environments. In sulfur-disproportionating cultures, as sulfite does not seem to be an intermediate in the process, a deeper search on the feasibility of sulfurtransferases to perform disproportionation might clarify the biochemistry of this important conversion in the biogeochemical sulfur cycle and for biotechnological applications based on sulfidogenesis.

Additionally, further assays at optimal conditions for the microorganisms in a continuous system are required to obtain a better and constant productivity, allowing 
detailed analysis of microbial physiology at different growth rates with controlled conditions. Besides, experiments at low $\mathrm{pH}$ with addition of metals for selective precipitation are still needed to confirm the biotechnological potential of those microorganisms. Moreover, different combinations of strains are possible and so the microbial interactions might open possibilities for application purposes. 



\section{REFERENCES}

Abou-Zeid, D. M., H. Biebl, C. Sproer and R. J. Muller (2004). "Propionispora hippei sp. nov., a novel Gram-negative, spore-forming anaerobe that produces propionic acid." Int J Syst Evol Microbiol 54 (Pt 3): 951-954.

Achour, A. R., P. Bauda and P. Billard (2007). "Diversity of arsenite transporter genes from arsenicresistant soil bacteria." Res Microbiol 158 (2): 128-137.

Adikesavan, A. K., P. Katsonis, D. C. Marciano, R. Lua, C. Herman and O. Lichtarge (2011). "Separation of recombination and SOS response in Escherichia coli RecA suggests LexA interaction sites." PLOS Genetics 7 (9): e1002244.

Ahemad, M. (2012). "Implication of bacterial resistance against heavy metals in bioremediation: a review." Institute of Integrative Omics and Applied Biotechnology Journal 3 (3): 8.

Aird, B. A., R. L. Heinrikson and J. Westley (1987). "Isolation and characterization of a prokaryotic sulfurtransferase." Journal of Biological Chemistry 262 (36): 17327-17335.

Al-Attar, S., Y. Yu, M. Pinkse, J. Hoeser, T. Friedrich, D. Bald and S. de Vries (2016). "Cytochrome bd displays significant quinol peroxidase activity." Sci Rep 6: 27631.

Al-Tarazi, M., A. B. M. Heesink, G. F. Versteeg, M. O. J. Azzam and K. Azzam (2005). Precipitation of $\mathrm{CuS}$ and $\mathrm{ZnS}$ in a bubble column reactor. Wiley InterScience. 51: 235-246.

Alain, K., N. Callac, M. Guégan, F. Lesongeur, P. Crassous, M. A. Cambon-Bonavita, J. Querellou and D. Prieur (2009). "Nautilia abyssi sp. nov., a thermophilic, chemolithoautotrophic, sulfur-reducing bacterium isolated from an East Pacific Rise hydrothermal vent." Int J Syst Evol Microbiol 59 (6): 1310-1315.

Alain, K., V. T. Marteinsson, M. L. Miroshnichenko, E. A. Bonch-Osmolovskaya, D. Prieur and J. L. Birrien (2002). "Marinitoga piezophila sp. nov., a rod-shaped, thermo-piezophilic bacterium isolated under high hydrostatic pressure from a deep-sea hydrothermal vent." Int J Syst Evol Microbiol 52 (4): 1331-1339.

Alain, K., S. Rolland, P. Crassous, F. Lesongeur, M. Zbinden, C. le Gall, A. Godfroy, A. Page, S. K. Juniper, M. A. Cambon-Bonavita, F. Duchiron and J. Querellou (2003). "Desulfurobacterium crinifex sp. nov., a novel thermophilic, pinkish-streamer forming, chemolithoautotrophic bacterium isolated from a Juan de Fuca Ridge hydrothermal vent and amendment of the genus Desulfurobacterium." Extremophiles 7(5): 361-370.

Alazard, D., M. Joseph, F. Battaglia-Brunet, J. L. Cayol and B. Ollivier (2010). "Desulfosporosinus acidiphilus sp. nov.: a moderately acidophilic sulfate-reducing bacterium isolated from acid mining drainage sediments : New taxa: Firmicutes (Class Clostridia, Order Clostridiales, Family Peptococcaceae)." Extremophiles 14 (3): 305-312.

Alexander, K. and M. Volini (1987). "Properties of an Escherichia coli rhodanese." J Biol Chem 262(14): 6595-6604.

Alphenaar, P. A., N. Groeneveld and A. C. Van Aelst (1994). "Scanning electron microscopical method for internalstructure analysis of anaerobic granular sludge." Micron 25 (2): 129-133.

Altschul, S. F., W. Gish, W. Miller, E. W. Myers and D. J. Lipman (1990). "Basic local alignment search tool." J Mol Biol 215 (3): 403-410.

Amaro, A. M., D. Chamorro, M. Seeger, R. Arredondo, I. Peirano and C. A. Jerez (1991). "Effect of external $\mathrm{pH}$ perturbations on in vivo protein synthesis by the acidophilic bacterium Thiobacillus ferrooxidans." J Bacteriol 173 (2): 910-915.

Amo, T., M. L. Paje, A. Inagaki, S. Ezaki, H. Atomi and T. Imanaka (2002). "Pyrobaculum calidifontis sp. nov., a novel hyperthermophilic archaeon that grows in atmospheric air." Archaea 1 (2): 113-121. 
Amundsen, S. K., J. Fero, L. M. Hansen, G. A. Cromie, J. V. Solnick, G. R. Smith and N. R. Salama (2008). "Helicobacter pylori AddAB helicase-nuclease and RecA promote recombinationrelated DNA repair and survival during stomach colonization." Mol Microbiol 69 (4): 9941007.

Antoine, E., V. Cilia, J. R. Meunier, J. Guezennec, F. Lesongeur and G. Barbier (1997). "Thermosipho melanesiensis sp. nov., a new thermophilic anaerobic bacterium belonging to the order Thermotogales, isolated from Deep-Sea Hydrothermal Vents in the Southwestern Pacific Ocean." Int J Syst Bacteriol 47 (4): 1118-1123.

Arab, H., H. Volker and M. Thomm (2000). "Thermococcus aegaeicus sp. nov. and Staphylothermus hellenicus sp. nov., two novel hyperthermophilic archaea isolated from geothermally heated vents off Palaeochori Bay, Milos, Greece." Int J Syst Evol Microbiol 50 (Pt 6): 2101-2108.

Aziz, R. K., D. Bartels, A. A. Best, M. DeJongh, T. Disz, R. A. Edwards, K. Formsma, S. Gerdes, E. M. Glass, M. Kubal, F. Meyer, G. J. Olsen, R. Olson, A. L. Osterman, R. A. Overbeek, L. K. McNeil, D. Paarmann, T. Paczian, B. Parrello, G. D. Pusch, C. Reich, R. Stevens, O. Vassieva, V. Vonstein, A. Wilke and O. Zagnitko (2008). "The RAST Server: Rapid Annotations using Subsystems Technology." BMC Genomics 9 (1): 1-15.

Badziong, W. and R. K. Thauer (1978). "Growth yields and growth rates of Desulfovibrio vulgaris (Marburg) growing on hydrogen plus sulfate and hydrogen plus thiosulfate as the sole energy sources." Arch Microbiol 117 (2): 209-214.

Bagchi, A. and T. C. Ghosh (2008). "Structural interaction between DsrE-DsrF-DsrH proteins involved in the transport of electrons in the dsr operon." J Biomol Struct Dyn 25 (5): 517 523.

Bagramyan, K. and A. Trchounian (2003). "Structural and functional features of formate hydrogen lyase, an enzyme of mixed-acid fermentation from Escherichia coli." Biochemistry (Mosc) 68 (11): 1159-1170.

Bak, F. and H. Cypionka (1987). "A novel type of energy metabolism involving fermentation of inorganic sulphur compounds." 326 (6116): 891-892.

Bak, F. and N. Pfennig (1987). "Chemolithotrophic growth of Desulfovibrio sulfodismutans sp. nov. by disproportionation of inorganic sulfur compounds." Arch Microbiol 147 (2): 184-189.

Baker-Austin, C. and M. Dopson (2007). "Life in acid: pH homeostasis in acidophiles." Trends Microbiol 15 (4): 165-171.

Balashova, V. V. (1985). "The use of molecular sulfur as an agent oxidizing hydrogen by the facultative anaerobic Pseudomonas strain." Mikrobiologya 54: 3.

Barbirato, F., C. Camarasa-Claret, J. P. Grivet and A. Bories (1995). "Glycerol fermentation by a new 1,3-propanediol-producing microorganism: Enterobacter agglomerans." Appl Microbiol Biotechnol 43 (5): 786-793.

Beijerink, W. M. (1895). "Über Spirillum desulfuricans als Ursache von Sulfatreduction." Centralb Bakteriol II 1 (49-59): 11.

Belyakova, E. V., E. P. Rozanova, I. A. Borzenkov, T. P. Tourova, M. A. Pusheva, A. M. Lysenko and T. V. Kolganova (2006). "The new facultatively chemolithoautotrophic, moderately halophilic, sulfate-reducing bacterium Desulfovermiculus halophilus gen. nov., sp. nov., isolated from an oil field." Microbiol 75 (2): 161-171.

Ben Hania, W., A. Postec, T. Aüllo, A. Ranchou-Peyruse, G. Erauso, C. Brochier-Armanet, M. Hamdi, B. Ollivier, S. Saint-Laurent, M. Magot and M. L. Fardeau (2013). "Mesotoga infera sp. nov., a mesophilic member of the order Thermotogales, isolated from an underground gas storage aquifer." Int J Syst Evol Microbiol 63 (Pt 8): 3003-3008. 
Benjamin, M. M. and A. R. Datta (1995). "Acid tolerance of enterohemorrhagic Escherichia coli." Appl Environ Microbiol 61 (4): 1669-1672.

Berks, B. C., M. D. Page, D. J. Richardson, A. Reilly, A. Cavill, F. Outen and S. J. Ferguson (1995). "Sequence analysis of subunits of the membrane-bound nitrate reductase from a denitrifying bacterium: the integral membrane subunit provides a prototype for the dihaem electroncarrying arm of a redox loop." Mol Microbiol 15 (2): 319-331.

Biebl, H. (2001). "Fermentation of glycerol by Clostridium pasteurianum — batch and continuous culture studies." J Ind Microbiol Biotechnol 27 (1): 18-26.

Biebl, H. and N. Pfennig (1977). "Growth of sulfate-reducing bacteria with sulfur as electron acceptor." Arch. Microbiol. 112: 3.

Biebl, H., H. Schwab-Hanisch, C. Sproer and H. Lunsdorf (2000). "Propionispora vibrioides, nov. gen., nov. sp., a new gram-negative, spore-forming anaerobe that ferments sugar alcohols." Arch Microbiol 174(4): 239-247.

Bielow, C., G. Mastrobuoni and S. Kempa (2016). "Proteomics quality control: quality control software for MaxQuant results." J Proteome Res 15 (3): 777-787.

Bijmans, M. F. M., M. Dopson, T. W. T. Peeters, P. N. L. Lens and C. J. N. Buisman (2009). "Sulfate reduction at $\mathrm{pH} 5$ in a high-rate membrane bioreactor: reactor performance and microbial community analyses." J Microbiol Biotechnol 19 (7): 698-708.

Birrien, J. L., X. Zeng, M. Jebbar, M. A. Cambon-Bonavita, J. Quérellou, P. Oger, N. Bienvenu, X. Xiao and D. Prieur (2011). "Pyrococcus yayanosii sp. nov., an obligate piezophilic hyperthermophilic archaeon isolated from a deep-sea hydrothermal vent." Int J Syst Evol Micr 61(12): 2827-2881.

Biswas, A., J. N. Gagnon, S. J. Brouns, P. C. Fineran and C. M. Brown (2013). "CRISPRTarget: bioinformatic prediction and analysis of crRNA targets." RNA Biol 10(5): 817-827.

Blum, J. S., S. Han, B. Lanoil, C. Saltikov, B. Witte, F. R. Tabita, S. Langley, T. J. Beveridge, L. Jahnke and R. S. Oremland (2009). "Ecophysiology of "Halarsenatibacter silvermanii" Strain SLAS-1(T), gen. nov., sp. nov., a facultative chemoautotrophic arsenate respirer from Salt-Saturated Searles Lake, California." Appl Environ Microbiol 75(7): 1950-1960.

Blumentals, I. I., M. Itoh, G. J. Olson and R. M. Kelly (1990). "Role of polysulfides in reduction of elemental sulfur by the hyperthermophilic archaebacterium Pyrococcus furiosus." Appl Environ Microbiol 56(5): 8.

Boetzer, M. and W. Pirovano (2012). "Toward almost closed genomes with GapFiller." Genome Biol 13(6): 1-9.

Boisvert, S., F. Laviolette and J. Corbeil (2010). "Ray: simultaneous assembly of reads from a mix of high-throughput sequencing technologies." J Comput Biol 17(11): 1519-1533.

Bokranz, M., M. Gutmann, C. Körtner, E. Kojro, F. Fahrenholz, F. Lauterbach and A. Kröger (1991). "Cloning and nucleotide sequence of the structural genes encoding the formate dehydrogenase of Wolinella succinogenes." Arch Microbiol 156(2): 119-128.

Bonch-Osmolovskaya, E. A., M. L. Miroshnichenko, N. A. Chernykh, N. A. Kostrikina, E. V. Pikuta and F. A. Rainey (1997). "Reduction of elemental sulfur by moderately thermophilic organotrophic bacteria and the description of Thermoanaerobacter sulfurophilus sp. nov." Microbiology 66(5): 7.

Bonch-Osmolovskaya, E. A., M. L. Miroshnichenko, N. A. Kostrikina, N. A. Chernych and G. A. Zavarzin (1990). "Thermoproteus uzoniensis sp. nov., a new extremely thermophilic archaebacterium from Kamchatka continental hot springs." J Bacteriol 154 (6): 556-559.

Bonch-Osmolovskaya, E. A., A. I. Slesarev, M. L. Miroshnichenko, T. P. Svetlichnaya and V. A. Alekseev (1988). "Characteristics of Desulfurococcus amylolyticus n. sp. - a new extremely 
thermophilic archaebacterium isolated from thermal springs of Kamchatka and Kunashir Island." Mikrobiologiya 57: 8.

Bonch-Osmolovskaya, E. A., T. G. Sokolova, N. A. Kostrikina and G. A. Zavarzin (1990). "Desulfurella acetivorans gen. nov. and sp. nov. - a new thermophilic sulfur-reducing eubacterium." Arch. Microbiol. 153: 5.

Boulegue, J. (1978). "Solubility of elemental sulfur in water at 298 K." Phosphorus Sulfur Silicon Relat Elem 5 (1): 127-128.

Boyd, E. S. and G. K. Druschel (2013). "Involvement of intermediate sulfur species in biological reduction of elemental sulfur under acidic, hydrothermal conditions." Appl Environ Microbiol 79 (6): 2061-2068.

Boyd, E. S., R. A. Jackson, G. Encarnacion, J. A. Zahn, T. Beard, W. D. Leavitt, Y. Pi, C. L. Zhang, A. Pearson and G. G. Geesey (2007). "Isolation, characterization, and ecology of sulfurrespiring Crenarchaea inhabiting acid-sulfate-chloride-containing geothermal springs in Yellowstone National Park." Appl Environ Microbiol 73 (20): 6669-6677.

Bradley, A. S., W. D. Leavitt and D. T. Johnston (2011). "Revisiting the dissimilatory sulfate reduction pathway." Geobiology 9 (5): 446-457.

Bratty, M., R. Lawrence, D. Kratochvil and B. Marchant (2006). Applications of biological $\mathrm{H}_{2} \mathrm{~S}$ production from elemental sulfur in the treatment of heavy metal pollution including acid rock drainage. 7th International Conference on Acid Rock Drainage (ICARD). R. I. Barnhisel. St. Louis MO, American Society of Mining and Reclamation (ASMR).

Breher, F. (2004). Elemental sulfur and sulfur-rich compounds, WILEY-VCH Verlag.

Brito, E. M., N. Villegas-Negrete, I. A. Sotelo-Gonzalez, C. A. Caretta, M. Goni-Urriza, C. Gassie, F. Hakil, Y. Colin, R. Duran, F. Gutierrez-Corona, H. A. Pinon-Castillo, G. CuevasRodriguez, O. Malm, J. P. Torres, A. Fahy, G. E. Reyna-Lopez and R. Guyoneaud (2014). "Microbial diversity in Los Azufres geothermal field (Michoacan, Mexico) and isolation of representative sulfate and sulfur reducers." Extremophiles 18 (2): 385-398.

Brunner, E. and W. Woll (1980). "Solubility of sulfur in hydrogen sulfide and sour gases C1 - SPE." Soc Petrol Eng J 8.

Bryant, F. O. and M. W. Adams (1989). "Characterization of hydrogenase from the hyperthermophilic archaebacterium, Pyrococcus furiosus." J Biol Chem 264 (9): 50705079.

Bryant, R. D., J. W. Costerton and E. J. Laishley (1984). "The role of Thiobacillus albertis glycocalyx in the adhesion of cells to elemental sulfur." Can J Microbiol 30 (1): 81-90.

Burggraf, S., H. W. Jannasch, B. Nicolaus and K. O. Stetter (1990). "Archaeoglobus profundus sp. nov., represents a new species within the sulfate-reducing archaebacteria." $\underline{\text { Syst Appl }}$ Microbiol 13 (1): 24-28.

Burton, N. P. and P. R. Norris (2000). "Microbiology of acidic, geothermal springs of Montserrat: environmental rDNA analysis." Extremophiles 4 (5): 315-320.

Cabrera, G., R. Perez, J. M. Gomez, A. Abalos and D. Cantero (2006). "Toxic effects of dissolved heavy metals on Desulfovibrio vulgaris and Desulfovibrio sp. strains." J Hazard Mater 135 (1-3): 40-46.

Caccavo Jr., F., D. J. Lonergan, D. R. Lovley, M. Davis, J. F. Stolz and M. J. McInerney (1994). "Geobacter sulfurreducens sp. nov., a hydrogen- and acetate-oxidizing dissimilatory metalreducing microorganism." Appl Environ Microbiol 60 (10): 8.

Cai, J., Y. Wang, D. Liu, Y. Zeng, Y. Xue, Y. Ma and Y. Feng (2007). "Fervidobacterium changbaicum sp. nov., a novel thermophilic anaerobic bacterium isolated from a hot spring of the Changbai Mountains, China." Int J Syst Evol Microbiol 57 (10): 2333-2336. 
Cai, L., G. Liu, C. Rensing and G. Wang (2009). "Genes involved in arsenic transformation and resistance associated with different levels of arsenic-contaminated soils." BMC Microbiology 9 (1): 1-11.

Cammack, R., G. Fauque, J. J. G. Moura and J. LeGall (1984). "ESR studies of cytochrome c3 from Desulfovibrio desulfuricans strain Norway 4: Midpoint potentials of the four haems, and interactions with ferredoxin and colloidal sulphur." Biochim Biophys Acta 784: 7.

Canfield, D. E. (2004). "The evolution of the Earth surface sulfur reservoir." Am J Sci 304 (10): 839861.

Canfield, D. E. and J. Farquhar (2012). The global sulfur cycle. Fundamentals of Geobiology, John Wiley \& Sons, Ltd 49-64.

Cárdenas, J. P., F. Moya, P. Covarrubias, A. Shmaryahu, G. Levicán, D. S. Holmes and R. Quatrini (2012). "Comparative genomics of the oxidative stress response in bioleaching microorganisms." Hydrometallurgy 127-128: 162-167.

Castro, H., K. R. Reddy and A. Ogram (2002). "Composition and function of sulfate-reducing prokaryotes in eutrophic and pristine areas of the Florida Everglades." Appl Environ Microbiol 68(12): 6129-6137.

Chamkh, F., C. Sproer, P. C. Lemos, S. Besson, A. G. El Asli, R. Bennisse, M. Labat, M. Reis and A. I. Qatibi (2009). "Desulfovibrio marrakechensis sp. nov., a 1,4-tyrosol-oxidizing, sulfatereducing bacterium isolated from olive mill wastewater." Int J Syst Evol Microbiol 59 (Pt 5): 936-942.

Chauncey, T. R. and J. Westley (1983). "Improved purification and sulfhydryl analysis of thiosulfate reductase." Biochim Biophys Acta 744 (3): 304-311.

Childers, S. E. and K. M. Noll (1994). "Characterization and regulation of sulfur reductase activity in Thermotoga neapolitana." Appl Environ Microbiol 60 (7): 2622-2626.

Chong, P. L. G. (2010). "Archaebacterial bipolar tetraether lipids: Physico-chemical and membrane properties." Chem Phys Lipids 163 (3): 253-265.

Chong, S. C., Y. Liu, M. Cummins, D. L. Valentine and D. R. Boone (2002). "Methanogenium marinum sp. nov., a $\mathrm{H}_{2}$-using methanogen from Skan Bay, Alaska, and kinetics of $\mathrm{H}_{2}$ utilization." Antonie Van Leeuwenhoek 81(1-4): 263-270.

Chrismas, N. A. M., G. Barker, A. M. Anesio and P. Sánchez-Baracaldo (2016). "Genomic mechanisms for cold tolerance and production of exopolysaccharides in the Arctic cyanobacterium Phormidesmis priestleyi BC1401." BMC Genomics 17 (1): 533.

Christiansen, N. and B. K. Ahring (1996). "Desulfitobacterium hafniense sp. nov., an anaerobic, reductively dechlorinating bacterium." Int J Syst Bacteriol 46 (2): 442-448.

Cline, J. D. (1969). "Spectrophotometric determination of hydrogen sulfide in natural waters." Limnol Oceanogr 14 (3): 454-458.

Coates, J. D., V. K. Bhupathiraju, L. A. Achenbach, M. J. McLnerney and D. R. Lovley (2001). "Geobacter hydrogenophilus, Geobacter chapellei and Geobacter grbiciae, three new, strictly anaerobic, dissimilatory Fe(III)-reducers." Int J Syst Evol Microbiol 51 (Pt 2): 581588.

Cotter, P. D. and C. Hill (2003). "Surviving the acid test: responses of gram-positive bacteria to low pH." Microbiol Mol Biol Rev 67 (3): 429-453, table of contents.

Cox, J. and M. Mann (2008). "MaxQuant enables high peptide identification rates, individualized p.p.b.-range mass accuracies and proteome-wide protein quantification." 26 (12): 13671372 . 
Cox, J., N. Neuhauser, A. Michalski, R. A. Scheltema, J. V. Olsen and M. Mann (2011). "Andromeda: a peptide search engine integrated into the MaxQuant environment." I Proteome Res 10 (4): 1794-1805.

Cox, J. C., D. G. Nicholls and W. J. Ingledew (1979). "Transmembrane electrical potential and transmembrane $\mathrm{pH}$ gradient in the acidophile Thiobacillus ferrooxidans." Biochem J $\mathbf{1 7 8}$ (1): 195-200.

Crossman, L., M. Holden, A. Pain and J. Parkhill (2004). "Genomes beyond compare." Nature Rev Microbiol 2 (8): 616-617.

Croteau, D. L., M. J. DellaVecchia, L. Perera and B. Van Houten (2008). "Cooperative damage recognition by UvrA and UvrB: identification of UvrA residues that mediate DNA binding." DNA Repair (Amst) 7 (3): 392-404.

Dahle, H. and N. K. Birkeland (2006). "Thermovirga lienii gen. nov., sp. nov., a novel moderately thermophilic, anaerobic, amino-acid-degrading bacterium isolated from a North Sea oil well." Int J Syst Evol Microbiol 56(7): 1539-1545.

Darbon, E., K. Ito, H. S. Huang, T. Yoshimoto, S. Poncet and J. Deutscher (1999). "Glycerol transport and phosphoenolpyruvate-dependent enzyme I- and HPr-catalysed phosphorylation of glycerol kinase in Thermus flavus." Microbiology 145 (Pt 11): 32053212 .

Davey, M. E., W. A. Wood, R. Key, K. Nakamura and D. A. Stahl (1993). "Isolation of three species of Geotoga and Petrotoga: Two new genera, representing a new lineage in the bacterial line of descent distantly related to the "Thermotogales"." Syst Appl Microbiol 16 (2): 191-200.

David, V., B. Bozdogan, J.-L. Mainardi, R. Legrand, L. Gutmann and R. Leclercq (2004). "Mechanism of Intrinsic Resistance to Vancomycin in Clostridium innocuum NCIB 10674." Journal of Bacteriology 186(11): 3415-3422.

De Rosa, M., A. Gambacorta and B. Nicolaus (1983). "A New type of cell membrane, in thermophilic archaebacteria, based on bipolar ether lipids." J Membr Sci 16 (0): 287-294.

DeWeerd, K. A., L. Mandelco, R. S. Tanner, C. R. Woese and J. M. Suflita (1990). "Desulfomonile tiedjei gen. nov. and sp. nov., a novel anaerobic, dehalogenating, sulfate-reducing bacterium." Arch Microbiol 154 (1): 23-30.

Dey, S., Z. Hu, X. L. Xu, J. C. Sacchettini and G. A. Grant (2005). "D-3-phosphoglycerate dehydrogenase from Mycobacterium tuberculosis is a link between the Escherichia coli and mammalian enzymes." J Biol Chem 280 (15): 14884-14891.

Dietrich, W. and O. Klimmek (2002). "The function of methyl-menaquinone-6 and polysulfide reductase membrane anchor (PsrC) in polysulfide respiration of Wolinella succinogenes." Eur J Biochem 269 (4): 1086-1095.

Dilworth, M. J. and A. R. Glenn (1999). "Problems of adverse pH and bacterial strategies to combat it." Novartis Found Symp 221: 4-14, discussion 14-18.

Dirmeier, R., J. Keller, D. Hafenbradl, F. J. Braun, R. Rachel, S. Burggraf and K. O. Stetter (1998). "Thermococcus acidamnovorans sp. nov., a new hyperthermophilic alkalophilic arcaheon growing on amino acids." Extremophiles 2: 6.

Dirmeier, R., M. Keller, G. Frey, H. Huber and K. O. Stetter (1998). "Purification and properties of an extremely thermostable membrane-bound sulfur-reducing complex from the hyperthermophilic Pyrodictium abyssi." Eur J Biochem 252 (3): 486-491.

Doetsch, R. N. (1981). Determinative methods of light microscopy. Manual of methods for general bacteriology, Washington, American Society for Microbiology. 
Dopson, M., C. Baker-Austin, P. R. Koppineedi and P. L. Bond (2003). "Growth in sulfidic mineral environments: metal resistance mechanisms in acidophilic micro-organisms." Microbiology 149 (8): 1959-1970.

Dopson, M. and D. S. Holmes (2014). "Metal resistance in acidophilic microorganisms and its significance for biotechnologies." Appl Microbiol Biotechnol 98 (19): 8133-8144.

Dopson, M. and D. B. Johnson (2012). "Biodiversity, metabolism and applications of acidophilic sulfur-metabolizing microorganisms." Environ Microbiol 14 (10): 2620-2631.

Dopson, M., E. B. Lindstrom and K. B. Hallberg (2002). "ATP generation during reduced inorganic sulfur compound oxidation by Acidithiobacillus caldus is exclusively due to electron transport phosphorylation." Extremophiles 6 (2): 123-129.

Dopson, M., F. Ossandon, L. Lövgren and D. S. Holmes (2014). "Metal resistance or tolerance? Acidophiles confront high metal loads via both abiotic and biotic mechanisms." Front Microbiol 5.

Dubinina, G., M. Grabovich, N. Leshcheva, F. A. Rainey and E. Gavrish (2011). "Spirochaeta perfilievii sp. nov., an oxygen-tolerant, sulfide-oxidizing, sulfur- and thiosulfate-reducing spirochaete isolated from a saline spring." Int J Syst Evol Microbiol 61 (1): 110-117.

Fardeau, M. L., M. Magot, B. K. Patel, P. Thomas, J. L. Garcia and B. Ollivier (2000). "Thermoanaerobacter subterraneus sp. nov., a novel thermophile isolated from oilfield water." Int J Syst Evol Microbiol 50 (Pt 6): 2141-2149.

Fardeau, M. L., B. Ollivier, B. K. Patel, M. Magot, P. Thomas, A. Rimbault, F. Rocchiccioli and J. L. Garcia (1997). "Thermotoga hypogea sp. nov., a xylanolytic, thermophilic bacterium from an oil-producing well." Int J Syst Bacteriol 47 (4): 1013-1019.

Fauque, G. D. and L. L. Barton (2012). "Hemoproteins in dissimilatory sulfate- and sulfur-reducing prokaryotes." Adv Microb Physiol 60: 1-90.

Feio, M. J., I. B. Beech, M. Carepo, J. M. Lopes, C. W. Cheung, R. Franco, J. Guezennec, J. R. Smith, J. I. Mitchell, J. J. Moura and A. R. Lino (1998). "Isolation and characterisation of a novel sulphate-reducing bacterium of the Desulfovibrio genus." Anaerobe 4 (2): 117-130.

Ferrer, A., J. Rivera, C. Zapata, J. Norambuena, Á. Sandoval, R. Chávez, O. Orellana and G. Levicán (2016). "Cobalamin protection against oxidative stress in the acidophilic iron-oxidizing bacterium Leptospirillum Group II CF-1." Front Microbiol 7 (748).

Ferrer, M., O. V. Golyshina, A. Beloqui, P. N. Golyshin and K. N. Timmis (2007). "The cellular machinery of Ferroplasma acidiphilum is iron-protein-dominated." Nature 445 (7123): 9194.

Fiala, G. and K. Stetter (1986). "Pyrococcus furiosus sp. nov. represents a novel genus of marine heterotrophic archaebacteria growing optimally at $100^{\circ} \mathrm{C}$." 145 (1): 56-61.

Finneran, K. T., H. M. Forbush, C. V. G. VanPraagh and D. R. Lovley (2002). "Desulfitobacterium metallireducens sp. nov., an anaerobic bacterium that couples growth to the reduction of metals and humic acids as well as chlorinated compounds." Int J Syst Evol Microbiol 52 (6): 1929-1935.

Finster, K. (2008). "Microbiological disproportionation of inorganic sulfur compounds." J Sulfur Chem 29 (3-4): 281-292.

Finster, K., F. Bak and N. Pfennig (1994). "Desulfuromonas acetexigens sp. nov., a dissimilatory sulfur-reducing eubacterium from anoxic freshwater sediments." Arch Microbiol 161 (4): 328-332.

Finster, K., J. D. Coates, W. Liesack and N. Pfennig (1997). "Desulfuromonas thiophila sp. nov., a new obligately sulfur-reducing bacterium from anoxic freshwater sediment." Int J Syst Bacteriol 47 (3): 5. 
Finster, K., W. Leiesack and B. O. Thamdrup (1998). "Elemental sulfur and thiosulfate disproportionation by Desulfocapsa sulfoexigens sp. nov., a new anaerobic bacterium isolated from marine surface sediment." Appl Environ Microbiol 64 (1): 7.

Finster, K. W., K. U. Kjeldsen, M. Kube, R. Reinhardt, M. Mussmann, R. Amann and L. Schreiber (2013). "Complete genome sequence of Desulfocapsa sulfexigens, a marine deltaproteobacterium specialized in disproportionating inorganic sulfur compounds." $\underline{\text { Stand }}$ Genomic Sci 8 (1): 58-68.

Fischer, F., W. Zillig, K. O. Stetter and G. Schreiber (1983). "Chemolithoautotrophic metabolism of anaerobic extremely thermophilic archaebacteria " Nature 301: 511-513.

Flamholz, A., E. Noor, A. Bar-Even and R. Milo (2012). "eQuilibrator-the biochemical thermodynamics calculator." Nucleic Acids Res 40 (D1): D770-D775.

Flora, S. J., M. Mittal and A. Mehta (2008). "Heavy metal induced oxidative stress \& its possible reversal by chelation therapy." Indian J Med Res 128 (4): 501-523.

Florentino, A. P., C. Brienza, A. J. Stams and I. Sánchez-Andrea (2016). "Desulfurella amilsii sp. nov., a novel acidotolerant sulfur-respiring bacterium isolated from acidic river sediments." Int J Syst Evol Microbiol 66 (3): 1249-1253.

Florentino, A. P., J. Weijma, A. J. Stams and I. Sánchez-Andrea (2015). "Sulfur reduction in acid rock drainage environments." Environ Sci Technol 49 (19): 11746-11755.

Florentino, A. P., J. Weijma, A. J. M. Stams and I. Sánchez-Andrea (2016). Ecophysiology and application of acidophilic sulfur-reducing microorganisms. Biotechnology of Extremophiles: Advances and Challenges. H. P. Rampelotto. Cham, Springer International Publishing: 141-175.

Flores, G. E., R. C. Hunter, Y. Liu, A. Mets, S. Schouten and A. L. Reysenbach (2012). "Hippea jasoniae sp. nov. and Hippea alviniae sp. nov., thermoacidophilic members of the class Deltaproteobacteria isolated from deep-sea hydrothermal vent deposits." Int J Syst Evol Microbiol 62 (Pt 6): 1252-1258.

Foucher, S., F. Battaglia-Brunet, I. Ignatiadis and D. Morin (2001). "Treatment by sulfate-reducing bacteria of Chessy acid-mine drainage and metals recovery." Chem Eng Sci 56 (4): 16391645.

Franz, B., T. Gehrke, H. Lichtenberg, J. Hormes, C. Dahl and A. Prange (2009). "Unexpected extracellular and intracellular sulfur species during growth of Allochromatium vinosum with reduced sulfur compounds." Microbiology 155 (Pt 8): 2766-2774.

Franz, B., H. Lichtenberg, J. Hormes, H. Modrow, C. Dahl and A. Prange (2007). "Utilization of solid "elemental" sulfur by the phototrophic purple sulfur bacterium Allochromatium vinosum: a sulfur K-edge X-ray absorption spectroscopy study." Microbiology 153 (Pt 4): 1268-1274.

Frederiksen, T.-M. and K. Finster (2003). "Sulfite-oxido-reductase is involved in the oxidation of sulfite in Desulfocapsa sulfoexigens during disproportionation of thiosulfate and elemental sulfur." Biodegradation 14 (3): 189-198.

French, R. (2002). Pliny the Elder on Science and Technology, Oxford.

Fu, H., J. Yuan and H. Gao (2015). "Microbial oxidative stress response: Novel insights from environmental facultative anaerobic bacteria." Arch Biochem Biophys 584: 28-35.

Fuchs, G. (2011). "Alternative pathways of carbon dioxide fixation: insights into the early evolution of life?" Annu Rev Microbiol 65 (1): 631-658.

Gadd, G. M. (1992). "Metals and microorganisms: A problem of definition." FEMS Microbiol Lett 100 (1): 197-203. 
Gallegos-Garcia, M., L. B. Celis, R. Rangel-Mendez and E. Razo-Flores (2009). "Precipitation and recovery of metal sulfides from metal containing acidic wastewater in a sulfidogenic downflow fluidized bed reactor." Biotechnol Bioeng 102 (1): 91-99.

Garlapati, V. K., U. Shankar and A. Budhiraja (2016). "Bioconversion technologies of crude glycerol to value added industrial products." Biotechnol Rep 9: 9-14.

Garrity, G. (2001). The Archaea and the deeply branching and phototrophic Bacteria, Springer-verlag.

Gebhardt, N. A., R. K. Thauer, D. Linder, P. Kaulfers and N. Pfennig (1985). "Mechanism of acetate oxidation to $\mathrm{CO}_{2}$ with elemental sulfur in Desulfuromonas acetoxidans*" Arch. Microbiol. 141: 7.

Gehrke, T., J. Telegdi, D. Thierry and W. Sand (1998). "Importance of extracellular polymeric substances from Thiobacillus ferrooxidans for bioleaching." Appl Environ Microbiol 64 (7): 2743-2747.

Ghosh, W. and B. Dam (2009). "Biochemistry and molecular biology of lithotrophic sulfur oxidation by taxonomically and ecologically diverse bacteria and archaea." FEMS Microbiol Rev $\mathbf{3 3}$ (6): 999-1043.

Gilmour, C. C., D. A. Elias, A. M. Kucken, S. D. Brown, A. V. Palumbo, C. W. Schadt and J. D. Wall (2011). "Sulfate-reducing bacterium Desulfovibrio desulfuricans ND132 as a model for understanding bacterial mercury methylation." Appl Environ Microbiol 77 (12): 39383951.

Giuffrè, A., V. B. Borisov, M. Arese, P. Sarti and E. Forte (2014). "Cytochrome bd oxidase and bacterial tolerance to oxidative and nitrosative stress." Biochim Biophys Acta, Bioenerg 1837(7): 1178-1187.

Giuliani, M.-C., C. Jourlin-Castelli, G. Leroy, A. Hachani and M. T. Giudici-Orticoni (2010). "Characterization of a new periplasmic single-domain rhodanese encoded by a sulfurregulated gene in a hyperthermophilic bacterium Aquifex aeolicus." Biochimie 92 (4): 388397.

Goevert, D. and R. Conrad (2010). "Stable carbon isotope fractionation by acetotrophic sulfurreducing bacteria." FEMS Microbiol Ecol 71 (2): 218-225.

Golyshina, O. V. and K. N. Timmis (2005). "Ferroplasma and relatives, recently discovered cell wall-lacking archaea making a living in extremely acid, heavy metal-rich environments." Environ Microbiol 7 (9): 1277-1288.

González, J. M., Y. Masuchi, F. T. Robb, J. W. Ammerman, D. L. MAeder, M. Yanagibayashi, J. Tamaoka and C. Kato (1998). "Pyrococcus horikoshii sp. nov., a hyperthermophilic archaeon isolated from a hydrothermal vent at the Okinawa Trough." Extremophiles 2: 8.

Goris, J., K. Konstantinidis, J. Klappenbach, T. Coenye, P. Vandamme and J. Tiedje (2007). "DNADNA hybridization values and their relationship to whole-genome sequence similarities." Int J Syst Evol Microbiol 57.

Gottschalk, G. and B. Averhoff (1990). "Process for the microbial preparation of 1,3-propanediol from glycerol." EP 0373230 A1.

Götz, D., A. Banta, T. J. Beveridge, A. I. Rushdi, B. R. T. Simoneit and A. L. Reysenbach (2002). "Persephonella marina gen. nov., sp. nov. and Persephonella guaymasensis sp. nov., two novel, thermophilic, hydrogen-oxidizing microaerophiles from deep-sea hydrothermal vents." Int J Syst Evol Microbiol 52( 4): 1349-1359.

Goulbourne, E., Jr., M. Matin, E. Zychlinsky and A. Matin (1986). "Mechanism of delta pH maintenance in active and inactive cells of an obligately acidophilic bacterium." J Bacteriol 166 (1): 59-65. 
Grabowski, A., B. J. Tindall, V. Bardin, D. Blanchet and C. Jeanthon (2005). "Petrimonas sulfuriphila gen. nov., sp. nov., a mesophilic fermentative bacterium isolated from a biodegraded oil reservoir." Int J Syst Evol Microbiol 55 (Pt 3): 1113-1121.

Gramp, J. P., H. Wang, J. M. Bigham, F. S. Jones and O. H. Tuovinen (2009). "Biogenic synthesis and reduction of fe(III)-hydroxysulfates." Geomicrobiol J 26 (4): 275-280.

Greene, A. C. (2014). The Family Desulfurellaceae. The Prokaryotes: Deltaproteobacteria and Epsilonproteobacteria. E. Rosenberg, E. F. DeLong, S. Lory, E. Stackebrandt and F. Thompson. Berlin, Heidelberg, Springer Berlin Heidelberg: 135-142.

Greene, A. C., B. K. Patel and S. Yacob (2009). "Geoalkalibacter subterraneus sp. nov., an anaerobic $\mathrm{Fe}(\mathrm{III})$ - and $\mathrm{Mn}$ (IV)-reducing bacterium from a petroleum reservoir, and emended descriptions of the family Desulfuromonadaceae and the genus Geoalkalibacter." Int J Syst Evol Microbiol 59 (Pt 4): 781-785.

Grein, F., A. R. Ramos, S. S. Venceslau and I. A. C. Pereira (2013). "Unifying concepts in anaerobic respiration: Insights from dissimilatory sulfur metabolism Biochim Biophys Acta, Bioenerg 1827 (2): 145-160.

Grimm, F., N. Dobler and C. Dahl (2010). "Regulation of dsr genes encoding proteins responsible for the oxidation of stored sulfur in Allochromatium vinosum." Microbiology 156 (Pt 3): 764773.

Grissa, I., G. Vergnaud and C. Pourcel (2007). "CRISPRFinder: a web tool to identify clustered regularly interspaced short palindromic repeats." Nucleic Acids Res $\mathbf{3 5}$ (Web Server issue): W52-57.

Grootscholten, T., K. Keesman and P. Lens (2008). "Modelling and on-line estimation of zinc sulphide precipitation in a continuously stirred tank reactor." Sep Purif Technol 63 (3): 654660 .

Gu, M. X., Q. Li, S. Y. Zhou, W. D. Chen and T. M. Guo (1993). "Experimental and modeling studies on the phase behavior of high $\mathrm{H}_{2} \mathrm{~S}$-content natural gas mixtures " Fluid Phase Equilib 82(0): 173-182.

Hagen, W. R., P. J. Silva, M. A. Amorim, P. L. Hagedoorn, H. Wassink, H. Haaker and F. T. Robb (2000). "Novel structure and redox chemistry of the prosthetic groups of the iron-sulfur flavoprotein sulfide dehydrogenase from Pyrococcus furiosus; evidence for a [2Fe-2S] cluster with Asp(Cys) $)_{3}$ ligands." J Biol Inorg Chem 5 (4): 527-534.

Hallenbeck, P. C., M. A. Clark and E. L. Barrett (1989). "Characterization of anaerobic sulfite reduction by Salmonella typhimurium and purification of the anaerobically induced sulfite reductase." J Bacteriol 171 (6): 3008-3015.

Hamilton-Brehm, S. D., R. A. Gibson, S. J. Green, E. C. Hopmans, S. Schouten, M. T. J. van der Meer, J. P. Shields, J. S. S. Damsté and J. G. Elkins (2013). "Thermodesulfobacterium geofontis sp. nov., a hyperthermophilic, sulfate-reducing bacterium isolated from Obsidian Pool, Yellowstone National Park." Extremophiles 17 (2): 251-263.

Hanna, M. N., R. J. Ferguson, Y. H. Li and D. G. Cvitkovitch (2001). "uvrA is an acid-inducible gene involved in the adaptive response to low pH in Streptococcus mutans." J Bacteriol 183 (20): 5964-5973.

Hao, O. J., L. Huang, J. M. Chen and R. L. Buglass (1994). "Effects of metal additions on sulfate reduction activity in wastewaters." Toxicol Environ Chem 46 (4): 197-212.

Hardisty, D. S., G. A. Olyphant, J. B. Bell, A. P. Johnson and L. M. Pratt (2013). "Acidophilic sulfur disproportionation." Geochim Cosmochim Acta 113: 136-151. 
Harneit, K., A. Göksel, D. Kock, J. H. Klock, T. Gehrke and W. Sand (2006). "Adhesion to metal sulfide surfaces by cells of Acidithiobacillus ferrooxidans, Acidithiobacillus thiooxidans and Leptospirillum ferrooxidans." Hydrometallurgy 83 (1-4): 245-254.

Hartshorne, R. S., C. L. Reardon, D. Ross, J. Nuester, T. A. Clarke, A. J. Gates, P. C. Mills, J. K. Fredrickson, J. M. Zachara, L. Shi, A. S. Beliaev, M. J. Marshall, M. Tien, S. Brantley, J. N. Butt and D. J. Richardson (2009). "Characterization of an electron conduit between bacteria and the extracellular environment." Proc Natl Acad Sci USA 106 (52): 22169-22174.

Hassen, A., N. Saidi, M. Cherif and A. Boudabous (1998). "Resistance of environmental bacteria to heavy metals." Bioresour Technol 64 (1): 7-15.

Heberle, H., G. V. Meirelles, F. R. da Silva, G. P. Telles and R. Minghim (2015). "InteractiVenn: a web-based tool for the analysis of sets through Venn diagrams." BMC Bioinformatics 16: 169.

Hedderich, R., O. Klimmek, A. Kröger, R. Dirmeier, M. Keller and K. O. Stetter (1999). "Anaerobic respiration with elemental sulfur and with disulfides." FEMS Microbiol Rev 22: 29.

Hedrich, S. and D. B. Johnson (2014). "Remediation and selective recovery of metals from acidic mine waters using novel modular bioreactors." Environ Sci Technol 48 (20): 12206-12212.

Heijne, A. T., F. Liu, R. v. d. Weijden, J. Weijma, C. J. N. Buisman and H. V. M. Hamelers (2010). "Copper recovery combined with electricity production in a microbial fuel cell." Environ Sci Technol 44 (11): 4376-4381.

Heinzinger, N. K., S. Y. Fujimoto, M. A. Clark, M. S. Moreno and E. L. Barrett (1995). "Sequence analysis of the phs operon in Salmonella typhimurium and the contribution of thiosulfate reduction to anaerobic energy metabolism." J Bacteriol 177 (10): 2813-2820.

Hernandez-Eugenio, G., M. L. Fardeau, J. L. Cayol, B. K. C. Patel, P. Thomas, H. Macarie, J. L. Garcia and B. Ollivier (2002). "Sporanaerobacter acetigenes gen. nov., sp. nov., a novel acetogenic, facultatively sulfur-reducing bacterium." Int J Syst Evol Microbiol 52 (4): 1217 1223.

Hernandez-Eugenio, G., M. L. Fardeau, B. K. C. Patel, H. Macarie, J. L. Garcia and B. Ollivier (2000). "Desulfovibrio mexicanus sp. nov., a sulfate-reducing bacterium isolated from an Upflow Anaerobic Sludge Blanket (UASB) Reactor treating cheese wastewaters." Anaerobe 6 (5): 305-312.

Hernandez, D., P. Francois, L. Farinelli, M. Osteras and J. Schrenzel (2008). "De novo bacterial genome sequencing: millions of very short reads assembled on a desktop computer." Genome Res 18 (5): 802-809.

Hernandez, M. E. and D. K. Newman (2001). "Extracellular electron transfer." Cell Mol Life Sci 58 (11): 1562-1571.

Heunis, T., S. Deane, S. Smit and L. M. T. Dicks (2014). "Proteomic profiling of the acid stress response in Lactobacillus plantarum 423." J Proteome Res 13 (9): 4028-4039.

Hinsley, A. P. and B. C. Berks (2002). "Specificity of respiratory pathways involved in the reduction of sulfur compounds by Salmonella enterica." Microbiology 148 (11): 3631-3638.

Hoe, C.-H., C. A. Raabe, T. S. Rozhdestvensky and T.-H. Tang (2013). "Bacterial sRNAs: Regulation in stress." Int J of Med Microbiol 303 (5): 217-229.

Hoffert, J. R. (1947). "Acid mine drainage." Ind Eng Chem 39 (5): 642-646.

Holyoak, C. D., M. Stratford, Z. McMullin, M. B. Cole, K. Crimmins, A. J. Brown and P. J. Coote (1996). "Activity of the plasma membrane $\mathrm{H}(+)$-ATPase and optimal glycolytic flux are required for rapid adaptation and growth of Saccharomyces cerevisiae in the presence of the weak-acid preservative sorbic acid." Appl Environ Microbiol 62 (9): 3158-3164.

Homer (1998). Odissey. Web, Cambridge Harvard UP. 
Huber, H., S. Diller, C. Horn and R. Rachel (2002). "Thermovibrio ruber gen. nov., sp. nov., an extremely thermophilic, chemolithoautotrophic, nitrate-reducing bacterium that forms a deep branch within the phylum Aquificae." Int J Syst Evol Microbiol 52 (5): 1859-1865.

Huber, R., D. Dyba, H. Huber, S. Burggraf and R. Rachel (1998). "Sulfur-inhibited Thermosphaera aggregans sp. nov., a new genus of hyperthermophilic archaea isolated after its prediction from environmentally derived 16S rRNA sequences." Int J of Syst Bacteriol 48 (1): 31-38.

Huber, R., W. Eder, S. Heldwein, G. Wanner, H. Huber, R. Rachel and K. O. Stetter (1998). "Thermocrinis ruber gen. nov., sp. nov., a pink-filament-forming hyperthermophilic bacterium isolated from Yellowstone National Park." Appl Environ Microbiol 64 (10): 3576-3583.

Huber, R., J. K. Kristjansson and K. O. Stetter (1987). "Pyrobaculum gen. nov., a new genus of neutrophilic, rod-shaped archaebacteria from continental solfataras growing optimally at $100^{\circ}$ C." Arch Microbiol 149 (2): 95-101.

Huber, R., T. A. Langworthy, H. König, M. Thomm, C. R. Woese, U. B. Sleytr and K. O. Stetter (1986). "Thermotoga maritima sp. nov. represents a new genus of unique extremely thermophilic euhacteria growing up to $90^{\circ} \mathrm{C}$." Arch Microbiol 144: 10.

Huber, R., P. Rossnagel, C. R. Woese, R. Rachel, T. A. Langworthy and K. O. Stetter (1996). "Formation of ammonium from nitrate during chemolithoautotrophic growth of the extremely thermophilic bacterium Ammonifex degensii gen. nov. sp. nov." Syst Appl Microbiol 19 (1): 40-49.

Huber, R., T. Wilharm, D. Huber, A. Trincone, S. Burggraf, H. König, R. Reinhard, I. Rockinger, H. Fricke and K. O. Stetter (1992). "Aquifex pyrophilus gen. nov. sp. nov., represents a novel group of marine hyperthermophilic hydrogen-oxidizing bacteria." Syst Appl Microbiol 15 (3): 340-351.

Hügler, M., C. O. Wirsen, G. Fuchs, C. D. Taylor and S. M. Sievert (2005). "Evidence for autotrophic $\mathrm{CO}_{2}$ fixation via the reductive tricarboxylic acid cycle by members of the $\varepsilon$ subdivision of Proteobacteria." J Bacteriol 187 (9): 3020-3027.

Huisman, J. L., G. Schouten and C. Schultz (2006). "Biologically produced sulphide for purification of process streams, effluent treatment and recovery of metals in the metal and mining industry." Hydrometallurgy 83 (1-4): 106-113.

Hulshof, A. H., D. W. Blowes and W. D. Gould (2006). "Evaluation of in situ layers for treatment of acid mine drainage: a field comparison." Water Res 40 (9): 1816-1826.

Huntemann, M., M. Lu, M. Nolan, A. Lapidus, S. Lucas, N. Hammon, S. Deshpande, J. F. Cheng, R. Tapia, C. Han, L. Goodwin, S. Pitluck, K. Liolios, I. Pagani, N. Ivanova, G. Ovchinikova, A. Pati, A. Chen, K. Palaniappan, M. Land, L. Hauser, C. D. Jeffries, J. C. Detter, E. M. Brambilla, M. Rohde, S. Spring, M. Goker, T. Woyke, J. Bristow, J. A. Eisen, V. Markowitz, P. Hugenholtz, N. C. Kyrpides, H. P. Klenk and K. Mavromatis (2011). "Complete genome sequence of the thermophilic sulfur-reducer Hippea maritima type strain (MH(2))." Stand Genomic Sci 4 (3): 303-311.

Hutkins, R. W. and N. L. Nannen (1993). "pH homeostasis in Lactic Acid Bacteria" J Dairy Sci 76 (8): 2354-2365.

Ingram-Smith, C., S. R. Martin and K. S. Smith (2006). "Acetate kinase: not just a bacterial enzyme." Trends Microbiol 14 (6): 249-253.

Isaksen, M. F. and B. B. Jorgensen (1996). "Adaptation of psychrophilic and psychrotrophic sulfatereducing bacteria to permanently cold marine environments." Appl Environ Microbiol 62 (2): 408-414. 
Itoh, T., K. Suzuki and T. Nakase (1998). "Thermocladium modestius gen. nov., sp. nov., a new genus of rod-shaped, extremely thermophilic crenarchaeote." Int J Syst Bacteriol 48 (Pt 3): 879887.

Itoh, T., K. Suzuki and T. Nakase (2002). "Vulcanisaeta distributa gen. nov., sp. nov., and Vulcanisaeta souniana sp. nov., novel hyperthermophilic, rod-shaped crenarchaeotes isolated from hot springs in Japan." Int J Syst Evol Microbiol 52 (Pt 4): 1097-1104.

Itoh, T., K. Suzuki, P. C. Sánchez and T. Nakase (1999). "Caldivirga maquilingensis gen. nov., sp. nov., a new genus of rod-shaped crenarchaeote isolated from a hot spring in the Philippines." Int J Syst Bacteriol 49 (Pt 3): 1157-1163.

Itoh, T., K. Suzuki, P. C. Sánchez and T. Nakase (2003). "Caldisphaera lagunensis gen. nov., sp. nov., a novel thermoacidophilic crenarchaeote isolated from a hot spring at Mt Maquiling, Philippines." Int J Syst Evol Microbiol 53 (Pt 4): 1149-1154.

Itoh, T., T. Yamaguchi, P. Zhou and T. Takashina (2005). "Natronolimnobius baerhuensis gen. nov., sp. nov. and Natronolimnobius innermongolicus sp. nov., novel haloalkaliphilic archaea isolated from soda lakes in Inner Mongolia, China." Extremophiles 9 (2): 111-116.

Jain, P. and S. Sinha (2008). "Neutrophiles: acid challenge and comparison with acidophiles." Internet J Microbiol 7 (1): 10.

Jameson, E., O. F. Rowe, K. B. Hallberg and D. B. Johnson (2010). "Sulfidogenesis and selective precipitation of metals at low $\mathrm{pH}$ mediated by Acidithiobacillus spp. and acidophilic sulfatereducing bacteria." Hydrometallurgy 104 (3-4): 488-493.

Jankielewicz, A., O. Klimmek and A. Kröger (1995). "The electron transfer from hydrogenase and formate dehydrogenase to polysulfide reductase in the membrane of Wolinella succinogenes." Biochim Biophys Acta 1231 (2): 157-162.

Janssen, A. J., R. Ruitenberg and C. J. Buisman (2001). "Industrial applications of new sulphur biotechnology." Water Sci Technol 44 (8): 85-90.

Ji, G. and S. Silver (1995). "Bacterial resistance mechanisms for heavy metals of environmental concern." J Ind Microbiol 14 (2): 61-75.

Jochimsen, B., S. Peinemann-Simon, H. Volker, D. Stuben, R. Botz, P. Stoffers, P. R. Dando and M. Thomm (1997). "Stetteria hydrogenophila, gen. nov. and sp. nov., a novel mixotrophic sulfur-dependent crenarchaeote isolated from Milos, Greece." Extremophiles 1 (2).

Johnson, D. B. (1995). "Acidophilic microbial communities: candidates for bioremediation of acidic mine effluents." Int Biodeter Biodegr 18.

Johnson, D. B. (1998). "Biodiversity and ecology of acidophilic microorganisms." FEMS Microbiol Ecol 27 (4): 307-317.

Johnson, D. B. (2003). "Chemical and microbiological characteristics of mineral spoils and drainage waters at abandoned coal and metal mines." Water Air Soil Poll 3 (1): 47-66.

Johnson, D. B. (2010). The Biogeochemistry of Biomining. Geomicrobiology: Molecular and Environmental Perspective. L. L. Barton, M. Mandl and A. Loy. Dordrecht, Springer Netherlands: 401-426.

Johnson, D. B. and K. B. Hallberg (2005). "Acid mine drainage remediation options: a review." Sci Total Environ 338 (1-2): 3-14.

Jones, R. M., S. Hedrich and D. B. Johnson (2013). "Acidocella aromatica sp. nov.: an acidophilic heterotrophic alphaproteobacterium with unusual phenotypic traits." Extremophiles 17 (5): 10.

Joshi, V. J. and D. D. Santani (2012). "Physicochemical characterization and heavy meta concentration in effluent of textile industry." Univers J Environ Res Technol 2 (2): 4. 
Junier, P., T. Junier, S. Podell, D. R. Sims, J. C. Detter, A. Lykidis, C. S. Han, N. S. Wigginton, T. Gaasterland and R. Bernier-Latmani (2010). "The genome of the Gram-positive metal- and sulfate-reducing bacterium Desulfotomaculum reducens strain MI-1." Environ Microbiol 12 (10): 2738-2754.

Kaksonen, A. H., J. J. Plumb, P. D. Franzmann and J. A. Puhakka (2004). "Simple organic electron donors support diverse sulfate-reducing communities in fluidized-bed reactors treating acidic metal- and sulfate-containing wastewater." FEMS Microbiol Ecol 47 (3): 279-289.

Kaksonen, A. H. and J. A. Puhakka (2007). "Sulfate reduction based bioprocesses for the treatment of acid mine drainage and the recovery of metals." Eng Life Sci 7 (6): 541-564.

Kaksonen, A. H., M. L. Riekkola-Vanhanen and J. A. Puhakka (2003). "Optimization of metal sulphide precipitation in fluidized-bed treatment of acidic wastewater." Water Res 37 (2): 255-266.

Kaksonen, A. H., S. Spring, P. Schumann, R. M. Kroppenstedt and J. A. Puhakka (2006). "Desulfotomaculum thermosubterraneum sp. nov., a thermophilic sulfate-reducer isolated from an underground mine located in a geothermally active area." Int J Syst Evol Microbiol 56 (Pt 11): 2603-2608.

Kamyshny, A., I. Ekeltchik, J. Gun and O. Lev (2006). "Method for the determination of inorganic polysulfide distribution in aquatic systems." Anal Chem 78 (8): 2631-2639.

Kanjee, U. and W. A. Houry (2013). "Mechanisms of acid resistance in Escherichia coli." Annu Rev Microbiol 67: 65-81.

Kannan, G., J. C. Wilks, D. M. Fitzgerald, B. D. Jones, S. S. BonDurant and J. L. Slonczewski (2008). "Rapid acid treatment of Escherichia coli: transcriptomic response and recovery." BMC Microbiology 8 (1): 37.

Kao, C. M., J. K. Liu, Y. L. Chen, C. T. Chai and S. C. Chen (2005). "Factors affecting the biodegradation of PCP by Pseudomonas mendocina NSYSU." J Hazard Mater 124 (1-3): 68-73.

Kato, S., R. Nakamura, F. Kai, K. Watanabe and K. Hashimoto (2010). "Respiratory interactions of soil bacteria with (semi)conductive iron-oxide minerals." Environ Microbiol 12 (12): 31143123.

Kelly, D. P. and A. P. Wood (2000). "Reclassification of some species of Thiobacillus to the newly designated genera Acidithiobacillus gen. nov., Halothiobacillus gen. nov. and Thermithiobacillus gen. nov." Int J Syst Evol Microbiol 50 (2): 511-516.

Kimura, S., K. B. Hallberg and D. B. Johnson (2006). "Sulfidogenesis in low pH (3.8-4.2) media by a mixed population of acidophilic bacteria." Biodegradation 17 (2): 159-167.

Klausen, M., A. Heydorn, P. Ragas, L. Lambertsen, A. Aaes-Jorgensen, S. Molin and T. TolkerNielsen (2003). "Biofilm formation by Pseudomonas aeruginosa wild type, flagella and type IV pili mutants." Mol Microbiol 48 (6): 1511-1524.

Kleinjan, W. E., A. de Keizer and A. J. H. Janssen (2005). "Equilibrium of the reaction between dissolved sodium sulfide and biologically produced sulfur." Colloids Surf B Biointerfaces 43 (3-4): 228-237.

Klimmek, O. (2005). The biological cycle of sulfur. Metal ions in biological systems, CRC Press. 43: 105-130.

Klimmek, O., A. Kröger, R. Steudel and G. Holdt (1991). "Growth of Wolinella succinogenes with polysulphide as terminal acceptor of phosphorylative electron transport." Arch Microbiol 155 (2): 177-182. 
Knickerbocker, C., D. K. Nordstrom and G. Southam (2000). "The role of "blebbing" in overcoming the hydrophobic barrier during biooxidation of elemental sulfur by Thiobacillus thiooxidans." Chem Geol 169: 9.

Knoblauch, C., K. Sahm and B. B. Jorgensen (1999). "Psychrophilic sulfate-reducing bacteria isolated from permanently cold arctic marine sediments: description of Desulfofrigus oceanense gen. nov., sp. nov., Desulfofrigus fragile sp. nov., Desulfofaba gelida gen. nov., sp. nov., Desulfotalea psychrophila gen. nov., sp. nov. and Desulfotalea arctica sp. nov." Int J Syst Bacteriol 49 (Pt 4): 1631-1643.

König, H. and K. O. Stetter (1982). "Isolation and characterization of Methanolobus tindarius, sp. nov., a coccoid methanogen growing only on methanol and methylamines." Zentralblatt für Bakteriologie Mikrobiologie und Hygiene: I. Abt. Originale C: Allgemeine, angewandte und ökologische Mikrobiologie 3 (4): 478-490.

König, J., K. J. Keesman, A. H. M. Veeken and P. N. L. Lens (2006). "Dynamic modelling and process control of ZnS precipitation." Separ Sci Technol 41 (6): 1025-1042.

Konings, W. N., S.-V. Albers, S. Koning and A. J. M. Driessen (2002). "The cell membrane plays a crucial role in survival of bacteria and archaea in extreme environments." Antonie van Leeuwenhoek 81 (1): 61-72.

Konings, W. N., S. V. Albers, S. Koning and A. J. M. Driessen (2002). "The cell membrane plays a crucial role in survival of bacteria and archaea in extreme environments." Antonie van Leeuwenhoek 81: 12.

Koschorreck, M. (2008). "Microbial sulphate reduction at a low pH." FEMS Microbiol Ecol 64 (3): 329-342.

Krafft, T., R. Gross and A. Kröger (1995). "The function of Wolinella succinogenes psr genes in electron transport with polysulphide as the terminal electron acceptor." Eur J Biochem 230 (2): 601-606.

Kreis-Kleinschmidt, V., F. Fahrenholz, E. Kojro and A. Kröger (1995). "Periplasmic sulphide dehydrogenase (sud) from Wolinella succinogenes: Isolation, nucleotide sequence of the sud gene and its expression in Escherichia coli." Eur J Biochem 227 (1-2): 137-142.

Kretschmann, H., F. J. Carduck, W. D. Deckwer, C. Tag and H. Biebl (1989). "Fermentative Herstellung von 1,3-Propandiol." GBF mbH-Henkel KGaA).

Krulwich, T. A., R. Agus, M. Schneier and A. A. Guffanti (1985). "Buffering capacity of bacilli that grow at different $\mathrm{pH}$ ranges." J Bacteriol 162 (2): 768-772.

Kublanov, I. V., S. K. Bidjieva, A. V. Mardanov and E. A. Bonch-Osmolovskaya (2009). "Desulfurococcus kamchatkensis sp. nov., a novel hyperthermophilic protein-degrading archaeon isolated from a Kamchatka hot spring." Int J Syst Evol Microbiol 59 (7): 17431747.

Kumar, A., D. Augustine, S. Sudhindran, A. M. Kurian, K. R. Dinesh, S. Karim and R. Philip (2011). "Weissella confusa: a rare cause of vancomycin-resistant Gram-positive bacteraemia." J Med Microbiol 60 (Pt 10): 1539-1541.

Kutney, G. (2013). Chapter 2 - The sulfur age. Sulfur (Second Edition). Oxford, ChemTec Publishing: 5-41.

L'Haridon, S., V. Cilia, P. Messner, G. Raguénès, A. Gambacorta, U. B. Sleytr, D. Prieur and C. Jeanthon (1998). "Desulfurobacterium thermolithotrophum gen. nov., sp. nov., a novel autotrophic, sulphur-reducing bacterium isolated from a deep-sea hydrothermal vent." Int J Syst Bacteriol 48 (3): 701-711.

L'Haridon, S., M. L. Miroshnichenko, M. Hippe, M. L. Fardeau, E. A. Bonch-Osmolovskaya, E. Stackebrandt and C. Jeanthon (2001). "Thermosipho geolei sp. nov., a thermophilic 
bacterium isolated from a continental petroleum reservoir in Western Siberia." Int J Syst Evol Microbiol 51: 8.

L'Haridon, S., A.-L. Reysenbach, B. J. Tindall, P. Schönheit, A. Banta, U. Johnsen, P. Schumann, A. Gambacorta, E. Stackebrandt and C. Jeanthon (2006). "Desulfurobacterium atlanticum sp. nov., Desulfurobacterium pacificum sp. nov. and Thermovibrio guaymasensis sp. nov., three thermophilic members of the Desulfurobacteriaceae fam. nov., a deep branching lineage within the Bacteria." Int J Syst Evol Microbiol 56 (12): 2843-2852.

Labrenz, M., G. K. Druschel, T. Thomsen-Ebert, B. Gilbert, S. A. Welch, K. M. Kemner, G. A. Logan, R. E. Summons, G. De Stasio, P. L. Bond, B. Lai, S. D. Kelly and J. F. Banfield (2000). "Formation of sphalerite $(\mathrm{ZnS})$ deposits in natural biofilms of sulfate-reducing bacteria." Science 290(5497): 1744-1747.

Lages, F., M. Silva-Graca and C. Lucas (1999). "Active glycerol uptake is a mechanism underlying halotolerance in yeasts: a study of 42 species." Microbiology 145 (Pt 9): 2577-2585.

Laska, S., F. Lottspeich and A. Kletzin (2003). "Membrane-bound hydrogenase and sulfur reductase of the hyperthermophilic and acidophilic archaeon Acidianus ambivalens." Microbiology 149 (9): 2357-2371.

Ledgham, F., B. Quest, T. Vallaeys, M. Mergeay and J. Covès (2005). "A probable link between the DedA protein and resistance to selenite." Res Microbiol 156 (3): 367-374.

Lee, Y. J., C. S. Romanek and J. Wiegel (2009). "Desulfosporosinus youngiae sp. nov., a sporeforming, sulfate-reducing bacterium isolated from a constructed wetland treating acid mine drainage." Int J Syst Evol Microbiol 59 (Pt 11): 2743-2746.

Lens, P. N. L., L. W. Hulshoff Pol, P. Wilderer and T. Asano (2002). Water recycling and resource recovery in industry: analysis, technologies and implementation. London, IWA.

Leone, L., D. Ferri, C. Manfredi, P. Persson, A. Shchukarev, S. Sjöberg and J. Loring (2007). "Modeling the acid-base properties of bacterial surfaces: A combined spectroscopic and potentiometric study of the gram-positive bacterium Bacillus subtilis." Environ Sci Technol 41 (18): 6465-6471.

Leoneti, A. B., V. Aragão-Leoneti and S. V. W. B. de Oliveira (2012). "Glycerol as a by-product of biodiesel production in Brazil: Alternatives for the use of unrefined glycerol." Renew Energy 45: 138-145.

Lewis, A. E. (2010). "Review of metal sulphide precipitation." Hydrometallurgy 104 (2): 222-234.

Li, C., K. Lesnik and H. Liu (2013). "Microbial conversion of waste glycerol from biodiesel production into value-added products." Energies 6 (9): 4739.

Liamleam, W. and A. P. Annachhatre (2007). "Electron donors for biological sulfate reduction." Biotechnol Adv 25 (5): 452-463.

Libiad, M., A. Sriraman and R. Banerjee (2015). "Polymorphic variants of human rhodanese exhibit differences in thermal stability and sulfur transfer kinetics." J Biol Chem 290 (39): 2357923588.

Lien, T. and J. Beeder (1997). "Desulfobacter vibrioformis sp. nov., a sulfate reducer from a water-oil separation system." Int J Syst Bacteriol 47 (4): 1124-1128.

Liesack, W. and K. Finster (1994). "Phylogenetic analysis of five strains of Gram-negative, obligately anaerobic, sulfur-reducing bacteria and description of Desulfuromusa gen. nov., including Desulfuromusa kysingii sp. nov., Desulfuromusa bakii sp. nov., and Desulfuromusa succinoxidans sp. nov." Int J Syst Bacteriol 44 (4): 753-758.

Lima de Silva, A. A., M. A. R. de Carvalho, S. A. L. de Souza, P. M. T. Dias, R. G. da Silva Filho, C. S. de Meirelles Saramago, C. A. de Melo Bento and E. Hofer (2012). "Heavy metal 
tolerance (Cr, Ag AND $\mathrm{Hg}$ ) in bacteria isolated from sewage." Braz J Microbiol 43 (4): 1620-1631.

Loh, J. T. and T. L. Cover (2006). "Requirement of Histidine Kinases HP0165 and HP1364 for acid resistance in Helicobacter pylori." Infect Immun 74 (5): 3052-3059.

Lopez-Archilla, A. I., I. Marin and R. Amils (2001). "Microbial community composition and ecology of an acidic aquatic environment: The Tinto River, Spain." Microbiol Ecol 41 (1): 20-35.

Lovley, D. R. (1991). "Dissimilatory Fe(III) and Mn(IV) reduction." Microbiol Rev 55 (2): 259-287.

Lovley, D. R., J. L. Fraga, E. L. Blunt-Harris, L. A. Hayes, E. J. P. Phillips and J. D. Coates (1998). "Humic substances as a mediator for microbially catalyzed metal reduction." Acta Hydrochim Hydrobiol 26 (3): 152-157.

Lovley, D. R., D. E. Holmes and K. P. Nevin (2004). "Dissimilatory Fe(III) and Mn(IV) reduction." Adv Microb Physiol 49: 219-286.

Lovley, D. R., E. J. P. Phillips, D. J. Lonergan and P. K. Widman (1995). "Fe(III) and $\mathrm{S}^{0}$ reduction by Pelobacter carbinolicus." Appl Environ Microbiol 61 (6): 7.

Luijten, M. L. G. C., J. de Weert, H. Smidt, H. T. S. Boschker, W. M. de Vos, G. Schraa and A. J. M. Stams (2003). "Description of Sulfurospirillum halorespirans sp. nov., an anaerobic, tetrachloroethene-respiring bacterium, and transfer of Dehalospirillum multivorans to the genus Sulfurospirillum as Sulfurospirillum multivorans comb. nov." Int J Syst Evol Microbiol 53 (3): 787-793.

Luli, G. W. and W. R. Strohl (1990). "Comparison of growth, acetate production, and acetate inhibition of Escherichia coli strains in batch and fed-batch fermentations." Appl Environ Microbiol 56.

Ma, K. and M. W. Adams (1994). "Sulfide dehydrogenase from the hyperthermophilic archaeon Pyrococcus furiosus: a new multifunctional enzyme involved in the reduction of elemental sulfur." J Bacteriol 176 (21): 6509-6517.

Ma, K. and M. W. W. Adams (2001). Ferredoxin:NADP oxidoreductase from Pyrococcus furiosus. Methods Enzymol, Academic Press. 334: 40-45.

Ma, K., R. N. Schicho, R. M. Kelly and M. W. Adams (1993). "Hydrogenase of the hyperthermophile Pyrococcus furiosus is an elemental sulfur reductase or sulfhydrogenase: evidence for a sulfur-reducing hydrogenase ancestor." Proc Natl Acad Sci USA 90 (11): 5341-5344.

Ma, K., R. Weiss and M. W. Adams (2000). "Characterization of hydrogenase II from the hyperthermophilic archaeon Pyrococcus furiosus and assessment of its role in sulfur reduction." J Bacteriol 182 (7): 1864-1871.

Macalady, J. and J. F. Banfield (2003). "Molecular geomicrobiology: genes and geochemical cycling." Earth Planet Sci Lett 209 (1-2): 1-17.

Macy, J., I. Schröder, R. Thauer and A. Kröger (1986). "Growth the Wolinella succinogenes on $\mathrm{H}_{2} \mathrm{~S}$ plus fumarate and on formate plus sulfur as energy sources." 144 (2): 147-150.

Madigan, M. T. (2012). Brock biology of microorganisms. San Francisco, Benjamin Cummings.

Magot, M., M. L. Fardeau, O. Arnauld, C. Lanau, B. Ollivier, P. Thomas and B. K. C. Patel (1997). "Spirochaeta smaragdinae sp. nov., a new mesophilic strictly anaerobic spirochete from an oil field " FEMS Microbiol Lett 155: 7.

Magot, M., G. Ravot, X. Campaignolle, B. Ollivier, B. K. C. Patel, M. L. Fardeau, P. Thomas, J. L. Crolet and J. L. Garcia (1997). "Dethiosulfovibrio peptidovorans gen. nov., sp. nov., a new anaerobic, slightly halophilic, thiosulfate-reducing bacterium fromcorroding offshore oil wells." Int J Syst Bacteriol 47 (3): 7.

Makarova, K. S., Y. I. Wolf, O. S. Alkhnbashi, F. Costa, S. A. Shah, S. J. Saunders, R. Barrangou, S. J. J. Brouns, E. Charpentier, D. H. Haft, P. Horvath, S. Moineau, F. J. M. Mojica, R. M. 
Terns, M. P. Terns, M. F. White, A. F. Yakunin, R. A. Garrett, J. van der Oost, R. Backofen and E. V. Koonin (2015). "An updated evolutionary classification of CRISPR-Cas systems." Nat Rev Microbiol 13 (11): 722-736.

Markowitz, V. M., I.-M. A. Chen, K. Palaniappan, K. Chu, E. Szeto, M. Pillay, A. Ratner, J. Huang, T. Woyke, M. Huntemann, I. Anderson, K. Billis, N. Varghese, K. Mavromatis, A. Pati, N. N. Ivanova and N. C. Kyrpides (2014). "IMG 4 version of the integrated microbial genomes comparative analysis system." Nucleic Acids Res 42 (D1): D560-D567.

Mckie, D. (1953). "Antoine lavoisier: Scientist, economist, social reformer." Ann Intern Med 38 (4): 892-892.

Meier-Kolthoff, J. P., A. F. Auch, H.-P. Klenk and M. Göker (2013). "Genome sequence-based species delimitation with confidence intervals and improved distance functions." BMC Bioinformatics 14 (1): 1-14.

Menes, R. J. and L. Muxí (2002). "Anaerobaculum mobile sp. nov., a novel anaerobic, moderately thermophilic, peptide-fermenting bacterium that uses crotonate as an electron acceptor, and emended description of the genus Anaerobaculum." Int J Syst Evol Microbiol 52 (1): 157164.

Michel, C., M. Brugna, C. Aubert, A. Bernadac and M. Bruschi (2001). "Enzymatic reduction of chromate: comparative studies using sulfate-reducing bacteria." Appl Microbiol Biotechnol 55 (1): 95-100.

Miller, T. L. and C. Lin (2002). "Description of Methanobrevibacter gottschalkii sp. nov., Methanobrevibacter thaueri sp. nov., Methanobrevibacter woesei sp. nov. and Methanobrevibacter wolinii sp. nov." Int J Syst Evol Microbiol 52 (3): 819-822.

Miranda-Tello, E., M. L. Fardeau, C. Joulian, M. Magot, P. Thomas, J. L. Tholozan and B. Ollivier (2007). "Petrotoga halophila sp. nov., a thermophilic, moderately halophilic, fermentative bacterium isolated from an offshore oil well in Congo." Int J Syst Evol Microbiol 57 (1): 40-44.

Miranda-Tello, E., M. L. Fardeau, P. Thomas, F. Ramirez, L. Casalot, J. L. Cayol, J. L. Garcia and B. Ollivier (2004). "Petrotoga mexicana sp. nov., a novel thermophilic, anaerobic and xylanolytic bacterium isolated from an oil-producing well in the Gulf of Mexico." Int J Syst Evol Microbiol 54 (Pt 1): 169-174.

Miroshnichenko, M. L., G. A. Gongadze, A. M. Lysenko and E. A. Bonch-Osmolovskaya (1994). "Desulfurella multipotens sp. nov., a new sulfur-respiring thermophilic eubacterium from Raoul Island (Kermadec archipelago, New Zealand)." Arch Microbiol 161 (1): 88-93.

Miroshnichenko, M. L., N. A. Kostrikina, N. A. Chernyh, N. V. Pimenov, T. P. Tourova, A. N. Antipov, S. Spring, E. Stackebrandt and E. A. Bonch-Osmolovskaya (2003). "Caldithrix abyssi gen. nov., sp. nov., a nitrate-reducing, thermophilic, anaerobic bacterium isolated from a Mid-Atlantic Ridge hydrothermal vent, represents a novel bacterial lineage." Int J Syst Evol Microbiol 53 (Pt 1): 323-329.

Miroshnichenko, M. L., A. V. Lebedinsky, N. A. Chernyh, T. P. Tourova, T. V. Kolganova, S. Spring and E. A. Bonch-Osmolovskaya (2009). "Caldimicrobium rimae gen. nov., sp. nov., an extremely thermophilic, facultatively lithoautotrophic, anaerobic bacterium from the Uzon Caldera, Kamchatka." Int J Syst Evol Microbiol 59 (5): 1040-1044.

Miroshnichenko, M. L., F. A. Rainey, H. Hippe, N. A. Chernyh, N. A. Kostrikina and E. A. BonchOsmolovskaya (1998). "Desulfurella karnchatkensis sp. nov. and Desulfurella propionica sp. nov., new sulfur respiring thermophilic bacteria from Kamchatka thermal environments." Int J Syst Bacteriol 48: 5. 
Miroshnichenko, M. L., F. A. Rainey, M. Rhode and E. A. Bonch-Osmolovskaya (1999). "Hippea maritima gen. nov., sp. nov., a new genus of thermophilic, sulfur-reducing bacterium from submarine hot vents." Int J Syst Bacteriol 49: 6.

Möbius, C. H., I. Demel, A. Schmid, U. Temper, A. Carozzi, C. Buisman, J. Weijma, H. H. M. Rijnaarts, T. L. G. Hendrickx and M. Brockmann (2015). Anwendung für organisch und anorganisch belastete Abwässer anderer Industriebereiche. Anaerobtechnik: Abwasser-, Schlamm- und Reststoffbehandlung, Biogasgewinnung. K.-H. Rosenwinkel, H. Kroiss, N. Dichtl, C.-F. Seyfried and P. Weiland. Berlin, Heidelberg, Springer Berlin Heidelberg: 541601.

Morais-Silva, F. O., A. M. Rezende, C. Pimentel, C. I. Santos, C. Clemente, A. Varela-Raposo, D. M. Resende, S. M. da Silva, L. M. de Oliveira, M. Matos, D. A. Costa, O. Flores, J. C. Ruiz and C. Rodrigues-Pousada (2014). "Genome sequence of the model sulfate reducer Desulfovibrio gigas: a comparative analysis within the Desulfovibrio genus." Microbiologyopen 3 (4): 513-530.

Mori, K., T. Kakegawa, Y. Higashi, K. Nakamura, A. Maruyama and S. Hanada (2004). "Oceanithermus desulfurans sp. nov., a novel thermophilic, sulfur-reducing bacterium isolated from a sulfide chimney in Suiyo Seamount." Int J Syst Evol Microbiol 54 (5): 1561-1566.

Mori, K., H. Kim, T. Kakegawa and S. Hanada (2003). "A novel lineage of sulfate-reducing microorganisms: Thermodesulfobiaceae fam. nov., Thermodesulfobium narugense, gen. nov., sp. nov., a new thermophilic isolate from a hot spring." Extremophiles 7 (4): 283-290.

Mori, K., K. Yamaguchi, Y. Sakiyama, T. Urabe and K. Suzuki (2009). "Caldisericum exile gen. nov., sp. nov., an anaerobic, thermophilic, filamentous bacterium of a novel bacterial phylum, Caldiserica phyl. nov., originally called the candidate phylum OP5, and description of Caldisericaceae fam. nov., Caldisericales ord. nov. and Caldisericia classis nov." Int J Syst Evol Microbiol 59 (11): 2894-2898.

Moser, D. P. and K. H. Nealson (1996). "Growth of the facultative anaerobe Shewanella putrefaciens by elemental sulfur reduction." Appl Environ Microbiol 62 (6): 6.

Myers, C. R. and K. H. Nealson (1988). "Bacterial manganese reduction and growth with manganese oxide as the sole electron acceptor." Science 240 (4857): 1319-1321.

Nakano, S., M. Fukaya and S. Horinouchi (2006). "Putative ABC transporter responsible for acetic acid resistance in Acetobacter aceti." Appl Environ Microbiol 72 (1): 497-505.

Ňancucheo, I. and D. B. Johnson (2012). "Selective removal of transition metals from acidic mine waters by novel consortia of acidophilic sulfidogenic bacteria." Microbial Biotech 5 (1): 3444.

Narasingarao, P. and M. M. Haggblom (2007). "Pelobacter seleniigenes sp. nov., a selenate-respiring bacterium." Int J Syst Evol Microbiol 57 (Pt 9): 1937-1942.

Nazina, T. N., E. P. Rozanova, E. V. Belyakova, A. M. Lysenko, A. B. Poltaraus, T. P. Tourova, G. A. Osipov and S. S. Belyaev (2008). "Description of "Desulfotomaculum nigrificans subsp. salinus" as a New Species, Desulfotomaculum salinum sp. nov." Microbiology 74 (5): 8.

Neculita, C. M., G. J. Zagury and B. Bussière (2007). "Passive treatment of acid mine drainage in bioreactors using sulfate-reducing bacteria." J Environ Qual 36 (1): 1-16.

Nesbø, C. L., D. M. Bradnan, A. Adebusuyi, M. Dlutek, A. K. Petrus, J. Foght, W. F. Doolittle and K. M. Noll (2012). "Mesotoga prima gen. nov., sp. nov., the first described mesophilic species of the Thermotogales." Extremophiles 16 (3): 387-393.

Neuner, A., H. Jannasch, S. Belkin and K. O. Stetter (1990). "Thermococcus litoralis sp. nov.: A new species of extremely thermophilic marine archaebacteria." 153 (2): 205-207. 
Newman, D. K. and R. Kolter (2000). "A role for excreted quinones in extracellular electron transfer." Nature 405 (6782): 94-97.

Ng, K. Y., R. Sawada, S. Inoue, K. Kamimura and T. Sugio (2000). "Purification and some properties of sulfur reductase from the iron-oxidizing bacterium Thiobacillus ferrooxidans NASF-1." Biosci Bioeng 90 (2): 199-203.

Nielsen, M. B., K. U. Kjeldsen and K. Ingvorsen (2006). "Desulfitibacter alkalitolerans gen. nov., sp. nov., an anaerobic, alkalitolerant, sulfite-reducing bacterium isolated from a district heating plant." Int J Syst Evol Microbiol 56 (Pt 12): 2831-2836.

Nunoura, T., H. Oida, M. Miyazaki and Y. Suzuki (2008). "Thermosulfidibacter takaii gen. nov., sp. nov., a thermophilic, hydrogen-oxidizing, sulfur-reducing chemolithoautotroph isolated from a deep-sea hydrothermal field in the Southern Okinawa Trough." Int J Syst Evol Microbiol 58 (3): 659-665.

Nunoura, T., H. Oida, M. Miyazaki, Y. Suzuki, K. Takai and K. Horikoshi (2007). "Marinitoga okinawensis sp. nov., a novel thermophilic and anaerobic heterotroph isolated from a deepsea hydrothermal field, Southern Okinawa Trough." Int J Syst Evol Microbiol 57 (Pt 3): 467-471.

O'Toole, G. A. and R. Kolter (1998). "Flagellar and twitching motility are necessary for Pseudomonas aeruginosa biofilm development." Mol Microbiol 30 (2): 295-304.

Ohmura, N., K. Sasaki, N. Matsumoto and H. Saiki (2002). "Anaerobic respiration using $\mathrm{Fe}^{3+}, \mathrm{S}^{0}$, and $\mathrm{H}_{2}$ in the chemolithoautotrophic bacterium Acidithiobacillus ferrooxidans." J Bacteriol 184 (8): 2081-2087.

Ohmura, N., K. Tsugita, J. I. Koizumi and H. Saika (1996). "Sulfur-binding protein of flagella of Thiobacillus ferrooxidans." J Bacteriol 178 (19): 5776-5780.

Ollivier, B., R. Cord-Ruwisch, E. C. Hatchikian and J. L. Garcia (1988). "Characterization of Desulfovibrio fructosovorans sp. nov." Arch Microbiol 149 (5): 447-450.

Osburn, M. R. and J. P. Amend (2011). "Thermogladius shockii gen. nov., sp. nov., a hyperthermophilic crenarchaeote from Yellowstone National Park, USA." Arch Microbiol 193 (1): 45-52.

Osorio, H., S. Mangold, Y. Denis, I. Ñancucheo, M. Esparza, D. B. Johnson, V. Bonnefoy, M. Dopson and D. S. Holmes (2013). "Anaerobic sulfur metabolism coupled to dissimilatory iron reduction in the extremophile Acidithiobacillus ferrooxidans." Appl Environ Microbiol 79 (7): 2172-2181.

Ouattara, A. S., B. K. Patel, J. L. Cayol, N. Cuzin, A. S. Traore and J. L. Garcia (1999). "Isolation and characterization of Desulfovibrio burkinensis sp. nov. from an African ricefield, and phylogeny of Desulfovibrio alcoholivorans." Int J Syst Bacteriol 49 (Pt 2): 639-643.

Ouattara, A. S., A. S. Traore and J.-L. Garcia (1992). "Characterization of Anaerovibrio burkinabensis sp. nov., a lactate-fermenting bacterium isolated from rice field soils." Int J Syst Evol Microbiol 42 (3): 390-397.

Pagani, I., A. Lapidus, M. Nolan, S. Lucas, N. Hammon, S. Deshpande, J. F. Cheng, O. Chertkov, K. Davenport, R. Tapia, C. Han, L. Goodwin, S. Pitluck, K. Liolios, K. Mavromatis, N. Ivanova, N. Mikhailova, A. Pati, A. Chen, K. Palaniappan, M. Land, L. Hauser, Y. J. Chang, C. D. Jeffries, J. C. Detter, E. Brambilla, K. P. Kannan, O. D. Djao, M. Rohde, R. Pukall, S. Spring, M. Goker, J. Sikorski, T. Woyke, J. Bristow, J. A. Eisen, V. Markowitz, P. Hugenholtz, N. C. Kyrpides and H. P. Klenk (2011). "Complete genome sequence of Desulfobulbus propionicus type strain (1pr3)." Stand Genomic Sci 4 (1): 100-110.

Palmieri, G., M. Di Palo, A. Scaloni, S. Orrù, G. Marino and G. Sannia (1996). "Glutamate-1semialdehyde aminotransferase from Sulfolobus solfataricus." Biochem J 320(2): 541-545. 
Pan-Hou, H., M. Kiyono, H. Omura, T. Omura and G. Endo (2002). "Polyphosphate produced in recombinant Escherichia coli confers mercury resistance." FEMS Microbiol Lett 207 (2): 159-164.

Pelsh, A. O. (1936). "Hydrobiology of Karabugaz bay of the Caspian sea." Trudy Solyan Laboratory Akademie Nauk 5 (49): 31.

Pender, S., M. Toomey, M. Carton, D. Eardly, J. W. Patching, E. Colleran and V. O'Flaherty (2004). "Long-term effects of operating temperature and sulphate addition on the methanogenic community structure of anaerobic hybrid reactors." Water Res 38 (3): 619-630.

Pereira, I. A. C., A. Ramos, F. Grein, M. Marques, S. Da Silva and S. Venceslau (2011). "A comparative genomic analysis of energy metabolism in sulfate-reducing bacteria and archaea." Front Microbiol 2 (69).

Pereira, P. M., Q. He, F. M. A. Valente, A. V. Xavier, J. Zhou, I. A. C. Pereira and R. O. Louro (2008). "Energy metabolism in Desulfovibrio vulgaris Hildenborough: insights from transcriptome analysis." Antonie van Leeuwenhoek 93 (4): 347-362.

Perevalova, A. A., V. A. Svetlichny, I. V. Kublanov, N. A. Chernyh, N. A. Kostrikina, T. P. Tourova, B. B. Kuznetsov and E. A. Bonch-Osmolovskaya (2005). "Desulfurococcus fermentans sp. nov., a novel hyperthermophilic archaeon from a Kamchatka hot spring, and emended description of the genus Desulfurococcus." Int J Syst Evol Microbiol 55 (3): 995-999.

Pfennig, N. (1975). "The phototrophic bacteria and their role in the sulfur cycle." Plant Soil 43 (1-3): 1-16.

Pfennig, N. and H. Biebl (1976). "Desulfuromonas acetoxidans gen. nov. and sp. nov., a new anaerobic, sulfur-reducing, acetate-oxidizing bacterium." Arch Mikrobiol 110 (1): 10.

Pihl, T. D., L. K. Black, B. A. Schulman and R. J. Maier (1992). "Hydrogen-oxidizing electron transport components in the hyperthermophilic archaebacterium Pyrodictium brockii." $\underline{\mathrm{J}}$ Bacteriol 174 (1): 137-143.

Pihl, T. D. and R. J. Maier (1991). "Purification and characterization of the hydrogen uptake hydrogenase from the hyperthermophilic archaebacterium Pyrodictium brockii." J Bacteriol 173 (6): 1839-1844.

Pihl, T. D., R. N. Schicho, L. K. Black, B. A. Schulman, R. J. Maier and R. M. Kelly (1990). "Hydrogen-sulfur autotrophy in the hyperthermophilic archaebacterium, Pyrodictium brockii." Biotechnol Genet Eng Rev 8 (1): 345-378.

Pihl, T. D., R. N. Schicho, R. M. Kelly and R. J. Maier (1989). "Characterization of hydrogen-uptake activity in the hyperthermophile Pyrodictium brockii." Proc Natl Acad Sci USA 86 (1): 138-141.

Podosokorskaya, O. A., A. Y. Merkel, T. V. Kolganova, N. A. Chernyh, M. L. Miroshnichenko, E. A. Bonch-Osmolovskaya and I. V. Kublanov (2011). "Fervidobacterium riparium sp. nov., a thermophilic anaerobic cellulolytic bacterium isolated from a hot spring." Int J Syst Evol Microbiol 61(Pt 11): 2697-2701.

Postec, A., C. L. Breton, M. L. Fardeau, F. Lesongeur, P. Pignet, J. Querellou, B. Ollivier and A. Godfroy (2005). "Marinitoga hydrogenitolerans sp. nov., a novel member of the order Thermotogales isolated from a black smoker chimney on the Mid-Atlantic Ridge." Int J Syst Evol Microbiol 55 (3): 1217-1221.

Prokofeva, M. I., N. A. Kostrikina, T. V. Kolganova, T. P. Tourova, A. M. Lysenko, A. V. Lebedinsky and E. A. Bonch-Osmolovskaya (2009). "Isolation of the anaerobic thermoacidophilic crenarchaeote Acidilobus saccharovorans sp. nov. and proposal of Acidilobales ord. nov., including Acidilobaceae fam. nov. and Caldisphaeraceae fam. nov." Int J Syst Evol Microbiol 59 (12): 3116-3122. 
Prokofeva, M. I., M. L. Miroshnichenko, N. A. Kostrikina, N. A. Chernyh, B. B. Kuznetsov, T. P. Tourova and E. A. Bonch-Osmolovskaya (2000). "Acidilobus aceticus gen. nov., sp. nov., a novel anaerobic thermoacidophilic archaeon from continental hot vents in Kamchatka." Int J Syst Evol Microbiol 50 (6): 2001-2008.

Pudritz, R., P. H. and J. S. (2007). Planetary systems and the origins of life. Cambridge, Cambridge University Press.

Puranamaneewiwat, N., S. Tajima and H. Niamsup (2006). "Proteomic analysis of Bradyrhizobium japonicum USDA110 in acidic condition." Chiang Mai J Sci 33 (3): 12.

Quast, C., E. Pruesse, P. Yilmaz, J. Gerken, T. Schweer, P. Yarza, J. Peplies and F. O. Glockner (2013). "The SILVA ribosomal RNA gene database project: improved data processing and web-based tools." Nucleic Acids Research 41 (Database issue): D590-596.

Rabus, R., T. A. Hansen and F. Widdel (2013). Dissimilatory sulfate- and sulfur-reducing prokaryotes. The prokaryotes: prokaryotic physiology and biochemistry. E. Rosenberg, E. F. DeLong, S. Lory, E. Stackebrandt and F. Thompson. Berlin, Heidelberg, Springer Berlin Heidelberg: 309-404.

Rainey, F. A. and B. Hollen (2005). Class IV. Deltaproteobacteria class nov. Bergey's Manual® of Systematic Bacteriology, Springer: 923-924.

Rainey, F. A. and E. Stackebrandt (1993). "Transfer of the type species of the genus Themobacteroides to the genus Themoanaerobacter as Themoanaerobacter acetoethylicus (Ben-Bassat and Zeikus 1981) comb. nov., description of Coprothemobacter gen. nov., and reclassification of Themobacteroides proteolyticus as Coprothennobacter proteolyticus (Ollivier et al. 1985) comb. nov. ." Int J Syst Evol Microbiol 43 (4): 3.

Ramamoorthy, S., H. Sass, H. Langner, P. Schumann, R. M. Kroppenstedt, S. Spring, J. Overmann and R. F. Rosenzweig (2006). "Desulfosporosinus lacus sp. nov., a sulfate-reducing bacterium isolated from pristine freshwater lake sediments." Int J Syst Evol Microbiol $\mathbf{5 6}$ (Pt 12): 2729-2736.

Rapp, G. (2009). Introduction and History. Archaeomineralogy. Berlin, Heidelberg, Springer Berlin Heidelberg: 1-16.

Ravot, G., L. Casalot, B. Ollivier, G. Loison and M. Magot (2005). "rdlA, a new gene encoding a rhodanese-like protein in Halanaerobium congolense and other thiosulfate-reducing anaerobes." Res Microbiol 156 (10): 1031-1038.

Ravot, G., M. Magot, B. Ollivier, B. K. C. Patel, E. Ageron, P. A. D. Grimont, P. Thomas and J. L. Garcia (1997). "Haloanaerobium congolense sp. nov., an anaerobic, moderately halophilic, thiosulfate- and sulfur-reducing bacterium from an African oil field." FEMS Microbiol Lett 147(1): 81-88.

Ravot, G., B. Ollivier, M. Magot, B. Patel, J. Crolet, M. Fardeau and J. Garcia (1995). "Thiosulfate eduction, an important physiological feature shared by members of the order Thermotogales." Appl Environ Microbiol 61 (5): 2053-2055.

Rees, G. N., B. K. C. Patel, G. S. Grassia and A. J. Sheehy (1997). "Anaerobaculum thermoterrenum gen. nov., sp. nov., a novel, thermophilic bacterium which ferments citrate." Int J Syst Bacteriol 47 (1): 150-154.

Reguera, G., K. D. McCarthy, T. Mehta, J. S. Nicoll, M. T. Tuominen and D. R. Lovley (2005). "Extracellular electron transfer via microbial nanowires." Nature 435 (7045): 1098-1101.

Reguera, G., K. D. McCarthy, T. Mehta, J. S. Nicoll, M. T. Tuominen and D. R. Lovley (2005). "Extracellular electron transfer via microbial nanowires." 435 (7045): 1098-1101.

Richard, H. T. and J. W. Foster (2003). "Acid resistance in Escherichia coli." Adv Appl Microbiol 52: 167-186. 
Richardson, D. J. (2000). "Bacterial respiration: a flexible process for a changing environment." Microbiology 146 ( Pt 3): 551-571.

Richter, K., M. Schicklberger and J. Gescher (2012). "Dissimilatory reduction of extracellular electron acceptors in anaerobic respiration." Appl Environ Microbiol 78 (4): 913-921.

Ringel, M., R. Gross, T. Krafft, A. Kröger and R. Schauder (1996). "Growth of Wolinella succinogenes with elemental sulfur in the absence of polysulfide." Arch Microbiol 165 (1): 62-64.

Robertson, W. J., J. P. Bowman, P. D. Franzmann and B. J. Mee (2001). "Desulfosporosinus meridiei sp. nov., a spore-forming sulfate-reducing bacterium isolated from gasolene-contaminated groundwater." Int J Syst Bacteriol 51: 8.

Rocha, E. R., T. Selby, J. P. Coleman and C. J. Smith (1996). "Oxidative stress response in an anaerobe, Bacteroides fragilis: a role for catalase in protection against hydrogen peroxide." J Bacteriol 178 (23): 6895-6903.

Rohwerder, T. and W. Sand (2003). "The sulfane sulfur of persulfides is the actual substrate of the sulfur-oxidizing enzymes from Acidithiobacillus and Acidiphilium spp." Microbiology 149 (7): 1699-1710.

Roman, P., M. F. M. Bijmans and A. J. H. Janssen (2014). "Quantification of individual polysulfides in lab-scale and full-scale desulfurisation bioreactors." Environ Chem 11 (6): 702-708.

Romney, M., S. Cheung and V. Montessori (2001). "Erysipelothrix rhusiopathiae endocarditis and presumed osteomyelitis." Can J Infect Dis Med Microbiol 12 (4): 254-256.

Roof, J. G. (1971). "Solubility of sulfur in hydrogen sulfide and in carbon disulfide at elevated temperature and pressure C1 - SPE." Soc Petrol Eng J 11 (3): 5.

Rosen, B. P. (2002). "Biochemistry of arsenic detoxification." FEBS Lett 529 (1): 86-92.

Rosenberg, E., E. DeLong, S. Lory, E. Stackebrandt, F. Thompson, R. Rabus, T. A. Hansen and F. Widdel (2013). Dissimilatory sulfate- and sulfur-reducing prokaryotes. The Prokaryotes, Springer Berlin Heidelberg: 309-404.

Saeed, M. O., M. M. Alamoudi and A.-H. A. H. (1987). "Pseudornonas associated with disease in cultured rabbit-fish Siganus rivulatus in the Red Sea." Dis aquat org 3: 4.

Sakurai, H., T. Ogawa, M. Shiga and K. Inoue (2010). "Inorganic sulfur oxidizing system in green sulfur bacteria." Photosynth Res 104 (2-3): 163-176.

Sallam, A. and A. Steinbüchel (2009). "Clostridium sulfidigenes sp. nov., a mesophilic, proteolytic, thiosulfate- and sulfur-reducing bacterium isolated from pond sediment." Int J Syst Evol Microbiol 59 (7): 1661-1665.

Sampaio, R. M. M., R. A. Timmers, Y. Xu, K. J. Keesman and P. N. L. Lens (2009). "Selective precipitation of $\mathrm{Cu}$ from $\mathrm{Zn}$ in a $\mathrm{pS}$ controlled continuously stirred tank reactor." J Hazard Mater 165 (1): 256-265.

Sánchez-Andrea, I., K. Knittel, R. Amann, R. Amils and J. L. Sanz (2012). "Quantification of Tinto River sediment microbial communities: importance of sulfate-reducing bacteria and their role in attenuating acid mine drainage." Appl Environ Microbiol 78 (13): 4638-4645.

Sánchez-Andrea, I., N. Rodriguez, R. Amils and J. L. Sanz (2011). "Microbial diversity in anaerobic sediments at Rio Tinto, a naturally acidic environment with a high heavy metal content." Appl Environ Microbiol 77 (17): 6085-6093.

Sánchez-Andrea, I., J. L. Sanz, M. F. Bijmans and A. J. Stams (2014). "Sulfate reduction at low pH to remediate acid mine drainage." J Hazard Mater 269: 98-109.

Sánchez-Andrea, I., J. L. Sanz and A. J. Stams (2014). "Microbacter margulisiae gen. nov., sp. nov., a propionigenic bacterium isolated from sediments of an acid rock drainage pond." Int $\mathrm{J}$ Syst Evol Microbiol 64 (Pt 12): 3936-3942. 
Sánchez-Andrea, I., A. J. Stams, R. Amils and J. L. Sanz (2013). "Enrichment and isolation of acidophilic sulfate-reducing bacteria from Tinto River sediments." Environ Microbiol Rep 5(5): 672-678.

Sánchez-Andrea, I., A. J. Stams, S. Hedrich, I. Nancucheo and D. B. Johnson (2015). "Desulfosporosinus acididurans sp. nov.: an acidophilic sulfate-reducing bacterium isolated from acidic sediments." Extremophiles 19 (1): 39-47.

Sánchez-Andrea, I., A. J. M. Stams, S. Hedrich, I. Ňancucheo and D. B. Johnson (2015). "Desulfosporosinus acididurans sp. nov.: an acidophilic sulfate-reducing bacterium isolated from acidic sediments." Extremophiles 19 (1): 39-47.

Sánchez-Andrea, I., A. J. M. Stams, J. Weijma, P. Gonzalez Contreras, H. Dijkman, R. A. Rozendal and D. B. Johnson (2016). "A case in support of implementing innovative bio-processes in the metal mining industry." FEMS Microbiol Lett 363 (11).

Sánchez-Andrea, I., D. Triana and J. L. Sanz (2012). "Bioremediation of acid mine drainage coupled with domestic wastewater treatment." Water Sci Technol 66 (11): 2425-2431.

Sanford, R. A., J. R. Cole, F. E. Löffler and J. M. Tiedje (1996). "Characterization of Desulfitobacterium chlororespirans sp. nov., which grows by coupling the oxidation of lactate to the reductive dechlorination of 3-chloro-4-hydroxybenzoate." Appl Environ Microbiol 62 (10): 9.

Santos, A. A., S. S. Venceslau, F. Grein, W. D. Leavitt, C. Dahl, D. T. Johnston and I. A. Pereira (2015). "A protein trisulfide couples dissimilatory sulfate reduction to energy conservation." Science 350 (6267): 1541-1545.

Sapra, R., K. Bagramyan and M. W. W. Adams (2003). "A simple energy-conserving system: Proton reduction coupled to proton translocation." Proc Natl Acad Sci USA 100 (13): 7545-7550.

Sarret, G., L. Avoscan, M. Carrière, R. Collins, N. Geoffroy, F. Carrot, J. Covès and B. Gouget (2005). "Chemical Forms of Selenium in the metal-resistant bacterium Ralstonia metallidurans $\mathrm{CH} 34$ exposed to selenite and selenate." Appl Environ Microbiol 71 (5): 2331-2337.

Sass, H. and H. Cypionka (2004). "Isolation of sulfate-reducing bacteria from the terrestrial deep subsurface and description of Desulfovibrio cavernae sp. nov." Syst Appl Microbiol 27 (5): 541-548.

Schauder, R. and E. Müller (1993). "Polysulfide as a possible substrate for sulfur-reducing bacteria." Arch Microbiol 160 (5): 377-382.

Schink, B. (1984). " Fermentation of 2,3-butanediol by Pelobacter carbinolicus sp. nov. and Pelobacter propionicus sp. nov., and evidence for propionate formation from C2 compounds. " Arch Microbiol 137: 9.

Schippers, A. and W. Sand (1999). "Bacterial leaching of metal sulfides proceeds by two indirect mechanisms via thiosulfate or via polysulfides and sulfur." Appl Environ Microbiol 65 (1): 319-321.

Schmid, J., V. Sieber and B. Rehm (2015). "Bacterial exopolysaccharides: biosynthesis pathways and engineering strategies." Front Microbiol 6: 496.

Schmitz, R. A., E. A. Bonch-Osmolovskaya and R. K. Thauer (1990). "Different mechanisms of acetate activation in Desulfurella acetivorans and Desulfuromonas acetoxidans." $\underline{\text { Arch }}$ Microbiol 154 (3): 274-279.

Scholz-Muramatsu, H., A. Neumann, M. Meßmer, E. Moore and G. Diekert (1995). "Isolation and characterization of Dehalospirillum multivorans gen. nov., sp. nov., a tetrachloroetheneutilizing, strictly anaerobic bacterium." Arch Microbiol 163 (1): 48-56. 
Schröder, I., A. Kröger and J. M. Macy (1988). "Isolation of the sulphur reductase and reconstitution of the sulphur respiration of Wolinella succinogenes." Arch Microbiol 149 (6): 572-579.

Scott, D. T., D. M. McKnight, E. L. Blunt-Harris, S. E. Kolesar and D. R. Lovley (1998). "Quinone moieties act as electron acceptors in the reduction of humic substances by humics-reducing microorganisms." Environ Sci Technol 32 (19): 2984-2989.

Segerer, A., T. A. Langworthy and K. O. Stetter (1988). "Thermoplasma acidophilum and Thermoplasma volcanium sp. nov. from Solfatara Fields." Syst Appl Microbiol 10 (2): 161171.

Segerer, A., A. Neuner, J. K. Kristjansson and K. O. Stetter (1986). "Acidianus infernus gen. nov., sp. nov., and Acidianus brierleyi Comb. nov.: Facultatively Aerobic, Extremely Acidophilic Thermophilic Sulfur-Metabolizing Archaebacteria." International Journal of Systematic Bacteriology 36(4): 559-564.

Segerer, A., A. Neuner, J. K. Kristjansson and K. O. Stetter (1986). "Acidianus infernus gen. nov., sp. nov., and Acidianus brierleyi comb. nov.: Facultatively aerobic, extremely acidophilic thermophilic sulfur-metabolizing archaebacteria." Int J Syst Bacteriol 36 (4): 559-564.

Segerer, A. H., A. Trincone, M. Gahrtz and K. O. Stetter (1991). "Stygiolobus azoricus gen. nov., sp. nov. represents a novel genus of anaerobic, extremely thermoacidophilic archaebacteria of the order Sulfolobales." Int J Syst Bacteriol 41 (4): 495-501.

Shelobolina, E. S., H. A. Vrionis, R. H. Findlay and D. R. Lovley (2008). "Geobacter uraniireducens sp. nov., isolated from subsurface sediment undergoing uranium bioremediation." Int J Syst Evol Microbiol 58 (5): 1075-1078.

Sheng, Y., I. A. Abreu, D. E. Cabelli, M. J. Maroney, A.-F. Miller, M. Teixeira and J. S. Valentine (2014). "Superoxide dismutases and superoxide reductases." Chem Rev 114 (7): 3854-3918.

Shimada, H., N. Nemoto, Y. Shida, T. Oshima and A. Yamagishi (2008). "Effects of pH and temperature on the composition of polar lipids in Thermoplasma acidophilum HO-62." $\mathrm{J}$ Bacteriol 190 (15): 5404-5411.

Sierra-Alvarez, R., S. Karri, S. Freeman and J. A. Field (2006). "Biological treatment of heavy metals in acid mine drainage using sulfate reducing bioreactors." Water Sci Technol 54 (2): 179185.

Singleton, D. R. and D. W. Smith (1988). "Improved assay for rhodanese in Thiobacillus spp." Appl Environ Microbiol 54 (11): 2866-2867.

Slonczewski, J. L., R. M. Macnab, J. R. Alger and A. M. Castle (1982). "Effects of pH and repellent tactic stimuli on protein methylation levels in Escherichia coli." J Bacteriol 152 (1): 384399.

Sorokin, D. Y., E. N. Detkova and G. Muyzer (2010). "Propionate and butyrate dependent bacterial sulfate reduction at extremely haloalkaline conditions and description of Desulfobotulus alkaliphilus sp. nov." Extremophiles 14 (1): 71-77.

Sorokin, D. Y., M. Foti, B. J. Tindall and G. Muyzer (2007). "Desulfurispirillum alkaliphilum gen. nov. sp. nov., a novel obligately anaerobic sulfur- and dissimilatory nitrate-reducing bacterium from a full-scale sulfide-removing bioreactor." Extremophiles 11 (2): 363-370.

Sorokin, D. Y. and G. Muyzer (2010). "Haloalkaliphilic spore-forming sulfidogens from soda lake sediments and description of Desulfitispora alkaliphila gen. nov., sp. nov." Extremophiles 14 (3): 313-320.

Sorokin, D. Y., T. P. Tourova, T. V. Kolganova, E. N. Detkova, E. A. Galinski and G. Muyzer (2011). "Culturable diversity of lithotrophic haloalkaliphilic sulfate-reducing bacteria in soda lakes and the description of Desulfonatronum thioautotrophicum sp. nov., 
Desulfonatronum thiosulfatophilum sp. nov., Desulfonatronovibrio thiodismutans sp. nov., and Desulfonatronovibrio magnus sp. nov." Extremophiles 15 (3): 391-401.

Sorokin, D. Y., T. P. Tourova, M. Mußmann and G. Muyzer (2008). "Dethiobacter alkaliphilus gen. nov. sp. nov., and Desulfurivibrio alkaliphilus gen. nov. sp. nov.: two novel representatives of reductive sulfur cycle from soda lakes." Extremophiles 12 (3): 431-439.

Sousa, F. J. R., L. M. T. R. Lima, A. B. F. Pacheco, C. L. P. Oliveira, I. Torriani, D. F. Almeida, D. Foguel, J. L. Silva and R. Mohana-Borges (2006). "Tetramerization of the LexA repressor in solution: implications for gene regulation of the E. coli SOS System at Acidic pH." J Mol Biol 359 (4): 1059-1074.

Stackebrandt, E., P. Schumann, E. Schüler and H. Hippe (2003). "Reclassification of Desulfotomaculum auripigmentum as Desulfosporosinus auripigmenti corrig., comb. nov." Int J Syst Evol Microbiol 53 (5): 1439-1443.

Stams, A. J. M., J. B. Van Dijk, C. Dijkema and C. M. Plugge (1993). "Growth of syntrophic propionate-oxidizing bacteria with fumarate in the absence of methanogenic bacteria." Appl Environ Microbiol 59 (4): 1114-1119.

Steed, V. S., M. T. Suidan, M. Gupta, T. Miyahara, C. M. Acheson and G. D. Sayles (2000). "Development of a sulfate-reducing biological process to remove heavy metals from acid mine drainage." Water Environ Res 72 (5): 530-535.

Stetter, K. O. (1996). "Hyperthermophilic prokaryotes." FEMS Microbiol Rev 18: 10.

Stetter, K. O., G. Fiala, G. Huber, R. Huber and A. Segerer (1990). "Hyperthermophilic microorganisms." FEMS Microbiol Lett 75 (2-3): 117-124.

Stetter, K. O. and G. Gaag (1983). "Reduction of molecular sulphur by methanogenic bacteria." Nature 305 (5932): 309-311.

Stetter, K. O., R. Huber, E. Blochl, M. Kurr, R. D. Eden, M. Fielder, H. Cash and I. Vance (1993). "Hyperthermophilic archaea are thriving in deep North Sea and Alaskan oil reservoirs." Nature 365 (6448): 743-745.

Steudel, R. (2000). The sulfur cycle. Environmental technologies to treat sulfur pollution. P. N. L. Lens and L. Hulshof. London, IWA Publishing: 1-31.

Steudel, R. (2003). Inorganic Polysulfides S n 2- and Radical Anions S n --. Elemental sulfur and sulfur-rich compounds II. R. Steudel. Berlin, Heidelberg, Springer Berlin Heidelberg: 127152.

Steudel, R. and B. Eckert (2003). Solid sulfur allotropes sulfur allotropes. Elemental sulfur and sulfur-rich compounds I, Springer Berlin Heidelberg. 230: 1-80.

Steudel, R., T. Göbel and G. Holdt (1989). "The molecular nature of the hydrophilic sulfur prepared from aqueous sulfide and sulfite (selmi sulfur sol)." Zeitschrift für Naturforschung. B 44(5): 526-530.

Steudel, R., W. E. Kleinjan, A. de Keizer and A. J. H. Janssen (2003). Biologically produced sulfur. Elemental sulfur and sulfur-rich compounds I, Springer Berlin Heidelberg. 230: 167-188.

Stoffels, L., M. Krehenbrink, B. C. Berks and G. Unden (2012). "Thiosulfate reduction in Salmonella enterica Is driven by the proton motive force." J Bacteriol 194 (2): 475-485.

Stolz, J. F., D. J. Ellis, J. S. Blum, D. Ahmann, D. R. Lovley and R. S. Oremland (1999). "Note: Sulfurospirillum barnesii sp. nov. and Sulfurospirillum arsenophilum sp. nov., new members of the Sulfurospirillum clade of the E-Proteobacteria." Int J Syst Bacteriol 49 (3): $1177-1180$.

Straub, K. L. and B. E. Buchholz-Cleven (2001). "Geobacter bremensis sp. nov. and Geobacter pelophilus sp. nov., two dissimilatory ferric-iron-reducing bacteria." Int J Syst Evol Microbiol 51 (5): 1805-1808. 
Surkov, A. V., M. E. Bottcher and J. Kuever (2000). "Stable sulfur isotope fractionation during the reduction of thiosulfate by Dethiosulfovibrio russensis." Arch Microbiol 174 (6): 448-451.

Surkov, A. V., G. A. Dubinina, A. M. Lysenko, F. O. Glöckner and J. Kuever (2001). "Dethiosulfovibrio russensis sp. nov., Dethosulfovibrio marinus $\mathrm{sp}$. nov. and Dethosulfovibrio acidaminovorans sp. nov., novel anaerobic, thiosulfate- and sulfurreducing bacteria isolated from 'Thiodendron' sulfur mats in different saline environments." Int J Syst Evol Microbiol 51 (2): 327-337.

Suzuki, I., D. Lee, B. Mackay, L. Harahuc and J. K. Oh (1999). "Effect of various ions, pH, and osmotic pressure on oxidation of elemental sulfur by Thiobacillus thiooxidans." Appl Environ Microbiol 65 (11): 5163-5168.

Suzuki, I., D. Lee, B. Mackay, L. Harahuc and J. K. Oh (1999). "Effect of Various Ions, pH, and osmotic pressure on oxidation of elemental sulfur by Thiobacillus thiooxidans." Appl Environ Microbiol 65 (11): 5163-5168.

Svetlichnyi, V. A., A. I. Slesarev, T. P. Svetlichnaya and G. A. Zavarzin (1987). "Caldococcus litoralis, gen. nov. sp. nov. - a new marine, extremely thermophilic, sulfur-reducing archaebacterium " Mikrobiologiya 56: 8.

Swenson, J. M., R. R. Facklam and C. Thornsberry (1990). "Antimicrobial susceptibility of vancomycin-resistant Leuconostoc, Pediococcus, and Lactobacillus species." Antimicrob Agents Chemother 34 (4): 543-549.

Takahashi, Y., K. Suto and C. Inoue (2010). "Polysulfide reduction by Clostridium relatives isolated from sulfate-reducing enrichment cultures." J Biosci Bioeng 109 (4): 372-380.

Takai, K., A. Inoue and K. Horikoshi (2002). "Methanothermococcus okinawensis sp. nov., a thermophilic, methane-producing archaeon isolated from a Western Pacific deep-sea hydrothermal vent system." Int J Syst Evol Microbiol 52 (Pt 4): 1089-1095.

Takai, K., H. Kobayashi, K. H. Nealson and K. Horikoshi (2003). "Deferribacter desulfuricans sp. nov., a novel sulfur-, nitrate- and arsenate-reducing thermophile isolated from a deep-sea hydrothermal vent." Int J Syst Evol Microbiol 53 (3): 839-846.

Takai, K., S. Nakagawa, Y. Sako and K. Horikoshi (2003). "Balnearium lithotrophicum gen. nov., sp. nov., a novel thermophilic, strictly anaerobic, hydrogen-oxidizing chemolithoautotroph isolated from a black smoker chimney in the Suiyo Seamount hydrothermal system." Int J Syst Evol Microbiol 53 (Pt 6): 1947-1954.

Takai, K., A. Sugai, T. Itoh and K. Horikoshi (2000). "Palaeococcus ferrophilus gen. nov., sp. nov., a barophilic, hyperthermophilic archaeon from a deep-sea hydrothermal vent chimney." Int J Syst Evol Microbiol 50 (Pt 2): 489-500.

Takakuwa, S., T. Fujimori and H. Iwasaki (1979). "Some properties of cell-sulfur adhesion in Thiobacillus thiooxidans." J Gen Appl Microbiol 25 (1): 21-29.

Tang, K., V. Baskaran and M. Nemati (2009). "Bacteria of the sulphur cycle: An overview of microbiology, biokinetics and their role in petroleum and mining industries." Biochem Eng J 44 (1): 73-94.

Tardy-Jacquenod, C., M. Magot, F. Laigret, M. Kaghad, B. K. Patel, J. Guezennec, R. Matheron and P. Caumette (1996). "Desulfovibrio gabonensis sp. nov., a new moderately halophilic sulfate-reducing bacterium isolated from an oil pipeline." Int J Syst Bacteriol 46 (3): 710715 .

Tebo, B. M. and A. Y. Obraztsova (1998). "Sulfate-reducing bacterium grows with Cr(VI), U(VI), Mn(IV), and Fe(III) as electron acceptors." FEMS Microbiol Lett 162 (1): 193-198. 
Tekerlekopoulou, A. G., G. Tsiamis, E. Dermou, S. Siozios, K. Bourtzis and D. V. Vayenas (2010). "The effect of carbon source on microbial community structure and $\mathrm{Cr}(\mathrm{VI})$ reduction rate." Biotechnol Bioeng 107 (3): 478-487.

Thabet, O. B. D., T. Wafa, K. Eltaief, J. L. Cayol, M. Hamdi, G. Fauque and M. L. Fardeau (2011). "Desulfovibrio legallis sp. nov.: A moderately halophilic, sulfate-reducing bacterium isolated from a wastewater digestor in Tunisia." Curr Microbiol 62 (2): 486-491.

Thamdrup, B., K. Finster, J. W. Hansen and F. Bak (1993). "Bacterial disproportionation of elemental sulfur coupled to chemical reduction of iron or manganese." Appl Environ Microbiol 59 (1): 101-108.

Thamdrup, B., K. Finster, J. W. Hansen and F. Bak (1993). "Bacterial disproportionation of elemental sulfur coupled to chemical reduction of iron or manganese." Appl Environ Microbiol 59 (1): 101-108.

Thauer, R. K., K. Jungermann and K. Decker (1977). "Energy conservation in chemotrophic anaerobic bacteria." Bact. Rev. 41: 100-180.

Thompson, S. A. and M. J. Blaser (1995). "Isolation of the Helicobacter pylori recA gene and involvement of the recA region in resistance to low pH." Infect Immun 63 (6): 2185-2193.

Trinkerl, M., A. Breunig, R. Schauder and H. König (1990). "Desulfovibrio termitidis sp. nov., a carbohydrate-degrading sulfate-reducing bacterium from the hindgut of a termite." Syst Appl Microbiol 13 (4): 372-377.

Tsukamoto, T. K., H. A. Killion and G. C. Miller (2004). "Column experiments for microbiological treatment of acid mine drainage: low-temperature, low-pH and matrix investigations." Water Res 38 (6): 1405-1418.

Tuovinen, O. H. (1979). "A method for the preparation of solidified colloidal sulphur media." Zentralblatt für Bakteriologie, Parasitenkunde, Infektionskrankheiten und Hygiene. Zweite Naturwissenschaftliche Abteilung: Mikrobiologie der Landwirtschaft, der Technologie und des Umweltschutzes 134 (1): 108-109.

Tuttle, J. H. and P. R. Dugan (1976). "Inhibition of growth, iron, and sulfur oxidation in Thiobacillus ferrooxidans by simple organic compounds." Can J Microbiol 22 (5): 719-730.

Tyson, G. W., J. Chapman, P. Hugenholtz, E. E. Allen, R. J. Ram, P. M. Richardson, V. V. Solovyev, E. M. Rubin, D. S. Rokhsar and J. F. Banfield (2004). "Community structure and metabolism through reconstruction of microbial genomes from the environment." Nature 428 (6978): $37-43$.

Unden, G. and J. Bongaerts (1997). "Alternative respiratory pathways of Escherichia coli: energetics and transcriptional regulation in response to electron acceptors." Biochim Biophys Acta 1320 (3): 217-234.

Unden, G. and P. Dunnwald (2008). "The aerobic and anaerobic respiratory chain of Escherichia coli and Salmonella enterica: Enzymes and energetics." EcoSal Plus 3 (1).

Utgikar, V. P., S. M. Harmon, N. Chaudhary, H. H. Tabak, R. Govind and J. R. Haines (2002). "Inhibition of sulfate-reducing bacteria by metal sulfide formation in bioremediation of acid mine drainage." Environ Toxicol 17 (1): 40-48.

Utkin, I., C. R. Woese and J. Wiegel (1994). "Isolation and characterization of Desulfitobacterium dehalogenans gen. nov., sp. nov., an anaerobic bacterium which reductively dechlorinates chlorophenolic compounds." Int J Syst Bacteriol 44 (4): 612-619.

Vallero, M. V. G. (2003). Sulfate reducing processes at extreme salinity and temperature. extending its application window, Wageningen University, 224. 
van der Veen, S., S. van Schalkwijk, D. Molenaar, W. M. de Vos, T. Abee and M. H. J. Wells-Bennik (2010). "The SOS response of Listeria monocytogenes is involved in stress resistance and mutagenesis." Microbiology 156 (2): 374-384.

van Gelder, A. H., D. Z. Sousa, W. I. Rijpstra, J. S. Damste, A. J. Stams and I. Sánchez-Andrea (2014). "Ercella succinigenes gen. nov., sp. nov., an anaerobic succinate-producing bacterium." Int J Syst Evol Microbiol 64 (Pt 7): 2449-2454.

Van Lier, J. B., K. C. Grolle, C. T. Frijters, A. J. Stams and G. Lettinga (1993). "Effects of acetate, propionate, and butyrate on the thermophilic anaerobic degradation of propionate by methanogenic sludge and defined cultures." Appl Environ Microbiol 59 (4): 1003-1011.

van Niel, E. W., P. A. Claassen and A. J. Stams (2003). "Substrate and product inhibition of hydrogen production by the extreme thermophile, Caldicellulosiruptor saccharolyticus." Biotechnol Bioeng 81 (3): 255-262.

Vandieken, V., C. Knoblauch and B. B. Jørgensen (2006). "Desulfovibrio frigidus sp. nov. and Desulfovibrio ferrireducens sp. nov., psychrotolerant bacteria isolated from Arctic fjord sediments (Svalbard) with the ability to reduce Fe(III)." Int J Syst Evol Microbiol 56 (4): 681-685.

Veeken, A. H. M. and W. H. Rulkens (2003). "Innovative developments in the selective removal and reuse of heavy metals from wastewaters." Water Sci Technol 47 (10): 8.

Vera, M., A. Schippers and W. Sand (2013). "Progress in bioleaching: fundamentals and mechanisms of bacterial metal sulfide oxidation-part A." Appl Microbiol Biotechnol 97 (17): 7529-7541.

Vetriani, C., M. D. Speck, S. V. Ellor, R. A. Lutz and V. Starovoytov (2004). "Thermovibrio ammonificans sp. nov., a thermophilic, chemolithotrophic, nitrate-ammonifying bacterium from deep-sea hydrothermal vents." Int J Syst Evol Microbiol 54 (1): 175-181.

Vignais, P. M., B. Billoud and J. Meyer (2001). "Classification and phylogeny of hydrogenases I." FEMS Microbiol Rev 25 (4): 455-501.

Voegele, R. T., G. D. Sweet and W. Boos (1993). "Glycerol kinase of Escherichia coli is activated by interaction with the glycerol facilitator." J Bacteriol 175 (4): 1087-1094.

Volkl, P., R. Huber, E. Drobner, R. Rachel, S. Burggraf, A. Trincone and K. O. Stetter (1993). "Pyrobaculum aerophilum sp. nov., a novel nitrate-reducing hyperthermophilic archaeum." Appl Environ Microbiol 59 (9): 2918-2926.

Wang, F., A. Tessier and J. Buffle (1998). "Voltammetric determination of elemental sulfur in pore waters." Limnol Oceanogr 43 (6): 1353-1361.

Wang, X., B. Lv, G. Cai, L. Fu, Y. Wu, X. Wang, B. Ren and H. Ma (2012). "A proton shelter inspired by the sugar coating of acidophilic archaea." Sci Rep 2: 892.

Watanabe, M., H. Kojima and M. Fukui (2013). "Desulfotomaculum intricatum sp. nov., a sulfate reducer isolated from freshwater lake sediment." Int J Syst Evol Microbiol 63(Pt 10):35743578.

Weijma, J., C. F. M. Copini, C. J. N. Buisman and C. E. Schultz (2002). Biological recovery of metals, sulfur and water in the mining and metallurgical industry. Water Recycling and Recovery in Industry P. N. L. Lens, L. W. Hulshoff Pol, P. Wilderer and T. Asano. London, IWA Publishing: 605-622.

Wery, N., F. Lesongeur, P. Pignet, V. Derennes, M. A. Cambon-Bonavita, A. Godfroy and G. Barbier (2001). "Marinitoga camini gen. nov., sp. nov., a rod-shaped bacterium belonging to the order Thermotogales, isolated from a deep-sea hydrothermal vent." Int J Syst Evol Microbiol 51 (2): 495-504.

Widdel, F. (1988). Microbiology and ecology of sulphate - and sulphur - reducing bacteria. New York, Willey - Interscience Publication. 
Widdel, F. and N. Pfennig (1991). The genus Desulfuromonas and other Gram-negative sulfurreducing eubacteria. The Prokaryotes. A. Balows, H. G. Trüper, M. Dworkin, W. Harder and K. H. Schleifer. Berlin, Springer-VErlag.

Wildgruber, G., M. Thomm, H. König, K. Ober, T. Richiuto and K. O. Stetter (1982). "Methanoplanus limicola, a plate-shaped methanogen representing a novel family, the methanoplanaceae." Arch Microbiol 132 (1): 31-36.

Williams, J. W. and S. Silver (1984). "Bacterial resistance and detoxification of heavy metals." Enzyme Microb Technol 6 (12): 530-537.

Willis, G., S. Hedrich, I. Nancucheo, D. B. Johnson and E. R. Donati (2013). "Microbial diversity in acidic anaerobic sediments at the geothermal Caviahue-Copahue system, Argentina." Adv Mat Res 825: 4.

Windberger, E., R. Huber, A. Trincome, H. Fricke and K. O. Stetter (1989). "Thermotoga thermarum sp. nov. and Therrnotoga neapolitana occurring in African continental solfataric springs. ." Arch Microbiol 151: 7.

Wolfe, R. S. and N. Pfennig (1977). "Reduction of sulfur by Spirillum 5175 and syntrophism with Chlorobium." Appl Environ Microbiol 33: 427-433.

Xin, H., T. Itoh, P. Zhou, K. Suzuki, M. Kamekura and T. Nakase (2000). "Natrinema versiforme sp. nov., an extremely halophilic archaeon from Aibi salt lake, Xinjiang, China." Int J Syst Evol Microbiol 50 (3): 1297-1303.

Xin, H., T. Itoh, P. Zhou, K. Suzuki and T. Nakase (2001). "Natronobacterium nitratireducens sp. nov., a aloalkaliphilic archaeon isolated from a soda lake in China." Int J Syst Bacteriol $\mathbf{5 1}$ (5): 1825-1829.

Yarza, P., P. Yilmaz, E. Pruesse, F. O. Glockner, W. Ludwig, K.-H. Schleifer, W. B. Whitman, J. Euzeby, R. Amann and R. Rossello-Mora (2014). "Uniting the classification of cultured and uncultured bacteria and archaea using 16S rRNA gene sequences." Nat Rev Microbiol 12 (9): 635-645.

Yoneda, Y., T. Yoshida, S. Kawaichi, T. Daifuku, K. Takabe and Y. Sako (2012). "Carboxydothermus pertinax sp. nov., a thermophilic, hydrogenogenic, Fe(III)-reducing, sulfur-reducing carboxydotrophic bacterium from an acidic hot spring." Int J Syst Evol Microbiol 62 (Pt 7): 1692-1697.

You, X. Y., C. Liu, S. Y. Wang, C. Y. Jiang, S. A. Shah, D. Prangishvili, Q. She, S. J. Liu and R. A. Garrett (2011). "Genomic analysis of Acidianus hospitalis W1 a host for studying crenarchaeal virus and plasmid life cycles." Extremophiles 15 (4): 487-497.

Younger, P. L., A. Jayaweera, A. Elliot, R. Wood, P. Amos, A. J. Daugherty, A. Martin, L. Bowden, A. C. Aplin and D. B. Johnson (2003). "Passive treatment of acidic mine waters in subsurface-flow systems: exploring RAPS and permeable reactive barriers." Land Contam Reclam 11 (2): 9.

Yunming, Z. (1986). "Ancient chinese sulfur manufacturing processes." Isis 77 (3): 487-497.

Zavarzina, D. G., T. N. Zhilina, T. P. Tourova, B. B. Kuznetsov, N. A. Kostrikina and E. A. BonchOsmolovskaya (2000). "Thermanaerovibrio velox sp. nov., a new anaerobic, thermophilic, organotrophic bacterium that reduces elemental sulfur, and emended description of the genus Thermanaerovibrio." Int J Syst Evol Microbiol 50 (Pt 3): 1287-1295.

Zeng, X., X. Zhang, L. Jiang, K. Alain, M. Jebbar and Z. Shao (2013). "Palaeococcus pacificus sp. nov., an archaeon from deep-sea hydrothermal sediment." Int J Syst Evol Microbiol 63 (Pt 6): 2155-2159. 
Zhu, M. M., P. D. Lawman and D. C. Cameron (2002). "Improving 1,3-propanediol production from glycerol in a metabolically engineered Escherichia coli by reducing accumulation of snglycerol-3-phosphate." Biotechnol Prog 18 (4): 694-699.

Zillig, W., A. Gierl, G. Schreiber, S. Wunderl, D. Janekovic, K. O. Stetter and H. P. Klenk (1983). "The archaebacterium Thermofilum pendens represents, a novel genus of the thermophilic, anaerobic sulfur-respiring Thermoproteales." Syst Appl Microbiol 4 (1): 79-87.

Zillig, W., I. Holz, D. Janekovic, H. P. Klenk, E. Imsel, J. Trent, S. Wunderl, V. H. Forjaz, R. Coutinho and T. Ferreira (1990). "Hyperthermus butylicus, a hyperthermophilic sulfurreducing archaebacterium that ferments peptides." J Bacteriol 172 (7): 3959-3965.

Zillig, W., S. Yeats, I. Holz, A. Böck, M. Rettenberger, F. Gropp and G. Simon (1986). "Desulfurolobus ambivalens, gen. nov., sp. nov., an autotrophic archaebacterium facultatively oxidizing or reducing sulfur." Syst Appl Microbiol 8 (3): 197-203.

Zöphel, A., M. C. Kennedy, H. Beinert and P. M. H. Kroneck (1991). "Investigations on microbial sulfur respiration." Eur J Biochem 195 (3): 849-856.

Zwietering, M. H., I. Jongenburger, F. M. Rombouts and K. van 't Riet (1990). "Modeling of the bacterial growth curve." Appl Environ Microbiol 56 (6): 1875-1881.

Zychlinsky, E. and A. Matin (1983). "Cytoplasmic pH homeostasis in an acidophilic bacterium, Thiobacillus acidophilus." J Bacteriol 156 (3): 1352-1355. 


\section{Summary}

Sulfur cycle is one of the main geochemical cycles on Earth. Oxidation and reduction reactions of sulfur are mostly biotic and performed by microorganisms (Chapter 1). The oxidation of metallic sulfide-ores, which produce sulfur-rich waters with low $\mathrm{pH}$ and high heavy metals content is important in the sulfur cycle. Acidophilic sulfur-reducing microorganisms are of interest as they may be used to recover heavy metals. Acidotolerant sulfur-reducing bacteria are studied in this thesis.

Chapter 2 shows that the ability of sulfur reduction is wide-spread in the microbial world. Elemental sulfur reduction can occur directly or via polysulfide as intermediate. Four different enzymes are described to be involved in the sulfur reduction pathways. Most sulfur respirers have been isolated from environments with high temperatures and neutral $\mathrm{pH}$. However, some sulfur reducers can grow at $\mathrm{pH}$ as low as 1 and mechanisms to grow at low $\mathrm{pH}$ are described. Sulfur reduction at different $\mathrm{pH}$ is a way to selectively precipitate metals. Metal recovery by sulfur reduction is more advantageous than sulfate reduction as less electron donor needed.

Enrichments for sulfur reducers with various electron donors at low $\mathrm{pH}$ and mesophilic conditions were performed from sediments of the acidic Tinto river (Spain). A solid-media with colloidal sulfur was developed to facilitate the isolation of true elemental sulfur reducers at low $\mathrm{pH}$. This strategy resulted in the isolation of a sulfur-reducing bacterium, strain TR1. The enrichment and isolation procedure were described in Chapter 3. The isolate showed tolerance to metals, and grows at a broad temperature and $\mathrm{pH}$ range, which is advantageous to precipitate and recover heavy metals from acidic water, without the need to neutralize the water. In Chapter 4, the morphological, biochemical and physiological properties of the isolate led to the description of Desulfurella amilsii TR1 sp. nov. D. amilsii uses a limited range of electron donors, which included acetate, formate, lactate, and $\mathrm{H}_{2} / \mathrm{CO}_{2}$. Besides elemental sulfur, thiosulfate was used as an electron acceptor and the isolate can grow by disproportionation of elemental sulfur into sulfide and sulfate.

The draft genome sequence of $D$. amilsii TR1 and a comparative genomic analysis with the members of Desulfurellaceae family are reported in Chapter 5. Hippea species encode polysulfide reductase and a sulfide dehydrogenase. Desulfurella species do not possess the polysulfide reductase, but possess the sulfide dehydrogenase. D. amilsii is the only member of the family encoding sulfur reductase. This enzyme was suggested to play a role in sulfur reduction at low $\mathrm{pH}$. Genes encoding resistance to acidic conditions were reported for all Desulfurellaceae members, but only D. amilsii and D. acetivorans can grow at low $\mathrm{pH}$ Sulfur respiration by $D$. amilsii was studied in Chapter 6. The requirement for cell-sulfur interaction at $\mathrm{pH} 3.5$ and $\mathrm{pH} 6.5$ was evaluated. D. amilsii clearly benefits from contact with the insoluble substrate. Differential proteomics was used to get insight into the 
metabolism. Sulfur reductases were not detected in the proteome dataset, indicating that these membrane-bound proteinsare not well detected by proteomics. Different rhodaneselike proteins were highly abundant at low and neutral $\mathrm{pH}$, while indications were obtained that the sulfide dehydrogenase is a ferredoxin:NADP oxidoreductase. We suggest that sulfurtransferases might play a key role in sulfur/polysulfide reduction in D. amilsii. Genes involved in acid resistance are constitutively expressed. The reductive TCA cycle is used for $\mathrm{CO}_{2}$ fixation.

The sulfur metabolism of D. amilsii was further investigated in Chapter 7. Cultures grown on acetate with sulfur or thiosulfate and cultures grown by disproportionation of elemental sulfur were compared. Different rhodanese-like sulfurtransferases were abundant at the different conditions. Sulfurtransferases were the only known sulfur reducing enzymes detected indicating their importance. Respiration of thiosulfate likely involves thiosulfate reductase and a dissimilatory sulfite reductase, which were highly abundant when grown with thiosulfate. Analysis of the heterotrophic cultures suggests acetate activation by acetyl-CoA synthetase and oxidation of acetyl-CoA via the TCA cycle.

In Chapter 8 the isolation and characterization of Lucifera butyrica strain ALE is descibed $L$. butyrica uses a wide range of substrates, including sugars and glycerol, which are not used by $D$. amilsii. When growing on glycerol $L$. butyrica produced acetate, ethanol and 1,3-propanediol as major products. Elemental sulfur reduction by this bacterium, was not efficient and led to the production of maximum $2.5 \mathrm{mM}$ of sulfide. When L. butyrica grew in a co-culture with $D$. amilsii, the acetate produced by $L$. butyrica was consumed by D. amilsii and sulfide production was boosted. The co-culture strategy broadens the substrate range of sulfur reduction at low $\mathrm{pH}$.

Research described in this thesis gives insight into the physiology and application of sulfur reducers at low pH, summarized in Chapter 9. Further research is needed to test the acidophilic sulfur reduction and metal recovery at full scale. 


\section{List of publications}

Florentino, A. P., J. Weijma, A. J. Stams and I. Sánchez-Andrea (2015). "Sulfur reduction in acid rock drainage environments." Environmental Science and Technology 49 (19): 11746-11755.

Florentino, A. P., J. Weijma, A. J. M. Stams and I. Sánchez-Andrea (2016). Ecophysiology and application of acidophilic sulfur-reducing microorganisms. Biotechnology of Extremophiles: Advances and Challenges. H. P. Rampelotto. Cham, Springer International Publishing: 141-175.

Florentino, A. P., C. Brienza, A. J. Stams and I. Sánchez-Andrea (2016). "Desulfurella amilsii sp. nov., a novel acidotolerant sulfur-respiring bacterium isolated from acidic river sediments." International Journal of Systematic and Evoluionary Microbiology 66 (3): 1249-1253.

Florentino, A. P., A. J. Stams and I. Sánchez-Andrea (2017). "Genome sequence of Desulfurella amilsii strain TR1 and comparative genomics of Desulfurellaceae family" Frontiers in Microbiology 8:222. doi: 10.3389/fmicb.2017.00222.

Florentino, A. P., Inês Pereira, Michael van den Born, Sjef Boeren, Alfons J. M. Stams, Irene Sánchez-Andrea (2017). Mechanisms for sulfur reduction in Desulfurella amilsii at low and circumneutral $\mathrm{pH}$ (In preparation).

Florentino, A. P., Inês Pereira, Sjef Boeren, Alfons J. M. Stams, Irene Sánchez-Andrea (2017). New insights into sulfur metabolism from differential proteomoc analysis of the acidotolerant sulfurreducing bacterium Desulfurella amilsii TR1 (In preparation).

Sánchez-Andrea, I., Florentino, A. P., Semerel, J., Strepis, N., Sousa, D. Z., Stams, A. J. M. (2017). Beneficial co-culture of Desulfurella amilsii with a novel versatile fermentative microorganism: Lucifera butyrica gen. nov. sp. nov. (In preparation). 


\section{Co-author afiliations}

Alfons J. M. Stams, Irene Sánchez-Andrea, Claudio Brienza, Michael van den Born, Jeltzlin Semerel, Nikolas Strepis, Diana Z. M. Sousa

Laboratory of Microbiology, Wageningen University, Helix Building, Stippeneng 4, 6708 WE Wageningen, The Netherlands.

\section{Alfons J. M. Stams}

Centre of Biological Engineering, University of Minho, Braga, Portugal.

\section{Nikolas Strepis}

Laboratory of Systems and Synthetic Biology, Wageningen University, Helix Building, Stippeneng 4, 6708 WE Wageningen, The Netherlands.

\section{Sjef Boeren}

Laboratory of Biochemistry, Wageningen University, Stippeneng 4, 6708 WE, Wageningen, The Netherlands.

\section{Inês A. C. Pereira}

Instituto de Tecnologia Quimica e Biologica António Xavier, Universidade Nova de Lisboa, Av. da Republica-EAN, 2780-157, Oeiras, Portugal. 


\section{About the author}

Anna Patrícya Florentino was born on the $1^{\text {st }}$ of January, 1985, in Maceió, Brazil. After completing her secondary school in Maceió in 2002, she moved to Fortaleza and started her BSc studies in Biological Sciences at the State University of Ceará in Brazil, finishing in 2007. After her graduation, she joined the Federal University of Ceará to start her MSc studies in Civil Engineering, with specialization in Environmental Sanitation, in which she focused on the application os microalgae harvested from

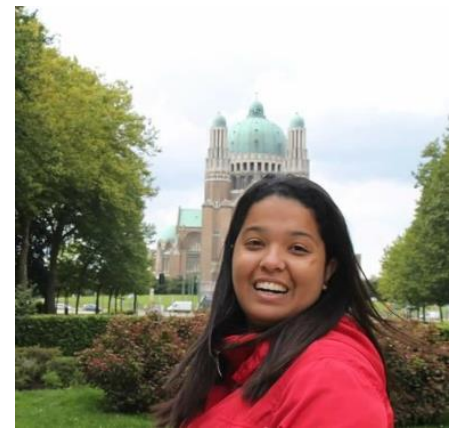
wastewater treatment ponds for the production of biodiesel. She obtained her MSc degree in January 2013, when she moved to The Netherlands to start her PhD study at Wageningen University. At the Laboratory of Microbiology, she worked with elemental sulfur reduction at low $\mathrm{pH}$ for the precipitation of heavy metals in solution. This work was performed under the supervision of Dr. Irene Sánchez-Andrea, Prof. Dr. Alfons Stams and Dr. Jan Weijma and its results are presented in this thesis. 


\section{Acknowledgements}

When I was a child, my Grandpa often took me for a walk, and I asked: "where are we going?", to what he always replied: "there and back, just to see how far it is, birdie". I grew up and never got away from the nest, until the day I decided to come to The Netherlands to do my $\mathrm{PhD}$. My Grandpa then said: "Go, birdie! You are ready to raise your highest flight alone. When you are done, if I am still here, come and tell me how far you went..." With these words and the evoked sense of mystery and motivation, I faced my biggest fear to lose what I was leaving behind and flew out of my nest to live the greatest journey of my life. At first, I felt a bit insecure, but I met some people whose valuable support, direction, advice, and friendship proved I flew high because I was never alone.

First and foremost, I would like to express my deepest gratitude to you, Irene. It was such a privilege for me to be your first $\mathrm{PhD}$ student! Thank you for your help, encouragement, advice, care, kindness, patience, and great sense of humor over the past four years. It was fantastic to share this journey with you. I am positive I would not have managed without your assistance. Thank you for all and for always! You were the best supervisor and the best example I could have had! And I am very happy for that!

Fons, thank you for accepting me as your student; it was a great honor to be part of your research group. The support, help and motivation you provided me, backed by your great knowledge and joyful talks, were fundamental for my development as a researcher. You will be always my model of enthusiasm and modesty in science.

Jan Weijma, thank you for the talks and always so kind comments on my performance. Claudio, Michael and Jeltzlin, I was lucky to have the opportunity to learn a lot while teaching you. You all made valuable contributions not only to my thesis, but for my vocational training. Thanks for being part of this story! Bastian, I am so grateful for your guidance through the genome analysis I performed. You are a fount of patience and kindness! Sjef, you were always available to help me to overcome the proteomics issues. Thank you for being always happy to welcome me and my endless questions. Nikolas, thank you for your help with the genome analysis for the last chapter, and for making time for all my doubts! Inês Pereira, I was amazed by your enthusiasm when we met to talk about my research. My great honor to collaborate with you in two chapters of this thesis. I am also grateful to the members of the thesis committee for the time invested on it and for the critical assessments. Alexis and Mariana thanks for the great help in designing the cover of my thesis. You are fantastic!

My dear paranymphs, I am happy I met you on my way! Martijn, it was a great pleasure to have you as my officemate and to call you my friend! Thank you for being so attentive and gentle to me and to everyone who needs your help. You are Super! Nam, it is so nice to count on you and share so many good moments with you and your lovely family! Thank you for all the support, the dinners, the nice talks and, above all, for your friendship!

Officemates, you survived! Thank you all so much for the nice atmosphere we had! Vicente, thank you for your help, advices and cheerfulness! I am glad I could laugh at life with you every day for almost three years, even when 'it was not funny'. Lara, I am happy we could share nice moments here and in USA. There is still one thing I cannot understand, though: We shared the bed in Las Vegas and the bed bugs bit exclusively me... 
Why?! Thank you for being always there when I needed. Ahmad, maybe you did not realize, but you taught me so much by telling me the story of your life! I see things even more positively since then. Thanks a lot! Peer, I would not forget you, my officemate for the shortest period ever... It was funny to share those few days with you trying to replace Vicente in the office. Being paranymph of Nam with you was also a cool experience. Daan, you are a nice researcher! I pretty much enjoyed our short period as officemates! Nice jokes, nice atmosphere! Thanks a lot! Cristina, you were often disturbing me... Che palle! But I always missed you and your Methanosaeta when you were not there! Thanks for all! I am happy you are around! Yuan, it was nice to have you in the same office for a while! You are a kind and funny girl! Thank you for the nice moments and talks! Sara, unfortunately you came only for three months, the three months I was struggling with some chapters of my thesis. It was very nice to have you as officemate, always so kind and helpful. Thanks a lot! Ton van Gelder, I am so happy I could work with you and be your officemate. Always so gentle and in a good mood person. Thank you for all your help along the last four years, for making my measurements possible in the HPLC machines, for making time for my questions, for having always something nice to say and for nicely predicting the weather. Monika, it is always good to have a cheerful person around! I really appreciate your positivity and sense of humor! A good officemate! I am grateful for your help! Thank you also for organizing dinners and for trying to bring MicFys socially together now and then.

Susakul, I am so lucky to meet fantastic friends as you on my way. Always so attentive and patient! Thank you so much for your friendship and for all the help you gave me along the past four years! I will always remember you! Diana, although you do not speak proper Portuguese, we can communicate quite well. It was nice to work with you in the MicFys course for two years! I like your talks and definitely will remember them as model. Thank you for being so sweet and positive! It was pleasant to have you always nearby! Caroline, I was always amazed by your didactic, the way you make complex concepts simple. If one day I manage to be as clear as you in my talks, I will be sure I became a good teacher. Thank you for inspiring me! Aleks and Nico, you are adorable guys! Thank you for the always cheerful conversations we could have!

Catalina, Samet, Neda, Jueeli, Nohemi, Petra, Michael Visser, Monir, Rik, Sabina, Sudarshan, Indra, Joyshree, Prarthana, Siavash, Hikma, Teresita, Romy, Marcelle, Peng Peng, Lennart, Teunke, Dorett, Yifan, Denny, my pleasure to meet you in Wageningen! Thanks for the nice talks we had! Tom van der Weijer, Tom Schonewille, Steven, Ineke, Philippe and Sjon, thanks for helping me whenever I needed. Wim, I am so grateful for your availability and quick solutions for everyone's problems. You are essential for Microbiology to work at its full speed! Anja, you are always so gentle and helpful! I am happy I could have your attention with the countless paper work along these four years!

$\mathrm{PhD}$ trip 2015 committee, you are great, guys! Aleks, Nico, Kees, Ruben, Yue, Marteen and Jasper Sloothaak, it was an amazing experience to organize the $\mathrm{PhD}$ trip with you. We worked a lot, but it was great to see the fruitful and enjoyable trip we provided to Microbiology PhD students at that time. I am happy to be part of this group! Detmer, thank you for your valuable help during the $\mathrm{PhD}$ trip! And for being always 
positive and kind! It is easy to work with you! LooWee, Johanna, Alex Umanetc, Klaudyna, Ioannis Mougiakos, Ying, it was a great experience to travel around USA with you! Golden memories!!!

Outside the university, I could also meet very nice friends that made me feel at home. Brazilians... they are everywhere! Cristina Ferreira, meeting you and your lovely family in Wageningen was a great present. Thank you for all the support you gave me when I arrived. I am glad I can call you friend! Anabele, thank you for making me feel at home, especially during the last four Christmas! I appreciated every single moment. Cynara and Rafa, you are awesome, guys! I am so happy I met you in my journey! Thank you for all the support and friendship, especially when I fell sick (which was a constant in the first two years). Gabi Fontanelli and Igor, such an amazing time we spent together. My pleasure to have endless talks with you. Thank you for making part of this story! Brenda and Leo, you are always with me! Thank you for everything! Dani and Gabi Angioletti, you came as a present for my last year! From Wageningen to life, I am positive about that!

Thiago Ortiz, Loiane, Amanda Saúde, Márcio, Paulo, Mariana Artur, Nilma, Mariana Reis, Milene, Wilson, Thiago Almeida, Rangel, unforgettable moments we shared! I am happy to have met you! Mauricio, Fernanda, Greice, Gunther, Jacqueline, Laura, Débora, Iago, Fernando, Nathalia, Julia, it was nice to meet you all! Thank you!

Back in Brazil, I would like to express my gratitude to André Bezerra! This story could only be real because of your help! You were a great supervisor during my masters and motivated me to come to The Netherlands, contacting Fons and making everything possible. I am happy and proud I was your student, as I will be eternally grateful.

Lydia, Laura, Ivo, Zilma, Carolina, Moacir, Alessandra, Claver, Natalia, Magda, Mayara, Alexandre Colzi, Elisa, Ana Flávia, Carlos, Aida, Norma, Teca, Dalila, thank you for supporting me and encouraging me now and then when life was heavy. I am glad I have the best friends in the world.

Mom, you are the sweetest part of me! I am so glad I have your support and care. Thank you for being present all these years, even when there was a big ocean between us. To you, my love and gratitude!

Dad... I did it! I am thankful not only for all the investment and support you gave for my education, but for triggering my motivation and my love for Science. To you, my love and this thesis.

At the end of this journey, I think about my Grandpa. I am so glad he is there... and I can now visit him, grab a coconut, sit on a hammock, and tell him how far I went. Likely, he will not get the grandiosity of my $\mathrm{PhD}$ diploma, but I am positive he is waiting to listen to all my adventures and stories about the amazing people I have met and wonderful countries I have visited. I know he will be proud of the birdie who left the fear behind and tried her highest and best flight... 'there and back to see how far it is'. But for her, far is a concept that no longer exists.

Alone I could have done so little, but we were together, and so, we did so much!

Muito obrigada!

Anna Patrícya Florentino

Wageningen, 21 March 2017. 


\section{SENSE}

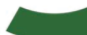

Netherlands Research School for the

Socio-Economic and Natural Sciences of the Environment

\section{I P L O M A}

For specialised PhD training

The Netherlands Research School for the Socio-Economic and Natural Sciences of the Environment

(SENSE) declares that

\section{Anna Patrícya Florentino de Souza Silva}

born on 1 January 1985 in Maceió, Brazil

has successfully fulfilled all requirements of the Educational Programme of SENSE.

Wageningen, 21 March 2017

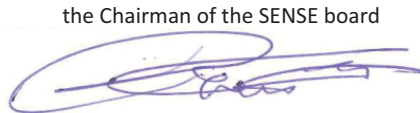

Prof. dr. Huub Rijnaarts

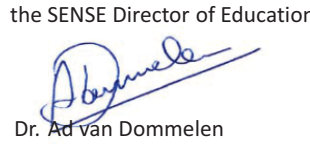

Dr. Advan Dommelen

The SENSE Research School has been accredited by the Royal Netherlands Academy of Arts and Sciences (KNAW)

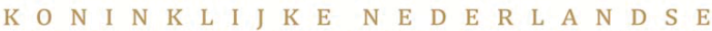

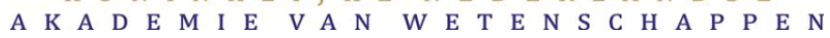




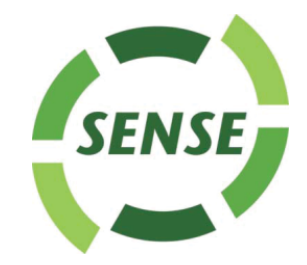

The SENSE Research School declares that Ms Anna Florentino de Souza Silva has successfully fulfilled all requirements of the Educational PhD Programme of SENSE with a work load of $33.9 \mathrm{EC}$, including the following activities:

\section{SENSE PhD Courses}

- Environmental research in context (2013)

- Writing week (2014)

- Research in context activity: 'Co-organising a PhD trip to Californian research institutes for participants from the laboratory of microbiology and the laboratory of systems and synthetic biology' (2015)

\section{Other PhD and Advanced MSc Courses}

- Scientific publishing, Wageningen University (2013)

- Scientific integrity, Wageningen University (2013)

o Project and time management, Wageningen University (2014)

- ARB/SILVA basic training in software for sequence data, Wageningen University (2014)

- Techniques for writing and presenting a scientific paper, Wageningen University (2015)

- Soehngen Institute of Anaerobic Microbiology (SIAM) summer school, Texel (2016)

- SIAM metagenomics course, Radboud University, Nijmegen (2016)

\section{Management and Didactic Skills Training}

- Supervising two MSc students with thesis entitled 'Isolation and characterisation of a sulfur-reducing bacterium isolated from an extreme environment' (2014) and 'Elucidating the sulfur metabolism in Desulfurella amilsii' (2016)

- Supervising BSc student with thesis entitled 'Phenotypic characterisation of a sulfurreducing, glycerol-oxidizing bacterium isolated from acidic river sediments' (2016)

- Supervising lab practicals for the BSc-course 'Microbial physiology' (2015 - 2016)

\section{Poster Presentations}

- A sulfur reducer isolated from Tinto river, an acid rock. Workshop Microbial Sulfur Metabolism, 12-15 April 2015, Helsingør, Denmark

- Sulfur reduction at low $\mathrm{pH}$ : from environment to application. $11^{\text {th }}$ International Congress on Extremophiles, 12-16 September 2016, Kyoto, Japan

SENSE Coordinator PhD Education 
The doctoral study program was supported by the Conselho Nacional de Desenvolvimento Cientifíco e Tecnológico (CNPq), an organization of the Brazilian Government for the development of Science and Technology. Research was also supported by the Gravitation grant (project 024.002.002) from The Netherlands Ministry of Education, Culture and Science, and by the project 323009 of the European Research Council (ERC) grant.

Cover design: Anna P. Florentino | Alexis Barros | Mariana Sandel

Thesis layout : Anna P. Florentino

Printing: Proefschriftmaken.nl || Digiforce Vianen

Financial support from the Laboratory of Microbiology (Wageningen University) for printing this thesis is gratefully acknowledged. 